May 1999 • NREL/TP-580-25688

\title{
Environmental Life Cycle Implications of Fuel Oxygenate Production from California Biomass
}

K.L. Kadam, National Renewable Energy Laboratory

V.J. Camobreco \& B.E. Glazebrook, Ecobalance Inc.

L.H. Forrest \& W.A. Jacobson, TSS Consultants

D.C. Simeroth, California Air Resources Board

W.J. Blackburn, California Energy Commission

K.C. Nehoda, California Department of Forestry and Fire Protection

\section{National Renewable Energy Laboratory}

1617 Cole Boulevard

Golden, Colorado 80401-3393

NREL is a U.S. Department of Energy Laboratory

Operated by Midwest Research Institute $\bullet$ Battelle $\bullet$ Bechtel

Contract No. DE-AC36-98-G010337 
May 1999 • NREL/TP-580-25688

\section{Environmental Life Cycle Implications of Fuel Oxygenate Production from California Biomass}

K.L. Kadam, National Renewable Energy Laboratory V.J. Camobreco \& B.E. Glazebrook, Ecobalance Inc.

L.H. Forrest \& W.A. Jacobson, TSS Consultants

D.C. Simeroth, California Air Resources Board W.J. Blackburn, California Energy Commission K.C. Nehoda, California Department of Forestry and Fire Protection

Prepared under Task No. WG900101

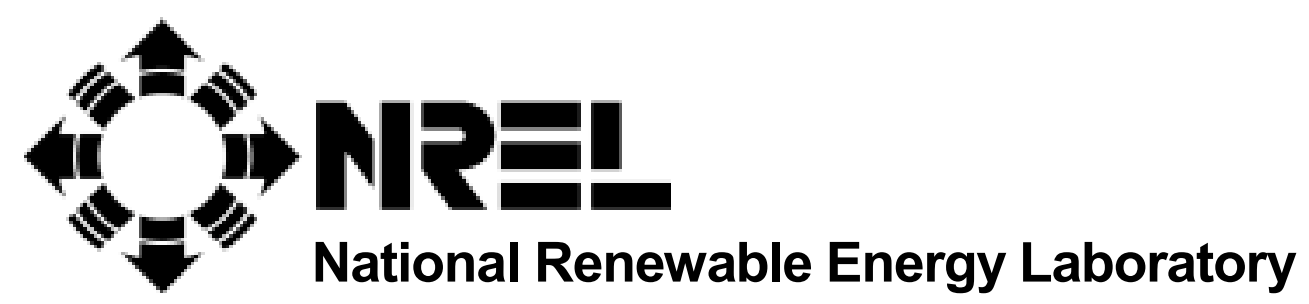

1617 Cole Boulevard

Golden, Colorado 80401-3393

NREL is a U.S. Department of Energy Laboratory

Operated by Midwest Research Institute $\bullet$ Battelle $\bullet$ Bechtel

Contract No. DE-AC36-98-G010337 


\section{NOTICE}

This report was prepared as an account of work sponsored by an agency of the United States government. Neither the United States government nor any agency thereof, nor any of their employees, makes any warranty, express or implied, or assumes any legal liability or responsibility for the accuracy, completeness, or usefulness of any information, apparatus, product, or process disclosed, or represents that its use would not infringe privately owned rights. Reference herein to any specific commercial product, process, or service by trade name, trademark, manufacturer, or otherwise does not necessarily constitute or imply its endorsement, recommendation, or favoring by the United States government or any agency thereof. The views and opinions of authors expressed herein do not necessarily state or reflect those of the United States government or any agency thereof.

Available to DOE and DOE contractors from:

Office of Scientific and Technical Information (OSTI)

P.O. Box 62

Oak Ridge, TN 37831

Prices available by calling 423-576-8401

Available to the public from:

National Technical Information Service (NTIS)

U.S. Department of Commerce

5285 Port Royal Road

Springfield, VA 22161

$703-605-6000$ or $800-553-6847$

or

DOE Information Bridge

http://www.doe.gov/bridge/home.html

Printed on paper containing at least $50 \%$ wastepaper, including $20 \%$ postconsumer waste 


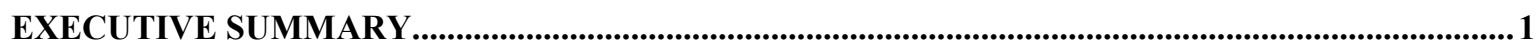

Project Overview 1

Bioethanol and ETBE Production Potential 1

Baseline Results 2

Sensitivity Analysis $\quad 4$

Conclusions $\quad 5$

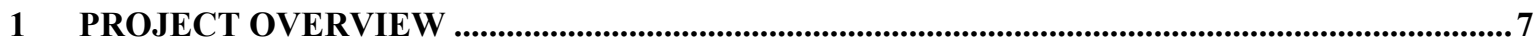

$\begin{array}{lll}1.1 & \text { Background } & 7\end{array}$

1.2 Project Phases 9

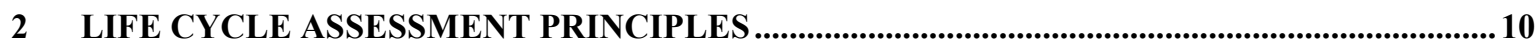

$\begin{array}{lll}2.1 & \text { Overview } & 10\end{array}$

2.2 Methodology 11

3 PROJECT SCOPING OPTIONS AND DECISIONS...........................................................................13

$\begin{array}{lll}3.1 & \text { Project Parameters } & 14\end{array}$

$\begin{array}{lll}3.2 & \text { Product Parameters } & 17\end{array}$

3.3 Process Parameters $\quad 19$

3.4 LCA-Specific Parameters 19

3.5 Summary of Scoping Decisions and Approaches 20

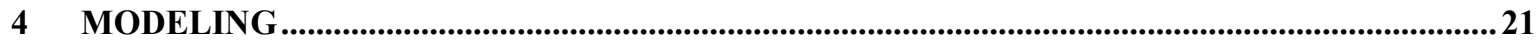

4.1 Option 1: MTBE Production + Biomass Burning 21

4.2 Option 2: ETBE Production from Biomass 28

4.3 Isobutylene Production $\quad 39$

4.4 Electricity Production $\quad 40$

4.5 Steam Production $\quad 45$

4.6 Gasoline System 47

4.7 Gasoline Transport $\quad 53$

4.8 Oxygenated Gasoline Fuel Combustion $\quad 54$

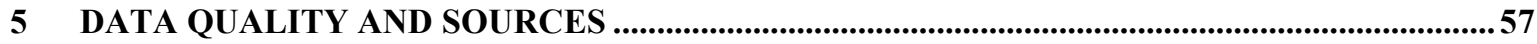

5.1 Data Quality 57

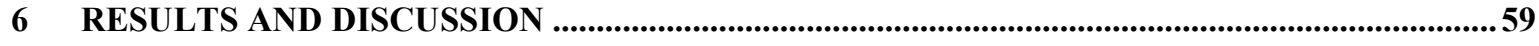

6.1 Presentation of Results 59

NREL, CARB, CEC, CDF, Ecobalance Inc., TSS Consultants

Final Report $\quad$ Kadam et al. 
$\begin{array}{lll}6.2 & \text { Life Cycle Energy Balance } & 61\end{array}$

$\begin{array}{lll}6.3 & \text { Mass Flowchart } & 62\end{array}$

6.4 Baseline Scenario Results and Discussion $\quad 63$

6.5 Comparison of Baseline Scenarios 94

6.6 California Specific Emissions $\quad 94$

6.7 Carbon Balance $\quad 95$

6.8 Impact Assessment and Biomass Disposal Options 99

$\begin{array}{lll}6.9 & \text { Sensitivity Analysis } & 104\end{array}$

7 CONCLUSIONS .............................................................................................................................................. 110

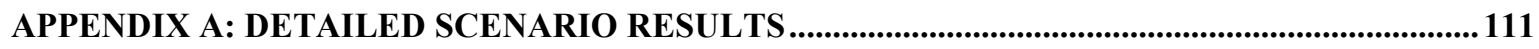

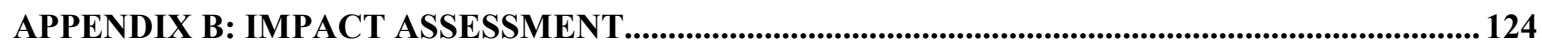

$\begin{array}{ll}\text { Background } & 124\end{array}$

Overview of Life Cycle Impact Assessment Indices $\quad 125$

APPENDIX C: POTENTIAL CALIFORNIA BIOMASS AVAILABILITY .............................................130

$\begin{array}{lr}\text { Introduction } & 130\end{array}$

$\begin{array}{lr}\text { Estimated California Biomass Volumes } & 130\end{array}$

Areas of Biomass Concentrations in California $\quad 133$

Projected Biomass Collection, Harvesting, Processing and Transportation Costs 137

APPENDIX D: GASOLINE MODELING ....................................................................................................140

$\begin{array}{ll}\text { Crude Oil Extraction } & 140\end{array}$

Crude Oil Transport to Refinery $\quad 154$

$\begin{array}{ll}\text { Crude Oil Refining } & 160\end{array}$

$\begin{array}{ll}\text { Petroleum Products Transport } & 169\end{array}$

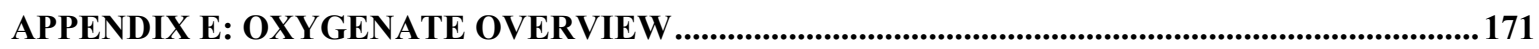

Oxygenates/Gasoline Octane Enhancers 171

$\begin{array}{ll}\text { MTBE } & 171\end{array}$

Ethanol $\quad 172$

ETBE 172

APPENDIX F: PROJECT MANAGEMENT AND REVIEW ...................................................................173

$\begin{array}{ll}\text { Project Management } & 173\end{array}$

$\begin{array}{ll}\text { Project Review } & 173\end{array}$

APPENDIX G: STAKEHOLDER LIST ..................................................................................................175

APPENDIX H: RESPONSES TO REVIEW COMMITTEE COMMENTS...........................................178

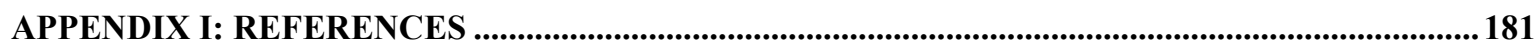

Section 1: Project Overview - References 181

NREL, CARB, CEC, CDF, Ecobalance Inc., TSS Consultants

Final Report Kadam et al. 
Section 2: Life Cycle assessment Principles - References 181

Section 4: Modeling - References $\quad 182$

Section 5: Data Quality and Sources- References $\quad 183$

Appendix B: Impact Assessment - References

Appendix D: Gasoline Modeling - References

Appendix E: Oxygenate Overview - References 184 
Table 1: Biomass-Derived Ethanol and ETBE Production Potential in California 1

Table 2: Near-Term ETBE Production in California $\quad 2$

Table 3: Ethanol and ETBE Yield by Biomass Type 2

Table 4: Relative Differences between ETBE Scenario and MTBE Scenario 3

Table 5: Environmental Inventory Flows Considered 16

Table 6: Comparison of ETBE versus MTBE Use in Reformulated Gasoline $\quad 18$

Table 7: Summary of Scoping Decisions and Approaches 20

Table 8: Natural Gas Venting Methane Emissions $\quad 22$

Table 9: Inputs for Methanol Production $\quad 24$

Table 10: Inputs for MTBE Production $\quad 26$

Table 11: Emission Factors for Forest Residue Burning $\quad 27$

Table 12: Emission Factors for Rice Straw Burning $\quad 27$

Table 13: Emission Factors for Chaparral Burning $\quad 27$

Table 14: Summary of Fuel Consumption for Biomass Harvesting 29

Table 15: Forest Residue/Thinnings Composition-Whole Tree Chips 30

Table 16: Rice Straw Composition 30

Table 17: Chaparral Composition-Whole Tree $\quad 31$

Table 18: Data Summary for Concentrated Acid Process 34

Table 19: Data Summary for Enzymatic Process 36

Table 20: Waste-to-Energy Plant Locations in California 37

Table 21: Inputs for ETBE Production $\quad 39$

Table 22: C4 Fraction Composition 39

Table 23: Coal Firing Configurations/Firing Types $\quad 42$

Table 24: Bituminous Coal Combustion Emissions (kg/ton of coal burned) 42

Table 25: Bituminous Coal Combustion Emissions Factors (kg/ton of coal burned) 43

Table 26: Coal Fixed Carbon Content $\quad 43$

Table 27: Electricity Production by NERC Region $\quad 45$

Table 28: California Net System Power $\quad 46$

Table 29: Production of an Average U.S. Refinery $\quad 49$

Table 30: Fraction of Total Refinery Energy Used by Each Process $\quad 50$

Table 31: Fraction of Refinery Process Energy Used by Types of Refinery Products 51

Table 32: Fraction of Total Refinery Energy Used by Category of Refined Product 52

Table 33: Diesel Fuel's Share of Total Distillates $\quad 52$

Table 34: Vehicle Emission Factors $\quad 55$

NREL, CARB, CEC, CDF, Ecobalance Inc., TSS Consultants

March, 1999

Final Report

Kadam et al. 
Table 35: Reformulated Gasoline Benefits $\quad 55$

Table 36: Average Fuel Consumption Values $\quad 55$

Table 37: Data Quality $\quad 58$

Table 38: Description of Scenarios Studied $\quad 59$

Table 39: Ethanol and ETBE Yield by Biomass Type $\quad 59$

Table 40: Explanation of Negative Values in Summary Tables $\quad 60$

Table 41 : Speciated Sources of Non-Methane Hydrocarbon Emissions $\quad 60$

Table 42: Results Summary for Rice Straw Feedstock—Enzyme Process 63

Table 43: Results Summary for Rice Straw Feedstock-Acid Process $\quad 68$

Table 44: Results Summary for Forest Residue Feedstock—Enzyme Process 73

Table 45: Results Summary for Forest Residue Feedstock-Acid Process 78

Table 46: Results Summary for Chaparral Feedstock—Enzyme Process $\quad 83$

Table 47: Results Summary for Chaparral Feedstock—Acid Process $\quad 89$

Table 48: Summary Data for Baseline Scenarios $\quad 94$

Table 49: Carbon Balance for Rice Straw Feedstock—Enzyme Process 96

Table 50: Carbon Balance for Forest Residue Feedstock—Enzyme Process 96

Table 51: Carbon Balance for Chaparral Feedstock—Enzyme Process 97

Table 52: Carbon Balance for Rice Straw Feedstock—Acid Process 97

Table 53: Carbon Balance for Forest Residue Feedstock—Acid Process 98

Table 54: Carbon Balance for Chaparral Feedstock-Acid Process 98

Table 55: Impact Assessment Summary 99

Table 56: Difference in Modeling Out-of-State MTBE/ETBE Production 104

Table 57: Comparison of California and Out-of-State ETBE/MTBE Production 105

Table 58: Comparison of the Two Biomass Disposal Options 106

Table 59: Comparison of E10 versus MTBE Use in Reformulated Gasoline 107

Table 60: Tailpipe Emissions Factors in Grams/Gallon of Fuel Burned 107

Table 61: Hotsoak Evaporative Emissions Factors in Grams 107

Table 62: Diurnal (0-24hr) Evaporative Emissions Factors in Grams 108

Table 63: Summary Data for E10 Sensitivity Analysis 108

Table 64: Scenarios Studied $\quad 111$

Table 65: Rice Straw Biomass, Enzyme-Based Ethanol Production, and Lignin Cogeneration 112

Table 66: Rice Straw Biomass, Enzyme-Based Ethanol Production, and Lignin Biomass Power 113

Table 67: Rice Straw Biomass, Conc. Acid-Based Ethanol Production, and Lignin Cogeneration 114

Table 68: Rice Straw Biomass, Conc. Acid-Based Ethanol Production, and Lignin Biomass Power 115

Table 69: Forest Residue Biomass, Enzyme-Based Ethanol Production, and Lignin Cogeneration 116

Table 70: Forest Residue Biomass, Enzyme-Based Ethanol Production, and Lignin Biomass Power 117

NREL, CARB, CEC, CDF, Ecobalance Inc., TSS Consultants

March, 1999

Final Report Kadam et al. 
Table 71: Forest Residue Biomass, Conc. Acid-Based Ethanol Production, and Lignin Cogeneration 118

Table 72: Forest Residue Biomass, Conc. Acid-Based Ethanol Production, and Lignin Biomass Power 119

Table 73: Chaparral Biomass, Enzyme-Based Ethanol Production, and Lignin Cogeneration 120

Table 74: Chaparral Biomass, Enzyme-Based Ethanol Production, and Lignin Biomass Power 121

Table 75: Chaparral Biomass, Conc. Acid-Based Ethanol Production, and Lignin Cogeneration 122

Table 76: Chaparral Biomass, Conc. Acid-Based Ethanol Production, and Lignin Biomass Power 123

Table 77: Greenhouse Gas Potential Factors 126

Table 78: Acidification Potential Reactions $\quad 126$

Table 79: Eutrophication Potential Factors $\quad 127$

Table 80: Rice Acreage and Rice Straw Generation for the Sacramento Valley 133

Table 81: California Rice Acreage Harvested, 1986-1997 133

Table 82: Forest Residues in Northeastern California $\quad 135$

Table 83: Estimated Cost of XYZ Thinning Sale Delivered to Ethanol Facility 138

Table 84: Cost Estimates for Delivering Rice Straw to a User Facility 138

Table 85: Production of Crude Oil by Technology Type and Origin 141

Table 86: Crude Oil Production Wastewater Constituents and Concentrations 142

Table 87: Natural Gas Venting and Flaring from Crude Oil Wells 143

Table 88: VOC Emissions for Onshore Crude Oil Wells 143

Table 89: Speciated VOC Data for Onshore Crude Oil Wells 144

Table 90: Natural Gas Venting, Flaring, and Coproduct Production from Onshore Extraction Wells 144

Table 91: Production of Typical Domestic Conventional Onshore Crude Oil Well 145

Table 92: Production of Typical Foreign Conventional Onshore Crude Oil Well 145

Table 93: Crude Oil Production Wastewater Constituents and Concentrations 147

Table 94: Natural Gas Venting and Flaring from Conventional Offshore Extraction Wells 147

Table 95: Speciated VOC Emissions for Offshore Crude Oil Production $\quad 148$

Table 96: Natural Gas Venting, Flaring, and Coproduct Production from Offshore Extraction Wells 149

Table 97: Production of Typical Domestic Conventional Offshore Crude Oil Well 149

Table 98: Production of Typical Foreign Conventional Offshore Crude Oil Well 149

Table 99: VOC Emissions for Onshore Crude Oil Wells with $\mathrm{CO}_{2}$ Extraction 151

Table 100: Speciated VOC Data for Onshore Crude Oil Wells 152

Table 101: VOC Emissions for Onshore Crude Oil Wells 154

Table 102: Speciated VOC Data for Onshore Crude Oil Wells 154

Table 103: Refinery Receipts of Crude Oil by Source and by PADD (1993) 155

Table 104: Refinery Receipts of Crude Oil by Method of Transportation and by PADD (1993) 155

Table 105: Material Inputs to U.S. Refineries 162

Table 106: Energy Inputs to Petroleum Refineries 163

NREL, CARB, CEC, CDF, Ecobalance Inc., TSS Consultants

March, 1999

Final Report

Kadam et al. 
Table 107: Refinery Energy Sources from the Crude Oil Stream 163

Table 108: Petroleum Refining Process Emissions 164

Table 109: Refinery Process Flows 164

Table 110: Wastewater Production in Crude Oil Refineries 165

Table 111: Crude Oil Refinery Wastewater Composition $\quad 165$

Table 112: Solid Waste Produced from Crude Oil Refining 165

Table 113: Production of an Average U.S. Refinery 166

Table 114: Fraction of Total Refinery Energy Used by Each Process 167

Table 115: Fraction of Refinery Process Energy Used by Types of Refinery Products 168

Table 116: Fraction of Total Refinery Energy Used by Category of Refined Product 169

Table 117: Diesel Fuel's Share of Total Distillates 169

Table 118: U.S. Consumption of Oxygenates/Gasoline Octane Enhancers 171 


\section{FIGURES}

Figure 1: Life Cycle Analysis Principles $\quad 11$

Figure 2: Elements of the Scoping Phase for Life Cycle Analysis $\quad 13$

Figure 3: General System Boundaries for the Comparison of ETBE and MTBE Use in RFG 14

$\begin{array}{ll}\text { Figure 4: Option } 1 \text { Systems } & 21\end{array}$

Figure 5: Fixed Bed Finishing Reactor $\quad 25$

Figure 6: Catalytic Distillation Finishing Reactor 26

Figure 7: Option 2 Systems 28

Figure 8: Composition of Forest Residue Feedstock 29

Figure 9: Composition of Rice Straw Feedstock 29

Figure 10: Composition of Chaparral Feedstock 30

Figure 11: Concentrated Acid Process Flow Diagram 32

Figure 12: Enzymatic Process Flow Diagram 35

Figure 13: Map of the NERC regions in the United States and in Canada 47

Figure 14: Gasoline Production Systems $\quad 47$

Figure 15: Gasoline Transportation Modeling 53

Figure 16: Gasoline Transportation Emissions Modeling $\quad 54$

Figure 17: Mass Flow Diagram for Rice Straw with the Enzyme Process $\quad 62$

Figure 18: Rice Straw (Enzyme Process) Carbon Monoxide Emissions $\quad 65$

Figure 19: Rice Straw (Enzyme Process) $\mathrm{NO}_{\mathrm{x}}$ Emissions 65

Figure 20: Rice Straw (Enzyme Process) Particulate Emissions 65

Figure 21: Rice Straw (Enzyme Process) $\mathrm{SO}_{\mathrm{x}}$ Emissions $\quad 65$

Figure 22: Rice Straw (Enzyme Process) Non-Methane Hydrocarbon Emissions 66

Figure 23: Rice Straw (Enzyme Process) Non-Methane Hydrocarbon Emissions for Option 2 by Source 66

Figure 24: Rice Straw (Enzyme Process) Non-Methane Hydrocarbon Emissions for Option 1 bySource 66

Figure 25: Rice Straw (Enzyme Process) Total Energy Consumption $\quad 67$

Figure 26: Rice Straw (Enzyme Process) Nonrenewable and Renewable Energy Consumption 67

Figure 27: Mass Flow Diagram for Rice Straw_Acid Process $\quad 69$

Figure 28: Rice Straw (Acid Process) Carbon Monoxide Emissions 70

Figure 29: Rice Straw (Acid Process) $\mathrm{NO}_{\mathrm{x}}$ Emissions $\quad 70$

Figure 30: Rice Straw (Acid Process) Non-Methane Hydrocarbon Emissions 70

Figure 31: Rice Straw (Acid Process) $\mathrm{SO}_{\mathrm{x}}$ Emissions $\quad 70$

Figure 32: Rice Straw (Acid Process) Particulate Emissions 71

NREL, CARB, CEC, CDF, Ecobalance Inc., TSS Consultants

March, 1999

Final Report

Kadam et al. 
Figure 33: Rice Straw (Acid Process) Particulate Emissions for Option 2 by Source 71

Figure 34: Rice Straw (Acid Process) Particulate Emissions for Option 1 by Source 71

Figure 35: Rice Straw (Acid Process) Total Energy Consumption 72

Figure 36: Rice Straw (Acid Process) Nonrenewable and Renewable Energy Consumption 72

Figure 37: Mass Flow Diagram for Forest Residue_Enzyme Process $\quad 74$

Figure 38: Forest Residue (Enzyme Process) Carbon Monoxide Emissions 75

Figure 39: Forest Residue (Enzyme Process) $\mathrm{NO}_{\mathrm{x}}$ Emissions $\quad 75$

Figure 40: Forest Residue (Enzyme Process) Particulate Emissions 75

Figure 41: Forest Residue (Enzyme Process) $\mathrm{SO}_{\mathrm{x}}$ Emissions $\quad 75$

Figure 42: Forest Residue (Enzyme Process) Non-Methane Hydrocarbon Emissions 76

Figure 43: Forest Residue (Enzyme Process) Non-Methane Hydrocarbon Emissions for Option 2 by Source76

Figure 44: Forest Residue (Enzyme Process) Non-Methane Hydrocarbon Emissions for Option 1 by Source76

Figure 45: Forest Residue (Enzyme Process) Total Energy Consumption 77

Figure 46: Forest Residue (Enzyme Process) Nonrenewable and Renewable Energy Consumption 77

Figure 47: Mass Flow Diagram for Forest Residue-Acid Process 79

Figure 48: Forest Residue (Acid Process) Carbon Monoxide Emissions $\quad 80$

Figure 49: Forest Residue (Acid Process) Particulate Emissions $\quad 80$

Figure 50: Forest Residue (Acid Process) Non-methane Hydrocarbon Emissions 80

Figure 51: Forest Residue (Acid Process) $\mathrm{SO}_{\mathrm{x}}$ Emissions $\quad 80$

Figure 52: Forest Residue (Acid Process) $\mathrm{NO}_{\mathrm{x}}$ Emissions $\quad 81$

Figure 53: Forest Residue (Acid Process) NOx Emissions for Option 2 by Source $\quad 81$

Figure 54: Forest Residue (Acid Process) NOx Emissions for Option 1 by Source $\quad 81$

Figure 55: Forest Residue (Acid Process) Total Energy Consumption $\quad 82$

Figure 56: Forest Residue (Acid Process) Nonrenewable and Renewable Energy Consumption 82

Figure 57: Mass Flow Diagram for Chaparral-Enzyme Process $\quad 85$

Figure 58: Chaparral (Enzyme Process) Carbon Monoxide Emissions 86

Figure 59: Chaparral (Enzyme Process) Particulate Emissions 86

Figure 60: Chaparral (Enzyme Process) Non-methane Hydrocarbon Emissions 86

Figure 61: Chaparral (Enzyme Process) $\mathrm{SO}_{\mathrm{x}}$ Emission $\quad 86$

Figure 62: Chaparral (Enzyme Process) $\mathrm{NO}_{\mathrm{x}}$ Emissions $\quad 87$

Figure 63: Chaparral (Enzyme Process) $\mathrm{NO}_{\mathrm{x}}$ Emissions for Option 2 by Source $\quad 87$

Figure 64: Chaparral (Enzyme Process) $\mathrm{NO}_{\mathrm{x}}$ Emissions for Option 1 by Source $\quad 87$

Figure 65: Chaparral (Enzyme Process) Total Energy Consumption 88

Figure 66: Chaparral (Enzyme Process) Nonrenewable and Renewable Energy Consumption $\quad 88$

$\begin{array}{ll}\text { Figure 67: Mass Flow Diagram for Chaparral—Acid Process } & 90\end{array}$

Figure 68: Chaparral (Acid Process) Carbon Monoxide Emissions 91

NREL, CARB, CEC, CDF, Ecobalance Inc., TSS Consultants

March, 1999

Final Report

Kadam et al. 
Figure 69: Chaparral (Acid Process) Non-methane Hydrocarbon Emissions 91

Figure 70: Chaparral (Acid Process) $\mathrm{SO}_{\mathrm{x}}$ Emissions 91

Figure 71: Chaparral (Acid Process) Particulate Emissions 91

Figure 72: Chaparral (Acid Process) $\mathrm{NO}_{\mathrm{x}}$ Emissions $\quad 92$

Figure 73: Chaparral (Acid Process) $\mathrm{NO}_{\mathrm{x}}$ Emissions for Option 2 by Source 92

Figure 74: Chaparral (Acid Process) $\mathrm{NO}_{\mathrm{x}}$ Emissions for Option 1 by Source 92

Figure 75: Chaparral (Acid Process) Total Energy Consumption 93

Figure 76: Chaparral (Acid Process) Nonrenewable and Renewable Energy Consumption 93

Figure 77: Overview of Carbon Balance $\quad 95$

Figure 78: Greenhouse Effect Impact Potential 100

Figure 79: Air Acidification Impact Potential $\quad 101$

Figure 80: Eutrophication Impact Potential 102

Figure 81: Natural Resource Depletion Potential 103

Figure 82: Life Cycle Impact Assessment Framework 125

Figure 83: Natural Resource Depletion Impact Equations $\quad 129$

Figure 84: Sacramento Valley Rice Straw Availability 134

Figure 85: Forest Residue Biomass Potential 136

$\begin{array}{ll}\text { Figure 86: Southern California Chaparral Residue Availability } & 137\end{array}$

$\begin{array}{ll}\text { Figure 87: Petroleum Products Modeling } & 140\end{array}$

Figure 88: Conventional Onshore Crude Oil Extraction 141

Figure 89: Conventional Offshore Crude Oil Extraction 146

Figure 90: Advanced Onshore (Steam Injection) Crude Oil Extraction 150

Figure 91: Advanced Onshore ( $\mathrm{CO}_{2}$ Injection) Crude Oil Extraction $\quad 152$

Figure 92: Crude Oil Transportation Modeling 158

Figure 93: Crude Oil Transportation Modeling $\quad 160$

Figure 94: Petroleum Refining System Description $\quad 161$

Figure 95: Petroleum Products Transportation Modeling 170

NREL, CARB, CEC, CDF, Ecobalance Inc., TSS Consultants

March, 1999

Final Report

Kadam et al. 


\section{ACKNOWLEDGMENTS}

This work was supported by the Bioconversion Element of the Office of Fuels Development of the U.S. Department of Energy, the California Air Resources Board, the California Energy Commission, and the California Department of Forestry and Fire Protection. The authors wish to thank these entities not only for their financial support but also for their wisdom in recognizing the importance of this study. The members of the Review Committee (see Appendix F) deserve a special mention for their thoughtful review of this report and many useful comments and suggestions. We also acknowledge many colleagues (too numerous to name) at our respective establishments for their valuable feedback and discussion. 


\section{EXECUTIVE SUMMARY}

\section{Project OVERVIEW}

The open burning of biomass generates significant air emissions annually in California. Historically, some important sources of these emissions have been the open-field burning of excess rice straw, and the burning of forest residue and chaparral. These can especially be of concern where they are emitted during days when ground-level ozone concentrations are elevated. Open burning can be seen as a "disposal method" for these biomass sources. One means of reducing air emissions and other negative impacts associated with this disposal method is to use this biomass as a feedstock for ethanol production. Biomass-derived ethanol can be used as a fuel oxygenate, either by itself or in the form of its ether derivative, ethyl tertiary-butyl ether (ETBE). This oxygenate can be used as a substitute for methyl tertiary-butyl ether (MTBE), which is currently being used in reformulated gasoline in the state of California and elsewhere in the United States. Therefore, the focus of this report is to quantify and compare the comprehensive environmental flows over the life cycles of two disposal scenarios: (1) the burning of the biomass plus the production and use of MTBE, and (2) the conversion of the biomass into ETBE and its subsequent use.

To facilitate the presentation of results, these two scenarios are referred to as the MTBE scenario and the ETBE scenario, respectively. The results of the study were compared in terms of potential impacts of the pollutants emitted (e.g., greenhouse gases, acidification potential, etc.). This was not a risk assessment study and did not consider MTBE or ETBE contamination of groundwater. A study of this nature would need to be site-specific and is outside the scope of this investigation. This report shows the life cycle emissions of the two scenarios, meaning that the results are summarized over different locations and different time frames. Therefore, it does not take into account the fact that open burning results in a pulse of emissions at one time and location versus ETBE combustion in a vehicle that takes place over a longer period of time and at different locations. This report only shows the difference in the total emissions of the two options and does not account for concentrations of pollutants at a given time. For the same reasons, ozone-forming potential was not calculated, which again would require site- and timedependent data that were not collected for this study.

\section{BIOEThanol ANd ETBE Production Potential}

Table 1 summarizes the volumes of ethanol and ETBE that could be produced if all of the biomass that is available and can be collected in California is converted to ethanol. While not all of the accessible biomass would likely be available for ethanol and ETBE production, these values are illustrative. More discussion of the availability of the biomass types can be found in Appendix C.

Table 1: Biomass-Derived Ethanol and ETBE Production Potential in California

\begin{tabular}{lcccc}
\hline Biomass Source & $\begin{array}{c}\text { Estimated Availability } \\
\text { in California } \\
\text { million metric bone } \\
\text { dry tons/yr }\end{array}$ & $\begin{array}{c}\text { Ethanol Production } \\
\text { Method }\end{array}$ & $\begin{array}{c}\text { Ethanol Production } \\
\text { Potential } \\
\text { million liters/yr }\end{array}$ & $\begin{array}{c}\text { ETBE Production } \\
\text { Potential } \\
\text { million liters/yr }\end{array}$ \\
\hline \hline Rice Straw & 1.4 & Enzyme & 439.7 & $1,033.7$ \\
Forest Residue & \multirow{2}{*}{5.7} & Acid & 396.4 & 932.0 \\
& & Enzyme & $1,965.0$ & $4,619.0$ \\
Chaparral & \multirow{2}{*}{2.0} & Acid & $1,596.7$ & $3,753.0$ \\
& & Enzyme & 235.7 & 553.9 \\
\hline
\end{tabular}

Of the amount of MTBE that is consumed annually in California, only $15 \%$ is produced within the state; the remaining $85 \%$ is imported. Therefore, using existing plant capacity for ether production and infrastructure, only the $15 \%$ in-state production can potentially be offset in the near-term. Table 2 gives an idea of how much ETBE could be produced in California each year using this approach. There are some options available for satisfying the 
rest of the oxygenate demand using biomass-derived ETBE; however, their feasibility would depend on economical and market factors, which are beyond the scope of this study. It should be noted that this limitation only applies to ethers, and that biomass-derived ethanol produced within the state can potentially fulfill the entire oxygenate demand. This option was analyzed as part of the sensitivity analysis discussed later.

Table 2: Near-Term ETBE Production in California

\begin{tabular}{ccccc}
\hline \multicolumn{2}{c}{$\begin{array}{c}\text { MTBE Produced in } \\
\text { California } \\
\text { million } \\
\text { liters } / \mathrm{yr}\end{array}$} & $\begin{array}{c}\text { ETBE Needed on } \\
\text { theusand }\end{array}$ & $\begin{array}{c}\text { Oxygen-Equivalent Basis } \\
\mathrm{kg} \mathrm{ETBE} / \mathrm{kg} \text { MTBE } / \mathrm{yr}\end{array}$ & $\begin{array}{c}\text { ETBE Needed for Near-Term } \\
\text { Scenario } \\
\text { thousand metric } \\
\text { tons } / \mathrm{yr}\end{array}$ \\
\hline \hline 56.8 & 42.2 & 1.162 & 65.8 & 49.0 \\
\hline
\end{tabular}

Table 3 summarizes the amounts of ethanol and ETBE that can be produced by biomass type and by ethanol production method. These values are normalized for one metric bone-dry ton of biomass. The final two columns also show the equivalent amount of MTBE and gasoline this amount of ETBE would displace. That is, the $549.7 \mathrm{~kg}$ of ETBE produced from rice straw using the enzyme process would offset the use of $472.7 \mathrm{~kg}$ of MTBE and $77 \mathrm{~kg}$ of gasoline. This difference is because ETBE has a slightly higher heating value than MTBE.

Table 3: Ethanol and ETBE Yield by Biomass Type

\begin{tabular}{|c|c|c|c|c|c|}
\hline \multirow{2}{*}{$\begin{array}{l}\text { Biomass Source } \\
\text { One metric bone dry } \\
\text { ton }(1000 \mathrm{~kg})\end{array}$} & \multirow{2}{*}{$\begin{array}{c}\text { Ethanol } \\
\text { Production } \\
\text { Method }\end{array}$} & \multirow{2}{*}{$\begin{array}{c}\text { Ethanol } \\
\text { Produced } \\
\text { (liters) }\end{array}$} & \multirow{2}{*}{$\begin{array}{c}\text { ETBE } \\
\text { Produced }^{a} \\
\text { (liters) }^{\text {(iiters }}\end{array}$} & \multicolumn{2}{|c|}{ Equivalent in MTBE plus Gasoline } \\
\hline & & & & MTBE (liters) & Gasoline (liters) \\
\hline \multirow[t]{2}{*}{ Rice Straw } & Enzyme & 314.1 & 738.3 & 635.9 & 104.3 \\
\hline & Acid & 283.2 & 665.7 & 573.4 & 94.0 \\
\hline \multirow[t]{2}{*}{ Forest Residue } & Enzyme & 344.7 & 810.3 & 698.1 & 114.2 \\
\hline & Acid & 280.1 & 658.4 & 567.2 & 92.9 \\
\hline \multirow[t]{2}{*}{ Chaparral } & Enzyme & 117.8 & 277.0 & 238.6 & 39.0 \\
\hline & Acid & 105.7 & 248.4 & 213.9 & 35.1 \\
\hline
\end{tabular}

a Ethanol and isobutylene are reacted to produce ETBE; hence, the increase in volume.

\section{BASELINE RESULTS}

The results of the study are presented for six scenarios modeled using different feedstocks and methods of producing ethanol. More precisely, each of the three feedstocks (rice straw, forest residue, and chaparral) was modeled using an enzyme process and a concentrated acid process to produce ethanol. These scenarios follow the base-case assumption that the entire amount of lignin-rich residue generated during the production of ethanol is used for onsite cogeneration of steam and electricity.

In terms of net environmental flows, the production of ETBE from any of the three biomass feedstocks produces lower emissions than open-field burning the biomass and the production of MTBE. Specifically, criteria air pollutants - including non-methane hydrocarbons, carbon monoxide, oxides of nitrogen and particulates - show significantly lower net emissions with the production of ETBE. However, in the production of ethanol for ETBE, higher water effluents (e.g., nitrates) result.

Table 4 summarizes the differences between the two scenarios for criteria air pollutants, carbon dioxide, and energy consumption. The differences are expressed as percentages by which the values for the ETBE scenario were different from those for the MTBE scenario [i.e., 100x(MTBE value-ETBE value)/MTBE value]. A positive value indicates the percentage by which the values for the ETBE scenario were lower than those for the MTBE scenario 
and vice versa. For example, the ETBE scenario, with rice straw conversion via enzymatic hydrolysis, had a $97 \%$ reduction in carbon monoxide emissions compared to those for the MTBE scenario.

Table 4: Relative Differences between ETBE Scenario and MTBE Scenario

\begin{tabular}{lcccccc}
\hline \multicolumn{1}{c}{ Environmental Flow } & \multicolumn{2}{c}{ Rice Straw } & \multicolumn{2}{c}{ Forest Residue } & \multicolumn{2}{c}{ Chaparral } \\
& Enzyme & Acid & Enzyme & Acid & Enzyme & Acid \\
\hline \hline Carbon Monoxide & $97 \%$ & $95 \%$ & $98 \%$ & $98 \%$ & $97 \%$ & $96 \%$ \\
Non-methane & $61 \%$ & $64 \%$ & $57 \%$ & $61 \%$ & $97 \%$ & $89 \%$ \\
Hydrocarbons & & & & & & \\
Nitrogen Oxides $\left(\mathrm{NO}_{\mathrm{x}}\right)$ & $69 \%$ & $57 \%$ & $69 \%$ & $54 \%$ & $23 \%$ & $\mathbf{- 1 0 2 \%}$ \\
Particulates & $89 \%$ & $44 \%$ & $93 \%$ & $68 \%$ & $96 \%$ & $81 \%$ \\
Sulfur Oxides $\left(\mathrm{SO}_{\mathrm{x}}\right)$ & $84 \%$ & $81 \%$ & $87 \%$ & $79 \%$ & $83 \%$ & $58 \%$ \\
Carbon Dioxide & $52 \%$ & $25 \%$ & $58 \%$ & $35 \%$ & $68 \%$ & $-9 \%$ \\
Total Energy & $16 \%$ & $\mathbf{- 2 6 \%}$ & $23 \%$ & $\mathbf{- 1 5 \%}$ & $6 \%$ & $\mathbf{- 1 1 5 \%}$ \\
Consumption & & & & & & \\
\hline
\end{tabular}

It should be noted that this report shows the life cycle emissions of the two options, meaning that the results are summarized over different locations and different time frames. Therefore, it does not take into account the fact that open burning results in a pulse of emissions at one time and location versus ETBE combustion in a vehicle that takes place over a period of time and at different locations. This report only shows the difference in the total emissions of the two options and does not account for concentrations of pollutants at a given time.

\section{Rice Straw}

For the rice straw feedstock using the enzyme process scenario, the conversion of the biomass to ETBE leads to a decrease from the MTBE scenario for almost all of the environmental flows. The one exception is nitrates in water run-offs.

Nitrates (which are not listed in Table 4 above) are significantly higher for the ETBE scenario mainly because of the use of corn steep liquor (CSL) during ethanol fermentation. Agricultural operations lead to water run-offs containing fertilizer-derived nitrates. CSL is a by-product of corn wet-milling and has nitrates emissions associated with its production. It is, however, not mandatory that CSL be used during ethanol fermentation, and nonagricultural based alternatives are possible. It should be noted that the nitrates emissions occur at the geographical site where corn is grown, i.e., near the farm.

The four impact assessment categories - eutrophication potential, depletion of natural resources, greenhouse gas potential, and air acidification potential - show lower values for the ETBE scenario than for the MTBE scenario. Thus, despite higher nitrates values, the ETBE scenario shows a lower eutrophication potential. Also, the renewable portion of the total energy consumed is higher for the ETBE scenario than for the MTBE scenario. Using a renewable resource such as biomass in general helps to reduce the depletion of nonrenewable resources, and power generation using a low-sulfur residue allows for lower $\mathrm{SO}_{\mathrm{x}}$ emissions and air acidification.

The relative life cycle flows are mostly similar when a concentrated acid process is used instead of an enzymatic process for ethanol production. In terms of the criteria pollutants, the acid-based process results in higher emissions than the enzyme-based process; however, the emissions are still lower than the emissions for the MTBE scenario. The major difference arises from the fact that the acid process requires more energy than the enzyme process in the form of natural gas used to generate steam, contributing to the criteria pollutants. Also, use of additional natural gas in the concentrated acid process leads to a greater depletion of natural resources than that for the MTBE scenario. 


\section{Forest Residue}

The forest residue yields results similar to those for rice straw. Rice straw is burned in place, whereas forest residue is collected before burning. In spite of this, the reduction in total energy consumption (compared to the MTBE scenario) is higher for forest residue. This is attributable to the lower heating value of the rice-straw fuel residue due to its high silica content.

\section{Chaparral}

For chaparral conversion via the enzymatic process, the ETBE scenario yields values that are much lower than those for the MTBE scenario for most of the environmental flows. The exceptions are those values that are dependent on ethanol production, such as nitrates. Many of the other emissions for the ETBE scenario are lower because of the relatively high amount of lignin in chaparral. This leads to lower $\mathrm{SO}_{\mathrm{x}}, \mathrm{NO}_{\mathrm{x}}$, and fossil $\mathrm{CO}_{2}$ emissions because of the correspondingly high electricity offset credits. Additionally, chaparral is also high in extractives, which are converted to biogas during wastewater treatment. The biogas is used as an energy source, which also provides similar offset credits. For these reasons, chaparral yields lower values - when compared to either forest residue or rice straw-for the four impact categories examined-eutrophication, depletion of natural resources, air acidification, and greenhouse gas potential. Chaparral also results in lower emissions of the criteria pollutants than those for forest residue or rice straw.

Another key observation is that the reduction in total energy consumption (compared to the MTBE scenario) is the lowest for chaparral. This is because of higher energy required during its collection and during ethanol distillation, which receives a more dilute feed due to chaparral's low sugar content.

Using the concentrated acid process instead of the enzyme process yields similar relative performance of the ETBE option versus the MTBE option. The general discussion above regarding the differences between the two ethanol processes using rice straw applies also to chaparral.

\section{SENSITIVITY ANALYSIS}

The results presented above were relative to the base case for the ETBE scenario, i.e., on-site cogeneration of steam and electricity using the ligneous residue generated during the production of ethanol, and etherification of ethanol to yield ETBE. To gain further insights into the process, two variations on the theme were evaluated: 1) Shipping the fuel residue off-site to an existing biomass power plant, and 2) bypassing etherification and using ethanol itself as an oxygenate. These are elucidated below.

\section{Shipping of Fuel Residue}

Shipping the fuel residue off-site to an existing biomass power plant is another practical way to utilize fuel residue without having to build an on-site power plant. The emissions related to drying the residue further and transporting it a given distance ( 50 miles was the distance used in the analysis) are added to the ETBE scenario. The differences between the two scenarios are lower than those for the base case; however, the general conclusions do not change.

\section{0\% Ethanol Blend (E10)}

The environmental impact was evaluated for the case of using ethanol as a direct fuel additive as opposed to transforming the ethanol first into ETBE before being added to gasoline. A blend of $10 \%$ by volume of ethanol with gasoline was used to model an ethanol-based reformulated gasoline. The $10 \%$ blend (referred to as E10) was used as it represents a fairly standard blend of ethanol with gasoline and has similar properties as MTBE reformulated gasoline.

As opposed to the baseline model, there is a difference in the emissions from the combustion of E10 reformulated gasoline versus MTBE reformulated gasoline. This is because in the baseline model both the fuels have the same oxygen level and heating value. In this case study, the two fuels have the same heating value but not the same oxygen level; the E10 blended fuel has 3.5\% oxygen compared to $2 \%$ oxygen for the baseline fuel. The difference in the composition of the fuels causes differences in the tailpipe emissions of vehicles using the fuels. Therefore, the 
emissions from the combustion of the fuels were taken into account in the comparison. Also, the E10 blended fuel has higher evaporative emissions than MTBE blended fuel, so evaporative emissions during blending operations were also taken into account.

Overall, except for water effluents (nitrates and COD) and $\mathrm{NO}_{\mathrm{x}}$ emissions, the $\mathrm{E} 10$ scenario has lower emission values than those for the MTBE scenario; many of the higher emissions for the E10 option are attributable to the ethanol production step. The differences between this sensitivity scenario and the baseline scenario are due to the fact that more ethanol is required for the former.

A major difference between the E10 and ETBE scenarios is that the E10 scenario is not limited by isobutylene availability, and ethanol produced within the state can potentially satisfy all of the oxygenate demand, i.e., it can substitute MTBE that is produced in the state as well as that is imported.

\section{CONCLUSIONS}

It is likely that agricultural burning and forestry residue disposal will be problematic issues in California for the foreseeable future. This study provides specific quantitative data on biomass disposal options in California and environmental implications of ether-based oxygenates for gasoline. While the study does not include information on the current concern over MTBE groundwater contamination, it does provide data on true environmental costs of fuel systems that may be useful for public policy makers now confronting the difficult choices of oxygenate use.

The life cycle assessment performed in this study demonstrates the potentially significant benefits of using ETBE derived from California biomass. Overall, the results show that there is a significant difference between Options 1 and 2 (MTBE scenario and ETBE scenario, respectively); the magnitude of this difference varies with the types of biomass feedstocks and ethanol production processes. However, in all cases, the comparison of the ETBE scenario with the MTBE scenario revealed a fundamental difference in terms of energy derived from renewable sources and concomitant benefits of reduced greenhouse gas emissions. This difference can be significant when aiming to shift fuel choices to renewables.

Important benefits are also found with the ETBE scenario with regard to emissions reductions. The ETBE scenarios have lower net energy consumption and carbon dioxide emissions, which - although not regulated or mandated by state or federal laws - are desirable attributes. Specifically, the following prevailing trends were discernible for the ETBE scenarios

Lower net values for:

- $\quad$ Carbon monoxide

- $\mathrm{SO}_{\mathrm{x}}$ and $\mathrm{NO}_{\mathrm{x}}$

- Particulates

- Carbon dioxide

- Fossil energy consumption

Hence, implementation of the ETBE scenario would facilitate the improvement of air quality. Emissions of nitrates in water runoffs, however, were somewhat higher for ETBE production. This is due to the use of CSL during ethanol fermentation. It should be noted that these nitrate emissions are upstream of the ethanol production step and occur at the geographical site where corn is grown.

The four impact assessment categories - eutrophication potential, depletion of natural resources, greenhouse gas potential, and air acidification potential - exhibit lower values for the ETBE scenario as compared to the MTBE scenario. The ETBE scenario manages to achieve a lower eutrophication potential in spite of the higher nitrates values. Hence, the ETBE scenario is shown to commonly exhibit lower values than the MTBE scenario for key environmental criteria, both regulated and unregulated. The same can be said when the E10 scenario is compared with the MTBE scenario if we exclude the case of chaparral-acid process. 
Finally, this effort is part of a larger picture for transportation fuels. This work may be used as a stepping stone for future studies to develop additional life cycle inventories, such as those for low-ethanol blends (e.g., $10 \%$ ethanol blend using a low RVP gasoline), high-ethanol blends (e.g., E85-85\% ethanol, 15\% gasoline blend), and others. 


\subsection{BACKGROUND}

\subsubsection{Purpose of the Study}

Historically, a large portion ( $>90 \%)$ of the excess agricultural residue produced in California (approximately 10 million dry metric tons per year) has been disposed of through the use of open-field burning. Because of concerns over the amount of air pollutants released through this practice, federal, state, and local air quality agencies have been tightening regulations related to the burning of agricultural biomass. In looking at the alternatives to burning, a California Legislative Committee determined that the production of ethanol from the excess biomass was a viable option.

A related concern is the growing volume of dead/diseased trees, underbrush, and small diameter green trees in California that are creating a severe forest management problem. With the state government's concern about burning as a management option, some of this forest biomass is available for ethanol production.

Besides the above two sources of feedstock, chaparral or brush can be another source of biomass that, if not removed, can eventually be consumed by wildfires in California. Although little commercial use is made of chaparral, the brush lands surrounding a considerable number of California's homes in the wildland areas could be a major source of biomass for an ethanol facility. In fact, the existence of these homes could justify greater investments to mechanically remove the chaparral and transport it to an ethanol facility. The local, state, and federal entities responsible for wildland fire protection would also be supportive of assessing the potential conversion of chaparral to ethanol since it is one of their major fuel loading problems.

One of the uses of biomass-derived ethanol is as a fuel oxygenate. The Clean Air Act Amendments of 1990 mandated the sale of oxygenated fuels in ambient air quality nonattainment areas; ${ }^{1}$ so there has been a sharp increase in the demand for these products. The two main oxygenates sold in the United States are methyl tertiarybutyl ether (MTBE) and ethanol. However, MTBE is currently the oxygenate of choice in California for reasons explained below.

The California Cleaner-Burning Gasoline regulations specify a summertime Reid vapor pressure (RVP) standard, ${ }^{2}$ which limits the evaporation of volatile organic compounds, and oxygen content limits, which apply equally regardless of the oxygenate used (typically MTBE).

Until the start of the Cleaner-Burning Gasoline program, state law allowed blends of gasoline with $10 \%$ ethanol (3.5 wt.\% oxygen) an exemption from the RVP standard. However, in the Cleaner-Burning Gasoline program, the California Air Resources Board (CARB) established comprehensive gasoline specifications that apply to all fuels, including ethanol blends. This effectively eliminated the RVP waiver previously available to ethanol blends. In essence, ethanol blends do not qualify for the RVP exemption because the oxygen content limits preclude the use of greater than $2.7 \%$ oxygen to avoid $\mathrm{NO}_{\mathrm{x}}$ increases.

Hence, the direct replacement of MTBE with ethyl tertiary butyl ether (ETBE) is the focus of this study; however, the E10 option is also analyzed as part of the sensitivity analysis. Although the benefits of utilizing these three feedstocks for ETBE production are qualitatively evident, the environmental aspects of the biomass disposal options (burning or ETBE production) have not been comprehensively assessed. In fact, the full set of environmental aspects associated with a product such as a fuel additive is very broad, both in terms of the environmental media or issues involved and in terms of the scope of industrial processes involved.

\footnotetext{
1 Geographical areas whose air quality does not meet federal air quality standards (for CO, ozone, and particulate matter) designed to protect public health.

2 The State of California limits the RVP for summertime gasoline to 7.0 psi. 
The purpose of the present study is to quantify and compare the comprehensive sets of flows to and from the environment (raw material and energy use, wastes, emissions, etc.) associated with the disposal options for California biomass over their life cycles.

\subsubsection{Project Partners}

This project was being conducted by the National Renewable Energy Laboratory (NREL) and the State of California through CARB, the California Energy Commission (CEC), and California Department of Forestry and Fire Protection (CDF). TSS Consultants, Inc. of Rancho Cordova, California, and Ecobalance, Inc. of Rockville, Maryland, served as consultants on this project.

\subsubsection{Related Research}

Biomass-derived ethanol has recently been the subject of life cycle analyses (LCAs) from both environmental and economic perspectives. In 1993 three of the U.S. Department of Energy's (DOE) laboratories completed a life cycle comparison of biomass ethanol and reformulated gasoline [1,2,3]. There has also been a series of studies estimating the life cycle energy balance of ethanol derived from corn [4,5]. The most recent of these studies, by researchers with the U.S. Department of Agriculture's Economic Research Service, includes a review of this literature and summarizes the factors contributing to variability in published results and conclusions on this issue. There are also a few reports that have focused on the state of California:

- Craig, Unnasch, and Lowell, The Effect of Fuel Cycle Energy Efficiency and Transportation Efficiency on Greenhouse Gas Emissions, March 1991

- Unnasch, Moyer, Lowell, and Jackson, Comparing the Impacts of Different Transportation Fuels on Greenhouse Effect, April 1989

- Darrow, Comparison of Fuel Cycle Emissions for Electric Vehicle and Ultralow Emissions Natural Gas Vehicle, May 1994; Darrow, Light Duty Vehicle Full Fuel Cycle Emissions Analysis; April 1994.

The objective of the current study goes beyond these past projects by quantifying and comparing the comprehensive sets of flows associated with the disposal options for California biomass, including air emissions, water effluents, solid waste, and the consumption/depletion of resources. However, the analysis does not include an examination of toxicological effects, since that is beyond the capacity of the LCA tool. All of these flows are examined over the product life cycle, from production and extraction of raw materials, through intermediate conversion processes, transportation, distribution, and use. Net life cycle energy consumption ("energy balance") is one component of the more comprehensive scope of an LCA such as undertaken in this study. Life Cycle Cost assessment is outside the scope of the present study.

\subsubsection{Stakeholder Involvement}

For several reasons, a key ingredient of this project is the involvement of a broad group of interested stakeholders. Firstly, the results of a life cycle study such as this are strongly influenced by decisions made at the study outset, related to scoping, modeling, and methodology. Objectivity as well as acceptance of the results depends upon widespread critique and feedback from stakeholders on tentative scoping, modeling, and methodological decisions.

Secondly, the quality and utility of the study's results depend upon the use of data characterizing processes throughout the life cycles of biomass disposal alternatives that are comprehensive, accurate, validly comparable, and up-to-date.

For both reasons, the formative and early stages of this project allowed for input and comment on the approach from all stakeholders. These stakeholders included government agencies (federal, state, and local), the petroleum industry, ethanol producers, ethanol trade associations, timber industry companies, the biomass electricity industry, the biomass collection industry, agriculture groups, environmental groups, consumer groups, and fuel users. 


\subsection{Project PHASES}

The project was divided into three tasks, which corresponded to the three project phases:

- TAsk I: Establish ApProach to Life CyCle ANALYsis

* Step 1: Establish Draft Scoping Document

* Step 2: Present and Discuss Draft Scoping Document with Key Stakeholders

* Step 3: Prepare Final Scoping Document

- TASK II: DeVElop DATABASE FOR LifE CYCle ANALYSIS

* Step 1: Obtain Data on Resource Production, Collection and Distribution

* Step 2: Obtain Data on Existing Biomass Disposal Method

* Step 3: Obtain Data on ETBE Production

* Step 4: Obtain Data on MTBE Production

* Step 5: Input Data into the LCA Database

* Step 6: Report on the LCA Database

- TASK III: CONDUCT LIFE CyCle ANALYSIS

* Step 1: Develop Models for ETBE and MTBE Production

* Step 2: Generate Final Report 


\subsection{OVERVIEW}

Life cycle assessment is a technique for assessing the environmental aspects and potential impacts associated with a product, by

- Compiling an inventory of relevant inputs and outputs of a system (life cycle inventory [LCI])

- Evaluating the potential environmental impacts associated with those inputs and outputs

- Interpreting the results of the inventory and impact phases in relation to the objectives of the study.

Life cycle assessment studies the environmental aspects and potential impacts throughout a product's life (i.e., cradle-to-grave) from raw material acquisition through production, use, and disposal. The general principle for extending the system boundaries is illustrated in Figure 1, although the boundaries may not all be relevant to the LCA of a transportation fuel.

In the most straightforward and transparent approach to LCI interpretation, the inventory results may be used as-is to help identify and prioritize opportunities for pollution prevention or increases in material and energy efficiency for processes within the life cycle. A particular advantage of LCI applied in this way is its comprehensiveness. LCAs help detect the shifting of environmental burdens from one life cycle stage to another (e.g., lower energy consumption during use, achieved at the cost of much higher manufacturing energy consumption), or from one medium to another (e.g., lower air emissions at the cost of increased solid waste).

Because the number of flows calculated during an LCI analysis is often very large, subsets of the flows are sometimes consolidated or aggregated to facilitate interpretation, especially when two or more products or processes are being compared using LCA. This consolidation/aggregation of flows has been given the (perhaps misleading) name of Life Cycle Impact Assessment (LCIA). In fact, it is not the impacts of the environmental flows in the inventory that are estimated using LCIA. Instead, the inventory flows are consolidated and aggregated using information about their relative potential strength of influence with respect to separate categories of potential environmental impact, thereby generating indicators. The results within each LCIA impact category are useful for comparison of one product or process versus another, but have little meaning in an absolute sense (i.e., relative to estimating the actual environmental impacts of a product or process).

Because the results of an LCI and an LCIA are influenced by a significant number of assumptions and uncertainties, the interpretation phase includes some sensitivity analyses. This allows an assessment of the robustness of the baseline results, project assumptions, methodological choices, future scenarios, and uncertainties. In this study, data quality was assessed for its 1) precision, 2) completeness, 3) representativeness, 4) consistency, and 5) the origin of the data (measured, calculated, estimated).

Principal aspects of LCI and LCIA are discussed briefly in the sections that follow. Further information about LCA methodology is provided in a number of publications from the Society of Environmental Toxicology and Chemistry $[1,2,3,4]$, the U.S. EPA [5,6,7], the International Organization for Standardization (ISO) $[8,9]$, as well as a few European sources $[10,11]$. 


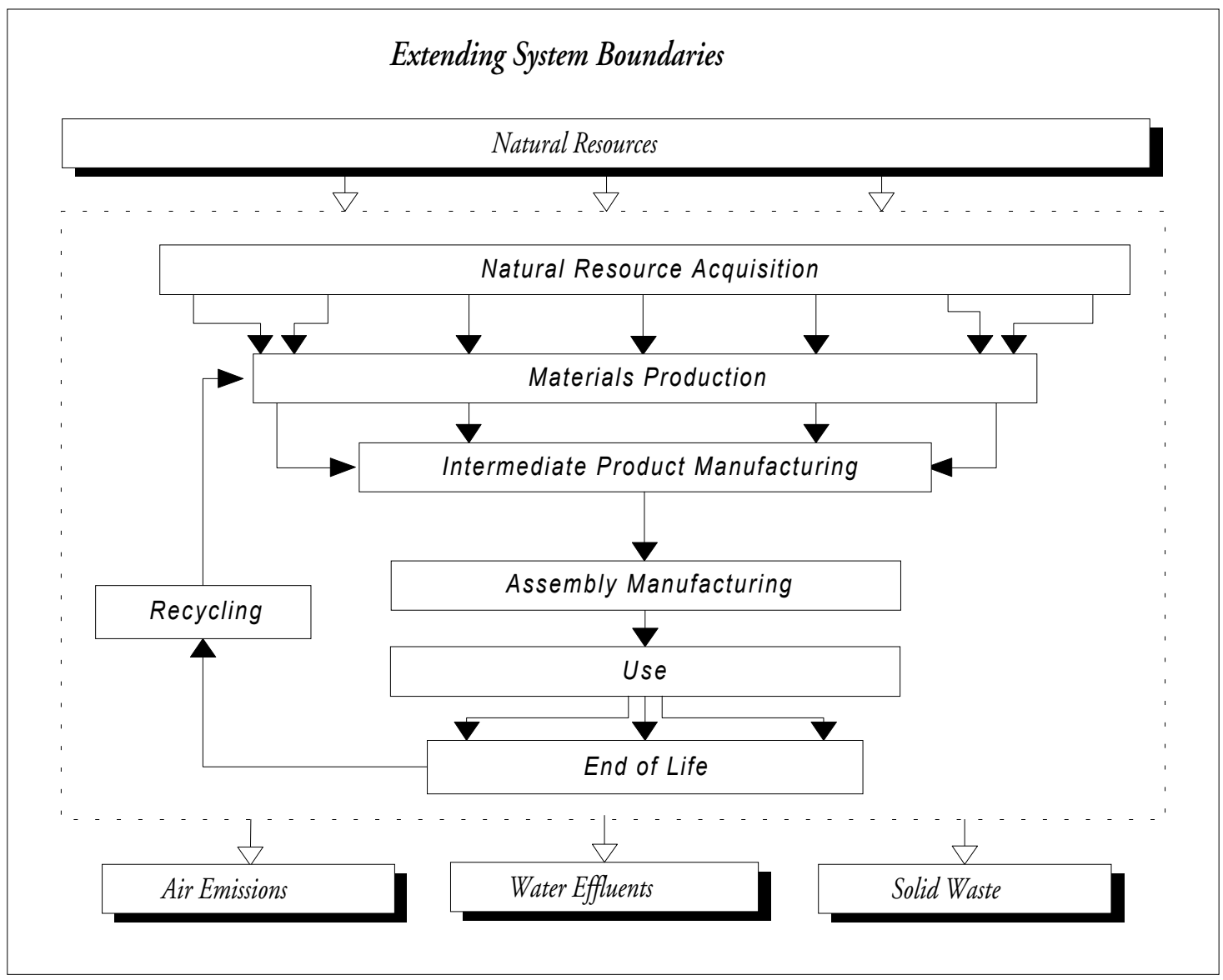

Figure 1: Life Cycle Analysis Principles

\subsection{MethodOLOGY}

\subsubsection{Functional Unit}

The comparison of different industrial systems can only be achieved if they perform the same function. Once this shared function is defined a unit has to be chosen in order to compare the systems on the same quantitative basis. All the energy and mass flows in the inventory are normalized to this functional unit. Examples of how this is done are presented below:

- The comparison of different indoor paints (solvent-borne, water-borne, etc.) would be made on the following basis:

* Function: covering a surface,

* Functional unit: the quantity of paint required to cover 10 square feet of wall (this function could be further refined to take into account secondary functions like opacity, washability, durability and lifetime, etc.).

- The comparison of different gasoline additives could be made on the following basis:

* Function: addition of oxygen to fuel,

* Functional unit: the quantity of additive required to achieve an oxygen content of $2 \%$. 


\subsubsection{Definition of the System Boundaries}

For each option being compared on a life cycle basis, the corresponding systems are then determined (i.e., relevant processes to be included in the system are selected). The three main issues to address, for each of the systems, are:

1) Exhaustivity of the systems. The LCA theoretical principle implies that each material and constituent be studied and traced back to natural resources, and forward through final disposal. The strict application of this principle would lead to the study of almost every industrial process, as all industrial operations work within a complex network.

In order to focus LCA projects on the main operations, quantitative rules are applied to exclude the constituents and ancillary materials whose impacts are estimated to be negligible compared to those of the overall studied system. Any systems that are excluded and the reasons for their exclusion will be provided in the presentation of the project.

2) Identification of steps/operations that are different from one system to another. As the project focuses on a comparison, steps that are functionally equivalent for the compared products could be excluded from both systems. On the other hand, steps or operations that are not functionally equivalent for the compared products should be taken into account, i.e., included in the system boundaries. Any excluded steps will be indicated in the project presentation.

3) Identification of coproducts and determination of the appropriate partitioning parameter. This facilitates proper allocation to a defined product its share of the total pollution, energy consumption and material flows for which the process is responsible.

\subsubsection{Interpretation: Life Cycle Impact Assessment}

In this section of the LCA, after the inventory has been prepared, there are two further steps that need to be considered:

1) Whether and how to aggregate/consolidate the inventory data using information about each flow's relative potential strength of influence with respect to separate categories of potential environmental impact; and

2) Whether and how to aggregate the results of the step mentioned above, across the impact categories considered.

Note that the first of these two steps is pursued in addition to the LCIA, not as a replacement for it.

Those attempting to develop a final "score" for comparing products or processes only use the second of these two aggregation steps. It was not used in this project because it is fraught with numerous problems whose discussion is beyond the scope of this document.

Uncertainties associated with input parameters were examined through sensitivity analysis, which includes an examination of data quality and its influence on the final report. 
This section presents the various parameters that should be considered in order to define precisely the scope of the project. These parameters can be addressed sequentially, as indicated in Figure 2. We begin by first considering "project" level parameters that involve high-level choices that can have a profound impact on the general orientation and outcome of the project. These choices involve geographic, temporal, technical, and environmental aspects of the life cycle scenarios considered. Next, we need to consider more specific product parameters, including the exact nature and form of the products studied and the type of application in which they are used. The third group of parameters involves the production processes used to make the product. The types of choices made for high-level project parameters influence both product- and process-related parameters. Finally, there is a group of parameters that must be defined regarding the methodology of the LCA itself.

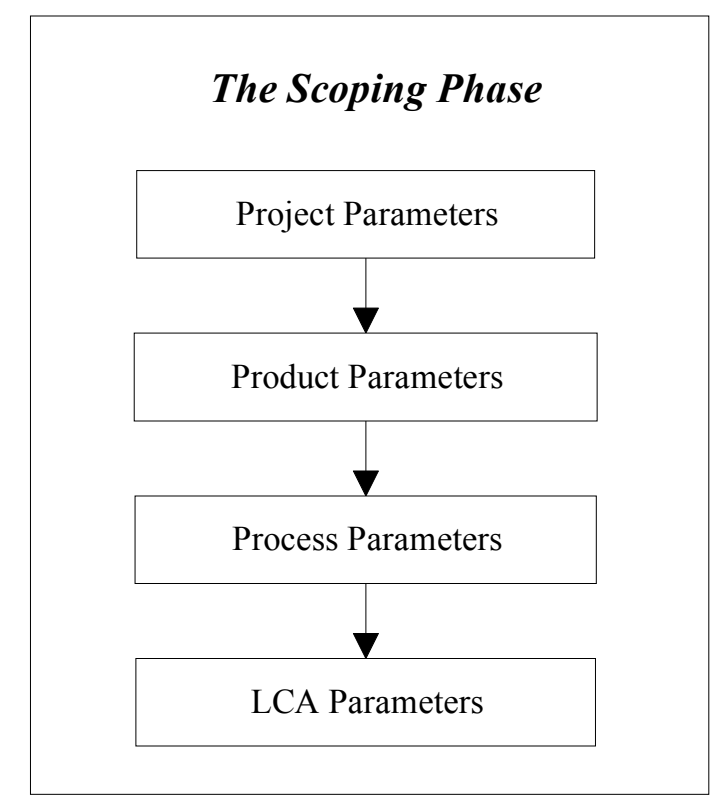

Figure 2: Elements of the Scoping Phase for Life Cycle Analysis

Subsequent sections address the separate scoping elements in turn, as follows:

$\begin{array}{lll}\text { Project Parameters } & \Rightarrow & \text { Section 3.1 } \\ \text { Product Parameters } & \Rightarrow & \text { Section 3.2 } \\ \text { Process Parameters } & \Rightarrow & \text { Section 3.3 } \\ \text { LCA-Specific Parameters } & \Rightarrow & \text { Section 3.4 }\end{array}$

The key criteria that have been accounted for in selecting an option for each parameter are:

- Relevance to the project's goals

- Availability of data, and

- $\quad$ Time and cost constraints 


\subsection{Project PARAMETERS}

\subsubsection{General System Boundaries}

Figure 3 shows the general system boundaries considered in this study of the use of ETBE derived from California biomass versus use of MTBE derived from natural gas in reformulated gasoline.

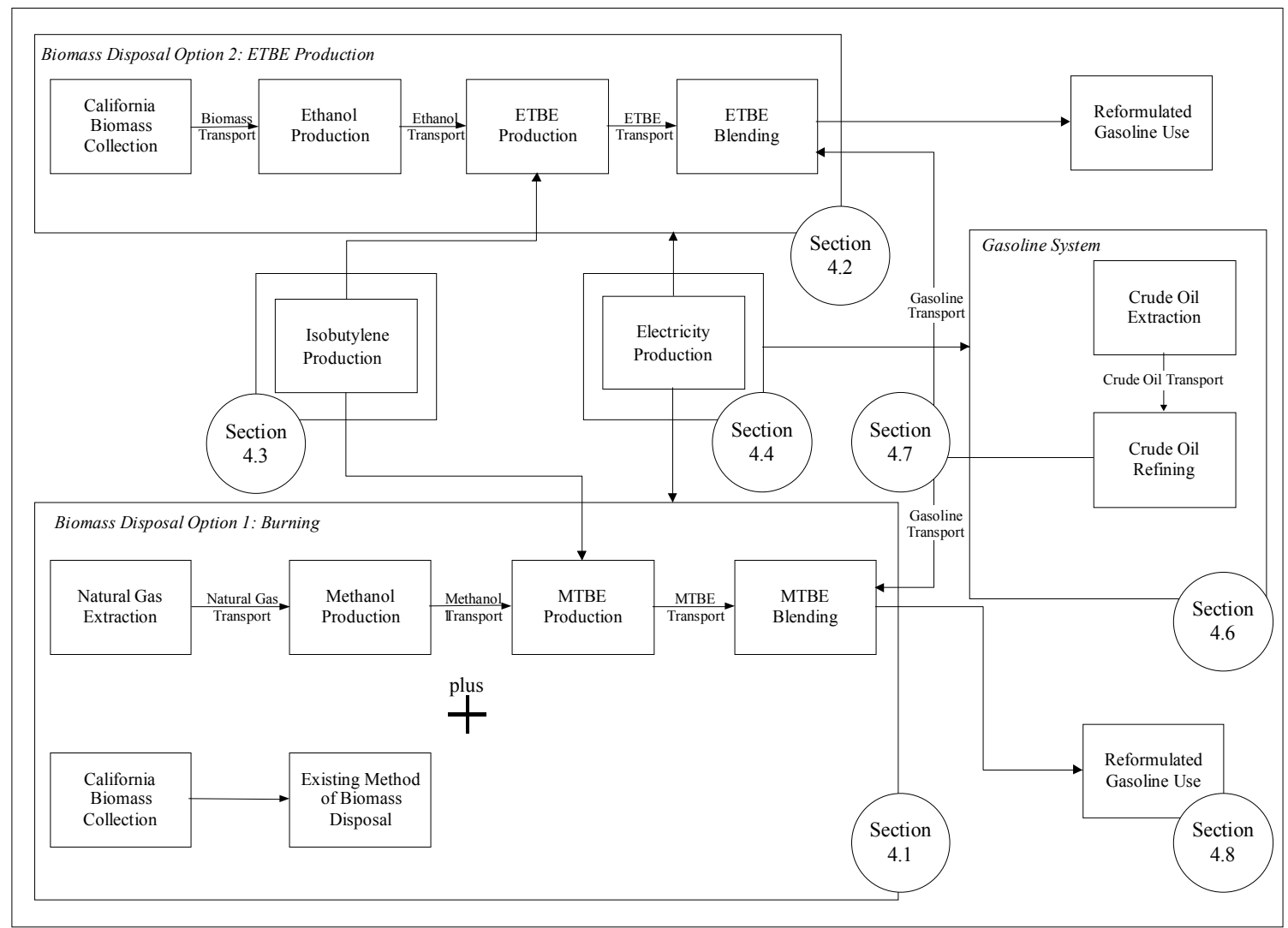

NOTE: Section numbers refer to section numbers in this report.

Figure 3: General System Boundaries for the Comparison of ETBE and MTBE Use in RFG

It should be noted that this project is not a simple comparison of ETBE versus MTBE use in reformulated gasoline but rather a comparison of two different methods for California biomass disposal. In one option, the biomass is collected and converted into ETBE and used in reformulated gasoline. In the other option the biomass is collected and disposed of via burning. However, the second option also involves the use of MTBE to satisfy the oxygenate requirements of the reformulated gasoline as the ETBE would not be available.

This affects the choice of the functional unit of comparison (Section 3.2.2), as it is linked not only to the use of reformulated gasoline but also, and primarily, to the disposal amounts for California biomass.

\subsubsection{Environmental Issues Considered}

The LCA methodology traditionally calls for the establishment of complete mass and energy balances for each process, including: energy consumption, raw material consumption, air emissions, water effluents, and solid waste. This comprehensive compilation exercise results in a quantification of all existing flows into the environment. However, this scheme has become increasingly questionable, due to: 
- Practical Reasons: an ever-expanding number of parameters can be tracked within an inventory, reflecting more comprehensive data measurements. For instance, including U.S. Toxic Release Inventory (TRI) data would result in a list of approximately 200 pollutants being released during gasoline production. Similarly, including radionucleide emissions from electricity production would result in tracking more than 150 specific flows. Managing such a large inventory list adds to the complexity of carrying out (since these additional flows should be collected for all sources within the system for the sake of consistency) as well as interpreting the LCA.

- More Fundamental Reasons: by restricting the inventory data collection to the data actually needed in a subsequent decision analysis, a more focused LCA can be carried out, which ensures that the issues at stake receive the highest priority and data quality. Some studies even restrict their data collection to pollutants contributing a single effect (e.g., greenhouse gases).

Therefore, it is important to understand the issues or impacts that are of greatest concern to the users (or decisionmakers) of the LCA and then tailor the data collection to meet their needs. It should be noted that an inventory number (e.g., quantity of lead) is only an indication of a potential impact. Additional data such as ambient concentration, pathways to human and ecological toxicity, and the existence of thresholds would be needed to assess the actual impact of this emission. These additional data are of the type required in risk assessment, in which exposure data are collected for a few emissions at a single site. An actual LCA would need to gather these additional data for all inventory flows and for all sites included in the system boundaries (generally well over a hundred). This type of actual impact assessment is as difficult (as the limits of inventories are well known) as impractical. $^{3}$

Life cycle assessment should consequently be considered as providing an indication of potential environmental impact, complementary to actual impacts evaluated by other tools. The following sections detail the most well known approaches for determination of these potential environmental impacts through the use of LCI results.

The following steps were used to facilitate interpretation of the inventory results through impact assessment:

- Classification: The organization of inventory data into environmental impact and resource consumption categories, such as global warming potential, acidification potential, eutrophication potential, natural resource depletion, etc.

- Characterization: Weighted summing of inventory data within each environmental impact category, based upon each flow's relative strength of potential influence upon the identified environmental impact or effect. ${ }^{4}$

The characterization step takes explicit account of the latest scientific assessments of the uncertainty inherent in the equivalency factors, such as global warming potentials. In addition, the discussion accompanying the characterization results clearly states that the results of a characterization analysis serve strictly to normalize the multiple flows within the LCI with respect to a particular environmental issue in terms of their relative strength of potential contribution to that issue. Characterization is not in any way intended to estimate the actual impact of the emissions upon environmental issues.

Furthermore, some of the inventory flows themselves may be highly uncertain, with an estimable magnitude of uncertainty. This uncertainty was appropriately combined with the uncertainty inherent in the equivalency factors used in the characterization step.

Table 5 indicates the environmental inventory flows and their corresponding impact assessment categories considered in this study:

\footnotetext{
${ }^{3}$ For instance, the Tellus Institute conducted such a comprehensive impact assessment for a single type of site (power plant) in a limited area (New York State). The study lasted for about two years and cost several hundreds of thousands of dollars.

${ }^{4}$ Further details concerning the characterization step, for many of the most commonly-studied environmental impact categories, are provided in chapters 3 and 4 of Heijungs, R., et al., eds., Environmental Life Cycle Assessment of Products.
} 
Table 5: Environmental Inventory Flows Considered

\begin{tabular}{|c|c|}
\hline Environmental Flows Considered & Associated Impact Category \\
\hline \multicolumn{2}{|c|}{ Natural Resources } \\
\hline Oil & Natural resources depletion \\
\hline Coal & Natural resources depletion \\
\hline Natural Gas & Natural resources depletion \\
\hline $\begin{array}{l}\text { Other Significant Resources Depending on } \\
\text { Decision Rules }\end{array}$ & Natural resources depletion ${ }^{5}$ \\
\hline \multicolumn{2}{|c|}{ Water Effluents } \\
\hline COD & Eutrophication potential \\
\hline BOD & Eutrophication potential \\
\hline Nitrates & Eutrophication potential \\
\hline Phosphates & Eutrophication potential \\
\hline Total Suspended Solids & Direct Use \\
\hline Metals & Direct Use \\
\hline \multicolumn{2}{|c|}{ Air Emissions } \\
\hline $\mathrm{CO}_{2}$ & Greenhouse effect potential \\
\hline $\mathrm{CH}_{4}$ & Greenhouse effect potential \\
\hline $\mathrm{N}_{2} \mathrm{O}$ & Greenhouse effect potential \\
\hline $\mathrm{NO}_{\mathrm{x}}$ & Acidification potential \\
\hline $\mathrm{SO}_{\mathrm{x}}$ & Acidification potential \\
\hline Particulate & Direct Use \\
\hline Hydrocarbons & Direct Use \\
\hline $\mathrm{CO}$ & Direct Use \\
\hline \multicolumn{2}{|c|}{ Solid Waste } \\
\hline Nonhazardous & Direct Use \\
\hline Hazardous & Direct Use \\
\hline \multicolumn{2}{|c|}{ Energy Use } \\
\hline Total Primary Energy & Direct Use \\
\hline Fossil Fuel Energy & Direct Use \\
\hline
\end{tabular}

Some of these environmental flows can potentially have impacts on the environment that go beyond the effects caused by just the flow itself. For this study, the potential impacts of the life cycle flows have been assessed for four impact assessment indicators: greenhouse effect potential, eutrophication potential, acidification potential, and natural resource depletion.

To calculate the impact indicators, each flow that is determined to be a contributor to one of these categories is weighted according to its impact in comparison to a set baseline, e.g., for greenhouse effect potential indicator the baseline is gram of $\mathrm{CO}_{2}$ equivalent. The value for the flow is multiplied by this weighting factor to give an impact score for the particular flow. The impact scores for all contributing flows are then summed to give an overall impact score for potential impact. The weighting of the environmental flows is based upon the best available scientific

\footnotetext{
5 Inflows such as sand, limestone, etc. could be used in the natural resources depletion index although their impact is zero because of their abundance in nature.

NREL, CARB, CEC, CDF, Ecobalance Inc., TSS Consultants

March, 1999 
knowledge; however, the score should be interpreted as potential impacts, not actual impacts. The exact methodology is discussed in more detail in Appendix B.

\subsubsection{Geographical Scope}

The focus of the project is the disposal of California biomass and the use of ETBE and MTBE in reformulated gasoline in California. However, the geographic scope of particular data items pertains to whatever locations are dictated by actual plant locations, feedstock origins, sources of electricity, etc.

\section{ETBE System}

The biomass used for ETBE production is of California origin. Hence, data on biomass collection, distribution, and alternative uses were California based. The production of ethanol and ETBE was assumed to occur in California. However, data on ancillary materials needed for the conversion of the biomass to ETBE may be based on a U.S. average situation.

\section{MTBE System}

MTBE is produced both in and out of California, so the system was examined based solely on MTBE production in California. The natural gas feedstock necessary for MTBE production was regionalized.

\section{Reformulated Gasoline System}

The production of gasoline was based on Ecobalance data and data provided by CEC. The combustion of the reformulated gasoline was assumed to occur in California.

\subsubsection{Temporal Scope}

The issue here is whether to study a current situation or to model a future situation or to model both current and future scenarios. Current and future scenarios could be quite different. For example, current scenarios would be limited to existing ethanol production technology as well as existing transportation vehicle scenarios and biomass availability scenarios. Future scenarios could be limited in the alternatives for biomass disposal as open-field burning is being phased out as an option.

One reason for studying a mid- to long-term time frame, is that a widespread use of biomass derived ETBE in the very near-term is not probable. However, the results of this study are data-driven, and the use of forecast or modeled (rather than current, empirically based) production, conversion, and end-use technology parameters would greatly increase the uncertainty in the final results.

For this study, the early part of the next decade has been selected as the production period. Empirical data still provide the most logical starting point for future projections or extrapolations.

\subsection{Product Parameters}

\subsubsection{Scenarios}

As was mentioned, the feedstock for producing ETBE was California biomass. However, there are a number of possibilities within this broad category. Different types of biomass are available in different parts of the state and during different seasons. Furthermore, the different types of biomass require distinct methods of collection and possible disposal alternatives. The three types of California biomass selected are as follows:

- Rice Straw

- Forest Residue and Thinnings

- Chaparral

The analysie of other agricultural residues such as wheat straw, orchard trimmings, and safflower stalks were not considered for this project.

NREL, CARB, CEC, CDF, Ecobalance Inc., TSS Consultants

March, 1999

Final Report

Kadam et al. 
This project involves the study of two separate ethanol production processes for the three biomass types: an enzymebased process and a concentrated acid-based process.

The alternative disposal method could be different for each type of biomass. These methods could include incorporation into building materials, use in commercial products, use as mulch or burning. In order to simplify the system under study, only one existing alternative for each biomass scenario was considered. Since one of the motivations behind the study is the mandate to reduce open-field burning and fires, prescribed burning is assumed to be the major disposal alternative for all three biomass types.

\subsubsection{Functional Unit}

The functional unit of this study is the disposal of a defined amount of California biomass. Two disposal options were examined: the production and use of ETBE from the biomass and the existing disposal method. The use of ETBE substitutes for the use of MTBE in reformulated gasoline since both of these compounds add oxygen content to reformulated gasoline. Therefore, ETBE and MTBE use is compared based on their oxygen contents. Additionally, the function of the reformulated gasoline is to provide energy as a transportation fuel. Therefore, the comparison of ETBE and MTBE in reformulated gasoline is also linked to the heating value of the fuels.

Table 6 shows the comparison of ETBE versus MTBE use in reformulated gasoline from a functional unit perspective (the base wt $\%$ oxygen is mandated at $2 \%$ ):

Table 6: Comparison of ETBE versus MTBE Use in Reformulated Gasoline

\begin{tabular}{|c|c|c|c|c|c|}
\hline & Gasoline & MTBE & ETBE & MTBE RFG & ETBE RFG \\
\hline \multirow{11}{*}{$\begin{array}{r}\text { Heating Value }(\mathrm{MJ} / \mathrm{l}) \text { : } \\
\text { wt } \% \text { Oxygen: } \\
\text { Density }(\mathrm{kg} / \mathrm{l}):\end{array}$} & 34.8 & 26.1 & 27.0 & 33.9 & 33.8 \\
\hline & $0 \%$ & $18.2 \%$ & $15.7 \%$ & $2.0 \%$ & $2.0 \%$ \\
\hline & 0.739 & 0.743 & 0.745 & 0.739 & 0.739 \\
\hline & & & wt \% MTBE: & $11.0 \%$ & \\
\hline & & & wt \% ETBE: & & $12.7 \%$ \\
\hline & & & wt \% Gasoline: & $89.0 \%$ & $87.3 \%$ \\
\hline & & & MTBE (kg/l of RFG): & 0.081 & \\
\hline & & & ETBE $(\mathrm{kg} / \mathrm{l}$ of RFG): & & 0.094 \\
\hline & & & asoline $(\mathrm{kg} / \mathrm{l}$ of $\mathrm{RFG})$ : & 0.658 & 0.645 \\
\hline & & Differenc & in Gasoline Use (kg): & 0.014 & \\
\hline & & & & $\frac{1 \mathrm{~kg} \text { ETBE }}{86 \mathrm{~kg} \mathrm{MTBE}}$ & $\frac{\text { uivalent to: }}{4 \mathrm{~kg} \text { Gasoline }}$ \\
\hline
\end{tabular}

It can be seen from Table 6 that slightly more ETBE is needed per gallon of reformulated gasoline (as compared to MTBE) to provide the same amount of oxygen content. However, this additional amount of ETBE provides additional heating value as well. It is assumed that the two gallons of reformulated gasoline (one with ETBE and one with MTBE) are equal in terms of heating value. ${ }^{6}$ Therefore, the comparison of one gallon of reformulated gasoline with ETBE versus one gallon of reformulated gasoline with MTBE would entail comparing $1 \mathrm{~kg}$ of ETBE with 0.86 of MTBE plus 0.14 of gasoline.

\footnotetext{
6 There is actually a $0.09 \%$ difference (33.87 vs. 33.84$)$ in heating value. However, this is felt to be negligible given the possible variation in heating values of the individual fuels.

NREL, CARB, CEC, CDF, Ecobalance Inc., TSS Consultants

March, 1999

Final Report

Kadam et al.
} 


\subsection{PRocess PARAMETERS}

Process parameters are strongly affected by the choices made on the previous project-related and product-related parameters. For example, the assumption of technology bases using the early part of the next decade for all processes leads to a number of conclusions about fuel production and feedstock supplies.

MTBE is produced via the selective reaction of isobutylene and methanol over an acidic ion-exchange resin catalyst, in the liquid phase. The resin typically consists of sulfonated styrene cross-linked with divinylbenzene. Reaction conditions are usually mild, with temperatures ranging from $30^{\circ} \mathrm{C}$ to $100^{\circ} \mathrm{C}$ and pressures between 7 and 14 atmospheres (100-200 psig). For MTBE to be economically competitive as an octane enhancer in gasoline, a lowcost isobutylene source is necessary. For this study it is assumed that methanol is produced from natural gas since a majority of methanol commercially made in the United States is derived from natural gas.

The process for ETBE production from ethanol is similar to the process used for MTBE, where ethanol reacts with isobutylene over an acidic ion exchange catalyst under similar conditions. However, there are a number of different processes available to convert biomass to ethanol. The conversion to ethanol through dilute acid pretreatment followed by simultaneous saccharification and fermentation (SSF) and distillation were used in the analysis of rice straw, forest residue, and chaparral. An alternative process, concentrated-acid hydrolysis followed by fermentation and distillation, was also examined.

Feedstock for gasoline is crude oil produced domestically and imported from foreign countries. Data characterizing the split between foreign and domestic crude oil supplies to fuel production were used, with regional differences taken into account.

\subsection{LCA-SPECIFIC PARAMETERS}

\subsubsection{Allocation Rules}

The production of both ethanol and natural gas-based fuel generates other products, which are recovered and used in other product systems. They are considered as coproducts. The problem is the apportioning or allocating of energy resources, raw materials, pollutants, etc. from the common production steps to the product studied (fuels) and the coproducts. Inputs and outputs of the common steps can be partitioned across the coproducts on various bases, including (for example):

- Mass

- Dry mass

- Energy content

- $\quad$ Energy content

For this analysis, there were three main processes that required allocation. Natural gas production used throughout the life cycle of both systems (but predominantly for methanol) produces sulfur as a coproduct. The emissions and energy use for the production of natural gas and sulfur were allocated on a mass basis (see Section 4.1.1.). Crude oil refining produces a number of petroleum products. This study was mainly interested in one of those products, namely gasoline. Allocation of the refinery energy use and emissions was done based on the process energy requirements of the different products (see Section 4.6.4.). Another process that required allocation was ethanol production. The production of ethanol also produces lignin as a coproduct, which can be used as an energy source. The allocation technique used in the study was to expand the system boundaries to include the use of the lignin residue either for on-site cogeneration or off-site electricity production. In this way the emissions from an alternate energy production method were offset by the use of the lignin. These offset emissions were accounted for as negative values in the life cycle. 


\subsubsection{Modeling Biomass-Based $\mathrm{CO}_{2}$ Emissions}

All of the content in carbon $(\mathrm{C})$ of the biomass portion of the ethanol is derived from the $\mathrm{CO}_{2}$ absorbed by plants while growing (photosynthesis). These carbon atoms are released at the end of life of the products, predominantly in the form of $\mathrm{CO}_{2}$, but also in the form of $\mathrm{CO}$, hydrocarbons or methane $\left(\mathrm{CH}_{4}\right)$ molecules. These carbon releases are offset (while not all at the same rate) by the $\mathrm{CO}_{2}$ uptake or sequestering during plant growth. A distinction was made between net carbon emissions from the production and subsequent combustion of biomass products and carbon emissions from the combustion of fossil fuels. The carbon uptake by plants was accounted for as a credit.

\subsection{SUMMARY OF SCOPING DECISIONS AND APPROACHES}

Table 7 summarizes the scoping decisions and approaches to be used in this project, which were described in the previous sections 3.1 through 3.4.

Table 7: Summary of Scoping Decisions and Approaches

\begin{tabular}{|c|c|c|c|}
\hline Element & Parameter Type & Decis & ion or Approach \\
\hline \multirow[t]{4}{*}{ Project } & Spatial & - Biomass: & California \\
\hline & & - Fuel Production: & Worldwide \\
\hline & & - Fuel use: & California \\
\hline & Temporal & \multicolumn{2}{|c|}{ Early part of the 2001 decade } \\
\hline \multirow[t]{7}{*}{ Product } & Biomass Scenarios & \multirow{3}{*}{$\begin{array}{l}\text { - } \text { Agricultural Residue: } \\
\text { - } \quad \text { Forest Residue: } \\
\text { - } \quad \text { Brush Growth: } \\
\end{array}$} & Rice Straw \\
\hline & & & Thinnings \\
\hline & & & Chaparral \\
\hline & Disposal Alternatives & \multirow{3}{*}{$\begin{array}{ll}\text { - } & \text { Agricultural Residue: } \\
\text { - } & \text { Forest Residue: } \\
\text { - } & \text { Brush Growth: } \\
\end{array}$} & Open Field Burning \\
\hline & & & Controlled Burning \\
\hline & & & Controlled Burning \\
\hline & Functional Unit & \multicolumn{2}{|c|}{$\begin{array}{l}\text { Disposal of a defined quantity of California biomass through the } \\
\text { production of fuel oxygenate. }\end{array}$} \\
\hline \multirow[t]{6}{*}{ Process } & ETBE & \multirow{3}{*}{$\begin{array}{l}\text { - Ethanol: } \\
\text { - Ethanol: } \\
\text { fermentation } \\
\text { - } \\
\text { ETBE: }\end{array}$} & dilute acid pretreatment, followed by SSF \\
\hline & & & concentrated acid treatment followed by \\
\hline & & & isobutylene reaction \\
\hline & MTBE & $\begin{array}{l}\text { - Methanol: } \\
\text { - MTBE: }\end{array}$ & $\begin{array}{l}\text { natural gas feedstock } \\
\text { isobutvlene reaction }\end{array}$ \\
\hline & Gasoline & - $\quad$ Feedstock: & domestic plus imports \\
\hline & & - Refining: & Early part of the 2001 decade \\
\hline \multirow[t]{3}{*}{ LCA } & Coproduct Allocation & \multicolumn{2}{|c|}{$\begin{array}{l}\text { Mass-based w/ sensitivity analysis; energy based for petroleum } \\
\text { products }\end{array}$} \\
\hline & Interpretation & \multicolumn{2}{|c|}{ Classification and characterization } \\
\hline & & \multicolumn{2}{|c|}{$\begin{array}{l}\text { Perform sensitivity analysis on uncertain or variable input } \\
\text { parameters }\end{array}$} \\
\hline
\end{tabular}




\subsection{OPTION 1: MTBE PRODUCTION + BIOMASS BURNING}

The first system (Figure 4) that was modeled consists of a combination of two elements: one liter of oxygenated fuel containing MTBE plus the environmental burdens from the open burning of one metric bone dry ton (MBDT) of biomass. The various components of this system are detailed in the sections below.

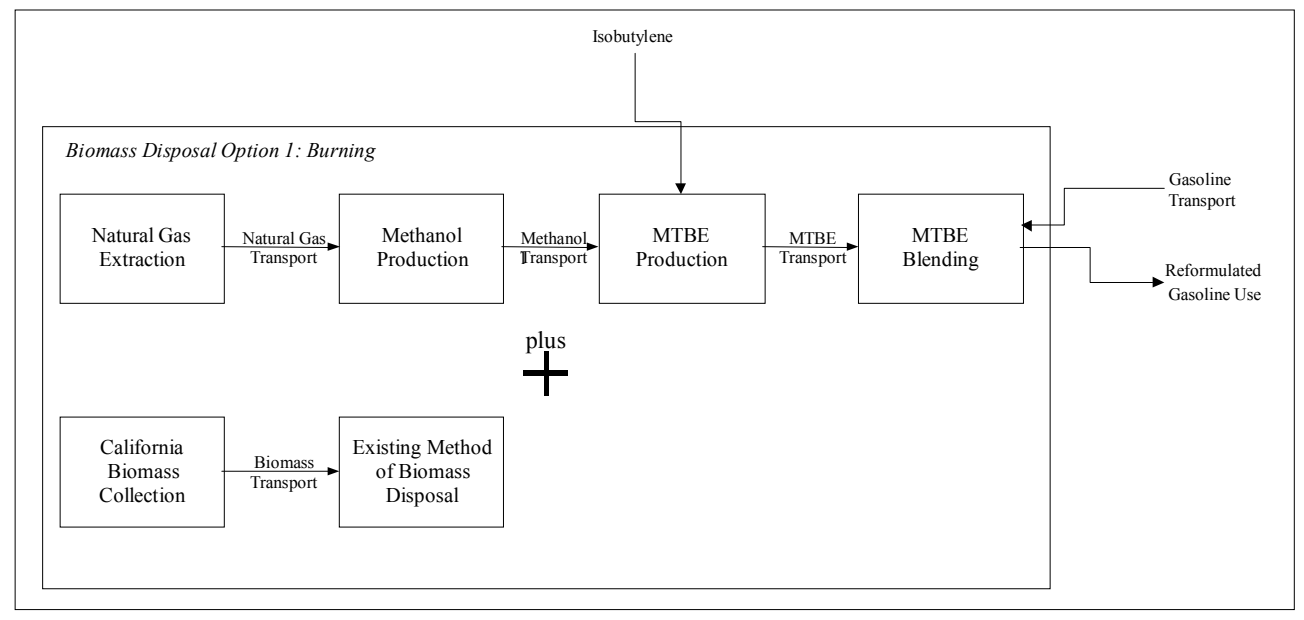

Figure 4: Option 1 Systems

The model for the production of MTBE consists of the production of natural gas, the conversion of the natural gas to methanol, the reaction of the methanol with isobutylene to produce MTBE, and finally the blending of MTBE with gasoline. Isobutylene and gasoline production, as well as the use of the oxygenated fuels, are modeled outside this system.

\subsubsection{Natural Gas Production}

Raw natural gas is a mixture of hydrocarbons, $\mathrm{N}_{2}, \mathrm{CO}_{2}$, sulfur compounds, and water. It may have any range of compounds from mostly methane to inert gases, such as nitrogen, carbon dioxide, and helium, and smaller amounts of ethane, propane, and butane. Natural gas may be extracted onshore, offshore, and in conjunction with petroleum extraction processes. The production model is based on data for U.S. production, which were adjusted to represent its use in California to produce methanol. Although some natural gas could be imported into California, foreign production was not studied because of lack of data. The U.S. model is used as a surrogate for foreign production as well. The adjustments for California use entailed modifying the transportation distance of the natural gas and the sweetening of the gas. The methodology, as it is explained below, details the modeling of U.S. average natural gas production.

\section{Natural Gas Extraction}

The process energy used to extract natural gas is apportioned among petroleum, natural gas, and natural gas liquids based on the following assumptions [1]:

- Almost all of the natural gas used for fuel goes toward field operations - natural gas lifting and reinjecting. The data in this section correspond with data provided by the Energy Information Administration (EIA). Any energy used to reinject natural gas into wells is excluded from the natural gas precombustion processes, since reinjection is mainly used in oil wells. 
- The amount of electricity used for field equipment and processing plants is little relative to the amount of gas they produce. Therefore, all capital equipment is excluded from the study boundaries.

Thus, energy in this model excludes gas reinjection energy requirements. Plant fuel is estimated at $3 \%$ of gas input to processing plants [1].

\section{Carbon Dioxide}

Carbon dioxide is vented into the atmosphere from the ground during natural gas extraction. The total amount of all non-hydrocarbon gases $\left(\mathrm{CO}, \mathrm{CO}_{2}\right.$, etc.) removed from raw natural gas is $4.4 \%$ of gas production, one-half of which consists of $\mathrm{CO}_{2}(2.2 \%)$. Approximately $85 \%$ of the $\mathrm{CO}_{2}$ escapes into the atmosphere.

\section{Other Air Emissions}

Other air emissions associated with natural gas extraction are assumed to come from the combustion of diesel oil, crude oil, residual fuel oil, and natural gas in miscellaneous machinery. Emission factors for diesel powered equipment come from AP-42 [2]. Emission data on combustion of the other fuels come from AP-42 and Ecobalance's database.

\section{Natural Gas Venting}

The quantity of fugitive methane and methane from venting was accounted for as one module in the model. ${ }^{7}$ The following table (Table 8) presents the source of methane and its percentage of gross production:

Table 8: Natural Gas Venting Methane Emissions

\begin{tabular}{lc}
\hline \multicolumn{1}{c}{ Source } & \% of total NG produced \\
\hline \hline Fugitive Emissions: Equipment Leaks & \\
---Compressor stations & $0.31 \%$ \\
---Production facilities & $0.08 \%$ \\
---Gas plants & $0.11 \%$ \\
---Metering and pressure-regulating stations & $0.14 \%$ \\
---Customer meter sets & $0.03 \%$ \\
Fugitive Emissions: Underground pipeline leaks & $0.22 \%$ \\
Vented Emissions: & \\
---Pneumatics & $0.21 \%$ \\
---Blow and purge & $0.14 \%$ \\
---Dehydrator glycol pumps & $0.05 \%$ \\
---Dehydrator vents & $0.02 \%$ \\
---Chemical injection pumps & $0.01 \%$ \\
& $1.30 \%$ \\
\hline
\end{tabular}

\section{Glycol Dehydration}

Glycol dehydration units are commonly used in natural gas operations to remove water from natural gas streams to prevent corrosion and the formation of hydrates in pipelines. This model takes into account the quantity of triethylene glycol consumed in the process as well as the vented methane emissions from dehydrator glycol pumps.

\footnotetext{
${ }^{7}$ All vented and fugitive methane emissions are based on a gross natural gas production of 22,130 billion scf in 1992.

NREL, CARB, CEC, CDF, Ecobalance Inc., TSS Consultants

March, 1999

Final Report Kadam et al.
} 
Triethylene glycol is used (circulated) for the dehydration process. The amount "consumed" is much less than the circulation rate. More specifically, typical losses of triethylene glycol are normally on the order of $16 \mathrm{~kg}$ triethylene glycol/million scm. It should be noted that most of this loss comes from carryover of the triethylene glycol from the glycol dehydrator and into the natural gas pipeline.

\section{Natural Gas Sweetening}

Gas sweetening, or the amine process, removes and recovers $\mathrm{H}_{2} \mathrm{~S}$. The recovered hydrogen sulfide gas is vented, flared in waste gas flares or modern smokeless flares, incinerated, or utilized for the production of elemental sulfur or sulfuric acid. Emissions due to only venting the gas into the environment are covered in the model. Vented gas is usually passed to a tail gas incinerator in which the $\mathrm{H}_{2} \mathrm{~S}$ is oxidized to $\mathrm{SO}_{2}$ and is then passed to the atmosphere out through a stack. Emissions are mostly $\mathrm{SO}_{2}$ due to the $100 \%$ conversion of $\mathrm{H}_{2} \mathrm{~S}_{\text {to }} \mathrm{SO}_{2}$. Very little particulate and $\mathrm{NO}_{\mathrm{x}}$ emissions are generated from this process, so we assume these emissions to be zero. For this model, $10 \%$ of total $\mathrm{H}_{2} \mathrm{~S}$ is vented. The remaining $90 \%$ is allocated by mass to the production of a sulfur-bearing coproduct such as sulfuric acid or liquid sulfur dioxide.

In terms of the question of what gas produced goes through the sweetening process, it is assumed that all gas is sweetened. Natural gas is considered "sour" if hydrogen sulfide is present in amounts greater than $0.065 \mathrm{~g} / \mathrm{sm}^{3}$ natural gas [2]. Hydrogen sulfide content was based on California production.

\section{Transportation}

Natural gas is transported by way of high-pressure transmission lines. Compressors along these lines may be powered from different sources: gas-fueled reciprocating engines and gas turbines, and electric motors. Emissions are all different due to the different sources of power in the compressors.

Gas turbines and compressor engines are modeled in this study, but electric motors are neglected from the model for the following reason [1]. Averaging out the percentage horsepower for each type of power source for the pipeline, it was found that:

$\begin{array}{lr}\text { Turbines: } & 24.2 \% \\ \text { Engines: } & 73.4 \% \\ \text { Electric: } & 2.5 \%\end{array}$

Since electric power is so little relative to the other compressors $(2.5 \%)$, it is included in the turbine and engine values.

The quantity of natural gas consumed to transmit the natural gas product is assumed to be, on average, $4 \%$ of the product. This percentage was obtained by dividing "pipeline fuel" by "total delivered [natural gas] to customers" for several states [3]. The total fuel consumed for transport as a U.S. average comes from taking $4 \%$ of the total U.S. Interstate movements [3].

The criteria pollutant emission factors were obtained and averaged together from AP-42 and GRI-95/0270.1 [4]. AP-42 presents emission factors for each of four technologies: gas turbines, 2-cycle lean-burn engines, and 4-cycle lean- and rich-burn engines. The GRI-95/0270.1 report, in its description of host sites for data collection, describes the market share of the engines in the gas transmission service. As a result, the emission factors from AP-42 were incorporated with GRI-95/0270.1 and recorded as a weighted average of the technologies according to the following market share breakdown:

$$
\begin{array}{lll}
\text { - } & \text { Gas Turbine: } & 10 \% \\
\text { - } & \text { 2-Cycle Lean Burn: } & 48 \%(53 \% * 90 \%) \\
\text { - } & \text { 4-Cycle Lean Burn: } & 21 \%(47 \% * 90 \% \text { divided by } 2) \\
\text { - } & \text { 4-Cycle Rich Burn: } & 21 \%(47 \% * 90 \% \text { divided by } 2)
\end{array}
$$

There were no available data regarding what percentage of these technologies had pollution control equipment, so emission factors for controlled and uncontrolled technologies for $\mathrm{CO}_{2}, \mathrm{NO}_{\mathrm{x}}, \mathrm{CO}$, total non-methane organic 
compounds, $\mathrm{CH}_{4}$, and PM-10 are averaged together where data are available. The technologies with pollution controls were averaged without a weighting factor.

\subsubsection{Methanol Production}

Methanol is produced via the reforming of natural gas, through a series of four steps: reforming, compression, synthesis, and purification. At the beginning of the process, the influx of raw natural gas is mixed with gas that has recycled through the system. This mixture passes first through a centrifugal compressor, and then, if necessary, through a steam turbine. As it exits, the pressurized gas is preheated through heat exchange with the reactor effluent, and then the stream is split into two flows.

When leaving the reactor, the gas flow is initially cooled by a heat exchange with the gas entering the reactor and the water used for the high pressure steam generators, and then by passing through a condenser where the methanol and water condense. This condensate moves on to a pressurized chamber, where the gas and liquid constituents are separated. The gas fraction is mostly recycled, and the raw methanol has the gas removed and is then distilled. In order to reach the level of purity required for MTBE production, the raw methanol passes through two separation columns to remove the lighter elements (gas, ethers, ketones...), the heavier alcohols, and the water. The emissions resulting from the production of methanol are limited, mainly some traces of alcohol (about $0.5 \%$ of the overall finished product) in the wastewater. The inputs for methanol production are shown in Table 9.

Table 9: Inputs for Methanol Production

\begin{tabular}{cc}
\hline & $\begin{array}{c}\text { Input (per } \\
\text { Kilogram } \\
\text { Methanol) }\end{array}$ \\
\hline \hline natural gas - & \\
fuel (kg) & 0.36 \\
raw material (kg) & 0.55 \\
electricity (MJ) & 0.16 \\
\hline
\end{tabular}

\subsubsection{MTBE Production}

Methyl tertiary-butyl ether is produced through a catalytic reaction between methanol and isobutylene over an acidic ion exchange resin:

\section{MTBE}

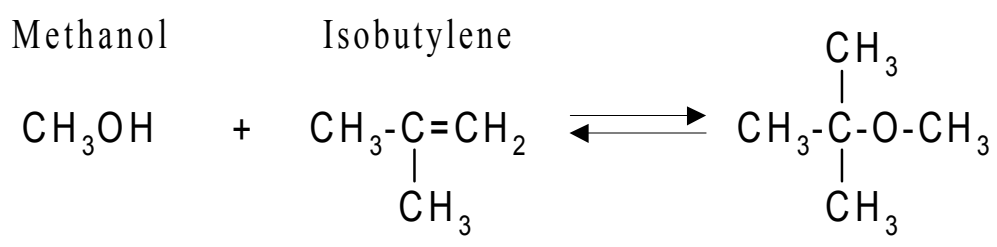

The process also leads to side reactions,

$$
\begin{aligned}
& \text { Isobutylene + water } \\
& \text { Methanol +methanol } \\
& \text { Isobutylene + isobutylene }
\end{aligned}
$$

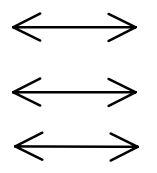

Tertiary Butyl Alcohol (TBA) water + Dimethyl Ether (DME)

Di-isobutylene (DIB) 
but conditions are controlled so that the selectivity of isobutylene and methanol to MTBE is very high. TBA, DME and DIB make up only a total of $0.6 \%$ of the outflow by weight. The presence of these coproducts has no adverse effect on the quality of the MTBE, since they are also acceptable octane gasoline components.

Even though most of the MTBE used in the California is actually produced out of state, it is assumed that the ETBE that is produced from biomass is only replacing the MTBE produced in California ( $15 \%$ of total demand). This is because the infrastructure for producing the remaining ETBE has not been determined. An analysis of the factors that would affect an increase in production capacity is beyond the scope of this study. Therefore, the baseline model only reflects MTBE produced in state, and oxygenate transport from non-local refineries is not included. (The case of producing $100 \%$ of total oxygenate demand is analyzed as a separate case in the sensitivity analysis.) California MTBE production is defined as a blend of two separate processes that differ mainly by the type of finishing reaction.

The first process (Figure 5) consists of an expanded bed front reactor and a fixed bed finishing reactor [5]. Most of the conversion occurs in the main reactor, which contains the catalyst. Unconverted methanol is recycled via a final methanol recovery step that consists of washing of the outflow to remove the methanol from the $\mathrm{C}_{4}$ raffinate, followed by a fractionation of the methanol/water mixture.

The second process (Figure 6) consists of an expanded bed front reactor with catalytic distillation as the finishing reaction. As with the first process, most of the conversion of isobutylene occurs in the main reactor.

As shown in Table 10, both of these reactions consume similar amounts of electricity, steam, and cooling water; their difference is more apparent in the rate at which they convert isobutylene to MTBE.

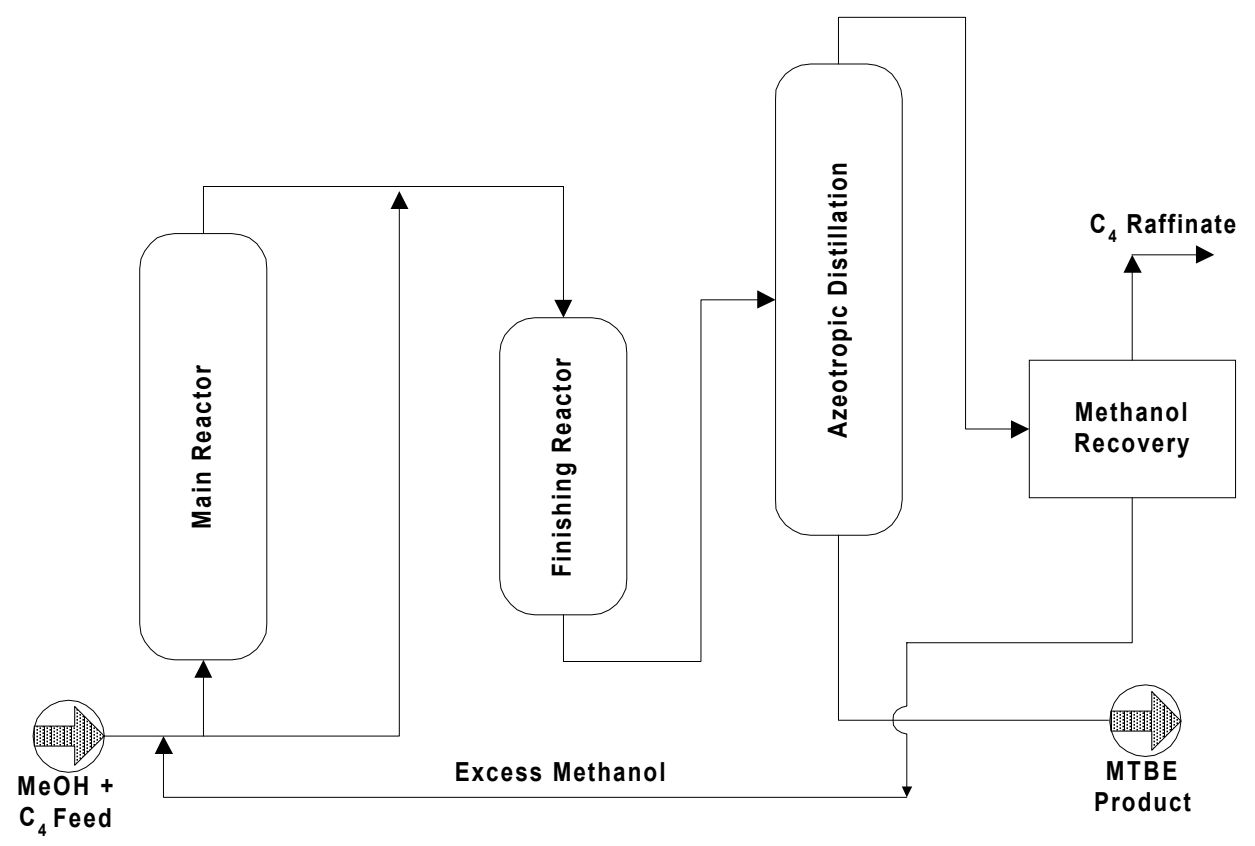

Figure 5: Fixed Bed Finishing Reactor 


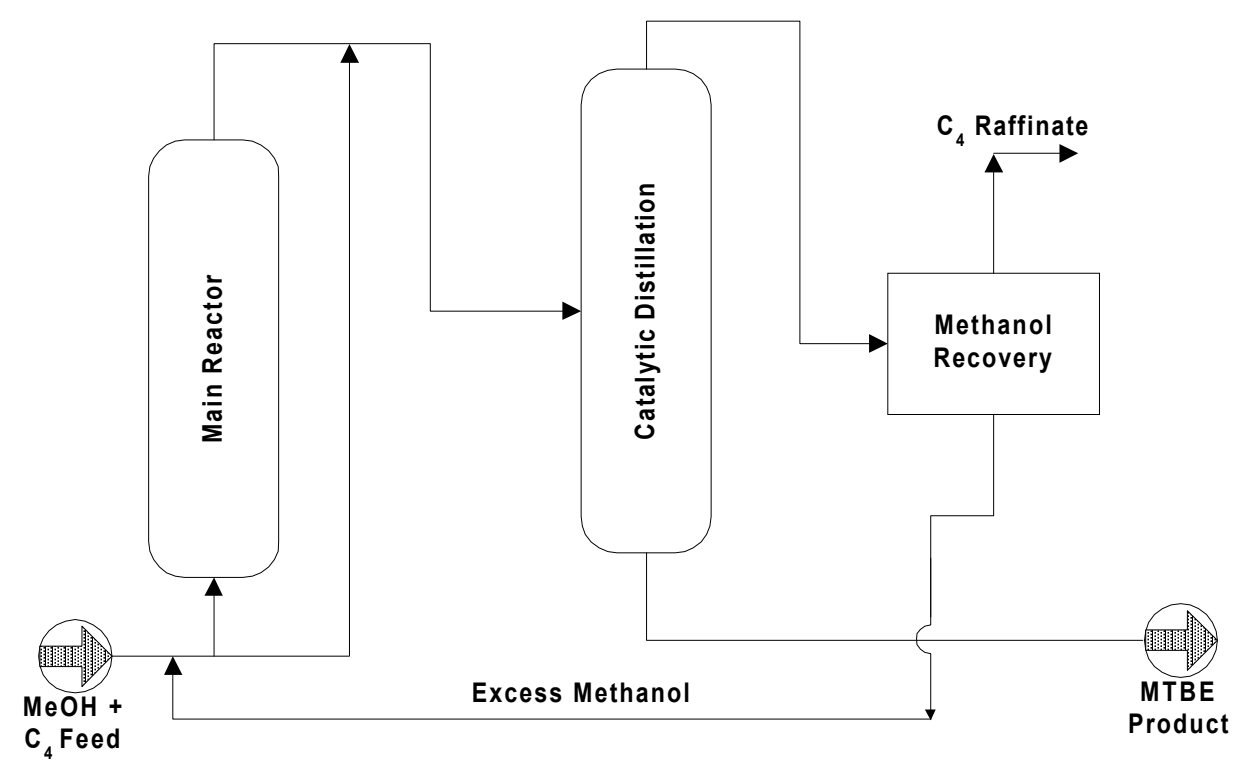

Figure 6: Catalytic Distillation Finishing Reactor

Table 10: Inputs for MTBE Production

\begin{tabular}{lcc}
\multicolumn{1}{c}{ Input } & $\begin{array}{c}\text { Fixed bed finishing } \\
\text { reactor }\end{array}$ & $\begin{array}{c}\text { Catalytic distillation } \\
\text { finishing reactor }\end{array}$ \\
\hline \hline Isobutylene conversion & $97 \%$ & $98 \%$ \\
Electricity & $234 \mathrm{MJ} / \mathrm{h}$ & $234 \mathrm{MJ} / \mathrm{h}$ \\
Steam & $5.5 \mathrm{t} / \mathrm{h}$ & $5.5 \mathrm{t} / \mathrm{h}$ \\
Cooling water & $300 \mathrm{~m}^{3} / \mathrm{h}$ & $300 \mathrm{~m}^{3} / \mathrm{h}$ \\
\hline
\end{tabular}

Values are given for a rate of 40,000 metric tons of MTBE produced per year.

\subsubsection{MTBE Blending}

It is assumed that the MTBE is matched with the gasoline it is blended with to produce the appropriate oxygenated fuel. No emissions are assumed from blending.

\subsubsection{Biomass Burning}

The standard disposal option for the three biomass types being examined (rice straw, forest residue, and chaparral) was determined to be burning. The type of burning depends on the actual biomass type: open-field burning for rice straw and prescribed burning for forest residue and chaparral. The pollutant emissions for each scenario were calculated using emission factors provided by the U.S. EPA and CARB. Carbon dioxide emissions for each scenario were based on the estimated carbon contents of the biomass types.

Forest Residue Burning

Prescribed burning is a land treatment, used under controlled conditions, to accomplish natural resource management objectives. Prescribed fire is a cost-effective and ecologically sound tool for forest management. Its use reduces the potential for destructive wildfires. The major concern derives from the smoke produced, which is a mixture of carbon, tars, liquids, and different gases. This open burning produces particles of widely ranging sizes, depending to some extent on the rate of energy release of the fire. 
In order to model the open burning of forest residues, emission factors from the U.S. EPA's AP-42 [2] were used. ${ }^{8}$ Wildfire emission factors were used as a good representation of the emissions from prescribed burning. ${ }^{9}$ Emissions from the harvesting of the forest residue were also included in the model. The emission factors gave data for emissions specific to California forests (Table 11). While the feedstock for the production of ethanol is set as a mix of $30 \%$ ponderosa pine and $70 \%$ white fir by weight, it is assumed that the emissions are independent of the type of tree that is burned.

Table 11: Emission Factors for Forest Residue Burning

\begin{tabular}{cccccc}
\hline $\begin{array}{c}\text { Geographic } \\
\text { Area }\end{array}$ & $\begin{array}{c}\text { Wildfire Fuel } \\
\text { Consumption } \\
\text { (MBDT/hectare) }\end{array}$ & Particulates & CO & VOCs & NO $_{\boldsymbol{x}}$ \\
\hline \hline California & 44 & 9.5 & 77.8 & 13.3 & 2.2 \\
\hline
\end{tabular}

\section{Rice Straw Burning}

The emissions from the open burning of rice straw were the driving concern behind this study, therefore open-field burning is set as the disposal option. The practice has been studied extensively, and emission factors have been calculated by CARB (Table 12), based upon a standard field density of 6.7 metric tons of rice straw per hectare [6]. No harvesting of the rice straw was assumed to take place, so emissions come only from the open burning of the material.

Table 12: Emission Factors for Rice Straw Burning

\begin{tabular}{cccccc}
\hline & $\boldsymbol{P M} \mathbf{1 0}$ & $\boldsymbol{V O C}$ & $\boldsymbol{N O}_{\boldsymbol{X}}$ & $\boldsymbol{S O}_{\boldsymbol{X}}$ & $\boldsymbol{C O}$ \\
\hline \hline Emission Factors (kg/hectare) & 23.3 & 5.8 & 19 & 4.1 & 211 \\
Emission Factors (kg/MBDT) & 3.7 & 1.0 & 3.1 & 0.7 & 34.7 \\
\hline
\end{tabular}

Chaparral Burning

The burning of chaparral is assumed to include the cutting and piling of the biomass prior to open burning. The emissions for open burning only were modeled using emission factors given by the U.S. EPA [2]. ${ }^{10}$ Data on emissions for the harvesting of chaparral (diesel chainsaw use, for example) were included in the model. The following table (Table 13) outlines the emission factors that were used for chaparral open burning:

Table 13: Emission Factors for Chaparral Burning

\begin{tabular}{ccccccc}
\hline & \multicolumn{4}{c}{ Pollutant (kg/MBDT) } \\
Fuel Configuration & PM- 2.5 & PM- 10 & Total & Monoxide & Methane & Nonmethane \\
\hline \hline Chaparral shrub & 11 & 12 & 23 & 111 & 5.0 & 13.8 \\
\hline
\end{tabular}

\footnotetext{
8 Wildfire and prescribed burning emission factors were used.

${ }^{9}$ Many large wildfires occur when there is low humidity and dry fuel, and they are wind driven with lots of oxygen (less smoke per fuel unit) during hot weather and deep mixing, with very hot burn temperature causing a high venting height. Frequently the emissions are transported far over the heads of people into higher levels of the atmosphere.

10 Wildfire and prescribed burning emission factors were used.

NREL, CARB, CEC, CDF, Ecobalance Inc., TSS Consultants

March, 1999

Final Report

Kadam et al.
} 


\subsection{OPTION 2: ETBE PRODUCTION FROM BIOMASS}

The second disposal option (Figure 7) assumes that rather than disposing of the biomass, it is converted to ethanol and subsequently to ETBE, which is blended with gasoline. The use of ETBE as an oxygenate is assumed to replace the use of MTBE in gasoline.

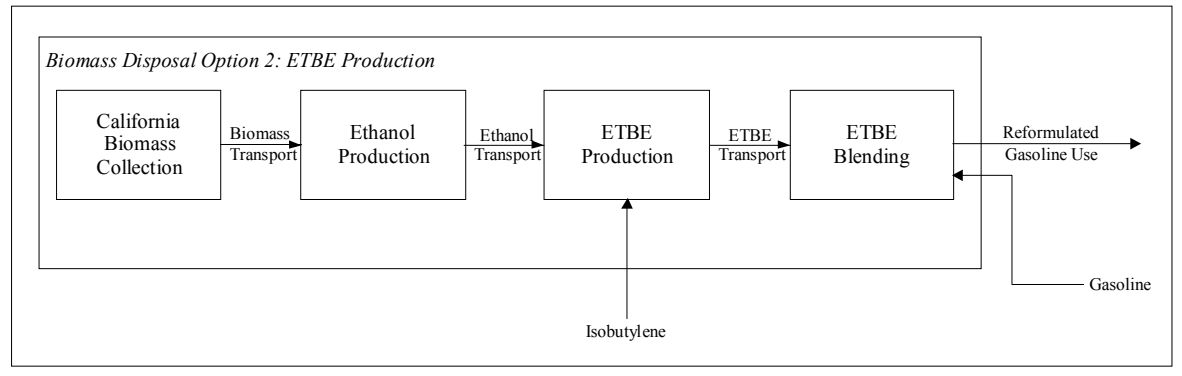

Figure 7: Option 2 Systems

\subsubsection{Biomass Harvesting}

Biomass harvesting is defined in the model as the fuel (energy) use and emissions from the gathering of the biomass and its transport to an ethanol production plant. Emissions data for diesel equipment were taken from the Ecobalance database and emissions from gasoline equipment were modeled using the AP-42 emission factors for light-duty truck use at low altitude. Detailed maps outlining the distribution of biomass throughout the state of California are provided in Appendix C.

\section{Forest Residue Harvesting}

The area where forest residue is harvested was modeled as a 35-mile radius circle around the site of the ethanol plant, and transportation emissions were calculated for 1 vehicle round trip. The collection data are assumed to be representative of the Quincy area (Northeast Plateau on the map). The equipment (and source of emissions) consists of two feller-bunchers, two grapple skidders, one whole tree chipper, and associated support equipment for road maintenance, equipment maintenance, moving equipment, and transportation of processed forest residue (chips). The average production rate was calculated to be nine loads per day at approximately $11.8 \mathrm{MBDT}$ per load, yielding 106.3 MBDT per day.

\section{Rice Straw Harvesting}

The rice fields are assumed to be 20 miles from the ethanol production plant, and transportation emissions were modeled for one vehicle round trip. The data for rice straw are representative of the Sacramento area. The equipment that is used during harvesting includes one tractor with rake, one tractor with big bale baler, one loader and associated support equipment for equipment maintenance, and transportation of baled rice straw. According to the data, on average, 9.1 MBDT of rice straw are baled per hour, amounting to 127.3 MBDT per day.

\section{Chaparral Harvesting}

The chaparral data are assumed to come from the South Coast Air Basin. Transportation emissions were modeled for 1 vehicle round trip assuming that the ethanol production plant is located 30 miles from the chaparral growth area. The data cover the clearing of a 40.5-hectare plot, yielding 1,181.2 MBDT of chaparral. The clearing of chaparral requires a 16-man crew with 4 chainsaws, 1 chipper, 1 front-end loader, and associated support equipment for moving equipment, equipment maintenance, and transportation of the processed chaparral residue (chips). About 0.2 hectares is cleared per day, with a yield of about 5.9 MBDT of chaparral per day. 
Table 14: Summary of Fuel Consumption for Biomass Harvesting

\begin{tabular}{lccc}
\hline Biomass Harvested & $\begin{array}{c}\text { Fuel } \\
\text { Consumption } \\
\text { (liters/day) }\end{array}$ & $\begin{array}{c}\text { Biomass } \\
\text { Harvested } \\
\text { (MBDT/day) }\end{array}$ & $\begin{array}{c}\text { Specific Fuel } \\
\text { Consumption } \\
\text { (liters/MBDT) }\end{array}$ \\
\hline \hline Rice Straw & 769.9 & 127.3 & 6.0 \\
Forest Residue & $1,910.3$ & 106.3 & 17.9 \\
Chaparral & 163.8 & 5.9 & 27.8 \\
\hline
\end{tabular}

The MBDT/day values in Table 14 were used to generate data on a unit MBDT basis and do not reflect total possible production rates.

\subsubsection{Ethanol Production}

Ethanol production from corn is a well-established technology with several plants located in the Midwestern United States. Using lignocellulosic biomass as a substrate to make ethanol is also a promising approach. Many sources of lignocellulosic biomass, such as agricultural residues, forestry residues, pulp and paper waste streams, and municipal solid waste, are abundant and underutilized resources, which can be converted to ethanol. Woody and herbaceous energy crops such as hybrid poplar and switchgrass can also be used as renewable resources for ethanol production.

The three biomass types chosen for this study are all lignocellulosic feedstocks, their primary organic components being cellulose, hemicellulose, and lignin. Figure 8 through Figure 10 show the approximate distribution of these components in these types of biomass. The detailed compositional analyses of these feedstocks are shown in Table 15, Table 16, and Table 17. It should be added that rice straw and forest residue have been studied as possible feedstocks for ethanol production, whereas chaparral has not been. Furthermore, the low sugar contents, combined with high lignin and extractives contents, make chaparral a technically challenging feedstock.

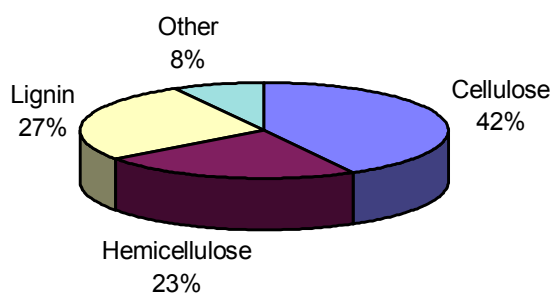

Figure 8: Composition of Forest Residue Feedstock

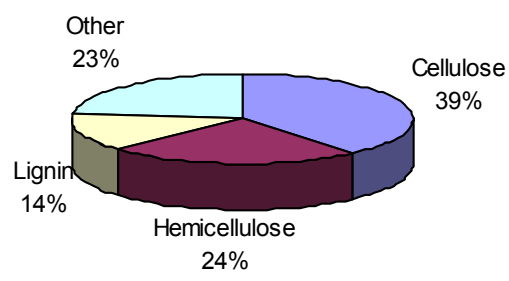

Figure 9: Composition of Rice Straw Feedstock

NREL, CARB, CEC, CDF, Ecobalance Inc., TSS Consultants

March, 1999

Final Report

Kadam et al. 


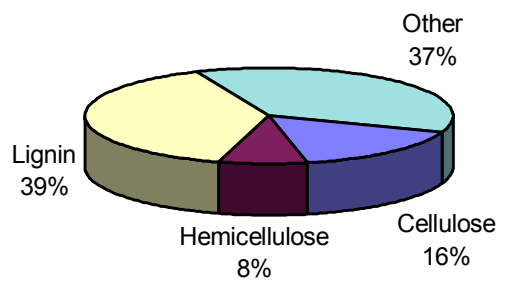

Figure 10: Composition of Chaparral Feedstock

Table 15: Forest Residue/Thinnings Composition-Whole Tree Chips

\begin{tabular}{lccc}
\hline Feedstock Component & $\begin{array}{c}\text { White Fir } \\
(\text { dry wt \%) }\end{array}$ & $\begin{array}{c}\text { Ponderosa Pine } \\
(\text { dry wt \%) }\end{array}$ & $\begin{array}{c}\text { 70/30 Mixed Feedstock } \\
\text { (dry wt \%) }\end{array}$ \\
\hline \hline Glucan & 43 & 38 & 40.5 \\
Mannan & 11 & 10 & 10.5 \\
Galactan & 3 & 5 & 4.0 \\
Xylan & 6 & 6 & 6.0 \\
Arabinan & 2 & 4 & 3.0 \\
Lignin & 28 & 25 & 26.5 \\
Extractives & 5 & 10 & 7.5 \\
Ash & 2 & 2 & 2.0 \\
& 100 & 100 & 100 \\
\hline
\end{tabular}

Table 16: Rice Straw Composition

\begin{tabular}{lc}
\hline \multicolumn{1}{c}{ Feedstock Component } & Dry $\boldsymbol{w t} \%$ \\
\hline \hline Glucan & 39.0 \\
Galactan & 0.5 \\
Mannan & 0.0 \\
Xylan & 20.5 \\
Arabinan & 3.4 \\
Lignin & 13.6 \\
Extractives \& other & 5.0 \\
Ash & 18.0 \\
& Total \\
\hline
\end{tabular}


Table 17: Chaparral Composition-Whole Tree

\begin{tabular}{lccccc}
\hline $\begin{array}{c}\text { Feedstock } \\
\text { Component }\end{array}$ & $\begin{array}{c}\text { Chemise } \\
\text { (dry wt \%) }\end{array}$ & $\begin{array}{c}\text { Hoaryleaf } \\
\text { Ceanothus } \\
\text { (dry wt \%) }\end{array}$ & $\begin{array}{c}\text { Scrub Oak } \\
\text { (dry wt \%) }\end{array}$ & $\begin{array}{c}\text { Black Sage } \\
\text { (dry wt \%) }\end{array}$ & $\begin{array}{c}\text { 50/25/20/5 Mixed } \\
\text { Feedstock } \\
\text { (dry wt \%) }\end{array}$ \\
\hline \hline Glucan & 16.8 & 9.7 & 14.2 & 12.0 & 12.5 \\
Mannan & 2.8 & 2.0 & 5.9 & 3.0 & 2.9 \\
Galactan & 0.0 & 1.5 & 2.1 & 0.6 & 0.8 \\
Xylan & 8.6 & 1.7 & 4.4 & 6.1 & 5.4 \\
Arabinan & 2.9 & 1.6 & 2.8 & 1.9 & 2.1 \\
Lignin & 36.2 & 40.7 & 29.7 & 40.2 & 39.0 \\
Extractives & 19.2 & 29.4 & 21.2 & 21.6 & 23.1 \\
Ash & 3.0 & 2.8 & 8.1 & 3.5 & 3.5 \\
Other & 10.6 & 10.5 & 11.5 & 10.9 & 10.8 \\
& 100 & 100 & 100 & 100 & 100 \\
\hline
\end{tabular}

The production of ethanol from biomass requires the following basic steps: pretreatment to hydrolyze the hemicellulose, hydrolysis of cellulose to produce glucose, fermentation of sugars to ethanol, and ethanol recovery. There are different process configurations, both enzyme based and non-enzyme based, that can be used to achieve the overall goal. In the non-enzyme based approach, acid is used for both hemicellulose and cellulose hydrolysis, and the mode is separate hydrolysis and cofermentation (SHCF); cofermentation refers to the fermentation of both six-carbon (hexoses, i.e., glucose, mannose, and galactose) and five-carbon (pentoses, i.e., xylose and arabinose) sugars to ethanol. In the enzymatic approach, dilute-acid pretreatment is used to hydrolyze the hemicellulose portion. The saccharification (hydrolysis) of cellulose to cellobiose and eventually to glucose is catalyzed by the synergistic action of cellulase and $\beta$-glucosidase enzymes. The mode of operation used is simultaneous saccharification and cofermentation (SSCF). In this study the following different biomass-to-ethanol conversion technologies are used:

- Concentrated sulfuric acid process

- Enzyme-based process.

The flow diagrams for the two technology options are shown in Figure 11 and Figure 12, and process descriptions are provided below.

\section{Concentrated Acid Process}

Arkenol, Inc. of Mission Viejo, California, has developed an improved version of the concentrated acid hydrolysis technology. The acid-based technology presented in this report is similar to the Arkenol technology. However, the process was independently modeled by NREL using the Aspen ${ }^{\circledR}$ simulator, and the estimates for inputs and outputs presented in this report may not necessarily reflect those that would be developed by Arkenol.

The concentrated acid process consists of four basic unit operations:

1) Hydrolysis

2) Separation of the acid and sugars

3) Ethanol fermentation

4) Product purification 


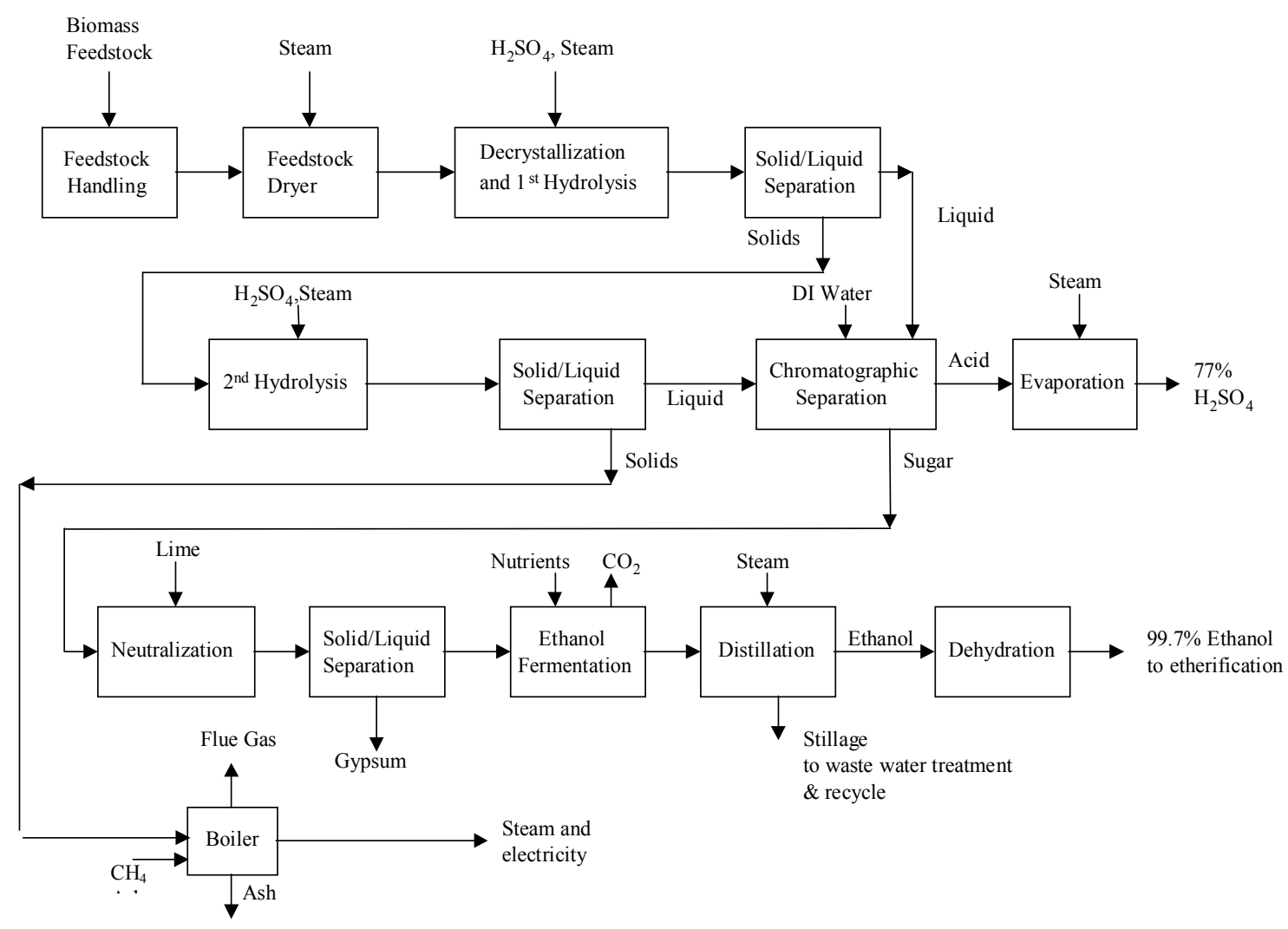

Figure 11: Concentrated Acid Process Flow Diagram

\section{Decrystallization and First Hydrolysis}

Prior to acid hydrolysis, the biomass is dried to a moisture content of approximately $10 \%$ and milled to an average size of $15 \mathrm{~mm}$. The feedstock is mixed with concentrated sulfuric acid at a concentration of $70 \%-77 \%$. The sulfuric acid to $\mathrm{C}+\mathrm{H}$ ratio is 1.25 to 1 . This step results in the disruption of the bonds between the crystalline cellulose chains, making the long chain cellulose accessible for hydrolysis. The resulting acid concentration is $30 \%$. The decrystallization is performed at temperatures in the range of $30^{\circ}$ to $50^{\circ} \mathrm{C}$. The addition of acid to the biomass results in the formation of a thick gel. In the first hydrolysis, the mixture of acid and biomass is heated to $100^{\circ} \mathrm{C}$ for 60 minutes to hydrolyze the cellulose. The resulting gel is pressed to obtain an acid-sugar stream (approximately $17 \%$ sugar and $35 \%$ acid, depending on feedstock composition).

\section{Second Hydrolysis}

The solids remaining after the first hydrolysis and solid/liquid separation are mixed with concentrated sulfuric acid until a concentration of $30 \%$ acid is again reached. The second hydrolysis step is very similar to the first hydrolysis step. The mixture is heated for 50 minutes at $100^{\circ} \mathrm{C}$ to effect further cellulose hydrolysis. The resulting gel is pressed to obtain a second acid-sugar stream (approximately 18\% sugar and 30\% acid, depending on feedstock composition), and the streams from the two hydrolysis steps are combined. The remaining lignin-rich solids are collected and optionally pelletized for fuel.

\section{Chromatographic Separation of Acid and Sugar}

The acid-sugar stream is further processed through a chromatographic separation column packed with a strong-acid polystyrene-divinylbenzene resin. Water is used as an eluant. As a result of this chromatographic separation process, 
two streams are collected: the $25 \%$ concentrated acid stream and the $12 \%-15 \%$ concentrated sugar stream. The sugar recovery is $95 \%$ whereas the acid recovery is $98 \%$. The acid stream is concentrated and recycled. The sugar stream, which contains no more than $1 \%$ acid, can then be fermented after the $\mathrm{pH}$ has been adjusted. Residual acid in the sugar stream is neutralized by adding lime, which forms a gypsum precipitate. Gypsum is removed in a solid/liquid separation step. This neutralization has the added benefit of precipitating unwanted metal hydroxides and other fermentation inhibitors.

\section{Concentration and Recycling of Acid}

The acid solution recovered from the separation unit can be concentrated and recycled to the earlier stages of the process. Concentration of the acid to $70 \%-77 \%$ is achieved through the use of a triple effect evaporator.

\section{Fermentation}

A recombinant Zymomonas mobilis can be used to ferment both six-carbon and five-carbon sugars. However, $Z$. mobilis is not suitable for softwood conversion, as this bacterium does not ferment mannose and galactose, two major hemicellulosic sugars prevalent in softwoods. A recombinant xylose-fermenting yeast can be used in the case of forest residue or thinnings. Recombinant E. coli and Klebsiella oxytoca are also possible choices.

An appropriate ethanologen is mixed with nutrients and added to the sugar solution where it efficiently converts both six-carbon and five-carbon sugars to ethanol and carbon dioxide.

The SHCF is carried out in continuous, anaerobic, fermenters. The flow of fermentation broth between fermenters is facilitated by gravity. Fermentation off gases, containing mostly carbon dioxide and ethanol vapor, are sent to the vent scrubber for ethanol recovery. The fermentation broth is sent to the distillation section for ethanol recovery.

\section{Distillation and Ethanol Dehydration}

Ethanol is separated from the fermentation beer by conventional distillation technology and dehydrated with conventional molecular sieve technology. The $99.7 \%$ ethanol is sent to the ETBE section. The stillage from the distillation column is sent to wastewater treatment and recycle.

\section{Ligneous Residue}

The ligneous residue, containing mostly lignin and cellulose, removed after the second hydrolysis step is $\mathrm{pH}$ adjusted and burned on-site to cogenerate steam and electricity that can be used by the process. A supplemental fuel is needed to generate steam needed by the process. The net electricity produced for this process is zero for all the three feedstocks. Alternatively, the residue can be sold as fuel to a nearby biomass-power plant. This option was studied as part of the sensitivity analysis.

\section{Data Summary for Concentrated Acid Process}

The estimates of inputs and outputs for the process were developed using an Aspen ${ }^{\circledR}$-based model and are shown in Table 18. The plant capacity was assumed to be 800 metric tons/d of dry feedstock.

\section{Enzymatic Process}

A generalized process was modeled based on Trichoderma reesei-derived cellulases for cellulose hydrolysis and an appropriate recombinant ethanologen for cofermentation of six-carbon and five-carbon sugars to ethanol. The enzyme-based process consists of four basic unit operations:

1) Pretreatment

2) Cellulase production

3) Ethanol production

4) Product purification. 
Table 18: Data Summary for Concentrated Acid Process

\begin{tabular}{lccc}
\hline \multicolumn{1}{c}{$\begin{array}{c}\text { Environmental } \\
\text { Flows }\end{array}$} & $\begin{array}{c}\text { Rice straw } \\
\mathrm{kg} / \mathrm{kg} \text { biomass }\end{array}$ & $\begin{array}{c}\text { Softwood } \\
\mathrm{kg} / \mathrm{kg} \text { biomass }\end{array}$ & $\begin{array}{c}\text { Chaparral } \\
\mathrm{kg} / \mathrm{kg} \text { biomass }\end{array}$ \\
\hline \hline Inputs & & & \\
Biomass & 1.000 & 1.000 & 1.000 \\
Lime & 0.025 & 0.025 & 0.025 \\
Water & 5.892 & 5.139 & 4.975 \\
$\mathrm{NH}_{3}$ & 0.001 & 0.001 & 0.000 \\
Diesel $_{\mathrm{CSL}}$ & 0.003 & 0.003 & 0.001 \\
$\mathrm{H}_{2} \mathrm{SO}_{4}$ & 0.035 & 0.034 & 0.034 \\
Natural gas $_{\text {Outputs }}$ & 0.051 & 0.045 & 0.047 \\
Ethanol & 0.279 & 0.187 & 0.119 \\
Gypsum & & & \\
Ash & 0.223 & 0.222 & 0.083 \\
Ligneous Residue & 0.059 & 0.058 & 0.058 \\
Wastewater & 0.176 & 0.020 & 0.034 \\
CO & 0.383 & 0.345 & 0.494 \\
\hline
\end{tabular}

Feedstock Preparation and Pretreatment

The biomass is milled to an average size of $15 \mathrm{~mm}$. A screw feeder conveys the biomass from the storage bunker to the acid impregnator. Dilute sulfuric acid and low-pressure steam are also fed to the acid impregnator. The acidic slurry is discharged from the acid impregnator into the pretreatment reactor. High-pressure steam and additional dilute sulfuric acid are fed to the reactor where hemicellulosic sugars are hydrolyzed to their respective monomers/oligomers (temperature $=160^{\circ}-180^{\circ} \mathrm{C}$, liquid phase acid concentration $=0.7 \%-1.0 \%$ wt.).

The hydrolyzed mash is discharged from the acid hydrolysis reactor into the lower-pressure flash drum where cooling quenches the reactions. The hydrolyzate is separated from the solids in a solid/liquid separation step. The hydrolyzate is then pumped to the neutralization and detoxification section. This involves continuous ion exchange using a weak-base anion resin followed by overliming. The process primarily removes acetic acid and other species that could be toxic to the microorganisms used.

Lime is used to neutralize the detoxified hydrolyzate; the neutralization reaction produces calcium sulfate, which is removed in a solid/liquid separation step. The neutralized hydrolyzate is pumped through a heat exchanger where it is cooled using cooling tower water to fermentation temperature. The hydrolyzate and solids from the solid/liquid separation step are then pumped to the ethanol fermentation section.

\section{Cellulase Production}

Cellulase production is by $T$. reesei using a slipstream of pretreated biomass as a carbon source. The fermentation is conducted in a fed-batch mode at $28^{\circ} \mathrm{C}$ and $\mathrm{pH} 5$. Corn steep liquor is used as a source of nitrogen and micronutrients. For a low-cost product such as ethanol, the enzyme need not be processed to any great extent to be useful. Whole broth from cellulase fermentation is actually more effective for the SSCF process. In this process, the whole fermentation broth is used as a source of cellulase enzyme. Because enzyme production is via the fed-batch mode and the SSCF is a continuous process, a surge storage tank is necessary. It is assumed that cellulase production using pretreated forest thinnings, rice straw, and chaparral as substrates is feasible. 


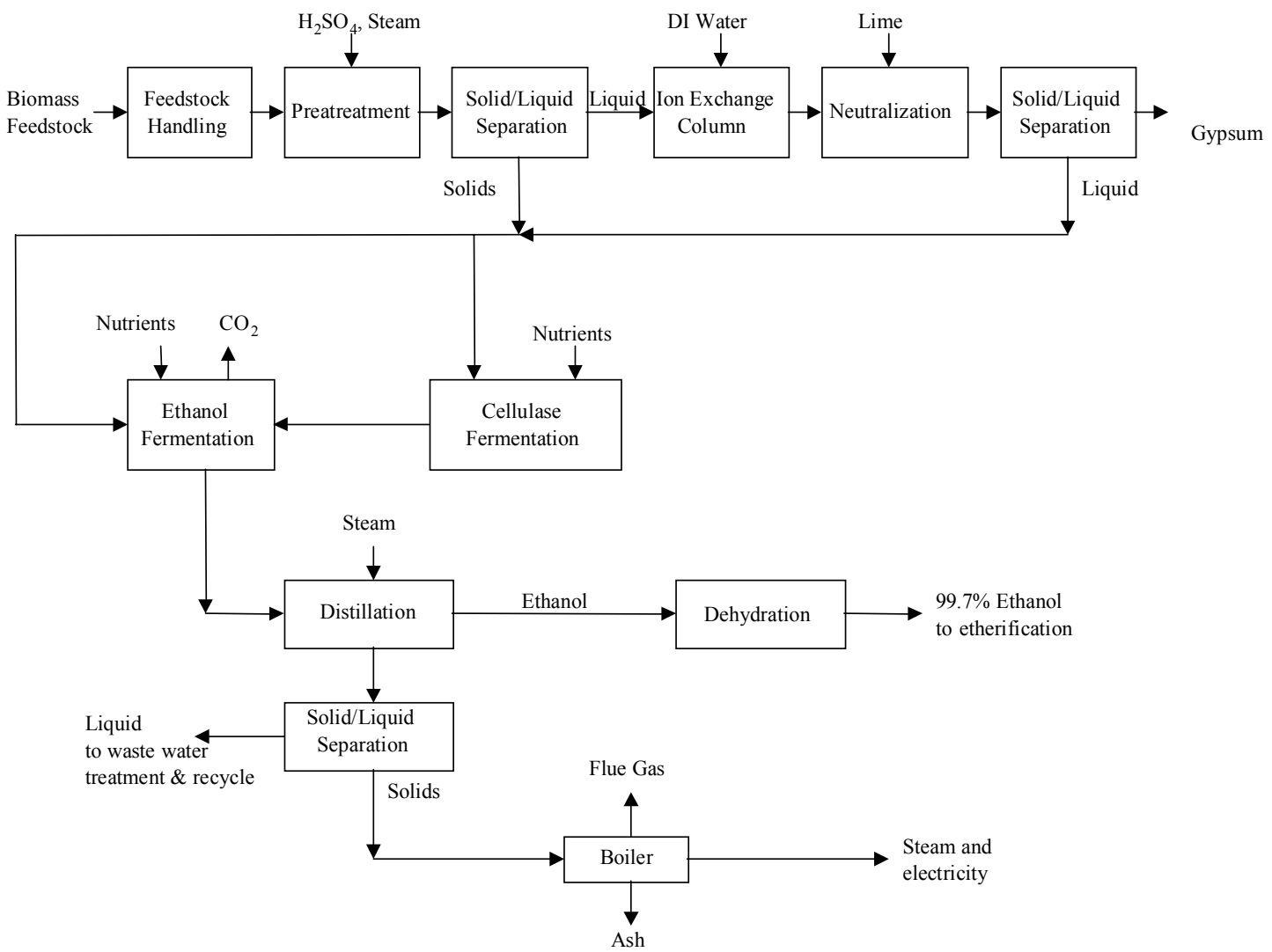

Figure 12: Enzymatic Process Flow Diagram

Ethanol Production

The simultaneous saccharification and cofermentation process converts cellulose and five-carbon sugars to ethanol and carbon dioxide. Cellulase catalyzes the hydrolysis of cellulose to glucose. A recombinant $Z$. mobilis can be used to ferment both six-carbon and five-carbon sugars for rice straw and chaparral, and recombinant xylose-fermenting yeast (or rDNA E. coli or K. oxytoca) can be used with forest thinnings.

The SSCF operation takes place in continuous anaerobic fermenters. Gravity drives the flow of fermentation broth between fermenters. Fermentation exhaust gases consisting of carbon dioxide and ethanol vapor are sent to the vent scrubber for ethanol recovery. The SSCF broth is pumped to the distillation section for the recovery of ethanol.

\section{Distillation and Ethanol Dehydration}

The fermentation broth is sent to the distillation section. Ethanol is separated from the fermentation beer by conventional distillation technology and dehydrated using conventional molecular sieve technology. The still bottoms are collected and the $99.7 \%$ ethanol is sent to the ETBE section. The lignin residue is further dewatered in a solid/liquid separation step. The liquid stream is sent to wastewater treatment and recycle.

\section{Ligneous Residue}

The dewatered ligneous residue is burned on-site to cogenerate steam and electricity that can be used by the process. With most feedstocks, excess electricity is generated, which can be sold. (Due to its high ash and low lignin contents, rice straw needs a supplemental fuel to generate steam needed by the process.) As in the acid process, the residue can alternatively be sold as fuel to a nearby biomass-power plant. This option was considered in the sensitivity analysis. 


\section{Data Summary for Enzymatic Process}

The estimates of inputs and outputs for the process were developed using NREL's Aspen ${ }^{\circledR}$-based model, with technology targets established for the early part of the next decade (see Table 19). The plant capacity was assumed to be 800 metric tons/d of dry feedstock.

Ligneous Residue

The ligneous residue recovered is burned on-site to cogenerate steam and electricity, which is used by the process. In some cases, the excess electricity can be sold. As an option, this residue can be sold as fuel to an existing biomass-power plant in the vicinity. Table 20 provides a list of some of the waste-to-energy plants in California, with information on the MW of power generated and the county where the plant is located. This alternative was examined as part of the sensitivity analysis. If this residue is sold, the electricity and steam required by the process will need to be imported.

\section{Sulfuric Acid}

The production of sulfuric acid $\left(\mathrm{H}_{2} \mathrm{SO}_{4}\right)$ was modeled based on the contact process according to the following reactions:

$$
\begin{aligned}
& 2 \mathrm{SO}_{2}+\mathrm{O}_{2} \rightarrow 2 \mathrm{SO}_{3} \\
& \mathrm{SO}_{3}+\mathrm{H}_{2} \mathrm{O} \rightarrow \mathrm{H}_{2} \mathrm{SO}_{4}
\end{aligned}
$$

Emissions information is based on data collected from a number of production plants worldwide, as well as engineering calculations.

\begin{tabular}{|c|c|c|c|}
\hline $\begin{array}{c}\text { Environmental } \\
\text { Flows }\end{array}$ & $\begin{array}{c}\text { Rice straw } \\
\mathrm{kg} / \mathrm{kg} \text { biomass }\end{array}$ & $\begin{array}{l}\text { Forest Residue } \\
\mathrm{kg} / \mathrm{kg} \text { biomass }\end{array}$ & $\begin{array}{c}\text { Chaparral } \\
\mathrm{kg} / \mathrm{kg} \text { biomass }\end{array}$ \\
\hline \multicolumn{4}{|l|}{ Inputs } \\
\hline Biomass & 1.000 & 1.000 & 1.000 \\
\hline Lime & 0.002 & 0.002 & 0.001 \\
\hline Water & 4.522 & 3.753 & 5.254 \\
\hline $\mathrm{NH}_{3}$ & 0.003 & 0.004 & 0.001 \\
\hline Diesel & 0.006 & 0.006 & 0.002 \\
\hline$C S L$ & 0.018 & 0.019 & 0.019 \\
\hline $\mathrm{H}_{2} \mathrm{SO}_{4}$ & 0.000 & 0.000 & 0.000 \\
\hline Natural gas & 0.041 & 0.000 & 0.000 \\
\hline \multicolumn{4}{|l|}{ Outputs } \\
\hline Ethanol & 0.248 & 0.272 & 0.093 \\
\hline Gypsum & 0.004 & 0.004 & 0.003 \\
\hline Ash & 0.178 & 0.021 & 0.035 \\
\hline Ligneous Residue & 0.453 & 0.435 & 0.578 \\
\hline Wastewater & 2.024 & 2.033 & 2.078 \\
\hline \multirow[t]{2}{*}{$\mathrm{CO}_{2}$} & 1.236 & 1.373 & 2.492 \\
\hline & $\mathrm{MJ} / \mathrm{kg}$ biomass & $\mathrm{MJ} / \mathrm{kg}$ biomass & $\mathrm{MJ} / \mathrm{kg}$ biomass \\
\hline Net electricity & 0.67 & 0.00 & 3.54 \\
\hline
\end{tabular}

Table 19: Data Summary for Enzymatic Process

NREL, CARB, CEC, CDF, Ecobalance Inc., TSS Consultants

March, 1999 
Table 20: Waste-to-Energy Plant Locations in California

\begin{tabular}{llcc}
\hline \multicolumn{1}{c}{ Plant Name } & \multicolumn{1}{c}{ Fuel Source (Cogen) } & $\begin{array}{c}\text { Online } \\
\text { (MW) }\end{array}$ & County \\
\hline \hline Wheelebrator-Shasta & Biomass & 50 & Anderson \\
Georgia Pacific (Martell) & Biomass - Woodwaste & 9.0 & Amador \\
Martell Cogeneration & Biomass - Woodwaste (Cogen) & 18.0 & Amador \\
Pacific Oroville Power & Biomass - Ag. \& Woodwaste & 18.0 & Butte \\
Koppers Industries & Biomass - Woodwaste (Cogen) & 6.0 & Butte \\
Waldham Energy & Biomass - Ag. Waste & 26.5 & Colusa \\
Western Rock Products & Biomass & 0.250 & San Bernardino \\
Big Valley Lumber & Biomass - Woodwaste (Cogen) & 5.0 & Lassen \\
Honey Lake Power & Biomass - Woodwaste (Cogen) & 30.0 & Lassen \\
Mt. Lassen Power & Biomass - Woodwaste (Cogen) & 10.5 & Lassen \\
Sierra Pacific Industries (Susanville) & Biomass - Woodwaste (Cogen) & 15.0 & Lassen \\
Lincoln Cogeneration & Biomass - Woodwaste (Cogen) & 7.5 & Placer \\
Rio Bravo Rocklin & Biomass - Woodwaste & 25.0 & Placer \\
Collins Pine & Biomass - Woodwaste (Cogen) & 12.0 & Plumas \\
Sierra Pacific Industries (Quincy) & Biomass - Woodwaste (Cogen) & 20.0 & Plumas \\
Mecca Plant & Biomass - Ag. \& Woodwaste & 49.9 & Riverside \\
Sierra Pacific Industries (Loyalton) & Biomass - Woodwaste (Cogen) & 20.0 & Sierra \\
Woodland Biomass & Biomass - Ag. \& Woodwaste & 25.0 & Yolo \\
\hline
\end{tabular}

Corn Steep Liquor

Corn steep liquor production involves the steeping of harvested corn for a period of from 24 to 48 hours in a light sulfurous acid solution. The burdens from the production of corn were allocated according to the mass of corn matter that stays in the steeping liquor after the corn is removed. Other allocation methods could be used including allocation based on the economic value of the coproducts. Different allocation methods could effect the results of the study in terms of nitrate emissions. Most of the nitrate emissions for the overall study are due to growing the corn necessary to produce the CSL.

The production of sulfurous acid was assumed to be negligible. The only emissions from the steeping process consist of $\mathrm{SO}_{\mathrm{x}}$ emissions from the steeping tanks. Emission factors from the U.S. EPA AP-42 were used.

\section{Lime}

The production process for lime was modeled to include the following steps:

- Limestone extraction

- Limestone crushing

- Limestone calcination: $\quad \mathrm{CaCO}_{3} \rightarrow \mathrm{CaO}+\mathrm{CO}_{2}$

The transport of limestone to the calcination facility was not taken into account, since it was assumed to be inconsequential. Limestone crushing yields $50 \%$ in mass of small pieces (coproducts) which are sold. Electricity consumption for crushing was allocated on a mass basis. Emission data were gathered from a major European lime producer. 


\section{Ammonia}

The production of synthetic anhydrous ammonia is modeled as using a natural gas reforming process, in which natural gas used as feedstock (and fuel). It was assumed that the natural gas consumption consists of:

- $60 \%$ feedstock (the feedstock value of the ammonia $=23.61 \mathrm{MJ}$ )

- $40 \%$ fuel

There is no $\mathrm{CO}_{2}$ recovery from the reforming process. Energy requirements for the process are based on Fertilizer Institute data [7]. Air emissions were modeled using AP-42: process emissions plus emissions from a Natural Gas industrial boiler.

\subsubsection{ETBE Production}

As was explained in the section on MTBE modeling (section 3.1.7), the production capacity of ETBE in the state of California is limited to $15 \%$ of California's oxygenate demand, namely due to the limited availability of isobutylene and the small number of facilities. Therefore, even if there is sufficient biomass to produce enough ETBE to completely replace the MTBE that is consumed, there is currently no way of producing more than $15 \%$ of the total demand in state. For the production of the remaining $85 \%$ of demand, there are a number of options:

1) The remaining ETBE would be produced out of state, requiring shipping the ethanol to Texas, and subsequent shipping of the ETBE back to California.

2) The construction of additional plants in California to meet the remaining $85 \%$ of demand, which would also require the importation of sufficient isobutylene.

3) The construction of new plants that have a combined paraffin isomerization/etherification process, such as the STeam Active Reforming — or the "STAR" - process and the High Conversion Etherification Process patented by Phillips Petroleum [8]. The process allows for the conversion of California sources of butane to isobutylene for use during the ETBE production process.

Since these decisions have an economic basis, the best decision is beyond the scope of this study, and it is assumed that the model only reflects the production of enough ETBE to replace the MTBE produced in California. This is consistent with the near-term scope of this study.

Since thermodynamics do not favor the production of ETBE, there is a less efficient use of isobutylene in the model. The reaction for producing ETBE is as modeled below:

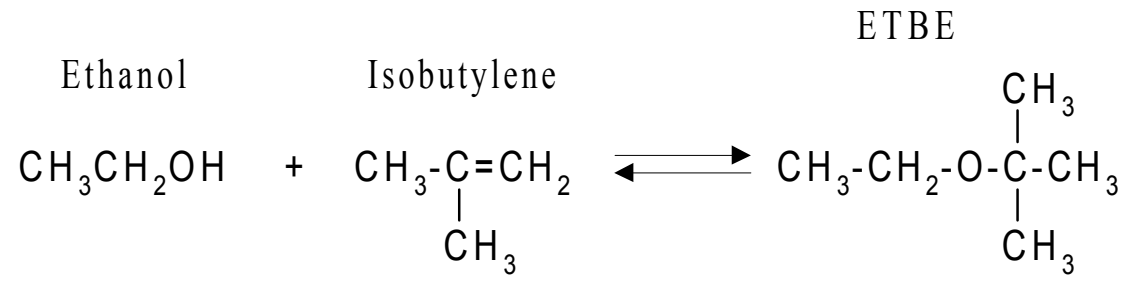

As with the production of MTBE, this process leads to side reactions,

Isobutylene + water
Ethanol + Ethanol
Isobutylene + isobutylene

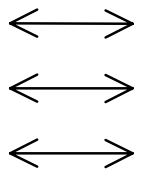

Tertiary Butyl Alcohol (TBA)

water + Diethyl Ether (DEE)

Di-isobutylene (DIB)

but conditions are controlled so that the selectivity of isobutylene and ethanol to ETBE is very high. TBA, DEE and DIB make up less than $1 \%$ of the outflow by weight. The presence of these coproducts has no adverse effect on the quality of the ETBE, since they are also acceptable octane gasoline components. 
The azeotropic properties of ethanol with $\mathrm{C}_{4}$ compounds widely differ from those of methanol. The excess ethanol feeding the reaction is therefore mostly recovered with the ETBE product. Ethanol free ETBE is produced by the addition of an ethanol separation step: distillation, adsorption, and extraction. Removal of ethanol from the $\mathrm{C}_{4}$ raffinate is achieved via an ethanol recovery section similar to that used in the MTBE model. The inputs for ETBE production are given in Table 21.

Table 21: Inputs for ETBE Production

\begin{tabular}{lcc}
\hline \multicolumn{1}{c}{ Input } & $\begin{array}{c}\text { Fixed bed finishing } \\
\text { reactor }\end{array}$ & $\begin{array}{c}\text { Catalytic distillation } \\
\text { finishing reactor }\end{array}$ \\
\hline \hline Isobutylene conversion & $92 \%$ & $95 \%$ \\
Electricity & $234 \mathrm{MJ} / \mathrm{h}$ & $234 \mathrm{MJ} / \mathrm{h}$ \\
Steam & $5.5 \mathrm{t} / \mathrm{h}$ & $5.5 \mathrm{t} / \mathrm{h}$ \\
Cooling water & $300 \mathrm{~m}^{3} / \mathrm{h}$ & $300 \mathrm{~m}^{3} / \mathrm{h}$ \\
\hline
\end{tabular}

Values are given for a rate of 40,000 metric tons of ETBE produced per year.

\subsubsection{ETBE Blending}

It is assumed that the ETBE is matched with the gasoline it is blended with to produce the appropriate oxygenated fuel. No emissions are assumed from blending.

\subsection{ISObUtylene PRODUCTION}

Isobutylene is normally obtained from a $\mathrm{C}_{4}$ fraction that results from the cracking of petroleum fractions and natural gas. This fraction contains a mixture of butylenes and butanes. Generally speaking, there are two commercially important processes for producing isobutylene: steam cracking of saturated hydrocarbons derived from natural gas or crude oil (yielding 40\%-50\% isobutylene), and catalytic cracking of high boiling petroleum fractions (yielding $15 \%-20 \%$ isobutylene). The latter process is the process that is used predominantly in the United States. An approximate composition of this feed is given in Table 22.

Table 22: C4 Fraction Composition

\begin{tabular}{cc}
\hline Composition & Weight \% \\
\hline \hline Propane & 0.1 \\
Isobutane & 34.6 \\
n butane & 11.0 \\
Isobutylene & $\mathbf{1 5 . 0}$ \\
1 butene & 12.8 \\
t2 butene & 15.8 \\
C2 butene & 9.6 \\
Butadiene & 0.1 \\
C5 & 1.0 \\
\hline
\end{tabular}

The model for the production of the $\mathrm{C}_{4}$ fraction follows the petroleum refining model that is detailed in section 4.6. 


\subsection{ELECTRICITY PRODUCTION}

The electricity grid model includes the following:

- Pre-combustion processes: coal mining (surface and underground) and transportation, natural gas extraction and transportation, crude oil extraction (off-shore and on-shore) refining, and transportation, production of nuclear fuel ( $\mathrm{UF}_{6}$, accumulation and fuel rod manufacturing), and hydroelectric power production

- Combustion in power plants

- Distribution (losses: 7.7\%)

\subsubsection{Natural Gas}

The approach to modeling natural gas production is covered at the beginning of section 4.1.1 above.

\subsubsection{Natural Gas Combustion}

Natural gas is combusted in gas boilers. Emissions from the combustion of natural gas (except for $\mathrm{NO}_{\mathrm{x}}$ ) are mainly due to improper operating conditions, such as inefficient mixing of fuel and air in the boiler, or an insufficient amount of air, etc. Emissions vary by the type and size of combustor and operating conditions.

Emissions factors for gas boilers were obtained from AP-42 for $\mathrm{NO}_{\mathrm{x}}, \mathrm{CO}, \mathrm{SO}_{\mathrm{x}}$, particulate matter, $\mathrm{CO}$, and VOCs. Emissions factors modeled are uncontrolled emissions.

\subsubsection{Coal}

The processes that make up coal production include extraction of coal, cleaning and preparation of coal for use at utility plants, and transportation to the utilities.

\section{Coal Mining}

Materials and energy consumed in mining and cleaning of coal comes from Delucchi [1]. These energy data are modeled in conjunction with the quantity of coal produced in 1987 reported by EIA [9].

Emissions due to mining coal are those from the combustion of diesel oil of mining equipment, and methane, released directly from the mine. Emissions factors for the diesel oil combustion come from AP-42. While mining data from 1987 are used, the quantity of methane released from the mines comes from a later year [10]. These data give the value for methane releases from total coal production as $0.6 \%$ to $0.9 \%$ (averaged to $0.75 \%$ ).

Waste from mining is generated from activities such as portal construction and mine ventilation, and is assumed to be $32 \%$ of underground mined coal produced. Eastern surface mining waste totals $27 \%$ of mined output and western surface mining produces waste equaling $10 \%$ of mined output [11].

Coal mining is regionalized by taking into account a weighted average of surface mining (eastern and western surface mining modeled as the same process) and underground mining [9].

\section{Coal Cleaning}

Coal cleaning removes impurities, such as sulfur, ash, and rock, from the mined coal. The processes included are initial preparation, fine and coarse coal processing, and final preparation of coal. Emission factors are modeled for mechanical, as opposed to chemical, separation processes.

The quantity of coal used in cleaning was derived from average mining/cleaning data [1]. The coal component is assumed to be the energy source for cleaning and preparation. Therefore, the quantity of coal used in the model as energy for cleaning was found by taking the ratio of coal consumed to coal produced. This number was found to be $0.05 \%$ of total coal consumed $\left(4.1 \times 10^{5}\right.$ tons consumed to clean and prepare $8.3 \times 10^{8}$ tons of coal). 


\section{Transportation from Site of Extraction to Power Plant}

Coal may be transported by different transportation means, including rail, road, pipeline, and river. The expression used to describe the energy intensity of transporting coal (or any other material) is joules per ton-kilometer. It is safe to assume that for the most part, the carrier returns empty. For example, $91 \%$ of the unit train cars that carry coal return empty to the mine, and trucks return empty unless they can find a similar product to transport back [1]. Therefore, all transportation data assume a one-way haul.

Rail

The 1987 national average length of haul for coal by means of rail is 788 kilometers [1,9]. This distance may be applied to the U.S. Northeast since bituminous coal may travel from states such as Kentucky and Tennessee to the most Northeastern states of the United States, and coal may also come from closer sources, such as West Virginia. It is assumed that diesel fuel is used for rail transportation [1]. The energy consumed is averaged out to be $4.2 \times 10^{5}$ joules per ton-kilometer.

Truck

The average haul distance for coal delivery is 97 kilometers for a round trip [1,12]. It is assumed that diesel fuel is used for truck transportation. The energy consumed is averaged out to be $1.7 \times 10^{6}$ joules per ton-kilometer [1].

\section{Ship}

The national average length of haul for coal by means of water is 724 kilometers although DOE estimates one-way transportation for eastern barges to be 306 kilometers [11]. It is assumed that ships use residual fuel oil. Since the former source of data is most recent but the latter is more specific to eastern bituminous coal, the two figures are averaged out to 515 kilometers. The energy consumed is averaged $3.9 \times 10^{5}$ joules per ton-kilometer.

\section{Slurry Pipeline}

Data for energy consumed in coal transportation by slurry pipeline gives an average energy consumed for this mode of transport of $5.2 \times 10^{5}$ joules per ton-kilometer [1]. Included in this average is energy used for slurry preparation, pipeline pumping, dewatering facilities, and specifically, energy used in the Black Mesa Pipeline, which runs 439 kilometers from the Black Mesa Coal Mine in Arizona to the Mohave Power Plant in Laughlin, Nevada. The estimated average length of haul for a pipeline is 483 kilometers, including the pipeline itself, tramway transportation, and conveyor belts.

\subsubsection{Coal Combustion}

Energy consumed and emissions associated with combustion of coal in utility boilers come from a variety of sources. Emissions and total coal burned were obtained from the 1994 Interim Inventory based on the Form EIA767 data. ${ }^{11}$ Emissions factors for pollutants not provided in the Interim Inventory are obtained from AP-42.

Emissions are presented for each individual firing configuration. Because firing configurations have varying combustion requirements (coal combustion temperatures, firing methods, and emissions control equipment, etc.), they emit varying amounts of pollutants.

The firing configurations included in the model are:

- $\quad$ Pulverized coal fired, dry bottom and wall fired;

- Pulverized coal fired, dry bottom and tangentially-fired;

- Pulverized coal-fired and wet bottom;

- $\quad$ Spreader stoker;

\footnotetext{
11 Database provided by the U.S. EPA.

NREL, CARB, CEC, CDF, Ecobalance Inc., TSS Consultants
}

March, 1999

Final Report

Kadam et al. 
- Fluidized bed combustor; and

- Cyclone furnace.

The Interim Inventory provides actual air emissions (VOCs, $\mathrm{NO}_{\mathrm{x}}, \mathrm{CO}, \mathrm{SO}_{\mathrm{x}}$, and $\mathrm{PM}-10$ ) by specific type of coal (bituminous, subbituminous, and lignite) and by furnace type. The firing types provided are also identified by a Source Classification Code (SCC). Each firing type was placed into a broader category of firing configurations using SCC numbers.

The following table (Table 23) presents the firing types and how they were placed in the firing configuration category, based on SCC numbers. Firing types were grouped together so that a weighted percentage of boilers and amount of specific coal fed into the boilers would be obtained since different firing configurations emit differing quantities of pollutants.

Table 23: Coal Firing Configurations/Firing Types

\begin{tabular}{ll}
\hline \multicolumn{1}{c}{ Firing Configuration (AP-42) } & \multicolumn{1}{c}{ Firing Types (Interim Inventory) } \\
\hline \hline Pulverized coal fired, dry bottom, wall fired & Front Furnace \\
& Arch Furnace $(50 \%)^{12}$ \\
& Rear Furnace \\
& Spreader Stoker $(80 \%)^{13}$ \\
& Opposed Furnace \\
Pulverized coal fired, dry bottom and tangentially-fired & Vertical Furnace \\
Pulverized coal-fired, wet bottom & Tangential Furnace \\
Spreader stoker & Arch Furnace $(50 \%)$ \\
Fluidized bed combustor & Spreader Stoker $(20 \%)$ \\
Cyclone furnace & Fluidized Bed \\
\hline
\end{tabular}

Several steps were made to obtain actual emissions in pounds per ton of bituminous coal. The tonnage for each emission was summed for each firing configuration. This figure was divided by the total amount of bituminous coal consumed for each firing configuration, to obtain actual emissions per firing configuration. The results of this calculation are presented in Table 24.

Where actual emissions data were not available, such as for $\mathrm{N}_{2} \mathrm{O}$, methane, and trace elements, emissions factors were obtained from AP-42 (Table 25).

The model also takes into account all carbon dioxide emissions, which are calculated by multiplying the fuel carbon concentration by the ratio of molecular/atomic weights of $\mathrm{CO}_{2}$ and $\mathrm{C}$ [13]. The fixed carbon content and the $\mathrm{CO}_{2}$ emissions factor (in $\mathrm{g} / \mathrm{kg}$ coal) are presented in Table 26.

Finally, the model takes the weighted average of each of the firing configurations for each type of coal. For example, the emissions from the spreader stoker for bituminous coal combustion are omitted from the model, since bituminous coal combusted in the spreader stoker is a negligible representation of all of the bituminous coal fed into the firing configurations.

12 About half of the arch furnace boilers had SCC numbers for dry-bottom wall-fired units and the other half for wet-bottom units.

13 An estimated $80 \%$ of the spreader stoker boilers had SCC numbers for dry-bottom wall-fired units and the other $20 \%$ belonged in the spreader stoker category of firing configurations.

NREL, CARB, CEC, CDF, Ecobalance Inc., TSS Consultants

March, 1999

Final Report

Kadam et al. 
Table 24: Bituminous Coal Combustion Emissions (kg/ton of coal burned) ${ }^{14}$

\begin{tabular}{|c|c|c|c|c|c|}
\hline Firing Configuration & VOC's ${ }^{15}$ & $N O_{x}$ & $\mathrm{CO}$ & $S O_{x}$ & $P M-10$ \\
\hline $\begin{array}{l}\text { Pulverized Coal-Fired, Dry Bottom, Wall } \\
\text { Fired }\end{array}$ & 0.03 & 9.0 & 0.27 & 19.8 & 0.33 \\
\hline $\begin{array}{l}\text { Pulverized Coal-Fired, Dry Bottom, } \\
\text { Tangentially-Fired }\end{array}$ & 0.03 & 6.8 & 0.27 & 21.4 & 0.44 \\
\hline Pulverized Coal-Fired, Wet Bottom & 0.04 & 12.5 & 0.27 & 13.7 & 11.2 \\
\hline Spreader Stoker & 0.03 & 9.1 & 0.55 & 19.4 & 0.20 \\
\hline Fluidized Bed Combustor & 0.03 & 4.4 & 0.00 & 6.4 & 0.21 \\
\hline Cyclone Burner & 0.03 & 16.8 & 0.27 & 37.9 & 0.04 \\
\hline
\end{tabular}

Table 25: Bituminous Coal Combustion Emissions Factors

\begin{tabular}{lc}
\hline \multicolumn{1}{c}{ Boiler Type } & $\begin{array}{c}\mathrm{N}_{2} \boldsymbol{O} \\
\text { (kg/ton of coal burned) }\end{array}$ \\
\hline \hline Pulverized Coal-Fired, Dry Bottom, Wall Fired & 0.04 \\
Pulverized Coal-Fired, Dry Bottom, Tangentially-Fired & 0.01 \\
Pulverized Coal-Fired, Wet Bottom & 0.04 \\
Spreader Stoker16 & 0.04 \\
Fluidized Bed Combustor ${ }^{17}$ & 2.6 \\
Cyclone Furnace & 0.04 \\
\hline \multicolumn{2}{c}{ Table 26: Coal Fixed Carbon Content } \\
\hline Fixed Carbon Content (\%) & CO $_{2}$ Emissions Factor $(\mathrm{g} / \mathrm{kg})$ \\
\hline \hline
\end{tabular}

Emissions Control Technology

Because there are actual plant data for VOCs, $\mathrm{NO}_{x}, \mathrm{CO}, \mathrm{SO}_{2}$, and particulate matter, emission control technologies for some of the major pollutants of concern, such as $\mathrm{NO}_{\mathrm{x}}$ and $\mathrm{SO}_{\mathrm{x}}$, are already taken into account.

Lime and limestone, used for flue gas desulfurization (FGD), are modeled. Coal utility plants use different methods for scrubbing, such as limestone slurries and dry spraying, and use lime and limestone as the primary FGD materials. Quantities of lime and limestone vary, depending on the type of coal, the molar ratio needed to scrub the $\mathrm{SO}_{\mathrm{x}}$, and the percentage of $\mathrm{SO}_{\mathrm{x}}$ (by weight) in the coal. FGD for bituminous coal is modeled according to the general scrubbing material for that type of coal and based on its percentage by weight of $\mathrm{SO}_{\mathrm{x}}{ }^{18}$

\footnotetext{
14 Interim Inventory provides emissions on a 1000 tons per year basis.

15 Includes methane and non-methane VOCs.

16 Emissions factors averaged over spreader stoker, spreader stoker with multiple cyclones and reinjection, and spreader stoker with multiple cyclones, without reinjection.

17 Emissions factors averaged over fluidized bed combustor: bubbling bed and circulating bed.

18 Data collected from a source at a coal utility plant in North America (1996), a source at American Electric Power Company (1997) and from the Electric Power Annual 1994.
}

NREL, CARB, CEC, CDF, Ecobalance Inc., TSS Consultants

March, 1999 


\subsubsection{Coal Post-Combustion}

The coal combustion process produces waste that must be disposed of off-site, including coal ash (resulting from coal combustion) and sludge (resulting from FGD). In 1984, $69 \times 10^{6}$ tons and $16 \times 10^{6}$ tons of coal ash and sludge, respectively, were generated from electrical facilities [1]. Energy and emissions to remove coal ash and sludge are modeled. Since the quantity of sludge is approximately $25 \%$ of the amount of coal ash, all energy and emissions to remove and dispose of sludge are considered to be about $25 \%$ of those found for the disposal of coal ash.

Energy to transport and place sludge and coal ash from the plant to the respective storage locations is modeled. The moisture content of coal ash (in \% weight of ash) at the point it is removed from the silo is assumed to be approximately $17 \% .{ }^{19}$ The distance from the power plant to the coal ash and FGD sludge landfills is assumed to be one mile.

The trucks used to transport the materials are tandem trucks, filled based on weight of the material. The tandem truck carries an actual payload of about 25 metric tons, and consumes 0.14 liters of diesel fuel per metric ton of material per trip.

\subsubsection{Heavy Fuel Oil}

Fuel oil pre-combustion is outlined below.

AP-42 contains emissions factors for the combustion of residual fuel oil nos. 4, 5, and 6, for normal and tangential firing configurations at utilities. Emissions factors of $\mathrm{NO}_{\mathrm{x}}, \mathrm{SO}_{2}, \mathrm{SO}_{3}, \mathrm{CO}$, total organic compounds, non-methane total organic compounds, and methane are provided.

Emissions controls include combustion and post-combustion $\mathrm{NO}_{\mathrm{x}}$ and $\mathrm{SO}_{\mathrm{x}}$ technologies. These control technologies were incorporated into the $\mathrm{NO}_{\mathrm{x}}$ and $\mathrm{SO}_{\mathrm{x}}$ emissions so that emissions data are more representative of actual emissions, as opposed to uncontrolled emissions alone.

$\mathrm{SO}_{\mathrm{x}}$ is scrubbed from fuel oil burners the same way it is for coal combustion. Lime and limestone are used as the FGD material. Fuel oil boilers use about 50\% lime and 50\% limestone as FGD material. The quantity of $\mathrm{SO}_{\mathrm{x}}$ scrubbed is about $90 \%$ of total $\mathrm{SO}_{\mathrm{x}}$ for fuel oil [2]. The quantity of lime and limestone that is used is calculated by assuming that the $\mathrm{SO}_{2}$ is the remaining $10 \%$ of $\mathrm{SO}_{2}$ that was not scrubbed. Therefore, $90 \%$ of the total $\mathrm{SO}_{2}$ is found, and is multiplied by the grams of a mole of $\mathrm{CaO}$ and $\mathrm{CaCO}_{3}$ that is needed to scrub a mole of $\mathrm{SO}_{2}(0.88$ and 1.56 , respectively).

\subsubsection{Nuclear Power Production}

Uranium contains two different isotopes- $-{ }^{238} \mathrm{U}$ and ${ }^{235} \mathrm{U} ;{ }^{235} \mathrm{U}$ is used as a fuel for nuclear reactors because it is fissionable, so the atoms can be split, releasing large amounts of heat. However, natural uranium consists of more than $99 \%{ }^{238} \mathrm{U}$ and less than $1 \%{ }^{235} \mathrm{U}$. To be used as a fuel, its ${ }^{235} \mathrm{U}$ content must be enriched to $3 \%-5 \%$.

The data included in the upstream portion of nuclear energy production are uranium hexafluoride (UF6) manufacturing, enrichment of ${ }^{235} \mathrm{U}$, and fuel rods manufacturing $[14,15]$.

\subsubsection{Hydroelectric Power Production}

Hydroelectric power generation refers to water used to generate electricity at plants in which turbine generators are driven by falling water.

The emissions due to hydroelectric power production are primarily the greenhouse gases $\mathrm{CO}_{2}$ and $\mathrm{CH}_{4}$, generated because of the decomposing flooded biomass in the reservoir, and emissions from capital equipment and construction of the facility: steel and concrete production, transportation to the reservoir, and construction energy. However, capital equipment and construction are not included in this model, for the same reasons that are outlined in the next section.

\begin{tabular}{l}
19 Moisture content may be anywhere from $8 \%$ to $25 \%$. Data from an American power plant (confidential client of Ecobalance \\
$\begin{array}{lr}\text { Inc.), } 1996 . \\
\text { NREL, CARB, CEC, CDF, Ecobalance Inc., TSS Consultants }\end{array}$ \\
\hline Final Report
\end{tabular} 
Therefore, the remaining part of hydroelectricity that is modeled is the greenhouse gas emissions $\left(\mathrm{CO}_{2}\right.$ and $\left.\mathrm{CH}_{4}\right)$ from operation of the plant. Chamberland $[16]^{20}$ provides life cycle data on few hydroelectric power sites in northern Canada, and the Federal Energy Regulatory Commission ${ }^{21}$ provides U.S. hydroelectric plant information such as average annual generation, plant capacity, and reservoir area and depth.

The data obtained on greenhouse gases emissions do not distinguish flooded biomass decomposition from new biomass decomposition and are assumed to refer only to flooded biomass.

\subsubsection{Capital Equipment Exclusion}

In LCA, one might include capital equipment, or production and transportation of concrete and steel, as well as construction burdens, in the system boundaries. However, for this electricity generation comparison, capital equipment has been excluded for the following reasons:

- It may be assumed that most electricity production facilities are made up of comparable quantities of concrete and steel. Therefore, the burdens due to capital equipment are the same for all sources, so any quantities that are capital equipment-related may be subtracted out of both sides of the results in each comparison.

- Dr. Ian Boustead in Eco-balance-Methodology for Commodity Thermoplastics [17] states: “....although the inventory flows associated with the construction of capital plant and buildings are high, their effect upon the products they produce is usually negligible because of the large total throughput that is usually achieved in their lifetime."

- The energy used in the construction of large energy facilities and other equipment used in fuel cycles (including electric power plants, oil wells, oil tankers and hydroelectric plants) is negligible (less than $1 \%$ ) compared with the energy produced or carried by that equipment over its useful life [1].

\subsubsection{Electricity Grids}

The following tables (Table 27 and Table 28) show the electricity production percentages for the different North American Electric Reliability Council (NERC) regions in the North America [18].

Note that the percentages are given for the U.S. portion of the region listed. Some regions are split between Canada and the United States (WSCC for example), however, the electricity production percentages are given for only the U.S. portion. The different NERC regions are described in Figure 13.

The electricity model was tailored to the specific NERC region from which the modeled material is derived. Data were gathered for the production of renewable energy in California, based on information obtained from CEC and AP-42. In order to model the use of electricity in California for specific systems, the following distribution of fuel types was used [19].

\subsection{Steam Production}

The energy necessary to convert water to steam is based on the enthalpy of the steam $(2.6 \mathrm{MJ} / \mathrm{kg}$ at approximately $150 \mathrm{psi}$ and $350^{\circ} \mathrm{F}$ ) and a boiler efficiency of $80 \%$. Steam is assumed to be produced by combusting fuel in industrial boilers. The fuel can consist of coal, natural gas or heavy fuel oil.

\footnotetext{
20 Chamberland's life cycle study is based on a group of facilities in northern Canada whose average lifespan is 100 years and produces annually $62,200 \mathrm{GWh}$ of electricity.

21 FERC database, 1996.

NREL, CARB, CEC, CDF, Ecobalance Inc., TSS Consultants

March, 1999

Final Report

Kadam et al.
} 
Table 27: Electricity Production by NERC Region

\begin{tabular}{lccccc}
\hline & \multicolumn{3}{c}{ NERC Region } \\
\multicolumn{1}{c}{ Fuel Type } & NPCC & ECAR & WSCC & ERCOT & SERC \\
\hline \hline HFO & $10.7 \%$ & $0.3 \%$ & $0.1 \%$ & $0.1 \%$ & $3.4 \%$ \\
Hydro & $15.4 \%$ & $0.5 \%$ & $40.6 \%$ & $0.3 \%$ & $4.6 \%$ \\
Natural gas & $18.3 \%$ & $0.5 \%$ & $10.2 \%$ & $37.4 \%$ & $5.9 \%$ \\
Nuclear & $35.1 \%$ & $10.4 \%$ & $12.8 \%$ & $17.1 \%$ & $29.5 \%$ \\
Coal & $20.5 \%$ & $88.3 \%$ & $36.3 \%$ & $45.2 \%$ & $56.6 \%$ \\
\hline
\end{tabular}

\begin{tabular}{lccccc}
\hline \multicolumn{1}{c}{ Fuel Type } & MAAC & MAPP & MAIN & SPP & U.S. Average \\
\hline \hline HFO & $3.1 \%$ & $0.5 \%$ & $0.5 \%$ & $0.3 \%$ & $2 \%$ \\
Hydro & $0.8 \%$ & $8.4 \%$ & $1.4 \%$ & $2.9 \%$ & $9.8 \%$ \\
Natural gas & $5.3 \%$ & $0.9 \%$ & $1.7 \%$ & $28.3 \%$ & $10.2 \%$ \\
Nuclear & $40.8 \%$ & $15.9 \%$ & $42.4 \%$ & $15.7 \%$ & $23 \%$ \\
Coal & $50 \%$ & $74.3 \%$ & $54 \%$ & $52.8 \%$ & $55 \%$ \\
\hline
\end{tabular}

${ }^{*}$ Heavy Fuel Oil

Table 28: California Net System Power

\begin{tabular}{lc}
\hline \multicolumn{1}{c}{ Fuel Type } & Net System Power \\
\hline \hline Coal & $17 \%$ \\
Large Hydroelectric & $24 \%$ \\
Natural Gas & $35 \%$ \\
Nuclear & $14 \%$ \\
Eligible Renewables & $11 \%$ \\
Total: & $\mathbf{1 0 0 \%}$ \\
\hline
\end{tabular}

The assumed heating values of the three fuels are as follows:

- Natural Gas - $52 \mathrm{MJ} / \mathrm{kg}$

- Heavy Fuel Oil - $42 \mathrm{MJ} / \mathrm{kg}$

- $\quad$ Coal $-29.3 \mathrm{MJ} / \mathrm{kg}$

The emission factors for industrial boilers were obtained from AP-42. These numbers were compared with a study done by the Argonne National Laboratory [20], to verify and expand on the U.S. EPA emission factors.

All the factors reported are for uncontrolled emissions. If control technologies are used, the emission factors should be reduced by the efficiencies of the control devices.

Heavy fuel oil production emission factors are shown in section 4.4.6, and natural gas production emissions are outlined above in section 4.1.1. 


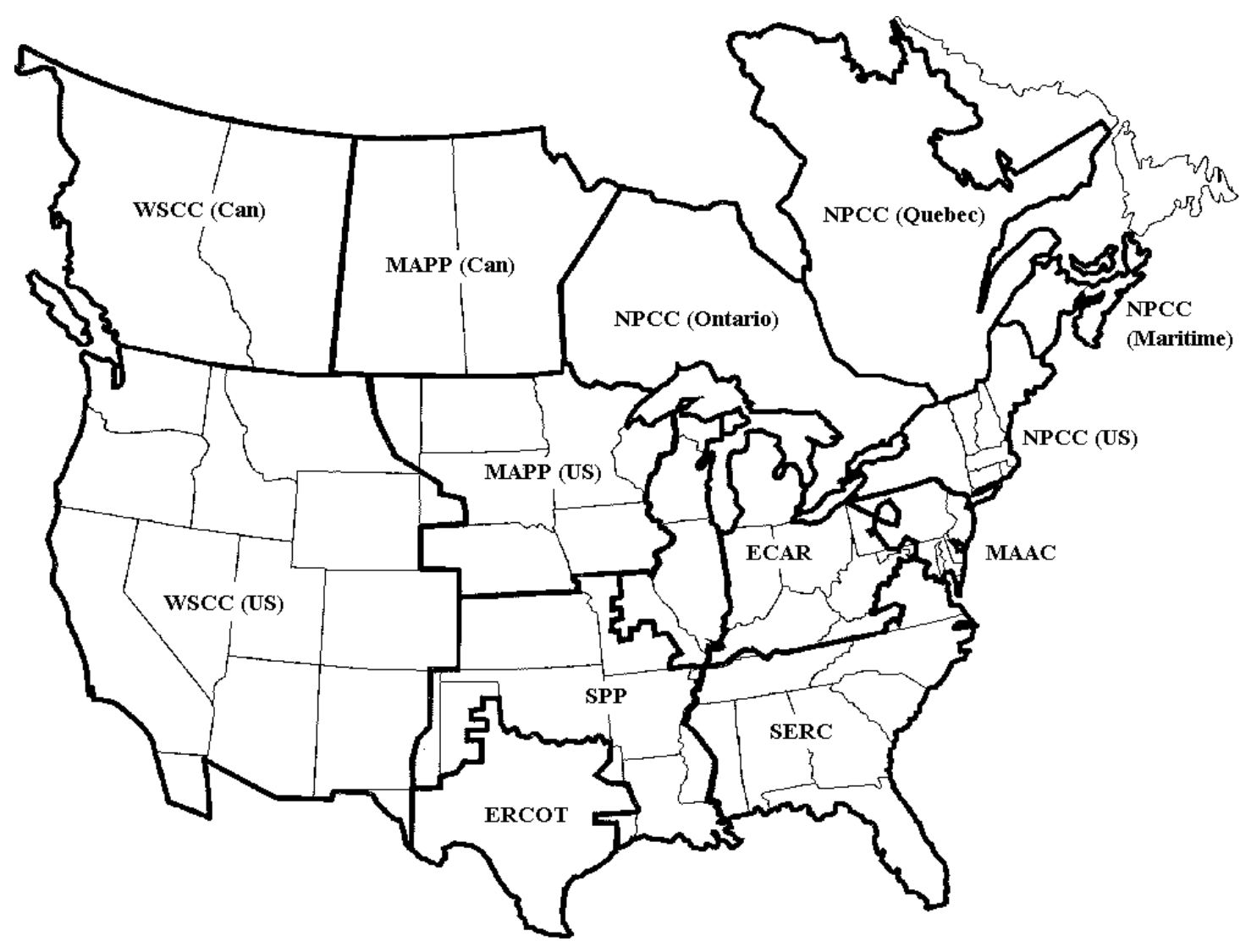

Figure 13: Map of the NERC regions in the United States and in Canada

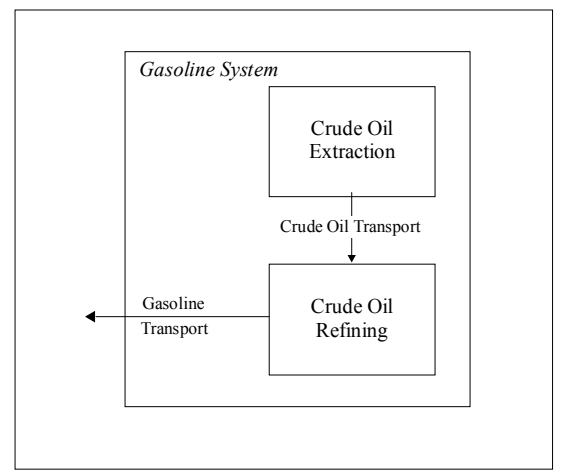

Figure 14: Gasoline Production Systems

This section includes pre-combustion data for gasoline. The pre-combustion steps includes extraction of crude oil from the ground, transportation of the crude oil to a refinery, and refining the crude oil into finished refinery products (Figure 14). Transportation of the finished refinery products to the point of use is also included at this stage. The model was regionalized to California whenever possible. For a full description of petroleum products modeling see Appendix D. 


\subsubsection{Geographical Boundaries}

The modeling of refined petroleum products production includes worldwide crude oil extraction and U.S. refinery operations. Foreign crude oil extraction and transportation to the United States is modeled because half of the U.S. supply of crude oil is imported. The transport of finished refinery products into the United States is not studied because foreign refinery products only accounts for a small percentage of the total finished refinery products used in the United States in 1994 [21], and may be accounted for under domestic refinery production. In addition, domestic refinery data are more accurate and reliable.

\subsubsection{Crude Oil Extraction}

There are three separate methods for crude oil extraction and recovery: onshore production, offshore production, and thermal enhanced recovery, which entails the underground injection of carbon dioxide or steam produced by natural gas boilers. ${ }^{22}$ All of these methods were modeled.

Heater treater separators are used to separate the crude oil, natural gas, and water mixture that is extracted. As natural gas is produced as a coproduct of crude oil production, emissions were allocated between gross natural gas and crude oil production on a mass-based method. The emissions associated with the venting and flaring of some of the natural gas extracted from the well was also accounted for.

The inflows associated with the three different methods of crude oil extraction include electricity used in pumping, and natural gas used as fuel to run the heater treater systems. Outflows include air emissions, water effluents, and solid waste.

\subsubsection{Transportation}

The United States is broken up into Petroleum Administration for Defense Districts (PADDs) in order to ensure that each region or PADD is supplied with enough petroleum for strategic defense reasons. The transportation distances used in this report were based on the PADD in which California is located. The amount of foreign and domestic crude oil transported into each PADD was estimated from refinery receipts of crude oil that is known for each PADD [22] $]^{23}$. The mix of foreign and domestic crude oil shipped to the PADD in which California is located was also used in this model.

Distances used to model transportation of are based on national averages, obtained from the following types of data and methods of calculation:

Domestic Tanker and Domestic Barge [12]: Report lists tons and ton-miles of crude oil transported by tanker and barge on all U.S. waterways. Average miles are calculated by dividing total ton-miles traveled by total tons transported. This is done separately for both tanker and barge.

Domestic Pipeline [22]: Association of Oil Pipelines lists total ton-miles of crude oil carried in domestic pipelines. Average miles are calculated by dividing total ton-miles of crude oil, carried in domestic pipelines, by tons of crude oil received at refineries via pipeline. Foreign pipeline distance is calculated the same way.

Domestic Rail [23]: Association of Oil Pipelines lists total ton-miles of crude oil carried by rail in the United States. Average miles are calculated by dividing total ton-miles of crude oil, carried by rail, by tons of crude oil received at refineries via railroad tank cars.

\footnotetext{
22 Shares of each production type were obtained from the Oil \& Gas Journal Database, using numbers obtained in 1994. Note that the Other Enhanced/Advanced category includes all advanced crude oil extraction techniques except water flooding. It was assumed that the emissions associated with thermal advanced recovery as listed by Tyson et al. (November 1993, Fuel Cycle evaluations of Biomass-Ethanol and Reformulated Gasoline) applied to the percentage of wells operating with the other Enhanced/Advanced techniques obtained from the Oil \& Gas Journal Database.

231993 data were used because that was the latest year for which information used to calculate transportation distances could be found (see Section 3.3.2).

NREL, CARB, CEC, CDF, Ecobalance Inc., TSS Consultants

March, 1999

Final Report

Kadam et al.
} 
Domestic Truck [24]: Association of Oil Pipelines lists estimated total ton-miles of crude oil transported by motor carriers in the United States. Average miles are calculated by dividing total ton-miles of crude oil, transported by motor carriers, by tons of crude oil received at refineries via truck.

Foreign Tanker [1,21]: The Petroleum Supply Annual lists imports of crude oil by country for each PADD (in barrels). PADD I crude oil is assumed to all arrive at New York. PADD II and III oil is assumed to arrive at Houston. PADD V oil is assumed to arrive at Los Angeles. PADD IV does not receive any foreign oil other than from Canada.

Nautical miles between ports of origin and U.S. ports (New York, Houston, and Los Angeles) are given in Delucchi's study, based on information from the Defense Mapping Agency [25]. From this information a weighted average is calculated, for each PADD, by multiplying barrels imported from each country by the distance from that country to the specified U.S. port of entry. These results, in barrel-miles for each PADD, are added together and then divided by the total number of barrels imported to get an average distance in miles traveled by the foreign tankers.

\subsubsection{Crude Oil Refining}

The inflows associated with refining include crude oil, natural gas, liquefied petroleum gas, steam, electricity, and coal [21]. Outflows for this process include air emissions [2], water effluents, and solid waste. The California electricity grid was used to model refinery electricity use.

Allocation of refining processes must be addressed. Petroleum refineries produce a number of different products from the amount of crude oil that they receive. Additional complexity is introduced by the fact that the refinery product mix is variable, both among refineries and even with time for a given integrated refinery.

The simplest allocation procedure would be to allocate total refinery releases (and consumption) among the products on a mass output basis. The following table (Table 29) outlines how this would be done, based on the output of a generic U.S. refinery:

Table 29: Production of an Average U.S. Refinery

\begin{tabular}{rlc}
\hline \multicolumn{1}{c}{ Refinery Flow } & Mass $(\mathrm{kg} / \mathrm{yr})$ & Mass $(\%)$ \\
\hline \hline Diesel Oil (< 0.05\% Sulfur, kg): & $9.30 \times 10^{10}$ & $12.8 \%$ \\
Diesel Oil (> 0.05\% Sulfur, kg): & $6.76 \times 10^{10}$ & $9.33 \%$ \\
Gasoline: & $3.08 \times 10^{11}$ & $42.5 \%$ \\
Heavy Fuel Oil: & $4.52 \times 10^{10}$ & $6.24 \%$ \\
Jet Fuel (kg): & $6.53 \times 10^{10}$ & $9.01 \%$ \\
Kerosene (kg): & $2.74 \times 10^{9}$ & $0.38 \%$ \\
Misc. Refinery Products (U.S., kg): & $2.19 \times 10^{9}$ & $0.30 \%$ \\
Petroleum Coke (kg): & $4.12 \times 10^{10}$ & $5.69 \%$ \\
LP Gas: & $1.92 \times 10^{10}$ & $2.66 \%$ \\
Asphalt (kg): & $2.72 \times 10^{10}$ & $3.75 \%$ \\
Lubricants (kg): & $8.87 \times 10^{9}$ & $1.22 \%$ \\
Petrochemical Feedstocks (kg): & $4.04 \times 10^{10}$ & $5.57 \%$ \\
Petroleum Waxes (kg): & $9.71 \times 10^{8}$ & $0.13 \%$ \\
Naphthas (kg): & $2.35 \times 10^{9}$ & $0.33 \%$ \\
Total: & $7.24 \times 10^{11}$ & \\
\hline &
\end{tabular}


However, this would result in the same LCI profile for every kg or refinery product regardless of its characteristics (e.g., one $\mathrm{kg}$ of diesel fuel would have the same profile as one $\mathrm{kg}$ of gasoline).

An objection to the mass allocation approach, which is based on output share, is that a kilogram of different refinery products requires different amounts of processing, thus requiring different amounts of energy input and leading to different amounts of releases.

An alternative allocation method would be one based on the share of the total process energy required to produce the refinery product.

This method of allocating refinery flows based on process energy requirements is outlined in the following steps:

- Calculate the percentage of total refinery energy used by each different process within the refinery.

- Calculate a specific refinery product's share of each process' energy consumption.

- Multiply the two results in order to get the percentage of total refinery energy allocated to a single refinery product production for each process. Adding the results of each process gives the percentage of total refinery energy allocated to a total single refinery product.

- Allocate emissions and energy use based on the percentage of total refinery energy allocated to a total single refinery product. (From step 3 above)

Many different studies have been done in the past in order to estimate total refinery energy allocation to the different processes within a refinery [1]. These studies, however, were predominantly done in the late 1970s and early 1980s and their relevance to today's refinery processes is not fully known. This is complicated by the fact that refinery energy requirements are considered proprietary information so it is difficult to confirm the past studies findings.

For this project, an additional study done by White et al. [26] ${ }^{24}$ was used with two studies listed by Delucchi [1] to help estimate refinery process energy allocation. This study may not be completely applicable, for the reasons outlined above, but it was found to be the most comprehensive and descriptive of what had been done.

The three refinery models list energy consumption for different refinery processes. This information is used to calculate the percentage of total refinery energy used by each different process within the refinery. ${ }^{25}$ Error! Not a valid bookmark self-reference. lists the results.

For this study, the average values for fraction of total refinery energy used by each process were used. Averaging the values from the three studies is thought to help compensate for the differences in refinery configurations and size.

An individual refinery product's share of each process' energy consumption can be calculated from information provided in a recent DOE study [1] and information on refinery production [21]. The DOE study allocates energy use in different refinery process areas to gasoline, total distillates and residual fuel in proportion to process energy output of the different products. ${ }^{26}$ Table 31 shows the results. The values in Table 31 can be multiplied by the average fraction of total refinery energy used by each process to determine the total process energy required to produce each of the four different types of refinery fuels shown above. The results of this are shown in Table 32 .

24 The authors were, at the time of the study, all members of Mobil Research and Development Corp., Princeton and Paulsboro, NJ.

25 Note: White et al. do not take into account increased energy requirements for producing low sulfur diesel fuel. Therefore, energy values from White et al. for hydrogen manufacture and hydrodesulfurizer have been increased to account for removal of more sulfur. The increase is based on assuming that the energy consumption given in White et al. represented removal of $1.25 \%$ of the sulfur in the incoming crude (crude oil $=1.5 \%$ sulfur, diesel fuel $=0.25 \%$ sulfur). Then a linear increase is assumed in energy consumption based on removing $1.45 \%$ of the sulfur (low sulfur diesel fuel $=0.05 \%$ sulfur).

26 Allocation is based on the energy output of the three different products from each of the different refinery processes. For example alkylation, reforming, and isomerization produce only high-octane gasoline components. Therefore, the process energy associated with alkylation, reforming, and isomerization is allocated entirely to gasoline production.

NREL, CARB, CEC, CDF, Ecobalance Inc., TSS Consultants

March, 1999

Final Report

Kadam et al. 
Table 30: Fraction of Total Refinery Energy Used by Each Process

\begin{tabular}{lcccc}
\hline \multicolumn{1}{c}{ Refinery Process } & \multicolumn{3}{c}{ Fraction of Total Refinery Energy } \\
\hline \hline Crude distillation & Lawerence & Haynes & White et al. & Average \\
Catalytic cracking & 0.276 & 0.364 & 0.266 & 0.302 \\
Thermal cracking & 0.314 & 0.065 & 0.124 & 0.168 \\
Hydrocracking & 0 & 0.033 & 0 & 0.011 \\
Desulfurization & 0 & 0.044 & 0 & 0.015 \\
Hydrotreating & 0.02 & 0 & 0.046 & 0.022 \\
Alkylation & 0 & 0.085 & 0.068 & 0.051 \\
Reforming & 0.065 & 0.069 & 0.040 & 0.058 \\
Coking & 0.191 & 0.225 & 0.140 & 0.185 \\
Visbreaking & 0.038 & 0.032 & 0.077 & 0.049 \\
Propylene concentration & 0 & 0.007 & 0 & 0.002 \\
Isomerization & 0.05 & 0 & 0 & 0.017 \\
Hydrogen & 0.042 & 0.002 & 0 & 0.015 \\
Depentanizer & 0 & 0.025 & 0.070 & 0.032 \\
Naphtha Pretreater & 0 & 0 & 0.0167 & 0.006 \\
Saturated gas plant & 0 & 0 & 0.054 & 0.018 \\
Unsaturated gas plant & 0.003 & 0.055 & 0.035 & 0.012 \\
Finishing and other & 0.999 & 1.006 & 0.064 & 0.021 \\
& & 0 & 0 & 0.019 \\
\hline
\end{tabular}

Table 31: Fraction of Refinery Process Energy Used by Types of Refinery Products

\begin{tabular}{|c|c|c|c|c|}
\hline \multirow[b]{2}{*}{ Refinery Process } & \multicolumn{4}{|c|}{ Fraction of Process Energy } \\
\hline & Gasoline & Distillate & Residual & Other \\
\hline Crude distillation & 0.454 & 0.302 & 0.07 & 0.174 \\
\hline Catalytic cracking & 0.55 & 0.365 & 0.085 & 0 \\
\hline Thermal cracking & 0.454 & 0.302 & 0.07 & 0.174 \\
\hline Hydrocracking & 0.541 & 0.359 & 0 & 0.1 \\
\hline Desulfurization & 0.454 & 0.302 & 0.07 & 0.174 \\
\hline Hydrotreating & 0.541 & 0.359 & 0 & 0.1 \\
\hline Alkylation & 1 & 0 & 0 & 0 \\
\hline Reforming & 1 & 0 & 0 & 0 \\
\hline Coking & 0.541 & 0.359 & 0 & 0.1 \\
\hline Visbreaking & 0 & 1 & 0 & 0 \\
\hline Propylene concentration & 0 & 0 & 0 & 1 \\
\hline Isomerization & 1 & 0 & 0 & 0 \\
\hline Hydrogen & 0.541 & 0.359 & 0 & 0.1 \\
\hline Depentanizer & 1 & 0 & 0 & 0 \\
\hline Naphtha Pretreater & 0.994 & 0 & 0 & 0.006 \\
\hline Saturated gas plant & 0.89 & 0 & 0 & 0.11 \\
\hline Unsaturated gas plant & 0.89 & 0 & 0 & 0.11 \\
\hline Finishing and other & 0.454 & 0.302 & 0.07 & 0.174 \\
\hline
\end{tabular}


Table 32: Fraction of Total Refinery Energy Used by Category of Refined Product

\begin{tabular}{lcccc}
\hline \multicolumn{1}{c}{ Refinery Process } & \multicolumn{3}{c}{ Fraction of Total Refinery Energy } & Other \\
\hline \hline Crude distillation & Gasoline & Distillate & Residual & 0.021 \\
Catalytic cracking & 0.14 & 0.091 & 0.014 & 0 \\
Thermal cracking & 0.09 & 0.061 & 0.0008 & 0.0019 \\
Hydrocracking & 0.0050 & 0.0033 & 0 & 0.0015 \\
Desulfurization & 0.008 & 0.0053 & 0.00154 & 0.0038 \\
Hydrotreating & 0.0100 & 0.0066 & 0 & 0.0051 \\
Alkylation & 0.028 & 0.018 & 0 & 0 \\
Reforming & 0.058 & 0 & 0 & 0 \\
Coking & 0.19 & 0 & 0 & 0.0049 \\
Visbreaking & 0.026 & 0.018 & 0 & 0 \\
Propylene concentration & 0 & 0.0023 & 0 & 0.0167 \\
Isomerization & 0 & 0 & 0 & 0 \\
Hydrogen & 0.0147 & 0 & 0 & 0.0032 \\
Depentanizer & 0.0171 & 0.0113 & 0 & 0 \\
Naphtha Pretreater & 0.0056 & 0 & 0 & 0.0001 \\
Saturated gas plant & 0.0178 & 0 & 0 & 0.0013 \\
Unsaturated gas plant & 0.0105 & 0 & 0 & 0.0023 \\
Finishing and other & 0.0189 & 0 & 0.0014 & 0.0034 \\
& 0.009 & 0.0058 & 0.0390 & 0.0967 \\
\hline
\end{tabular}

An example of how this allocation procedure is used to determine the allocation percentage for diesel fuel is shown below.

The results of Table 32 state that $22.3 \%$ of the total refinery energy is needed to produce distillate fuels. However, total distillates, as described in the DOE study, include diesel fuel, jet fuel, kerosene, and residual fuel. The fraction of total distillates taken up by diesel fuel is shown in the following table (Table 33).

Table 33: Diesel Fuel's Share of Total Distillates

\begin{tabular}{lcc}
\hline \multicolumn{1}{c}{ Distillates } & Mass (kg/yr) & Mass (\%) \\
\hline \hline Diesel Fuel: & $1.61 \times 10^{11}$ & $59 \%$ \\
Heavy Fuel Oil: & $4.52 \times 10^{10}$ & $17 \%$ \\
Jet Fuel (kg): & $6.53 \times 10^{10}$ & $24 \%$ \\
Kerosene (kg): & $2.74 \times 10^{9}$ & $1 \%$ \\
& Total: & $2.74 \times 10^{11}$ \\
\cline { 2 - 3 } & & \\
\hline
\end{tabular}

It is found that diesel fuel makes up 59\% of total distillate production on a mass basis. This result can be combined with the energy fraction needed to produce total distillates to give diesel fuel's share of refinery energy consumption as follows:

$$
22.3 \% \times 59 \%=13.2 \%
$$

The same method is used to calculate the allocation percentage for the other refinery products used in this study. For gasoline an allocation of $64.3 \%$ is used directly from Table 32. 


\subsection{GASOLINE TRANSPORT}

The transport modeling of gasoline to the point of use location is shown in Figure 15.

\subsubsection{Modes of Transport and Distance Transported}

It is assumed that a fraction of gasoline produced at the refinery is shipped to local point of use locations an average distance of 100 miles. The remaining fraction is shipped via pipeline to a tank farm where it is in turn shipped by truck 100 miles to a point of use location.

The fraction of gasoline shipped via pipeline is based on Association of Oil Pipelines, using data from Annual Report (Form 6) of oil pipeline companies to the Federal Energy Regulatory Commission. The report lists the percentage of total finished petroleum products that is shipped by pipelines, water carriers, motor carries, and railroads. The report states that $59 \%$ of the finished petroleum products are shipped via pipeline. The remaining $41 \%$ is assumed to be transported by truck. The Association of Oil Pipelines report also lists total ton-miles of finished petroleum products carried in domestic pipelines. Average pipeline transportation miles are calculated by dividing total ton-miles of petroleum products, carried in domestic pipelines, by tons of petroleum products shipped via pipeline. The result is 595 miles of pipeline transport.

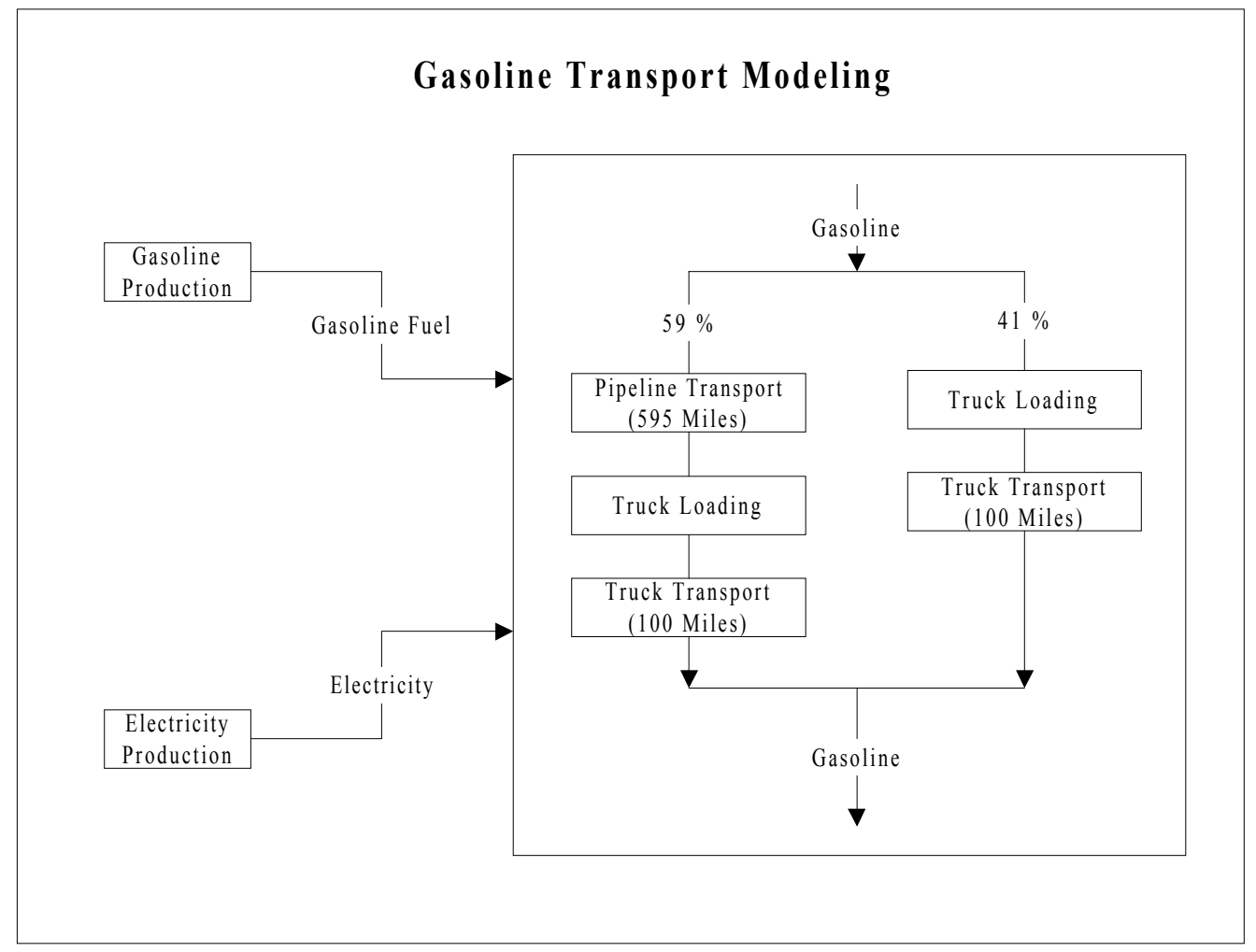

Figure 15: Gasoline Transportation Modeling

\subsubsection{Energy and Fugitive Emissions from Storage and Handling}

In addition to the energy requirements and subsequent emissions from the actual modes of transportation (e.g., truck diesel use and emissions, pipeline electricity requirements, and emissions from electricity production, etc.), there are also energy and emissions due to loading and unloading of the gasoline. The pumping requirements for gasoline are calculated by the same method as that for crude oil pumping (outlined in Section 4.6). The fugitive emissions from 
the loading, unloading and transportation of the gasoline are calculated using the same formulas as for the crude oil fugitive emissions (described in Section 4.6). The formulas are modified based on the gasoline properties (true vapor pressure, molecular weight of the vapors, etc.) as outlined in AP-42.

Note that fugitive tank emissions from the storage of gasoline at the refinery are accounted for in the refinery model. Also, fugitive tank emissions from the storage of gasoline at refueling locations are assumed to be negligible. Figure 16 represents how the emissions from gasoline transportation are modeled in this project.

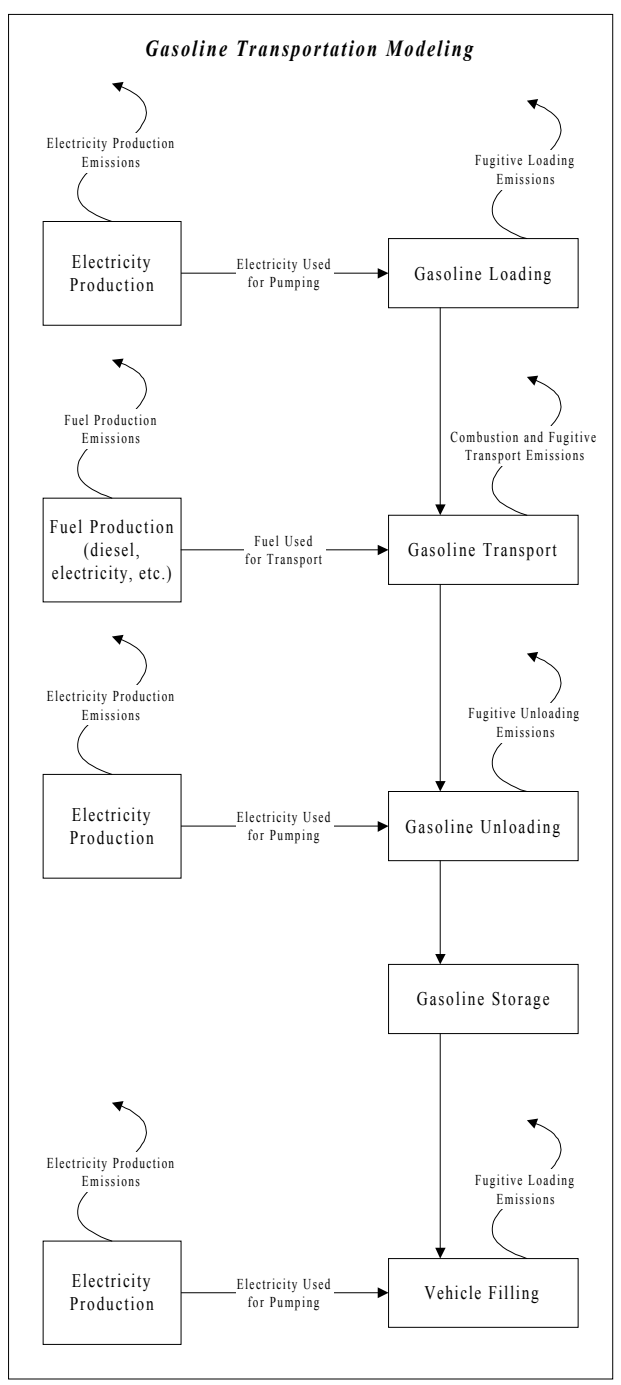

Figure 16: Gasoline Transportation Emissions Modeling

\subsection{OXYGenated Gasoline Fuel CoMbustion}

The modeling of oxygenated gasoline combustion is based on emissions from the use of equivalent amounts of ETBE and MTBE. The base is assumed to be the amount of ETBE that is produced from the conversion of one MBDT of biomass. Since the study assumes that the ETBE is a direct replacement for MTBE, and ETBE displaces slightly more gasoline than does MTBE (see Table 6), the combustion emissions were equal to the emissions from excess number of liters of MTBE oxygenated fuel. 


\subsubsection{Tailpipe Emissions}

The baseline emissions from the tailpipe of the vehicle modeled is based on emission standards from the U.S. EPA AP-42 for light-duty gasoline powered vehicles (Table 34).

Carbon dioxide emissions are based on converting $100 \%$ of the carbon in the gasoline to $\mathrm{CO}_{2}$, adjusting the value for the $\mathrm{CO}$ that is produced. The carbon content of the fuel is assumed to be $86 \%$ by weight.

These emissions are then converted using the percentage benefits from reformulated gasoline use for the year 2000 , provided by CARB (Table 35).

Table 34: Vehicle Emission Factors

\begin{tabular}{lc}
\hline Pollutant & $\begin{array}{c}\text { Emission Factors } \\
(\mathrm{g} / \mathrm{mile})\end{array}$ \\
\hline \hline Total VOC & 0.56 \\
Carbon Monoxide & 6.65 \\
Nitrogen Oxides & 0.81 \\
\hline
\end{tabular}

Table 35: Reformulated Gasoline Benefits: Year 2000

\begin{tabular}{lc}
\hline \multicolumn{1}{c}{ Pollutant } & $\begin{array}{c}\text { Reduction } \\
(\%)\end{array}$ \\
\hline \hline Total VOC (exhaust + evap.) & $18 \%$ \\
Carbon Monoxide & $9 \%$ \\
Nitrogen Oxides & $9 \%$ \\
\hline
\end{tabular}

Carbon dioxide reductions were calculated using the carbon content of the fuel. There are no reductions in total $\mathrm{CO}_{2}$ emissions that are modeled.

\subsubsection{Fuel Efficiency}

To give the emissions in terms of fuel consumed, a default fuel efficiency value was calculated to give the number of liters of gasoline used per mile. This value was based on a calculated average of data provided by DOE for 1997 mid-sized vehicles [27]. Average fuel consumption values are listed in Table 36.

Table 36: Average Fuel Consumption Values

\begin{tabular}{cc}
\hline City & Highway \\
\hline \hline 20 miles per gallon / & 28 miles per gallon / \\
5.3 miles per liter & 7.4 miles per liter \\
\hline
\end{tabular}

The fuel consumption for the vehicle was calculated as the inverse of the average fuel economy using the following equation, which was determined based on information published by DOE [27]:

$$
\mathrm{F}=0.45 / \mathrm{C}+0.55 / \mathrm{H}
$$


where,

$$
\begin{aligned}
& \mathrm{C}=\text { City fuel economy (miles/liter) } \\
& \mathrm{H}=\text { Highway fuel economy (miles/liter) }
\end{aligned}
$$

\subsubsection{Biomass versus Fossil Fuel Carbon Dioxide}

A portion of the $\mathrm{CO}_{2}$ that is generated from the combustion of the oxygenated fuel containing ETBE comes from biomass. The amount of $\mathrm{CO}_{2}$ that comes from biomass was calculated based on the non-isobutylene carbon content of the oxygenate. Biomass and fossil $\mathrm{CO}_{2}$ were reported separately in the model and results. $\mathrm{CO}_{2}$ sequestered in the biomass is carried through the LCA as $\mathrm{CO}_{2}$ (biomass) versus $\mathrm{CO}_{2}$ (fossil) which results from the combustion of petroleum resources.

The net biomass $\mathrm{CO}_{2}$ produced by the system is assumed to be zero. The positive values for biomass $\mathrm{CO}_{2}$ reported in the results are assumed to be offset by biomass $\mathrm{CO}_{2}$ uptake by the biomass during its growth. Plants use solar energy to fix carbon from carbon dioxide during photosynthesis. For this project, it will be assumed that $\mathrm{CO}_{2}$ uptake by the biomass will be released back to the environment through decomposition of plant residue, left in the field after harvesting, through the burning of the biomass itself, or through the burning of ETBE made from the biomass. Thus the net $\mathrm{CO}_{2}$ balance for growing and disposal of biomass is zero. Therefore, the $\mathrm{CO}_{2}$ (biomass) results are not used in the impact assessment phase to calculate greenhouse gas potential. 
For an LCA, there are two different types of data: primary and secondary [1]. Primary data are obtained directly from individual production plants or companies. Secondary data are published sources such as databases, industry or government publications, journals, or books. Another kind of secondary data also includes "educated guesses," or data coming from experts based on their knowledge in the field, but not published.

In general, the goals for data collection, quality, and utilization are to use the most recent data available that are representative of an industry or practice. The goals specifically for this study were to obtain data on the processes leading to MTBE production from natural gas, the disposal of biomass, the conversion of biomass into ETBE, and the use of MTBE and ETBE in oxygenated fuels.

\subsection{DATA QUALITY}

Data in an LCA should have indicators for reliability and completeness. The "reliability indicator" pertains to how data were obtained and verified, independent of the data quality goals outlined in the study. The "completeness indicator" pertains to how representative the data samples are, i.e., do the data represent an adequate sample size, and do the data cover an adequate period such that normal fluctuations are evened out. The completeness indicator is also treated as independent of the data quality goals outlined in the study. Presently, actual data indicators have not been established in LCA guidelines. Instead, a table is generally provided to indicate the type of data in each life cycle sector and the reliability and completeness for each.

Table 37 outlines the general data categories in this study and provides a description of each, the sources and whether they are primary or secondary, a "checklist" of the reliability criteria, including the geographical and temporal extent of the data, and limitations. 
Table 37: Data Quality

\begin{tabular}{|c|c|c|c|c|}
\hline Data Category & Description & $\begin{array}{l}\text { Primary or secondary; } \\
\quad \text { Source and date }\end{array}$ & $\begin{array}{l}\text { Geographic and temporal } \\
\text { representation }\end{array}$ & Reliability and Completeness \\
\hline $\begin{array}{l}\text { Natural Gas } \\
\text { Production }\end{array}$ & materials, energy, emissions & $\begin{array}{l}\text { Primary and secondary; Gas } \\
\text { Research Institute (1997) }\end{array}$ & $\begin{array}{c}\text { U.S. } \\
1990 \mathrm{~S}\end{array}$ & Reliable and complete \\
\hline $\begin{array}{l}\text { Methanol } \\
\text { Production }\end{array}$ & materials, energy, emissions & $\begin{array}{l}\text { Secondary; Petrochemical } \\
\text { Processes (1995) }\end{array}$ & $\begin{array}{l}\text { U.S., World } \\
\text { 1980s, 1990s }\end{array}$ & Reliable but incomplete \\
\hline $\begin{array}{l}\text { MTBE } \\
\text { Production }\end{array}$ & materials, energy & $\begin{array}{l}\text { Secondary; French Petroleum } \\
\text { Institute (1994) }\end{array}$ & $\begin{array}{c}\text { World } \\
\text { 1980s, 1990s }\end{array}$ & $\begin{array}{l}\text { Reliable but incomplete since there is no data } \\
\text { regarding process emissions }\end{array}$ \\
\hline $\begin{array}{l}\text { MTBE } \\
\text { Blending }\end{array}$ & materials, emissions & $\begin{array}{c}\text { Secondary; } \\
\text { U.S. AP-42 (1995) }\end{array}$ & $\begin{array}{l}\text { U.S., California } \\
\text { 1990s }\end{array}$ & Complete and somewhat reliable \\
\hline $\begin{array}{l}\text { Biomass } \\
\text { Burning }\end{array}$ & materials, emissions & $\begin{array}{l}\text { Secondary/Primary; U.S. } \\
\text { EPA AP-42 / CARB (1997) }\end{array}$ & $\begin{array}{l}\text { U.S., California } \\
1990 \mathrm{~s}\end{array}$ & $\begin{array}{l}\text { Reliable but incomplete since the emissions do not } \\
\text { take into account the effect of burning conditions }\end{array}$ \\
\hline $\begin{array}{c}\text { Biomass } \\
\text { Harvesting }\end{array}$ & materials, energy, emissions & $\begin{array}{l}\text { Primary; TSS Consultants } \\
\text { (1997) }\end{array}$ & $\begin{array}{l}\text { California } \\
\text { 1990s }\end{array}$ & Reliable and complete \\
\hline $\begin{array}{c}\text { Ethanol } \\
\text { Production }\end{array}$ & materials, energy, emissions & Primary; NREL (1998) & $\begin{array}{l}\text { U.S. } \\
1990 \mathrm{~S}\end{array}$ & Reliable and complete \\
\hline $\begin{array}{c}\text { ETBE } \\
\text { Production }\end{array}$ & materials, energy & $\begin{array}{l}\text { Secondary; French Petroleum } \\
\text { Institute (1994) }\end{array}$ & $\begin{array}{l}\text { World, California } \\
\text { 1980s, 1990s }\end{array}$ & $\begin{array}{l}\text { Reliable but somewhat incomplete since there is } \\
\text { no data regarding process emissions }\end{array}$ \\
\hline $\begin{array}{c}\text { ETBE } \\
\text { BLENDING }\end{array}$ & materials, emissions & $\begin{array}{c}\text { Secondary; U.S. AP-42 } \\
\text { (1997) }\end{array}$ & $\begin{array}{l}\text { U.S., California } \\
\text { 1990s }\end{array}$ & Complete and somewhat reliable \\
\hline $\begin{array}{l}\text { Isobutylene } \\
\text { Production }\end{array}$ & materials, energy, emissions & $\begin{array}{l}\text { Secondary; Petrochemical } \\
\text { Processes (1995) }\end{array}$ & $\begin{array}{c}\text { California } \\
\text { 1980s, 1990s }\end{array}$ & Somewhat reliable and incomplete \\
\hline $\begin{array}{l}\text { Electricity } \\
\text { Production }\end{array}$ & materials, energy, emissions & $\begin{array}{l}\text { Secondary; see references in } \\
\text { Section } 4.4\end{array}$ & $\begin{array}{l}\text { U.S., California } \\
\text { 1980s, 1990s }\end{array}$ & Reliable and complete \\
\hline $\begin{array}{c}\text { Steam } \\
\text { Production }\end{array}$ & materials, energy, emissions & $\begin{array}{c}\text { Secondary; U.S. EPA AP-42 } \\
\text { (1997) }\end{array}$ & $\begin{array}{l}\text { United States } \\
\text { 1980s, 1990s }\end{array}$ & Reliable and complete \\
\hline $\begin{array}{l}\text { Gasoline } \\
\text { Production }\end{array}$ & materials, energy, emissions & $\begin{array}{c}\text { Secondary; see references in } \\
\text { Section } 4.6\end{array}$ & $\begin{array}{l}\text { U.S., California, World } \\
1980 \mathrm{~s}, 1990 \mathrm{~s}\end{array}$ & Reliable and complete \\
\hline $\begin{array}{l}\text { Reformulated } \\
\text { Gasoline Use }\end{array}$ & materials, emissions & $\begin{array}{c}\text { Secondary; CARB / U.S. } \\
\text { EPA AP-42 (1997) }\end{array}$ & $\begin{array}{l}\text { California } \\
1990 \mathrm{~s}\end{array}$ & Reliable and complete \\
\hline
\end{tabular}




\subsection{PRESENTATION OF RESUlts}

The results are presented here for six different scenarios modeled from three different biomass feedstocks and two methods of ethanol production. These scenarios follow the base case assumption that all of the lignin generated during the production of ethanol is used for on-site cogeneration (which produces steam and electricity used at the ethanol facility). An additional six scenarios were modeled following the assumption that the lignin is shipped to a biomass power plant (which produces electricity). The detailed results from these additional scenarios are presented in Appendix A.

The three biomass feedstocks are rice straw, forest residue, and chaparral, each of which was modeled using an enzyme process and a concentrated acid process to produce ethanol. The exact nature of these scenarios is described in more detail in Section 4. The six scenarios are summarized in the following table (Table 38).

Table 38: Description of Scenarios Studied

\begin{tabular}{ccc}
\hline Scenario & Biomass Type & Ethanol Production Method \\
\hline \hline 1 & Rice Straw & Enzyme \\
2 & Rice Straw & Concentrated Acid \\
3 & Forest Residue & Enzyme \\
4 & Forest Residue & Concentrated Acid \\
5 & Chaparral & Enzyme \\
6 & Chaparral & Concentrated Acid \\
\hline
\end{tabular}

The results presentation is organized first by biomass type and then by ethanol production method. Each scenario has a table with values for the environmental flows that were deemed significant during the scoping phase. The results for each disposal option are presented as totals based on the functional unit of the study. As described in Section 3.2.2, the functional unit is disposal of one MBDT of biomass, and the conversion of the equivalent amount of biomass into a fuel oxygenate to produce a reformulated gasoline with $2 \%$ oxygen content. This functional unit results in differing quantities of ethanol, ETBE, and MTBE as shown in Table 39.

Table 39: Ethanol and ETBE Yield by Biomass Type

\begin{tabular}{lccccc}
\hline Biomass Source & $\begin{array}{c}\text { Ethanol } \\
\text { Production } \\
\text { One metric bone } \\
\text { dry ton (1000 kg) }\end{array}$ & $\begin{array}{c}\text { Ethanol } \\
\text { Produced } \\
\text { (liters) }\end{array}$ & $\begin{array}{c}\text { ETBE } \\
\text { Produced } \\
\text { (liters) }\end{array}$ & \multicolumn{2}{c}{ Equivalent in MTBE plus Gasoline } \\
Rice Straw & Enzyme & 314.1 & 738.3 & 635.9 & (liters) \\
& Acid & 283.2 & 665.7 & 573.4 & 94.0 \\
Forest Residue & Enzyme & 344.7 & 810.3 & 698.1 & 114.2 \\
& Acid & 280.1 & 658.4 & 567.2 & 92.9 \\
Chaparral & Enzyme & 117.8 & 277.0 & 238.6 & 39.0 \\
& Acid & 105.7 & 248.4 & 213.9 & 35.1 \\
\hline
\end{tabular}

There are some negative values in the results tables, which arise from the electricity offset of the ethanol biomass disposal option. These values are supplemented with a percentage difference, which indicates the degree to which the values for the ETBE scenario were different from those for the MTBE scenario, i.e., 100x(MTBE value - ETBE value)/MTBE value. A positive value indicates the percentage by which the values for the ETBE scenario were lower than those for the MTBE scenario, and vice versa. It should be noted that the percentages presented cannot be used to compare any other option for disposing of biomass to the conversion of biomass to ETBE, since the emissions would not be normalized to the same basis. 
Table 40 demonstrates the meaning of negative values in the following results tables.

Table 40: Explanation of Negative Values in Summary Tables

\begin{tabular}{|c|c|c|c|}
\hline & Flow & $\begin{array}{l}\text { Negative Value in the Totals for } \\
\text { Each Option } \\
\end{array}$ & $\begin{array}{l}\text { Negative Value in the \% } \\
\text { Difference Column } \\
\end{array}$ \\
\hline Inflows & All Raw Material Inflows & $\begin{array}{l}\text { Indicates an offset that is greater } \\
\text { than the use of materials for the } \\
\text { option. Primarily due to } \\
\text { electricity offset of energy related } \\
\text { materials. }\end{array}$ & $\begin{array}{l}\text { Indicates that the ETBE option has } \\
\text { higher raw material inflows than the } \\
\text { MTBE option. } \\
\text { (Unfavorable) }\end{array}$ \\
\hline Outflows & $\begin{array}{l}\text { All Air Emissions, Water } \\
\text { Effluents; and Solid Waste }\end{array}$ & $\begin{array}{l}\text { Indicates that electricity offset is } \\
\text { greater than the emission of the } \\
\text { pollutant for the option resulting } \\
\text { in a net negative value. }\end{array}$ & $\begin{array}{l}\text { Indicates that the ETBE option has } \\
\text { higher emissions than the MTBE } \\
\text { option. } \\
\text { (Unfavorable) }\end{array}$ \\
\hline \multirow[t]{3}{*}{ Energy } & Nonrenewable Energy & $\begin{array}{l}\text { Indicates that electricity offset is } \\
\text { greater than the energy use of the } \\
\text { option resulting in a net negative } \\
\text { value. }\end{array}$ & $\begin{array}{l}\text { Indicates that the ETBE option has } \\
\text { higher nonrenewable energy use } \\
\text { than the MTBE option. } \\
\text { (Unfavorable) }\end{array}$ \\
\hline & Renewable Energy & & $\begin{array}{l}\text { Indicates that the ETBE option has } \\
\text { higher renewable energy use than } \\
\text { the MTBE option. } \\
\text { (Favorable) }\end{array}$ \\
\hline & Total Primary Energy & & $\begin{array}{l}\text { Indicates that the ETBE option has } \\
\text { higher total energy use than the } \\
\text { MTBE option. }\end{array}$ \\
\hline
\end{tabular}

These tables are supplemented with figures that present criteria pollutant emissions for each disposal option, in terms of the functional unit. In situations where the criteria pollutant emissions for Option 2 are higher than those for Option 1, pie graphs are provided to show the life cycle stages that are the source of the emission. More detailed results, showing the percentage contribution of each life cycle stage to the total environmental flow, are provided in the Appendix A.

Note on the summary tables: The impact of a hydrocarbon emission is dependent on, among other things, its point of release and its composition. Since these data are not available, the impact from individual speciated emissions cannot be accurately assessed. Therefore all speciated non-methane hydrocarbon flows (see Table 41) have been aggregated to give a value for the net hydrocarbon emissions.

Table 41 : Speciated Sources of Non-Methane Hydrocarbon Emissions

\begin{tabular}{l}
\hline \multicolumn{1}{c}{ Non-Methane Hydrocarbon Sources } \\
\hline \hline Volatile Organic Compounds (VOC) \\
Ethanol (air emissions) \\
Furfural \\
Hydroxymethyl Furfural (HMF) \\
Aldehydes \\
Formaldehyde \\
Benzene \\
Hydrocarbons (except methane) \\
\hline
\end{tabular}


It should be noted that this report shows the life cycle emissions of the two options meaning that the results are summarized over different locations and different time frames. Therefore, it does not take into account the fact that open burning results in a pulse of emissions at one time and location versus ETBE combustion in a vehicle that takes place over a period of time and at different locations. This report only shows the difference in the total emissions of the two options and does not account for concentrations of pollutants at a given time.

\subsection{LIFE CYCLE ENERGY BALANCE}

LCIs provide an opportunity to quantify both the total energy demands and the overall energy efficiencies of processes and products. In this study, we track several different types of energy flows through each life cycle. For clarity, each of these energy flows is defined below.

- Total Primary Energy. All raw materials extracted from the environment can contain ${ }^{27}$ energy. In estimating the total primary energy inputs to each life cycle, we consider the cumulative energy content of all resources extracted from the environment.

- Feedstock Energy. Energy contained in raw materials that end up directly in the final product is termed "feedstock energy." For ethanol production, feedstock energy includes the energy contained in the biomass. Likewise, the natural gas converted to methanol contains primary energy that is considered a feedstock energy input for MTBE. Feedstock energy is a subset of the primary energy inputs.

- Process Energy. The second major subset of primary energy is "process energy." This is limited to energy inputs in the life cycle exclusive of the energy contained in the feedstock (as defined in the previous bullet). It is the energy contained in raw materials extracted from the environment that does not contribute to the energy of the product itself, but is needed in the processing of feedstock energy into its final product form. Process energy consists primarily of coal, natural gas, uranium, and hydroelectric power sources consumed directly or indirectly in the product life cycle.

- Fossil Energy. Because we are concerned about the renewable nature of ethanol/ETBE, we also track the primary energy that comes from fossil sources specifically (coal, oil and natural gas). All three of the previously defined energy flows can be categorized as fossil or nonfossil energy.

- Renewable Energy. Renewable energy refers to energy obtained from biomass sources, as is the case for ethanol production in this study. Renewable energy also refers to electricity production from renewable sources such as biomass and hydroelectricity.

The energy use of the different options studied is a good measure of the overall environmental performance of the option. The energy obtained from burning biomass and ethanol is considered renewable energy. Energy obtained from fossil fuels is considered nonrenewable. ETBE has both renewable and nonrenewable components as its synthesis requires isobutylene, which is derived from fossil fuel.

In the results tables the following energy values are reported: 1) fossil or nonrenewable energy, 2) renewable energy, 3 ) process energy, 4) feedstock energy, and 5) total primary energy. Criteria air pollutants are linked to the use of both nonrenewable and renewable energy, whereas natural resource depletion ${ }^{28}$ and fossil $\mathrm{CO}_{2}$ emissions are only linked to nonrenewable sources. Renewable energy use by the MTBE system is due to electricity use produced from renewable resources. Process energy indicates the net energy input to the process and can be useful in comparing process options. Feedstock energy describes the energy contained in the final product, which is available to do work in an engine. All other things being equal, feedstock energy is a function of the energy densities of each of the fuel oxygenates.

\footnotetext{
27 The energy "contained" in a raw material is the amount of energy that would be released by the complete combustion of that raw material. This "heat of combustion" can be measured in two different ways: as a higher heating value or a lower heating value. Combustion results in the formation of carbon dioxide and water. Higher heating values consider the amount of energy released when the final combustion products are gaseous carbon dioxide and liquid water. Lower heating values take into account the loss of energy associated with the vaporization of the liquid water combustion product. Our energy content is based on the lower heating values for each material.

28 Soil erosion is not included in the calculation of natural resource depletion since data were not available. The effects of biomass harvesting on soil erosion is more difficult to quantify than the removal of other natural resources, e.g., as coal and oil.
} 


\subsection{MASS FLOWCHART}

In addition to the results tables and graphs for each scenario, there is a mass flow diagram that outlines the system flows associated with each scenario. Once again, the value chosen for the comparison of the two different biomass disposal options is One MBDT of biomass. The example in Figure 17 shows the system flows associated with the two disposal options for rice straw:

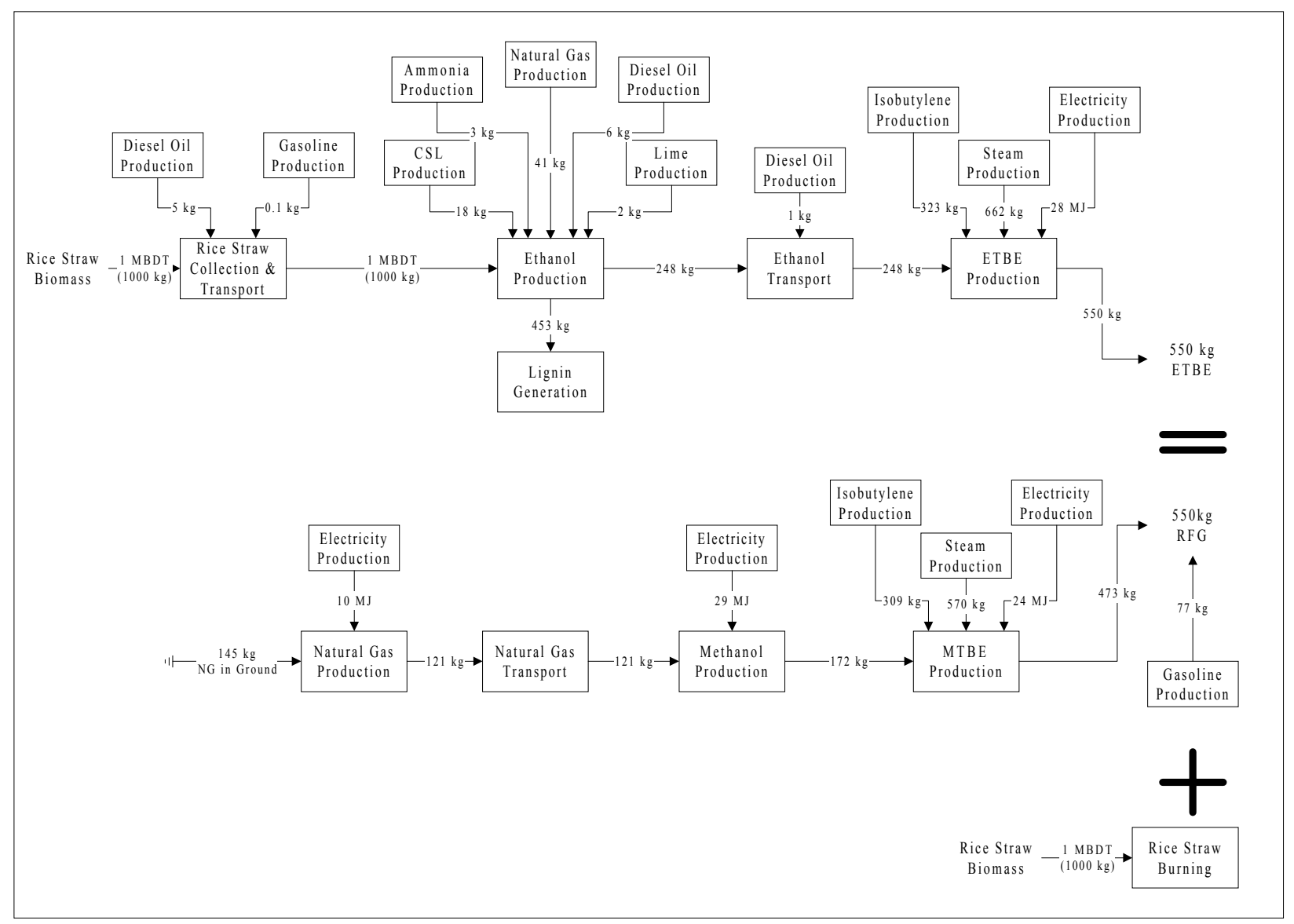

Figure 17: Mass Flow Diagram for Rice Straw with the Enzyme Process

How to Read the Mass Flow Diagram: The example in Figure 17 shows that the amount of MTBE used in the biomass burning option is dependent on the amount of ETBE produced from disposing one MBDT of biomass through ethanol production. As stated in Section 1.2, this study focused on the amount of oxygenates needed to perform the same function in reformulated gasoline. Based on Table 6, more ETBE is needed to produce the same amount of oxygen as MTBE but MTBE requires some additional gasoline to have the same heating value as the ETBE. This study looks at only the differences between ETBE and MTBE reformulated gasoline. Therefore, Figure 17 shows that $550 \mathrm{~kg}$ of ETBE effectively replaces $473 \mathrm{~kg}$ of MTBE and $77 \mathrm{~kg}$ of gasoline in reformulated gasoline production.

The different feedstocks and different ethanol production methods lead to different amounts of ethanol (and therefore, ETBE) that are produced. This is due to the fact that one MBDT of biomass yields different amounts of ethanol depending on the type of biomass and method of ethanol production. Different quantities of ETBE imply that different amounts of MTBE (and gasoline) need to be produced. Therefore, the life cycle results vary accordingly, as shown in the overall results. 


\subsection{BASELINE SCENARIO RESULTS AND DISCUSSION}

\subsubsection{Rice Straw Feedstock-Enzyme Process}

Table 42: Results Summary for Rice Straw Feedstock-Enzyme Process

\begin{tabular}{|c|c|c|c|c|c|}
\hline & Flow & Units & $\begin{array}{c}\text { OPTION 1: MTBE } \\
\text { Production/Use + } \\
\text { Biomass Burning }\end{array}$ & $\begin{array}{l}\text { OPTION 2: ETBE } \\
\text { Production/Use }\end{array}$ & $\begin{array}{l}\text { Change from } \\
\text { OPTION } 1 \text { to } \\
\text { OPTION } 2\end{array}$ \\
\hline \multirow[t]{3}{*}{ Inflows } & Coal & $\mathrm{kg}$ & 314 & 7 & $98 \%$ \\
\hline & Natural Gas & $\mathrm{kg}$ & 434 & 290 & $33 \%$ \\
\hline & Oil & $\mathrm{kg}_{\mathrm{n}}$ & 383 & 277 & $28 \%$ \\
\hline \multirow[t]{12}{*}{ Outflows } & Carbon Dioxide $\left(\mathrm{CO}_{2}\right.$, biomass $)$ & $\mathrm{g}$ & $1,521,110$ & $1,606,570$ & $-6 \%$ \\
\hline & Carbon Dioxide $\left(\mathrm{CO}_{2}\right.$, fossil $)$ & $\mathrm{g}$ & $2,929,590$ & $1,406,330$ & $52 \%$ \\
\hline & Carbon Monoxide (CO) & $\mathrm{g}$ & 32,121 & 1,037 & $97 \%$ \\
\hline & Hydrocarbons (except methane) & $\mathrm{g}$ & 10,204 & 3,990 & $61 \%$ \\
\hline & Methane $\left(\mathrm{CH}_{4}\right)$ & g & 3,452 & 1,317 & $62 \%$ \\
\hline & Nitrogen Oxides $\left(\mathrm{NO}_{\mathrm{x}}\right)$ & $\mathrm{g}$ & 8,449 & 2,586 & $69 \%$ \\
\hline & Nitrous Oxide $\left(\mathrm{N}_{2} \mathrm{O}\right)$ & $\mathrm{g}$ & 57 & 9 & $84 \%$ \\
\hline & Particulates (unspecified) & g & 7,281 & 788 & $89 \%$ \\
\hline & Sulfur Oxides $\left(\mathrm{SO}_{\mathrm{x}}\right)$ & $\mathrm{g}$ & 7,447 & 1,183 & $84 \%$ \\
\hline & COD & $\mathrm{g}$ & 761 & 118 & $84 \%$ \\
\hline & Nitrates $\left(\mathrm{NO}_{3}-\right)$ & $\mathrm{g}$ & 4 & 13 & $-204 \%$ \\
\hline & Waste (total) & $\mathrm{kg}$ & 512 & 190 & $63 \%$ \\
\hline \multirow[t]{5}{*}{ Energy } & Nonrenewable Energy & MJ & 40,525 & 20,688 & $49 \%$ \\
\hline & Renewable Energy & MJ & 74 & 13,455 & $-18203 \%$ \\
\hline & Process Energy & MJ & 20,628 & 13,133 & $36 \%$ \\
\hline & Feedstock Energy & MJ & 19,970 & 21,009 & $-5 \%$ \\
\hline & Total Primary Energy & MJ & 40,598 & 34,143 & $16 \%$ \\
\hline
\end{tabular}

For this scenario, Option 2 leads to a decrease from Option 1 for almost all of the environmental flows (Table 42). The exceptions are nitrates and renewable energy (an increase in renewable energy consumption is more desirable than a decrease). The higher values for these two parameters originate from the ethanol production step. The difference between the two options for biomass $\mathrm{CO}_{2}$ is not considered to be statistically significant.

\section{Criteria Pollutants}

Carbon monoxide emissions are lower for Option 2 by a factor of about 30, which is a significant advantage for Option 2. Similarly, particulate emissions are lower for Option 2 by a factor of ten, again a significant reduction for an important criteria pollutant. Particulate emissions from burning of rice straw are especially important since it contains high amounts of silica, although silica emissions are not regulated. It should be noted that most of the carbon monoxide and a lot of the particulate emissions are from biomass burning in Option 1 . The $\mathrm{SO}_{\mathrm{x}}$ emissions for Option 2 are lower by a factor of about seven, while the $\mathrm{NO}_{\mathrm{x}}$ and non-methane hydrocarbon emissions for Option 2 are lower by a factor of about three. These emissions are higher for Option 1 primarily because of higher emissions for MTBE production when compared to ETBE production. 


\section{Energy Consumption and $\mathrm{CO}_{2}$}

The total primary energy is less for Option 2 by $16 \%$, and the renewable portions of the total energy are $0.2 \%$ and $40 \%$ for Options 1 and 2, respectively. Process energy required is less for Option 2 by 36\%; this is despite the need for supplemental natural gas to generate the steam needed by the ethanol production step. The need for supplemental natural gas arises from the high ash and low lignin contents of rice straw. The ethanol yield per dry ton of rice straw is similar to those for forest residue and chaparral. Hence, the steam needed by the ethanol production step is about the same as well. However, the ligneous residue has a much lower heating value due to its higher ash and lower lignin contents, thereby requiring supplemental natural gas. The fossil-derived $\mathrm{CO}_{2}$ is still lower for Option 2 by $52 \%$, which is a substantial reduction in the emissions of $\mathrm{CO}_{2}$.

\section{Water Emissions}

Nitrates are significantly higher for Option 2 mainly because of the use of CSL during ethanol fermentation. CSL is a by-product of corn wet-milling, and agricultural operations lead to water run-offs containing fertilizer-derived nitrates. If this is perceived as a negative attribute of Option 2, alternatives to CSL need to be considered. However, as explained in the Impact Assessment section, the eutrophication potential is still lower for Option 2.

\section{Graphical Representation of Key Results}

The mass flow diagram for this system is shown in Section 0 (Figure 17). The following graphs show the comparative emissions for five criteria pollutants - carbon monoxide (Figure 18), nitrogen oxides (Figure 19), particulates (Figure 20), sulfur oxides (Figure 21), and nonmethane hydrocarbons (Figure 22 through Figure 24) - as well as energy consumption (Figure 25 and Figure 26). The first column represents values for Option 1, split out as values from MTBE production and biomass burning. The second column shows the flows for Option 2, ETBE production. The scales are kept the same throughout the entire results section, in order to facilitate comparison among the different biomass feedstocks and ethanol production methods. 


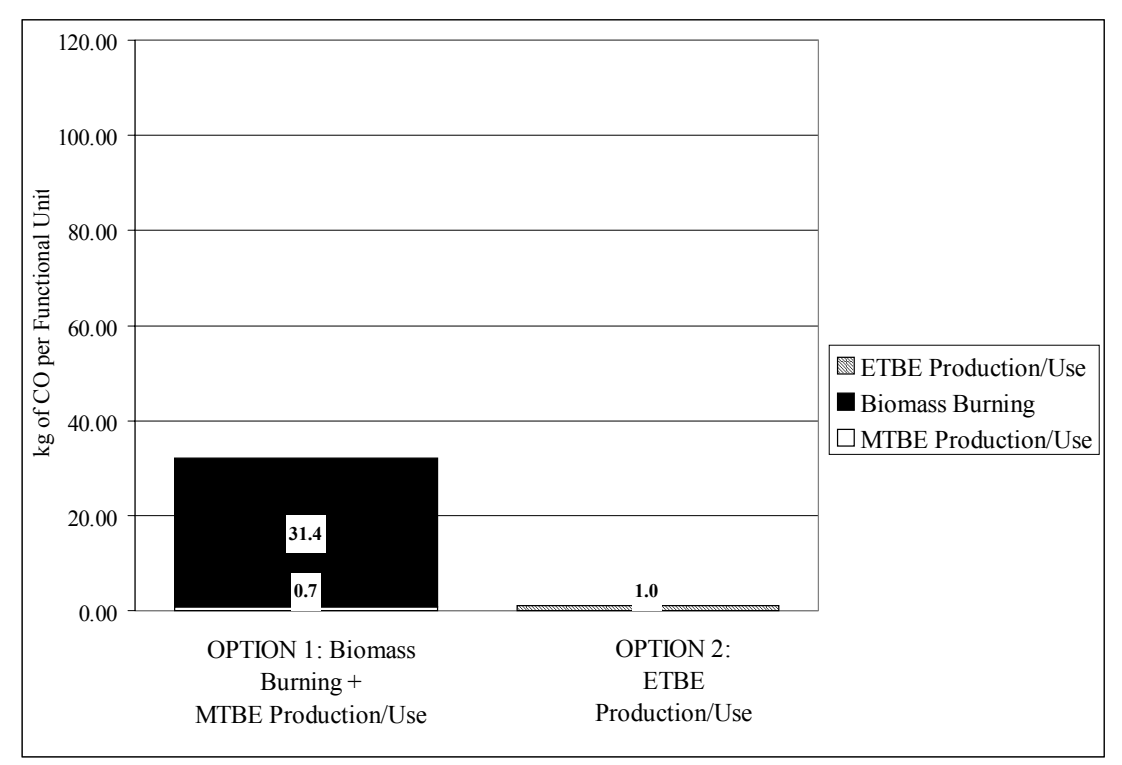

Figure 18: Rice Straw (Enzyme Process) Carbon Monoxide Emissions

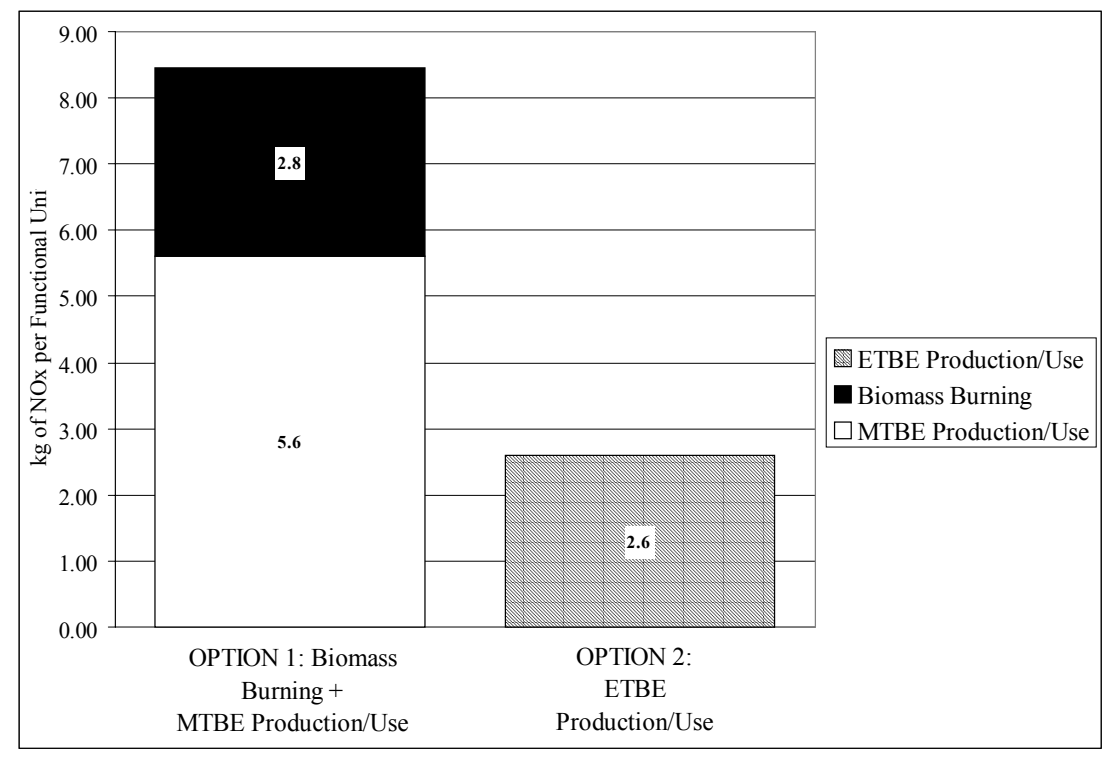

Figure 19: Rice Straw (Enzyme Process) NO ${ }_{x}$ Emissions

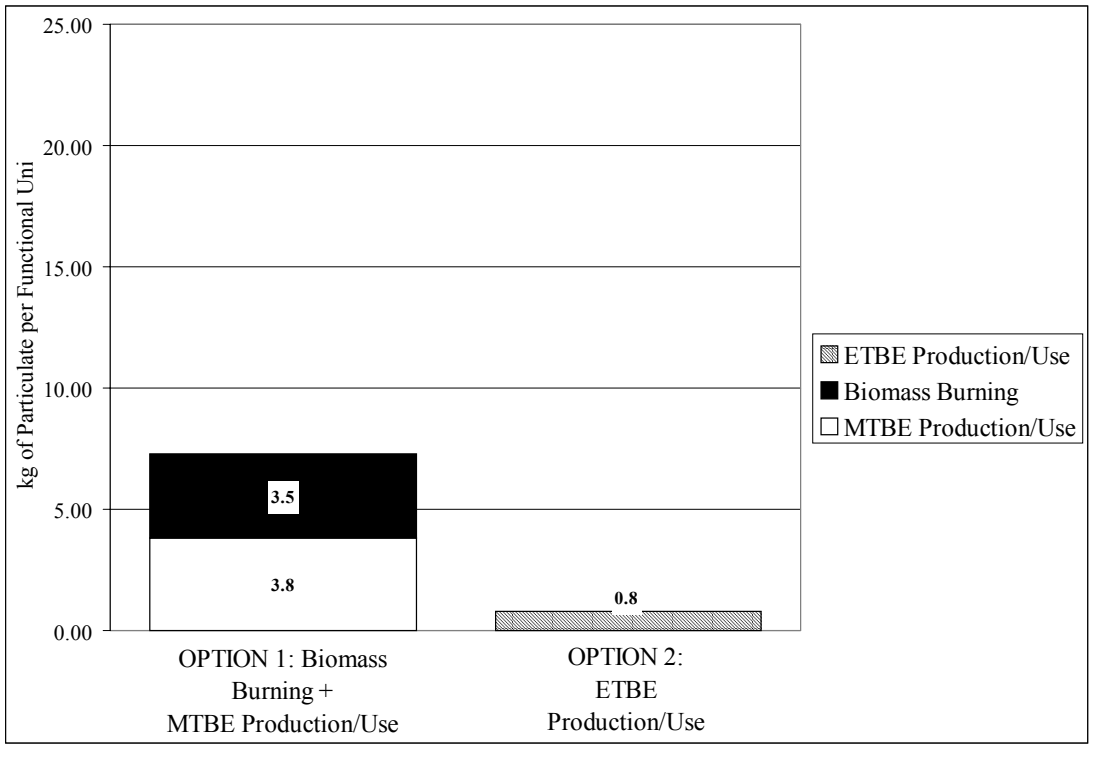

Figure 20: Rice Straw (Enzyme Process) Particulate Emissions

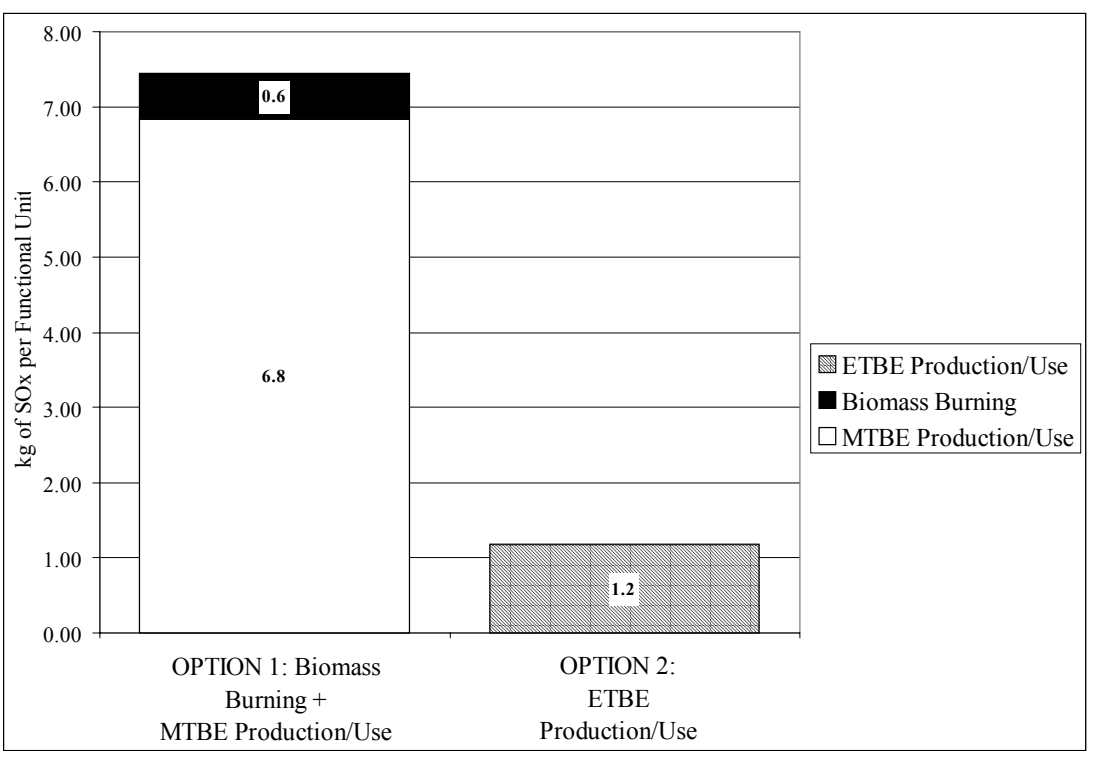

Figure 21: Rice Straw (Enzyme Process) SO Emissions $_{x}$ 


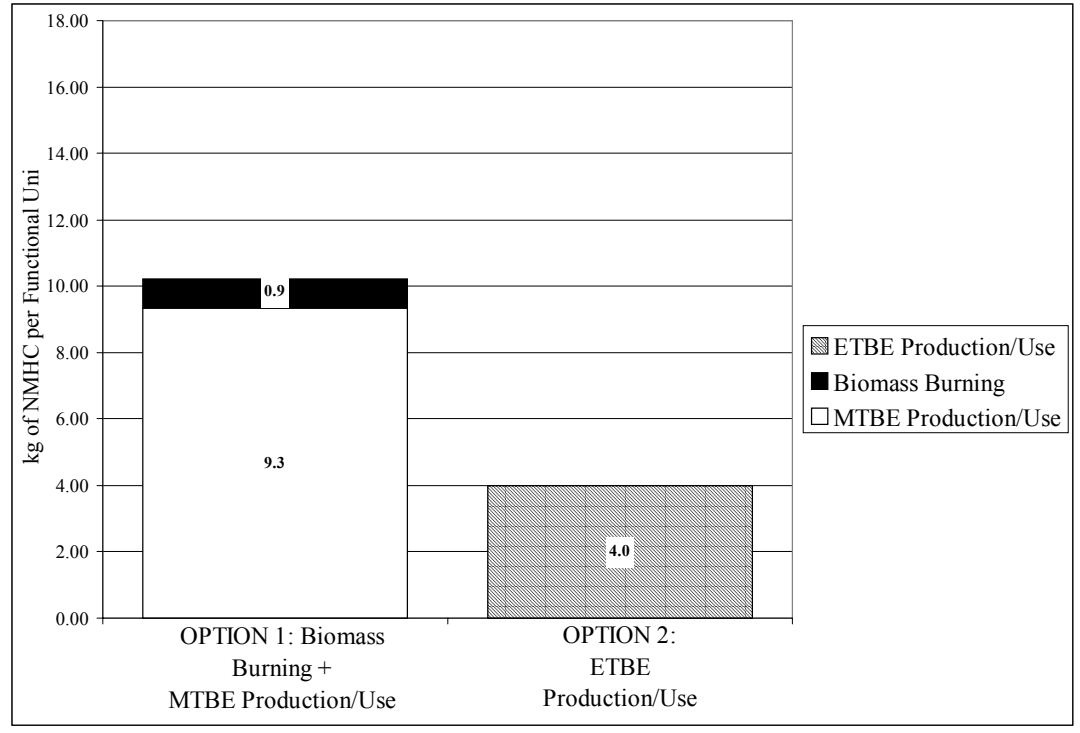

Figure 22: Rice Straw (Enzyme Process) Non-Methane Hydrocarbon Emissions

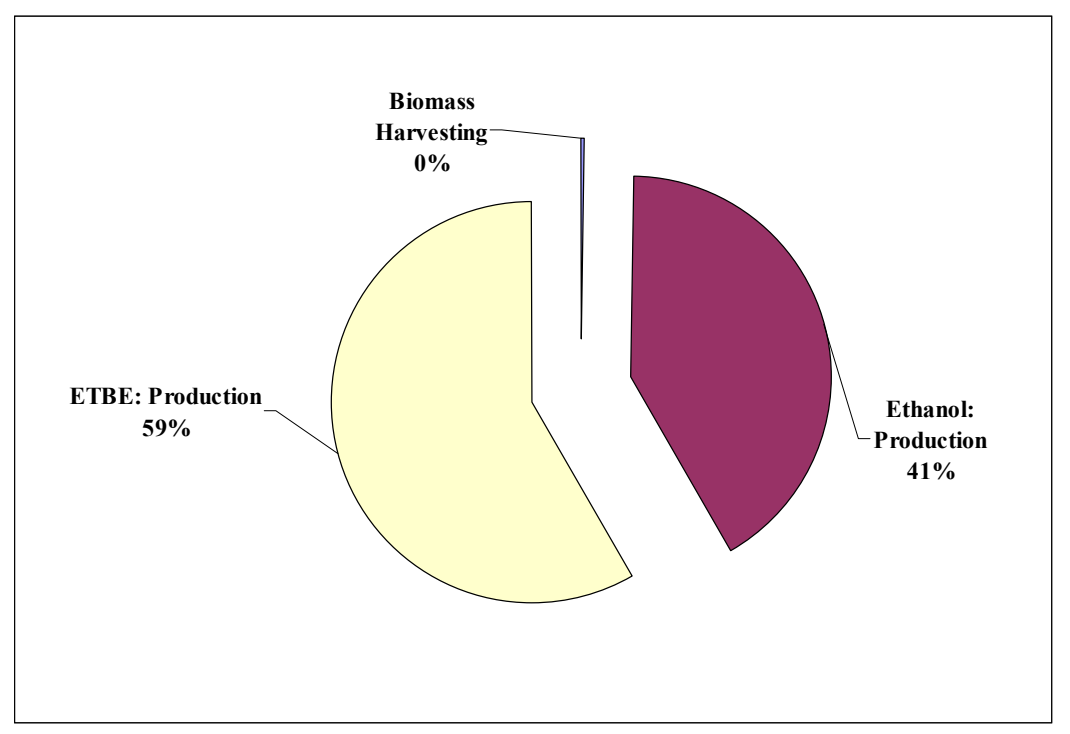

Figure 23: Rice Straw (Enzyme Process) Non-Methane Hydrocarbon Emissions for Option 2 by Source

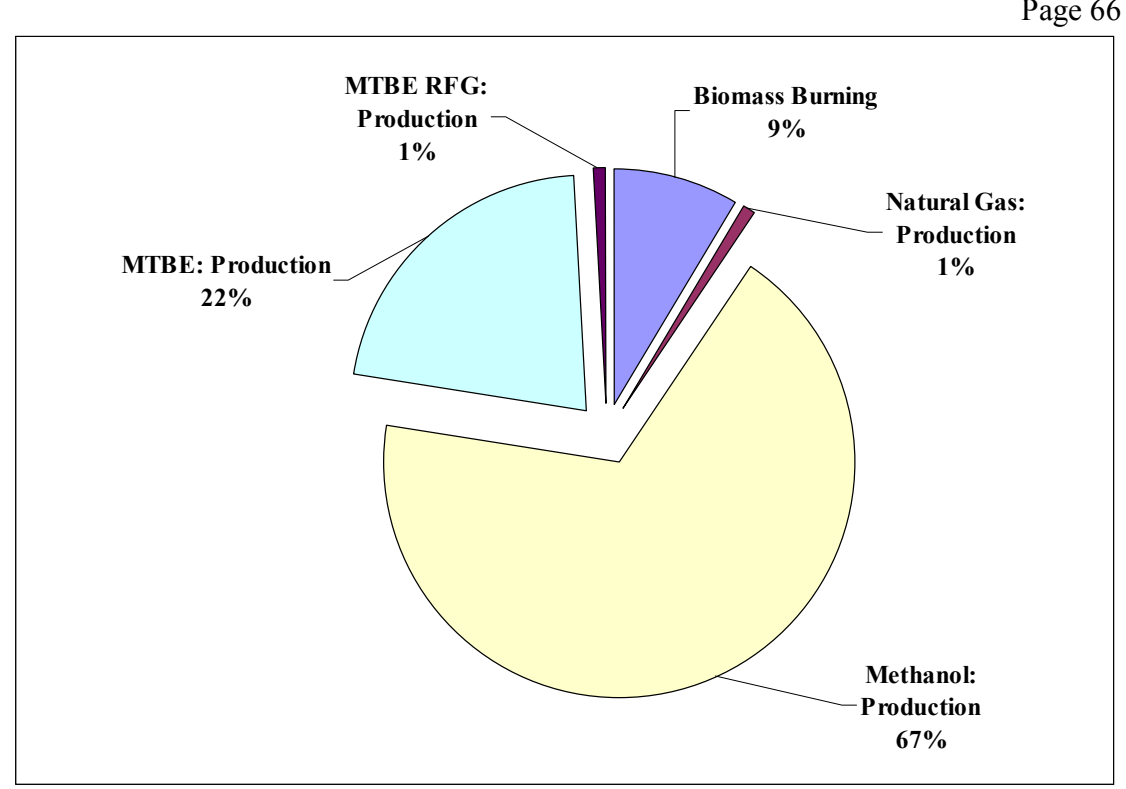

Figure 24: Rice Straw (Enzyme Process) Non-Methane Hydrocarbon Emissions for Option 1 bySource

The two pie charts (Figure 23, Figure 24) show which life cycle stages contributed to the total value for the non-methane hydrocarbon emissions in Figure 22. Figure 23 shows that the value for Option 2, while smaller than the total value for Option 1, is higher than that for the biomass burning portion of Option 1. Figure 23 also shows that these emissions are derived from the ETBE and ethanol production stage, where natural gas is used in the process. Figure 24 highlights the information that the main source of non-methane hydrocarbons for Option 1 is the MTBE and methanol production. 


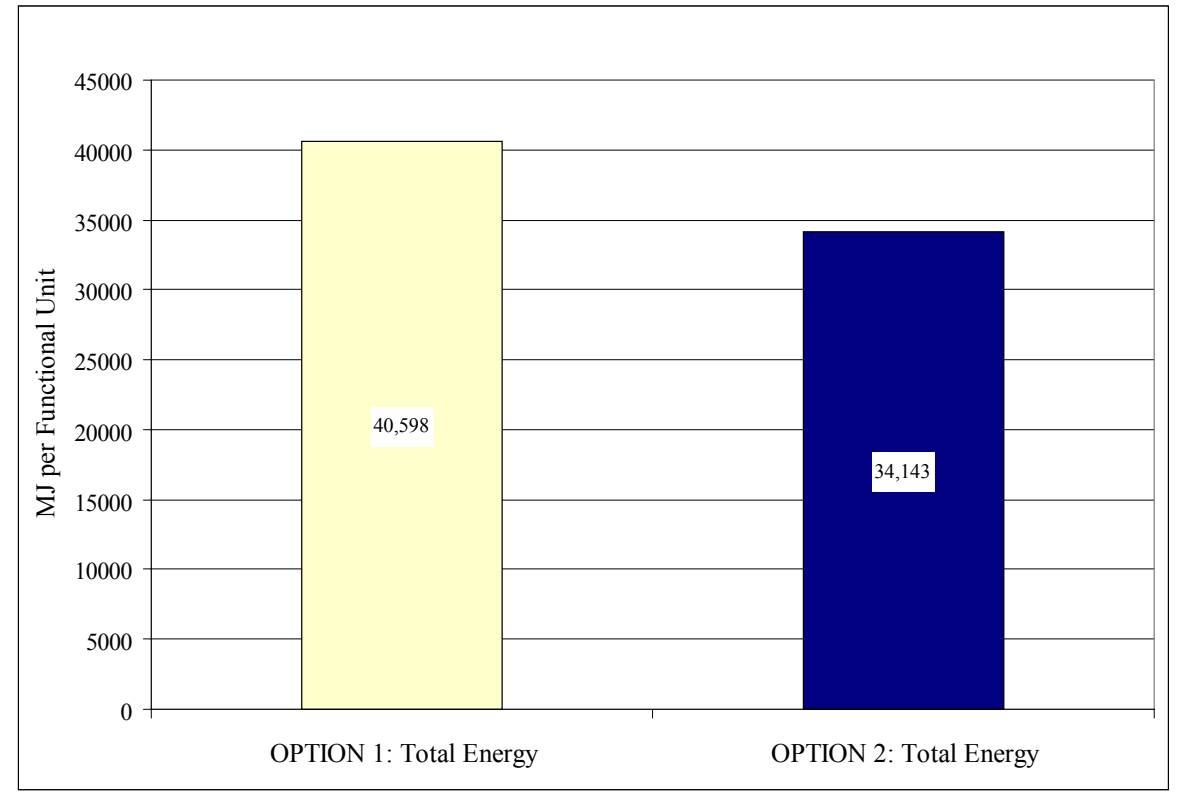

Figure 25: Rice Straw (Enzyme Process) Total Energy Consumption

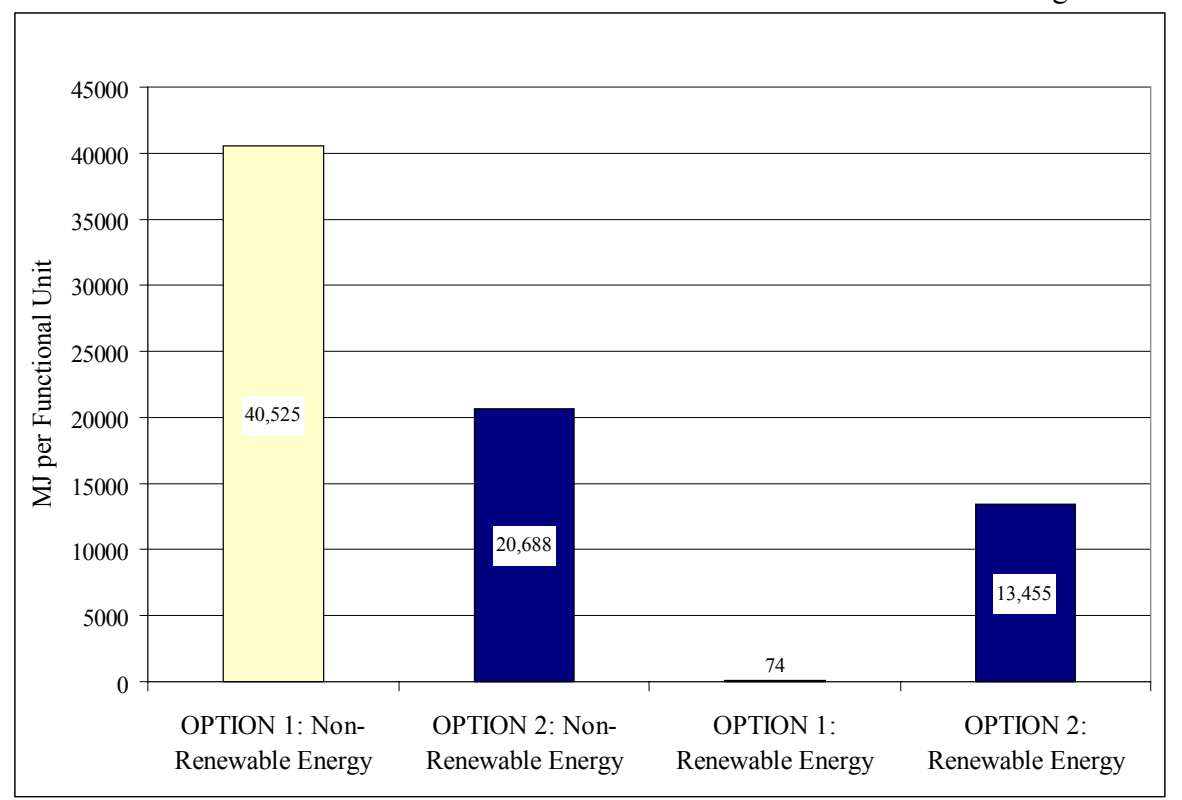

Figure 26: Rice Straw (Enzyme Process) Nonrenewable and Renewable Energy Consumption 


\subsubsection{Rice Straw Feedstock-Concentrated Acid Process}

Table 43: Results Summary for Rice Straw Feedstock—Acid Process

\begin{tabular}{|c|c|c|c|c|c|}
\hline & Flow & Units & $\begin{array}{c}\text { OPTION 1: MTBE } \\
\text { Production/Use + } \\
\text { Biomass Burning }\end{array}$ & $\begin{array}{l}\text { OPTION 2: ETBE } \\
\text { Production/Use }\end{array}$ & $\begin{array}{l}\text { Change from } \\
\text { OPTION } 1 \text { to } \\
\text { OPTION } 2\end{array}$ \\
\hline \multirow[t]{3}{*}{ Inflows } & Coal & $\mathrm{kg}$ & 282 & 8 & $97 \%$ \\
\hline & Natural Gas & $\mathrm{kg}$ & 391 & 567 & $-45 \%$ \\
\hline & Oil $\ldots \ldots \ldots \ldots \ldots \ldots$ & $\mathrm{kg}$ & 345 & 249 & $28 \%$ \\
\hline \multirow[t]{12}{*}{ Outflows } & Carbon Dioxide $\left(\mathrm{CO}_{2}\right.$, biomass $)$ & $\mathrm{g}$ & $1,521,110$ & $1,354,290$ & $11 \%$ \\
\hline & Carbon Dioxide $\left(\mathrm{CO}_{2}\right.$, fossil $)$ & $\mathrm{g}$ & $2,637,810$ & $1,979,070$ & $25 \%$ \\
\hline & Carbon Monoxide (CO) & $\mathrm{g}$ & 32,049 & 1,449 & $95 \%$ \\
\hline & Hydrocarbons (except methane) & $\mathrm{g}$ & 9,274 & 3,362 & $64 \%$ \\
\hline & Methane $\left(\mathrm{CH}_{4}\right)$ & g & 3,108 & 4,968 & $-60 \%$ \\
\hline & Nitrogen Oxides $\left(\mathrm{NO}_{\mathrm{x}}\right)$ & $\mathrm{g}$ & 7,890 & 3,407 & $57 \%$ \\
\hline & Nitrous Oxide $\left(\mathrm{N}_{2} \mathrm{O}\right)$ & $\mathrm{g}$ & 51 & 16 & $69 \%$ \\
\hline & Particulates (unspecified) & g & 6,902 & 3,846 & $44 \%$ \\
\hline & Sulfur Oxides $\left(\mathrm{SO}_{\mathrm{x}}\right)$ & g & 6,767 & 1,294 & $81 \%$ \\
\hline & $\mathrm{COD}$ & $\mathrm{g}$ & 685 & 94 & $86 \%$ \\
\hline & Nitrates $\left(\mathrm{NO}_{3}{ }^{-}\right)$ & $\mathrm{g}$ & 4 & 22 & $-466 \%$ \\
\hline & Waste (total) & $\mathrm{kg}$ & 461 & 253 & $45 \%$ \\
\hline \multirow[t]{5}{*}{ Energy } & Nonrenewable Energy & MJ & 36,489 & 34,153 & $6 \%$ \\
\hline & Renewable Energy & MJ & 66 & 11,774 & $-17688 \%$ \\
\hline & Process Energy & MJ & 18,574 & 27,010 & $-45 \%$ \\
\hline & Feedstock Energy & MJ & 17,981 & 18,917 & $-5 \%$ \\
\hline & Total Primary Energy & MJ & 36,555 & 45,926 & $-26 \%$ \\
\hline
\end{tabular}

The relative performance of Option 1 versus Option 2 with a concentrated acid process is mostly similar to that with an enzyme process, natural gas and primary energy consumption being major exceptions (Table 43). In terms of the criteria pollutants, the acid process is generally higher than the enzyme process for all of the emissions. The use of additional natural gas in the concentrated acid process leads to higher values for depletion of natural resources and greenhouse gas potential indicators. Methane emissions are also higher because of the additional natural gas that is required to run the acid process.

For a given feedstock, the concentrated acid process demands more energy than the enzymatic process. This is due to the thermal energy required in concentrating the diluted acid stream, obtained after chromatographic separation of acid and sugars, back to the concentration of $70 \%-77 \%$. The enzymatic process does not have this step or the concomitant energy needs. For these reasons, the relative performance of Option 2 with the concentrated acid process is lower for nonrenewable energy consumption, primary energy consumption, fossil $\mathrm{CO}_{2}, \mathrm{SO}_{\mathrm{x}}, \mathrm{NO}_{\mathrm{x}}$, nonmethane hydrocarbons and particulate emissions. 


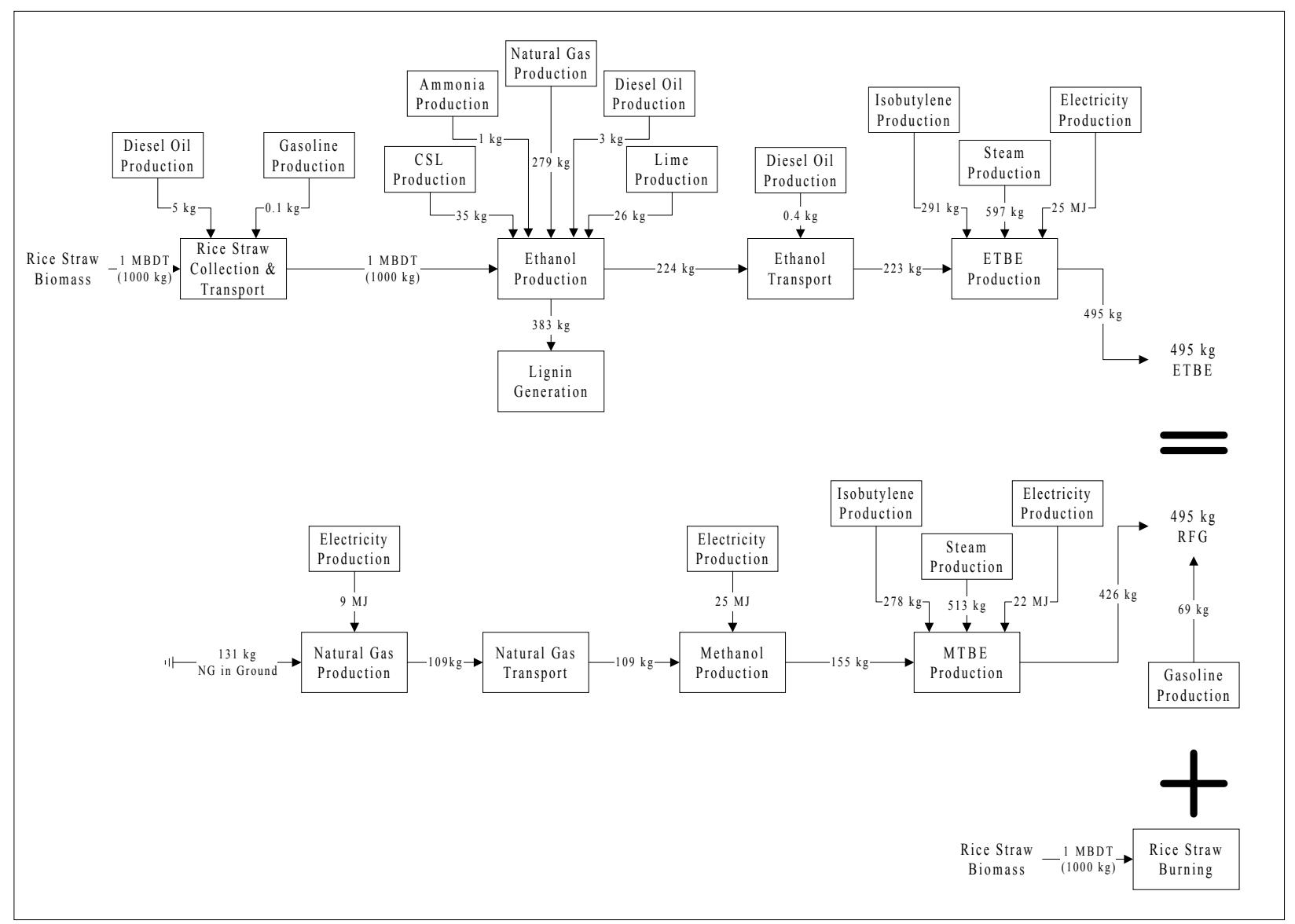

Figure 27: Mass Flow Diagram for Rice Straw-Acid Process

\section{Graphical Representation of Key Results}

The mass flow diagram for this system is shown in Figure 27. The following graphs show the comparative emissions for five criteria pollutants - carbon monoxide (Figure 28), nitrogen oxides (Figure 29), non-methane hydrocarbons (Figure 30), sulfur oxides (Figure 31), and particulates (Figure 32 through Figure 34) - as well as energy consumption (Figure 35 and Figure 36). The first column represents values for Option 1, split out as values from MTBE production and biomass burning. The second column shows the flows for Option 2, ETBE production. The scales are kept the same throughout the entire results section, in order to facilitate comparison among the different biomass feedstocks and ethanol production methods. 


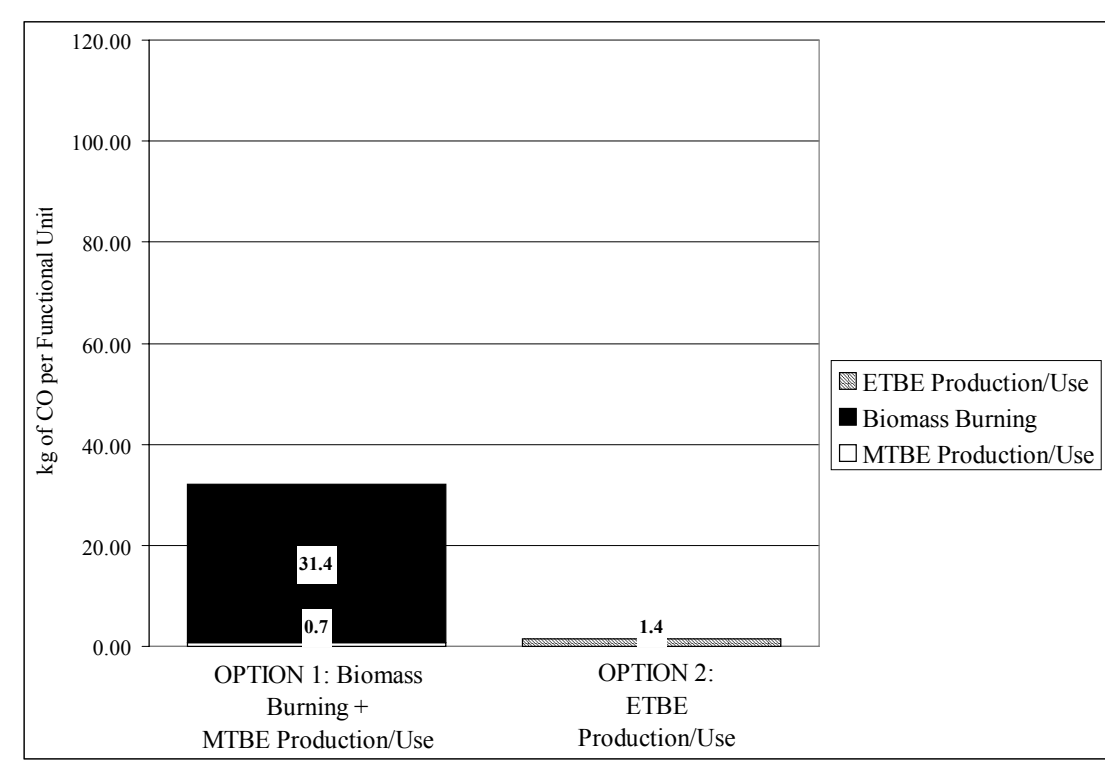

Figure 28: Rice Straw (Acid Process) Carbon Monoxide Emissions

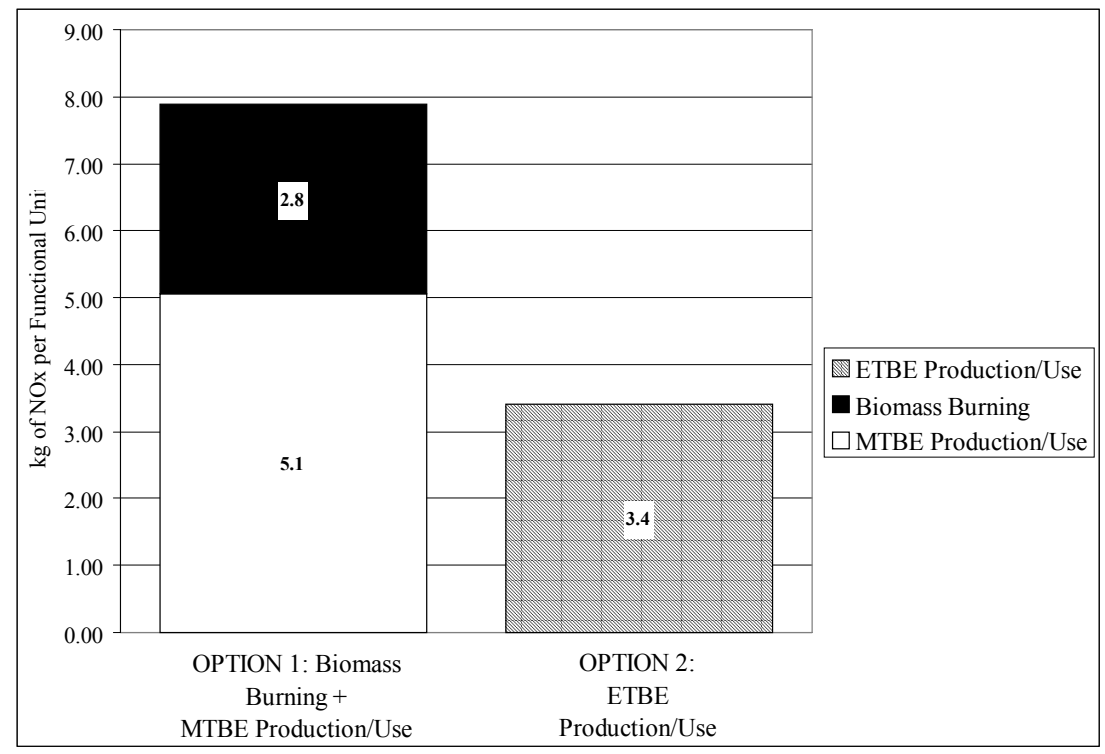

Figure 29: Rice Straw (Acid Process) $\mathrm{NO}_{\mathrm{x}}$ Emissions

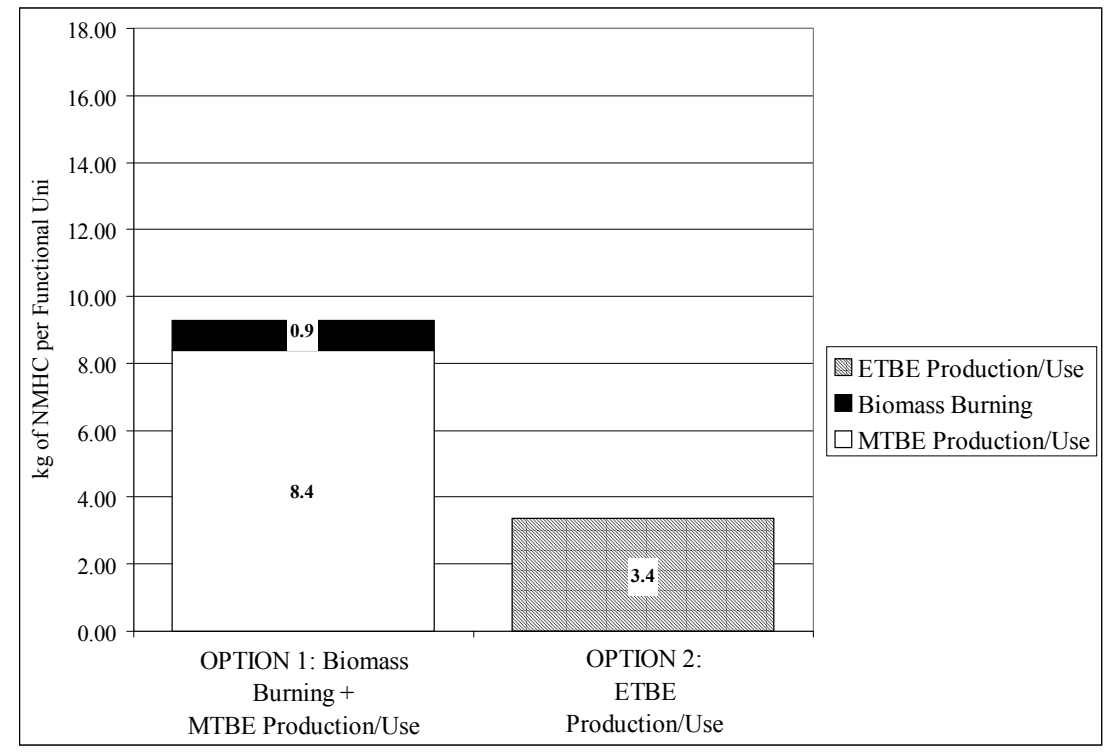

Figure 30: Rice Straw (Acid Process) Non-Methane Hydrocarbon Emissions

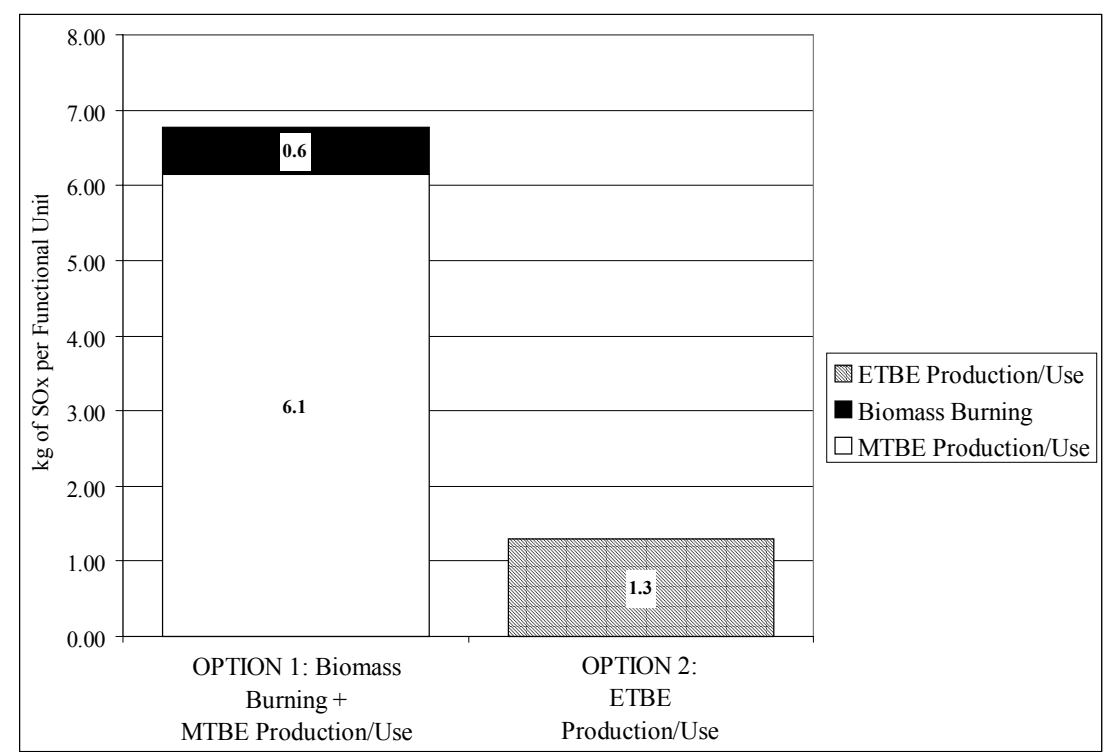

Figure 31: Rice Straw (Acid Process) $\mathrm{SO}_{\mathrm{x}}$ Emissions 


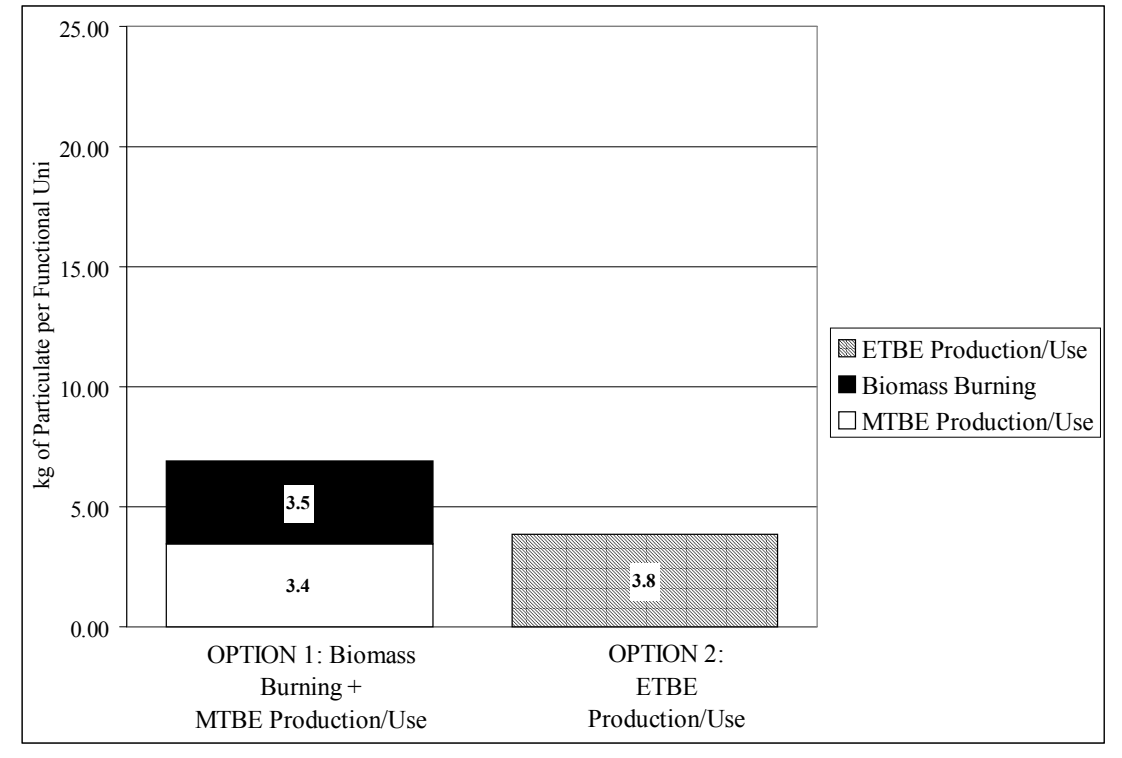

Figure 32: Rice Straw (Acid Process) Particulate Emissions

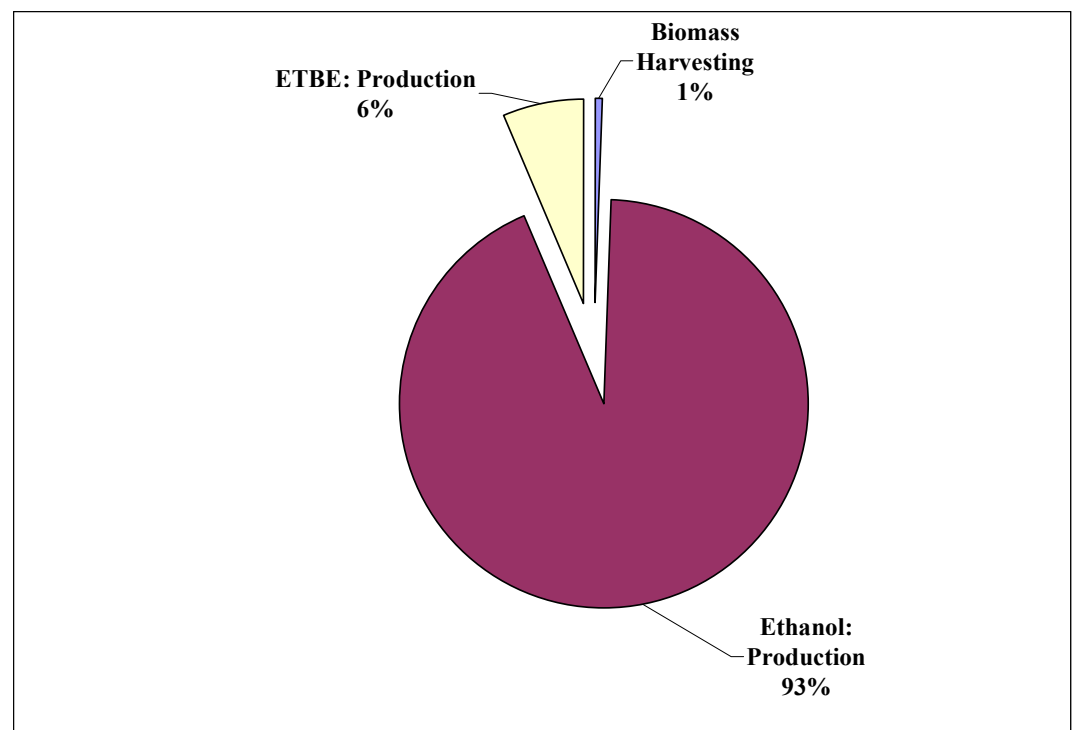

Figure 33: Rice Straw (Acid Process) Particulate Emissions for Option 2 by Source

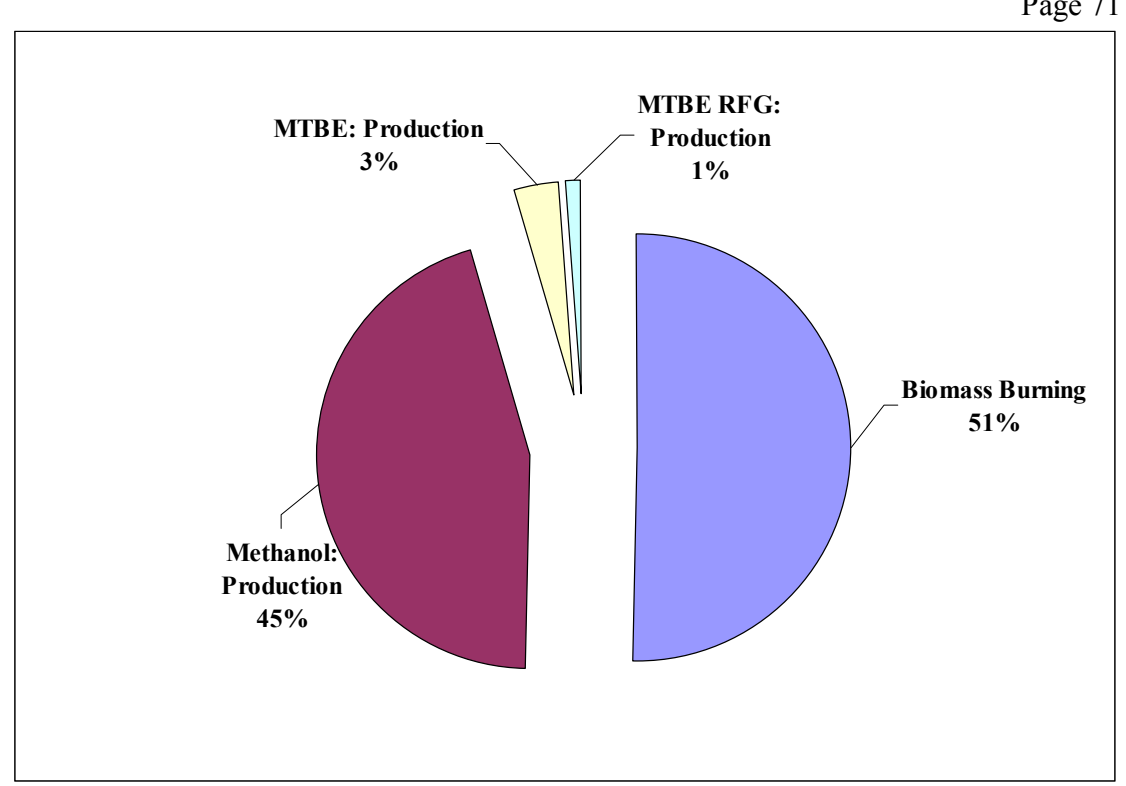

Figure 34: Rice Straw (Acid Process) Particulate Emissions for Option 1 by Source

The two pie charts (Figure 33, Figure 34) show which life cycle stages contributed to the total value for the particulate emissions in Figure 32. Figure 33 shows that the value for Option 2, while smaller than the total value for Option 1, is higher than that for MTBE production portion of Option 1. Figure 33 also shows that these emissions are derived from the ethanol production stage, where natural gas is used in the process. Figure 34 highlights the information that the main source of particulates for Option 1 is the burning of biomass and methanol production. 


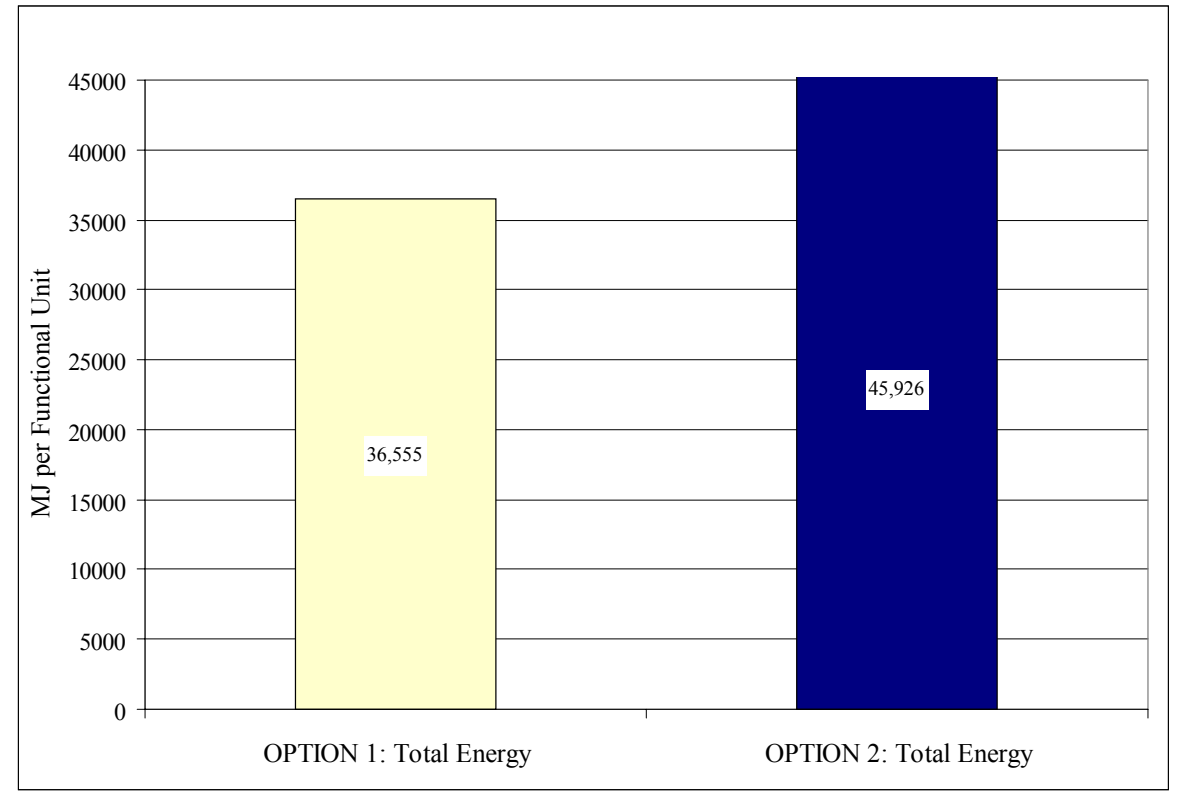

Figure 35: Rice Straw (Acid Process) Total Energy Consumption

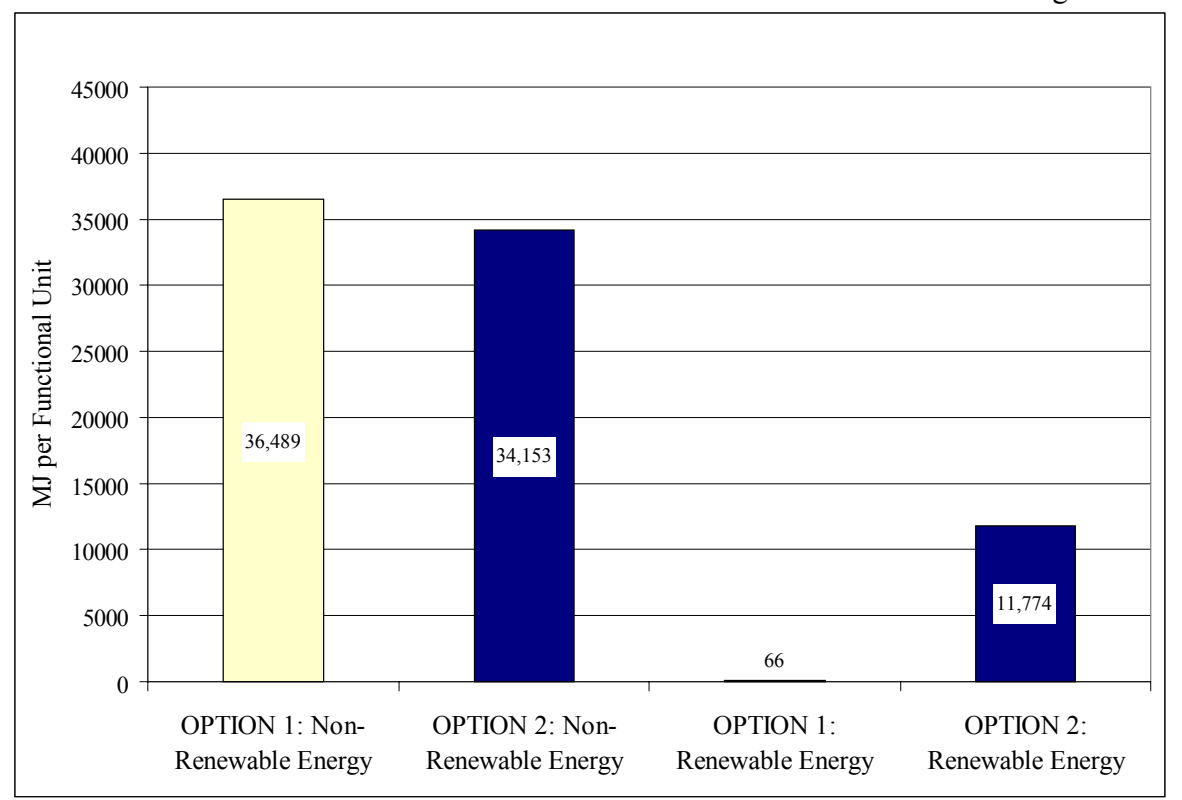

Figure 36: Rice Straw (Acid Process) Nonrenewable and Renewable Energy Consumption 


\subsubsection{Rice Straw Feedstock Summary}

The production of ETBE from a rice straw feedstock leads to a reduction in environmental flows over the burning of the rice straw and the production of MTBE. The production of ethanol in general has greater negative impacts on water effluents (e.g., nitrates); however, in terms of other criteria pollutants, the production of ETBE from rice straw leads to lower net emissions.

\subsubsection{Forest Residue Feedstock—Enzyme Process}

Table 44: Results Summary for Forest Residue Feedstock—Enzyme Process

\begin{tabular}{|c|c|c|c|c|c|}
\hline & Flow & Units & $\begin{array}{c}\text { OPTION 1: MTBE } \\
\text { Production/Use + } \\
\text { Biomass Burning }\end{array}$ & $\begin{array}{l}\text { OPTION 2: ETBE } \\
\text { Production/Use }\end{array}$ & $\begin{array}{l}\text { Change from } \\
\text { OPTION } 1 \text { to } \\
\text { OPTION } 2\end{array}$ \\
\hline \multirow[t]{3}{*}{ Inflows } & Coal & $\mathrm{kg}$ & 344 & -9 & $103 \%$ \\
\hline & Natural Gas & $\mathrm{kg}$ & 477 & 247 & $48 \%$ \\
\hline & Oil & $\mathrm{kg}$ & 427 & 314 & $27 \%$ \\
\hline \multirow[t]{12}{*}{ Outflows } & Carbon Dioxide $\left(\mathrm{CO}_{2}\right.$, biomass $)$ & $\mathrm{g}$ & $1,887,770$ & $1,925,160$ & $-2 \%$ \\
\hline & Carbon Dioxide $\left(\mathrm{CO}_{2}\right.$, fossil $)$ & $\mathrm{g}$ & $3,237,431$ & $1,361,190$ & $58 \%$ \\
\hline & Carbon Monoxide (CO) & $\mathrm{g}$ & 71,698 & 1,275 & $98 \%$ \\
\hline & Hydrocarbons (except methane) & $\mathrm{g}$ & 10,263 & 4,382 & $57 \%$ \\
\hline & Methane $\left(\mathrm{CH}_{4}\right)$ & $\mathrm{g}$ & 15,931 & 564 & $96 \%$ \\
\hline & Nitrogen Oxides $\left(\mathrm{NO}_{\mathrm{x}}\right)$ & $\mathrm{g}$ & 8,340 & 2,561 & $69 \%$ \\
\hline & Nitrous Oxide $\left(\mathrm{N}_{2} \mathrm{O}\right)$ & $\mathrm{g}$ & 65 & 7 & $89 \%$ \\
\hline & Particulates (unspecified) & $\mathrm{g}$ & 12,783 & 891 & $93 \%$ \\
\hline & Sulfur Oxides $\left(\mathrm{SO}_{\mathrm{x}}\right)$ & $\mathrm{g}$ & 7,515 & 982 & $87 \%$ \\
\hline & $\mathrm{COD}$ & $\mathrm{g}$ & 867 & 163 & $81 \%$ \\
\hline & Nitrates $\left(\mathrm{NO}_{3^{-}}\right)$ & $\mathrm{g}$ & 5 & 14 & $-196 \%$ \\
\hline & Waste (total) & $\mathrm{kg}$ & 562 & 15 & $97 \%$ \\
\hline \multirow[t]{5}{*}{ Energy } & Nonrenewable Energy & MJ & 44,842 & 18,748 & $58 \%$ \\
\hline & Renewable Energy & MJ & 81 & 15,708 & $-19282 \%$ \\
\hline & Process Energy & MJ & 23,012 & 11,405 & $50 \%$ \\
\hline & Feedstock Energy & MJ & 21,910 & 23,051 & $-5 \%$ \\
\hline & Total Primary Energy & MJ & 44,923 & 34,456 & $23 \%$ \\
\hline
\end{tabular}

For forest residue, Option 2 leads to a decrease from Option 1 for almost all of the environmental flows (Table 44). The exceptions are nitrates and renewable energy. As with rice straw, the higher values from these flows ensue from the ethanol production stage. The biomass $\mathrm{CO}_{2}$ values for the two options are statistically similar.

\section{Criteria Pollutants}

Carbon monoxide emissions are lower for Option 2 by a factor of about 60; this decrease is substantial and is twice that observed with rice straw. The difference is due to the differing burning-emissions profiles for forest residue and rice straw (see Table 11 and Table 12). Particulate emissions are lower for Option 2 by a factor of about 15, a significant decline. Again, most of the carbon monoxide and a lot of the particulate emissions in Option 1 accrue from biomass burning. The $\mathrm{SO}_{\mathrm{x}}$ emissions for Option 2 are lower by a factor of about eight, while $\mathrm{NO}_{\mathrm{x}}$ and nonmethane hydrocarbons emissions are lower for Option 2 are by a factor of about 3-4. As in the case of rice straw, these emissions are higher for Option 1 essentially because MTBE production is responsible for higher emissions when compared to ETBE production. 


\section{Energy Consumption and $\mathrm{CO}_{2}$}

The total primary energy is less for Option 2 by $23 \%$. The renewable portions of the total energy are $0.2 \%$ and $46 \%$ for Options 1 and 2, respectively. This is due to the excess electricity that is generated during the ethanol production stage. Process energy requirement is lower for Option 2 by 50\%; this reduction is higher than that for rice straw. Unlike rice straw, forest residue produces enough ligneous fuel to satisfy process steam and electricity needs, and excess electricity is treated as a credit. The fossil-derived $\mathrm{CO}_{2}$ is lower for Option 2 by $58 \%$, a sizable mitigation of $\mathrm{CO}_{2}$ emissions.

\section{Water Emissions}

As is the case with rice straw, Option 2 results in considerably higher nitrates that are attributable to the use of CSL during ethanol fermentation. However, as explained in the Impact Assessment section, the eutrophication potential is still lower for Option 2.

\section{Graphical Representation of Key Results}

The mass flow diagram for this system is shown in Figure 37. The graphs that follow show the comparative emissions for five criteria pollutants - carbon monoxide (Figure 38), nitrogen oxides (Figure 39), particulates (Figure 40), sulfur oxides (Figure 41), and non-methane hydrocarbons (Figure 42 through Figure 44) - as well as energy consumption (Figure 45 and Figure 46). The first column represents values for Option 1, split out as values from MTBE production and biomass burning. The second column shows the flows for Option 2, ETBE production. The scales are kept the same throughout the entire results section, in order to facilitate comparison among the different biomass feedstocks and ethanol production methods.

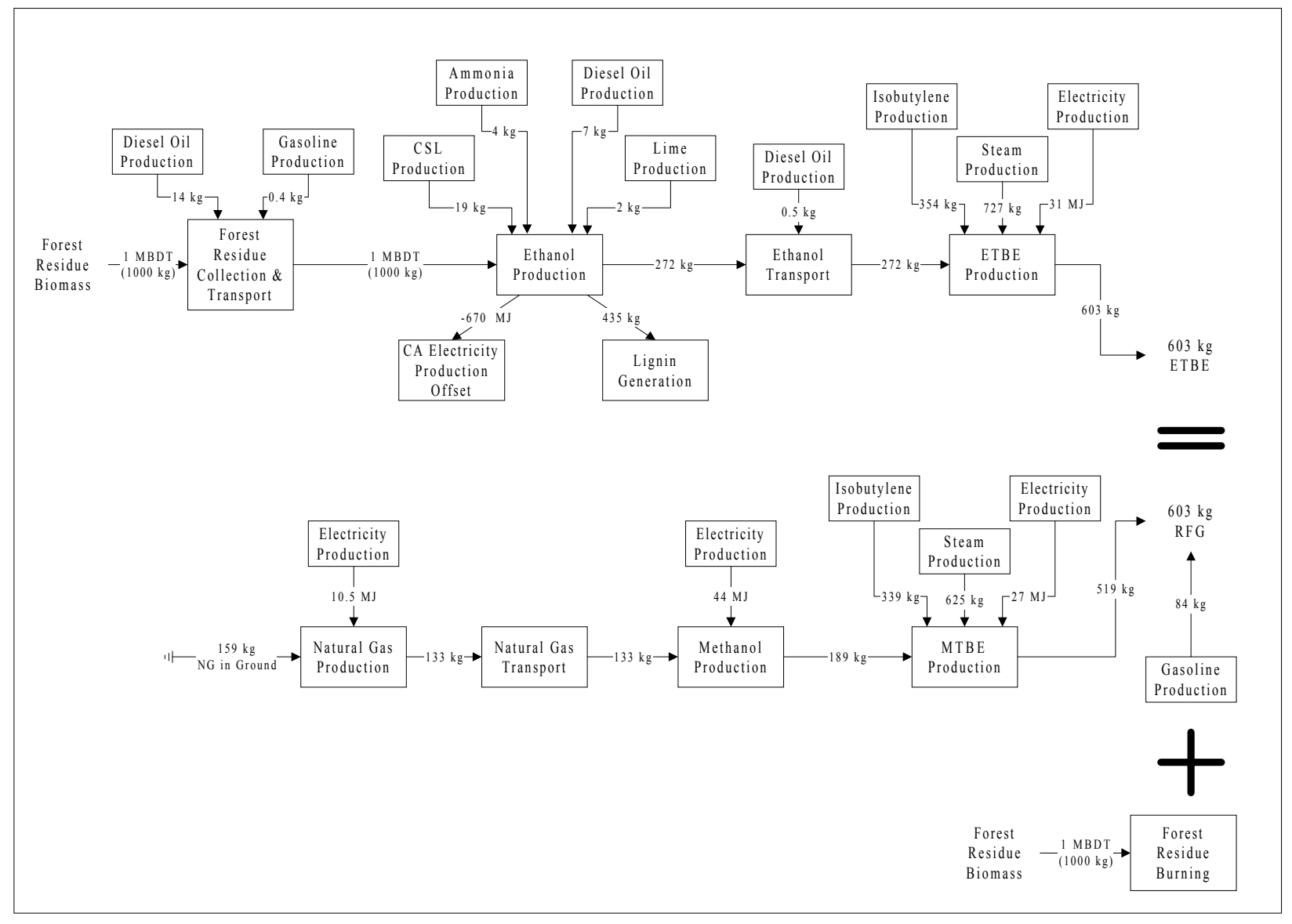

Figure 37: Mass Flow Diagram for Forest Residue—Enzyme Process 


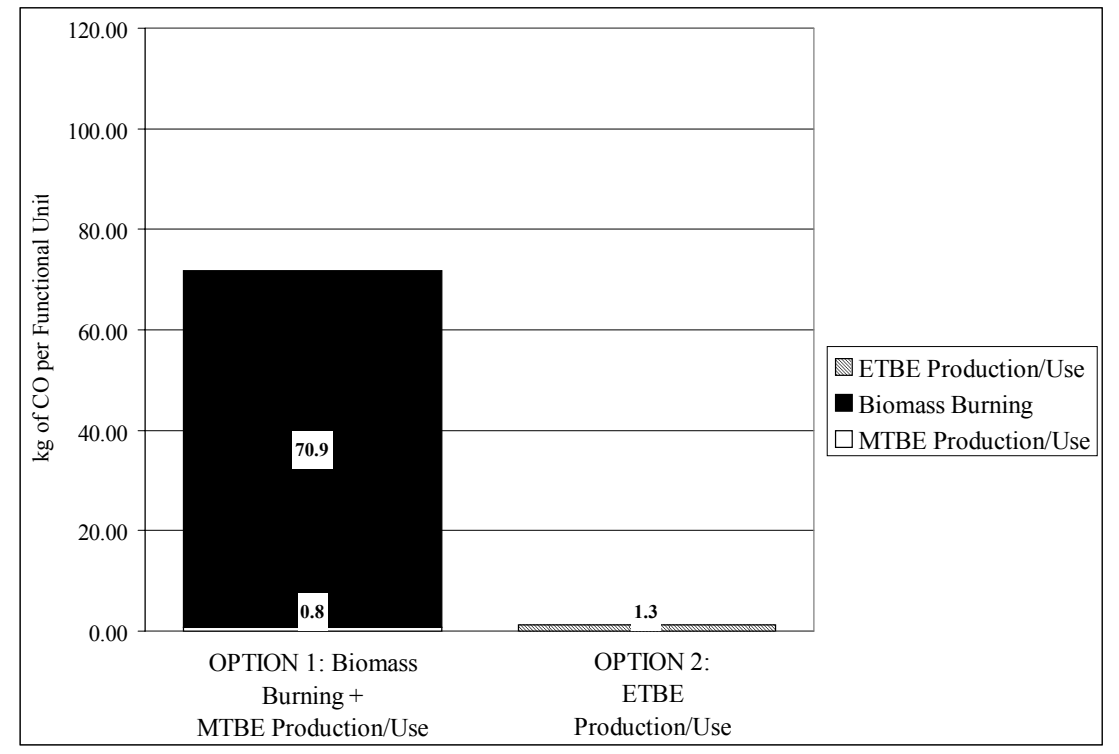

Figure 38: Forest Residue (Enzyme Process) Carbon Monoxide Emissions

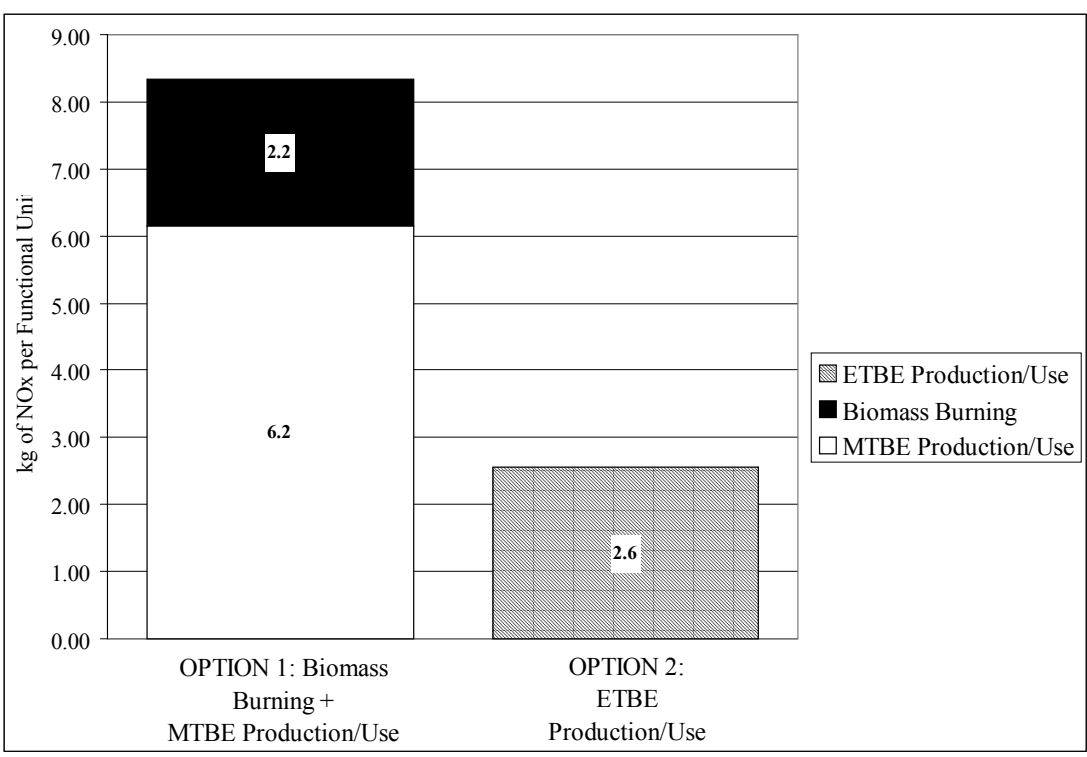

Figure 39: Forest Residue (Enzyme Process) NO $_{x}$ Emissions

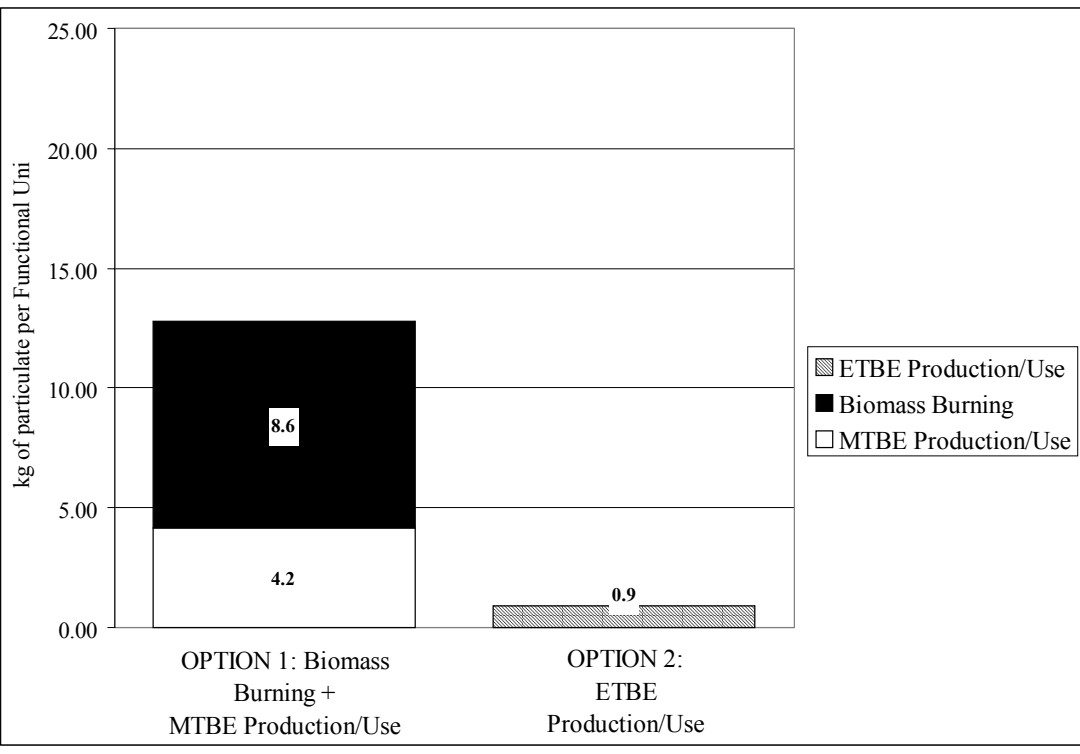

Figure 40: Forest Residue (Enzyme Process) Particulate Emissions

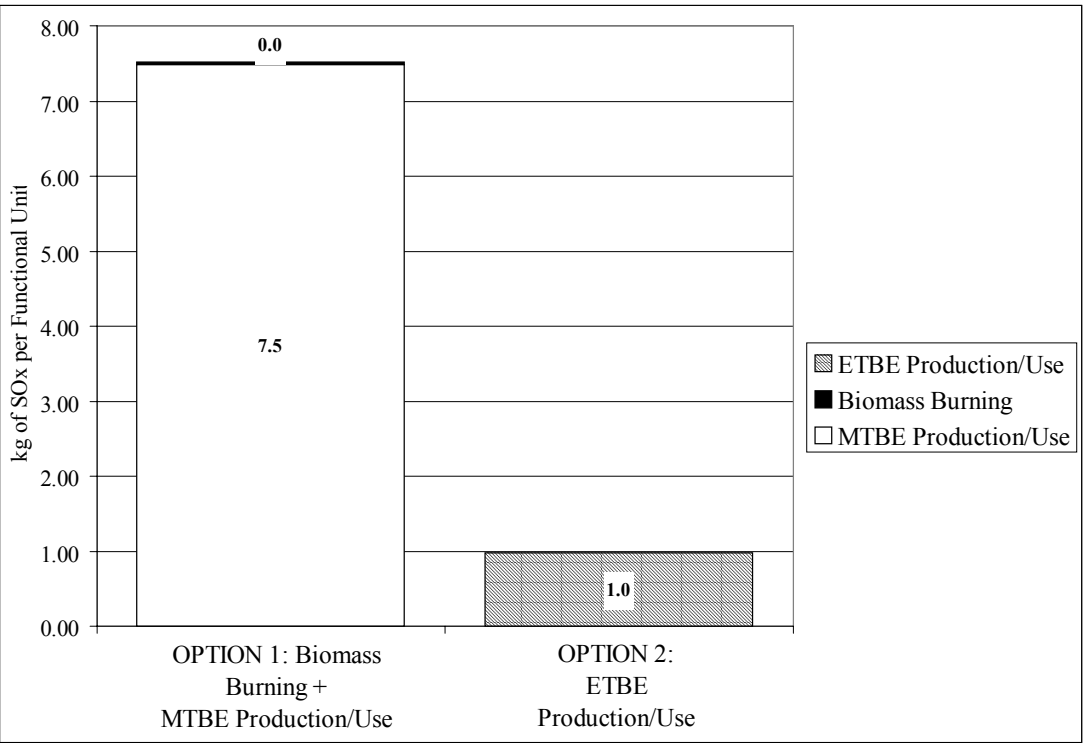

Figure 41: Forest Residue (Enzyme Process) $\mathrm{SO}_{\mathrm{x}}$ Emissions 


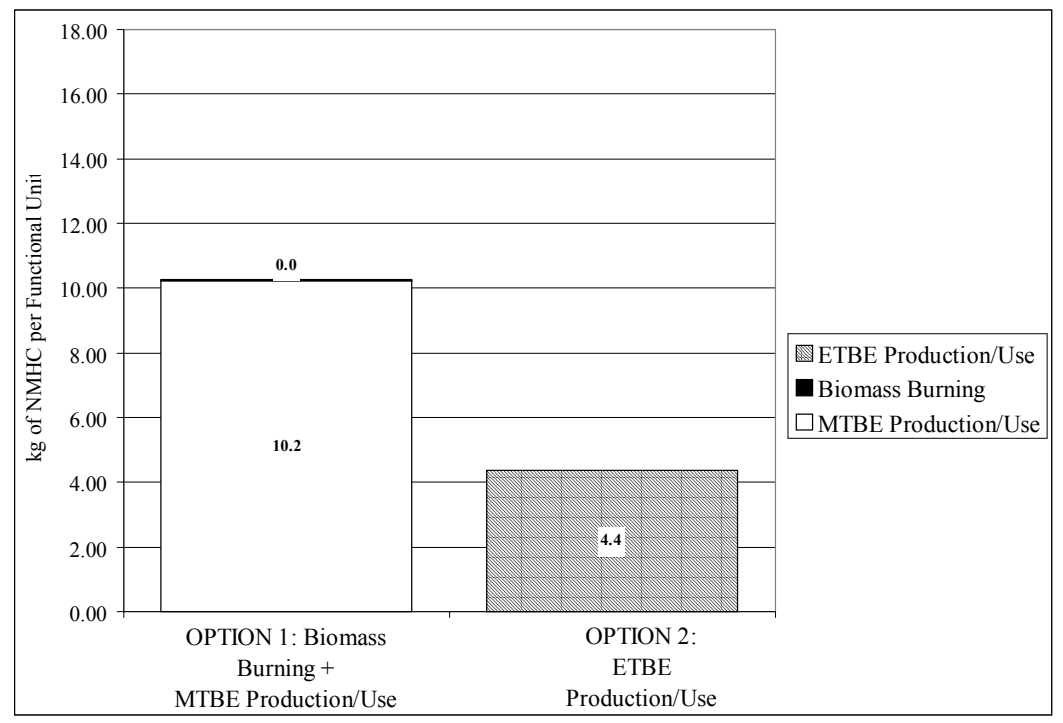

Figure 42: Forest Residue (Enzyme Process) Non-Methane Hydrocarbon Emissions

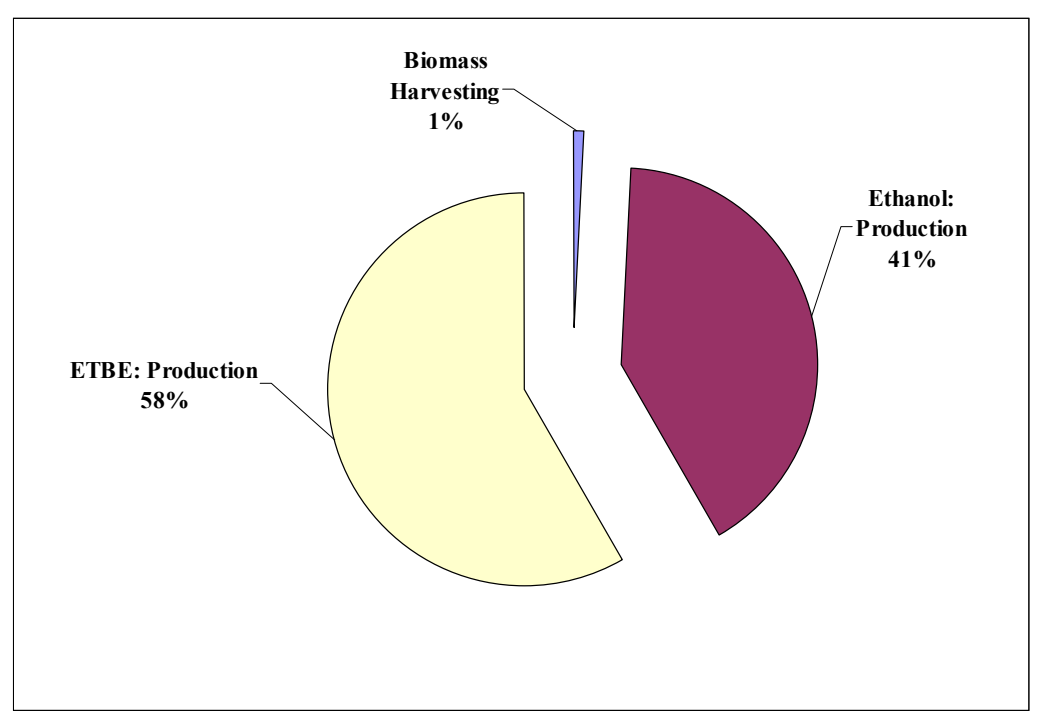

Figure 43: Forest Residue (Enzyme Process) Non-Methane Hydrocarbon Emissions for Option 2 by Source

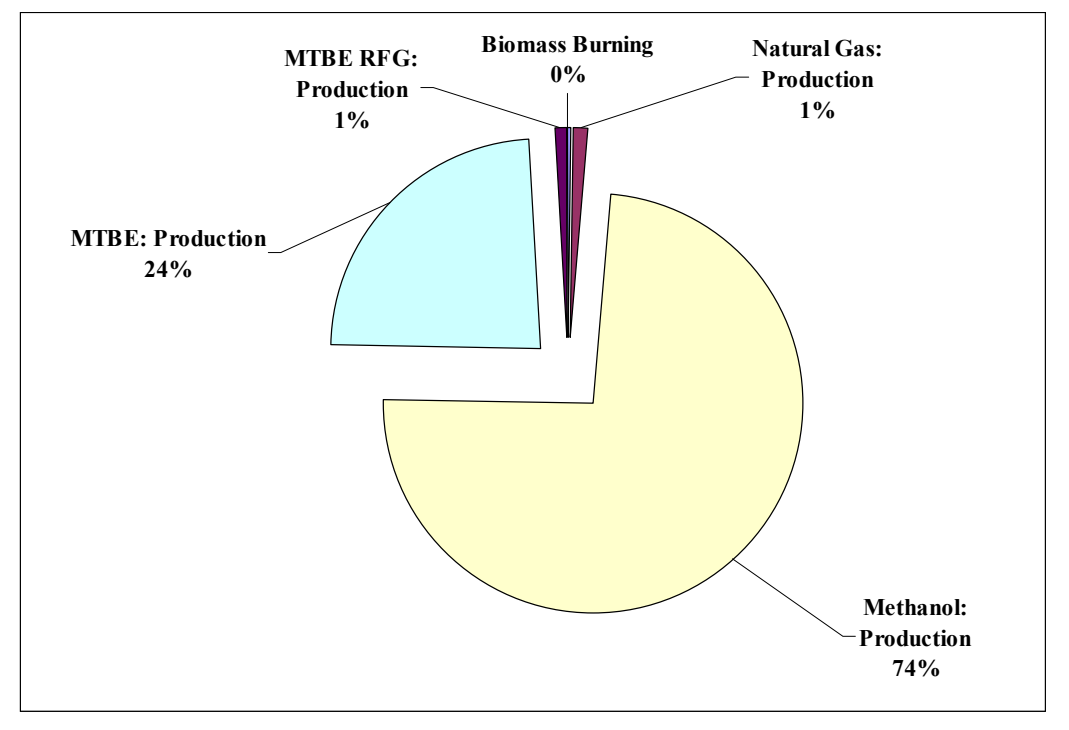

Figure 44: Forest Residue (Enzyme Process) Non-Methane Hydrocarbon Emissions for Option 1 by Source

The two pie charts (Figure 43, Figure 44) show which life cycle stages contributed to the total value for the non-methane hydrocarbon emissions in Figure 42. Figure 43 shows that the value for Option 2, while smaller than the total value for Option 1 , is higher than that for the biomass burning portion of Option 1. Figure 43 also shows that these emissions are derived from the ethanol and ETBE production stages, where natural gas is used in the process. Figure 44 highlights the information that the main source of non-methane hydrocarbons for Option 1 is the MTBE and methanol production. 


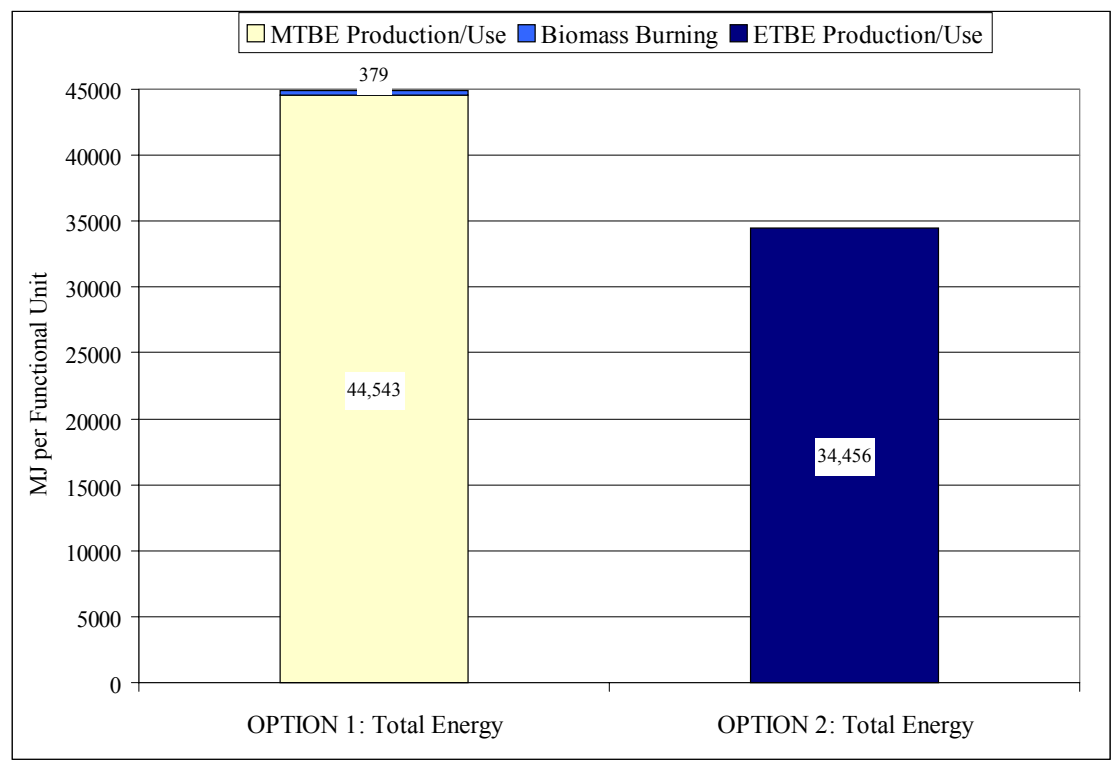

Figure 45: Forest Residue (Enzyme Process) Total Energy Consumption

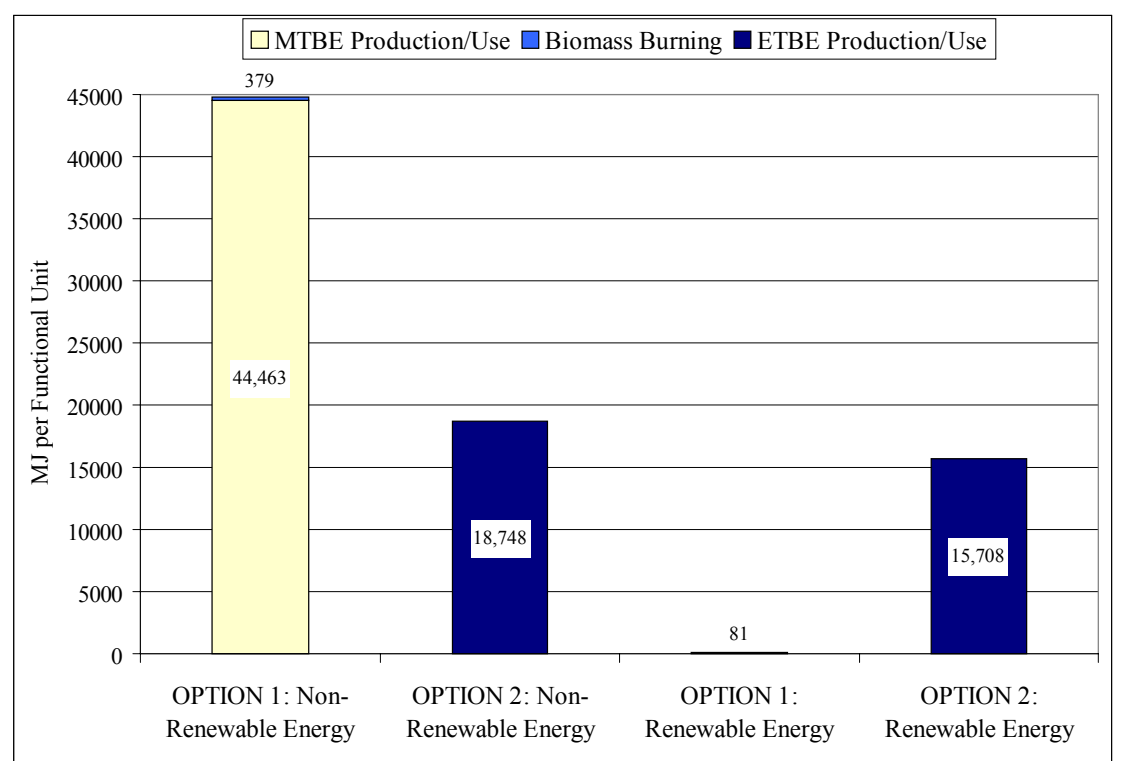

Figure 46: Forest Residue (Enzyme Process) Nonrenewable and Renewable Energy Consumption 


\subsubsection{Forest Residue Feedstock—Concentrated Acid Process}

Table 45: Results Summary for Forest Residue Feedstock—Acid Process

\begin{tabular}{|c|c|c|c|c|c|}
\hline & Flow & Units & $\begin{array}{c}\text { OPTION 1: MTBE } \\
\text { Production/Use + } \\
\text { Biomass Burning }\end{array}$ & $\begin{array}{l}\text { OPTION 2: ETBE } \\
\text { Production/Use }\end{array}$ & $\begin{array}{l}\text { Change from } \\
\text { OPTION } 1 \text { to } \\
\text { OPTION } 2\end{array}$ \\
\hline \multirow[t]{3}{*}{ Inflows } & Coal & $\mathrm{kg}$ & 281 & 8 & $97 \%$ \\
\hline & Natural Gas & $\mathrm{kg}$ & 390 & 455 & $-17 \%$ \\
\hline & Oil $\ldots \ldots \ldots \ldots \ldots \ldots$ & $\mathrm{kg}$ & 350 & 258 & $26 \%$ \\
\hline \multirow[t]{12}{*}{ Outflows } & Carbon Dioxide $\left(\mathrm{CO}_{2}\right.$, biomass $)$ & $\mathrm{g}$ & $1,887,770$ & $1,658,260$ & $12 \%$ \\
\hline & Carbon Dioxide $\left(\mathrm{CO}_{2}\right.$, fossil $)$ & $\mathrm{g}$ & $2,647,971$ & $1,742,200$ & $34 \%$ \\
\hline & Carbon Monoxide (CO) & $\mathrm{g}$ & 71,550 & 1,567 & $98 \%$ \\
\hline & Hydrocarbons (except methane) & $\mathrm{g}$ & 8,385 & 3,259 & $61 \%$ \\
\hline & Methane $\left(\mathrm{CH}_{4}\right)$ & g & 15,236 & 3,593 & $76 \%$ \\
\hline & Nitrogen Oxides $\left(\mathrm{NO}_{\mathrm{x}}\right)$ & $\mathrm{g}$ & 7,211 & 3,327 & $54 \%$ \\
\hline & Nitrous Oxide $\left(\mathrm{N}_{2} \mathrm{O}\right)$ & g & 53 & 16 & $69 \%$ \\
\hline & Particulates (unspecified) & g & 12,017 & 3,852 & $68 \%$ \\
\hline & Sulfur Oxides $\left(\mathrm{SO}_{\mathrm{x}}\right)$ & g & 6,141 & 1,299 & $79 \%$ \\
\hline & $\mathrm{COD}$ & $\mathrm{g}$ & 714 & 130 & $82 \%$ \\
\hline & Nitrates $\left(\mathrm{NO}_{3}{ }^{-}\right)$ & $\mathrm{g}$ & 4 & 21 & $-458 \%$ \\
\hline & Waste (total) & $\mathrm{kg}$ & 459 & 94 & $79 \%$ \\
\hline \multirow[t]{5}{*}{ Energy } & Nonrenewable Energy & MJ & 36,688 & 28,881 & $21 \%$ \\
\hline & Renewable Energy & MJ & 66 & 13,295 & $-19967 \%$ \\
\hline & Process Energy & MJ & 18,862 & 23,352 & $-24 \%$ \\
\hline & Feedstock Energy & MJ & 17,892 & 18,824 & $-5 \%$ \\
\hline & Total Primary Energy & MJ & 36,754 & 42,176 & $-15 \%$ \\
\hline
\end{tabular}

As with rice straw, the relative performance of Option 1 versus Option 2 with a concentrated acid process is mostly similar to that with an enzyme process, with the main exception of natural gas and energy use (Table 45). The acid process is generally responsible for higher emissions of the criteria pollutants than is the enzyme process. The need for auxiliary natural gas in the concentrated acid process results in higher values for depletion of natural resources and greenhouse gas potential indicators. This also yields higher methane emissions.

As the concentrated acid process requires more energy than the enzymatic process, the relative performance of Option 2 with the concentrated acid process is lower for nonrenewable energy consumption, primary energy consumption, fossil $\mathrm{CO}_{2}, \mathrm{SO}_{\mathrm{x}}, \mathrm{NO}_{\mathrm{x}}$, non-methane hydrocarbons, and particulate emissions.

\section{Graphical Representation of Key Results}

The mass flow diagram for this system is shown in Figure 47. The graphs that follow show the comparative emissions for five criteria pollutants - carbon monoxide (Figure 48), particulates (Figure 49), non-methane hydrocarbons (Figure 50), sulfur oxides (Figure 51), and nitrogen oxides (Figure 52 through Figure 54) - as well as energy consumption (Figure 55 and Figure 56). The first column represents values for Option 1, split out as values from MTBE production and biomass burning. The second column shows the flows for Option 2, ETBE production. The scales are kept the same throughout the entire results section, in order to facilitate comparison among the different biomass feedstocks and ethanol production methods. 


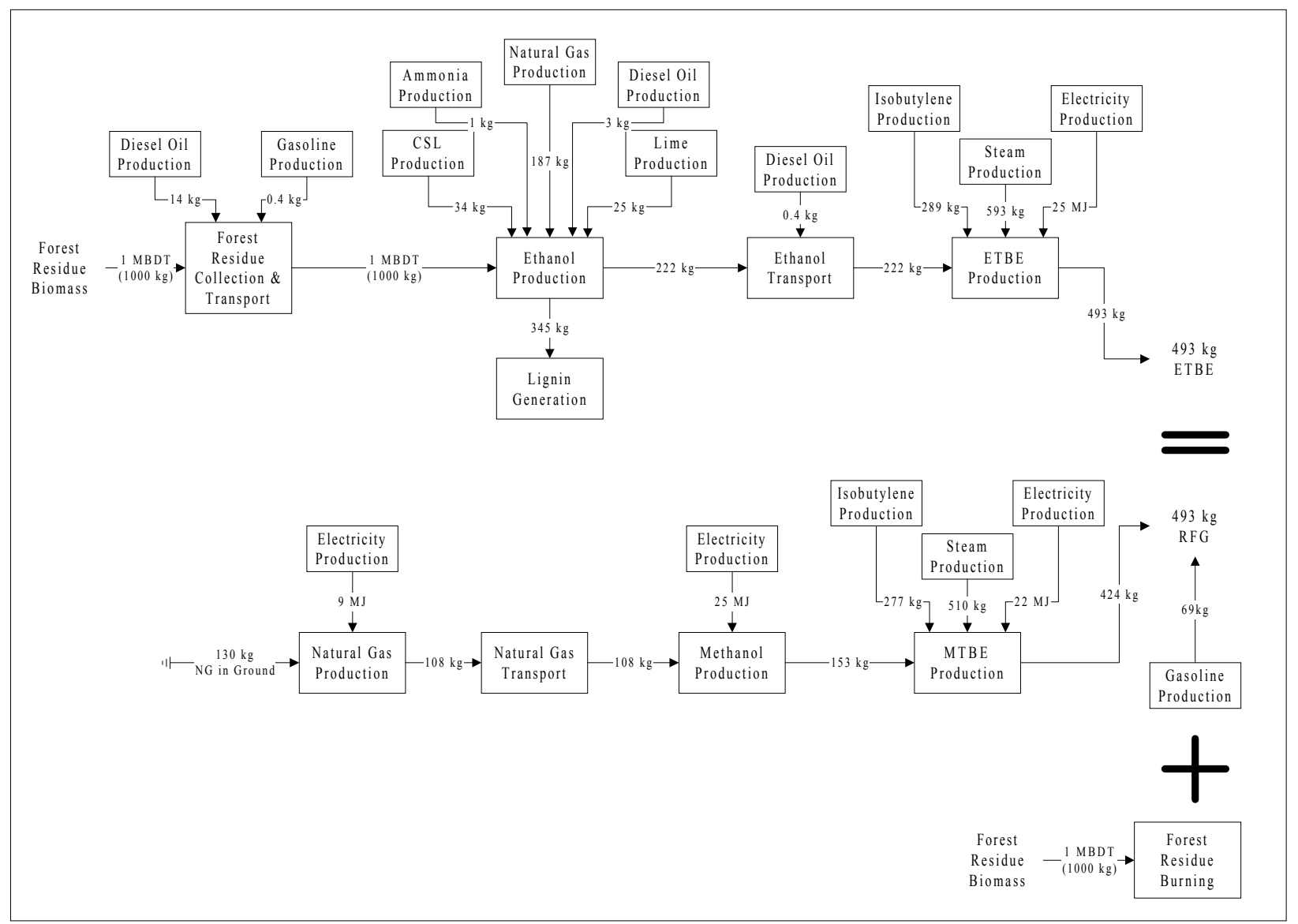

Figure 47: Mass Flow Diagram for Forest Residue-Acid Process 


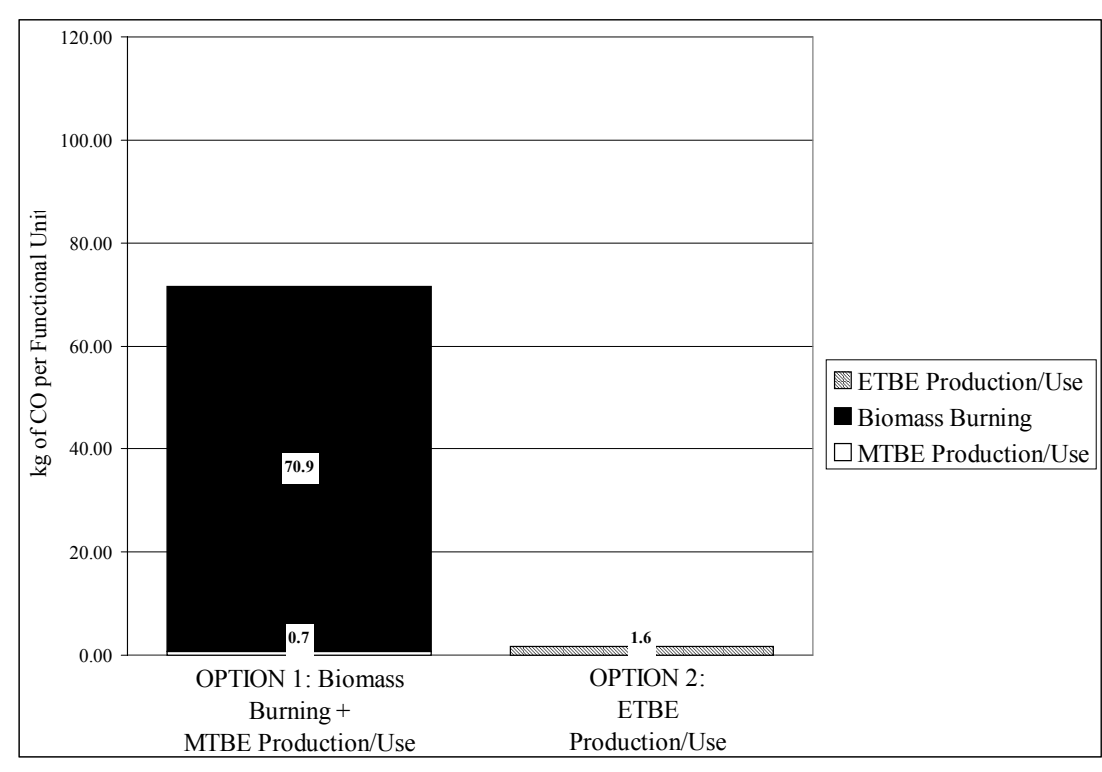

Figure 48: Forest Residue (Acid Process) Carbon Monoxide Emissions

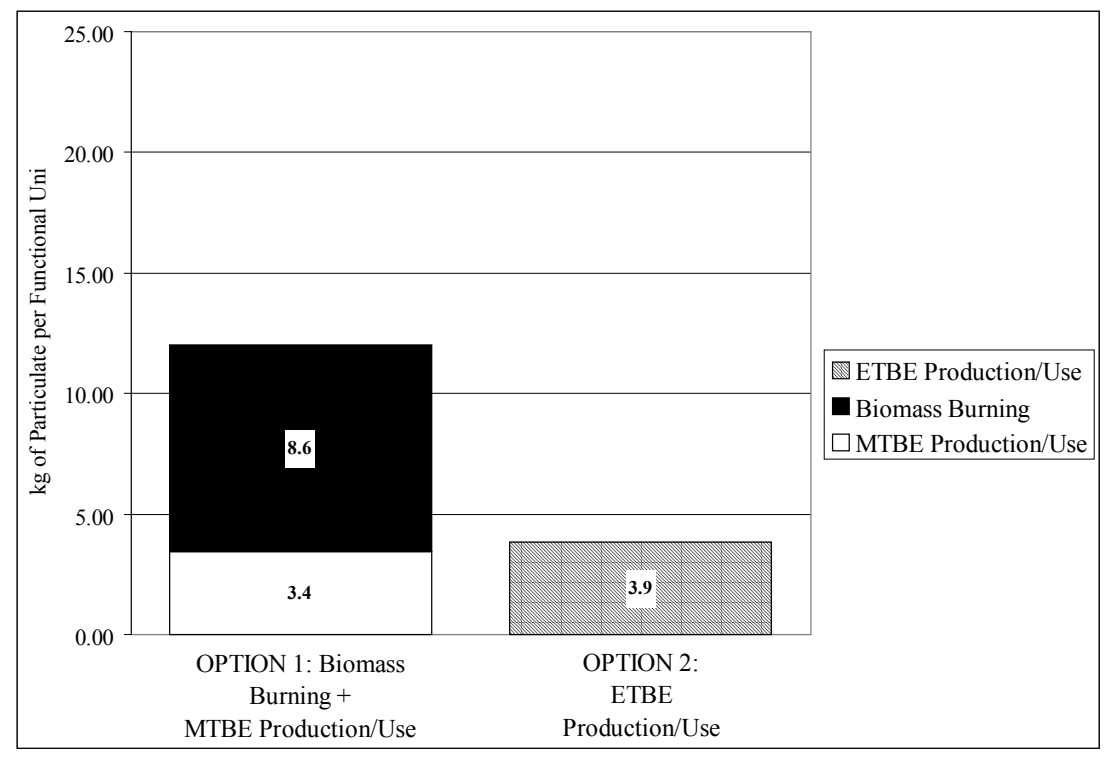

Figure 49: Forest Residue (Acid Process) Particulate Emissions

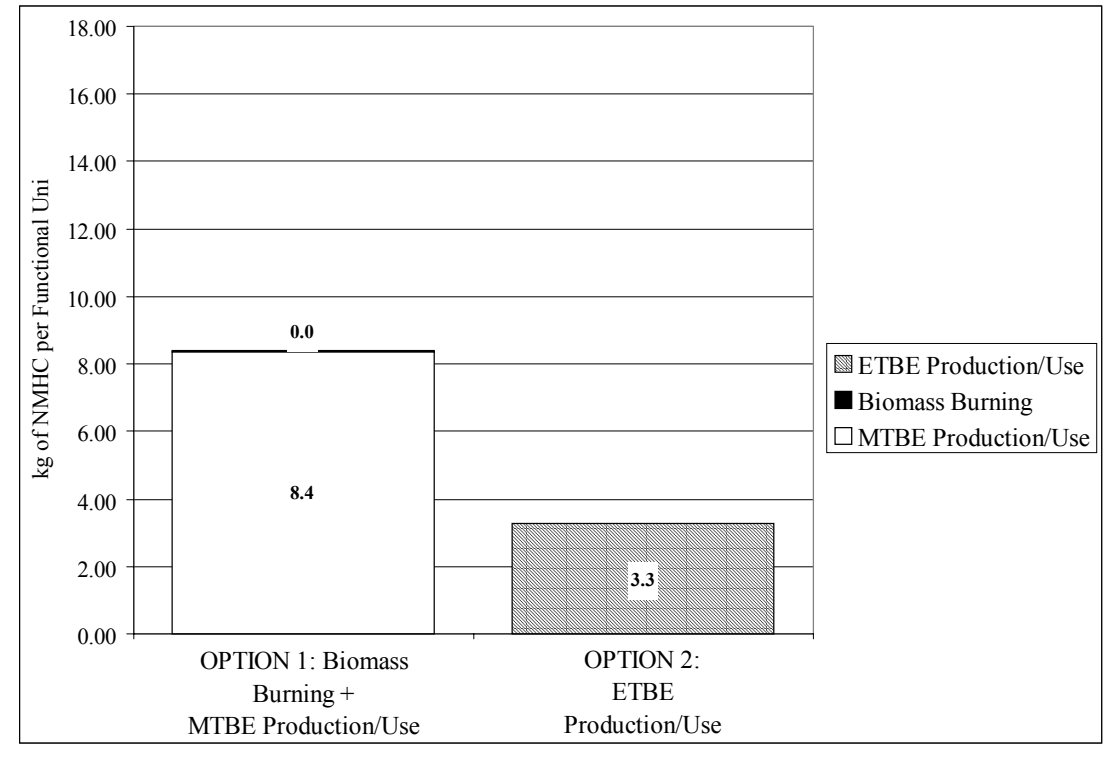

Figure 50: Forest Residue (Acid Process) Non-methane Hydrocarbon Emissions

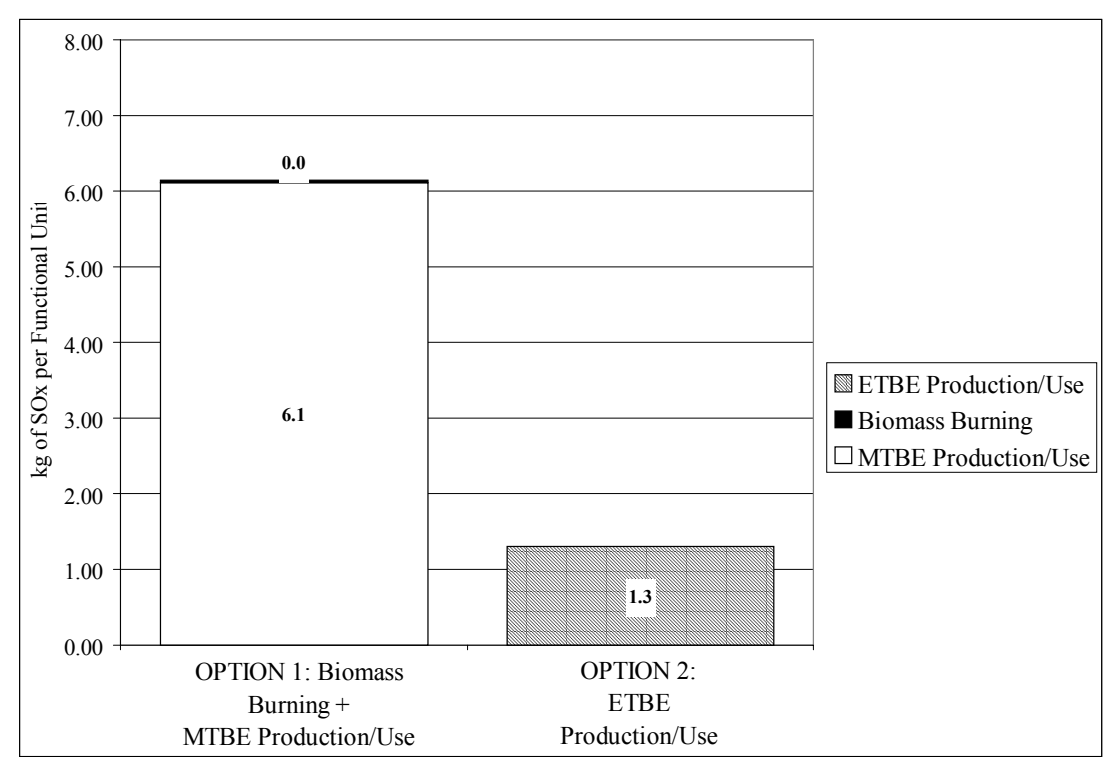

Figure 51: Forest Residue (Acid Process) $\mathrm{SO}_{\mathrm{x}}$ Emissions 


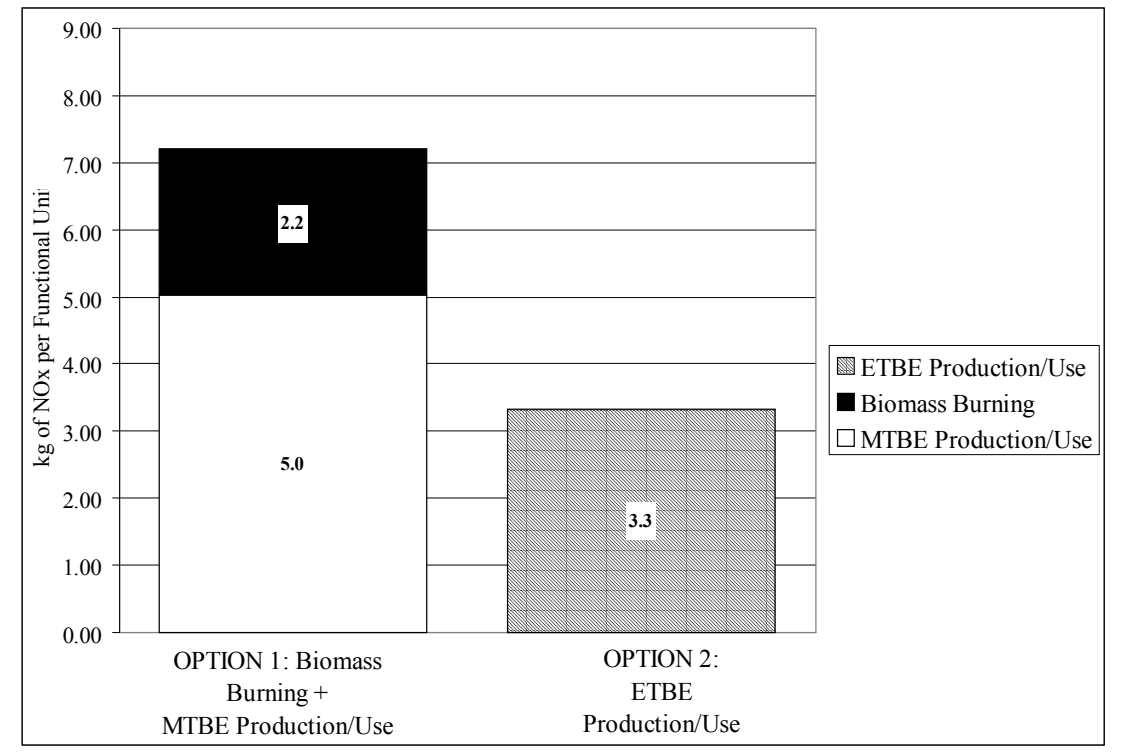

Figure 52: Forest Residue (Acid Process) NO $_{x}$ Emissions

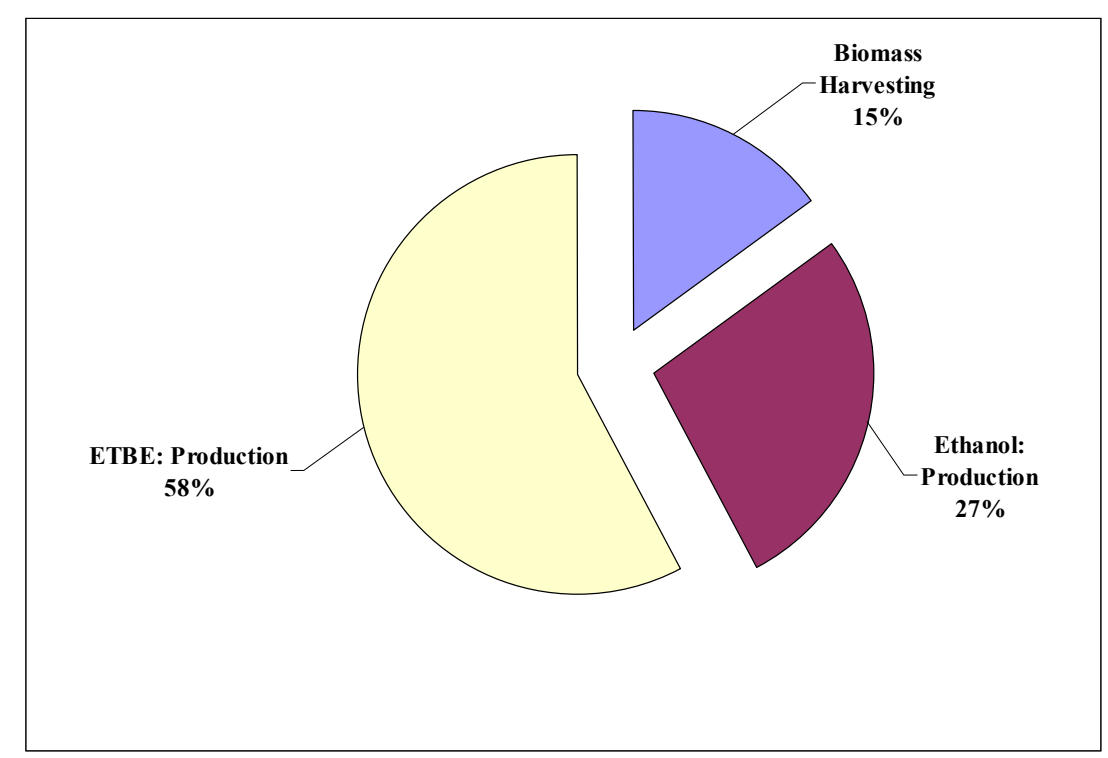

Figure 53: Forest Residue (Acid Process) NOx Emissions for Option 2 by Source

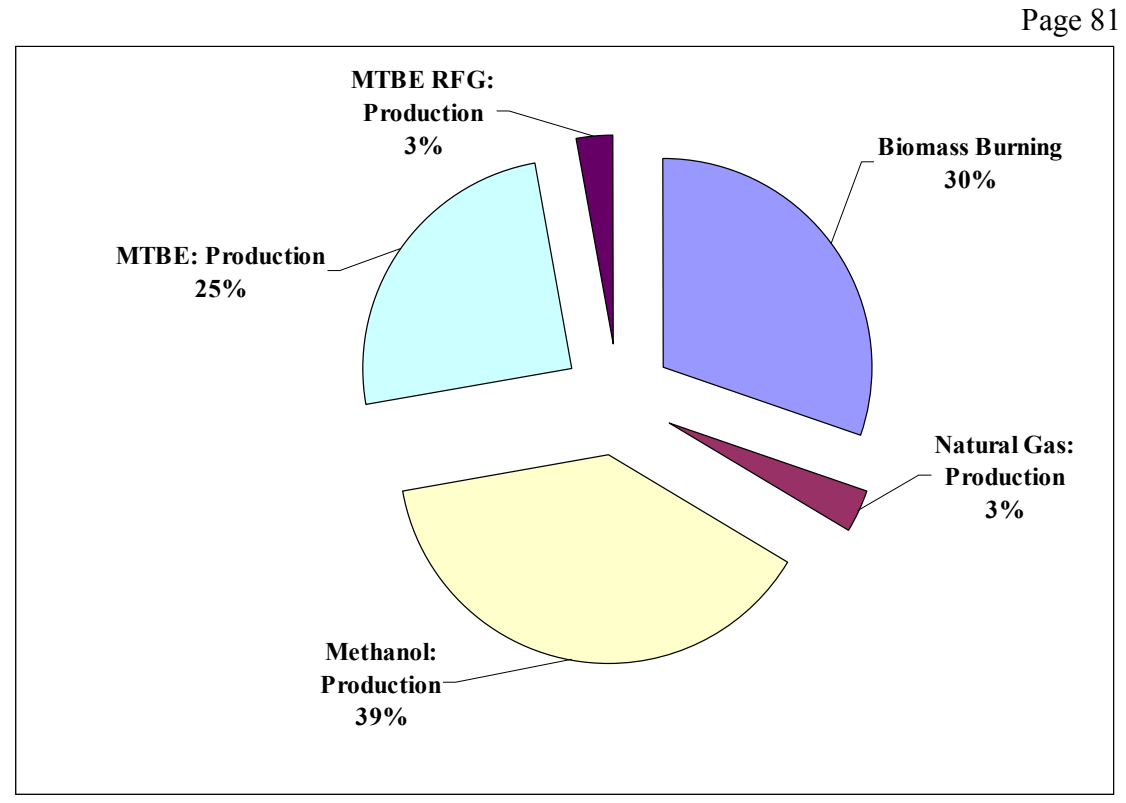

Figure 54: Forest Residue (Acid Process) NOx Emissions for Option 1 by Source

The two pie charts (Figure 53, Figure 54) show which life cycle stages contributed to the total value for the NOx emissions in Figure 52. Figure 53 shows that the value for Option 2, while smaller than the total value for Option 1 , is higher than that for biomass burning portion of Option 1. Figure 53 also shows that these emissions are primarily derived from the ETBE production stage. Figure 54 highlights that the main sources of $\mathrm{NO}_{\mathrm{x}}$ for Option 1 are the burning of biomass, MTBE and methanol production. 


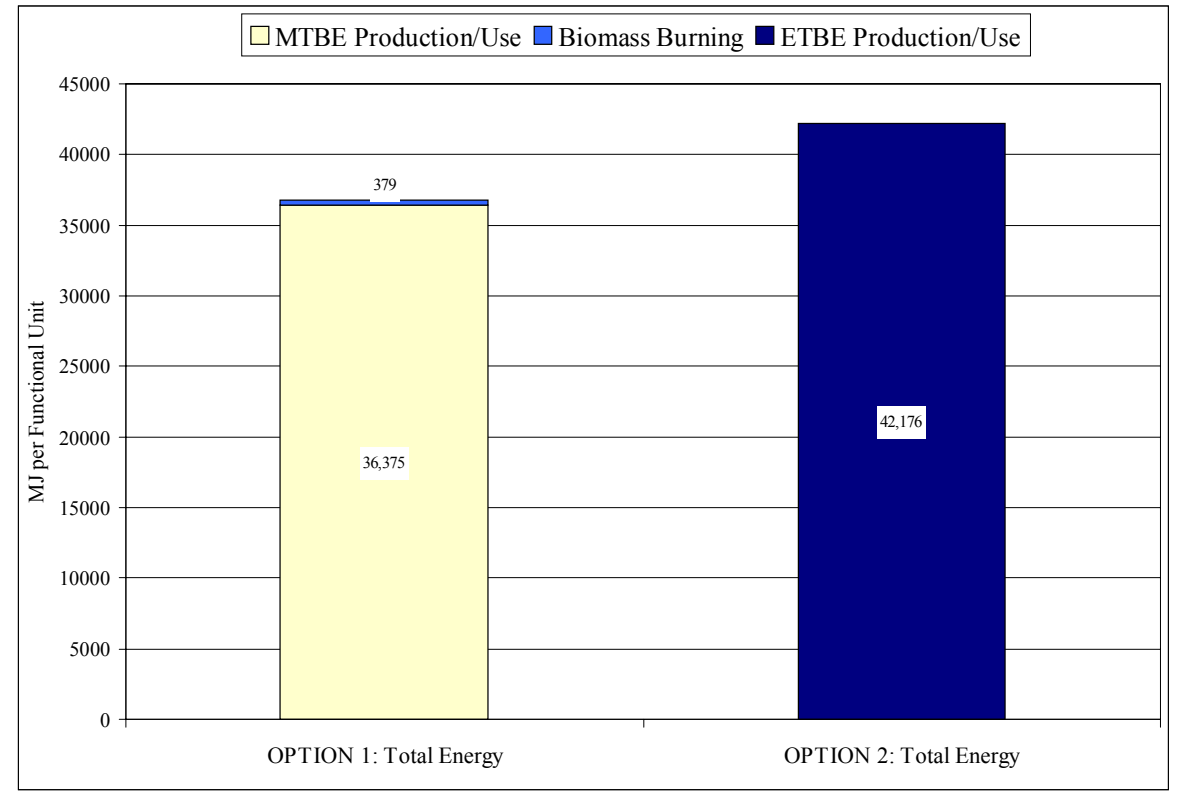

Figure 55: Forest Residue (Acid Process) Total Energy Consumption

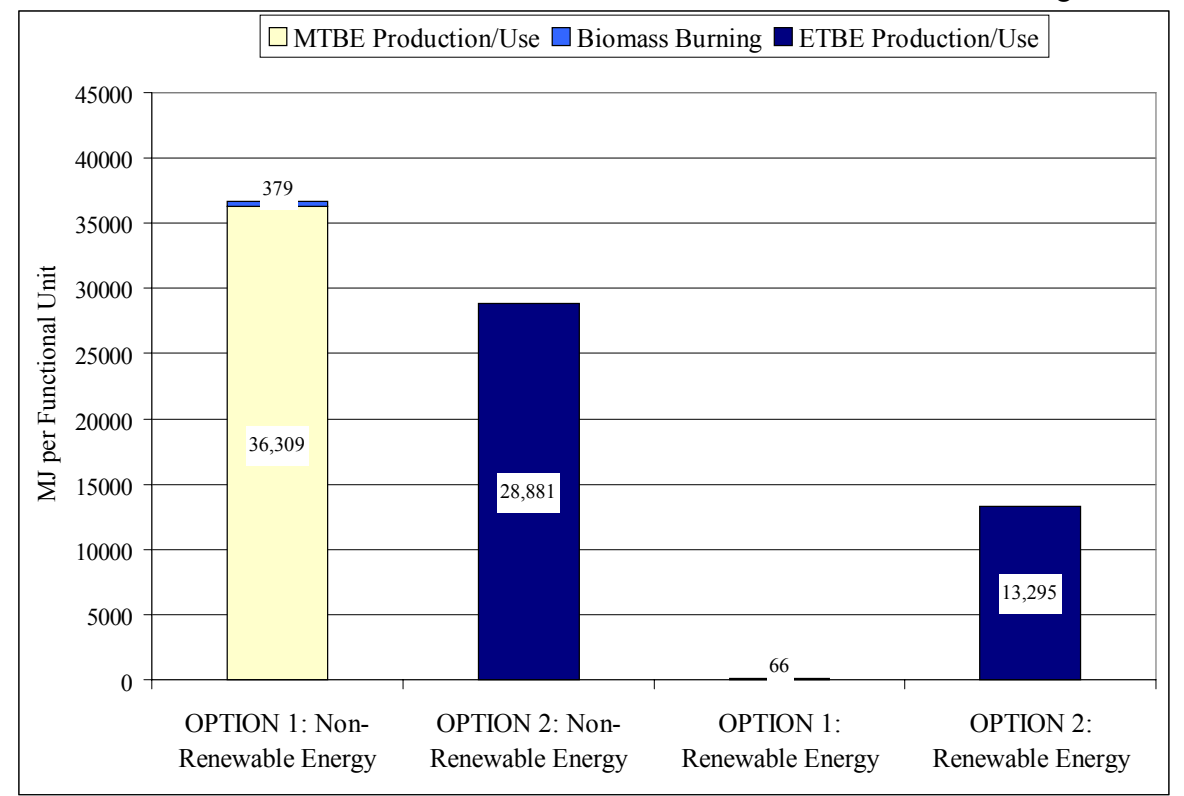

Figure 56: Forest Residue (Acid Process) Nonrenewable and Renewable Energy Consumption 


\subsubsection{Forest Residue Feedstock Summary}

The production of ETBE from a forest residue feedstock leads to a net reduction in environmental flows over producing of MTBE and allowing for the burning of forest biomass. For all of these scenarios, the production of ethanol has greater negative impacts on water effluents (e.g. nitrates). However, in the case of forest residue, all of the criteria pollutant emission values for ETBE production are lower than those values for MTBE production and biomass burning combined.

\subsubsection{Chaparral Feedstock-Enzyme Process}

Table 46: Results Summary for Chaparral Feedstock—Enzyme Process

\begin{tabular}{|c|c|c|c|c|c|}
\hline & Article & Units & $\begin{array}{l}\text { OPTION 1: MTBE } \\
\text { Production }+ \\
\text { Biomass Burning }\end{array}$ & $\begin{array}{l}\text { OPTION 2: ETBE } \\
\text { Production }\end{array}$ & $\begin{array}{l}\text { Change from } \\
\text { OPTION } 1 \text { to } \\
\text { OPTION } 2\end{array}$ \\
\hline \multirow[t]{3}{*}{ Inflows } & Coal & $\mathrm{kg}$ & 118 & -84 & $171 \%$ \\
\hline & Natural Gas & $\mathrm{kg}$ & 165 & 6 & $96 \%$ \\
\hline & Oil & $\mathrm{kg}$ & 160 & 203 & $-27 \%$ \\
\hline \multirow[t]{12}{*}{ Outflows } & Carbon Dioxide $\left(\mathrm{CO}_{2}\right.$, biomass $)$ & $\mathrm{g}$ & $1,931,340$ & $1,914,160$ & $1 \%$ \\
\hline & Carbon Dioxide $\left(\mathrm{CO}_{2}\right.$, fossil $)$ & $\mathrm{g}$ & $1,148,478$ & 366,154 & $68 \%$ \\
\hline & Carbon Monoxide (CO) & $\mathrm{g}$ & 101,738 & 2,672 & $97 \%$ \\
\hline & Hydrocarbons (except methane) & $\mathrm{g}$ & 16,049 & 428 & $97 \%$ \\
\hline & Methane $\left(\mathrm{CH}_{4}\right)$ & $\mathrm{g}$ & 5,839 & -714 & $112 \%$ \\
\hline & Nitrogen Oxides $\left(\mathrm{NO}_{\mathrm{x}}\right)$ & g & 2,404 & 1,841 & $23 \%$ \\
\hline & Nitrous Oxide $\left(\mathrm{N}_{2} \mathrm{O}\right)$ & $\mathrm{g}$ & 25 & 10 & $62 \%$ \\
\hline & Particulates (unspecified) & g & 21,483 & 930 & $96 \%$ \\
\hline & Sulfur Oxides $\left(\mathrm{SO}_{\mathrm{x}}\right)$ & $\mathrm{g}$ & 2,610 & 439 & $83 \%$ \\
\hline & COD & g & 375 & 401 & $-7 \%$ \\
\hline & Nitrates $\left(\mathrm{NO}_{3}^{-}\right)$ & $\mathrm{g}$ & 2 & 11 & $-615 \%$ \\
\hline & Waste (total) & $\mathrm{kg}$ & 193 & -57 & $130 \%$ \\
\hline \multirow[t]{5}{*}{ Energy } & Nonrenewable Energy & MJ & 16,081 & 2,895 & $82 \%$ \\
\hline & Renewable Energy & MJ & 29 & 12,197 & $-42685 \%$ \\
\hline & Process Energy & MJ & 8,629 & 7,222 & $16 \%$ \\
\hline & Feedstock Energy & MJ & 7,481 & 7,870 & $-5 \%$ \\
\hline & Total Primary Energy & MJ & 16,110 & 15,092 & $6 \%$ \\
\hline
\end{tabular}

Using chaparral as a feedstock, Option 2 leads to a decrease from Option 1 for almost all of the environmental flows; nitrates and renewable energy are again the two major exceptions (Table 46). As with rice straw and forest residue, these exceptions stem from the ethanol production stage. The difference between the two options for COD values is not regarded as statistically significant.

\section{Criteria Pollutants}

Carbon monoxide emissions are lower for Option 2 by a factor of about 40; this decrease is smaller than that observed with forest residue but is higher than that for rice straw. These differences are ascribed to the differing burning-emissions profiles of the three feedstocks (see Table 11 through Table 13). Particulate emissions are lower for Option 2 by a factor of 23, indicating an appreciable decrease. As with rice straw and forest residue, biomass burning in Option 1 is the source of most of the carbon monoxide and a lot of the particulate emissions. The $\mathrm{SO}_{\mathrm{x}}$ emissions for Option 2 are lower by a factor of about seven, while $\mathrm{NO}_{\mathrm{x}}$ and non-methane hydrocarbons emissions are lower for Option 2 by a factor of about 1.3 and 38, respectively. As in the case of rice straw, the $\mathrm{SO}_{\mathrm{x}}$ and $\mathrm{NO}_{\mathrm{x}}$ 
emissions are higher for Option 1, essentially because MTBE production is responsible for higher emissions in comparison to ETBE production. Unlike with rice straw and forest residue, however, the majority of the nonmethane hydrocarbons emissions are also from biomass burning in Option 1. This is due to the very high extractives content of chaparral. As chaparral burning is eliminated in Option 2, the decrease in non-methane hydrocarbons emissions is dramatic.

\section{Energy Consumption and $\mathrm{CO}_{2}$}

The total primary energy consumption is less for Option 2 by $6 \%$, which is not statistically significant. Process energy needed is less for Option 2 by 16\%; this reduction is lower than that for either rice straw or forest residue. This is mainly due to the energy expended during chaparral collection, which is more energy intensive than either rice straw or forest residue collection. Another reason is that, due to chaparral's low sugar content, the ethanol stream fed to the distillation step is more dilute, requiring more energy per unit weight of ethanol.

The renewable contributions of the total energy are $0.2 \%$ and $80 \%$ for Options 1 and 2, respectively. The fossilderived $\mathrm{CO}_{2}$ is lower for Option 2 by $68 \%$, a large abatement of $\mathrm{CO}_{2}$ emissions. The higher values for renewable energy and $\mathrm{CO}_{2}$ mitigation are due to the excess electricity that is generated during the ethanol production stage. Compared to rice straw or forest residue, chaparral contains a relatively high amount of lignin. This leads to lower $\mathrm{SO}_{\mathrm{x}}, \mathrm{NO}_{\mathrm{x}}$, and fossil $\mathrm{CO}_{2}$ emissions because of the correspondingly high electricity offset credits. Furthermore, chaparral is also high in extractives, which are converted to biogas during wastewater treatment, and the methanerich biogas is also used as fuel. This likewise provides similar offset credits.

\section{Water Emissions}

As is the case with the other two feedstocks, considerably higher nitrates ensue from Option 2, which again are associated with the use of CSL during ethanol fermentation. However, as explained in the Impact Assessment section, the eutrophication potential is still lower for Option 2. 


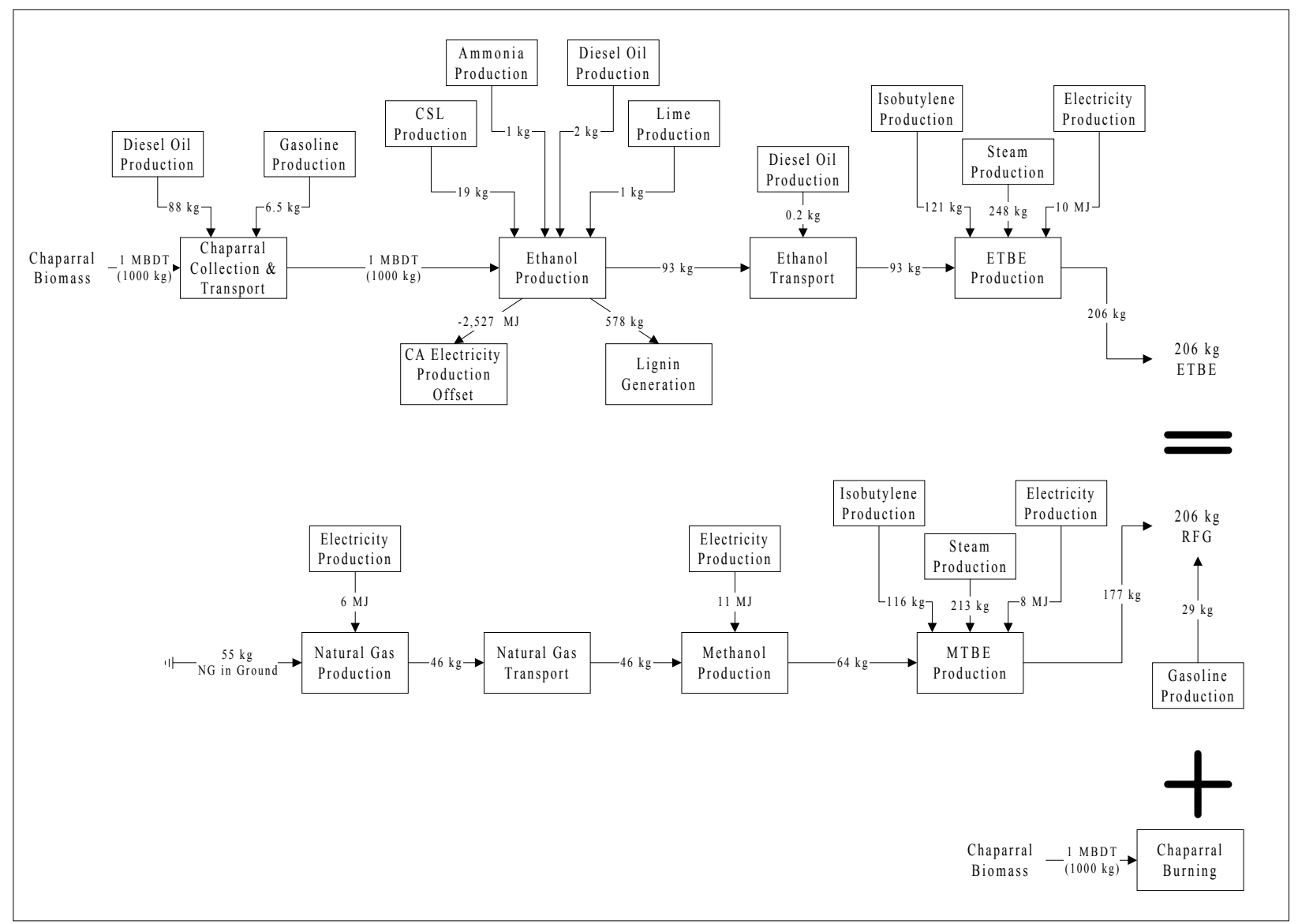

Figure 57: Mass Flow Diagram for Chaparral-Enzyme Process

\section{Graphical Representation of Key Results}

The mass flow diagram for this system is shown in Figure 57. The graphs that follow show the comparative emissions for five criteria pollutants - carbon monoxide (Figure 58), particulates (Figure 59), non-methane hydrocarbons (Figure 60), sulfur oxides (Figure 61), and nitrogen oxides (Figure 62 through Figure 64) - as well as energy consumption (Figure 65 and Figure 66). The first column represents values for Option 1, split out as values from MTBE production and biomass burning. The second column shows the flows for Option 2, ETBE production. The scales are kept the same throughout the entire results section, in order to facilitate comparison among the different biomass feedstocks and ethanol production methods. 


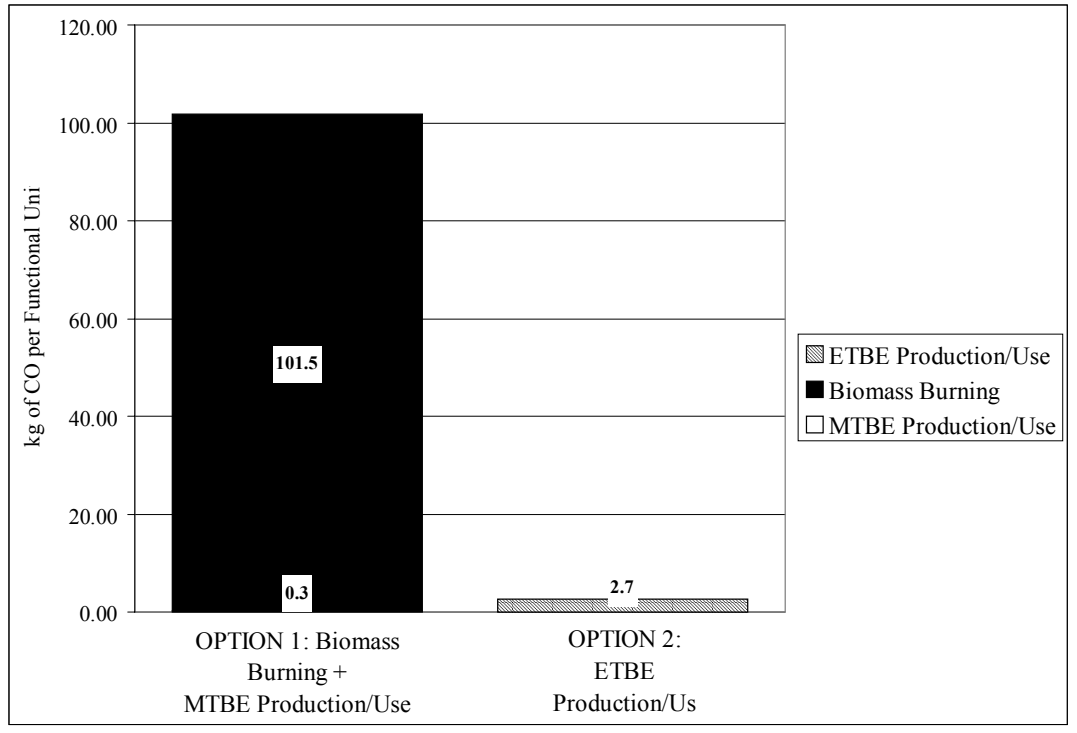

Figure 58: Chaparral (Enzyme Process) Carbon Monoxide Emissions

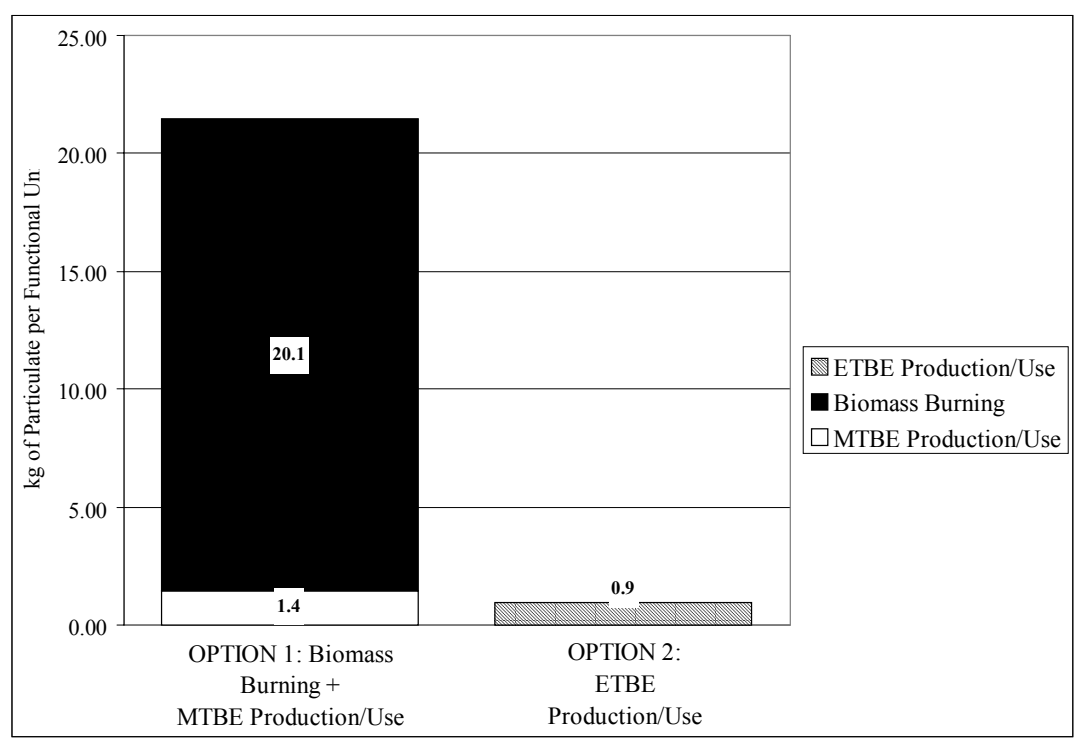

Figure 59: Chaparral (Enzyme Process) Particulate Emissions

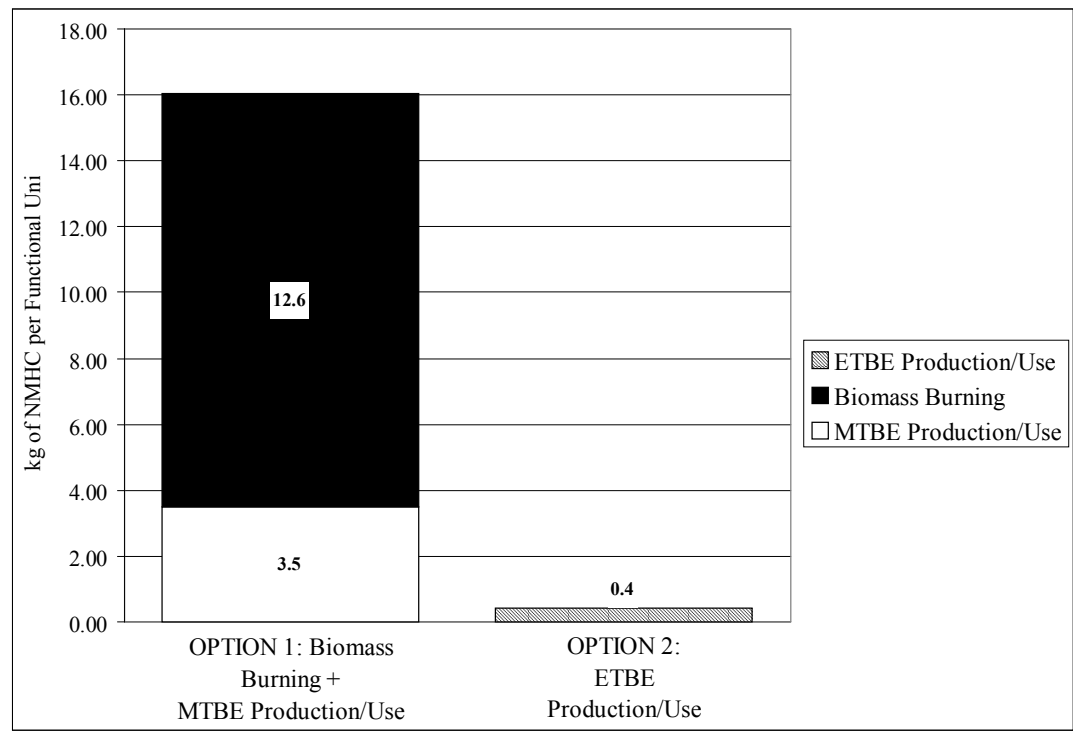

Figure 60: Chaparral (Enzyme Process) Non-methane Hydrocarbon Emissions

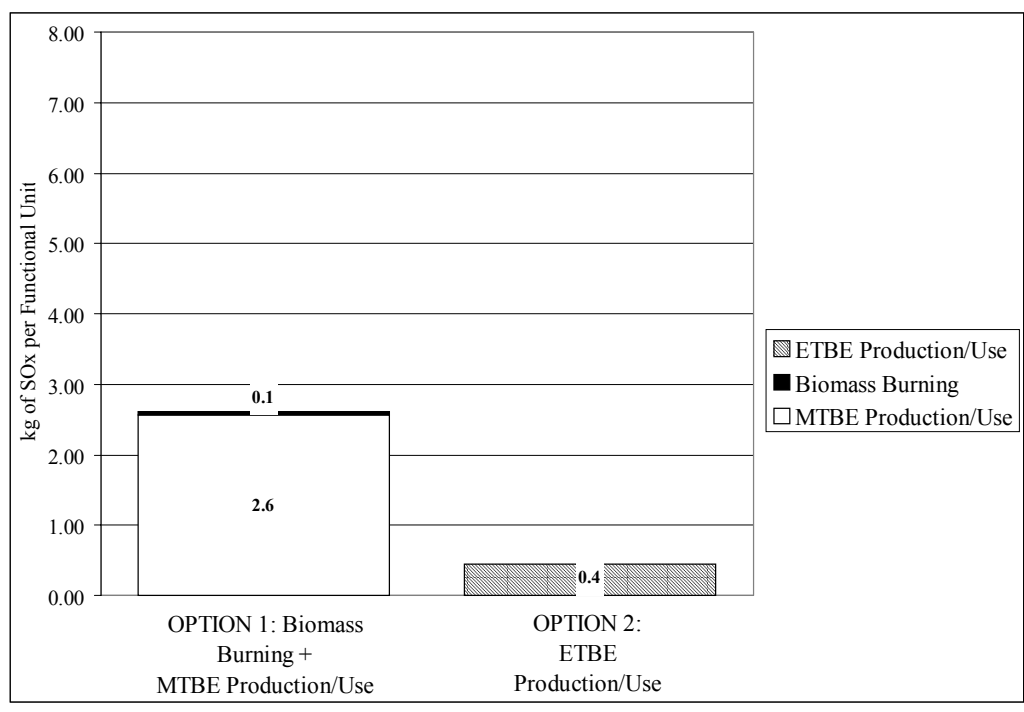

Figure 61: Chaparral (Enzyme Process) $\mathrm{SO}_{\mathrm{x}}$ Emission 


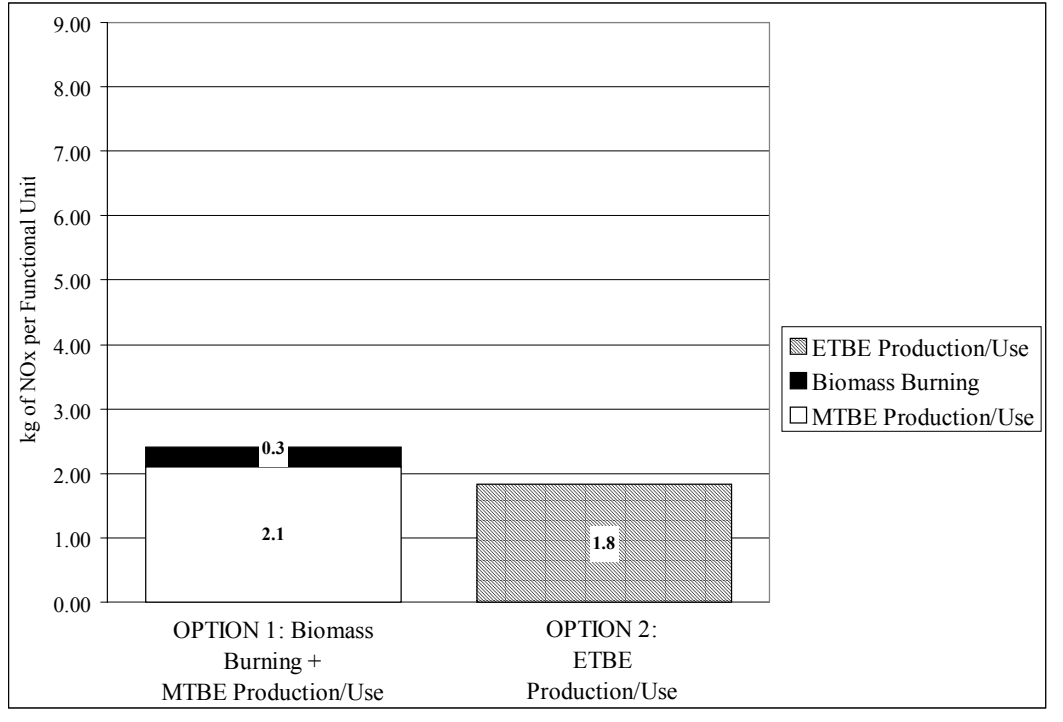

Figure 62: Chaparral (Enzyme Process) $\mathrm{NO}_{\mathrm{x}}$ Emissions

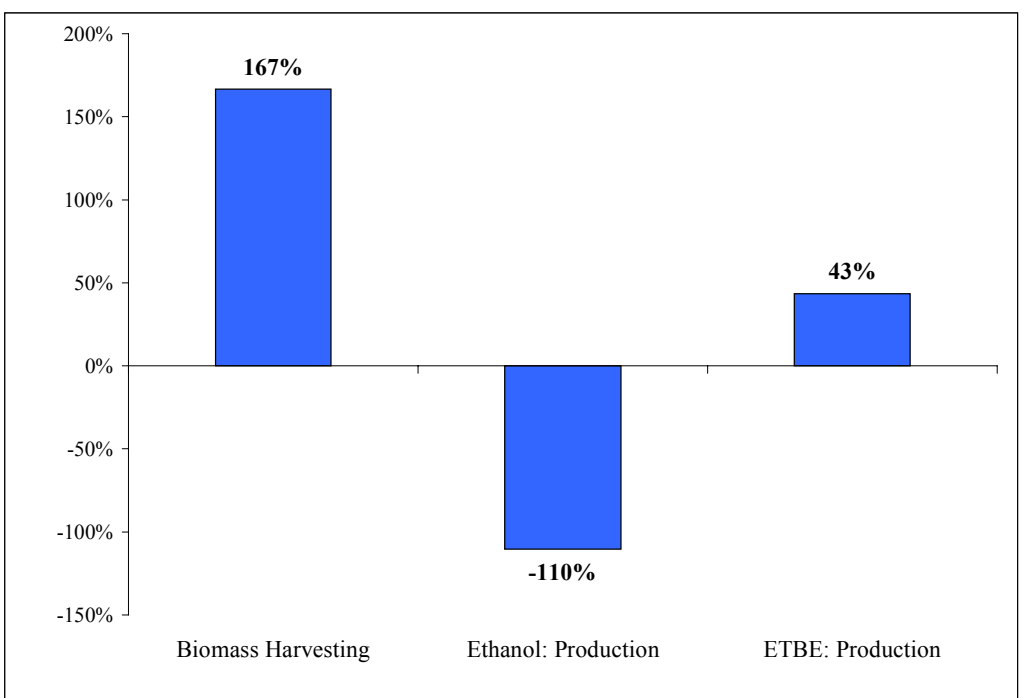

Figure 63: Chaparral (Enzyme Process) $\mathrm{NO}_{\mathrm{x}}$ Emissions for Option 2 by Source

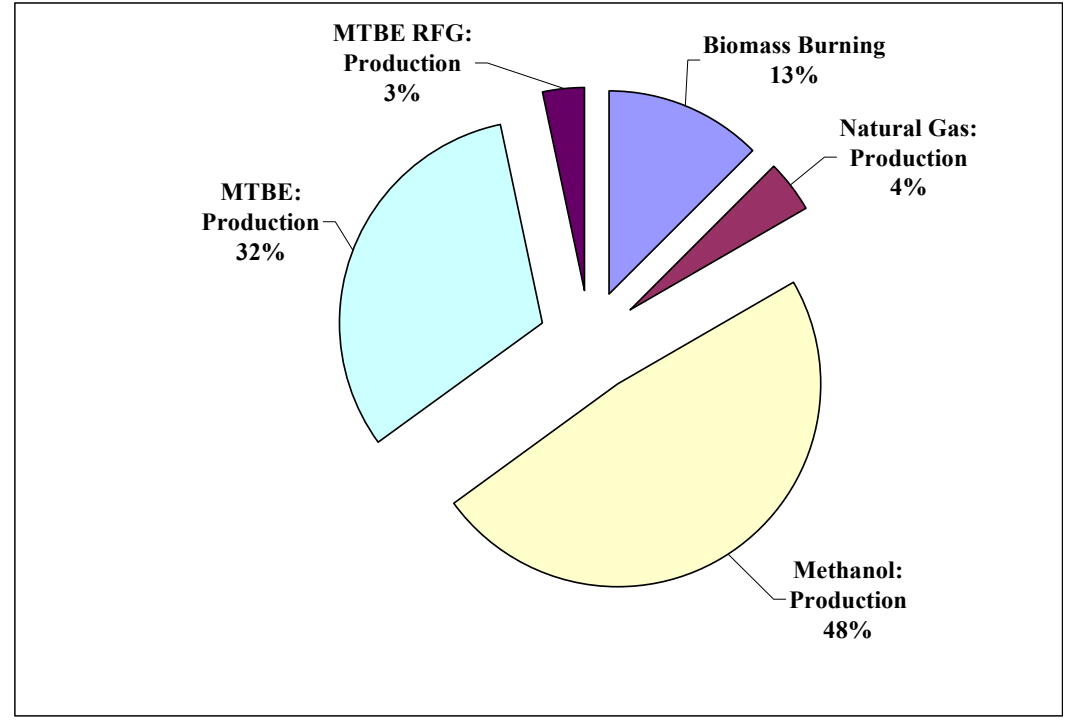

Figure 64: Chaparral (Enzyme Process) $\mathrm{NO}_{\mathrm{x}}$ Emissions for Option 1 by Source

The bar graph (Figure 63) and the pie chart (Figure 64) indicate which life cycle stages contributed to the total value for the nitrogen oxide emissions in Figure 62. The first chart (Figure 63) shows that the ethanol production stage has a negative $\mathrm{NO}_{\mathrm{x}}$ emission, where the excess lignin is burned to generate electricity. This electricity generation provides an offset of $\mathrm{NO}_{x}$ emissions from the biomass collection and etherification steps. For Option 1, the main source of $\mathrm{NO}_{\mathrm{x}}$ emissions is the production of methanol (Figure 64) 


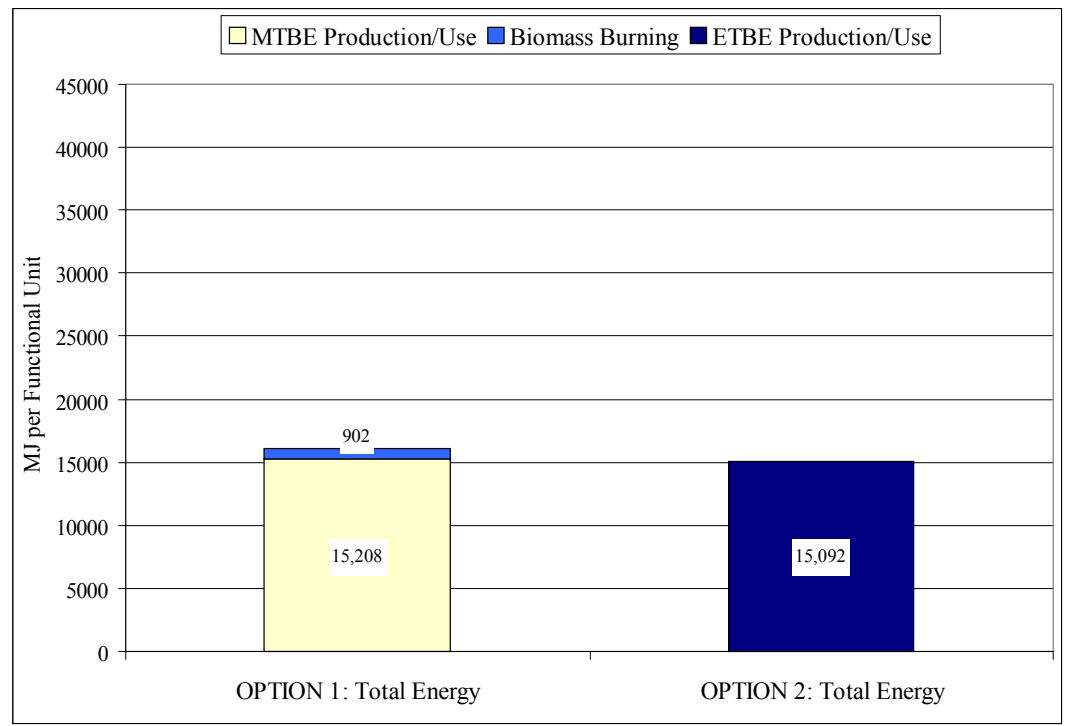

Figure 65: Chaparral (Enzyme Process) Total Energy Consumption

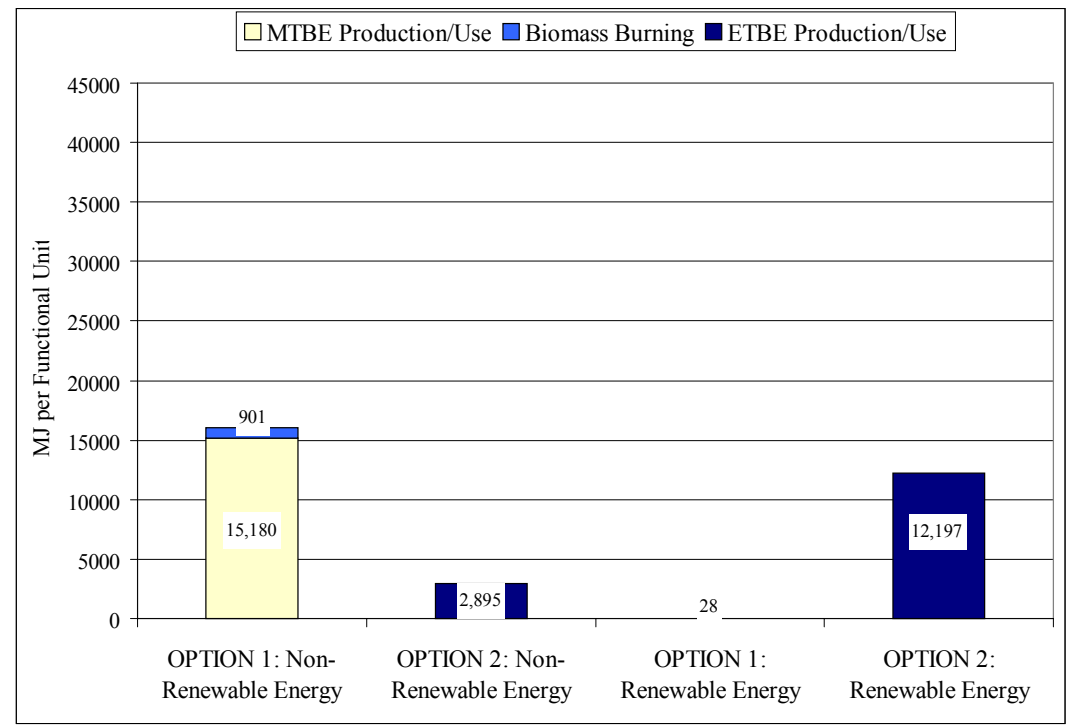

Figure 66: Chaparral (Enzyme Process) Nonrenewable and Renewable Energy Consumption 
6.4.8 Chaparral Feedstock-Concentrated Acid Process

Table 47: Results Summary for Chaparral Feedstock—Acid Process

\begin{tabular}{|c|c|c|c|c|c|}
\hline & Article & Units & $\begin{array}{c}\text { OPTION 1: MTBE } \\
\text { Production }+ \\
\text { Biomass Burning }\end{array}$ & $\begin{array}{l}\text { OPTION 2: ETBE } \\
\text { Production }\end{array}$ & $\begin{array}{l}\text { Change from } \\
\text { OPTION } 1 \text { to } \\
\text { OPTION } 2\end{array}$ \\
\hline \multirow[t]{3}{*}{ Inflows } & Coal & $\mathrm{kg}$ & 106 & 7 & $93 \%$ \\
\hline & Natural Gas & $\mathrm{kg}$ & 149 & 253 & $-70 \%$ \\
\hline & Oil & $\mathrm{kg}$ & 146 & 195 & $-34 \%$ \\
\hline \multirow[t]{12}{*}{ Outflows } & Carbon Dioxide $\left(\mathrm{CO}_{2}\right.$, biomass $)$ & $\mathrm{g}$ & $1,931,340$ & $1,814,130$ & $6 \%$ \\
\hline & Carbon Dioxide $\left(\mathrm{CO}_{2}\right.$, fossil $)$ & $\mathrm{g}$ & $1,036,259$ & $1,129,100$ & $-9 \%$ \\
\hline & Carbon Monoxide (CO) & $\mathrm{g}$ & 101,710 & 4,187 & $96 \%$ \\
\hline & Hydrocarbons (except methane) & g & 15,692 & 1,717 & $89 \%$ \\
\hline & Methane $\left(\mathrm{CH}_{4}\right)$ & g & 5,707 & 2,413 & $58 \%$ \\
\hline & Nitrogen Oxides $\left(\mathrm{NO}_{\mathrm{x}}\right)$ & $\mathrm{g}$ & 2,189 & 4,428 & $-102 \%$ \\
\hline & Nitrous Oxide $\left(\mathrm{N}_{2} \mathrm{O}\right)$ & $\mathrm{g}$ & 23 & 39 & $-67 \%$ \\
\hline & Particulates (unspecified) & g & 21,337 & 4,128 & $81 \%$ \\
\hline & Sulfur Oxides $\left(\mathrm{SO}_{\mathrm{x}}\right)$ & g & 2,349 & 979 & $58 \%$ \\
\hline & COD & g & 346 & 393 & $-14 \%$ \\
\hline & Nitrates $\left(\mathrm{NO}_{3}-\right)$ & g & 1 & 20 & $-1268 \%$ \\
\hline & Waste (total) & $\mathrm{kg}$ & 173 & 109 & $37 \%$ \\
\hline \multirow[t]{5}{*}{ Energy } & Nonrenewable Energy & MJ & 14,529 & 19,220 & $-32 \%$ \\
\hline & Renewable Energy & MJ & 26 & 12,013 & $-46655 \%$ \\
\hline & Process Energy & MJ & 7,839 & 24,168 & $-208 \%$ \\
\hline & Feedstock Energy & MJ & 6,716 & 7,065 & $-5 \%$ \\
\hline & Total Primary Energy & MJ & 14,555 & 31,233 & $-115 \%$ \\
\hline
\end{tabular}

The relative performance of Option 1 versus Option 2 with a concentrated acid process is generally similar to that with an enzyme process, and as with rice straw and forest residue, there are the principal exceptions of natural gas and energy demand (Table 47). Higher energy is expended during chaparral collection; the fuel consumption per dry ton of chaparral collected is about twice that for forest residue and about four times that for rice straw. Also, the ethanol distillation step requires more energy per unit weight of ethanol. The enzyme case has a net energy output, whereas the acid case is a net consumer of energy and does not have electricity offset credits. The chaparral-enzyme process scenario has enough offset credits to have lower $\mathrm{NO}_{x}, \mathrm{~N}_{2} \mathrm{O}$ and COD emissions (Table 46). However, for this particular chaparral-acid process scenario, $\mathrm{NO}_{x}, \mathrm{~N}_{2} \mathrm{O}$ and $\mathrm{COD}$ emissions end up higher for Option 2 compared to those for Option 1.

The use of additional natural gas in the concentrated acid process also results in higher values for depletion of natural resources and greenhouse gas potential indicators (besides $\mathrm{CO}_{2}$ generation during its combustion, higher methane use also results in correspondingly higher fugitive methane emissions during its production).

The higher energy requirements for the concentrated acid process, as compared to the enzymatic process, renders the relative performance of Option 2 with the concentrated acid process to be lower for nonrenewable energy, primary energy, fossil $\mathrm{CO}_{2}, \mathrm{SO}_{\mathrm{x}}, \mathrm{NO}_{\mathrm{x}}$, non-methane hydrocarbons, and particulate emissions. 


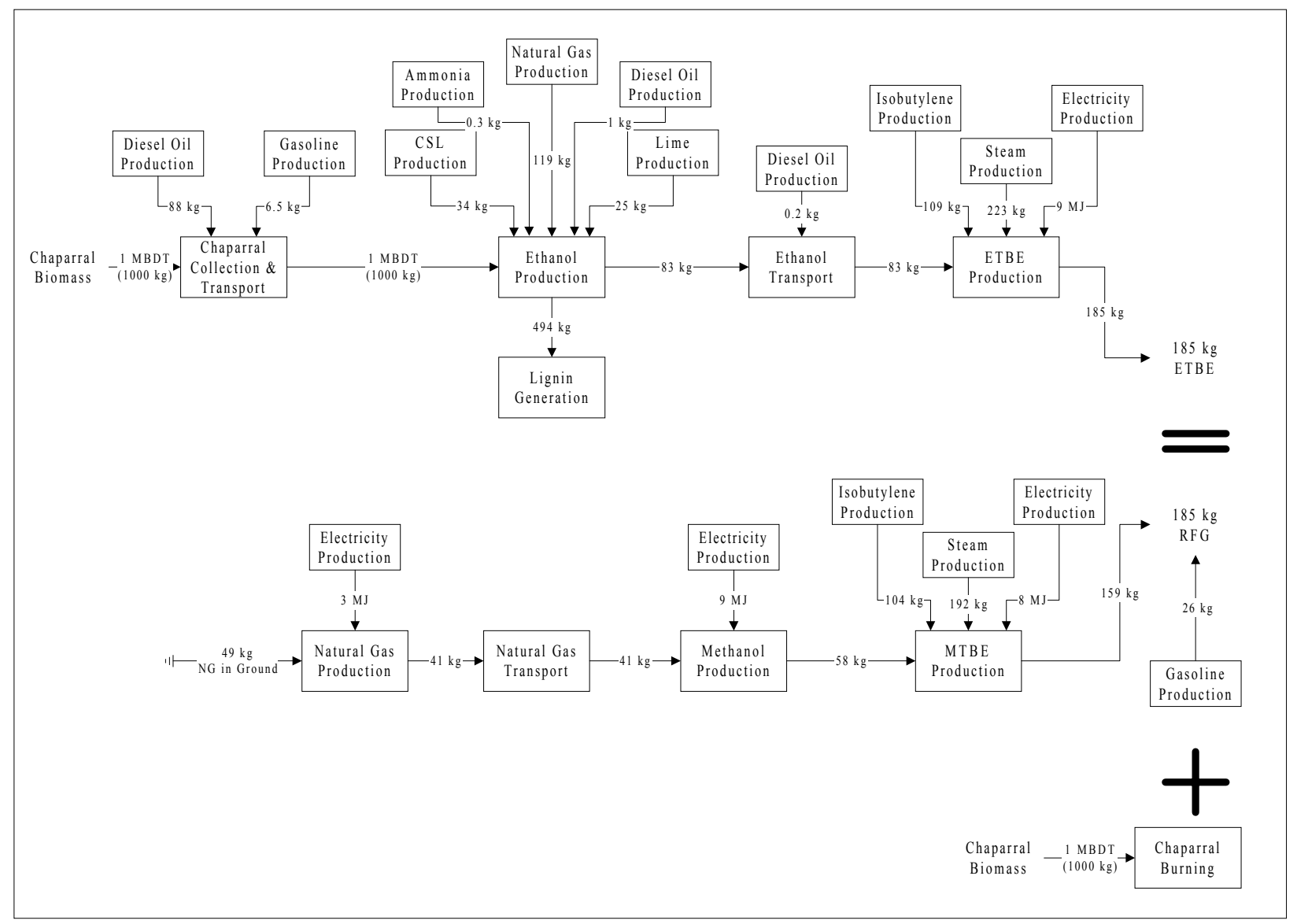

Figure 67: Mass Flow Diagram for Chaparral-Acid Process

\section{Graphical Representation of Key Results}

The mass flow diagram for this system is shown in Figure 67. The following graphs show the comparative emissions for five criteria pollutants - carbon monoxide (Figure 68), non-methane hydrocarbons (Figure 69), sulfur oxides (Figure 70), particulates (Figure 71), and nitrogen oxides (Figure 72 through Figure 74) - as well as energy consumption (Figure 75 and Figure 76). The first column represents values for Option 1, split out as values from MTBE production and biomass burning. The second column shows the flows for Option 2, ETBE production. The scales are kept the same throughout the entire results section, in order to facilitate comparison among the different biomass feedstocks and ethanol production methods. 


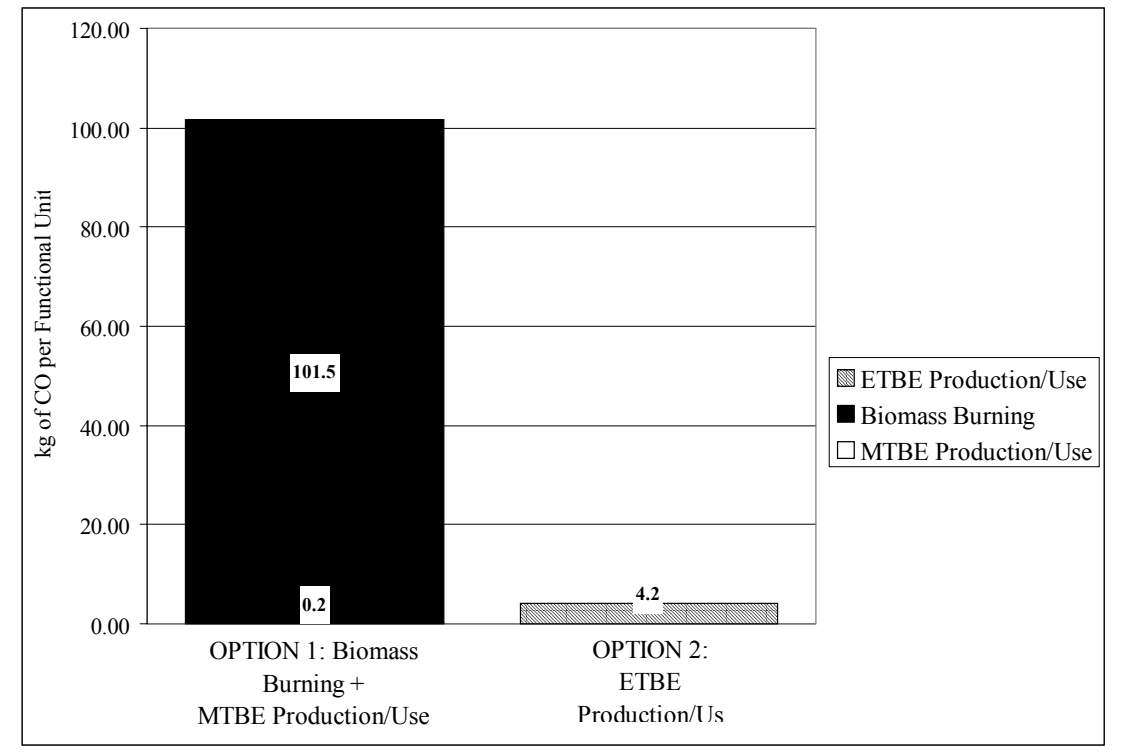

Figure 68: Chaparral (Acid Process) Carbon Monoxide Emissions

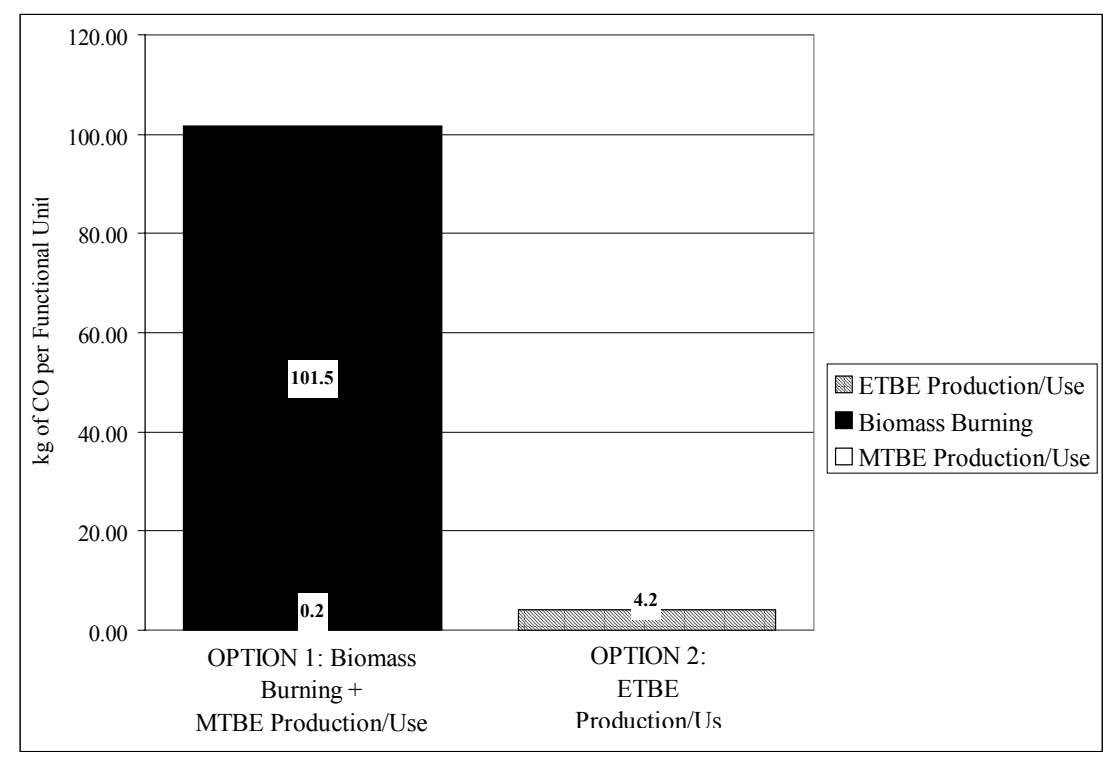

Figure 69: Chaparral (Acid Process) Non-methane Hydrocarbon Emissions

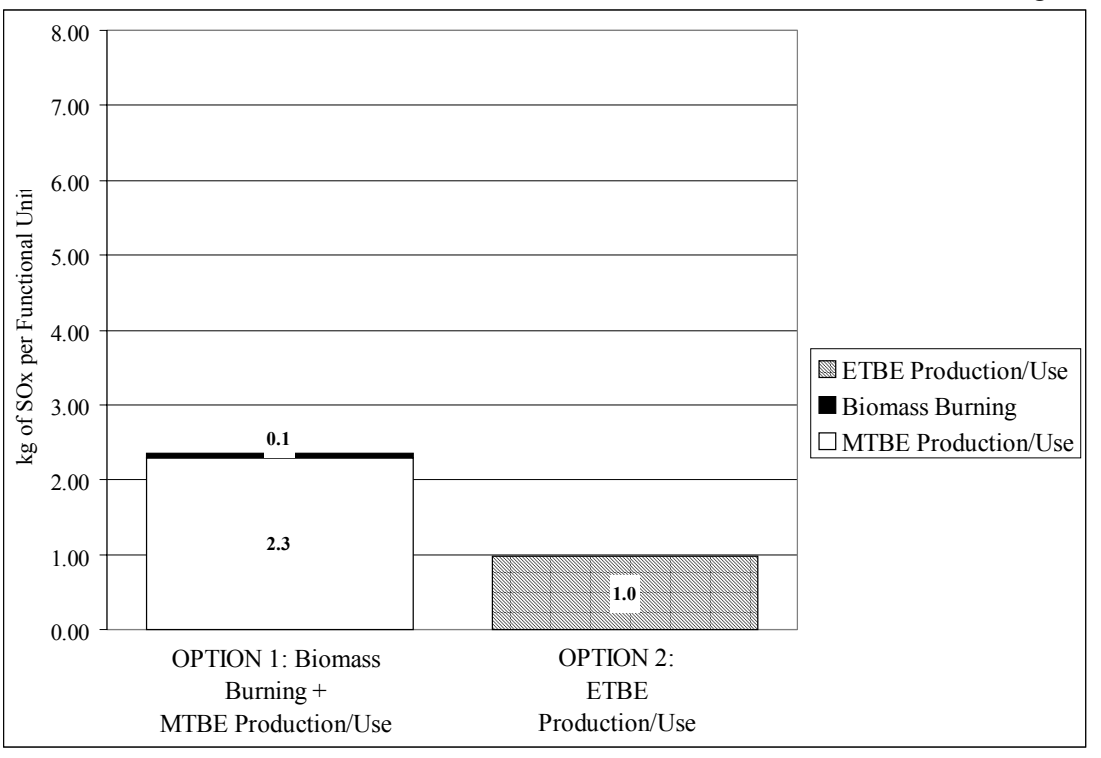

Figure 70: Chaparral (Acid Process) $\mathrm{SO}_{\mathrm{x}}$ Emissions

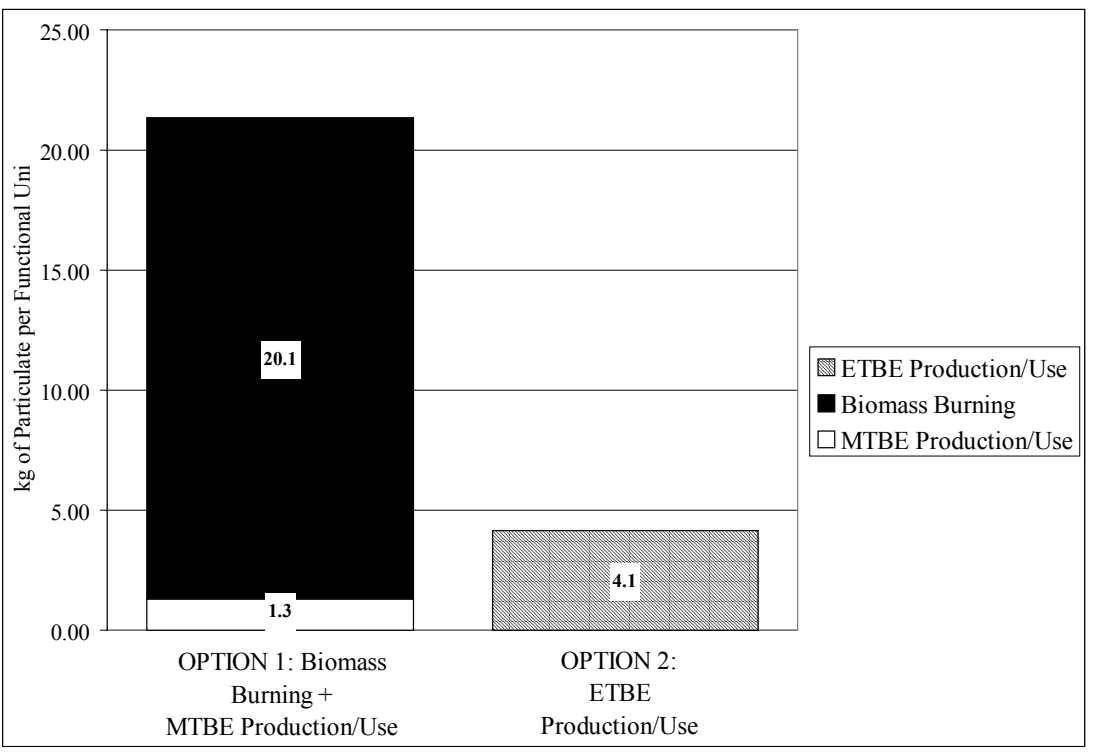

Figure 71: Chaparral (Acid Process) Particulate Emissions 


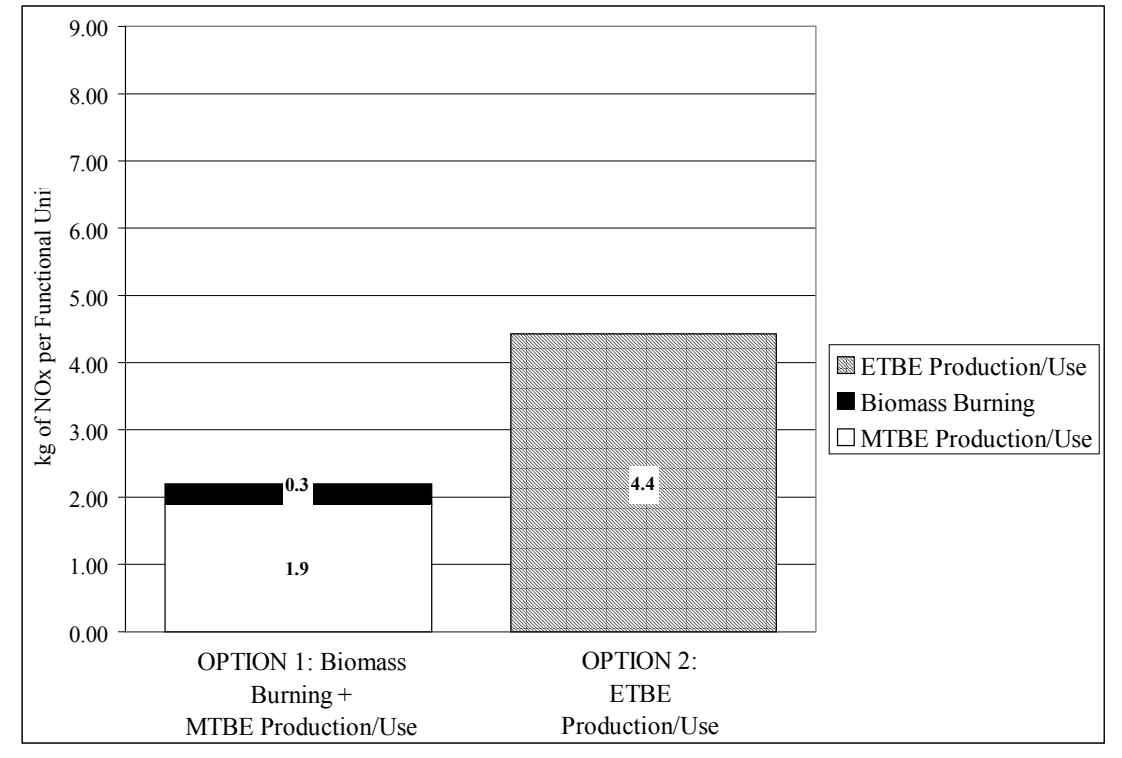

Figure 72: Chaparral (Acid Process) NO $_{x}$ Emissions

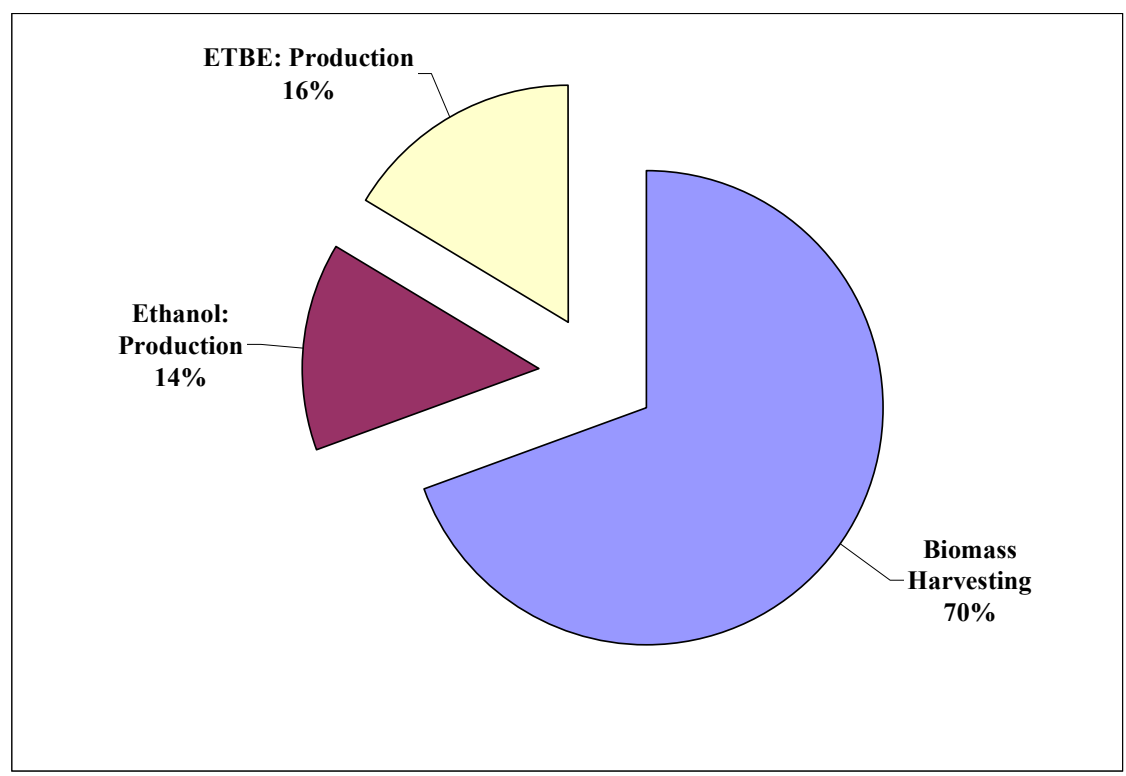

Figure 73: Chaparral (Acid Process) NO $\mathrm{N}_{\mathrm{x}}$ Emissions for Option 2 by Source

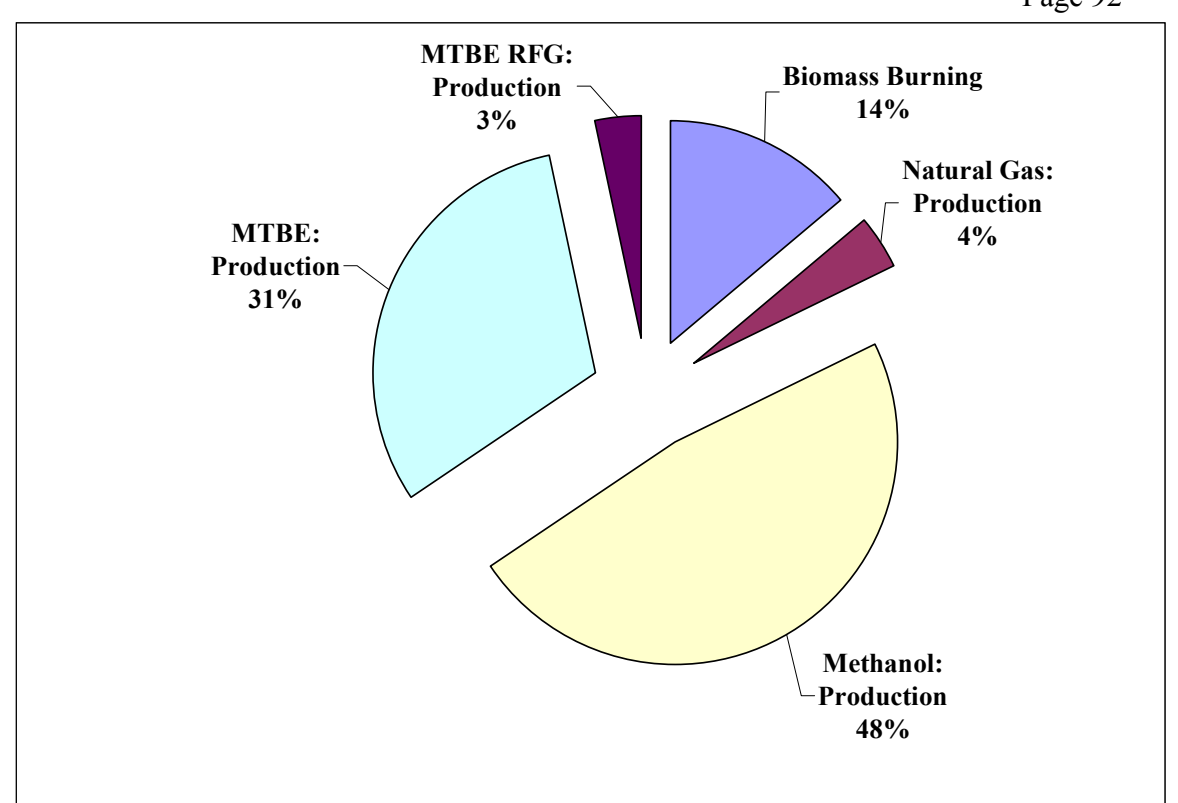

Figure 74: Chaparral (Acid Process) $\mathrm{NO}_{\mathrm{x}}$ Emissions for Option 1 by Source

The two pie charts (Figure 73, Figure 74) indicate which life cycle stages contributed to the total value for the nitrogen oxide emissions in Figure 72. Figure 73 shows that the main source of $\mathrm{NO}_{\mathrm{x}}$ emissions for Option 2 is from biomass harvesting. Harvesting for chaparral is energy intensive compared to collection of other feedstocks. For Option 1, the main source of $\mathrm{NO}_{\mathrm{x}}$ emissions is the production of methanol (Figure 74). 


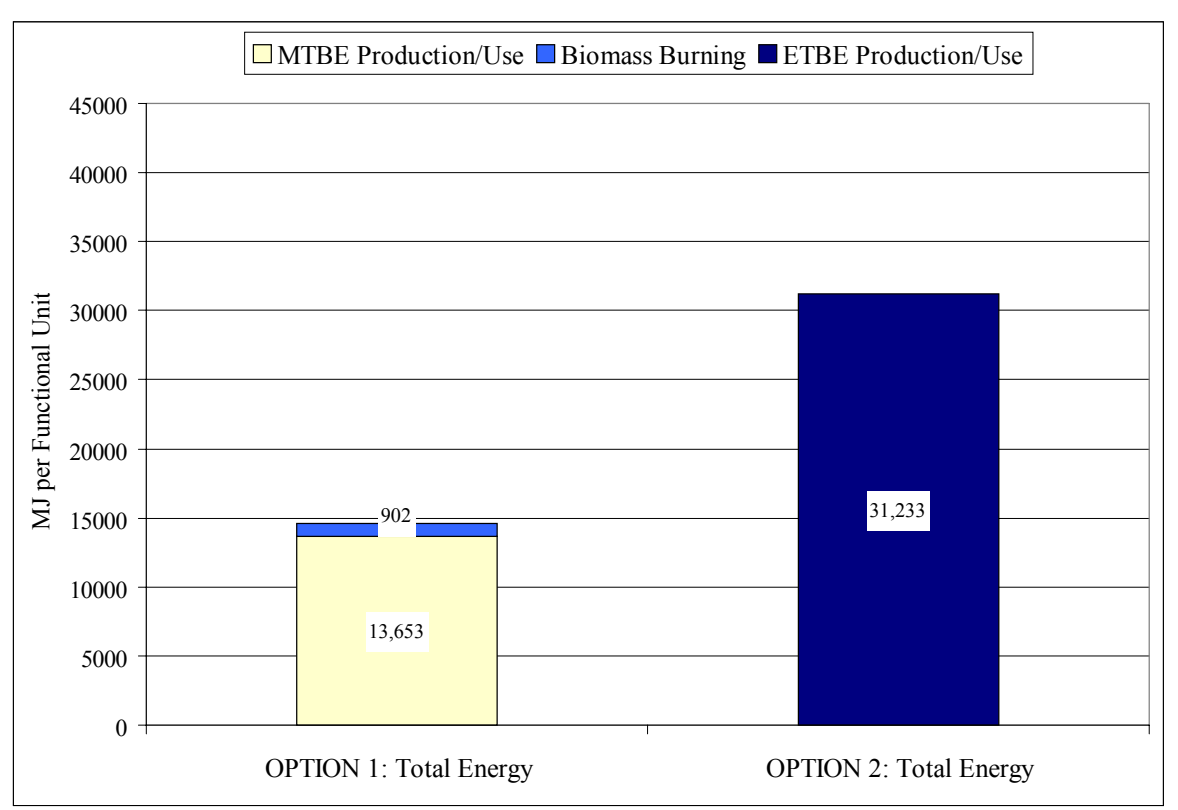

Figure 75: Chaparral (Acid Process) Total Energy Consumption

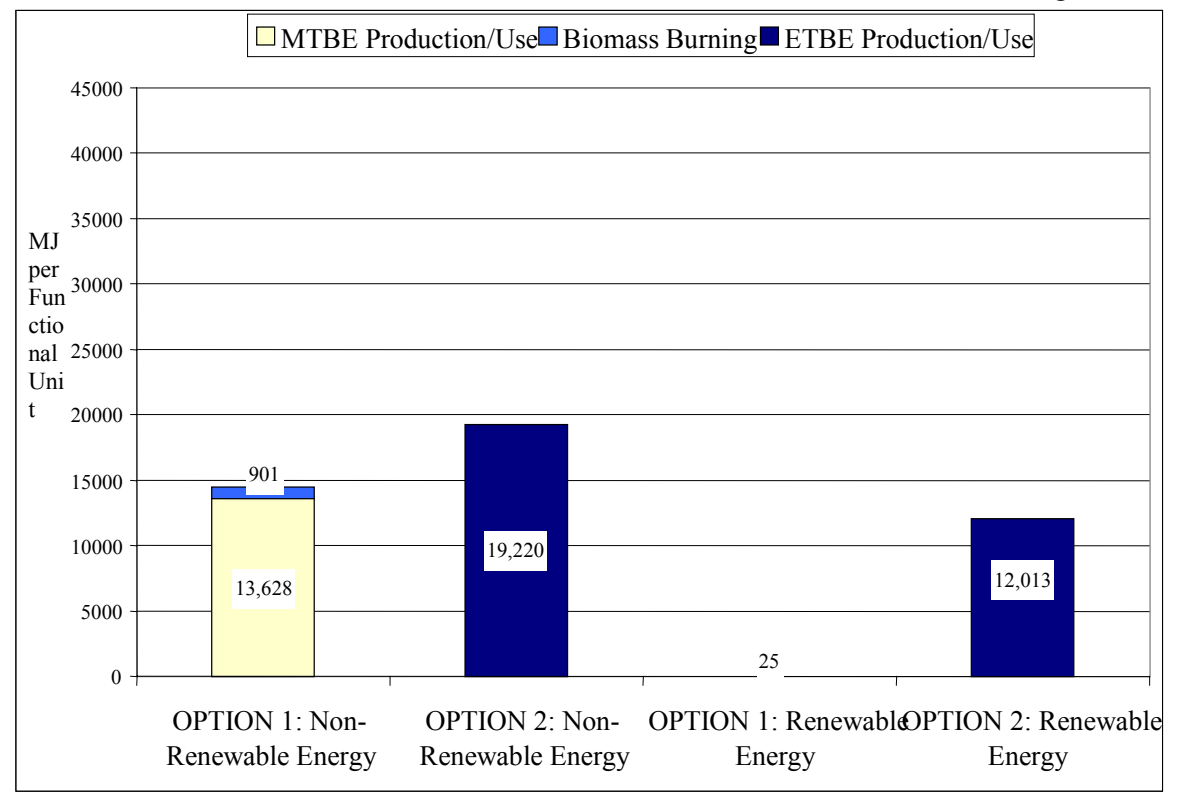

Figure 76: Chaparral (Acid Process) Nonrenewable and Renewable Energy Consumption 


\subsubsection{Chaparral Feedstock Summary}

The production of ETBE from chaparral feedstock through the enzymatic route leads to a net reduction in environmental flows over MTBE production and allowing for the burning of chaparral. However, if an acid-based ethanol process is used for chaparral, the ETBE option shows higher emissions of $\mathrm{NO}_{\mathrm{x}}, \mathrm{N}_{2} \mathrm{O}$, and fossil $\mathrm{CO}_{2}$. For both of these scenarios, the production of ethanol has greater negative impacts on water effluents (e.g., nitrates); however, the eutrophication potential is still lower for Option 2.

\subsection{COMPARISON OF BASELINE SCENARIOS}

Table 48 shows the summary of results for all of the baseline scenarios.

Table 48: Summary Data for Baseline Scenarios

\begin{tabular}{|c|c|c|c|c|c|c|c|}
\hline & \multirow[b]{3}{*}{ Flow } & \multicolumn{6}{|c|}{$\begin{array}{c}\text { Difference between Option } 2 \text { (ETBE Production) and Option } 1 \text { (Biomass } \\
\text { Burning + MTBE Production) }\end{array}$} \\
\hline & & \multicolumn{2}{|c|}{ Rice Straw } & \multicolumn{2}{|c|}{ Forest Residue } & \multicolumn{2}{|c|}{ Chaparral } \\
\hline & & Acid & Enzyme & Acid & Enzyme & Acid & Enzyme \\
\hline \multirow[t]{3}{*}{ Inflow } & Coal & $97 \%$ & $98 \%$ & $97 \%$ & $103 \%$ & $93 \%$ & $171 \%$ \\
\hline & Natural Gas & $-45 \%$ & $33 \%$ & $-17 \%$ & $48 \%$ & $-70 \%$ & $96 \%$ \\
\hline & Oil & $28 \%$ & $28 \%$ & $26 \%$ & $27 \%$ & $-34 \%$ & $-27 \%$ \\
\hline \multirow[t]{12}{*}{ Outflow } & Carbon Dioxide $\left(\mathrm{CO}_{2}\right.$, biomass $)$ & $11 \%$ & $-6 \%$ & $12 \%$ & $-2 \%$ & $6 \%$ & $1 \%$ \\
\hline & Carbon Dioxide $\left(\mathrm{CO}_{2}\right.$, fossil $)$ & $25 \%$ & $52 \%$ & $34 \%$ & $58 \%$ & $-9 \%$ & $68 \%$ \\
\hline & Carbon Monoxide (CO) & $95 \%$ & $97 \%$ & $98 \%$ & $98 \%$ & $96 \%$ & $97 \%$ \\
\hline & Hydrocarbons (except methane) & $64 \%$ & $61 \%$ & $61 \%$ & $57 \%$ & $89 \%$ & $97 \%$ \\
\hline & Methane $\left(\mathrm{CH}_{4}\right)$ & $-60 \%$ & $62 \%$ & $76 \%$ & $96 \%$ & $58 \%$ & $112 \%$ \\
\hline & Nitrogen Oxides $\left(\mathrm{NO}_{\mathrm{x}}\right.$ as $\left.\mathrm{NO}_{2}\right)$ & $57 \%$ & $69 \%$ & $54 \%$ & $69 \%$ & $-102 \%$ & $23 \%$ \\
\hline & Nitrous Oxide $\left(\mathrm{N}_{2} \mathrm{O}\right)$ & $69 \%$ & $84 \%$ & $69 \%$ & $89 \%$ & $-67 \%$ & $62 \%$ \\
\hline & Particulates (unspecified) & $44 \%$ & $89 \%$ & $68 \%$ & $93 \%$ & $81 \%$ & $96 \%$ \\
\hline & Sulfur Oxides $\left(\mathrm{SO}_{\mathrm{x}}\right.$ as $\left.\mathrm{SO}_{2}\right)$ & $81 \%$ & $84 \%$ & $79 \%$ & $87 \%$ & $58 \%$ & $83 \%$ \\
\hline & COD (Chemical Oxygen Demand) & $86 \%$ & $84 \%$ & $82 \%$ & $81 \%$ & $-14 \%$ & $-7 \%$ \\
\hline & Nitrates $\left(\mathrm{NO}_{3}^{-}\right)$ & $-466 \%$ & $-204 \%$ & $-458 \%$ & $-196 \%$ & $-1268 \%$ & $-615 \%$ \\
\hline & Waste (total) & $45 \%$ & $63 \%$ & $79 \%$ & $97 \%$ & $37 \%$ & $130 \%$ \\
\hline \multirow[t]{5}{*}{ Energy } & Nonrenewable Energy & $6 \%$ & $49 \%$ & $21 \%$ & $58 \%$ & $-32 \%$ & $82 \%$ \\
\hline & Renewable Energy & $-17688 \%$ & $-18203 \%$ & $-19967 \%$ & $-19282 \%$ & $-46655 \%$ & $-42685 \%$ \\
\hline & Process Energy & $-45 \%$ & $36 \%$ & $-24 \%$ & $50 \%$ & $-208 \%$ & $16 \%$ \\
\hline & Feedstock Energy & $-5 \%$ & $-5 \%$ & $-5 \%$ & $-5 \%$ & $-5 \%$ & $-5 \%$ \\
\hline & Total Primary Energy & $-26 \%$ & $16 \%$ & $-15 \%$ & $23 \%$ & $-115 \%$ & $6 \%$ \\
\hline
\end{tabular}

Positive values in the above table represent that Option 2 (biomass conversion to ethanol and ETBE reformulated gasoline) has lower environmental emissions compared to Option 1 (biomass burning and MTBE reformulated gasoline). Negative values indicate that Option 2 has higher emissions.

\subsection{CALifornia SPECific EMissions}

One of the key issues for the decision makers faced with two alternative disposal biomass options is the amount of emissions that are occurring within California and those occurring out of state. Currently the comparison is based on ETBE replacing MTBE that is produced within the state. This implies that all the emissions from ETBE and MTBE production occur within California. 
The only emissions occurring outside the state are associated with foreign ${ }^{29}$ crude oil extraction for producing the fuels used by both biomass disposal options, and production of the ancillary materials used for ethanol production. ${ }^{30}$ It should be noted that the nitrates emission in run-offs occurs where corn is grown, i.e., outside of California.

Section 6.9.1 outlines how the overall results would be affected if the ETBE and MTBE were produced out of state.

\subsection{CARBON BALANCE}

During the conversion of biomass into ETBE, biomass and fossil carbon flows through the system, as is illustrated in the following diagram (Figure 77). The feedstocks - rice straw, forest residue, or chaparral—photosynthetically absorb $\mathrm{CO}_{2}$, which is stored in the biomass in the form of carbon-bearing compounds. This carbon is converted to ETBE and eventually burned and returned to the atmosphere again as $\mathrm{CO}_{2}$.

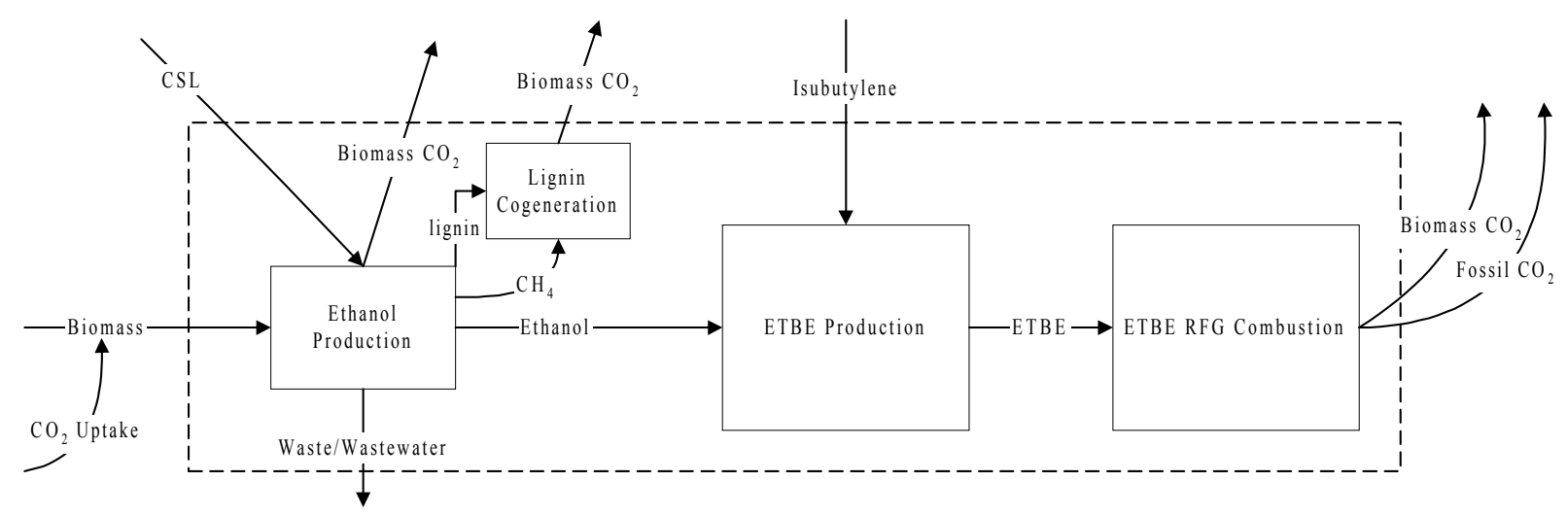

Figure 77: Overview of Carbon Balance

The box with the dashed line in Figure 77 indicates the system boundaries for the disposal Option 2. The flows that cross the system boundaries indicate carbon inflows into and outflows from the system. Overall, the outflows of carbon (biomass $\mathrm{CO}_{2}$ and carbon-containing waste) equal the net inflow of carbon (the inflow of biomass). The biomass carbon outflows for this system consist of $\mathrm{CO}_{2}$ from ethanol production (from fermentation and from the combustion of biomassderived $\left.\mathrm{CH}_{4}\right), \mathrm{CO}_{2}$ from the combustion of excess lignin during cogeneration, carbon-containing solid waste from ethanol production, and $\mathrm{CO}_{2}$ from the combustion of the biomass-derived portion of ETBE. Fossil $\mathrm{CO}_{2}$ values come from the combustion of the isobutylene-derived portion of ETBE. Although external methane is also needed for some of the scenarios during ethanol/ETBE production, it is considered as energy input and, hence, is not included in the carbon balance.

The following tables (Table 49 through Table 54) indicate the contribution of each of these inflows and outflows for the system shown above. The flows are given in terms of an inflow of 1 metric ton of biomass. The possible sources of errors in this exercise are: compositional analyses of biomass and lignin, assumptions regarding the fate of various carbon-bearing compounds in modeling the ETBE process, and common experimental/analytical inaccuracies and variabilities. Given these uncertainties, the carbon balance closure is generally reasonable, i.e., within $\pm 5 \%$.

29 Foreign refers to both overseas and domestic extraction that is occurring in other states.

30 Actually the production of ancillary materials could occur within California as well. 
Table 49: Carbon Balance for Rice Straw Feedstock-Enzyme Process

\begin{tabular}{|c|c|c|c|c|}
\hline & Mass (kg) & $\begin{array}{l}\text { Carbon } \\
\text { Content }\end{array}$ & $\begin{array}{c}\text { Total Carbon } \\
(\mathrm{kg})\end{array}$ & $\begin{array}{c}\text { Contribution to } \\
\text { Inflow/Outflow } \\
(\%)\end{array}$ \\
\hline \multicolumn{5}{|l|}{ Inflow } \\
\hline Biomass & $1,000.0$ & 0.4187 & 418.7 & $59.9 \%$ \\
\hline$C S L$ & 8.8 & 0.4500 & 4.0 & $0.6 \%$ \\
\hline Isobutylene & 323.0 & 0.8571 & 276.9 & $39.6 \%$ \\
\hline \multicolumn{5}{|l|}{ Outflow } \\
\hline $\mathrm{CO}_{2}$ from Ethanol & 237.2 & 0.2727 & 64.7 & $8.7 \%$ \\
\hline $\mathrm{CO}_{2}$ from Cellulase & 22.8 & 0.2727 & 6.2 & $0.8 \%$ \\
\hline Fuel Residue & 453.2 & 0.3807 & 172.5 & $23.2 \%$ \\
\hline $\mathrm{CO}_{2}$ from ETBE & $1,569.5$ & 0.2727 & 428.0 & $57.6 \%$ \\
\hline Methane & 26.0 & 0.7500 & 19.5 & $2.6 \%$ \\
\hline $\mathrm{CO}_{2}$ from Biogas & 26.0 & 0.2727 & 7.1 & $1.0 \%$ \\
\hline Waste water (solids) & 3.4 & 0.4000 & 1.3 & $0.2 \%$ \\
\hline Gypsum stream (soluble) & 10.8 & 0.4850 & 5.2 & $0.7 \%$ \\
\hline Aerobic treatment $\mathrm{CO}_{2}$ & 142.5 & 0.2727 & 38.9 & $5.2 \%$ \\
\hline
\end{tabular}

Table 50: Carbon Balance for Forest Residue Feedstock-Enzyme Process

\begin{tabular}{|c|c|c|c|c|}
\hline & Mass $(\mathrm{kg})$ & $\begin{array}{l}\text { Carbon } \\
\text { Content }\end{array}$ & $\begin{array}{c}\text { Total Carbon } \\
(\mathrm{kg})\end{array}$ & $\begin{array}{c}\text { Contribution to } \\
\text { Inflow/Outflow } \\
(\%)\end{array}$ \\
\hline \multicolumn{5}{|l|}{ Inflow } \\
\hline Biomass & $1,000.0$ & 0.5201 & 520.1 & $62.8 \%$ \\
\hline$C S L$ & 9.5 & 0.4500 & 4.3 & $0.5 \%$ \\
\hline Isobutylene & 354.0 & 0.8571 & 303.4 & $36.7 \%$ \\
\hline \multicolumn{5}{|l|}{ Outflow } \\
\hline $\mathrm{CO}_{2}$ from Ethanol & 260.4 & 0.2727 & 71.0 & $8.7 \%$ \\
\hline $\mathrm{CO}_{2}$ from Cellulase & 33.7 & 0.2727 & 9.2 & $1.1 \%$ \\
\hline Fuel Residue & 435.3 & 0.5951 & 259.0 & $31.7 \%$ \\
\hline $\mathrm{CO}_{2}$ from $\mathrm{ETBE}$ & $1,560.7$ & 0.2727 & 425.6 & $52.0 \%$ \\
\hline Methane & 19.4 & 0.7500 & 14.6 & $1.8 \%$ \\
\hline $\mathrm{CO}_{2}$ from Biogas & 19.4 & 0.2727 & 5.3 & $0.6 \%$ \\
\hline Waste water (solids) & 5.6 & 0.4000 & 2.3 & $0.3 \%$ \\
\hline Gypsum stream (soluble) & 13.8 & 0.4810 & 6.7 & $0.8 \%$ \\
\hline Aerobic treatment $\mathrm{CO}_{2}$ & 89.1 & 0.2727 & 24.3 & $3.0 \%$ \\
\hline
\end{tabular}


Table 51: Carbon Balance for Chaparral Feedstock-Enzyme Process

\begin{tabular}{|c|c|c|c|c|}
\hline & Mass (kg) & $\begin{array}{l}\text { Carbon } \\
\text { Content }\end{array}$ & $\begin{array}{c}\text { Total Carbon } \\
(\mathrm{kg})\end{array}$ & $\begin{array}{c}\text { Contribution to } \\
\text { Inflow/Outflow } \\
(\%)\end{array}$ \\
\hline \multicolumn{5}{|l|}{ Inflow } \\
\hline Biomass & $1,000.0$ & 0.5320 & 532.0 & $83.2 \%$ \\
\hline$C S L$ & 8.8 & 0.4500 & 4.0 & $0.6 \%$ \\
\hline Isobutylene & 121.0 & 0.8571 & 103.7 & $16.2 \%$ \\
\hline \multicolumn{5}{|l|}{ Outflow } \\
\hline $\mathrm{CO}_{2}$ from Ethanol & 88.9 & 0.2727 & 24.2 & $4.0 \%$ \\
\hline $\mathrm{CO}_{2}$ from Cellulase & 8.9 & 0.2727 & 2.4 & $0.4 \%$ \\
\hline Fuel Residue & 577.7 & 0.5882 & 339.8 & $53.9 \%$ \\
\hline $\mathrm{CO}_{2}$ from ETBE & 533.2 & 0.2727 & 145.4 & $23.1 \%$ \\
\hline Methane & 62.7 & 0.7500 & 47.0 & $7.7 \%$ \\
\hline $\mathrm{CO}_{2}$ from Biogas & 62.7 & 0.2727 & 17.1 & $2.8 \%$ \\
\hline Waste water (solids) & 4.7 & 0.4000 & 1.9 & $0.3 \%$ \\
\hline Gypsum stream (soluble) & 14.5 & 0.6370 & 9.2 & $1.5 \%$ \\
\hline Aerobic treatment $\mathrm{CO}_{2}$ & 157.1 & 0.2727 & 42.8 & $6.8 \%$ \\
\hline \multicolumn{5}{|c|}{ Inflow Carbon Accounted For: 99\% } \\
\hline
\end{tabular}

Table 52: Carbon Balance for Rice Straw Feedstock-Acid Process

\begin{tabular}{|c|c|c|c|c|}
\hline & Mass (kg) & $\begin{array}{l}\text { Carbon } \\
\text { Content }\end{array}$ & $\begin{array}{c}\text { Total Carbon } \\
(\mathrm{kg})\end{array}$ & $\begin{array}{c}\text { Contribution to } \\
\text { Inflow/Outflow } \\
(\%)\end{array}$ \\
\hline \multicolumn{5}{|l|}{ Inflow } \\
\hline Biomass & $1,000.0$ & 0.4187 & 418.7 & $61.9 \%$ \\
\hline$C S L$ & 19.1 & 0.4500 & 8.6 & $1.3 \%$ \\
\hline Isobutylene & 291.0 & 0.8571 & 249.4 & $36.9 \%$ \\
\hline \multicolumn{5}{|l|}{ Outflow } \\
\hline $\mathrm{CO}_{2}$ from Ethanol & 213.8 & 0.2727 & 58.3 & $9.1 \%$ \\
\hline $\mathrm{CO}_{2}$ from Cellulase & 0.0 & 0.2727 & 0.0 & $0.0 \%$ \\
\hline Fuel Residue & 383.0 & 0.3457 & 132.4 & $20.6 \%$ \\
\hline $\mathrm{CO}_{2}$ from $\mathrm{ETBE}$ & $1,283.8$ & 0.2727 & 350.1 & $54.5 \%$ \\
\hline Methane & 32.9 & 0.7500 & 24.6 & $3.8 \%$ \\
\hline $\mathrm{CO}_{2}$ from Biogas & 32.9 & 0.2727 & 9.0 & $1.4 \%$ \\
\hline Waste water (solids) & 32.4 & 0.4000 & 13.0 & $2.0 \%$ \\
\hline Gypsum stream (soluble) & 27.8 & 0.4550 & 12.6 & $2.0 \%$ \\
\hline Acid stream (sugars etc.) & 33.5 & 0.4003 & 13.5 & $2.1 \%$ \\
\hline Aerobic treatment $\mathrm{CO}_{2}$ & 104.9 & 0.2727 & 28.6 & $4.5 \%$ \\
\hline \multicolumn{5}{|c|}{ Inflow Carbon Accounted For: 95\% } \\
\hline
\end{tabular}


Table 53: Carbon Balance for Forest Residue Feedstock-Acid Process

\begin{tabular}{|c|c|c|c|c|}
\hline & Mass (kg) & $\begin{array}{l}\text { Carbon } \\
\text { Content }\end{array}$ & $\begin{array}{c}\text { Total Carbon } \\
(\mathrm{kg})\end{array}$ & $\begin{array}{c}\text { Contribution to } \\
\text { Inflow/Outflow } \\
(\%)\end{array}$ \\
\hline \multicolumn{5}{|l|}{ Inflow } \\
\hline Biomass & $1,000.0$ & 0.5201 & 520.1 & $67.1 \%$ \\
\hline CSL & 17.1 & 0.4500 & 7.7 & $1.0 \%$ \\
\hline Isobutylene & 289.0 & 0.8571 & 247.7 & $31.9 \%$ \\
\hline \multicolumn{5}{|l|}{ Outflow } \\
\hline $\mathrm{CO}_{2}$ from Ethanol & 212.5 & 0.2727 & 58.0 & $7.9 \%$ \\
\hline $\mathrm{CO}_{2}$ from Cellulase & 0.0 & 0.2727 & 0.0 & $0.0 \%$ \\
\hline Fuel Residue & 344.8 & 0.6080 & 209.7 & $28.6 \%$ \\
\hline $\mathrm{CO}_{2}$ from ETBE & $1,283.8$ & 0.2727 & 350.1 & $47.7 \%$ \\
\hline Methane & 37.9 & 0.7500 & 28.4 & $3.9 \%$ \\
\hline $\mathrm{CO}_{2}$ from Biogas & 37.9 & 0.2727 & 10.3 & $1.4 \%$ \\
\hline Waste water (solids) & 43.9 & 0.4000 & 17.6 & $2.4 \%$ \\
\hline Gypsum stream (soluble) & 32.8 & 0.4830 & 15.9 & $2.2 \%$ \\
\hline Acid stream (sugars etc.) & 35.5 & 0.4003 & 14.2 & $1.9 \%$ \\
\hline Aerobic treatment $\mathrm{CO}_{2}$ & 110.3 & 0.2727 & 30.1 & $4.1 \%$ \\
\hline \multicolumn{5}{|c|}{ Inflow Carbon Accounted For: 95\% } \\
\hline
\end{tabular}

Table 54: Carbon Balance for Chaparral Feedstock-Acid Process

\begin{tabular}{lcccc}
\hline & Mass (kg) & $\begin{array}{c}\text { Carbon } \\
\text { Content }\end{array}$ & $\begin{array}{c}\text { Total Carbon } \\
(\mathrm{kg})\end{array}$ & $\begin{array}{c}\text { Contribution to } \\
\text { Inflow/Outflow } \\
(\%)\end{array}$ \\
\hline \hline Inflow & & & & \\
Biomass & $1,000.0$ & 0.5320 & 532.0 & $84.0 \%$ \\
CSL & 17.9 & 0.4500 & 8.1 & $1.3 \%$ \\
Isobutylene & 109.0 & 0.8571 & 93.4 & $14.7 \%$ \\
\hline Outflow & & & & \\
$\mathrm{CO}_{2}$ from Ethanol & 79.8 & 0.2727 & 21.8 & $3.5 \%$ \\
$\mathrm{CO}_{2}$ from Cellulase & 0.0 & 0.2727 & 0.0 & $0.0 \%$ \\
Fuel Residue & 494.3 & 0.6178 & 305.4 & $49.8 \%$ \\
CO $_{2}$ from ETBE & 478.8 & 0.2727 & 130.6 & $21.3 \%$ \\
Methane $_{\text {CO }}$ from Biogas & 73.1 & 0.7500 & 54.8 & $8.9 \%$ \\
Waste water (solids) & 73.1 & 0.2727 & 19.9 & $3.2 \%$ \\
Gypsum stream (soluble) & 6.5 & 0.4000 & 2.6 & $0.4 \%$ \\
Acid stream (sugars etc.) & 28.5 & 0.6240 & 17.8 & $2.9 \%$ \\
Aerobic treatment CO ${ }_{2}$ & 28.6 & 0.4003 & 11.5 & $1.9 \%$ \\
& 180.9 & 0.2727 & 49.3 & $8.0 \%$ \\
& & & & \\
\hline
\end{tabular}




\subsection{IMPACT ASSESSMENT AND BIOMASS DISPOSAL OPTIONS}

In addition to the environmental flows that were analyzed for these six scenarios, impact indicator values were also calculated. These values give a sense of the potential impacts of some of the emissions from these scenarios. The four indices that were calculated are the greenhouse potential, acidification potential, eutrophication potential, and natural resources depletion. The method of calculation for each of these indicators is explained in more detail in Appendix B. It should be emphasized that only fossil $\mathrm{CO}_{2}$ was taken into account in calculating greenhouse potential.

These environmental impact indicators are used to give a broader insight into the environmental impacts of these six scenarios, by examining the potential impacts beyond the initial release. The following table (Table 55) gives the overall values for these impact indicators. The meaning of these values is addressed in the discussion following Table 55. The one thing that is evident from this table is that for most of the indicators, Burning + MTBE production (Option 1) is worse than ETBE production (Option 2) using either of the ethanol production methods.

Table 55: Impact Assessment Summary

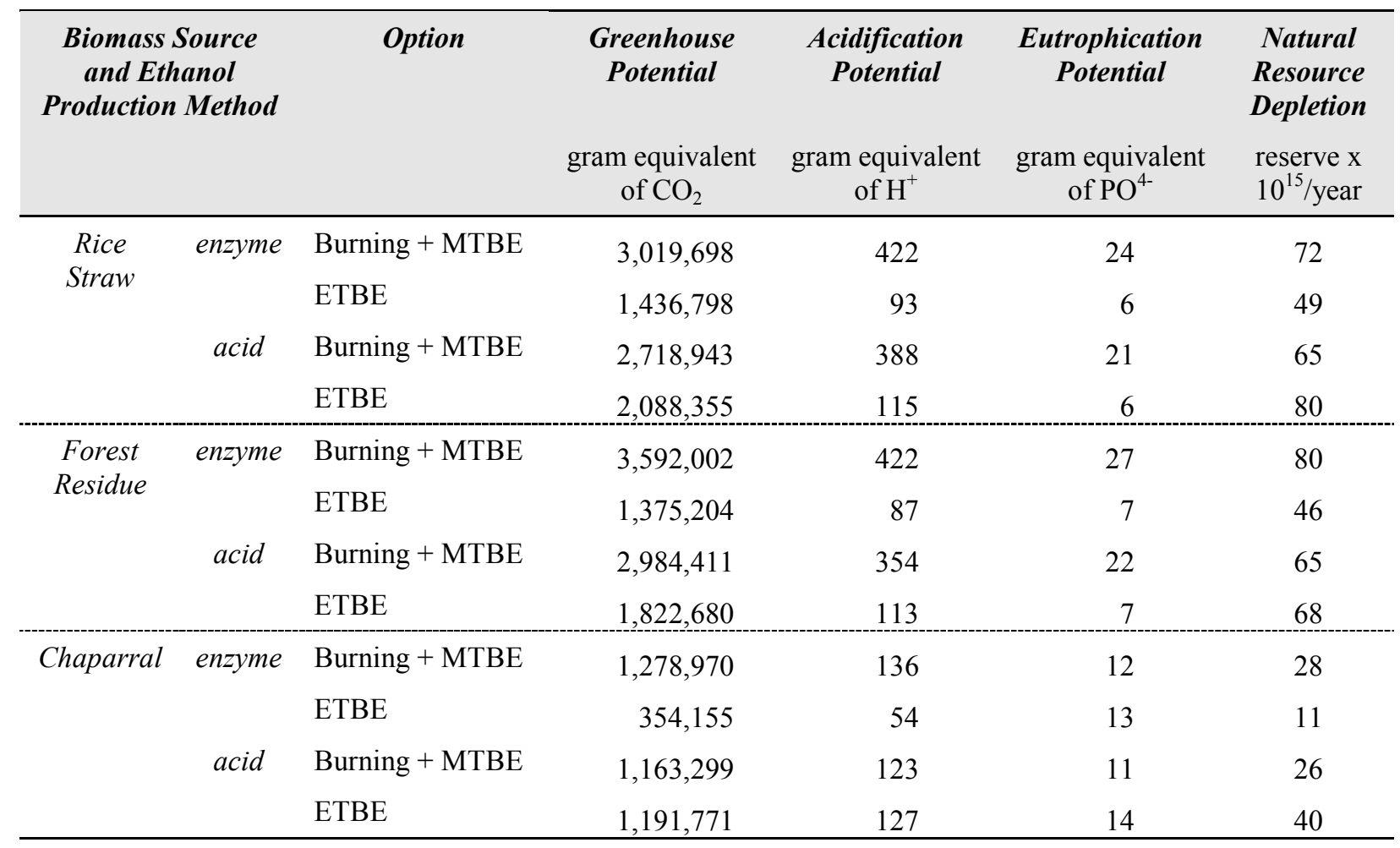

The following figures illustrate the differences among the different feedstock and ethanol production methods. The darker colored bars indicate the values for Burning + MTBE (Option 1), and the lighter colored bars indicate the ETBE Production (Option 2) values for both the enzyme and concentrated acid processes. The values for the two options for a particular biomass type and ethanol production method can be compared, simply by comparing the height of the lighter colored bar with that of the darker colored bar to its left.

\subsubsection{Greenhouse Potential}

The greenhouse potential values for Option 1 (Burning + MTBE) are predominantly larger than the values for Option 2 (Figure 78). The reason behind this is that there are more emissions from the combustion of the MTBE reformulated gasoline than from the combustion of the ETBE. This comes from the extra gasoline that is consumed in the MTBE reformulated gasoline.

The main driver for the greenhouse potential values for Option 2 comes from the combustion of the ETBE in the reformulated gasoline, which generates fossil $\mathrm{CO}_{2}$ corresponding to the amount of isobutylene in ETBE. The impact indicator value is also driven somewhat by the production of ETBE and the emissions from ethanol production. The 
difference between the two methods of producing ethanol (enzyme and acid) is due to the higher fossil energy requirements for the concentrated acid process (i.e. more energy use leads to higher $\mathrm{CO}_{2}$ emissions).

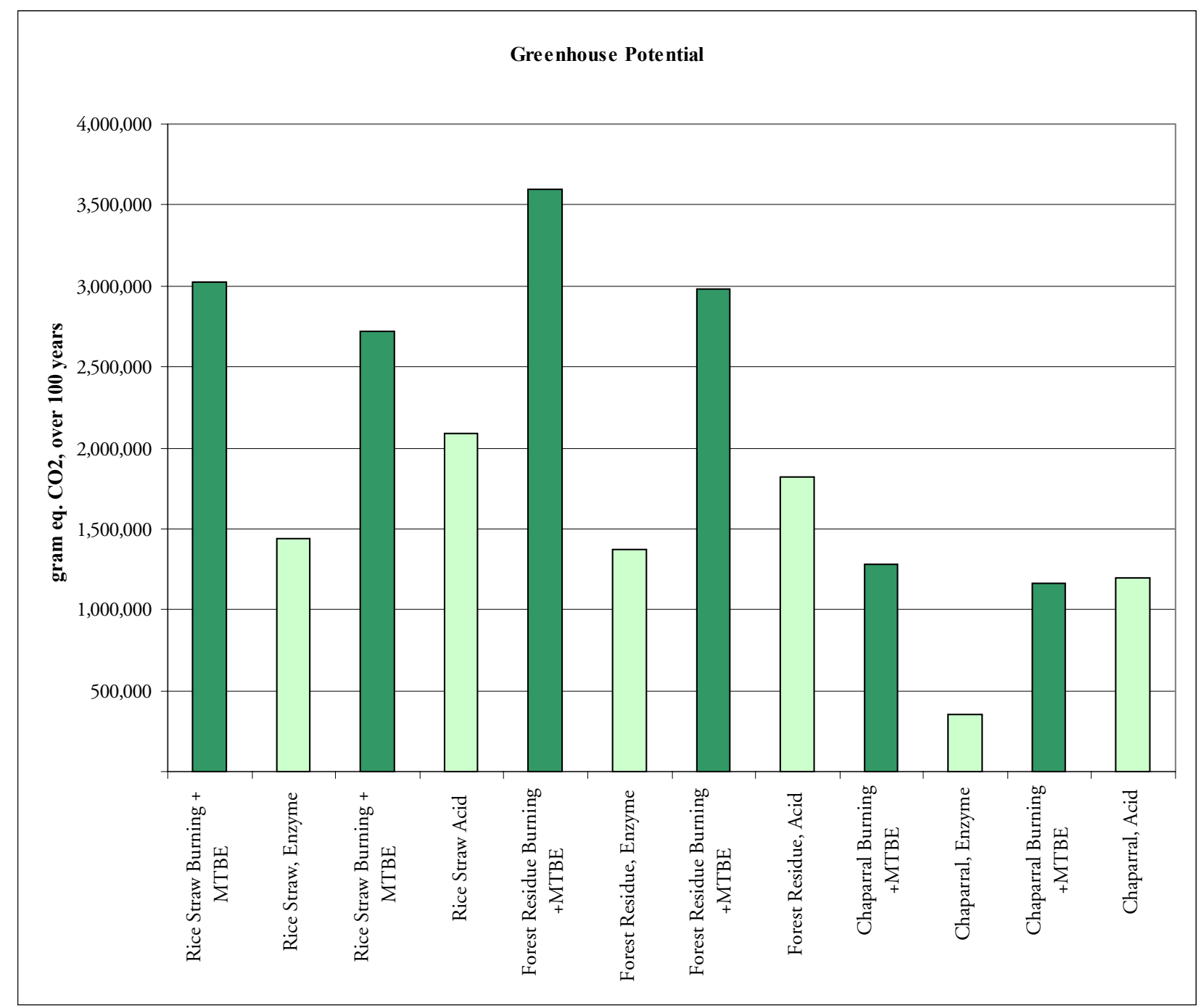

Figure 78: Greenhouse Effect Impact Potential

\subsubsection{Air Acidification Potential}

In Figure 79, the darker columns indicate that Option 1 generates more of an acidification impact than the comparative ETBE production scenarios. For Option 1, the use of electricity in the MTBE production process generates most of the emissions that contribute to the acidification values. The burning of the biomass itself also contributes to this impact value.

Similar to the Greenhouse Potential, the Air Acidification indicator values are affected by the electricity offset from lignin-based cogeneration. This is because electrical plants generate a large amount of $\mathrm{NO}_{\mathrm{x}}$ and $\mathrm{SO}_{\mathrm{x}}$. For Option 2, the emissions that contribute most to this impact value are generated mostly during the production of ETBE. 


\subsubsection{Eutrophication Impact Potential}

As shown in Figure 80, the eutrophication impact values are also higher for Option 1 than for Option 2. While all of the scenarios in Option 2 had high nitrate emissions than Option 1, the emissions of other water effluents drove the overall eutrophication impact values higher. The production of the fuel used to produce the reformulated gasoline as well as that used during the collection of the biomass were the main contributors to this value. The eutrophication impact values for chaparral are higher than those for forest residue or rice straw, since chaparral collection involves higher diesel consumption, which heavily contributes to the eutrophication potential. Unlike in the case of air-related impacts, the eutrophication potential is not greatly affected by the higher electricity offset credits.

The eutrophication values for all of the scenarios for Option 2 are driven by the water emissions from ethanol production. However, it is not the actual process that is the driver, but rather the upstream emissions from the production of raw materials used in the process (e.g., corn steep liquor, sulfuric acid, lime, etc.). These inputs are usually higher for the acid process than for the enzyme process, which explains why this impact value is generally higher for the acid process.

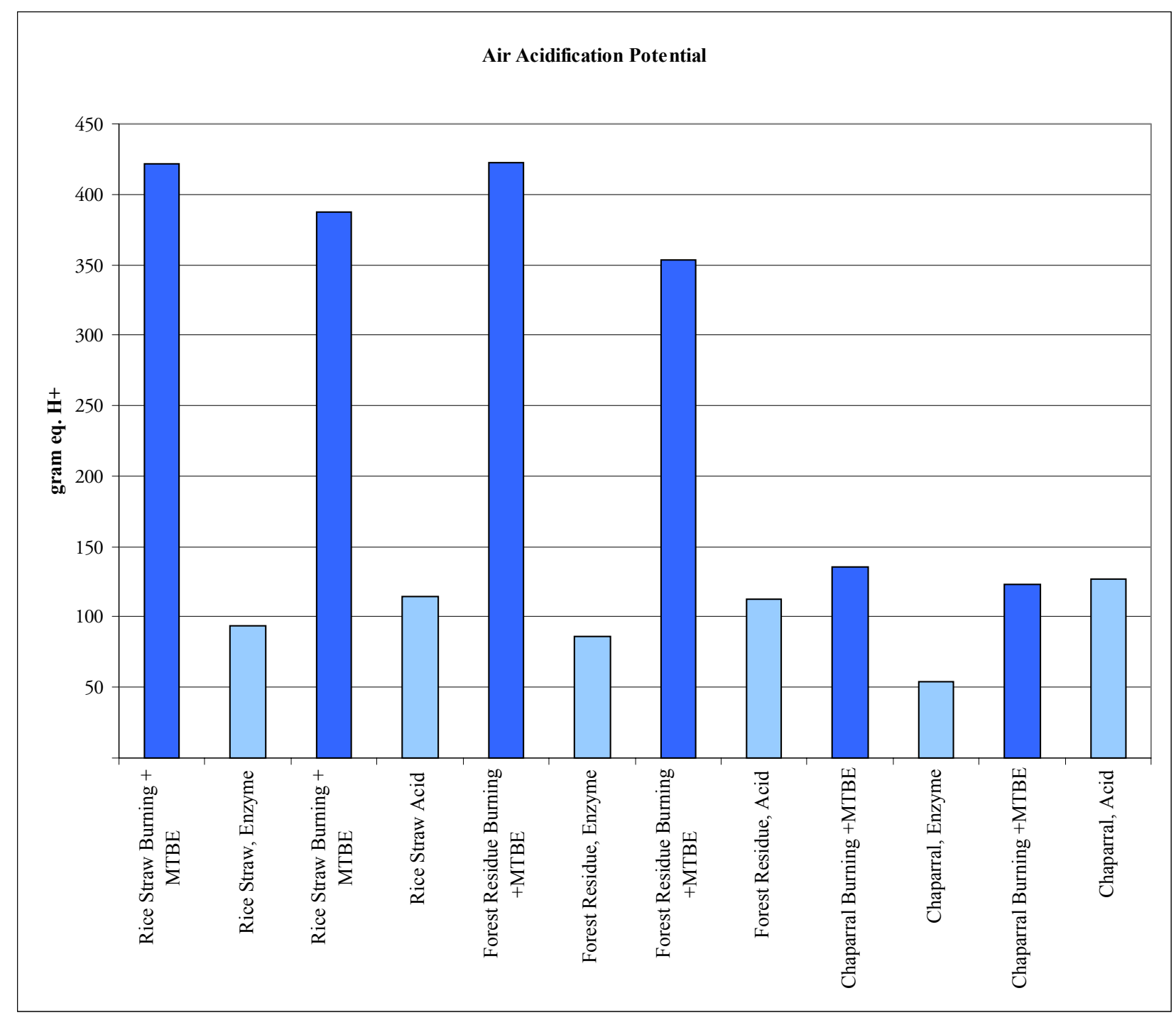

Figure 79: Air Acidification Impact Potential 


\subsubsection{Natural Resource Depletion Potential}

Figure 81 shows Natural Resource Depletion Potential for all the baseline scenarios. The natural resource values are driven to a large degree by how much of a designated natural resource the system consumes (e.g. coal, oil, phosphate, natural gas, uranium, bauxite, and iron). Natural gas consumption has the largest impact on the overall depletion potential, which leads to high impact values for many of the scenarios. The natural resource depletion values for Option 1 are driven by the production of the gasoline used in the reformulated gasoline and the production of the MTBE (which requires relatively large amounts of electricity and natural gas).

These values are higher than those for their comparative ETBE production scenarios, except in the case of the acid-based ethanol production scenarios. This is due to the amount of natural gas that is consumed during the production of the ethanol. For all of the scenarios, most of the natural gas consumption comes during the ETBE production process, where a substantial amount of electricity is consumed. For the concentrated acid process, there is also some natural gas consumed during the production of ethanol that leads to the values higher than those for the enzyme process. Once again, the amount of lignin that is produced by the chaparral leads to an electricity offset, which results in a reduction in natural gas, oil and coal consumption. The chaparral values (enzyme process) are not zero, however, because of the electricity consumption during the ETBE production step.

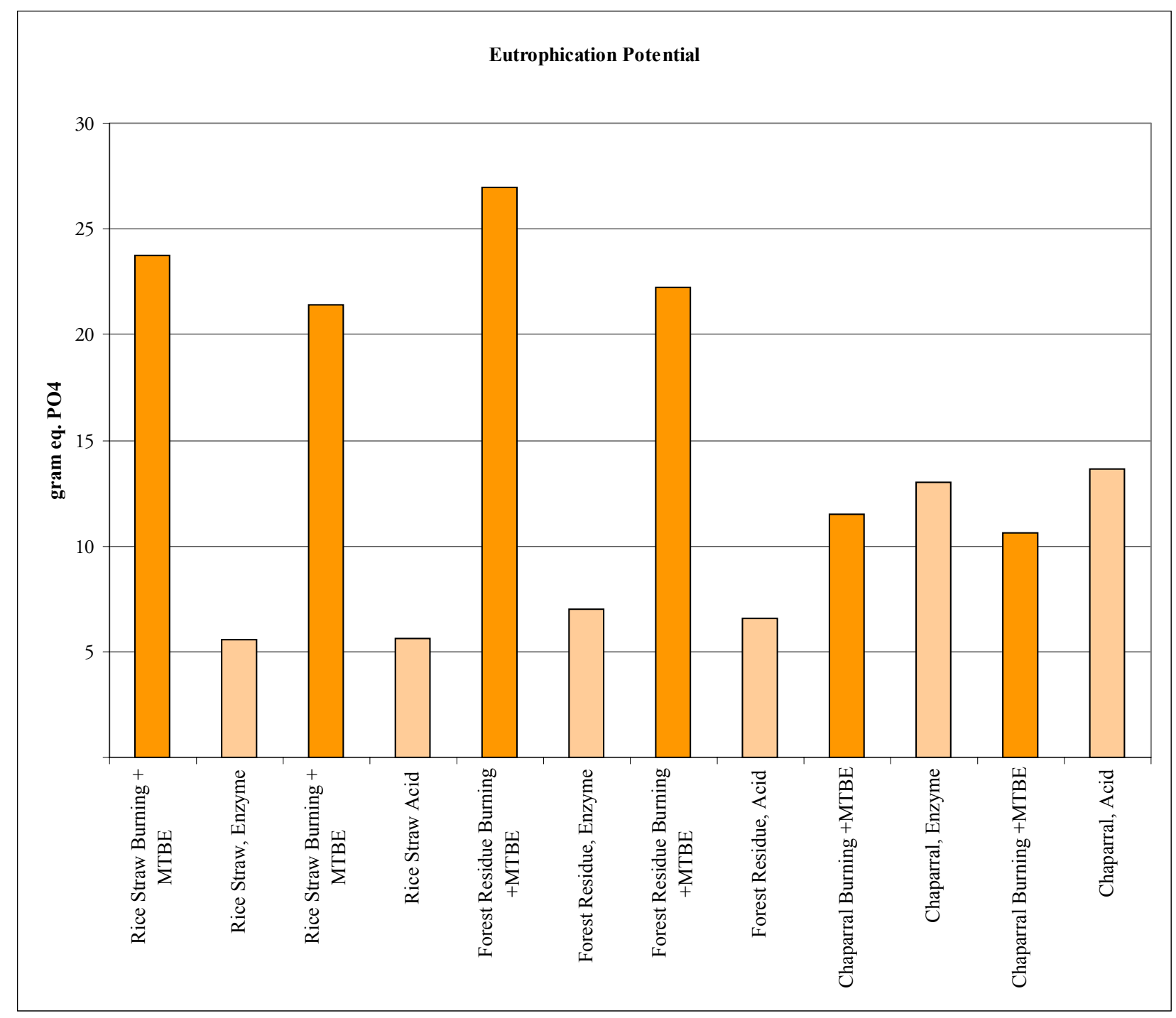

Figure 80: Eutrophication Impact Potential 


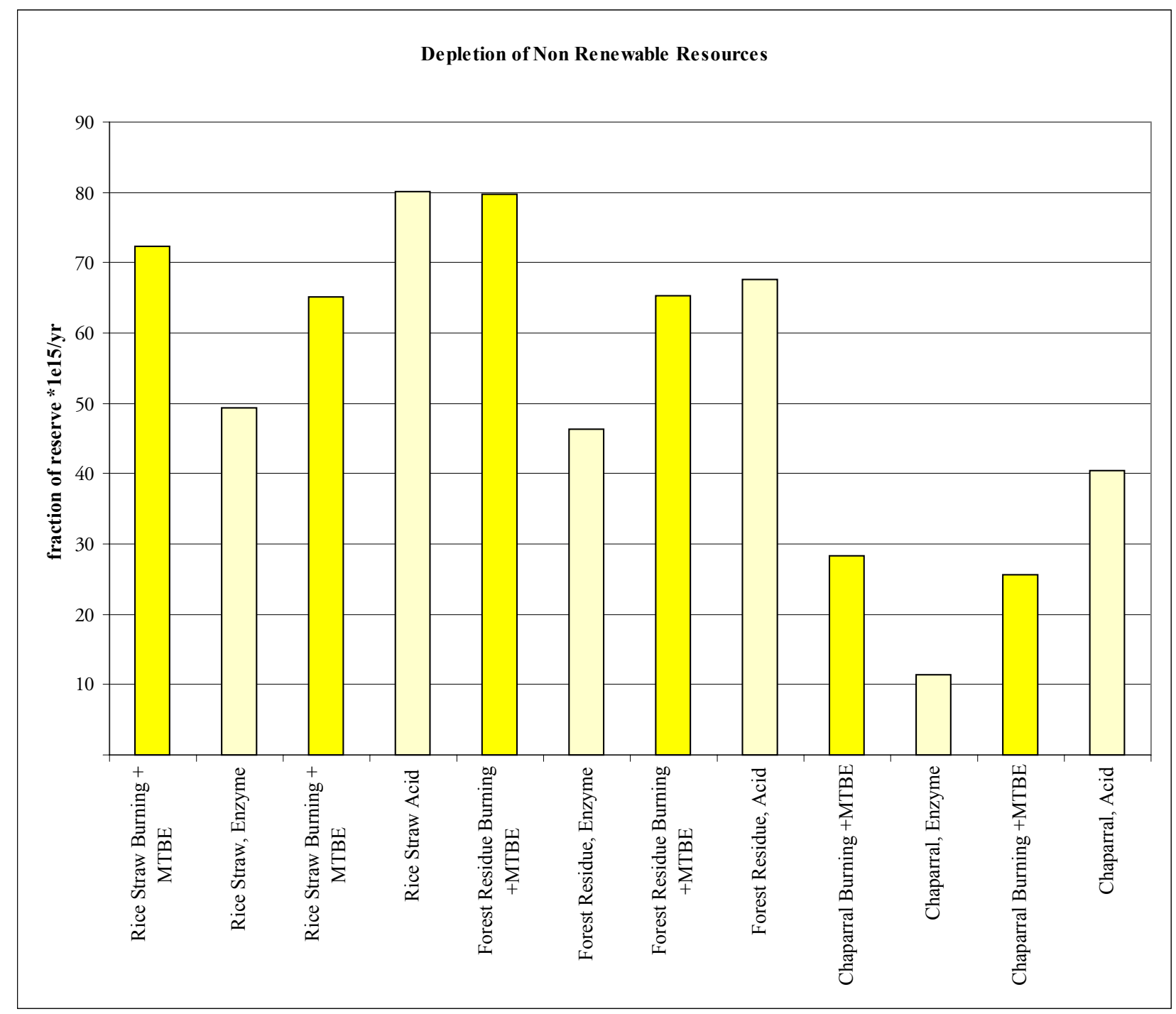

Figure 81: Natural Resource Depletion Potential

\subsubsection{Impact Potential for Chaparral}

Among the feedstocks, chaparral (enzyme process) exhibits the lowest potential values for greenhouse effect, air acidification, and natural resource depletion. This is related to the ETBE and electricity outputs of chaparral. Chaparral is low in sugar and high in lignin and extractives. This results in much less ETBE being generated from chaparral than from the other sources, as well as a greater output of lignin and biogas from the ethanol production process. The larger output of renewable energy leads to a lower natural resource depletion potential, and the lower amount of ETBE leads to smaller amounts of $\mathrm{CO}_{2}$ and $\mathrm{SO}_{\mathrm{x}}$ emitted from combustion. Additionally, the high electricity offset from cogeneration further decreases the greenhouse effect value. This is a key observation and brings up an interesting point: if low ethanol/ETBE yields per ton of biomass are good in terms of greenhouse effect, air acidification, and natural resource depletion potential, would a zero ethanol/ETBE yield be better, i.e., can we burn the biomass just to produce electricity? This would be tantamount to comparing biomass burning in the field versus in a biomass power plant. However, the biomass power industry in California has been suffering due to low electricity prices, and this may not be a feasible alternative, especially in light of the recent legislation on utility deregulation. Also, steam is cogenerated with electricity in the current scheme, and the ethanol plant uses this steam. Consequently, there would not be a steam host on site for the above scenario. 
Hence, considering these non-LCA factors and constraints, ethanol production and power generation need to coexist, since these two operations are synergistic and improve each other's economic performance. This can be accomplished in two ways. The turbo-generation section of the ethanol plant resembles a biomass power plant with cogeneration. Thus, the base-case scenario is similar to co-locating the ethanol plant with a biomass power plant. Shipping distance for fuel residue is zero for this co-location scenario. Another case would be to ship the fuel residue off-site to an existing biomass power plant; this option was considered in the sensitivity analysis.

\subsection{SENSITIVITY ANALYSIS}

\subsubsection{Total Replacement of MTBE with ETBE}

The baseline results of this study assume that the ETBE produced from biomass ethanol would be produced in the state of California. It is also assumed that it would be produced at the same facilities that are currently producing MTBE. In this way the ETBE is replacing MTBE production in California.

However, the current California MTBE capacity only covers $15 \%$ of the total MTBE used in California. The remaining $85 \%$ is assumed to be produced in Texas and shipped to California. This limited capacity is due to limitations in the ability to produce isobutylene in California. If the total amount of California biomass were utilized for ethanol (and ETBE) production it would exceed the $15 \%$ in state production. Therefore, it would also replace out-of-state production of MTBE.

Table 56 outlines the differences in modeling California production of MTBE and ETBE versus modeling out-of-state production. Only the changes in the modeling are shown in the table. It should be reiterated that the proposed scenario is a hypothetical one and may not be feasible from economic or marketing perspectives. It is presented to illustrate that even with the burden of transporting ethanol out of and ETBE into the state, the ETBE scenario shows lower values for key environmental flows when compared to the MTBE scenario.

Table 57 shows the comparison of the overall life cycle results for both biomass disposal options for forest residue biomass, Enzyme-based ethanol production and lignin cogeneration. For Option 1, the total results are presented for California and out-of-state production of MTBE. For Option 2, the total results are presented for California and out-ofstate production of ETBE. This table also presents the difference between California and out-of-state production. A value of $100 \%$ means the two locations are equal for that inventory flow. A value less than $100 \%$ means that the California production has lower emissions.

Table 56: Difference in Modeling Out-of-State MTBE/ETBE Production

\begin{tabular}{|c|c|c|}
\hline Life Cycle Phase & 15\% California Production & 85\% Outside California Production \\
\hline Ethanol Transport & $\begin{array}{l}\text { From assumed ethanol production } \\
\text { facility locations to California } \\
\text { refineries by truck. }\end{array}$ & $\begin{array}{l}\text { From assumed ethanol production } \\
\text { facility locations to Texas refineries } \\
\text { by train. }\end{array}$ \\
\hline ETBE Production & Using California electricity grid. & Using Texas electricity grid. \\
\hline ETBE Transport & None, assumed to be blended on site. & $\begin{array}{l}\text { From refineries in Texas to } \\
\text { California by train. }\end{array}$ \\
\hline Methanol Production & Using California electricity grid. & Using Texas electricity grid. \\
\hline MTBE Production & Using California electricity grid. & Using Texas electricity grid. \\
\hline MTBE Transport & None, assumed to be blended on site. & $\begin{array}{l}\text { From refineries in Texas to } \\
\text { California by train. }\end{array}$ \\
\hline
\end{tabular}


Table 57: Comparison of California and Out-of-State ETBE/MTBE Production

\begin{tabular}{|c|c|c|c|c|c|c|c|c|}
\hline & \multirow[b]{2}{*}{ Flows } & \multicolumn{4}{|c|}{$\begin{array}{l}\text { OPTION 1: MTBE Production } \\
\text { /Use + Biomass Burning }\end{array}$} & \multicolumn{3}{|c|}{$\begin{array}{l}\text { OP'TION 2: ETBE } \\
\text { Production/Use }\end{array}$} \\
\hline & & Unit & California & $\begin{array}{l}\text { Out of } \\
\text { State }\end{array}$ & $\begin{array}{c}\text { Calif./Out } \\
\text { of State }\end{array}$ & California & $\begin{array}{l}\text { Out of } \\
\text { State }\end{array}$ & $\begin{array}{c}\text { Calif./Out } \\
\text { of State }\end{array}$ \\
\hline \multirow[t]{3}{*}{ Inflows } & Coal & $\mathrm{kg}$ & 344 & 348 & $99 \%$ & -9 & -7 & $129 \%$ \\
\hline & Natural Gas & $\mathrm{kg}$ & 477 & 478 & $100 \%$ & 247 & 249 & $100 \%$ \\
\hline & Oil & $\mathrm{kg}$ & 427 & 434 & $99 \%$ & 314 & 324 & $97 \%$ \\
\hline \multirow[t]{12}{*}{ Outflows } & Carbon Dioxide $\left(\mathrm{CO}_{2}\right.$, biomass $)$ & $\mathrm{g}$ & $1,887,770$ & $1,887,770$ & $100 \%$ & $1,925,160$ & $1,925,900$ & $100 \%$ \\
\hline & Carbon Dioxide $\left(\mathrm{CO}_{2}\right.$, fossil $)$ & g & $3,237,431$ & $3,265,651$ & $99 \%$ & $1,361,190$ & $1,398,500$ & $97 \%$ \\
\hline & Carbon Monoxide (CO) & g & 71,698 & 71,761 & $100 \%$ & 1,275 & 1,374 & $93 \%$ \\
\hline & Hydrocarbons (except methane) & $\mathrm{g}$ & 10,263 & 10,256 & $100 \%$ & 4,382 & 4,404 & $99 \%$ \\
\hline & Methane $\left(\mathrm{CH}_{4}\right)$ & $\mathrm{g}$ & 15,931 & 15,973 & $100 \%$ & 564 & 602 & $94 \%$ \\
\hline & Nitrogen Oxides $\left(\mathrm{NO}_{\mathrm{x}}\right.$ as $\left.\mathrm{NO}_{2}\right)$ & $\mathrm{g}$ & 8,340 & 8,614 & $97 \%$ & 2,561 & 2,998 & $85 \%$ \\
\hline & Nitrous Oxide $\left(\mathrm{N}_{2} \mathrm{O}\right)$ & g & 65 & 65 & $99 \%$ & 7 & 8 & $86 \%$ \\
\hline & Particulates (unspecified) & $\mathrm{g}$ & 12,783 & 12,842 & $100 \%$ & 891 & 938 & $95 \%$ \\
\hline & Sulfur Oxides $\left(\mathrm{SO}_{\mathrm{x}}\right.$ as $\left.\mathrm{SO}_{2}\right)$ & g & 7,515 & 7,580 & $99 \%$ & 982 & 1,047 & $94 \%$ \\
\hline & COD (Chemical Oxygen Demand) & $\mathrm{g}$ & 867 & 887 & $98 \%$ & 163 & 196 & $83 \%$ \\
\hline & Nitrates $\left(\mathrm{NO}_{3}^{-}\right)$ & $\mathrm{g}$ & 5 & 5 & $100 \%$ & 14 & 14 & $100 \%$ \\
\hline & Waste (total) & $\mathrm{kg}$ & 276 & 277 & $100 \%$ & 20 & 21 & $96 \%$ \\
\hline \multirow[t]{5}{*}{ Energy } & Nonrenewable Energy & MJ & 44,842 & 45,233 & $99 \%$ & 18,748 & 19,299 & $97 \%$ \\
\hline & Renewable Energy & MJ & 81 & 58 & $140 \%$ & 15,708 & 15,696 & $100 \%$ \\
\hline & Process Energy & MJ & 23,012 & 23,381 & $98 \%$ & 11,405 & 11,944 & $95 \%$ \\
\hline & Feedstock Energy & MJ & 21,910 & 21,910 & $100 \%$ & 23,051 & 23,051 & $100 \%$ \\
\hline & Total Primary Energy & MJ & 44,923 & 45,291 & $99 \%$ & 34,456 & 34,995 & $98 \%$ \\
\hline
\end{tabular}

Table 58 also shows the comparison of the overall life cycle results for both biomass disposal options for forest residue biomass, enzyme-based ethanol production and lignin-based cogeneration. However, Table 57 compares the results for the same option (relative performance of in-state versus out-of-state production for a given option), while Table 58 compares the results for the different options (relative performance of Option 1 versus Option 2 for in-state versus out-ofstate production). Both California and out-of-state production of MTBE and ETBE are shown, and they differ in the ratios that are derived from the base information.

The percentages in the table represent the differences between both options. A value greater than $100 \%$ indicates that Option 1 is higher by that amount. A value less than $100 \%$ indicates that Option 1 is less than Option 2. An exception to this is negative numbers. A negative number is due to the negative values associated with electricity offset in the ethanol production system.

The results of Table 58 indicate that the out of state sensitivity analysis changes the results but does not change the conclusion regarding which option produces lower emissions.

\subsubsection{E10 Scenario}

A sensitivity analysis was also performed on using ethanol as a direct fuel additive as opposed to transforming it first into ETBE before being added to gasoline. As noted in the above sensitivity case, replacing $85 \%$ of the imported MTBE with ETBE is not a straightforward situation. Ethanol, however, can satisfy all of the oxygenate demand, i.e., it can substitute MTBE that is produced in the state as well as that is imported. This implies that the emissions will all be in-state emissions for $100 \%$ replacement of MTBE with ethanol. As mentioned in Section 6.9.1, the only emissions occurring outside the state are associated with foreign crude oil extraction for producing the fuels needed by both biomass disposal 
options, and production of the ancillary raw materials required during ethanol production. Again, the nitrate emissions in run-offs materialize where corn is grown, and hence, are outside of California.

A blend of $10 \%$ by volume of ethanol with gasoline (referred to as E10) was used as it represents a fairly standard blend of ethanol with gasoline and has similar properties as MTBE reformulated gasoline. It is possible to create a blend of reformulated gasoline with ethanol based on a $2 \%$ oxygen content (less than $10 \%$ volume of ethanol). However, this option was not studied because of the lack of data on the emissions of the fuel when burned and also on the gasoline used for this blend.

The functional unit of comparison for the study is different when ethanol is used instead of ETBE. Table 59 shows the new functional unit of comparison.

Table 58: Comparison of the Two Biomass Disposal Options

\begin{tabular}{|c|c|c|c|c|c|c|c|c|}
\hline & \multirow[b]{2}{*}{ Flows } & \multirow[b]{2}{*}{ Unit } & \multicolumn{3}{|c|}{ California Comparison } & \multicolumn{3}{|c|}{ Out of State Comparison } \\
\hline & & & Option 1 & Option 2 & $\begin{array}{c}\text { Option 1/ } \\
\text { Option } 2 \\
\end{array}$ & Option 1 & Option 2 & $\begin{array}{c}\text { Option } 1 \text { / } \\
\text { Option } 2 \\
\end{array}$ \\
\hline \multirow[t]{3}{*}{ Inflows } & Coal & $\mathrm{kg}$ & 344 & -9 & $-3,754 \%$ & 348 & -7 & $-4,873 \%$ \\
\hline & Natural Gas & $\mathrm{kg}$ & 477 & 247 & $193 \%$ & 478 & 249 & $192 \%$ \\
\hline & Oil & $\mathrm{kg}$ & 427 & 314 & $136 \%$ & 434 & 324 & $134 \%$ \\
\hline \multirow[t]{12}{*}{ Outflows } & Carbon Dioxide $\left(\mathrm{CO}_{2}\right.$, biomass $)$ & $\mathrm{g}$ & $1,887,770$ & $1,925,160$ & $98 \%$ & $1,887,770$ & $1,925,900$ & $98 \%$ \\
\hline & Carbon Dioxide $\left(\mathrm{CO}_{2}\right.$, fossil $)$ & $\mathrm{g}$ & $3,237,431$ & $1,361,190$ & $238 \%$ & $3,265,651$ & $1,398,500$ & $234 \%$ \\
\hline & Carbon Monoxide (CO) & $\mathrm{g}$ & 71,698 & 1,275 & $5,623 \%$ & 71,761 & 1,374 & $5,222 \%$ \\
\hline & Hydrocarbons (except methane) & $\mathrm{g}$ & 10,263 & 4,382 & $234 \%$ & 10,256 & 4,404 & $233 \%$ \\
\hline & Methane $\left(\mathrm{CH}_{4}\right)$ & $\mathrm{g}$ & 15,931 & 564 & $2,826 \%$ & 15,973 & 602 & $2,651 \%$ \\
\hline & Nitrogen Oxides $\left(\mathrm{NO}_{\mathrm{x}}\right.$ as $\left.\mathrm{NO}_{2}\right)$ & $\mathrm{g}$ & 8,340 & 2,561 & $326 \%$ & 8,614 & 2,998 & $287 \%$ \\
\hline & Nitrous Oxide $\left(\mathrm{N}_{2} \mathrm{O}\right)$ & $\mathrm{g}$ & 65 & 7 & $920 \%$ & 65 & 8 & $799 \%$ \\
\hline & Particulates (unspecified) & $\mathrm{g}$ & 12,783 & 891 & $1,435 \%$ & 12,842 & 938 & $1,369 \%$ \\
\hline & Sulfur Oxides $\left(\mathrm{SO}_{\mathrm{x}}\right.$ as $\left.\mathrm{SO}_{2}\right)$ & $\mathrm{g}$ & 7,515 & 982 & $765 \%$ & 7,580 & 1,047 & $724 \%$ \\
\hline & COD (Chemical Oxygen Demand) & $\mathrm{g}$ & 867 & 163 & $531 \%$ & 887 & 196 & $453 \%$ \\
\hline & Nitrates $\left(\mathrm{NO}_{3}^{-}\right)$ & $\mathrm{g}$ & 5 & 14 & $34 \%$ & 5 & 14 & $34 \%$ \\
\hline & Waste (total) & $\mathrm{kg}$ & 276 & 20 & $1,357 \%$ & 277 & 21 & $1,312 \%$ \\
\hline \multirow[t]{5}{*}{ Energy } & Nonrenewable Energy & MJ & 44,842 & 18,748 & $239 \%$ & 45,233 & 19,299 & $234 \%$ \\
\hline & Renewable Energy & MJ & 81 & 15,708 & $1 \%$ & 58 & 15,696 & $0 \%$ \\
\hline & Process Energy & MJ & 23,012 & 11,405 & $202 \%$ & 23,381 & 11944 & $196 \%$ \\
\hline & Feedstock Energy & MJ & 21,910 & 23,051 & $95 \%$ & 21,910 & 23051 & $95 \%$ \\
\hline & Total Primary Energy & $\mathrm{MJ}$ & 44,923 & 34,456 & $130 \%$ & 45,291 & 34,995 & $129 \%$ \\
\hline
\end{tabular}

The difference in heating values $(\sim 1 \%)$ of the two fuels is assumed to be negligible compared to the inherent uncertainties in the calculations. Therefore, the use of $1 \mathrm{~kg}$ of ethanol and $0.09 \mathrm{~kg}$ of gasoline is equivalent to the use of $1.02 \mathrm{~kg}$ of MTBE.

As opposed to the baseline model, there was a difference in the emissions from the combustion of E10 reformulated gasoline versus MTBE reformulated gasoline. The difference in the composition of the fuels causes differences in the tailpipe emissions of vehicles using the fuels. Therefore, the emissions from the combustion of the fuels were taken into account in the comparison. Also, the E10 blended fuel has higher evaporative emissions than MTBE blended fuel. Therefore, evaporative emissions were also taken into account. 
Table 59: Comparison of E10 versus MTBE Use in Reformulated Gasoline

\begin{tabular}{|c|c|c|c|c|c|}
\hline & Gasoline & MTBE & Ethanol & MTBE RFG & E10 RFG \\
\hline \multirow{11}{*}{$\begin{array}{r}\text { Heating Value (Mbtu/gal): } \\
\text { wt \% Oxygen: } \\
\text { Density (lb/gal): }\end{array}$} & 125 & 93.5 & 76 & 121.6 & 120.1 \\
\hline & $0 \%$ & $18.2 \%$ & $33 \%$ & $2.0 \%$ & $3.5 \%$ \\
\hline & 6.15 & 6.19 & 6.6 & 6.15 & 6.20 \\
\hline & & & wt \% MTBE: & $11.0 \%$ & \\
\hline & & & wt \% Ethanol: & & $10.7 \%$ \\
\hline & & & wt \% Gasoline: & $89.0 \%$ & $89.3 \%$ \\
\hline & & & MTBE (kg/gal): & 0.31 & \\
\hline & & & Ethanol (kg/gal): & & 0.30 \\
\hline & & & Gasoline (kg/gal): & 2.48 & 2.51 \\
\hline & & Difference & n Gasoline Use ( $\mathrm{kg})$ : & & 0.03 \\
\hline & & & & $\begin{array}{r}1 \mathrm{~kg} \text { Ethanol }+ \\
\underline{\mathrm{equ}} \\
1.02\end{array}$ & $\begin{array}{l}\text { g gasoline are } \\
\text { to: } \\
\mathrm{BE}\end{array}$ \\
\hline
\end{tabular}

The following table (Table 60) summarizes the tailpipe emissions for the two fuels studied ${ }^{31}$ :

Table 60: Tailpipe Emissions Factors in Grams/Gallon of Fuel Burned

\begin{tabular}{ccc}
\hline Emission & \multicolumn{2}{c}{ Oxygenate } \\
Category & MTBE & Ethanol as E10 \\
\hline $\mathrm{CH}_{4}$ & 0.67 & 0.77 \\
$\mathrm{NMHC}$ & 3.7 & 4.1 \\
$\mathrm{CO}$ & 67 & 68 \\
$\mathrm{CO}_{2}$ & 8,742 & 8,556 \\
$\mathrm{NO}_{\mathrm{x}}$ & 6.4 & 7.4 \\
$\mathrm{MTBE}$ & 0.14 & 0.0033 \\
Ethanol & $1.7 \times 10^{-4}$ & 0.22 \\
Benzene & 0.15 & 0.17 \\
Formaldehyde & 0.065 & 0.058 \\
\hline
\end{tabular}

The following two tables (Table 61 and Table 62) show the evaporative emissions of the two fuels studied:

Table 61: Hotsoak Evaporative Emissions Factors

\begin{tabular}{ccc}
\hline Emission & \multicolumn{2}{c}{ Oxygenate } \\
Category & MTBE & Ethanol as E10 \\
& $(\mathrm{g})$ & $(\mathrm{g})$ \\
\hline \hline NMHC & 0.13 & 0.19 \\
MTBE & 0.016 & 0.0041 \\
Ethanol & 0.0028 & 0.076 \\
\hline
\end{tabular}

31 Based on CARB data. 
Table 62: Diurnal (0-24hr) Evaporative Emissions Factors

\begin{tabular}{ccc}
\hline Emission & \multicolumn{2}{c}{ Oxygenate } \\
Category & MTBE & Ethanol as E10 \\
& $(\mathrm{g})$ & $(\mathrm{g})$ \\
\hline \hline $\mathrm{CH}_{4}$ & 0.0071 & $4.7 \times 10^{-4}$ \\
$\mathrm{NMHC}$ & 3.9 & 6.3 \\
MTBE & 0.408 & 0.129 \\
Ethanol & 0.011 & 0.846 \\
\hline
\end{tabular}

Both hotsoak and diurnal (0-24hr) evaporative emissions were taken into account. However, running evaporative emissions were not known and, therefore, not used in the comparison.

Table 63 shows the percentage difference between Option 2A (biomass conversion to ethanol and E10 reformulated gasoline) and Option 1 (biomass burning and MTBE reformulated gasoline). Positive values in Table 63 represent that Option 2A (biomass conversion to ethanol and E10 reformulated gasoline) has lower environmental emissions compared to Option 1 (biomass burning and MTBE reformulated gasoline). Negative values indicate that Option 2 has higher emissions.

Table 63: Summary Data for E10 Sensitivity Analysis

\begin{tabular}{|c|c|c|c|c|c|c|c|}
\hline & \multirow[b]{3}{*}{ Flow } & \multicolumn{6}{|c|}{$\begin{array}{c}\text { Difference between Option } 2 A \text { (Ethanol Production) and Option } 1 \\
\text { (Biomass Burning }+ \text { MTBE Production) }\end{array}$} \\
\hline & & \multicolumn{2}{|c|}{ Rice Straw } & \multicolumn{2}{|c|}{ Forest Residue } & \multicolumn{2}{|c|}{ Chaparral } \\
\hline & & Acid & Enzyme & Acid & Enzyme & Acid & Enzyme \\
\hline \multirow[t]{3}{*}{ Inflow } & Coal & $97 \%$ & $99 \%$ & $98 \%$ & $108 \%$ & $90 \%$ & $236 \%$ \\
\hline & Natural Gas & $-79 \%$ & $74 \%$ & $-24 \%$ & $103 \%$ & $-126 \%$ & $194 \%$ \\
\hline & Oil & $77 \%$ & $77 \%$ & $71 \%$ & $72 \%$ & $-62 \%$ & $-48 \%$ \\
\hline \multirow[t]{12}{*}{ Outflow } & Carbon Dioxide $\left(\mathrm{CO}_{2}\right.$, biomass $)$ & $-2 \%$ & $-20 \%$ & $1 \%$ & $-15 \%$ & $2 \%$ & $-4 \%$ \\
\hline & Carbon Dioxide $\left(\mathrm{CO}_{2}\right.$, fossil $)$ & $32 \%$ & $83 \%$ & $50 \%$ & $94 \%$ & $-30 \%$ & $110 \%$ \\
\hline & Carbon Monoxide (CO) & $82 \%$ & $82 \%$ & $91 \%$ & $90 \%$ & $94 \%$ & $95 \%$ \\
\hline & Hydrocarbons (except methane) & $53 \%$ & $48 \%$ & $47 \%$ & $41 \%$ & $89 \%$ & $98 \%$ \\
\hline & Methane $\left(\mathrm{CH}_{4}\right)$ & $-186 \%$ & $53 \%$ & $77 \%$ & $100 \%$ & $56 \%$ & $117 \%$ \\
\hline & Nitrogen Oxides $\left(\mathrm{NO}_{\mathrm{x}}\right.$ as $\left.\mathrm{NO}_{2}\right)$ & $64 \%$ & $81 \%$ & $61 \%$ & $83 \%$ & $-170 \%$ & $18 \%$ \\
\hline & Nitrous Oxide $\left(\mathrm{N}_{2} \mathrm{O}\right)$ & $40 \%$ & $70 \%$ & $43 \%$ & $81 \%$ & $-182 \%$ & $36 \%$ \\
\hline & Particulates (unspecified) & $31 \%$ & $90 \%$ & $65 \%$ & $94 \%$ & $80 \%$ & $96 \%$ \\
\hline & Sulfur Oxides $\left(\mathrm{SO}_{\mathrm{x}}\right.$ as $\left.\mathrm{SO}_{2}\right)$ & $87 \%$ & $93 \%$ & $85 \%$ & $100 \%$ & $45 \%$ & $93 \%$ \\
\hline & COD (Chemical Oxygen Demand) & $-578 \%$ & $-615 \%$ & $-293 \%$ & $-339 \%$ & $-331 \%$ & $-338 \%$ \\
\hline & Nitrates $\left(\mathrm{NO}_{3}^{-}\right)$ & $-815 \%$ & $-325 \%$ & $-802 \%$ & $-310 \%$ & $-2315 \%$ & $-1095 \%$ \\
\hline & Waste (total) & $-102 \%$ & $-38 \%$ & $30 \%$ & $88 \%$ & $-121 \%$ & $121 \%$ \\
\hline \multirow[t]{5}{*}{ Energy } & Nonrenewable Energy & $-15 \%$ & $75 \%$ & $16 \%$ & $94 \%$ & $-89 \%$ & $138 \%$ \\
\hline & Renewable Energy & $-36008 \%$ & $-37055 \%$ & $-40397 \%$ & $-39055 \%$ & $-91359 \%$ & $-83899 \%$ \\
\hline & Process Energy & $-430 \%$ & $-25 \%$ & $-98 \%$ & $48 \%$ & $-145 \%$ & $20 \%$ \\
\hline & Feedstock Energy & $-12 \%$ & $-12 \%$ & $-12 \%$ & $-12 \%$ & $-12 \%$ & $-12 \%$ \\
\hline & Total Primary Energy & $-83 \%$ & $5 \%$ & $-59 \%$ & $21 \%$ & $-253 \%$ & $-13 \%$ \\
\hline
\end{tabular}


It can be seen from Table 63 that the E10 Option, in comparison to the MTBE Option 1, results in a decrease in many of the environmental flows. The obvious exceptions are nitrates, COD, and renewable energy; in some particular scenarios $\mathrm{NO}_{x}, \mathrm{~N}_{2} \mathrm{O}$, and solid waste emissions are also greater. As with the ETBE scenarios, the higher values are related to ethanol production, and the nitrates and COD values stem from upstream emissions. For a given $\mathrm{kg}$ of $\mathrm{MTBE}, 0.52 \mathrm{~kg}$ of ethanol is used in the ETBE Option versus $0.98 \mathrm{~kg}$ ethanol in the E10 Option. This means that ethanol usage is almost doubled in the E10 Option compared to the ETBE Option, i.e., Option 2, and the ethanol-related emissions therefore are magnified. For example, nitrates are higher because CSL usage is proportionately elevated to satisfy the larger ethanol requirement. More biomass is also needed to make the requisite amount of ethanol for the E10 Option. The greater COD and solid waste values are from the increased energy consumption during biomass collection and supplementary methane usage, when applicable.

The higher $\mathrm{N}_{2} \mathrm{O}$ values for chaparral are related to the harvesting operation. The fuel used per dry ton of chaparral collected is about twice that for forest residue and about four times that for rice straw; this results in large emissions in general. This combined with the need for additional methane consumption makes the $\mathrm{NO}_{\mathrm{x}}$ and $\mathrm{N}_{2} \mathrm{O}$ emissions much bigger for the chaparral-acid process scenario compared to the MTBE scenario. The methane emissions are higher for rice straw-acid process because this scenario consumes the most methane of all the scenarios. This is again due to the low lignin and high ash contents of rice straw, characteristics which result in a lower heating value of the ligneous residue. This effect is amplified in the E10 Option.

Although the E10 Option does not have isobutylene production, it needs to burn extra gasoline due to the lower heating value of ethanol (see Table 6) to achieve the same energy content as the MTBE Option. Conversely, in the comparison of ETBE Option versus MTBE Option, the latter has to burn extra gasoline (the ETBE Option then has "negative" gasoline consumption, see Table 6).

It also bears repeating that the E10 RFG has a higher oxygen content than the baseline reformulated gasolines containing ETBE or MTBE. Hence, the comparison of E10 Option versus MTBE Option is different from the comparison of ETBE Option versus MTBE Option. These factors further explain the differences in environmental flows for the two options.

In terms of impact indicators, the total greenhouse gas potential is substantially lower for the E10 Option versus the MTBE Option (except for chaparral-acid process) due to lower fossil-based $\mathrm{CO}_{2}$, and so are the acidification, eutrophication, and natural resources depletion potentials (results not shown). Thus, it can be concluded that the production of ethanol from the forest residue and rice straw feedstock generally results in overall lower emissions than the burning of biomass and the production of MTBE, and especially in terms of criteria pollutants. 
It is likely that agricultural burning and forestry residue disposal will be problematic issues in California for the foreseeable future. This study provides specific quantitative data on biomass disposal options in California and environmental implications of oxygenates for gasoline. While the study does not include information on the current concern over MTBE groundwater contamination, it does provide data on true environmental costs of fuel systems that may be useful for public policy makers now confronting the difficult choices of oxygenate use.

The LCA performed in this study demonstrates the potentially significant benefits of using ETBE derived from California biomass. Overall the results show that there is a significant difference between Options 1 and 2 (MTBE scenario and ETBE scenario, respectively); the magnitude of this difference varies with the types of biomass feedstocks and ethanol production processes. However, in all cases, the comparison of the ETBE scenario with the MTBE scenario revealed a fundamental difference in energy derived from renewable sources, and the concomitant benefits of reduced greenhouse gas emissions. This difference can be significant when aiming to shift fuel choices to renewable sources.

Important advantages are also found with the ETBE scenario with regard to emissions reductions. The ETBE scenarios have lower net energy consumption and carbon dioxide emissions, which - although not regulated or mandated by state or federal laws - are desirable attributes. Specifically, the prevailing trends observed for the ETBE scenarios were lower net values for:

- Carbon monoxide

- $\mathrm{SO}_{\mathrm{x}}$ and $\mathrm{NO}_{\mathrm{x}}$

- Particulates

- Carbon dioxide

- Fossil energy consumption

Hence, implementation of the ETBE scenario would facilitate the improvement of air quality. Emissions of nitrates in water run-offs, however, were somewhat higher for ETBE production. This is due to the use of CSL during ethanol fermentation. CSL is a by-product of corn wet-milling and agricultural operations lead to water run-offs containing fertilizer-derived nitrates. It is not mandatory that CSL be used during ethanol fermentation, and non-agricultural based alternatives are possible. It should be noted that the nitrate emissions occur at the geographical site where corn is grown, i.e., near the farm.

The four impact assessment categories - eutrophication potential, depletion of natural resources, greenhouse gas potential, and air acidification potential - show lower values for the ETBE scenario than for the MTBE scenario. Thus, despite higher nitrates values, the ETBE scenario shows a lower eutrophication potential. Hence, the ETBE scenario is shown to commonly exhibit lower values than the MTBE scenario for key environmental criteria, both regulated and unregulated. The same can be said when the E10 scenario is compared with the MTBE scenario if we exclude the case of the chaparral-acid process.

Finally, this effort is part of a larger picture for transportation fuels. This work may be used as a stepping stone for future studies to develop additional fuel LCIs, such as those for ethanol/gasoline blends (e.g., 10\% ethanol using a low RVP gasoline), neat ethanol blends (e.g., E $85-85 \%$ ethanol, $15 \%$ gasoline blend), and others. 


\section{APPENDIX A: DETAILED SCENARIO RESUltS}

This section provides more detailed data (Table 64 through Table 76) for all 12 scenarios that were modeled (Table 64).

Table 64: Scenarios Studied

\begin{tabular}{cccc}
\hline Scenario & Biomass Type & Ethanol Production Method & Ligneous Residue Use \\
\hline \hline 1 & Rice Straw & Enzyme & Onsite Cogeneration \\
2 & Rice Straw & Enzyme & Biomass Power \\
3 & Rice Straw & Concentrated Acid & Onsite Cogeneration \\
4 & Rice Straw & Concentrated Acid & Biomass Power \\
5 & Forest Residue & Enzyme & Onsite Cogeneration \\
6 & Forest Residue & Enzyme & Biomass Power \\
7 & Forest Residue & Concentrated Acid & Onsite Cogeneration \\
8 & Forest Residue & Concentrated Acid & Biomass Power \\
9 & Chaparral & Enzyme & Onsite Cogeneration \\
10 & Chaparral & Enzyme & Biomass Power \\
11 & Chaparral & Concentrated Acid & Onsite Cogeneration \\
12 & Chaparral & Concentrated Acid & Biomass Power \\
\hline
\end{tabular}

Data are provided for inflows, outflows, energy consumption, and impact assessment values. The symbols used in the Articles column are explained below.
(r) $\quad=$ Raw material
(a) $=$ Air emission
(w) $=$ Water emission
$\mathrm{E}=$ Energy 
Table 65: Rice Straw Biomass, Enzyme-Based Ethanol Production, and Lignin Cogeneration

\begin{tabular}{|c|c|c|c|c|c|c|c|c|c|c|c|c|c|c|}
\hline Article & Units & $\begin{array}{l}\text { OPTION 1: } \\
\text { Total }\end{array}$ & $\begin{array}{l}\text { Biomass } \\
\text { Burning }\end{array}$ & $\begin{array}{l}\text { Natural Gas: } \\
\text { Production }\end{array}$ & $\begin{array}{l}\text { Methanol: } \\
\text { Production }\end{array}$ & $\begin{array}{l}\text { MTBE: } \\
\text { Production }\end{array}$ & $\begin{array}{l}\text { MTBE RFG: } \\
\text { Production }\end{array}$ & $\begin{array}{c}\text { MTBE } \\
\text { RFG: Use }\end{array}$ & $\begin{array}{c}\text { OPTION 2: } \\
\text { Total }\end{array}$ & $\begin{array}{c}\text { Biomass } \\
\text { Harvesting }\end{array}$ & $\begin{array}{l}\text { Ethanol: } \\
\text { Production }\end{array}$ & $\begin{array}{l}\text { Ethanol: } \\
\text { Transport }\end{array}$ & $\begin{array}{l}\text { ETBE: } \\
\text { Production }\end{array}$ & $\begin{array}{l}\text { ETBE RFG: } \\
\text { Use }\end{array}$ \\
\hline (r) Bauxite $\left(\mathrm{Al}_{2} \mathrm{O}_{3}\right.$, ore $)$ & $\mathrm{kg}$ & 0.09 & $0 \%$ & $0 \%$ & $0 \%$ & $100 \%$ & $0 \%$ & $0 \%$ & 0.10 & $0 \%$ & $0 \%$ & $0 \%$ & $100 \%$ & $0 \%$ \\
\hline (r) Coal (in ground) & $\mathrm{kg}$ & 314 & $0 \%$ & $0 \%$ & $97 \%$ & $2 \%$ & $1 \%$ & $0 \%$ & 7.08 & $3 \%$ & $11 \%$ & $0 \%$ & $86 \%$ & $0 \%$ \\
\hline (r) Iron (Fe, ore) & $\mathrm{kg}$ & 0.06 & $0 \%$ & $0 \%$ & $1 \%$ & $99 \%$ & $0 \%$ & $0 \%$ & 0.06 & $0 \%$ & $0 \%$ & $0 \%$ & $100 \%$ & $0 \%$ \\
\hline (r) Limestone $\left(\mathrm{CaCO}_{3}\right.$, in ground) & $\mathrm{kg}$ & 46 & $0 \%$ & $0 \%$ & $98 \%$ & $0 \%$ & $1 \%$ & $0 \%$ & 3.65 & $1 \%$ & $97 \%$ & $0 \%$ & $2 \%$ & $0 \%$ \\
\hline (r) Natural Gas (in ground) & $\mathrm{kg}$ & 434 & $0 \%$ & $26 \%$ & $19 \%$ & $51 \%$ & $4 \%$ & $0 \%$ & 290 & $0 \%$ & $18 \%$ & $0 \%$ & $81 \%$ & $0 \%$ \\
\hline (r) Oil (in ground) & $\mathrm{kg}$ & 383 & $0 \%$ & $0 \%$ & $12 \%$ & $66 \%$ & $22 \%$ & $0 \%$ & 277 & $2 \%$ & $2 \%$ & $0 \%$ & $95 \%$ & $0 \%$ \\
\hline (r) Phosphate Rock (in ground) & $\mathrm{kg}$ & 0 & $0 \%$ & $0 \%$ & $0 \%$ & $0 \%$ & $0 \%$ & $0 \%$ & 0.02 & $0 \%$ & $100 \%$ & $0 \%$ & $0 \%$ & $0 \%$ \\
\hline (r) Potash $\left(\mathrm{K}_{2} \mathrm{O}\right.$, in ground $)$ & $\mathrm{kg}$ & 0 & $0 \%$ & $0 \%$ & $0 \%$ & $0 \%$ & $0 \%$ & $0 \%$ & 0.01 & $0 \%$ & $100 \%$ & $0 \%$ & $0 \%$ & $0 \%$ \\
\hline (r) Uranium (U, ore) & $\mathrm{kg}$ & 0 & $0 \%$ & $7 \%$ & $33 \%$ & $17 \%$ & $43 \%$ & $0 \%$ & 0 & $7 \%$ & $26 \%$ & $1 \%$ & $67 \%$ & $0 \%$ \\
\hline Water Used (total) & liter & 546 & $0 \%$ & $0 \%$ & $7 \%$ & $91 \%$ & $2 \%$ & $0 \%$ & 36,672 & $0 \%$ & $0 \%$ & $0 \%$ & $100 \%$ & $0 \%$ \\
\hline Water: Unspecified Origin & liter & 533 & $0 \%$ & $0 \%$ & $7 \%$ & $93 \%$ & $0 \%$ & $0 \%$ & 521 & $0 \%$ & $1 \%$ & $0 \%$ & $99 \%$ & $0 \%$ \\
\hline (a) Carbon Dioxide $\left(\mathrm{CO}_{2}\right.$, biomass $)$ & $\mathrm{g}$ & $1,521,110$ & $100 \%$ & $0 \%$ & $0 \%$ & $0 \%$ & $0 \%$ & $0 \%$ & $1,606,570$ & $0 \%$ & $71 \%$ & $0 \%$ & $0 \%$ & $29 \%$ \\
\hline (a) Carbon Dioxide $\left(\mathrm{CO}_{2}\right.$, fossil $)$ & $\mathrm{g}$ & $2,929,590$ & $0 \%$ & $1 \%$ & $39 \%$ & $9 \%$ & $2 \%$ & $49 \%$ & $1,406,330$ & $1 \%$ & $11 \%$ & $0 \%$ & $20 \%$ & $68 \%$ \\
\hline (a) Carbon Monoxide (CO) & $\mathrm{g}$ & 32,121 & $98 \%$ & $0 \%$ & $1 \%$ & $1 \%$ & $0 \%$ & $0 \%$ & 1,037 & $6 \%$ & $71 \%$ & $1 \%$ & $22 \%$ & $0 \%$ \\
\hline (a) Hydrocarbons (except methane) & $\mathrm{g}$ & 9,184 & $0 \%$ & $1 \%$ & $75 \%$ & $24 \%$ & $0 \%$ & $0 \%$ & 2,372 & $1 \%$ & $2 \%$ & $0 \%$ & $97 \%$ & $0 \%$ \\
\hline (a) Volatile Organic Compounds (VOC) & $\mathrm{g}$ & 922 & $94 \%$ & $0 \%$ & $0 \%$ & $0 \%$ & $6 \%$ & $0 \%$ & 0.00 & $0 \%$ & $0 \%$ & $0 \%$ & $0 \%$ & $0 \%$ \\
\hline (a) ethanol & $\mathrm{g}$ & 0 & $0 \%$ & $0 \%$ & $100 \%$ & $0 \%$ & $0 \%$ & $0 \%$ & 214 & $0 \%$ & $100 \%$ & $0 \%$ & $0 \%$ & $0 \%$ \\
\hline (a) Furfural & $\mathrm{g}$ & 0 & $0 \%$ & $0 \%$ & $0 \%$ & $0 \%$ & $0 \%$ & $0 \%$ & 1,350 & $0 \%$ & $100 \%$ & $0 \%$ & $0 \%$ & $0 \%$ \\
\hline (a) HMF & $\mathrm{g}$ & 0 & $0 \%$ & $0 \%$ & $0 \%$ & $0 \%$ & $0 \%$ & $0 \%$ & 15 & $0 \%$ & $100 \%$ & $0 \%$ & $0 \%$ & $0 \%$ \\
\hline (a) Aldehydes & $\mathrm{g}$ & 5 & $0 \%$ & $7 \%$ & $89 \%$ & $3 \%$ & $2 \%$ & $0 \%$ & 0.32 & $1 \%$ & $50 \%$ & $0 \%$ & $48 \%$ & $0 \%$ \\
\hline (a) Formaldehyde & $\mathrm{g}$ & 0.80 & $0 \%$ & $1 \%$ & $48 \%$ & $14 \%$ & $37 \%$ & $0 \%$ & 0.31 & $6 \%$ & $50 \%$ & $0 \%$ & $44 \%$ & $0 \%$ \\
\hline (a) Benzene $\left(\mathrm{C}_{6} \mathrm{H}_{6}\right)$ & $\mathrm{g}$ & 92 & $0 \%$ & $46 \%$ & $30 \%$ & $17 \%$ & $6 \%$ & $0 \%$ & 39 & $1 \%$ & $51 \%$ & $0 \%$ & $48 \%$ & $0 \%$ \\
\hline (a) Hydrogen Chloride $(\mathrm{HCl})$ & $\mathrm{g}$ & 162 & $0 \%$ & $0 \%$ & $97 \%$ & $2 \%$ & $1 \%$ & $0 \%$ & 3.83 & $2 \%$ & $9 \%$ & $0 \%$ & $88 \%$ & $0 \%$ \\
\hline (a) Hydrogen Fluoride (HF) & $\mathrm{g}$ & 20 & $0 \%$ & $0 \%$ & $98 \%$ & $0 \%$ & $1 \%$ & $0 \%$ & 0.08 & $15 \%$ & $60 \%$ & $1 \%$ & $24 \%$ & $0 \%$ \\
\hline (a) Hydrogen Sulfide $\left(\mathrm{H}_{2} \mathrm{~S}\right)$ & $\mathrm{g}$ & 0.94 & $0 \%$ & $0 \%$ & $1 \%$ & $33 \%$ & $66 \%$ & $0 \%$ & 0.42 & $10 \%$ & $12 \%$ & $1 \%$ & $78 \%$ & $0 \%$ \\
\hline (a) Metals (unspecified) & $\mathrm{g}$ & 0.31 & $0 \%$ & $0 \%$ & $0 \%$ & $100 \%$ & $0 \%$ & $0 \%$ & 0.32 & $0 \%$ & $0 \%$ & $0 \%$ & $100 \%$ & $0 \%$ \\
\hline (a) Methane $\left(\mathrm{CH}_{4}\right)$ & $\mathrm{g}$ & 3,452 & $0 \%$ & $41 \%$ & $35 \%$ & $16 \%$ & $8 \%$ & $0 \%$ & 1,317 & $1 \%$ & $51 \%$ & $0 \%$ & $48 \%$ & $0 \%$ \\
\hline (a) Nitrogen Oxides $\left(\mathrm{NO}_{\mathrm{x}}\right.$ as $\left.\mathrm{NO}_{2}\right)$ & $\mathrm{g}$ & 8,449 & $34 \%$ & $3 \%$ & $37 \%$ & $24 \%$ & $3 \%$ & $0 \%$ & 2,586 & $7 \%$ & $10 \%$ & $1 \%$ & $83 \%$ & $0 \%$ \\
\hline (a) Nitrous Oxide $\left(\mathrm{N}_{2} \mathrm{O}\right)$ & $\mathrm{g}$ & 57 & $0 \%$ & $1 \%$ & $90 \%$ & $2 \%$ & $6 \%$ & $0 \%$ & 9.06 & $20 \%$ & $61 \%$ & $2 \%$ & $18 \%$ & $0 \%$ \\
\hline (a) Particulates (unspecified) & $\mathrm{g}$ & 7,281 & $48 \%$ & $0 \%$ & $47 \%$ & $4 \%$ & $1 \%$ & $0 \%$ & 788 & $3 \%$ & $62 \%$ & $0 \%$ & $35 \%$ & $0 \%$ \\
\hline (a) Sulfur Oxides $\left(\mathrm{SO}_{\mathrm{x}}\right.$ as $\left.\mathrm{SO}_{2}\right)$ & $\mathrm{g}$ & 7,447 & $8 \%$ & $0 \%$ & $75 \%$ & $13 \%$ & $4 \%$ & $0 \%$ & 1,183 & $1 \%$ & $15 \%$ & $0 \%$ & $84 \%$ & $0 \%$ \\
\hline (w) Ammonia $\left(\mathrm{NH}_{4}^{+}, \mathrm{NH}_{3}\right.$, as $\left.\mathrm{N}\right)$ & $\mathrm{g}$ & 16 & $0 \%$ & $0 \%$ & $4 \%$ & $20 \%$ & $76 \%$ & $0 \%$ & 4.08 & $8 \%$ & $12 \%$ & $1 \%$ & $80 \%$ & $0 \%$ \\
\hline (w) BOD (Biochemical Oxygen Demand) & $\mathrm{g}$ & 105 & $0 \%$ & $0 \%$ & $10 \%$ & $12 \%$ & $78 \%$ & $0 \%$ & 22 & $10 \%$ & $30 \%$ & $1 \%$ & $59 \%$ & $0 \%$ \\
\hline (w) COD (Chemical Oxygen Demand) & $\mathrm{g}$ & 761 & $0 \%$ & $0 \%$ & $0 \%$ & $8 \%$ & $91 \%$ & $0 \%$ & 118 & $15 \%$ & $28 \%$ & $1 \%$ & $55 \%$ & $0 \%$ \\
\hline (w) Metals (unspecified) & $\mathrm{g}$ & 95 & $0 \%$ & $0 \%$ & $0 \%$ & $97 \%$ & $3 \%$ & $0 \%$ & 97 & $0 \%$ & $0 \%$ & $0 \%$ & $100 \%$ & $0 \%$ \\
\hline (w) Hydrocarbons (unspecified) & $\mathrm{g}$ & 16 & $0 \%$ & $0 \%$ & $0 \%$ & $99 \%$ & $1 \%$ & $0 \%$ & 16 & $0 \%$ & $0 \%$ & $0 \%$ & $100 \%$ & $0 \%$ \\
\hline (w) Phenol $\left(\mathrm{C}_{6} \mathrm{H}_{6} \mathrm{O}\right)$ & $\mathrm{g}$ & 1.97 & $0 \%$ & $0 \%$ & $4 \%$ & $16 \%$ & $80 \%$ & $0 \%$ & 0.41 & $10 \%$ & $11 \%$ & $1 \%$ & $78 \%$ & $0 \%$ \\
\hline (w) Nitrates $\left(\mathrm{NO}_{3}-\right)$ & $\mathrm{g}$ & 4.23 & $0 \%$ & $0 \%$ & $27 \%$ & $73 \%$ & $0 \%$ & $0 \%$ & 13 & $0 \%$ & $75 \%$ & $0 \%$ & $25 \%$ & $0 \%$ \\
\hline (w) Oils (unspecified) & $\mathrm{g}$ & 71 & $0 \%$ & $0 \%$ & $7 \%$ & $39 \%$ & $53 \%$ & $0 \%$ & 32 & $4 \%$ & $4 \%$ & $0 \%$ & $91 \%$ & $0 \%$ \\
\hline (w) Suspended Matter (unspecified) & $\mathrm{g}$ & 451 & $0 \%$ & $0 \%$ & $4 \%$ & $14 \%$ & $82 \%$ & $0 \%$ & 87 & $11 \%$ & $13 \%$ & $1 \%$ & $75 \%$ & $0 \%$ \\
\hline Waste (nonhazardous) & $\mathrm{kg}$ & 512 & $0 \%$ & $0 \%$ & $98 \%$ & $1 \%$ & $1 \%$ & $0 \%$ & 190 & $0 \%$ & $97 \%$ & $0 \%$ & $3 \%$ & $0 \%$ \\
\hline E Feedstock Energy & MJ & 591 & $0 \%$ & $832 \%$ & $0 \%$ & $1961 \%$ & $587 \%$ & $-3280 \%$ & 1,065 & $0 \%$ & $835 \%$ & $0 \%$ & $1138 \%$ & $-1873 \%$ \\
\hline E Fuel Energy & MJ & 40,007 & $0 \%$ & $2 \%$ & $34 \%$ & $12 \%$ & $4 \%$ & $48 \%$ & 33,078 & $1 \%$ & $23 \%$ & $0 \%$ & $16 \%$ & $60 \%$ \\
\hline E Nonrenewable Energy & MJ & 40,525 & $0 \%$ & $14 \%$ & $33 \%$ & $40 \%$ & $12 \%$ & $0 \%$ & 20,688 & $1 \%$ & $15 \%$ & $0 \%$ & $84 \%$ & $0 \%$ \\
\hline E Renewable Energy & MJ & 74 & $0 \%$ & $1 \%$ & $51 \%$ & $39 \%$ & $8 \%$ & $0 \%$ & 13,455 & $0 \%$ & $100 \%$ & $0 \%$ & $0 \%$ & $0 \%$ \\
\hline E Total Primary Energy & MJ & 40,598 & $0 \%$ & $14 \%$ & $33 \%$ & $40 \%$ & $12 \%$ & $0 \%$ & 34,143 & $1 \%$ & $48 \%$ & $0 \%$ & $51 \%$ & $0 \%$ \\
\hline Eutrophication (water) & g eq. $\mathrm{PO}_{4}$ & 24 & $0 \%$ & $0 \%$ & $2 \%$ & $12 \%$ & $86 \%$ & $0 \%$ & 5.5 & $9 \%$ & $34 \%$ & $1 \%$ & $56 \%$ & $0 \%$ \\
\hline Depletion of Nonrenewable Resources & $\begin{array}{l}\text { frac. of } \\
\text { reserve* } 10^{15} / \mathrm{yr}\end{array}$ & 72 & $0 \%$ & $18 \%$ & $17 \%$ & $55 \%$ & $9 \%$ & $0 \%$ & 49 & $1 \%$ & $13 \%$ & $0 \%$ & $86 \%$ & $0 \%$ \\
\hline Air Acidification & g eq. $\mathrm{H}^{+}$ & 422 & $19 \%$ & $1 \%$ & $59 \%$ & $17 \%$ & $3 \%$ & $0 \%$ & 93 & $4 \%$ & $12 \%$ & $0 \%$ & $83 \%$ & $0 \%$ \\
\hline Greenhouse Effect (direct, 100 years) & g eq. $\mathrm{CO}_{2}$ & $3,019,698$ & $0 \%$ & $2 \%$ & $39 \%$ & $9 \%$ & $3 \%$ & $47 \%$ & $1,436,798$ & $1 \%$ & $12 \%$ & $0 \%$ & $21 \%$ & $66 \%$ \\
\hline
\end{tabular}


Table 66: Rice Straw Biomass, Enzyme-Based Ethanol Production, and Lignin Biomass Power

\begin{tabular}{|c|c|c|c|c|c|c|c|c|c|c|c|c|c|c|}
\hline Article & Units & $\begin{array}{c}\text { OPTION 1: } \\
\text { Total }\end{array}$ & $\begin{array}{l}\text { Biomass } \\
\text { Burning }\end{array}$ & $\begin{array}{l}\text { Natural Gas: } \\
\text { Production }\end{array}$ & $\begin{array}{l}\text { Methanol: } \\
\text { Production }\end{array}$ & $\begin{array}{l}\text { MTBE: } \\
\text { Production }\end{array}$ & $\begin{array}{l}\text { MTBE } \\
\text { RFG: } \\
\text { Production }\end{array}$ & $\begin{array}{c}\text { MTBE } \\
\text { RFG: Use }\end{array}$ & $\begin{array}{c}\text { OPTION 2: } \\
\text { Total }\end{array}$ & $\begin{array}{c}\text { Biomass } \\
\text { Harvesting }\end{array}$ & $\begin{array}{l}\text { Ethanol: } \\
\text { Production }\end{array}$ & $\begin{array}{l}\text { Ethanol: } \\
\text { Transport }\end{array}$ & $\begin{array}{c}\text { ETBE: } \\
\text { Production }\end{array}$ & $\begin{array}{l}\text { ETBE RFG: } \\
\text { Use }\end{array}$ \\
\hline (r) Bauxite $\left(\mathrm{Al}_{2} \mathrm{O}_{3}\right.$, ore $)$ & kg & 0.09 & $0 \%$ & $0 \%$ & $0 \%$ & $100 \%$ & $0 \%$ & $0 \%$ & 0.10 & $0 \%$ & $0 \%$ & $0 \%$ & $100 \%$ & $0 \%$ \\
\hline (r) Coal (in ground) & $\mathrm{kg}$ & 314 & $0 \%$ & $0 \%$ & $97 \%$ & $2 \%$ & $1 \%$ & $0 \%$ & -4.15 & $-5 \%$ & $252 \%$ & $0 \%$ & $-147 \%$ & $0 \%$ \\
\hline (r) Iron (Fe, ore) & $\mathrm{kg}$ & 0.06 & $0 \%$ & $0 \%$ & $1 \%$ & $99 \%$ & $0 \%$ & $0 \%$ & 0.06 & $0 \%$ & $0 \%$ & $0 \%$ & $100 \%$ & $0 \%$ \\
\hline (r) Limestone $\left(\mathrm{CaCO}_{3}\right.$, in ground) & $\mathrm{kg}$ & 46 & $0 \%$ & $0 \%$ & $98 \%$ & $0 \%$ & $1 \%$ & $0 \%$ & 3.72 & $1 \%$ & $97 \%$ & $0 \%$ & $2 \%$ & $0 \%$ \\
\hline (r) Natural Gas (in ground) & $\mathrm{kg}$ & 434 & $0 \%$ & $26 \%$ & $19 \%$ & $51 \%$ & $4 \%$ & $0 \%$ & 372 & $0 \%$ & $36 \%$ & $0 \%$ & $64 \%$ & $0 \%$ \\
\hline (r) Oil (in ground) & $\mathrm{kg}$ & 383 & $0 \%$ & $0 \%$ & $12 \%$ & $66 \%$ & $22 \%$ & $0 \%$ & 278 & $2 \%$ & $3 \%$ & $0 \%$ & $95 \%$ & $0 \%$ \\
\hline (r) Phosphate Rock (in ground) & $\mathrm{kg}$ & 0.00 & $0 \%$ & $0 \%$ & $0 \%$ & $0 \%$ & $0 \%$ & $0 \%$ & 0.02 & $0 \%$ & $100 \%$ & $0 \%$ & $0 \%$ & $0 \%$ \\
\hline (r) Potash $\left(\mathrm{K}_{2} \mathrm{O}\right.$, in ground $)$ & $\mathrm{kg}$ & 0.00 & $0 \%$ & $0 \%$ & $0 \%$ & $0 \%$ & $0 \%$ & $0 \%$ & 0.01 & $0 \%$ & $100 \%$ & $0 \%$ & $0 \%$ & $0 \%$ \\
\hline (r) Uranium (U, ore) & $\mathrm{kg}$ & 0.00 & $0 \%$ & $7 \%$ & $33 \%$ & $17 \%$ & $43 \%$ & $0 \%$ & -0.00041 & $-1 \%$ & $109 \%$ & $0 \%$ & $-8 \%$ & $0 \%$ \\
\hline Water Used (total) & liter & 546 & $0 \%$ & $0 \%$ & $7 \%$ & $91 \%$ & $2 \%$ & $0 \%$ & 36,671 & $0 \%$ & $0 \%$ & $0 \%$ & $100 \%$ & $0 \%$ \\
\hline Water: Unspecified Origin & liter & 533 & $0 \%$ & $0 \%$ & $7 \%$ & $93 \%$ & $0 \%$ & $0 \%$ & 520 & $0 \%$ & $1 \%$ & $0 \%$ & $99 \%$ & $0 \%$ \\
\hline (a) Carbon Dioxide $\left(\mathrm{CO}_{2}\right.$, biomass $)$ & $\mathrm{g}$ & $1,521,110$ & $100 \%$ & $0 \%$ & $0 \%$ & $0 \%$ & $0 \%$ & $0 \%$ & $1,532,090$ & $0 \%$ & $69 \%$ & $0 \%$ & $0 \%$ & $31 \%$ \\
\hline (a) Carbon Dioxide $\left(\mathrm{CO}_{2}\right.$, fossil) & $\mathrm{g}$ & $2,929,590$ & $0 \%$ & $1 \%$ & $39 \%$ & $9 \%$ & $2 \%$ & $49 \%$ & $1,578,910$ & $1 \%$ & $21 \%$ & $0 \%$ & $18 \%$ & $60 \%$ \\
\hline (a) Carbon Monoxide (CO) & g & 32,121 & $98 \%$ & $0 \%$ & $1 \%$ & $1 \%$ & $0 \%$ & $0 \%$ & 2,146 & $3 \%$ & $86 \%$ & $0 \%$ & $11 \%$ & $0 \%$ \\
\hline (a) Hydrocarbons (except methane) & $\mathrm{g}$ & 9,184 & $0 \%$ & $1 \%$ & $75 \%$ & $24 \%$ & $0 \%$ & $0 \%$ & 2,198 & $1 \%$ & $-6 \%$ & $0 \%$ & $105 \%$ & $0 \%$ \\
\hline (a) Volatile Organic Compounds (VOC) & $\mathrm{g}$ & 922 & $94 \%$ & $0 \%$ & $0 \%$ & $0 \%$ & $6 \%$ & $0 \%$ & 0.00 & $0 \%$ & $0 \%$ & $0 \%$ & $0 \%$ & $0 \%$ \\
\hline (a) Ethanol & $\mathrm{g}$ & $8.81 \mathrm{E}-07$ & $0 \%$ & $0 \%$ & $100 \%$ & $0 \%$ & $0 \%$ & $0 \%$ & 2,030 & $0 \%$ & $100 \%$ & $0 \%$ & $0 \%$ & $0 \%$ \\
\hline (a) Furfural & $\mathrm{g}$ & 0 & $0 \%$ & $0 \%$ & $0 \%$ & $0 \%$ & $0 \%$ & $0 \%$ & 54 & $0 \%$ & $100 \%$ & $0 \%$ & $0 \%$ & $0 \%$ \\
\hline $\begin{array}{l}\text { (a) } \mathrm{HMF} \\
\mathrm{l}\end{array}$ & $\mathrm{g}$ & 0 & $0 \%$ & $0 \%$ & $0 \%$ & $0 \%$ & $0 \%$ & $0 \%$ & 0.002 & $0 \%$ & $100 \%$ & $0 \%$ & $0 \%$ & $0 \%$ \\
\hline (a) Aldehydes & $\mathrm{g}$ & 4.99 & $0 \%$ & $7 \%$ & $89 \%$ & $3 \%$ & $2 \%$ & $0 \%$ & 0.44 & $1 \%$ & $64 \%$ & $0 \%$ & $35 \%$ & $0 \%$ \\
\hline (a) Formaldehyde & $\mathrm{g}$ & 0.80 & $0 \%$ & $1 \%$ & $48 \%$ & $14 \%$ & $37 \%$ & $0 \%$ & 0.57 & $3 \%$ & $73 \%$ & $0 \%$ & $24 \%$ & $0 \%$ \\
\hline (a) Benzene $\left(\mathrm{C}_{6} \mathrm{H}_{6}\right)$ & $\mathrm{g}$ & 92 & $0 \%$ & $46 \%$ & $30 \%$ & $17 \%$ & $6 \%$ & $0 \%$ & 69 & $0 \%$ & $73 \%$ & $0 \%$ & $27 \%$ & $0 \%$ \\
\hline (a) Hydrogen Chloride ( $\mathrm{HCl}$ ) & $\mathrm{g}$ & 162 & $0 \%$ & $0 \%$ & $97 \%$ & $2 \%$ & $1 \%$ & $0 \%$ & 4.08 & $2 \%$ & $15 \%$ & $0 \%$ & $83 \%$ & $0 \%$ \\
\hline (a) Hydrogen Fluoride (HF) & $\mathrm{g}$ & 20 & $0 \%$ & $0 \%$ & $98 \%$ & $0 \%$ & $1 \%$ & $0 \%$ & 0.11 & $11 \%$ & $71 \%$ & $1 \%$ & $17 \%$ & $0 \%$ \\
\hline (a) Hydrogen Sulfide $\left(\mathrm{H}_{2} \mathrm{~S}\right)$ & $\mathrm{g}$ & 0.94 & $0 \%$ & $0 \%$ & $1 \%$ & $33 \%$ & $66 \%$ & $0 \%$ & 0.42 & $9 \%$ & $13 \%$ & $1 \%$ & $77 \%$ & $0 \%$ \\
\hline (a) Metals (unspecified) & $\mathrm{g}$ & 0.31 & $0 \%$ & $0 \%$ & $0 \%$ & $100 \%$ & $0 \%$ & $0 \%$ & 0.32 & $0 \%$ & $0 \%$ & $0 \%$ & $100 \%$ & $0 \%$ \\
\hline (a) Methane $\left(\mathrm{CH}_{4}\right)$ & $\mathrm{g}$ & 3,452 & $0 \%$ & $41 \%$ & $35 \%$ & $16 \%$ & $8 \%$ & $0 \%$ & 2,367 & $1 \%$ & $73 \%$ & $0 \%$ & $27 \%$ & $0 \%$ \\
\hline (a) Nitrogen Oxides $\left(\mathrm{NO}_{\mathrm{x}}\right.$ as $\left.\mathrm{NO}_{2}\right)$ & g & 8,449 & $34 \%$ & $3 \%$ & $37 \%$ & $24 \%$ & $3 \%$ & $0 \%$ & 3,014 & $6 \%$ & $23 \%$ & $0 \%$ & $71 \%$ & $0 \%$ \\
\hline (a) Nitrous Oxide $\left(\mathrm{N}_{2} \mathrm{O}\right)$ & $\mathrm{g}$ & 57 & $0 \%$ & $1 \%$ & $90 \%$ & $2 \%$ & $6 \%$ & $0 \%$ & 33 & $5 \%$ & $89 \%$ & $0 \%$ & $5 \%$ & $0 \%$ \\
\hline (a) Particulates (unspecified) & $\mathrm{g}$ & 7,281 & $48 \%$ & $0 \%$ & $47 \%$ & $4 \%$ & $1 \%$ & $0 \%$ & 1,412 & $2 \%$ & $79 \%$ & $0 \%$ & $20 \%$ & $0 \%$ \\
\hline (a) Sulfur Oxides $\left(\mathrm{SO}_{\mathrm{x}}\right.$ as $\left.\mathrm{SO}_{2}\right)$ & $\mathrm{g}$ & 7,447 & $8 \%$ & $0 \%$ & $75 \%$ & $13 \%$ & $4 \%$ & $0 \%$ & 996 & $2 \%$ & $-1 \%$ & $0 \%$ & $99 \%$ & $0 \%$ \\
\hline (w) Ammonia $\left(\mathrm{NH}_{4}^{+}, \mathrm{NH}_{3}\right.$, as $\left.\mathrm{N}\right)$ & $\mathrm{g}$ & 16 & $0 \%$ & $0 \%$ & $4 \%$ & $20 \%$ & $76 \%$ & $0 \%$ & 4.09 & $8 \%$ & $13 \%$ & $1 \%$ & $79 \%$ & $0 \%$ \\
\hline (w) BOD (Biochemical Oxygen Demand) & $\mathrm{g}$ & 105 & $0 \%$ & $0 \%$ & $10 \%$ & $12 \%$ & $78 \%$ & $0 \%$ & 22 & $10 \%$ & $31 \%$ & $1 \%$ & $59 \%$ & $0 \%$ \\
\hline (w) COD (Chemical Oxygen Demand) & $\mathrm{g}$ & 761 & $0 \%$ & $0 \%$ & $0 \%$ & $8 \%$ & $91 \%$ & $0 \%$ & 121 & $15 \%$ & $30 \%$ & $1 \%$ & $54 \%$ & $0 \%$ \\
\hline (w) Metals (unspecified) & $\mathrm{g}$ & 95 & $0 \%$ & $0 \%$ & $0 \%$ & $97 \%$ & $3 \%$ & $0 \%$ & 97 & $0 \%$ & $0 \%$ & $0 \%$ & $100 \%$ & $0 \%$ \\
\hline (w) Hydrocarbons (unspecified) & $\mathrm{g}$ & 16 & $0 \%$ & $0 \%$ & $0 \%$ & $99 \%$ & $1 \%$ & $0 \%$ & 16 & $0 \%$ & $0 \%$ & $0 \%$ & $100 \%$ & $0 \%$ \\
\hline (w) Phenol $\left(\mathrm{C}_{6} \mathrm{H}_{6} \mathrm{O}\right)$ & g & 1.97 & $0 \%$ & $0 \%$ & $4 \%$ & $16 \%$ & $80 \%$ & $0 \%$ & 0.42 & $10 \%$ & $12 \%$ & $1 \%$ & $77 \%$ & $0 \%$ \\
\hline (w) Nitrates $\left(\mathrm{NO}_{3}^{-}\right)$ & $\mathrm{g}$ & 4.23 & $0 \%$ & $0 \%$ & $27 \%$ & $73 \%$ & $0 \%$ & $0 \%$ & 13 & $0 \%$ & $75 \%$ & $0 \%$ & $25 \%$ & $0 \%$ \\
\hline (w) Oils (unspecified) & $\mathrm{g}$ & 71 & $0 \%$ & $0 \%$ & $7 \%$ & $39 \%$ & $53 \%$ & $0 \%$ & 32 & $4 \%$ & $5 \%$ & $0 \%$ & $91 \%$ & $0 \%$ \\
\hline (w) Suspended Matter (unspecified) & $\mathrm{g}$ & 451 & $0 \%$ & $0 \%$ & $4 \%$ & $14 \%$ & $82 \%$ & $0 \%$ & 88 & $11 \%$ & $15 \%$ & $1 \%$ & $74 \%$ & $0 \%$ \\
\hline Waste (nonhazardous) & $\mathrm{kg}$ & 512 & $0 \%$ & $0 \%$ & $98 \%$ & $1 \%$ & $1 \%$ & $0 \%$ & 341 & $0 \%$ & $98 \%$ & $0 \%$ & $2 \%$ & $0 \%$ \\
\hline E Feedstock Energy & MJ & 591 & $0 \%$ & $832 \%$ & $0 \%$ & $1961 \%$ & $587 \%$ & $-3280 \%$ & 1,065 & $0 \%$ & $835 \%$ & $0 \%$ & $1138 \%$ & $-1873 \%$ \\
\hline E Fuel Energy & MJ & 40,007 & $0 \%$ & $2 \%$ & $34 \%$ & $12 \%$ & $4 \%$ & $48 \%$ & 36,139 & $1 \%$ & $29 \%$ & $0 \%$ & $15 \%$ & $55 \%$ \\
\hline E Nonrenewable Energy & MJ & 40,525 & $0 \%$ & $14 \%$ & $33 \%$ & $40 \%$ & $12 \%$ & $0 \%$ & 24,392 & $1 \%$ & $28 \%$ & $0 \%$ & $71 \%$ & $0 \%$ \\
\hline E Renewable Energy & MJ & 74 & $0 \%$ & $1 \%$ & $51 \%$ & $39 \%$ & $8 \%$ & $0 \%$ & 12,812 & $0 \%$ & $100 \%$ & $0 \%$ & $0 \%$ & $0 \%$ \\
\hline E Total Primary Energy & MJ & 40,598 & $0 \%$ & $14 \%$ & $33 \%$ & $40 \%$ & $12 \%$ & $0 \%$ & 37,204 & $1 \%$ & $52 \%$ & $0 \%$ & $47 \%$ & $0 \%$ \\
\hline Eutrophication (water) & g eq. $\mathrm{PO}_{4}$ & 24 & $0 \%$ & $0 \%$ & $2 \%$ & $12 \%$ & $86 \%$ & $0 \%$ & 5.60 & $9 \%$ & $34 \%$ & $1 \%$ & $55 \%$ & $0 \%$ \\
\hline Depletion of Nonrenewable Resources & $\begin{array}{l}\text { frac. of } \\
\text { reserve* } 10^{15} / \mathrm{yr}\end{array}$ & 72 & $0 \%$ & $18 \%$ & $17 \%$ & $55 \%$ & $9 \%$ & $0 \%$ & 59 & $1 \%$ & $27 \%$ & $0 \%$ & $72 \%$ & $0 \%$ \\
\hline Air Acidification & g eq. $\mathrm{H}^{+}$ & 422 & $19 \%$ & $1 \%$ & $59 \%$ & $17 \%$ & $3 \%$ & $0 \%$ & 97 & $4 \%$ & $15 \%$ & $0 \%$ & $80 \%$ & $0 \%$ \\
\hline Greenhouse Effect (direct, 100 years) & g eq. $\mathrm{CO}_{2}$ & $3,019,698$ & $0 \%$ & $2 \%$ & $39 \%$ & $9 \%$ & $3 \%$ & $47 \%$ & $1,638,881$ & $1 \%$ & $23 \%$ & $0 \%$ & $18 \%$ & $58 \%$ \\
\hline
\end{tabular}


Table 67: Rice Straw Biomass, Conc. Acid-Based Ethanol Production, and Lignin Cogeneration

\begin{tabular}{|c|c|c|c|c|c|c|c|c|c|c|c|c|c|c|}
\hline Article & Units & $\begin{array}{c}\text { OPTION 1: } \\
\text { Total } \\
\end{array}$ & $\begin{array}{l}\text { Biomass } \\
\text { Burning } \\
\end{array}$ & $\begin{array}{c}\text { Natural Gas: } \\
\text { Production }\end{array}$ & $\begin{array}{l}\text { Methanol: } \\
\text { Production }\end{array}$ & $\begin{array}{c}\text { MTBE: } \\
\text { Production }\end{array}$ & $\begin{array}{c}\text { MTBE RFG: } \\
\text { Production }\end{array}$ & $\begin{array}{c}\text { MTBE } \\
\text { RFG: Use } \\
\end{array}$ & $\begin{array}{c}\text { OPTION 2: } \\
\text { Total } \\
\end{array}$ & $\begin{array}{c}\text { Biomass } \\
\text { Harvesting } \\
\end{array}$ & $\begin{array}{c}\text { Ethanol: } \\
\text { Production }\end{array}$ & $\begin{array}{c}\text { Ethanol: } \\
\text { Transport } \\
\end{array}$ & $\begin{array}{c}\text { ETBE: } \\
\text { Production } \\
\end{array}$ & $\begin{array}{c}\text { ETBE RFG: } \\
\text { Use }\end{array}$ \\
\hline (r) Bauxite $\left(\mathrm{Al}_{2} \mathrm{O}_{3}\right.$, ore $)$ & $\mathrm{kg}$ & 0.08 & $0 \%$ & $0 \%$ & $0 \%$ & $100 \%$ & $0 \%$ & $0 \%$ & 0.09 & $0 \%$ & $0 \%$ & $0 \%$ & $100 \%$ & $0 \%$ \\
\hline (r) Coal (in ground) & $\mathrm{kg}$ & 282 & $0 \%$ & $0 \%$ & $97 \%$ & $2 \%$ & $1 \%$ & $0 \%$ & 8.21 & $2 \%$ & $31 \%$ & $0 \%$ & $67 \%$ & $0 \%$ \\
\hline (r) Iron $(\mathrm{Fe}$, ore $)$ & $\mathrm{kg}$ & 0.06 & $0 \%$ & $0 \%$ & $1 \%$ & $99 \%$ & $0 \%$ & $0 \%$ & 0.06 & $0 \%$ & $0 \%$ & $0 \%$ & $100 \%$ & $0 \%$ \\
\hline (r) Limestone $\left(\mathrm{CaCO}_{3}\right.$, in ground $)$ & $\mathrm{kg}$ & 42 & $0 \%$ & $0 \%$ & $98 \%$ & $0 \%$ & $1 \%$ & $0 \%$ & 46 & $0 \%$ & $100 \%$ & $0 \%$ & $0 \%$ & $0 \%$ \\
\hline (r) Natural Gas (in ground) & $\mathrm{kg}$ & 391 & $0 \%$ & $26 \%$ & $19 \%$ & $51 \%$ & $4 \%$ & $0 \%$ & 567 & $0 \%$ & $62 \%$ & $0 \%$ & $38 \%$ & $0 \%$ \\
\hline (r) Oil (in ground) & $\mathrm{kg}$ & 345 & $0 \%$ & $0 \%$ & $12 \%$ & $66 \%$ & $22 \%$ & $0 \%$ & 249 & $2 \%$ & $2 \%$ & $0 \%$ & $96 \%$ & $0 \%$ \\
\hline (r) Phosphate Rock (in ground) & $\mathrm{kg}$ & 0 & $0 \%$ & $0 \%$ & $0 \%$ & $0 \%$ & $0 \%$ & $0 \%$ & 0.046 & $0 \%$ & $100 \%$ & $0 \%$ & $0 \%$ & $0 \%$ \\
\hline (r) Potash $\left(\mathrm{K}_{2} \mathrm{O}\right.$, in ground) & $\mathrm{kg}$ & 0 & $0 \%$ & $0 \%$ & $0 \%$ & $0 \%$ & $0 \%$ & $0 \%$ & 0.012 & $0 \%$ & $100 \%$ & $0 \%$ & $0 \%$ & $0 \%$ \\
\hline (r) Uranium (U, ore) & $\mathrm{kg}$ & 0.00015 & $0 \%$ & $7 \%$ & $33 \%$ & $17 \%$ & $43 \%$ & $0 \%$ & $7.66 \mathrm{E}-05$ & $4 \%$ & $56 \%$ & $0 \%$ & $39 \%$ & $0 \%$ \\
\hline Water Used (total) & liter & 491 & $0 \%$ & $0 \%$ & $7 \%$ & $91 \%$ & $2 \%$ & $0 \%$ & 38,940 & $0 \%$ & $15 \%$ & $0 \%$ & $85 \%$ & $0 \%$ \\
\hline Water: Unspecified Origin & liter & 480 & $0 \%$ & $0 \%$ & $7 \%$ & $93 \%$ & $0 \%$ & $0 \%$ & 477 & $0 \%$ & $2 \%$ & $0 \%$ & $98 \%$ & $0 \%$ \\
\hline (a) Carbon Dioxide $\left(\mathrm{CO}_{2}\right.$, biomass $)$ & $\mathrm{g}$ & $1,521,110$ & $100 \%$ & $0 \%$ & $0 \%$ & $0 \%$ & $0 \%$ & $0 \%$ & $1,354,290$ & $0 \%$ & $68 \%$ & $0 \%$ & $0 \%$ & $32 \%$ \\
\hline (a) Carbon Dioxide $\left(\mathrm{CO}_{2}\right.$, fossil $)$ & $\mathrm{g}$ & $2,637,810$ & $0 \%$ & $1 \%$ & $39 \%$ & $9 \%$ & $2 \%$ & $49 \%$ & $1,979,070$ & $1 \%$ & $43 \%$ & $0 \%$ & $13 \%$ & $43 \%$ \\
\hline (a) Carbon Monoxide (CO) & $\mathrm{g}$ & 32,049 & $98 \%$ & $0 \%$ & $1 \%$ & $1 \%$ & $0 \%$ & $0 \%$ & 1,449 & $5 \%$ & $81 \%$ & $0 \%$ & $14 \%$ & $0 \%$ \\
\hline (a) Hydrocarbons (except methane) & $\mathrm{g}$ & 8,269 & $0 \%$ & $1 \%$ & $75 \%$ & $24 \%$ & $0 \%$ & $0 \%$ & 2,634 & $1 \%$ & $21 \%$ & $0 \%$ & $79 \%$ & $0 \%$ \\
\hline (a) Volatile Organic Compounds (VOC) & $\mathrm{g}$ & 917 & $95 \%$ & $0 \%$ & $0 \%$ & $0 \%$ & $5 \%$ & $0 \%$ & 0 & $0 \%$ & $0 \%$ & $0 \%$ & $0 \%$ & $0 \%$ \\
\hline (a) Ethanol & $\mathrm{g}$ & 7.93E-07 & $0 \%$ & $0 \%$ & $100 \%$ & $0 \%$ & $0 \%$ & $0 \%$ & 0 & $0 \%$ & $0 \%$ & $0 \%$ & $0 \%$ & $0 \%$ \\
\hline (a) Furfural & $\mathrm{g}$ & 0 & $0 \%$ & $0 \%$ & $0 \%$ & $0 \%$ & $0 \%$ & $0 \%$ & 146 & $0 \%$ & $100 \%$ & $0 \%$ & $0 \%$ & $0 \%$ \\
\hline (a) HMF & $\mathrm{g}$ & 0 & $0 \%$ & $0 \%$ & $0 \%$ & $0 \%$ & $0 \%$ & $0 \%$ & 437 & $0 \%$ & $100 \%$ & $0 \%$ & $0 \%$ & $0 \%$ \\
\hline (a) Aldehydes & $\mathrm{g}$ & 4.49 & $0 \%$ & $7 \%$ & $89 \%$ & $3 \%$ & $2 \%$ & $0 \%$ & 1.12 & $0 \%$ & $87 \%$ & $0 \%$ & $12 \%$ & $0 \%$ \\
\hline (a) Formaldehyde & $\mathrm{g}$ & 0.72 & $0 \%$ & $1 \%$ & $48 \%$ & $14 \%$ & $37 \%$ & $0 \%$ & 1.06 & $2 \%$ & $87 \%$ & $0 \%$ & $11 \%$ & $0 \%$ \\
\hline (a) Benzene $\left(\mathrm{C}_{6} \mathrm{H}_{6}\right)$ & $\mathrm{g}$ & 83 & $0 \%$ & $46 \%$ & $30 \%$ & $17 \%$ & $6 \%$ & $0 \%$ & 142 & $0 \%$ & $88 \%$ & $0 \%$ & $12 \%$ & $0 \%$ \\
\hline (a) Hydrogen Chloride $(\mathrm{HCl})$ & $\mathrm{g}$ & 146 & $0 \%$ & $0 \%$ & $97 \%$ & $2 \%$ & $1 \%$ & $0 \%$ & 4.17 & $2 \%$ & $25 \%$ & $0 \%$ & $73 \%$ & $0 \%$ \\
\hline (a) Hydrogen Fluoride (HF) & $\mathrm{g}$ & 18 & $0 \%$ & $0 \%$ & $98 \%$ & $0 \%$ & $1 \%$ & $0 \%$ & 0.16 & $7 \%$ & $82 \%$ & $1 \%$ & $10 \%$ & $0 \%$ \\
\hline (a) Hydrogen Sulfide $\left(\mathrm{H}_{2} \mathrm{~S}\right)$ & $\mathrm{g}$ & 0.85 & $0 \%$ & $0 \%$ & $1 \%$ & $33 \%$ & $66 \%$ & $0 \%$ & 0.36 & $11 \%$ & $8 \%$ & $1 \%$ & $80 \%$ & $0 \%$ \\
\hline (a) Metals (unspecified) & $\mathrm{g}$ & 0.28 & $0 \%$ & $0 \%$ & $0 \%$ & $100 \%$ & $0 \%$ & $0 \%$ & 0.29 & $0 \%$ & $0 \%$ & $0 \%$ & $100 \%$ & $0 \%$ \\
\hline (a) Methane $\left(\mathrm{CH}_{4}\right)$ & $\mathrm{g}$ & 3,108 & $0 \%$ & $41 \%$ & $35 \%$ & $16 \%$ & $8 \%$ & $0 \%$ & 4,968 & $0 \%$ & $88 \%$ & $0 \%$ & $11 \%$ & $0 \%$ \\
\hline (a) Nitrogen Oxides $\left(\mathrm{NO}_{\mathrm{x}}\right.$ as $\left.\mathrm{NO}_{2}\right)$ & $\mathrm{g}$ & 7,890 & $36 \%$ & $3 \%$ & $35 \%$ & $23 \%$ & $3 \%$ & $0 \%$ & 3,407 & $5 \%$ & $38 \%$ & $0 \%$ & $56 \%$ & $0 \%$ \\
\hline (a) Nitrous Oxide $\left(\mathrm{N}_{2} \mathrm{O}\right)$ & $\mathrm{g}$ & 51 & $0 \%$ & $1 \%$ & $90 \%$ & $2 \%$ & $6 \%$ & $0 \%$ & 16 & $11 \%$ & $79 \%$ & $1 \%$ & $9 \%$ & $0 \%$ \\
\hline (a) Particulates (unspecified) & $\mathrm{g}$ & 6,902 & $50 \%$ & $0 \%$ & $45 \%$ & $3 \%$ & $1 \%$ & $0 \%$ & 3,846 & $1 \%$ & $93 \%$ & $0 \%$ & $6 \%$ & $0 \%$ \\
\hline (a) Sulfur Oxides $\left(\mathrm{SO}_{\mathrm{x}}\right.$ as $\left.\mathrm{SO}_{2}\right)$ & $\mathrm{g}$ & 6,767 & $9 \%$ & $0 \%$ & $74 \%$ & $13 \%$ & $4 \%$ & $0 \%$ & 1,294 & $1 \%$ & $30 \%$ & $0 \%$ & $69 \%$ & $0 \%$ \\
\hline (w) Ammonia $\left(\mathrm{NH}_{4}^{+}, \mathrm{NH}_{3}\right.$, as $\left.\mathrm{N}\right)$ & $\mathrm{g}$ & 14 & $0 \%$ & $0 \%$ & $4 \%$ & $20 \%$ & $76 \%$ & $0 \%$ & 3.52 & $9 \%$ & $8 \%$ & $1 \%$ & $83 \%$ & $0 \%$ \\
\hline (w) BOD (Biochemical Oxygen Demand) & $\mathrm{g}$ & 95 & $0 \%$ & $0 \%$ & $10 \%$ & $12 \%$ & $78 \%$ & $0 \%$ & 17 & $13 \%$ & $15 \%$ & $1 \%$ & $71 \%$ & $0 \%$ \\
\hline (w) COD (Chemical Oxygen Demand) & $\mathrm{g}$ & 685 & $0 \%$ & $0 \%$ & $0 \%$ & $8 \%$ & $91 \%$ & $0 \%$ & 94 & $19 \%$ & $17 \%$ & $1 \%$ & $62 \%$ & $0 \%$ \\
\hline (w) Metals (unspecified) & $\mathrm{g}$ & 86 & $0 \%$ & $0 \%$ & $0 \%$ & $97 \%$ & $3 \%$ & $0 \%$ & 87 & $0 \%$ & $0 \%$ & $0 \%$ & $100 \%$ & $0 \%$ \\
\hline (w) Hydrocarbons (unspecified) & $\mathrm{g}$ & 14 & $0 \%$ & $0 \%$ & $0 \%$ & $99 \%$ & $1 \%$ & $0 \%$ & 15 & $0 \%$ & $0 \%$ & $0 \%$ & $100 \%$ & $0 \%$ \\
\hline (w) Phenol $\left(\mathrm{C}_{6} \mathrm{H}_{6} \mathrm{O}\right)$ & $\mathrm{g}$ & 1.77 & $0 \%$ & $0 \%$ & $4 \%$ & $16 \%$ & $80 \%$ & $0 \%$ & 0.36 & $11 \%$ & $6 \%$ & $1 \%$ & $82 \%$ & $0 \%$ \\
\hline (w) Nitrates $\left(\mathrm{NO}_{3}-\right.$-) & $\mathrm{g}$ & 3.81 & $0 \%$ & $0 \%$ & $27 \%$ & $73 \%$ & $0 \%$ & $0 \%$ & 22 & $0 \%$ & $86 \%$ & $0 \%$ & $14 \%$ & $0 \%$ \\
\hline (w) Oils (unspecified) & $\mathrm{g}$ & 64 & $0 \%$ & $0 \%$ & $7 \%$ & $39 \%$ & $53 \%$ & $0 \%$ & 29 & $4 \%$ & $4 \%$ & $0 \%$ & $91 \%$ & $0 \%$ \\
\hline (w) Suspended Matter (unspecified) & $\mathrm{g}$ & 406 & $0 \%$ & $0 \%$ & $4 \%$ & $14 \%$ & $82 \%$ & $0 \%$ & 78 & $12 \%$ & $11 \%$ & $1 \%$ & $75 \%$ & $0 \%$ \\
\hline Waste (nonhazardous) & $\mathrm{kg}$ & 461 & $0 \%$ & $0 \%$ & $98 \%$ & $1 \%$ & $1 \%$ & $0 \%$ & 253 & $0 \%$ & $98 \%$ & $0 \%$ & $2 \%$ & $0 \%$ \\
\hline E Feedstock Energy & MJ & 532 & $0 \%$ & $832 \%$ & $0 \%$ & $1961 \%$ & $587 \%$ & $-3280 \%$ & 959 & $0 \%$ & $835 \%$ & $0 \%$ & $1138 \%$ & $-1873 \%$ \\
\hline E Fuel Energy & MJ & 36,023 & $0 \%$ & $2 \%$ & $34 \%$ & $12 \%$ & $4 \%$ & $48 \%$ & 44,967 & $1 \%$ & $49 \%$ & $0 \%$ & $11 \%$ & $40 \%$ \\
\hline E Nonrenewable Energy & MJ & 36,489 & $0 \%$ & $14 \%$ & $33 \%$ & $40 \%$ & $12 \%$ & $0 \%$ & 34,153 & $1 \%$ & $53 \%$ & $0 \%$ & $46 \%$ & $0 \%$ \\
\hline E Renewable Energy & MJ & 66 & $0 \%$ & $1 \%$ & $51 \%$ & $39 \%$ & $8 \%$ & $0 \%$ & 11,774 & $0 \%$ & $100 \%$ & $0 \%$ & $0 \%$ & $0 \%$ \\
\hline E Total Primary Energy & MJ & 36,555 & $0 \%$ & $14 \%$ & $33 \%$ & $40 \%$ & $12 \%$ & $0 \%$ & 45,926 & $1 \%$ & $65 \%$ & $0 \%$ & $34 \%$ & $0 \%$ \\
\hline Eutrophication (water) & g eq. $\mathrm{PO}_{4}$ & 21 & $0 \%$ & $0 \%$ & $2 \%$ & $12 \%$ & $86 \%$ & $0 \%$ & 5.60 & $9 \%$ & $40 \%$ & $1 \%$ & $50 \%$ & $0 \%$ \\
\hline Depletion of Nonrenewable Resources & $\begin{array}{l}\text { frac. of } \\
\text { reserve* } 10^{15} / \mathrm{yr}\end{array}$ & 65 & $0 \%$ & $18 \%$ & $17 \%$ & $55 \%$ & $9 \%$ & $0 \%$ & 80 & $0 \%$ & $52 \%$ & $0 \%$ & $48 \%$ & $0 \%$ \\
\hline Air Acidification & g eq. $\mathrm{H}^{+}$ & 388 & $21 \%$ & $1 \%$ & $57 \%$ & $17 \%$ & $3 \%$ & $0 \%$ & 115 & $4 \%$ & $35 \%$ & $0 \%$ & $61 \%$ & $0 \%$ \\
\hline Greenhouse Effect (direct, 100 years) & g eq. $\mathrm{CO}_{2}$ & $2,718,943$ & $0 \%$ & $2 \%$ & $39 \%$ & $9 \%$ & $3 \%$ & $47 \%$ & $2,088,355$ & $1 \%$ & $45 \%$ & $0 \%$ & $13 \%$ & $41 \%$ \\
\hline
\end{tabular}


Table 68: Rice Straw Biomass, Conc. Acid-Based Ethanol Production, and Lignin Biomass Power

\begin{tabular}{|c|c|c|c|c|c|c|c|c|c|c|c|c|c|c|}
\hline Article & Units & $\begin{array}{l}\text { OPTION 1: } \\
\text { Total }\end{array}$ & $\begin{array}{l}\text { Biomass } \\
\text { Burning }\end{array}$ & $\begin{array}{l}\text { Natural Gas: } \\
\text { Production }\end{array}$ & $\begin{array}{l}\text { Methanol: } \\
\text { Production }\end{array}$ & $\begin{array}{l}\text { MTBE: } \\
\text { Production }\end{array}$ & $\begin{array}{c}\text { MTBE } \\
\text { RFG: } \\
\text { Production }\end{array}$ & $\begin{array}{c}\text { MTBE } \\
\text { RFG: Use }\end{array}$ & $\begin{array}{c}\text { OPTION 2: } \\
\text { Total }\end{array}$ & $\begin{array}{c}\text { Biomass } \\
\text { Harvesting }\end{array}$ & $\begin{array}{l}\text { Ethanol: } \\
\text { Production }\end{array}$ & $\begin{array}{l}\text { Ethanol: } \\
\text { Transport }\end{array}$ & $\begin{array}{l}\text { ETBE: } \\
\text { Production }\end{array}$ & $\begin{array}{l}\text { ETBE RFG: } \\
\text { Use }\end{array}$ \\
\hline (r) Bauxite $\left(\mathrm{Al}_{2} \mathrm{O}_{3}\right.$, ore $)$ & $\mathrm{kg}$ & 0.084 & $0 \%$ & $0 \%$ & $0 \%$ & $100 \%$ & $0 \%$ & $0 \%$ & 0.087 & $0 \%$ & $0 \%$ & $0 \%$ & $100 \%$ & $0 \%$ \\
\hline (r) Coal (in ground) & $\mathrm{kg}$ & 282 & $0 \%$ & $0 \%$ & $97 \%$ & $2 \%$ & $1 \%$ & $0 \%$ & 0.49 & $40 \%$ & $-1064 \%$ & $3 \%$ & $1120 \%$ & $0 \%$ \\
\hline (r) Iron $(\mathrm{Fe}$, ore $)$ & $\mathrm{kg}$ & 0.056 & $0 \%$ & $0 \%$ & $1 \%$ & $99 \%$ & $0 \%$ & $0 \%$ & 0.058 & $0 \%$ & $0 \%$ & $0 \%$ & $100 \%$ & $0 \%$ \\
\hline (r) Limestone $\left(\mathrm{CaCO}_{3}\right.$, in ground $)$ & $\mathrm{kg}$ & 42 & $0 \%$ & $0 \%$ & $98 \%$ & $0 \%$ & $1 \%$ & $0 \%$ & 46 & $0 \%$ & $100 \%$ & $0 \%$ & $0 \%$ & $0 \%$ \\
\hline (r) Natural Gas (in ground) & $\mathrm{kg}$ & 391 & $0 \%$ & $26 \%$ & $19 \%$ & $51 \%$ & $4 \%$ & $0 \%$ & 706 & $0 \%$ & $70 \%$ & $0 \%$ & $30 \%$ & $0 \%$ \\
\hline (r) Oil (in ground) & $\mathrm{kg}$ & 345 & $0 \%$ & $0 \%$ & $12 \%$ & $66 \%$ & $22 \%$ & $0 \%$ & 250 & $2 \%$ & $2 \%$ & $0 \%$ & $95 \%$ & $0 \%$ \\
\hline (r) Phosphate Rock (in ground) & $\mathrm{kg}$ & 0 & $0 \%$ & $0 \%$ & $0 \%$ & $0 \%$ & $0 \%$ & $0 \%$ & 0.046 & $0 \%$ & $100 \%$ & $0 \%$ & $0 \%$ & $0 \%$ \\
\hline (r) Potash $\left(\mathrm{K}_{2} \mathrm{O}\right.$, in ground) & $\mathrm{kg}$ & 0 & $0 \%$ & $0 \%$ & $0 \%$ & $0 \%$ & $0 \%$ & $0 \%$ & 0.012 & $0 \%$ & $100 \%$ & $0 \%$ & $0 \%$ & $0 \%$ \\
\hline (r) Uranium (U, ore) & $\mathrm{kg}$ & 0.0002 & $0 \%$ & $7 \%$ & $33 \%$ & $17 \%$ & $43 \%$ & $0 \%$ & -0.0003 & $-1 \%$ & $113 \%$ & $0 \%$ & $-12 \%$ & $0 \%$ \\
\hline Water Used (total) & liter & 491 & $0 \%$ & $0 \%$ & $7 \%$ & $91 \%$ & $2 \%$ & $0 \%$ & 38,940 & $0 \%$ & $15 \%$ & $0 \%$ & $85 \%$ & $0 \%$ \\
\hline Water: Unspecified Origin & liter & 480 & $0 \%$ & $0 \%$ & $7 \%$ & $93 \%$ & $0 \%$ & $0 \%$ & 477 & $0 \%$ & $2 \%$ & $0 \%$ & $98 \%$ & $0 \%$ \\
\hline (a) Carbon Dioxide ( $\mathrm{CO}_{2}$, biomass $)$ & $\mathrm{g}$ & $1,521,110$ & $100 \%$ & $0 \%$ & $0 \%$ & $0 \%$ & $0 \%$ & $0 \%$ & $1,349,980$ & $0 \%$ & $68 \%$ & $0 \%$ & $0 \%$ & $32 \%$ \\
\hline (a) Carbon Dioxide $\left(\mathrm{CO}_{2}\right.$, fossil $)$ & $\mathrm{g}$ & $2,637,810$ & $0 \%$ & $1 \%$ & $39 \%$ & $9 \%$ & $2 \%$ & $49 \%$ & $2,298,370$ & $1 \%$ & $51 \%$ & $0 \%$ & $11 \%$ & $37 \%$ \\
\hline (a) Carbon Monoxide (CO) & $\mathrm{g}$ & 32,049 & $98 \%$ & $0 \%$ & $1 \%$ & $1 \%$ & $0 \%$ & $0 \%$ & 2,539 & $3 \%$ & $89 \%$ & $0 \%$ & $8 \%$ & $0 \%$ \\
\hline (a) Hydrocarbons (except methane) & $\mathrm{g}$ & 8,269 & $0 \%$ & $1 \%$ & $75 \%$ & $24 \%$ & $0 \%$ & $0 \%$ & 2,561 & $1 \%$ & $18 \%$ & $0 \%$ & $81 \%$ & $0 \%$ \\
\hline (a) Volatile Organic Compounds (VOC) & $\mathrm{g}$ & 917 & $95 \%$ & $0 \%$ & $0 \%$ & $0 \%$ & $5 \%$ & $0 \%$ & 0.00 & $0 \%$ & $0 \%$ & $0 \%$ & $0 \%$ & $0 \%$ \\
\hline (a) Ethanol & $\mathrm{g}$ & $7.93 \mathrm{E}-07$ & $0 \%$ & $0 \%$ & $100 \%$ & $0 \%$ & $0 \%$ & $0 \%$ & 1,860 & $0 \%$ & $100 \%$ & $0 \%$ & $0 \%$ & $0 \%$ \\
\hline (a) Furfural & $\mathrm{g}$ & 0 & $0 \%$ & $0 \%$ & $0 \%$ & $0 \%$ & $0 \%$ & $0 \%$ & 37 & $0 \%$ & $100 \%$ & $0 \%$ & $0 \%$ & $0 \%$ \\
\hline (a) HMF & $\mathrm{g}$ & 0 & $0 \%$ & $0 \%$ & $0 \%$ & $0 \%$ & $0 \%$ & $0 \%$ & 0.41 & $0 \%$ & $100 \%$ & $0 \%$ & $0 \%$ & $0 \%$ \\
\hline (a) Aldehydes & $\mathrm{g}$ & 4.49 & $0 \%$ & $7 \%$ & $89 \%$ & $3 \%$ & $2 \%$ & $0 \%$ & 1.43 & $0 \%$ & $90 \%$ & $0 \%$ & $10 \%$ & $0 \%$ \\
\hline (a) Formaldehyde & $\mathrm{g}$ & 0.72 & $0 \%$ & $1 \%$ & $48 \%$ & $14 \%$ & $37 \%$ & $0 \%$ & 1.47 & $1 \%$ & $90 \%$ & $0 \%$ & $8 \%$ & $0 \%$ \\
\hline (a) Benzene $\left(\mathrm{C}_{6} \mathrm{H}_{6}\right)$ & $\mathrm{g}$ & 83 & $0 \%$ & $46 \%$ & $30 \%$ & $17 \%$ & $6 \%$ & $0 \%$ & 194 & $0 \%$ & $91 \%$ & $0 \%$ & $9 \%$ & $0 \%$ \\
\hline (a) Hydrogen Chloride $(\mathrm{HCl})$ & $\mathrm{g}$ & 146 & $0 \%$ & $0 \%$ & $97 \%$ & $2 \%$ & $1 \%$ & $0 \%$ & 4.58 & $2 \%$ & $31 \%$ & $0 \%$ & $66 \%$ & $0 \%$ \\
\hline (a) Hydrogen Fluoride (HF) & $\mathrm{g}$ & 17.91 & $0 \%$ & $0 \%$ & $98 \%$ & $0 \%$ & $1 \%$ & $0 \%$ & 0.21 & $5 \%$ & $86 \%$ & $0 \%$ & $8 \%$ & $0 \%$ \\
\hline (a) Hydrogen Sulfide $\left(\mathrm{H}_{2} \mathrm{~S}\right)$ & $\mathrm{g}$ & 0.85 & $0 \%$ & $0 \%$ & $1 \%$ & $33 \%$ & $66 \%$ & $0 \%$ & 0.37 & $11 \%$ & $10 \%$ & $1 \%$ & $79 \%$ & $0 \%$ \\
\hline (a) Metals (unspecified) & $\mathrm{g}$ & 0.28 & $0 \%$ & $0 \%$ & $0 \%$ & $100 \%$ & $0 \%$ & $0 \%$ & 0.29 & $0 \%$ & $0 \%$ & $0 \%$ & $100 \%$ & $0 \%$ \\
\hline (a) Methane $\left(\mathrm{CH}_{4}\right)$ & $\mathrm{g}$ & 3,108 & $0 \%$ & $41 \%$ & $35 \%$ & $16 \%$ & $8 \%$ & $0 \%$ & 6,735 & $0 \%$ & $91 \%$ & $0 \%$ & $8 \%$ & $0 \%$ \\
\hline (a) Nitrogen Oxides $\left(\mathrm{NO}_{\mathrm{x}}\right.$ as $\left.\mathrm{NO}_{2}\right)$ & $\mathrm{g}$ & 7,890 & $36 \%$ & $3 \%$ & $35 \%$ & $23 \%$ & $3 \%$ & $0 \%$ & 4,053 & $4 \%$ & $48 \%$ & $0 \%$ & $47 \%$ & $0 \%$ \\
\hline (a) Nitrous Oxide $\left(\mathrm{N}_{2} \mathrm{O}\right)$ & $\mathrm{g}$ & 51 & $0 \%$ & $1 \%$ & $90 \%$ & $2 \%$ & $6 \%$ & $0 \%$ & 39 & $5 \%$ & $91 \%$ & $0 \%$ & $4 \%$ & $0 \%$ \\
\hline (a) Particulates (unspecified) & $\mathrm{g}$ & 6,902 & $50 \%$ & $0 \%$ & $45 \%$ & $3 \%$ & $1 \%$ & $0 \%$ & 4,394 & $1 \%$ & $94 \%$ & $0 \%$ & $6 \%$ & $0 \%$ \\
\hline (a) Sulfur Oxides $\left(\mathrm{SO}_{\mathrm{x}}\right.$ as $\left.\mathrm{SO}_{2}\right)$ & $\mathrm{g}$ & 6,767 & $9 \%$ & $0 \%$ & $74 \%$ & $13 \%$ & $4 \%$ & $0 \%$ & 1,171 & $1 \%$ & $22 \%$ & $0 \%$ & $76 \%$ & $0 \%$ \\
\hline (w) Ammonia $\left(\mathrm{NH}_{4}^{+}, \mathrm{NH}_{3}\right.$, as $\left.\mathrm{N}\right)$ & $\mathrm{g}$ & 14 & $0 \%$ & $0 \%$ & $4 \%$ & $20 \%$ & $76 \%$ & $0 \%$ & 3.55 & $9 \%$ & $8 \%$ & $1 \%$ & $82 \%$ & $0 \%$ \\
\hline (w) BOD (Biochemical Oxygen Demand) & $\mathrm{g}$ & 95 & $0 \%$ & $0 \%$ & $10 \%$ & $12 \%$ & $78 \%$ & $0 \%$ & 17 & $13 \%$ & $17 \%$ & $1 \%$ & $69 \%$ & $0 \%$ \\
\hline (w) COD (Chemical Oxygen Demand) & $\mathrm{g}$ & 685 & $0 \%$ & $0 \%$ & $0 \%$ & $8 \%$ & $91 \%$ & $0 \%$ & 98 & $18 \%$ & $20 \%$ & $1 \%$ & $60 \%$ & $0 \%$ \\
\hline (w) Metals (unspecified) & $\mathrm{g}$ & 86 & $0 \%$ & $0 \%$ & $0 \%$ & $97 \%$ & $3 \%$ & $0 \%$ & 88 & $0 \%$ & $0 \%$ & $0 \%$ & $100 \%$ & $0 \%$ \\
\hline (w) Hydrocarbons (unspecified) & $\mathrm{g}$ & 14 & $0 \%$ & $0 \%$ & $0 \%$ & $99 \%$ & $1 \%$ & $0 \%$ & 15 & $0 \%$ & $0 \%$ & $0 \%$ & $100 \%$ & $0 \%$ \\
\hline (w) Phenol $\left(\mathrm{C}_{6} \mathrm{H}_{6} \mathrm{O}\right)$ & $\mathrm{g}$ & 1.77 & $0 \%$ & $0 \%$ & $4 \%$ & $16 \%$ & $80 \%$ & $0 \%$ & 0.36 & $11 \%$ & $7 \%$ & $1 \%$ & $81 \%$ & $0 \%$ \\
\hline (w) Nitrates $\left(\mathrm{NO}_{3}^{-}\right)$ & $\mathrm{g}$ & 3.81 & $0 \%$ & $0 \%$ & $27 \%$ & $73 \%$ & $0 \%$ & $0 \%$ & 22 & $0 \%$ & $86 \%$ & $0 \%$ & $14 \%$ & $0 \%$ \\
\hline (w) Oils (unspecified) & $\mathrm{g}$ & 64 & $0 \%$ & $0 \%$ & $7 \%$ & $39 \%$ & $53 \%$ & $0 \%$ & 29 & $4 \%$ & $5 \%$ & $0 \%$ & $91 \%$ & $0 \%$ \\
\hline (w) Suspended Matter (unspecified) & $\mathrm{g}$ & 406 & $0 \%$ & $0 \%$ & $4 \%$ & $14 \%$ & $82 \%$ & $0 \%$ & 79 & $12 \%$ & $13 \%$ & $1 \%$ & $74 \%$ & $0 \%$ \\
\hline Waste (nonhazardous) & $\mathrm{kg}$ & 461 & $0 \%$ & $0 \%$ & $98 \%$ & $1 \%$ & $1 \%$ & $0 \%$ & 406 & $0 \%$ & $99 \%$ & $0 \%$ & $1 \%$ & $0 \%$ \\
\hline E Feedstock Energy & MJ & 532 & $0 \%$ & $832 \%$ & $0 \%$ & $1961 \%$ & $587 \%$ & $-3280 \%$ & 959 & $0 \%$ & $835 \%$ & $0 \%$ & $1138 \%$ & $-1873 \%$ \\
\hline E Fuel Energy & MJ & 36,023 & $0 \%$ & $2 \%$ & $34 \%$ & $12 \%$ & $4 \%$ & $48 \%$ & 51,245 & $1 \%$ & $55 \%$ & $0 \%$ & $9 \%$ & $35 \%$ \\
\hline E Nonrenewable Energy & MJ & 36,489 & $0 \%$ & $14 \%$ & $33 \%$ & $40 \%$ & $12 \%$ & $0 \%$ & 40,942 & $1 \%$ & $61 \%$ & $0 \%$ & $38 \%$ & $0 \%$ \\
\hline E Renewable Energy & MJ & 66 & $0 \%$ & $1 \%$ & $51 \%$ & $39 \%$ & $8 \%$ & $0 \%$ & 11,262 & $0 \%$ & $100 \%$ & $0 \%$ & $0 \%$ & $0 \%$ \\
\hline E Total Primary Energy & MJ & 36,555 & $0 \%$ & $14 \%$ & $33 \%$ & $40 \%$ & $12 \%$ & $0 \%$ & 52,204 & $1 \%$ & $69 \%$ & $0 \%$ & $30 \%$ & $0 \%$ \\
\hline Eutrophication (water) & g eq. $\mathrm{PO}_{4}$ & 21 & $0 \%$ & $0 \%$ & $2 \%$ & $12 \%$ & $86 \%$ & $0 \%$ & 5.69 & $9 \%$ & $41 \%$ & $1 \%$ & $49 \%$ & $0 \%$ \\
\hline Depletion of Nonrenewable Resources & $\begin{array}{l}\text { frac. of } \\
\text { reserve* } 10^{15} / \mathrm{yr}\end{array}$ & 65 & $0 \%$ & $18 \%$ & $17 \%$ & $55 \%$ & $9 \%$ & $0 \%$ & 96 & $0 \%$ & $60 \%$ & $0 \%$ & $40 \%$ & $0 \%$ \\
\hline Air Acidification & g eq. $\mathrm{H}^{+}$ & 388 & $21 \%$ & $1 \%$ & $57 \%$ & $17 \%$ & $3 \%$ & $0 \%$ & 125 & $3 \%$ & $41 \%$ & $0 \%$ & $56 \%$ & $0 \%$ \\
\hline Greenhouse Effect (direct, 100 years) & g eq. $\mathrm{CO}_{2}$ & $2,718,943$ & $0 \%$ & $2 \%$ & $39 \%$ & $9 \%$ & $3 \%$ & $47 \%$ & $2,451,787$ & $1 \%$ & $53 \%$ & $0 \%$ & $11 \%$ & $35 \%$ \\
\hline
\end{tabular}


Table 69: Forest Residue Biomass, Enzyme-Based Ethanol Production, and Lignin Cogeneration

\begin{tabular}{|c|c|c|c|c|c|c|c|c|c|c|c|c|c|c|}
\hline Article & Units & $\begin{array}{c}\text { OPTION 1: } \\
\text { Total }\end{array}$ & $\begin{array}{l}\text { Biomass } \\
\text { Burning }\end{array}$ & $\begin{array}{l}\text { Natural Gas: } \\
\text { Production }\end{array}$ & $\begin{array}{l}\text { Methanol: } \\
\text { Production }\end{array}$ & $\begin{array}{l}\text { MTBE: } \\
\text { Production }\end{array}$ & $\begin{array}{l}\text { MTBE } \\
\text { RFG: } \\
\text { Production }\end{array}$ & $\begin{array}{c}\text { MTBE } \\
\text { RFG: Use }\end{array}$ & $\begin{array}{c}\text { OPTION 2: } \\
\text { Total }\end{array}$ & $\begin{array}{c}\text { Biomass } \\
\text { Harvesting }\end{array}$ & $\begin{array}{l}\text { Ethanol: } \\
\text { Production }\end{array}$ & $\begin{array}{l}\text { Ethanol: } \\
\text { Transport }\end{array}$ & $\begin{array}{l}\text { ETBE: } \\
\text { Production }\end{array}$ & $\begin{array}{l}\text { ETBE RFG: } \\
\text { Use }\end{array}$ \\
\hline (r) Bauxite $\left(\mathrm{Al}_{2} \mathrm{O}_{3}\right.$, ore $)$ & kg & 0.10 & $0 \%$ & $0 \%$ & $0 \%$ & $100 \%$ & $0 \%$ & $0 \%$ & 0.11 & $0 \%$ & $0 \%$ & $0 \%$ & $100 \%$ & $0 \%$ \\
\hline (r) Coal (in ground) & $\mathrm{kg}$ & 344 & $0 \%$ & $0 \%$ & $96 \%$ & $2 \%$ & $1 \%$ & $0 \%$ & -9.18 & $-6 \%$ & $179 \%$ & $0 \%$ & $-73 \%$ & $0 \%$ \\
\hline (r) Iron $(\mathrm{Fe}$, ore $)$ & $\mathrm{kg}$ & 0.069 & $0 \%$ & $0 \%$ & $1 \%$ & $99 \%$ & $0 \%$ & $0 \%$ & 0.071 & $0 \%$ & $0 \%$ & $0 \%$ & $100 \%$ & $0 \%$ \\
\hline (r) Limestone $\left(\mathrm{CaCO}_{3}\right.$, in ground) & $\mathrm{kg}$ & 51 & $0 \%$ & $0 \%$ & $98 \%$ & $0 \%$ & $1 \%$ & $0 \%$ & 3.49 & $2 \%$ & $95 \%$ & $0 \%$ & $2 \%$ & $0 \%$ \\
\hline (r) Natural Gas (in ground) & $\mathrm{kg}$ & 477 & $0 \%$ & $26 \%$ & $19 \%$ & $51 \%$ & $4 \%$ & $0 \%$ & 247 & $1 \%$ & $-6 \%$ & $0 \%$ & $105 \%$ & $0 \%$ \\
\hline (r) Oil (in ground) & $\mathrm{kg}$ & 427 & $2 \%$ & $0 \%$ & $11 \%$ & $65 \%$ & $22 \%$ & $0 \%$ & 314 & $5 \%$ & $2 \%$ & $0 \%$ & $92 \%$ & $0 \%$ \\
\hline (r) Phosphate Rock (in ground) & $\mathrm{kg}$ & 0 & $0 \%$ & $0 \%$ & $0 \%$ & $0 \%$ & $0 \%$ & $0 \%$ & 0.025 & $0 \%$ & $100 \%$ & $0 \%$ & $0 \%$ & $0 \%$ \\
\hline (r) Potash $\left(\mathrm{K}_{2} \mathrm{O}\right.$, in ground $)$ & $\mathrm{kg}$ & 0 & $0 \%$ & $0 \%$ & $0 \%$ & $0 \%$ & $0 \%$ & $0 \%$ & 0.006 & $0 \%$ & $100 \%$ & $0 \%$ & $0 \%$ & $0 \%$ \\
\hline (r) Uranium (U, ore) & $\mathrm{kg}$ & 0.00019 & $3 \%$ & $7 \%$ & $32 \%$ & $16 \%$ & $42 \%$ & $0 \%$ & -0.0006 & $-2 \%$ & $108 \%$ & $0 \%$ & $-6 \%$ & $0 \%$ \\
\hline Water Used (total) & liter & 600 & $0 \%$ & $0 \%$ & $7 \%$ & $90 \%$ & $2 \%$ & $0 \%$ & 43,988 & $0 \%$ & $9 \%$ & $0 \%$ & $91 \%$ & $0 \%$ \\
\hline Water: Unspecified Origin & liter & 585 & $0 \%$ & $0 \%$ & $7 \%$ & $93 \%$ & $0 \%$ & $0 \%$ & 570 & $0 \%$ & $1 \%$ & $0 \%$ & $99 \%$ & $0 \%$ \\
\hline (a) Carbon Dioxide $\left(\mathrm{CO}_{2}\right.$, biomass $)$ & $\mathrm{g}$ & $1,887,770$ & $100 \%$ & $0 \%$ & $0 \%$ & $0 \%$ & $0 \%$ & $0 \%$ & $1,925,160$ & $0 \%$ & $73 \%$ & $0 \%$ & $0 \%$ & $27 \%$ \\
\hline (a) Carbon Dioxide $\left(\mathrm{CO}_{2}\right.$, fossil) & $\mathrm{g}$ & $3,237,431$ & $1 \%$ & $1 \%$ & $38 \%$ & $9 \%$ & $2 \%$ & $48 \%$ & $1,361,190$ & $4 \%$ & $-4 \%$ & $0 \%$ & $23 \%$ & $77 \%$ \\
\hline (a) Carbon Monoxide (CO) & $\mathrm{g}$ & 71,698 & $99 \%$ & $0 \%$ & $0 \%$ & $0 \%$ & $0 \%$ & $0 \%$ & 1,275 & $16 \%$ & $64 \%$ & $0 \%$ & $20 \%$ & $0 \%$ \\
\hline (a) Hydrocarbons (except methane) & $\mathrm{g}$ & 10,096 & $0 \%$ & $1 \%$ & $75 \%$ & $24 \%$ & $0 \%$ & $0 \%$ & 2,213 & $2 \%$ & $-16 \%$ & $0 \%$ & $114 \%$ & $0 \%$ \\
\hline (a) Volatile Organic Compounds (VOC) & $\mathrm{g}$ & 59 & $0 \%$ & $0 \%$ & $0 \%$ & $0 \%$ & $100 \%$ & $0 \%$ & 0 & $0 \%$ & $0 \%$ & $0 \%$ & $0 \%$ & $0 \%$ \\
\hline (a) Ethanol & $\mathrm{g}$ & $9.66 \mathrm{E}-07$ & $0 \%$ & $0 \%$ & $100 \%$ & $0 \%$ & $0 \%$ & $0 \%$ & 207 & $0 \%$ & $100 \%$ & $0 \%$ & $0 \%$ & $0 \%$ \\
\hline (a) Furfural & $\mathrm{g}$ & 0 & $0 \%$ & $0 \%$ & $0 \%$ & $0 \%$ & $0 \%$ & $0 \%$ & 325 & $0 \%$ & $100 \%$ & $0 \%$ & $0 \%$ & $0 \%$ \\
\hline (a) HMF & $\mathrm{g}$ & 0 & $0 \%$ & $0 \%$ & $0 \%$ & $0 \%$ & $0 \%$ & $0 \%$ & 1,620 & $0 \%$ & $100 \%$ & $0 \%$ & $0 \%$ & $0 \%$ \\
\hline (a) Aldehydes & $\mathrm{g}$ & 5.48 & $0 \%$ & $7 \%$ & $89 \%$ & $3 \%$ & $2 \%$ & $0 \%$ & -0.02 & $-65 \%$ & $1043 \%$ & $-2 \%$ & $-876 \%$ & $0 \%$ \\
\hline (a) Formaldehyde & $\mathrm{g}$ & 0.91 & $3 \%$ & $1 \%$ & $47 \%$ & $14 \%$ & $36 \%$ & $0 \%$ & 0.23 & $23 \%$ & $10 \%$ & $1 \%$ & $66 \%$ & $0 \%$ \\
\hline (a) Benzene $\left(\mathrm{C}_{6} \mathrm{H}_{6}\right)$ & $\mathrm{g}$ & 101 & $0 \%$ & $46 \%$ & $30 \%$ & $17 \%$ & $6 \%$ & $0 \%$ & 16 & $4 \%$ & $-33 \%$ & $0 \%$ & $128 \%$ & $0 \%$ \\
\hline (a) Hydrogen Chloride $(\mathrm{HCl})$ & $\mathrm{g}$ & 178 & $0 \%$ & $0 \%$ & $96 \%$ & $2 \%$ & $1 \%$ & $0 \%$ & 4.18 & $7 \%$ & $5 \%$ & $0 \%$ & $89 \%$ & $0 \%$ \\
\hline (a) Hydrogen Fluoride (HF) & $\mathrm{g}$ & 22 & $0 \%$ & $0 \%$ & $98 \%$ & $0 \%$ & $1 \%$ & $0 \%$ & 0.08 & $43 \%$ & $30 \%$ & $1 \%$ & $25 \%$ & $0 \%$ \\
\hline (a) Hydrogen Sulfide $\left(\mathrm{H}_{2} \mathrm{~S}\right)$ & $\mathrm{g}$ & 1.08 & $5 \%$ & $0 \%$ & $0 \%$ & $31 \%$ & $63 \%$ & $0 \%$ & 0.53 & $22 \%$ & $10 \%$ & $1 \%$ & $67 \%$ & $0 \%$ \\
\hline (a) Metals (unspecified) & $\mathrm{g}$ & 0.34 & $0 \%$ & $0 \%$ & $0 \%$ & $100 \%$ & $0 \%$ & $0 \%$ & 0.35 & $0 \%$ & $0 \%$ & $0 \%$ & $100 \%$ & $0 \%$ \\
\hline (a) Methane $\left(\mathrm{CH}_{4}\right)$ & $\mathrm{g}$ & 15,931 & $76 \%$ & $10 \%$ & $8 \%$ & $4 \%$ & $2 \%$ & $0 \%$ & 564 & $7 \%$ & $-30 \%$ & $0 \%$ & $123 \%$ & $0 \%$ \\
\hline (a) Nitrogen Oxides $\left(\mathrm{NO}_{\mathrm{x}}\right.$ as $\left.\mathrm{NO}_{2}\right)$ & $\mathrm{g}$ & 8,340 & $26 \%$ & $4 \%$ & $41 \%$ & $27 \%$ & $3 \%$ & $0 \%$ & 2,561 & $19 \%$ & $-12 \%$ & $1 \%$ & $92 \%$ & $0 \%$ \\
\hline (a) Nitrous Oxide $\left(\mathrm{N}_{2} \mathrm{O}\right)$ & $\mathrm{g}$ & 65 & $3 \%$ & $1 \%$ & $87 \%$ & $2 \%$ & $6 \%$ & $0 \%$ & 7.02 & $75 \%$ & $-2 \%$ & $2 \%$ & $25 \%$ & $0 \%$ \\
\hline (a) Particulates (unspecified) & $\mathrm{g}$ & 12,783 & $67 \%$ & $0 \%$ & $30 \%$ & $2 \%$ & $1 \%$ & $0 \%$ & 891 & $8 \%$ & $58 \%$ & $0 \%$ & $34 \%$ & $0 \%$ \\
\hline (a) Sulfur Oxides $\left(\mathrm{SO}_{\mathrm{x}}\right.$ as $\left.\mathrm{SO}_{2}\right)$ & $\mathrm{g}$ & 7,515 & $0 \%$ & $0 \%$ & $82 \%$ & $14 \%$ & $4 \%$ & $0 \%$ & 982 & $5 \%$ & $-15 \%$ & $0 \%$ & $111 \%$ & $0 \%$ \\
\hline (w) Ammonia $\left(\mathrm{NH}_{4}^{+}, \mathrm{NH}_{3}\right.$, as $\left.\mathrm{N}\right)$ & $\mathrm{g}$ & 18 & $3 \%$ & $0 \%$ & $4 \%$ & $19 \%$ & $74 \%$ & $0 \%$ & 5.01 & $19 \%$ & $10 \%$ & $1 \%$ & $71 \%$ & $0 \%$ \\
\hline (w) BOD (Biochemical Oxygen Demand) & $\mathrm{g}$ & 119 & $3 \%$ & $0 \%$ & $10 \%$ & $11 \%$ & $76 \%$ & $0 \%$ & 28 & $23 \%$ & $26 \%$ & $1 \%$ & $51 \%$ & $0 \%$ \\
\hline (w) COD (Chemical Oxygen Demand) & $\mathrm{g}$ & 867 & $4 \%$ & $0 \%$ & $0 \%$ & $8 \%$ & $88 \%$ & $0 \%$ & 163 & $33 \%$ & $22 \%$ & $1 \%$ & $44 \%$ & $0 \%$ \\
\hline (w) Metals (unspecified) & $\mathrm{g}$ & 105 & $0 \%$ & $0 \%$ & $0 \%$ & $97 \%$ & $3 \%$ & $0 \%$ & 107 & $0 \%$ & $0 \%$ & $0 \%$ & $99 \%$ & $0 \%$ \\
\hline (w) Hydrocarbons (unspecified) & $\mathrm{g}$ & 17 & $0 \%$ & $0 \%$ & $0 \%$ & $99 \%$ & $1 \%$ & $0 \%$ & 18 & $0 \%$ & $0 \%$ & $0 \%$ & $100 \%$ & $0 \%$ \\
\hline (w) Phenol $\left(\mathrm{C}_{6} \mathrm{H}_{6} \mathrm{O}\right)$ & $\mathrm{g}$ & 2.23 & $3 \%$ & $0 \%$ & $4 \%$ & $15 \%$ & $77 \%$ & $0 \%$ & 0.53 & $23 \%$ & $10 \%$ & $1 \%$ & $67 \%$ & $0 \%$ \\
\hline (w) Nitrates $\left(\mathrm{NO}_{3}-\right)$ & $\mathrm{g}$ & 4.64 & $0 \%$ & $0 \%$ & $27 \%$ & $73 \%$ & $0 \%$ & $0 \%$ & 14 & $0 \%$ & $74 \%$ & $0 \%$ & $26 \%$ & $0 \%$ \\
\hline (w) Oils (unspecified) & $\mathrm{g}$ & 80 & $3 \%$ & $0 \%$ & $7 \%$ & $38 \%$ & $52 \%$ & $0 \%$ & 37 & $10 \%$ & $4 \%$ & $0 \%$ & $86 \%$ & $0 \%$ \\
\hline (w) Suspended Matter (unspecified) & $\mathrm{g}$ & 513 & $3 \%$ & $0 \%$ & $3 \%$ & $13 \%$ & $80 \%$ & $0 \%$ & 113 & $26 \%$ & $11 \%$ & $1 \%$ & $63 \%$ & $0 \%$ \\
\hline Waste (nonhazardous) & $\mathrm{gg}$ & 562 & $0 \%$ & $0 \%$ & $98 \%$ & $1 \%$ & $1 \%$ & $0 \%$ & 15 & $4 \%$ & $49 \%$ & $0 \%$ & $47 \%$ & $0 \%$ \\
\hline E Feedstock Energy & MJ & 648 & $0 \%$ & $832 \%$ & $0 \%$ & $1961 \%$ & $587 \%$ & $-3280 \%$ & 1,168 & $0 \%$ & $835 \%$ & $0 \%$ & $1138 \%$ & $-1873 \%$ \\
\hline E Fuel Energy & MJ & 44,275 & $1 \%$ & $2 \%$ & $33 \%$ & $12 \%$ & $4 \%$ & $48 \%$ & 33,288 & $2 \%$ & $14 \%$ & $0 \%$ & $17 \%$ & $66 \%$ \\
\hline E Nonrenewable Energy & MJ & 44,842 & $1 \%$ & $14 \%$ & $33 \%$ & $40 \%$ & $12 \%$ & $0 \%$ & 18,748 & $4 \%$ & $-6 \%$ & $0 \%$ & $102 \%$ & $0 \%$ \\
\hline E Renewable Energy & MJ & 81 & $0 \%$ & $1 \%$ & $51 \%$ & $39 \%$ & $8 \%$ & $0 \%$ & 15,708 & $0 \%$ & $100 \%$ & $0 \%$ & $0 \%$ & $0 \%$ \\
\hline E Total Primary Energy & MJ & 44,923 & $1 \%$ & $14 \%$ & $33 \%$ & $40 \%$ & $12 \%$ & $0 \%$ & 34,456 & $2 \%$ & $42 \%$ & $0 \%$ & $55 \%$ & $0 \%$ \\
\hline Eutrophication (water) & $\mathrm{g}$ eq. $\mathrm{PO}_{4}$ & 27 & $3 \%$ & $0 \%$ & $2 \%$ & $12 \%$ & $83 \%$ & $0 \%$ & 7.00 & $22 \%$ & $28 \%$ & $1 \%$ & $49 \%$ & $0 \%$ \\
\hline Depletion of Nonrenewable Resources & $\begin{array}{l}\text { frac. of } \\
\text { reserve* } 10^{15} / \mathrm{yr}\end{array}$ & 80 & $1 \%$ & $18 \%$ & $17 \%$ & $55 \%$ & $9 \%$ & $0 \%$ & 46 & $3 \%$ & $-3 \%$ & $0 \%$ & $100 \%$ & $0 \%$ \\
\hline Air Acidification & geq. $\mathrm{H}^{+}$ & 422 & $11 \%$ & $2 \%$ & $64 \%$ & $19 \%$ & $4 \%$ & $0 \%$ & 87 & $14 \%$ & $-13 \%$ & $0 \%$ & $98 \%$ & $0 \%$ \\
\hline Greenhouse Effect (direct, 100 years) & g eq. $\mathrm{CO}_{2}$ & $3,592,002$ & $8 \%$ & $2 \%$ & $36 \%$ & $8 \%$ & $2 \%$ & $43 \%$ & $1,375,204$ & $4 \%$ & $-4 \%$ & $0 \%$ & $24 \%$ & $76 \%$ \\
\hline
\end{tabular}


Table 70: Forest Residue Biomass, Enzyme-Based Ethanol Production, and Lignin Biomass Power

\begin{tabular}{|c|c|c|c|c|c|c|c|c|c|c|c|c|c|c|}
\hline Article & Units & $\begin{array}{l}\text { OPTION 1: } \\
\text { Total }\end{array}$ & $\begin{array}{l}\text { Biomass } \\
\text { Burning }\end{array}$ & $\begin{array}{l}\text { Natural Gas: } \\
\text { Production }\end{array}$ & $\begin{array}{l}\text { Methanol: } \\
\text { Production }\end{array}$ & $\begin{array}{l}\text { MTBE: } \\
\text { Production }\end{array}$ & $\begin{array}{l}\text { MTBE } \\
\text { RFG: } \\
\text { Production } \\
\end{array}$ & $\begin{array}{c}\text { MTBE } \\
\text { RFG: Use }\end{array}$ & $\begin{array}{c}\text { OPTION 2: } \\
\text { Total }\end{array}$ & $\begin{array}{c}\text { Biomass } \\
\text { Harvesting }\end{array}$ & $\begin{array}{l}\text { Ethanol: } \\
\text { Production }\end{array}$ & $\begin{array}{l}\text { Ethanol: } \\
\text { Transport }\end{array}$ & $\begin{array}{l}\text { ETBE: } \\
\text { Production }\end{array}$ & $\begin{array}{l}\text { ETBE RFG: } \\
\text { Use }\end{array}$ \\
\hline (r) Bauxite $\left(\mathrm{Al}_{2} \mathrm{O}_{3}\right.$, ore $)$ & $\mathrm{kg}$ & 0.10 & $0 \%$ & $0 \%$ & $0 \%$ & $100 \%$ & $0 \%$ & $0 \%$ & 0.11 & $0 \%$ & $0 \%$ & $0 \%$ & $100 \%$ & $0 \%$ \\
\hline (r) Coal (in ground) & $\mathrm{kg}$ & 344 & $0 \%$ & $0 \%$ & $96 \%$ & $2 \%$ & $1 \%$ & $0 \%$ & -3.49 & $-17 \%$ & $309 \%$ & $-1 \%$ & $-191 \%$ & $0 \%$ \\
\hline (r) Iron $(\mathrm{Fe}$, ore $)$ & $\mathrm{kg}$ & 0.069 & $0 \%$ & $0 \%$ & $1 \%$ & $99 \%$ & $0 \%$ & $0 \%$ & 0.071 & $0 \%$ & $0 \%$ & $0 \%$ & $100 \%$ & $0 \%$ \\
\hline (r) Limestone $\left(\mathrm{CaCO}_{3}\right.$, in ground) & $\mathrm{kg}$ & 51 & $0 \%$ & $0 \%$ & $98 \%$ & $0 \%$ & $1 \%$ & $0 \%$ & 3.64 & $2 \%$ & $96 \%$ & $0 \%$ & $2 \%$ & $0 \%$ \\
\hline (r) Natural Gas (in ground) & $\mathrm{kg}$ & 477 & $0 \%$ & $26 \%$ & $19 \%$ & $51 \%$ & $4 \%$ & $0 \%$ & 433 & $1 \%$ & $40 \%$ & $0 \%$ & $60 \%$ & $0 \%$ \\
\hline (r) Oil (in ground) & $\mathrm{kg}$ & 427 & $2 \%$ & $0 \%$ & $11 \%$ & $65 \%$ & $22 \%$ & $0 \%$ & 315 & $5 \%$ & $3 \%$ & $0 \%$ & $92 \%$ & $0 \%$ \\
\hline (r) Phosphate Rock (in ground) & $\mathrm{kg}$ & 0 & $0 \%$ & $0 \%$ & $0 \%$ & $0 \%$ & $0 \%$ & $0 \%$ & 0.025 & $0 \%$ & $100 \%$ & $0 \%$ & $0 \%$ & $0 \%$ \\
\hline (r) Potash $\left(\mathrm{K}_{2} \mathrm{O}\right.$, in ground $)$ & $\mathrm{kg}$ & 0 & $0 \%$ & $0 \%$ & $0 \%$ & $0 \%$ & $0 \%$ & $0 \%$ & 0.006 & $0 \%$ & $100 \%$ & $0 \%$ & $0 \%$ & $0 \%$ \\
\hline (r) Uranium (U, ore) & $\mathrm{kg}$ & 0.00019 & $3 \%$ & $7 \%$ & $32 \%$ & $16 \%$ & $42 \%$ & $0 \%$ & -0.00042 & $-2 \%$ & $111 \%$ & $0 \%$ & $-9 \%$ & $0 \%$ \\
\hline Water Used (total) & liter & 600 & $0 \%$ & $0 \%$ & $7 \%$ & $90 \%$ & $2 \%$ & $0 \%$ & 43,989 & $0 \%$ & $9 \%$ & $0 \%$ & $91 \%$ & $0 \%$ \\
\hline Water: Unspecified Origin & liter & 585 & $0 \%$ & $0 \%$ & $7 \%$ & $93 \%$ & $0 \%$ & $0 \%$ & 571 & $0 \%$ & $1 \%$ & $0 \%$ & $99 \%$ & $0 \%$ \\
\hline (a) Carbon Dioxide $\left(\mathrm{CO}_{2}\right.$, biomass $)$ & $\mathrm{g}$ & $1,887,770$ & $100 \%$ & $0 \%$ & $0 \%$ & $0 \%$ & $0 \%$ & $0 \%$ & $1,830,090$ & $0 \%$ & $72 \%$ & $0 \%$ & $0 \%$ & $28 \%$ \\
\hline (a) Carbon Dioxide $\left(\mathrm{CO}_{2}\right.$, fossil $)$ & $\mathrm{g}$ & $3,237,431$ & $1 \%$ & $1 \%$ & $38 \%$ & $9 \%$ & $2 \%$ & $48 \%$ & $1,822,980$ & $3 \%$ & $23 \%$ & $0 \%$ & $17 \%$ & $57 \%$ \\
\hline (a) Carbon Monoxide (CO) & $\mathrm{g}$ & 71,698 & $99 \%$ & $0 \%$ & $0 \%$ & $0 \%$ & $0 \%$ & $0 \%$ & 2,321 & $9 \%$ & $80 \%$ & $0 \%$ & $11 \%$ & $0 \%$ \\
\hline (a) Hydrocarbons (except methane) & $\mathrm{g}$ & 10,096 & $0 \%$ & $1 \%$ & $75 \%$ & $24 \%$ & $0 \%$ & $0 \%$ & 2,459 & $2 \%$ & $-5 \%$ & $0 \%$ & $103 \%$ & $0 \%$ \\
\hline (a) Volatile Organic Compounds (VOC) & $\mathrm{g}$ & 59 & $0 \%$ & $0 \%$ & $0 \%$ & $0 \%$ & $100 \%$ & $0 \%$ & 0 & $0 \%$ & $0 \%$ & $0 \%$ & $0 \%$ & $0 \%$ \\
\hline (a) Ethanol & $\mathrm{g}$ & $9.66 \mathrm{E}-07$ & $0 \%$ & $0 \%$ & $100 \%$ & $0 \%$ & $0 \%$ & $0 \%$ & 2,450 & $0 \%$ & $100 \%$ & $0 \%$ & $0 \%$ & $0 \%$ \\
\hline (a) Furfural & $\mathrm{g}$ & 0 & $0 \%$ & $0 \%$ & $0 \%$ & $0 \%$ & $0 \%$ & $0 \%$ & 16 & $0 \%$ & $100 \%$ & $0 \%$ & $0 \%$ & $0 \%$ \\
\hline (a) HMF & $\mathrm{g}$ & 0 & $0 \%$ & $0 \%$ & $0 \%$ & $0 \%$ & $0 \%$ & $0 \%$ & 0.17 & $0 \%$ & $100 \%$ & $0 \%$ & $0 \%$ & $0 \%$ \\
\hline (a) Aldehydes & $\mathrm{g}$ & 5.48 & $0 \%$ & $7 \%$ & $89 \%$ & $3 \%$ & $2 \%$ & $0 \%$ & 0.56 & $2 \%$ & $68 \%$ & $0 \%$ & $30 \%$ & $0 \%$ \\
\hline (a) Formaldehyde & $\mathrm{g}$ & 0.91 & $3 \%$ & $1 \%$ & $47 \%$ & $14 \%$ & $36 \%$ & $0 \%$ & 0.72 & $7 \%$ & $72 \%$ & $0 \%$ & $21 \%$ & $0 \%$ \\
\hline (a) Benzene $\left(\mathrm{C}_{6} \mathrm{H}_{6}\right)$ & $\mathrm{g}$ & 101 & $0 \%$ & $46 \%$ & $30 \%$ & $17 \%$ & $6 \%$ & $0 \%$ & 85 & $1 \%$ & $75 \%$ & $0 \%$ & $24 \%$ & $0 \%$ \\
\hline (a) Hydrogen Chloride $(\mathrm{HCl})$ & $\mathrm{g}$ & 178 & $0 \%$ & $0 \%$ & $96 \%$ & $2 \%$ & $1 \%$ & $0 \%$ & 4.71 & $6 \%$ & $16 \%$ & $0 \%$ & $79 \%$ & $0 \%$ \\
\hline (a) Hydrogen Fluoride (HF) & $\mathrm{g}$ & 22 & $0 \%$ & $0 \%$ & $98 \%$ & $0 \%$ & $1 \%$ & $0 \%$ & 0.15 & $23 \%$ & $62 \%$ & $1 \%$ & $14 \%$ & $0 \%$ \\
\hline (a) Hydrogen Sulfide $\left(\mathrm{H}_{2} \mathrm{~S}\right)$ & $\mathrm{g}$ & 1.08 & $5 \%$ & $0 \%$ & $0 \%$ & $31 \%$ & $63 \%$ & $0 \%$ & 0.54 & $22 \%$ & $11 \%$ & $1 \%$ & $66 \%$ & $0 \%$ \\
\hline (a) Metals (unspecified) & $\mathrm{g}$ & 0.34 & $0 \%$ & $0 \%$ & $0 \%$ & $100 \%$ & $0 \%$ & $0 \%$ & 0.35 & $0 \%$ & $0 \%$ & $0 \%$ & $100 \%$ & $0 \%$ \\
\hline (a) Methane $\left(\mathrm{CH}_{4}\right)$ & $\mathrm{g}$ & 15,931 & $76 \%$ & $10 \%$ & $8 \%$ & $4 \%$ & $2 \%$ & $0 \%$ & 2,906 & $1 \%$ & $75 \%$ & $0 \%$ & $24 \%$ & $0 \%$ \\
\hline (a) Nitrogen Oxides $\left(\mathrm{NO}_{\mathrm{x}}\right.$ as $\left.\mathrm{NO}_{2}\right)$ & $\mathrm{g}$ & 8,340 & $26 \%$ & $4 \%$ & $41 \%$ & $27 \%$ & $3 \%$ & $0 \%$ & 3,664 & $14 \%$ & $22 \%$ & $0 \%$ & $64 \%$ & $0 \%$ \\
\hline (a) Nitrous Oxide $\left(\mathrm{N}_{2} \mathrm{O}\right)$ & $\mathrm{g}$ & 65 & $3 \%$ & $1 \%$ & $87 \%$ & $2 \%$ & $6 \%$ & $0 \%$ & 37 & $14 \%$ & $81 \%$ & $0 \%$ & $5 \%$ & $0 \%$ \\
\hline (a) Particulates (unspecified) & $\mathrm{g}$ & 12,783 & $67 \%$ & $0 \%$ & $30 \%$ & $2 \%$ & $1 \%$ & $0 \%$ & 1,457 & $5 \%$ & $74 \%$ & $0 \%$ & $21 \%$ & $0 \%$ \\
\hline (a) Sulfur Oxides $\left(\mathrm{SO}_{\mathrm{x}}\right.$ as $\left.\mathrm{SO}_{2}\right)$ & $\mathrm{g}$ & 7,515 & $0 \%$ & $0 \%$ & $82 \%$ & $14 \%$ & $4 \%$ & $0 \%$ & 1,126 & $4 \%$ & $-1 \%$ & $0 \%$ & $96 \%$ & $0 \%$ \\
\hline (w) Ammonia $\left(\mathrm{NH}_{4}^{+}, \mathrm{NH}_{3}\right.$, as $\left.\mathrm{N}\right)$ & $\mathrm{g}$ & 18 & $3 \%$ & $0 \%$ & $4 \%$ & $19 \%$ & $74 \%$ & $0 \%$ & 5.09 & $18 \%$ & $11 \%$ & $1 \%$ & $70 \%$ & $0 \%$ \\
\hline (w) BOD (Biochemical Oxygen Demand) & $\mathrm{g}$ & 119 & $3 \%$ & $0 \%$ & $10 \%$ & $11 \%$ & $76 \%$ & $0 \%$ & 29 & $22 \%$ & $27 \%$ & $1 \%$ & $50 \%$ & $0 \%$ \\
\hline (w) COD (Chemical Oxygen Demand) & $\mathrm{g}$ & 867 & $4 \%$ & $0 \%$ & $0 \%$ & $8 \%$ & $88 \%$ & $0 \%$ & 167 & $32 \%$ & $24 \%$ & $1 \%$ & $43 \%$ & $0 \%$ \\
\hline (w) Metals (unspecified) & $\mathrm{g}$ & 105 & $0 \%$ & $0 \%$ & $0 \%$ & $97 \%$ & $3 \%$ & $0 \%$ & 107 & $0 \%$ & $0 \%$ & $0 \%$ & $99 \%$ & $0 \%$ \\
\hline (w) Hydrocarbons (unspecified) & $\mathrm{g}$ & 17 & $0 \%$ & $0 \%$ & $0 \%$ & $99 \%$ & $1 \%$ & $0 \%$ & 18 & $0 \%$ & $0 \%$ & $0 \%$ & $100 \%$ & $0 \%$ \\
\hline (w) Phenol $\left(\mathrm{C}_{6} \mathrm{H}_{6} \mathrm{O}\right)$ & $\mathrm{g}$ & 2.23 & $3 \%$ & $0 \%$ & $4 \%$ & $15 \%$ & $77 \%$ & $0 \%$ & 0.54 & $23 \%$ & $10 \%$ & $1 \%$ & $66 \%$ & $0 \%$ \\
\hline (w) Nitrates $\left(\mathrm{NO}_{3}^{-}\right)$ & $\mathrm{g}$ & 4.64 & $0 \%$ & $0 \%$ & $27 \%$ & $73 \%$ & $0 \%$ & $0 \%$ & 14 & $0 \%$ & $74 \%$ & $0 \%$ & $26 \%$ & $0 \%$ \\
\hline (w) Oils (unspecified) & $\mathrm{g}$ & 80 & $3 \%$ & $0 \%$ & $7 \%$ & $38 \%$ & $52 \%$ & $0 \%$ & 37 & $10 \%$ & $4 \%$ & $0 \%$ & $85 \%$ & $0 \%$ \\
\hline (w) Suspended Matter (unspecified) & $\mathrm{g}$ & 513 & $3 \%$ & $0 \%$ & $3 \%$ & $13 \%$ & $80 \%$ & $0 \%$ & 115 & $25 \%$ & $12 \%$ & $1 \%$ & $62 \%$ & $0 \%$ \\
\hline Waste (nonhazardous) & $\mathrm{kg}$ & 562 & $0 \%$ & $0 \%$ & $98 \%$ & $1 \%$ & $1 \%$ & $0 \%$ & 49 & $1 \%$ & $84 \%$ & $0 \%$ & $14 \%$ & $0 \%$ \\
\hline E Feedstock Energy & MJ & 648 & $0 \%$ & $832 \%$ & $0 \%$ & $1961 \%$ & $587 \%$ & $-3280 \%$ & 1,168 & $0 \%$ & $835 \%$ & $0 \%$ & $1138 \%$ & $-1873 \%$ \\
\hline E Fuel Energy & MJ & 44,275 & $1 \%$ & $2 \%$ & $33 \%$ & $12 \%$ & $4 \%$ & $48 \%$ & 42,468 & $2 \%$ & $33 \%$ & $0 \%$ & $14 \%$ & $52 \%$ \\
\hline E Nonrenewable Energy & MJ & 44,842 & $1 \%$ & $14 \%$ & $33 \%$ & $40 \%$ & $12 \%$ & $0 \%$ & 28,473 & $3 \%$ & $30 \%$ & $0 \%$ & $67 \%$ & $0 \%$ \\
\hline E Renewable Energy & MJ & 81 & $0 \%$ & $1 \%$ & $51 \%$ & $39 \%$ & $8 \%$ & $0 \%$ & 15,163 & $0 \%$ & $100 \%$ & $0 \%$ & $0 \%$ & $0 \%$ \\
\hline E Total Primary Energy & MJ & 44,923 & $1 \%$ & $14 \%$ & $33 \%$ & $40 \%$ & $12 \%$ & $0 \%$ & 43,637 & $2 \%$ & $54 \%$ & $0 \%$ & $44 \%$ & $0 \%$ \\
\hline Eutrophication (water) & g eq. $\mathrm{PO}_{4}$ & 27 & $3 \%$ & $0 \%$ & $2 \%$ & $12 \%$ & $83 \%$ & $0 \%$ & 7.12 & $22 \%$ & $29 \%$ & $1 \%$ & $48 \%$ & $0 \%$ \\
\hline Depletion of Nonrenewable Resources & $\begin{array}{l}\text { frac. of } \\
\text { reserve* } 10^{15} / \mathrm{yr}\end{array}$ & 80 & $1 \%$ & $18 \%$ & $17 \%$ & $55 \%$ & $9 \%$ & $0 \%$ & 68 & $2 \%$ & $30 \%$ & $0 \%$ & $68 \%$ & $0 \%$ \\
\hline Air Acidification & g eq. $\mathrm{H}^{+}$ & 422 & $11 \%$ & $2 \%$ & $64 \%$ & $19 \%$ & $4 \%$ & $0 \%$ & 115 & $11 \%$ & $15 \%$ & $0 \%$ & $74 \%$ & $0 \%$ \\
\hline Greenhouse Effect (direct, 100 years) & g eq. $\mathrm{CO}_{2}$ & $3,592,002$ & $8 \%$ & $2 \%$ & $36 \%$ & $8 \%$ & $2 \%$ & $43 \%$ & $1,895,491$ & $3 \%$ & $25 \%$ & $0 \%$ & $17 \%$ & $55 \%$ \\
\hline
\end{tabular}


Table 71: Forest Residue Biomass, Conc. Acid-Based Ethanol Production, and Lignin Cogeneration

\begin{tabular}{|c|c|c|c|c|c|c|c|c|c|c|c|c|c|c|}
\hline Article & Units & $\begin{array}{l}\text { OPTION 1: } \\
\text { Total }\end{array}$ & $\begin{array}{l}\text { Biomass } \\
\text { Burning }\end{array}$ & $\begin{array}{l}\text { Natural Gas: } \\
\text { Production }\end{array}$ & $\begin{array}{l}\text { Methanol: } \\
\text { Production }\end{array}$ & $\begin{array}{l}\text { MTBE: } \\
\text { Production }\end{array}$ & $\begin{array}{l}\text { MTBE } \\
\text { RFG: } \\
\text { Production }\end{array}$ & $\begin{array}{c}\text { MTBE } \\
\text { RFG: Use }\end{array}$ & $\begin{array}{c}\text { OPTION 2: } \\
\text { Total }\end{array}$ & $\begin{array}{l}\text { Biomass } \\
\text { Harvesting }\end{array}$ & $\begin{array}{l}\text { Ethanol: } \\
\text { Production }\end{array}$ & $\begin{array}{l}\text { Ethanol: } \\
\text { Transport }\end{array}$ & $\begin{array}{l}\text { ETBE: } \\
\text { Production }\end{array}$ & $\begin{array}{l}\text { ETBE RFG: } \\
\text { Use }\end{array}$ \\
\hline (r) Bauxite $\left(\mathrm{Al}_{2} \mathrm{O}_{3}\right.$, ore $)$ & $\mathrm{kg}$ & 0.083 & $0 \%$ & $0 \%$ & $0 \%$ & $100 \%$ & $0 \%$ & $0 \%$ & 0.087 & $0 \%$ & $0 \%$ & $0 \%$ & $100 \%$ & $0 \%$ \\
\hline (r) Coal (in ground) & $\mathrm{kg}$ & 281 & $0 \%$ & $0 \%$ & $96 \%$ & $2 \%$ & $1 \%$ & $0 \%$ & 7.90 & $7 \%$ & $23 \%$ & $0 \%$ & $69 \%$ & $0 \%$ \\
\hline (r) Iron $(\mathrm{Fe}$, ore $)$ & $\mathrm{kg}$ & 0.056 & $0 \%$ & $0 \%$ & $1 \%$ & $99 \%$ & $0 \%$ & $0 \%$ & 0.058 & $0 \%$ & $0 \%$ & $0 \%$ & $100 \%$ & $0 \%$ \\
\hline (r) Limestone $\left(\mathrm{CaCO}_{3}\right.$, in ground) & $\mathrm{kg}$ & 41 & $0 \%$ & $0 \%$ & $98 \%$ & $0 \%$ & $1 \%$ & $0 \%$ & 45 & $0 \%$ & $100 \%$ & $0 \%$ & $0 \%$ & $0 \%$ \\
\hline (r) Natural Gas (in ground) & $\mathrm{kg}$ & 390 & $0 \%$ & $26 \%$ & $19 \%$ & $51 \%$ & $4 \%$ & $0 \%$ & 455 & $0 \%$ & $53 \%$ & $0 \%$ & $47 \%$ & $0 \%$ \\
\hline (r) Oil (in ground) & $\mathrm{kg}$ & 350 & $2 \%$ & $0 \%$ & $11 \%$ & $65 \%$ & $22 \%$ & $0 \%$ & 258 & $6 \%$ & $2 \%$ & $0 \%$ & $92 \%$ & $0 \%$ \\
\hline (r) Phosphate Rock (in ground) & $\mathrm{kg}$ & 0 & $0 \%$ & $0 \%$ & $0 \%$ & $0 \%$ & $0 \%$ & $0 \%$ & 0.045 & $0 \%$ & $100 \%$ & $0 \%$ & $0 \%$ & $0 \%$ \\
\hline (r) Potash $\left(\mathrm{K}_{2} \mathrm{O}\right.$, in ground $)$ & $\mathrm{kg}$ & 0 & $0 \%$ & $0 \%$ & $0 \%$ & $0 \%$ & $0 \%$ & $0 \%$ & 0.011 & $0 \%$ & $100 \%$ & $0 \%$ & $0 \%$ & $0 \%$ \\
\hline (r) Uranium (U, ore) & $\mathrm{kg}$ & 0.00016 & $3 \%$ & $7 \%$ & $32 \%$ & $16 \%$ & $42 \%$ & $0 \%$ & 0.00007 & $14 \%$ & $44 \%$ & $0 \%$ & $42 \%$ & $0 \%$ \\
\hline Water Used (total) & liter & 490 & $0 \%$ & $0 \%$ & $7 \%$ & $90 \%$ & $2 \%$ & $0 \%$ & 38,025 & $0 \%$ & $14 \%$ & $0 \%$ & $86 \%$ & $0 \%$ \\
\hline Water: Unspecified Origin & liter & 478 & $0 \%$ & $0 \%$ & $7 \%$ & $93 \%$ & $0 \%$ & $0 \%$ & 474 & $0 \%$ & $2 \%$ & $0 \%$ & $98 \%$ & $0 \%$ \\
\hline (a) Carbon Dioxide $\left(\mathrm{CO}_{2}\right.$, biomass $)$ & $\mathrm{g}$ & $1,887,770$ & $100 \%$ & $0 \%$ & $0 \%$ & $0 \%$ & $0 \%$ & $0 \%$ & $1,658,260$ & $0 \%$ & $74 \%$ & $0 \%$ & $0 \%$ & $26 \%$ \\
\hline (a) Carbon Dioxide $\left(\mathrm{CO}_{2}\right.$, fossil $)$ & $\mathrm{g}$ & $2,647,971$ & $1 \%$ & $1 \%$ & $38 \%$ & $9 \%$ & $2 \%$ & $48 \%$ & $1,742,200$ & $3 \%$ & $33 \%$ & $0 \%$ & $15 \%$ & $49 \%$ \\
\hline (a) Carbon Monoxide (CO) & $\mathrm{g}$ & 71,550 & $99 \%$ & $0 \%$ & $0 \%$ & $0 \%$ & $0 \%$ & $0 \%$ & 1,567 & $13 \%$ & $74 \%$ & $0 \%$ & $13 \%$ & $0 \%$ \\
\hline (a) Hydrocarbons (except methane) & $\mathrm{g}$ & 8,248 & $0 \%$ & $1 \%$ & $75 \%$ & $24 \%$ & $0 \%$ & $0 \%$ & 2,549 & $2 \%$ & $17 \%$ & $0 \%$ & $81 \%$ & $0 \%$ \\
\hline (a) Volatile Organic Compounds (VOC) & $\mathrm{g}$ & 48 & $0 \%$ & $0 \%$ & $0 \%$ & $0 \%$ & $100 \%$ & $0 \%$ & 0 & $0 \%$ & $0 \%$ & $0 \%$ & $0 \%$ & $0 \%$ \\
\hline (a) Ethanol & $\mathrm{g}$ & $7.89 \mathrm{E}-07$ & $0 \%$ & $0 \%$ & $100 \%$ & $0 \%$ & $0 \%$ & $0 \%$ & 0 & $0 \%$ & $0 \%$ & $0 \%$ & $0 \%$ & $0 \%$ \\
\hline (a) Furfural & $\mathrm{g}$ & 0 & $0 \%$ & $0 \%$ & $0 \%$ & $0 \%$ & $0 \%$ & $0 \%$ & 55 & $0 \%$ & $100 \%$ & $0 \%$ & $0 \%$ & $0 \%$ \\
\hline (a) HMF & $\mathrm{g}$ & 0 & $0 \%$ & $0 \%$ & $0 \%$ & $0 \%$ & $0 \%$ & $0 \%$ & 552 & $0 \%$ & $100 \%$ & $0 \%$ & $0 \%$ & $0 \%$ \\
\hline (a) Aldehydes & $\mathrm{g}$ & 4.48 & $0 \%$ & $7 \%$ & $89 \%$ & $3 \%$ & $2 \%$ & $0 \%$ & 0.81 & $2 \%$ & $81 \%$ & $0 \%$ & $17 \%$ & $0 \%$ \\
\hline (a) Formaldehyde & $\mathrm{g}$ & 0.74 & $3 \%$ & $1 \%$ & $47 \%$ & $14 \%$ & $35 \%$ & $0 \%$ & 0.80 & $7 \%$ & $78 \%$ & $0 \%$ & $15 \%$ & $0 \%$ \\
\hline (a) Benzene $\left(\mathrm{C}_{6} \mathrm{H}_{6}\right)$ & $\mathrm{g}$ & 83 & $0 \%$ & $46 \%$ & $30 \%$ & $17 \%$ & $6 \%$ & $0 \%$ & 101 & $1 \%$ & $83 \%$ & $0 \%$ & $17 \%$ & $0 \%$ \\
\hline (a) Hydrogen Chloride $(\mathrm{HCl})$ & $\mathrm{g}$ & 145 & $0 \%$ & $0 \%$ & $96 \%$ & $2 \%$ & $1 \%$ & $0 \%$ & 4.03 & $7 \%$ & $18 \%$ & $0 \%$ & $75 \%$ & $0 \%$ \\
\hline (a) Hydrogen Fluoride (HF) & $\mathrm{g}$ & 18 & $0 \%$ & $0 \%$ & $98 \%$ & $0 \%$ & $1 \%$ & $0 \%$ & 0.14 & $24 \%$ & $64 \%$ & $1 \%$ & $11 \%$ & $0 \%$ \\
\hline (a) Hydrogen Sulfide $\left(\mathrm{H}_{2} \mathrm{~S}\right)$ & $\mathrm{g}$ & 0.90 & $6 \%$ & $0 \%$ & $0 \%$ & $31 \%$ & $62 \%$ & $0 \%$ & 0.44 & $27 \%$ & $6 \%$ & $1 \%$ & $66 \%$ & $0 \%$ \\
\hline (a) Metals (unspecified) & $\mathrm{g}$ & 0.28 & $0 \%$ & $0 \%$ & $0 \%$ & $100 \%$ & $0 \%$ & $0 \%$ & 0.29 & $0 \%$ & $0 \%$ & $0 \%$ & $100 \%$ & $0 \%$ \\
\hline (a) Methane $\left(\mathrm{CH}_{4}\right)$ & $\mathrm{g}$ & 15,236 & $80 \%$ & $8 \%$ & $7 \%$ & $3 \%$ & $2 \%$ & $0 \%$ & 3,593 & $1 \%$ & $83 \%$ & $0 \%$ & $16 \%$ & $0 \%$ \\
\hline (a) Nitrogen Oxides $\left(\mathrm{NO}_{\mathrm{x}}\right.$ as $\left.\mathrm{NO}_{2}\right)$ & $\mathrm{g}$ & 7,211 & $30 \%$ & $3 \%$ & $39 \%$ & $25 \%$ & $3 \%$ & $0 \%$ & 3,327 & $15 \%$ & $27 \%$ & $0 \%$ & $58 \%$ & $0 \%$ \\
\hline (a) Nitrous Oxide $\left(\mathrm{N}_{2} \mathrm{O}\right)$ & $\mathrm{g}$ & 53 & $4 \%$ & $1 \%$ & $86 \%$ & $2 \%$ & $6 \%$ & $0 \%$ & 16 & $32 \%$ & $58 \%$ & $1 \%$ & $9 \%$ & $0 \%$ \\
\hline (a) Particulates (unspecified) & $\mathrm{g}$ & 12,017 & $72 \%$ & $0 \%$ & $26 \%$ & $2 \%$ & $1 \%$ & $0 \%$ & 3,852 & $2 \%$ & $92 \%$ & $0 \%$ & $6 \%$ & $0 \%$ \\
\hline (a) Sulfur Oxides $\left(\mathrm{SO}_{\mathrm{x}}\right.$ as $\left.\mathrm{SO}_{2}\right)$ & $\mathrm{g}$ & 6,141 & $0 \%$ & $0 \%$ & $81 \%$ & $14 \%$ & $4 \%$ & $0 \%$ & 1,299 & $4 \%$ & $28 \%$ & $0 \%$ & $68 \%$ & $0 \%$ \\
\hline (w) Ammonia $\left(\mathrm{NH}_{4}^{+}, \mathrm{NH}_{3}\right.$, as $\left.\mathrm{N}\right)$ & $\mathrm{g}$ & 15 & $4 \%$ & $0 \%$ & $4 \%$ & $19 \%$ & $73 \%$ & $0 \%$ & 4.11 & $23 \%$ & $6 \%$ & $1 \%$ & $71 \%$ & $0 \%$ \\
\hline (w) BOD (Biochemical Oxygen Demand) & $\mathrm{g}$ & 98 & $4 \%$ & $0 \%$ & $9 \%$ & $11 \%$ & $75 \%$ & $0 \%$ & 21 & $30 \%$ & $13 \%$ & $1 \%$ & $56 \%$ & $0 \%$ \\
\hline (w) COD (Chemical Oxygen Demand) & $\mathrm{g}$ & 714 & $5 \%$ & $0 \%$ & $0 \%$ & $8 \%$ & $87 \%$ & $0 \%$ & 130 & $41 \%$ & $12 \%$ & $1 \%$ & $45 \%$ & $0 \%$ \\
\hline (w) Metals (unspecified) & $\mathrm{g}$ & 86 & $0 \%$ & $0 \%$ & $0 \%$ & $97 \%$ & $3 \%$ & $0 \%$ & 87 & $0 \%$ & $0 \%$ & $0 \%$ & $99 \%$ & $0 \%$ \\
\hline (w) Hydrocarbons (unspecified) & $\mathrm{g}$ & 14 & $0 \%$ & $0 \%$ & $0 \%$ & $99 \%$ & $1 \%$ & $0 \%$ & 14 & $0 \%$ & $0 \%$ & $0 \%$ & $100 \%$ & $0 \%$ \\
\hline (w) Phenol $\left(\mathrm{C}_{6} \mathrm{H}_{6} \mathrm{O}\right)$ & $\mathrm{g}$ & 1.84 & $4 \%$ & $0 \%$ & $4 \%$ & $15 \%$ & $77 \%$ & $0 \%$ & 0.44 & $28 \%$ & $5 \%$ & $1 \%$ & $66 \%$ & $0 \%$ \\
\hline (w) Nitrates $\left(\mathrm{NO}_{3}^{-}\right)$ & $\mathrm{g}$ & 3.79 & $0 \%$ & $0 \%$ & $27 \%$ & $73 \%$ & $0 \%$ & $0 \%$ & 21 & $0 \%$ & $86 \%$ & $0 \%$ & $14 \%$ & $0 \%$ \\
\hline (w) Oils (unspecified) & $\mathrm{g}$ & 66 & $3 \%$ & $0 \%$ & $7 \%$ & $38 \%$ & $52 \%$ & $0 \%$ & 31 & $12 \%$ & $4 \%$ & $0 \%$ & $84 \%$ & $0 \%$ \\
\hline (w) Suspended Matter (unspecified) & $\mathrm{g}$ & 422 & $4 \%$ & $0 \%$ & $3 \%$ & $13 \%$ & $79 \%$ & $0 \%$ & 96 & $30 \%$ & $8 \%$ & $1 \%$ & $61 \%$ & $0 \%$ \\
\hline Waste (nonhazardous) & $\mathrm{kg}$ & 459 & $0 \%$ & $0 \%$ & $98 \%$ & $1 \%$ & $1 \%$ & $0 \%$ & 94 & $1 \%$ & $93 \%$ & $0 \%$ & $6 \%$ & $0 \%$ \\
\hline E Feedstock Energy & MJ & 529 & $0 \%$ & $832 \%$ & $0 \%$ & $1961 \%$ & $587 \%$ & $-3280 \%$ & 954 & $0 \%$ & $835 \%$ & $0 \%$ & $1138 \%$ & $-1873 \%$ \\
\hline E Fuel Energy & MJ & 36,225 & $1 \%$ & $2 \%$ & $33 \%$ & $12 \%$ & $4 \%$ & $48 \%$ & 41,222 & $2 \%$ & $43 \%$ & $0 \%$ & $11 \%$ & $43 \%$ \\
\hline E Nonrenewable Energy & MJ & 36,688 & $1 \%$ & $14 \%$ & $33 \%$ & $40 \%$ & $12 \%$ & $0 \%$ & 28,881 & $3 \%$ & $43 \%$ & $0 \%$ & $54 \%$ & $0 \%$ \\
\hline E Renewable Energy & MJ & 66 & $1 \%$ & $1 \%$ & $51 \%$ & $39 \%$ & $8 \%$ & $0 \%$ & 13,295 & $0 \%$ & $100 \%$ & $0 \%$ & $0 \%$ & $0 \%$ \\
\hline E Total Primary Energy & MJ & 36,754 & $1 \%$ & $14 \%$ & $33 \%$ & $40 \%$ & $12 \%$ & $0 \%$ & 42,176 & $2 \%$ & $61 \%$ & $0 \%$ & $37 \%$ & $0 \%$ \\
\hline Eutrophication (water) & g eq. $\mathrm{PO}_{4}$ & 22 & $4 \%$ & $0 \%$ & $2 \%$ & $12 \%$ & $82 \%$ & $0 \%$ & 6.59 & $24 \%$ & $33 \%$ & $1 \%$ & $42 \%$ & $0 \%$ \\
\hline Depletion of Nonrenewable Resources & $\begin{array}{l}\text { frac. of } \\
\text { reserve* } 10^{15} / \mathrm{yr}\end{array}$ & 65 & $1 \%$ & $18 \%$ & $17 \%$ & $55 \%$ & $9 \%$ & $0 \%$ & 68 & $2 \%$ & $42 \%$ & $0 \%$ & $56 \%$ & $0 \%$ \\
\hline Air Acidification & g eq. $\mathrm{H}^{+}$ & 354 & $14 \%$ & $2 \%$ & $63 \%$ & $19 \%$ & $4 \%$ & $0 \%$ & 113 & $11 \%$ & $27 \%$ & $0 \%$ & $61 \%$ & $0 \%$ \\
\hline Greenhouse Effect (direct, 100 years) & g eq. $\mathrm{CO}_{2}$ & $2,984,411$ & $9 \%$ & $2 \%$ & $35 \%$ & $8 \%$ & $2 \%$ & $43 \%$ & $1,822,680$ & $3 \%$ & $35 \%$ & $0 \%$ & $15 \%$ & $47 \%$ \\
\hline
\end{tabular}


Table 72: Forest Residue Biomass, Conc. Acid-Based Ethanol Production, and Lignin Biomass Power

\begin{tabular}{|c|c|c|c|c|c|c|c|c|c|c|c|c|c|c|}
\hline Article & Units & $\begin{array}{l}\text { OPTION 1: } \\
\text { Total }\end{array}$ & $\begin{array}{l}\text { Biomass } \\
\text { Burning }\end{array}$ & $\begin{array}{l}\text { Natural Gas: } \\
\text { Production }\end{array}$ & $\begin{array}{l}\text { Methanol: } \\
\text { Production }\end{array}$ & $\begin{array}{l}\text { MTBE: } \\
\text { Production }\end{array}$ & $\begin{array}{c}\text { MTBE } \\
\text { RFG: } \\
\text { Production } \\
\end{array}$ & $\begin{array}{c}\text { MTBE } \\
\text { RFG: Use }\end{array}$ & $\begin{array}{l}\text { OPTION 2: } \\
\text { Total }\end{array}$ & $\begin{array}{c}\text { Biomass } \\
\text { Harvesting }\end{array}$ & $\begin{array}{l}\text { Ethanol: } \\
\text { Production }\end{array}$ & $\begin{array}{l}\text { Ethanol: } \\
\text { Transport }\end{array}$ & $\begin{array}{l}\text { ETBE: } \\
\text { Production }\end{array}$ & $\begin{array}{l}\text { ETBE RFG: } \\
\text { Use }\end{array}$ \\
\hline (r) Bauxite $\left(\mathrm{Al}_{2} \mathrm{O}_{3}\right.$, ore $)$ & $\mathrm{kg}$ & 0.083 & $\overline{0 \%}$ & $0 \%$ & $0 \%$ & $100 \%$ & $0 \%$ & $0 \%$ & 0.087 & $0 \%$ & $0 \%$ & $0 \%$ & $100 \%$ & $0 \%$ \\
\hline (r) Coal (in ground) & $\mathrm{kg}$ & 281 & $0 \%$ & $0 \%$ & $96 \%$ & $2 \%$ & $1 \%$ & $0 \%$ & -8.91 & $-7 \%$ & $168 \%$ & $0 \%$ & $-61 \%$ & $0 \%$ \\
\hline (r) Iron $(\mathrm{Fe}$, ore $)$ & $\mathrm{kg}$ & 0.056 & $0 \%$ & $0 \%$ & $1 \%$ & $99 \%$ & $0 \%$ & $0 \%$ & 0.058 & $0 \%$ & $0 \%$ & $0 \%$ & $100 \%$ & $0 \%$ \\
\hline (r) Limestone $\left(\mathrm{CaCO}_{3}\right.$, in ground) & $\mathrm{kg}$ & 41 & $0 \%$ & $0 \%$ & $98 \%$ & $0 \%$ & $1 \%$ & $0 \%$ & 45 & $0 \%$ & $100 \%$ & $0 \%$ & $0 \%$ & $0 \%$ \\
\hline (r) Natural Gas (in ground) & $\mathrm{kg}$ & 390 & $0 \%$ & $26 \%$ & $19 \%$ & $51 \%$ & $4 \%$ & $0 \%$ & 688 & $0 \%$ & $69 \%$ & $0 \%$ & $31 \%$ & $0 \%$ \\
\hline (r) Oil (in ground) & $\mathrm{kg}$ & 350 & $2 \%$ & $0 \%$ & $11 \%$ & $65 \%$ & $22 \%$ & $0 \%$ & 259 & $6 \%$ & $2 \%$ & $0 \%$ & $91 \%$ & $0 \%$ \\
\hline (r) Phosphate Rock (in ground) & $\mathrm{kg}$ & 0 & $0 \%$ & $0 \%$ & $0 \%$ & $0 \%$ & $0 \%$ & $0 \%$ & 0.045 & $0 \%$ & $100 \%$ & $0 \%$ & $0 \%$ & $0 \%$ \\
\hline (r) Potash $\left(\mathrm{K}_{2} \mathrm{O}\right.$, in ground) & $\mathrm{kg}$ & 0 & $0 \%$ & $0 \%$ & $0 \%$ & $0 \%$ & $0 \%$ & $0 \%$ & 0.011 & $0 \%$ & $100 \%$ & $0 \%$ & $0 \%$ & $0 \%$ \\
\hline (r) Uranium (U, ore) & $\mathrm{kg}$ & 0.00016 & $3 \%$ & $7 \%$ & $32 \%$ & $16 \%$ & $42 \%$ & $0 \%$ & -0.0006 & $-2 \%$ & $106 \%$ & $0 \%$ & $-5 \%$ & $0 \%$ \\
\hline Water Used (total) & liter & 490 & $0 \%$ & $0 \%$ & $7 \%$ & $90 \%$ & $2 \%$ & $0 \%$ & 38,024 & $0 \%$ & $14 \%$ & $0 \%$ & $86 \%$ & $0 \%$ \\
\hline Water: Unspecified Origin & liter & 478 & $0 \%$ & $0 \%$ & $7 \%$ & $93 \%$ & $0 \%$ & $0 \%$ & 473 & $0 \%$ & $2 \%$ & $0 \%$ & $98 \%$ & $0 \%$ \\
\hline (a) Carbon Dioxide ( $\mathrm{CO}_{2}$, biomass $)$ & $\mathrm{g}$ & $1,887,770$ & $100 \%$ & $0 \%$ & $0 \%$ & $0 \%$ & $0 \%$ & $0 \%$ & $1,581,390$ & $0 \%$ & $73 \%$ & $0 \%$ & $0 \%$ & $27 \%$ \\
\hline (a) Carbon Dioxide $\left(\mathrm{CO}_{2}\right.$, fossil) & $\mathrm{g}$ & $2,647,971$ & $1 \%$ & $1 \%$ & $38 \%$ & $9 \%$ & $2 \%$ & $48 \%$ & $2,266,400$ & $2 \%$ & $49 \%$ & $0 \%$ & $11 \%$ & $38 \%$ \\
\hline (a) Carbon Monoxide (CO) & $\mathrm{g}$ & 71,550 & $99 \%$ & $0 \%$ & $0 \%$ & $0 \%$ & $0 \%$ & $0 \%$ & 2,512 & $8 \%$ & $83 \%$ & $0 \%$ & $8 \%$ & $0 \%$ \\
\hline (a) Hydrocarbons (except methane) & $\mathrm{g}$ & 8,248 & $0 \%$ & $1 \%$ & $75 \%$ & $24 \%$ & $0 \%$ & $0 \%$ & 2,323 & $2 \%$ & $9 \%$ & $0 \%$ & $89 \%$ & $0 \%$ \\
\hline (a) Volatile Organic Compounds (VOC) & $\mathrm{g}$ & 48 & $0 \%$ & $0 \%$ & $0 \%$ & $0 \%$ & $100 \%$ & $0 \%$ & 0 & $0 \%$ & $0 \%$ & $0 \%$ & $0 \%$ & $0 \%$ \\
\hline (a) Ethanol & $\mathrm{g}$ & $7.89 \mathrm{E}-07$ & $0 \%$ & $0 \%$ & $100 \%$ & $0 \%$ & $0 \%$ & $0 \%$ & 2,010 & $0 \%$ & $100 \%$ & $0 \%$ & $0 \%$ & $0 \%$ \\
\hline (a) Furfural & $\mathrm{g}$ & 0 & $0 \%$ & $0 \%$ & $0 \%$ & $0 \%$ & $0 \%$ & $0 \%$ & 13 & $0 \%$ & $100 \%$ & $0 \%$ & $0 \%$ & $0 \%$ \\
\hline (a) HMF & $\mathrm{g}$ & 0 & $0 \%$ & $0 \%$ & $0 \%$ & $0 \%$ & $0 \%$ & $0 \%$ & 0.77 & $0 \%$ & $100 \%$ & $0 \%$ & $0 \%$ & $0 \%$ \\
\hline (a) Aldehydes & $\mathrm{g}$ & 4.48 & $0 \%$ & $7 \%$ & $89 \%$ & $3 \%$ & $2 \%$ & $0 \%$ & 1.30 & $1 \%$ & $89 \%$ & $0 \%$ & $10 \%$ & $0 \%$ \\
\hline (a) Formaldehyde & $\mathrm{g}$ & 0.74 & $3 \%$ & $1 \%$ & $47 \%$ & $14 \%$ & $35 \%$ & $0 \%$ & 1.49 & $4 \%$ & $88 \%$ & $0 \%$ & $8 \%$ & $0 \%$ \\
\hline (a) Benzene $\left(\mathrm{C}_{6} \mathrm{H}_{6}\right)$ & $\mathrm{g}$ & 83 & $0 \%$ & $46 \%$ & $30 \%$ & $17 \%$ & $6 \%$ & $0 \%$ & 188 & $0 \%$ & $91 \%$ & $0 \%$ & $9 \%$ & $0 \%$ \\
\hline (a) Hydrogen Chloride $(\mathrm{HCl})$ & $\mathrm{g}$ & 145 & $0 \%$ & $0 \%$ & $96 \%$ & $2 \%$ & $1 \%$ & $0 \%$ & 4.71 & $6 \%$ & $30 \%$ & $0 \%$ & $64 \%$ & $0 \%$ \\
\hline (a) Hydrogen Fluoride (HF) & $\mathrm{g}$ & 18 & $0 \%$ & $0 \%$ & $98 \%$ & $0 \%$ & $1 \%$ & $0 \%$ & 0.23 & $15 \%$ & $77 \%$ & $0 \%$ & $7 \%$ & $0 \%$ \\
\hline (a) Hydrogen Sulfide $\left(\mathrm{H}_{2} \mathrm{~S}\right)$ & $\mathrm{g}$ & 0.90 & $6 \%$ & $0 \%$ & $0 \%$ & $31 \%$ & $62 \%$ & $0 \%$ & 0.45 & $27 \%$ & $8 \%$ & $1 \%$ & $65 \%$ & $0 \%$ \\
\hline (a) Metals (unspecified) & $\mathrm{g}$ & 0.28 & $0 \%$ & $0 \%$ & $0 \%$ & $100 \%$ & $0 \%$ & $0 \%$ & 0.29 & $0 \%$ & $0 \%$ & $0 \%$ & $100 \%$ & $0 \%$ \\
\hline (a) Methane $\left(\mathrm{CH}_{4}\right)$ & $\mathrm{g}$ & 15,236 & $80 \%$ & $8 \%$ & $7 \%$ & $3 \%$ & $2 \%$ & $0 \%$ & 6,537 & $1 \%$ & $91 \%$ & $0 \%$ & $9 \%$ & $0 \%$ \\
\hline (a) Nitrogen Oxides $\left(\mathrm{NO}_{x}\right.$ as $\left.\mathrm{NO}_{2}\right)$ & $\mathrm{g}$ & 7,211 & $30 \%$ & $3 \%$ & $39 \%$ & $25 \%$ & $3 \%$ & $0 \%$ & 4,093 & $12 \%$ & $41 \%$ & $0 \%$ & $47 \%$ & $0 \%$ \\
\hline (a) Nitrous Oxide $\left(\mathrm{N}_{2} \mathrm{O}\right)$ & $\mathrm{g}$ & 53.15 & $4 \%$ & $1 \%$ & $86 \%$ & $2 \%$ & $6 \%$ & $0 \%$ & 37 & $14 \%$ & $82 \%$ & $0 \%$ & $4 \%$ & $0 \%$ \\
\hline (a) Particulates (unspecified) & $\mathrm{g}$ & 12,017 & $72 \%$ & $0 \%$ & $26 \%$ & $2 \%$ & $1 \%$ & $0 \%$ & 4,288 & $2 \%$ & $93 \%$ & $0 \%$ & $6 \%$ & $0 \%$ \\
\hline (a) Sulfur Oxides $\left(\mathrm{SO}_{\mathrm{x}}\right.$ as $\left.\mathrm{SO}_{2}\right)$ & $\mathrm{g}$ & 6,141 & $0 \%$ & $0 \%$ & $81 \%$ & $14 \%$ & $4 \%$ & $0 \%$ & 993 & $5 \%$ & $6 \%$ & $0 \%$ & $89 \%$ & $0 \%$ \\
\hline (w) Ammonia $\left(\mathrm{NH}_{4}^{+}, \mathrm{NH}_{3}\right.$, as $\left.\mathrm{N}\right)$ & $\mathrm{g}$ & 15 & $4 \%$ & $0 \%$ & $4 \%$ & $19 \%$ & $73 \%$ & $0 \%$ & 4.14 & $22 \%$ & $7 \%$ & $1 \%$ & $70 \%$ & $0 \%$ \\
\hline (w) BOD (Biochemical Oxygen Demand) & $\mathrm{g}$ & 98 & $4 \%$ & $0 \%$ & $9 \%$ & $11 \%$ & $75 \%$ & $0 \%$ & 21 & $30 \%$ & $15 \%$ & $1 \%$ & $54 \%$ & $0 \%$ \\
\hline (w) COD (Chemical Oxygen Demand) & $\mathrm{g}$ & 714 & $5 \%$ & $0 \%$ & $0 \%$ & $8 \%$ & $87 \%$ & $0 \%$ & 134 & $40 \%$ & $15 \%$ & $1 \%$ & $44 \%$ & $0 \%$ \\
\hline (w) Metals (unspecified) & $\mathrm{g}$ & 86 & $0 \%$ & $0 \%$ & $0 \%$ & $97 \%$ & $3 \%$ & $0 \%$ & 87 & $0 \%$ & $0 \%$ & $0 \%$ & $99 \%$ & $0 \%$ \\
\hline (w) Hydrocarbons (unspecified) & $\mathrm{g}$ & 14 & $0 \%$ & $0 \%$ & $0 \%$ & $99 \%$ & $1 \%$ & $0 \%$ & 14 & $0 \%$ & $0 \%$ & $0 \%$ & $100 \%$ & $0 \%$ \\
\hline (w) Phenol $\left(\mathrm{C}_{6} \mathrm{H}_{6} \mathrm{O}\right)$ & $\mathrm{g}$ & 1.84 & $4 \%$ & $0 \%$ & $4 \%$ & $15 \%$ & $77 \%$ & $0 \%$ & 0.44 & $28 \%$ & $6 \%$ & $1 \%$ & $66 \%$ & $0 \%$ \\
\hline (w) Nitrates $\left(\mathrm{NO}_{3}^{-}\right)$ & $\mathrm{g}$ & 3.79 & $0 \%$ & $0 \%$ & $27 \%$ & $73 \%$ & $0 \%$ & $0 \%$ & 21 & $0 \%$ & $86 \%$ & $0 \%$ & $14 \%$ & $0 \%$ \\
\hline (w) Oils (unspecified) & $\mathrm{g}$ & 66 & $3 \%$ & $0 \%$ & $7 \%$ & $38 \%$ & $52 \%$ & $0 \%$ & 31 & $12 \%$ & $4 \%$ & $0 \%$ & $84 \%$ & $0 \%$ \\
\hline (w) Suspended Matter (unspecified) & $\mathrm{g}$ & 422 & $4 \%$ & $0 \%$ & $3 \%$ & $13 \%$ & $79 \%$ & $0 \%$ & 98 & $29 \%$ & $10 \%$ & $1 \%$ & $59 \%$ & $0 \%$ \\
\hline Waste (nonhazardous) & $\mathrm{kg}$ & 459 & $0 \%$ & $0 \%$ & $98 \%$ & $1 \%$ & $1 \%$ & $0 \%$ & 95 & $1 \%$ & $93 \%$ & $0 \%$ & $6 \%$ & $0 \%$ \\
\hline E Feedstock Energy & MJ & 529 & $0 \%$ & $832 \%$ & $0 \%$ & $1961 \%$ & $587 \%$ & $-3280 \%$ & 954 & $0 \%$ & $835 \%$ & $0 \%$ & $1138 \%$ & $-1873 \%$ \\
\hline E Fuel Energy & MJ & 36,225 & $1 \%$ & $2 \%$ & $33 \%$ & $12 \%$ & $4 \%$ & $48 \%$ & 51,576 & $2 \%$ & $55 \%$ & $0 \%$ & $9 \%$ & $35 \%$ \\
\hline E Nonrenewable Energy & MJ & 36,688 & $1 \%$ & $14 \%$ & $33 \%$ & $40 \%$ & $12 \%$ & $0 \%$ & 40,059 & $2 \%$ & $59 \%$ & $0 \%$ & $39 \%$ & $0 \%$ \\
\hline E Renewable Energy & MJ & 66 & $1 \%$ & $1 \%$ & $51 \%$ & $39 \%$ & $8 \%$ & $0 \%$ & 12,471 & $0 \%$ & $100 \%$ & $0 \%$ & $0 \%$ & $0 \%$ \\
\hline E Total Primary Energy & MJ & 36,754 & $1 \%$ & $14 \%$ & $33 \%$ & $40 \%$ & $12 \%$ & $0 \%$ & 52,530 & $2 \%$ & $69 \%$ & $0 \%$ & $30 \%$ & $0 \%$ \\
\hline Eutrophication (water) & g eq. $\mathrm{PO}_{4}$ & 22 & $4 \%$ & $0 \%$ & $2 \%$ & $12 \%$ & $82 \%$ & $0 \%$ & 6.69 & $24 \%$ & $34 \%$ & $1 \%$ & $42 \%$ & $0 \%$ \\
\hline Depletion of Nonrenewable Resources & $\begin{array}{c}\text { frac. of } \\
\text { reserve* } 10^{15} / \mathrm{yr}\end{array}$ & 65 & $1 \%$ & $18 \%$ & $17 \%$ & $55 \%$ & $9 \%$ & $0 \%$ & 95 & $1 \%$ & $59 \%$ & $0 \%$ & $40 \%$ & $0 \%$ \\
\hline Air Acidification & g eq. $\mathrm{H}^{+}$ & 354 & $14 \%$ & $2 \%$ & $63 \%$ & $19 \%$ & $4 \%$ & $0 \%$ & 120 & $10 \%$ & $32 \%$ & $0 \%$ & $58 \%$ & $0 \%$ \\
\hline Greenhouse Effect (direct, 100 years) & g eq. $\mathrm{CO}_{2}$ & $2,984,411$ & $9 \%$ & $2 \%$ & $35 \%$ & $8 \%$ & $2 \%$ & $43 \%$ & $2,415,189$ & $2 \%$ & $51 \%$ & $0 \%$ & $11 \%$ & $35 \%$ \\
\hline
\end{tabular}


Table 73: Chaparral Biomass, Enzyme-Based Ethanol Production, and Lignin Cogeneration

\begin{tabular}{|c|c|c|c|c|c|c|c|c|c|c|c|c|c|c|}
\hline Article & Units & $\begin{array}{c}\text { OPTION 1: } \\
\text { Total }\end{array}$ & $\begin{array}{l}\text { Biomass } \\
\text { Burning }\end{array}$ & $\begin{array}{l}\text { Natural Gas: } \\
\text { Production }\end{array}$ & $\begin{array}{l}\text { Methanol: } \\
\text { Production }\end{array}$ & $\begin{array}{l}\text { MTBE: } \\
\text { Production }\end{array}$ & $\begin{array}{c}\text { MTBE } \\
\text { RFG: } \\
\text { Production } \\
\end{array}$ & $\begin{array}{c}\text { MTBE } \\
\text { RFG: Use }\end{array}$ & $\begin{array}{l}\text { OPTION 2: } \\
\text { Total }\end{array}$ & $\begin{array}{c}\text { Biomass } \\
\text { Harvestin } \\
\mathrm{g} \\
\end{array}$ & $\begin{array}{l}\text { Ethanol: } \\
\text { Production }\end{array}$ & $\begin{array}{l}\text { Ethanol: } \\
\text { Transport }\end{array}$ & $\begin{array}{l}\text { ETBE: } \\
\text { Production }\end{array}$ & $\begin{array}{l}\text { ETBE RFG: } \\
\text { Use }\end{array}$ \\
\hline (r) Bauxite (Al2O3, ore) & $\mathrm{kg}$ & 0.035 & $0 \%$ & $0 \%$ & 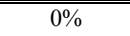 & $100 \%$ & $0 \%$ & $0 \%$ & 0.036 & $0 \%$ & $0 \%$ & 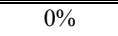 & 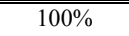 & $0 \%$ \\
\hline (r) Coal (in ground) & $\mathrm{kg}$ & 118 & $1 \%$ & $0 \%$ & $96 \%$ & $2 \%$ & $1 \%$ & $0 \%$ & -84 & $-5 \%$ & $107 \%$ & $0 \%$ & $-3 \%$ & $0 \%$ \\
\hline (r) Iron (Fe, ore) & $\mathrm{kg}$ & 0.023 & $0 \%$ & $0 \%$ & $1 \%$ & $99 \%$ & $0 \%$ & $0 \%$ & 0.024 & $0 \%$ & $0 \%$ & $0 \%$ & $100 \%$ & $0 \%$ \\
\hline (r) Limestone ( $\mathrm{CaCO} 3$, in ground) & $\mathrm{kg}$ & 17 & $1 \%$ & $0 \%$ & $98 \%$ & $0 \%$ & $1 \%$ & $0 \%$ & 3.04 & $17 \%$ & $82 \%$ & $0 \%$ & $1 \%$ & $0 \%$ \\
\hline (r) Natural Gas (in ground) & $\mathrm{kg}$ & 165 & $2 \%$ & $26 \%$ & $19 \%$ & $50 \%$ & $4 \%$ & $0 \%$ & 5.79 & $244 \%$ & $-1674 \%$ & $0 \%$ & $1530 \%$ & $0 \%$ \\
\hline (r) Oil (in ground) & $\mathrm{kg}$ & 160 & $11 \%$ & $0 \%$ & $10 \%$ & $59 \%$ & $20 \%$ & $0 \%$ & 203 & $51 \%$ & $0 \%$ & $0 \%$ & $49 \%$ & $0 \%$ \\
\hline (r) Phosphate Rock (in ground) & $\mathrm{kg}$ & 0 & $0 \%$ & $0 \%$ & $0 \%$ & $0 \%$ & $0 \%$ & $0 \%$ & 0.026 & $0 \%$ & $100 \%$ & $0 \%$ & $0 \%$ & $0 \%$ \\
\hline (r) Potash (K2O, in ground) & $\mathrm{kg}$ & 0 & $0 \%$ & $0 \%$ & $0 \%$ & $0 \%$ & $0 \%$ & $0 \%$ & 0.006 & $0 \%$ & $100 \%$ & $0 \%$ & $0 \%$ & $0 \%$ \\
\hline (r) Uranium (U, ore) & $\mathrm{kg}$ & 0.000076 & $16 \%$ & $6 \%$ & $28 \%$ & $14 \%$ & $36 \%$ & $0 \%$ & -0.0035 & $-2 \%$ & $102 \%$ & $0 \%$ & $0 \%$ & $0 \%$ \\
\hline Water Used (total) & liter & 207 & $1 \%$ & $0 \%$ & $7 \%$ & $89 \%$ & $2 \%$ & $0 \%$ & 13,762 & $0 \%$ & $0 \%$ & $0 \%$ & $100 \%$ & $0 \%$ \\
\hline Water: Unspecified Origin & liter & 200 & $0 \%$ & $0 \%$ & $7 \%$ & $93 \%$ & $0 \%$ & $0 \%$ & 191 & $0 \%$ & $-1 \%$ & $0 \%$ & $101 \%$ & $0 \%$ \\
\hline (a) Carbon Dioxide (CO2, biomass) & $\mathrm{g}$ & $1,931,340$ & $100 \%$ & $0 \%$ & $0 \%$ & $0 \%$ & $0 \%$ & $0 \%$ & $1,914,160$ & $0 \%$ & $91 \%$ & $0 \%$ & $0 \%$ & $9 \%$ \\
\hline (a) Carbon Dioxide ( $\mathrm{CO} 2$, fossil) & $\mathrm{g}$ & $1,148,478$ & $4 \%$ & $1 \%$ & $37 \%$ & $9 \%$ & $2 \%$ & $46 \%$ & 366,154 & $93 \%$ & $-119 \%$ & $0 \%$ & $29 \%$ & $97 \%$ \\
\hline (a) Carbon Monoxide (CO) & $\mathrm{g}$ & 101,738 & $100 \%$ & $0 \%$ & $0 \%$ & $0 \%$ & $0 \%$ & $0 \%$ & 2,672 & $55 \%$ & $42 \%$ & $0 \%$ & $3 \%$ & $0 \%$ \\
\hline (a) Hydrocarbons (except methane) & $\mathrm{g}$ & 15,991 & $78 \%$ & $0 \%$ & $16 \%$ & $5 \%$ & $0 \%$ & $0 \%$ & -872 & $-31 \%$ & $230 \%$ & $0 \%$ & $-99 \%$ & $0 \%$ \\
\hline (a) Volatile Organic Compounds (VOC) & $\mathrm{g}$ & 20 & $0 \%$ & $0 \%$ & $0 \%$ & $0 \%$ & $100 \%$ & $0 \%$ & 0 & $0 \%$ & $0 \%$ & $0 \%$ & $0 \%$ & $0 \%$ \\
\hline (a) Ethanol & $\mathrm{g}$ & $3.30 \mathrm{E}-07$ & $0 \%$ & $0 \%$ & $100 \%$ & $0 \%$ & $0 \%$ & $0 \%$ & 211 & $0 \%$ & $100 \%$ & $0 \%$ & $0 \%$ & $0 \%$ \\
\hline (a) Furfural & $\mathrm{g}$ & 0 & $0 \%$ & $0 \%$ & $0 \%$ & $0 \%$ & $0 \%$ & $0 \%$ & 745 & $0 \%$ & $100 \%$ & $0 \%$ & $0 \%$ & $0 \%$ \\
\hline (a) HMF & $\mathrm{g}$ & 0 & $0 \%$ & $0 \%$ & $0 \%$ & $0 \%$ & $0 \%$ & $0 \%$ & 368 & $0 \%$ & $100 \%$ & $0 \%$ & $0 \%$ & $0 \%$ \\
\hline (a) Aldehydes & $\mathrm{g}$ & 1.89 & $1 \%$ & $6 \%$ & $88 \%$ & $3 \%$ & $2 \%$ & $0 \%$ & -1.01 & $-8 \%$ & $114 \%$ & $0 \%$ & $-6 \%$ & $0 \%$ \\
\hline (a) Formaldehyde & $\mathrm{g}$ & 0.36 & $16 \%$ & $1 \%$ & $41 \%$ & $12 \%$ & $31 \%$ & $0 \%$ & 0.39 & $86 \%$ & $1 \%$ & $0 \%$ & $13 \%$ & $0 \%$ \\
\hline (a) Benzene (C6H6) & $\mathrm{g}$ & 35 & $3 \%$ & $45 \%$ & $30 \%$ & $17 \%$ & $6 \%$ & $0 \%$ & -24 & $-19 \%$ & $149 \%$ & $0 \%$ & $-29 \%$ & $0 \%$ \\
\hline (a) Hydrogen Chloride $(\mathrm{HCl})$ & $\mathrm{g}$ & 61 & $1 \%$ & $0 \%$ & $96 \%$ & $2 \%$ & $1 \%$ & $0 \%$ & 2.85 & $62 \%$ & $-7 \%$ & $0 \%$ & $44 \%$ & $0 \%$ \\
\hline (a) Hydrogen Fluoride (HF) & $\mathrm{g}$ & 7.49 & $1 \%$ & $0 \%$ & $98 \%$ & $0 \%$ & $1 \%$ & $0 \%$ & 0.21 & $108 \%$ & $-11 \%$ & $0 \%$ & $3 \%$ & $0 \%$ \\
\hline (a) Hydrogen Sulfide (H2S) & $\mathrm{g}$ & 0.48 & $26 \%$ & $0 \%$ & $0 \%$ & $24 \%$ & $49 \%$ & $0 \%$ & 0.90 & $85 \%$ & $2 \%$ & $0 \%$ & $14 \%$ & $0 \%$ \\
\hline (a) Metals (unspecified) & $\mathrm{g}$ & 0.12 & $0 \%$ & $0 \%$ & $0 \%$ & $100 \%$ & $0 \%$ & $0 \%$ & 0.12 & $0 \%$ & $0 \%$ & $0 \%$ & $100 \%$ & $0 \%$ \\
\hline (a) Methane (CH4) & $\mathrm{g}$ & 5,839 & $78 \%$ & $9 \%$ & $8 \%$ & $3 \%$ & $2 \%$ & $0 \%$ & -714 & $-34 \%$ & $167 \%$ & $0 \%$ & $-33 \%$ & $0 \%$ \\
\hline (a) Nitrogen Oxides ( $\mathrm{NOx}$ as $\mathrm{NO} 2$ ) & $\mathrm{g}$ & 2,404 & $13 \%$ & $4 \%$ & $48 \%$ & $32 \%$ & $3 \%$ & $0 \%$ & 1,841 & $167 \%$ & $-110 \%$ & $0 \%$ & $43 \%$ & $0 \%$ \\
\hline (a) Nitrous Oxide $(\mathrm{N} 2 \mathrm{O})$ & $\mathrm{g}$ & 25 & $16 \%$ & $1 \%$ & $76 \%$ & $2 \%$ & $5 \%$ & $0 \%$ & 9.67 & $333 \%$ & $-240 \%$ & $1 \%$ & $6 \%$ & $0 \%$ \\
\hline (a) Particulates (unspecified) & $\mathrm{g}$ & 21,483 & $93 \%$ & $0 \%$ & $6 \%$ & $0 \%$ & $0 \%$ & $0 \%$ & 930 & $46 \%$ & $43 \%$ & $0 \%$ & $11 \%$ & $0 \%$ \\
\hline (a) Sulfur Oxides ( $\mathrm{SOx}$ as $\mathrm{SO} 2$ ) & $\mathrm{g}$ & 2,610 & $2 \%$ & $0 \%$ & $80 \%$ & $14 \%$ & $4 \%$ & $0 \%$ & 439 & $68 \%$ & $-53 \%$ & $0 \%$ & $85 \%$ & $0 \%$ \\
\hline (w) Ammonia (NH4+, $\mathrm{NH} 3$, as $\mathrm{N}$ ) & $\mathrm{g}$ & 7.45 & $21 \%$ & $0 \%$ & $3 \%$ & $16 \%$ & $60 \%$ & $0 \%$ & 7.43 & $85 \%$ & $-1 \%$ & $0 \%$ & $16 \%$ & $0 \%$ \\
\hline (w) BOD (Biochemical Oxygen Demand) & $\mathrm{g}$ & 50 & $21 \%$ & $0 \%$ & $8 \%$ & $9 \%$ & $62 \%$ & $0 \%$ & 50 & $85 \%$ & $5 \%$ & $0 \%$ & $10 \%$ & $0 \%$ \\
\hline (w) COD (Chemical Oxygen Demand) & $\mathrm{g}$ & 375 & $24 \%$ & $0 \%$ & $0 \%$ & $6 \%$ & $69 \%$ & $0 \%$ & 401 & $91 \%$ & $3 \%$ & $0 \%$ & $6 \%$ & $0 \%$ \\
\hline (w) Metals (unspecified) & $\mathrm{g}$ & 36 & $1 \%$ & $0 \%$ & $0 \%$ & $96 \%$ & $3 \%$ & $0 \%$ & 39 & $7 \%$ & $0 \%$ & $0 \%$ & $93 \%$ & $0 \%$ \\
\hline (w) Hydrocarbons (unspecified) & $\mathrm{g}$ & 5.83 & $0 \%$ & $0 \%$ & $0 \%$ & $99 \%$ & $1 \%$ & $0 \%$ & 6.15 & $2 \%$ & $0 \%$ & $0 \%$ & $98 \%$ & $0 \%$ \\
\hline (w) Phenol (C6H6O) & $\mathrm{g}$ & 0.94 & $22 \%$ & $0 \%$ & $3 \%$ & $12 \%$ & $63 \%$ & $0 \%$ & 0.97 & $86 \%$ & $2 \%$ & $0 \%$ & $13 \%$ & $0 \%$ \\
\hline (w) Nitrates (NO3-) & $\mathrm{g}$ & 1.58 & $0 \%$ & $0 \%$ & $27 \%$ & $73 \%$ & $0 \%$ & $0 \%$ & 11 & $0 \%$ & $89 \%$ & $0 \%$ & $11 \%$ & $0 \%$ \\
\hline (w) Oils (unspecified) & $\mathrm{g}$ & 32 & $17 \%$ & $0 \%$ & $6 \%$ & $33 \%$ & $44 \%$ & $0 \%$ & 36 & $68 \%$ & $1 \%$ & $0 \%$ & $31 \%$ & $0 \%$ \\
\hline (w) Suspended Matter (unspecified) & $\mathrm{g}$ & 217 & $22 \%$ & $0 \%$ & $3 \%$ & $11 \%$ & $64 \%$ & $0 \%$ & 223 & $87 \%$ & $2 \%$ & $0 \%$ & $11 \%$ & $0 \%$ \\
\hline Waste (nonhazardous) & $\mathrm{kg}$ & 193 & $0 \%$ & $0 \%$ & $97 \%$ & $1 \%$ & $1 \%$ & $0 \%$ & -57 & $-7 \%$ & $111 \%$ & $0 \%$ & $-4 \%$ & $0 \%$ \\
\hline E Feedstock Energy & MJ & 221 & $0 \%$ & $832 \%$ & $0 \%$ & $1961 \%$ & $587 \%$ & $-3280 \%$ & 399 & $0 \%$ & $835 \%$ & $0 \%$ & $1138 \%$ & $-1873 \%$ \\
\hline E Fuel Energy & MJ & 15,889 & $6 \%$ & $2 \%$ & $32 \%$ & $11 \%$ & $3 \%$ & $46 \%$ & 14,693 & $35 \%$ & $0 \%$ & $0 \%$ & $13 \%$ & $51 \%$ \\
\hline E Nonrenewable Energy & MJ & 16,081 & $6 \%$ & $14 \%$ & $31 \%$ & $38 \%$ & $11 \%$ & $0 \%$ & 2,895 & $179 \%$ & $-304 \%$ & $0 \%$ & $225 \%$ & $0 \%$ \\
\hline E Renewable Energy & MJ & 29 & $3 \%$ & $1 \%$ & $50 \%$ & $38 \%$ & $8 \%$ & $0 \%$ & 12,197 & $0 \%$ & $100 \%$ & $0 \%$ & $0 \%$ & $0 \%$ \\
\hline E Total Primary Energy & MJ & 16,110 & $6 \%$ & $14 \%$ & $31 \%$ & $38 \%$ & $11 \%$ & $0 \%$ & 15,092 & $34 \%$ & $22 \%$ & $0 \%$ & $43 \%$ & $0 \%$ \\
\hline Eutrophication (water) & g eq. $\mathrm{PO}_{4}$ & 12 & $23 \%$ & $0 \%$ & $1 \%$ & $10 \%$ & $66 \%$ & $0 \%$ & 13 & $82 \%$ & $9 \%$ & $0 \%$ & $9 \%$ & $0 \%$ \\
\hline Depletion of Nonrenewable Resources & $\begin{array}{l}\text { frac. of } \\
\text { reserve*10 } 10^{15 /} \\
\text { yr }\end{array}$ & 28 & $5 \%$ & $18 \%$ & $16 \%$ & $53 \%$ & $9 \%$ & $0 \%$ & 11 & $66 \%$ & $-106 \%$ & $0 \%$ & $140 \%$ & $0 \%$ \\
\hline Air Acidification & geq. $\mathrm{H}^{+}$ & 136 & $6 \%$ & $2 \%$ & $68 \%$ & $20 \%$ & $4 \%$ & $0 \%$ & 54 & $141 \%$ & $-95 \%$ & $0 \%$ & $54 \%$ & $0 \%$ \\
\hline Greenhouse Effect (direct, 100 years) & g eq. $\mathrm{CO}_{2}$ & $1,278,970$ & $12 \%$ & $2 \%$ & $34 \%$ & $8 \%$ & $2 \%$ & $42 \%$ & 354,155 & $100 \%$ & $-133 \%$ & $0 \%$ & $32 \%$ & $100 \%$ \\
\hline
\end{tabular}


Table 74: Chaparral Biomass, Enzyme-Based Ethanol Production, and Lignin Biomass Power

\begin{tabular}{|c|c|c|c|c|c|c|c|c|c|c|c|c|c|c|}
\hline Article & Units & $\begin{array}{c}\text { OPTION 1: } \\
\text { Total }\end{array}$ & $\begin{array}{l}\text { Biomass } \\
\text { Burning }\end{array}$ & $\begin{array}{l}\text { Natural Gas: } \\
\text { Production }\end{array}$ & $\begin{array}{l}\text { Methanol: } \\
\text { Production }\end{array}$ & $\begin{array}{l}\text { MTBE: } \\
\text { Production }\end{array}$ & $\begin{array}{c}\text { MTBE } \\
\text { RFG: } \\
\text { Production } \\
\end{array}$ & $\begin{array}{c}\text { MTBE } \\
\text { RFG: Use }\end{array}$ & $\begin{array}{c}\text { OPTION 2: } \\
\text { Total }\end{array}$ & $\begin{array}{c}\text { Biomass } \\
\text { Harvesting }\end{array}$ & $\begin{array}{l}\text { Ethanol: } \\
\text { Production }\end{array}$ & $\begin{array}{l}\text { Ethanol: } \\
\text { Transport }\end{array}$ & $\begin{array}{l}\text { ETBE: } \\
\text { Production }\end{array}$ & $\begin{array}{l}\text { ETBE RFG: } \\
\text { Use }\end{array}$ \\
\hline (r) Bauxite (Al2O3, ore) & $\overline{\mathrm{kg}}$ & 0.035 & $0 \%$ & 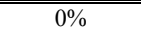 & 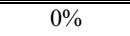 & $100 \%$ & $0 \%$ & 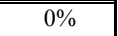 & 0.036 & $0 \%$ & $0 \%$ & $0 \%$ & $100 \%$ & $0 \%$ \\
\hline (r) Coal (in ground) & $\mathrm{kg}$ & 118 & $1 \%$ & $0 \%$ & $96 \%$ & $2 \%$ & $1 \%$ & $0 \%$ & -36 & $-11 \%$ & $117 \%$ & $0 \%$ & $-6 \%$ & $0 \%$ \\
\hline (r) Iron ( $\mathrm{Fe}$, ore) & $\mathrm{kg}$ & 0.023 & $0 \%$ & $0 \%$ & $1 \%$ & $99 \%$ & $0 \%$ & $0 \%$ & 0.024 & $0 \%$ & $0 \%$ & $0 \%$ & $100 \%$ & $0 \%$ \\
\hline (r) Limestone ( $\mathrm{CaCO} 3$, in ground) & $\mathrm{kg}$ & 17 & $1 \%$ & $0 \%$ & $98 \%$ & $0 \%$ & $1 \%$ & $0 \%$ & 3.19 & $16 \%$ & $83 \%$ & $0 \%$ & $1 \%$ & $0 \%$ \\
\hline (r) Natural Gas (in ground) & $\mathrm{kg}$ & 165 & $2 \%$ & $26 \%$ & $19 \%$ & $50 \%$ & $4 \%$ & $0 \%$ & 176 & $8 \%$ & $42 \%$ & $0 \%$ & $50 \%$ & $0 \%$ \\
\hline (r) Oil (in ground) & $\mathrm{kg}$ & 160 & $11 \%$ & $0 \%$ & $10 \%$ & $59 \%$ & $20 \%$ & $0 \%$ & 205 & $50 \%$ & $1 \%$ & $0 \%$ & $48 \%$ & $0 \%$ \\
\hline (r) Phosphate Rock (in ground) & $\mathrm{kg}$ & 0 & $0 \%$ & $0 \%$ & $0 \%$ & $0 \%$ & $0 \%$ & $0 \%$ & 0.026 & $0 \%$ & $100 \%$ & $0 \%$ & $0 \%$ & $0 \%$ \\
\hline (r) Potash (K2O, in ground) & $\mathrm{kg}$ & 0 & $0 \%$ & $0 \%$ & $0 \%$ & $0 \%$ & $0 \%$ & $0 \%$ & 0.006 & $0 \%$ & $100 \%$ & $0 \%$ & $0 \%$ & $0 \%$ \\
\hline (r) Uranium (U, ore) & $\mathrm{kg}$ & 0.00008 & $16 \%$ & $6 \%$ & $28 \%$ & $14 \%$ & $36 \%$ & $0 \%$ & -0.0016 & $-4 \%$ & $105 \%$ & $0 \%$ & $-1 \%$ & $0 \%$ \\
\hline Water Used (total) & liter & 207 & $1 \%$ & $0 \%$ & $7 \%$ & $89 \%$ & $2 \%$ & $0 \%$ & 13,765 & $0 \%$ & $0 \%$ & $0 \%$ & $100 \%$ & $0 \%$ \\
\hline Water: Unspecified Origin & liter & 200 & $0 \%$ & $0 \%$ & $7 \%$ & $93 \%$ & $0 \%$ & $0 \%$ & 194 & $0 \%$ & $0 \%$ & $0 \%$ & $100 \%$ & $0 \%$ \\
\hline (a) Carbon Dioxide (CO2, biomass) & $\mathrm{g}$ & $1,931,340$ & $100 \%$ & $0 \%$ & $0 \%$ & $0 \%$ & $0 \%$ & $0 \%$ & $1,915,010$ & $0 \%$ & $91 \%$ & $0 \%$ & $0 \%$ & $9 \%$ \\
\hline (a) Carbon Dioxide ( $\mathrm{CO} 2$, fossil) & $\mathrm{g}$ & $1,148,478$ & $4 \%$ & $1 \%$ & $37 \%$ & $9 \%$ & $2 \%$ & $46 \%$ & 890,771 & $38 \%$ & $10 \%$ & $0 \%$ & $12 \%$ & $40 \%$ \\
\hline (a) Carbon Monoxide (CO) & $\mathrm{g}$ & 101,738 & $100 \%$ & $0 \%$ & $0 \%$ & $0 \%$ & $0 \%$ & $0 \%$ & 3,660 & $40 \%$ & $58 \%$ & $0 \%$ & $2 \%$ & $0 \%$ \\
\hline (a) Hydrocarbons (except methane) & $\mathrm{g}$ & 15,991 & $78 \%$ & $0 \%$ & $16 \%$ & $5 \%$ & $0 \%$ & $0 \%$ & 288 & $94 \%$ & $-295 \%$ & $0 \%$ & $301 \%$ & $0 \%$ \\
\hline (a) Volatile Organic Compounds (VOC) & $\mathrm{g}$ & 20 & $0 \%$ & $0 \%$ & $0 \%$ & $0 \%$ & $100 \%$ & $0 \%$ & 0 & $0 \%$ & $0 \%$ & $0 \%$ & $0 \%$ & $0 \%$ \\
\hline (a) Ethanol & $\mathrm{g}$ & $3.30 \mathrm{E}-07$ & $0 \%$ & $0 \%$ & $100 \%$ & $0 \%$ & $0 \%$ & $0 \%$ & 261 & $0 \%$ & $100 \%$ & $0 \%$ & $0 \%$ & $0 \%$ \\
\hline (a) Furfural & $\mathrm{g}$ & 0 & $0 \%$ & $0 \%$ & $0 \%$ & $0 \%$ & $0 \%$ & $0 \%$ & 14 & $0 \%$ & $100 \%$ & $0 \%$ & $0 \%$ & $0 \%$ \\
\hline (a) HMF & $\mathrm{g}$ & 0 & $0 \%$ & $0 \%$ & $0 \%$ & $0 \%$ & $0 \%$ & $0 \%$ & 0.05 & $0 \%$ & $100 \%$ & $0 \%$ & $0 \%$ & $0 \%$ \\
\hline (a) Aldehydes & $\mathrm{g}$ & 1.89 & $1 \%$ & $6 \%$ & $88 \%$ & $3 \%$ & $2 \%$ & $0 \%$ & -0.065 & $-124 \%$ & $312 \%$ & $0 \%$ & $-88 \%$ & $0 \%$ \\
\hline (a) Formaldehyde & $\mathrm{g}$ & 0.36 & $16 \%$ & $1 \%$ & $41 \%$ & $12 \%$ & $31 \%$ & $0 \%$ & 0.722 & $47 \%$ & $46 \%$ & $0 \%$ & $7 \%$ & $0 \%$ \\
\hline (a) Benzene (C6H6) & $\mathrm{g}$ & 35 & $3 \%$ & $45 \%$ & $30 \%$ & $17 \%$ & $6 \%$ & $0 \%$ & 39 & $12 \%$ & $70 \%$ & $0 \%$ & $18 \%$ & $0 \%$ \\
\hline (a) Hydrogen Chloride $(\mathrm{HCl})$ & $\mathrm{g}$ & 61 & $1 \%$ & $0 \%$ & $96 \%$ & $2 \%$ & $1 \%$ & $0 \%$ & 3.35 & $53 \%$ & $9 \%$ & $0 \%$ & $38 \%$ & $0 \%$ \\
\hline (a) Hydrogen Fluoride (HF) & $\mathrm{g}$ & 7.49 & $1 \%$ & $0 \%$ & $98 \%$ & $0 \%$ & $1 \%$ & $0 \%$ & 0.27 & $83 \%$ & $14 \%$ & $0 \%$ & $3 \%$ & $0 \%$ \\
\hline (a) Hydrogen Sulfide (H2S) & $\mathrm{g}$ & 0.48 & $26 \%$ & $0 \%$ & $0 \%$ & $24 \%$ & $49 \%$ & $0 \%$ & 0.90 & $84 \%$ & $3 \%$ & $0 \%$ & $13 \%$ & $0 \%$ \\
\hline (a) Metals (unspecified) & $\mathrm{g}$ & 0.12 & $0 \%$ & $0 \%$ & $0 \%$ & $100 \%$ & $0 \%$ & $0 \%$ & 0.12 & $0 \%$ & $0 \%$ & $0 \%$ & $100 \%$ & $0 \%$ \\
\hline (a) Methane (CH4) & $\mathrm{g}$ & 5,839 & $78 \%$ & $9 \%$ & $8 \%$ & $3 \%$ & $2 \%$ & $0 \%$ & 1,437 & $17 \%$ & $67 \%$ & $0 \%$ & $16 \%$ & $0 \%$ \\
\hline (a) Nitrogen Oxides ( $\mathrm{NOx}$ as $\mathrm{NO} 2$ ) & $\mathrm{g}$ & 2,404 & $13 \%$ & $4 \%$ & $48 \%$ & $32 \%$ & $3 \%$ & $0 \%$ & 3,804 & $81 \%$ & $-2 \%$ & $0 \%$ & $21 \%$ & $0 \%$ \\
\hline (a) Nitrous Oxide $(\mathrm{N} 2 \mathrm{O})$ & $\mathrm{g}$ & 25 & $16 \%$ & $1 \%$ & $76 \%$ & $2 \%$ & $5 \%$ & $0 \%$ & 57 & $56 \%$ & $43 \%$ & $0 \%$ & $1 \%$ & $0 \%$ \\
\hline (a) Particulates (unspecified) & $\mathrm{g}$ & 21,483 & $93 \%$ & $0 \%$ & $6 \%$ & $0 \%$ & $0 \%$ & $0 \%$ & 1,690 & $25 \%$ & $69 \%$ & $0 \%$ & $6 \%$ & $0 \%$ \\
\hline (a) Sulfur Oxides ( $\mathrm{SOx}$ as $\mathrm{SO} 2$ ) & $\mathrm{g}$ & 2,610 & $2 \%$ & $0 \%$ & $80 \%$ & $14 \%$ & $4 \%$ & $0 \%$ & 48 & $627 \%$ & $-1307 \%$ & $1 \%$ & $779 \%$ & $0 \%$ \\
\hline (w) Ammonia (NH4+, $\mathrm{NH} 3$, as $\mathrm{N}$ ) & $\mathrm{g}$ & 7.45 & $21 \%$ & $0 \%$ & $3 \%$ & $16 \%$ & $60 \%$ & $0 \%$ & 7.64 & $82 \%$ & $2 \%$ & $0 \%$ & $16 \%$ & $0 \%$ \\
\hline (w) BOD (Biochemical Oxygen Demand) & $\mathrm{g}$ & 50 & $21 \%$ & $0 \%$ & $8 \%$ & $9 \%$ & $62 \%$ & $0 \%$ & 51 & $84 \%$ & $6 \%$ & $0 \%$ & $10 \%$ & $0 \%$ \\
\hline (w) COD (Chemical Oxygen Demand) & $\mathrm{g}$ & 375 & $24 \%$ & $0 \%$ & $0 \%$ & $6 \%$ & $69 \%$ & $0 \%$ & 405 & $90 \%$ & $4 \%$ & $0 \%$ & $6 \%$ & $0 \%$ \\
\hline (w) Metals (unspecified) & $\mathrm{g}$ & 36 & $1 \%$ & $0 \%$ & $0 \%$ & $96 \%$ & $3 \%$ & $0 \%$ & 39 & $7 \%$ & $0 \%$ & $0 \%$ & $93 \%$ & $0 \%$ \\
\hline (w) Hydrocarbons (unspecified) & $\mathrm{g}$ & 5.83 & $0 \%$ & $0 \%$ & $0 \%$ & $99 \%$ & $1 \%$ & $0 \%$ & 6.15 & $2 \%$ & $0 \%$ & $0 \%$ & $98 \%$ & $0 \%$ \\
\hline (w) Phenol (C6H6O) & $\mathrm{g}$ & 0.94 & $22 \%$ & $0 \%$ & $3 \%$ & $12 \%$ & $63 \%$ & $0 \%$ & 0.97 & $85 \%$ & $2 \%$ & $0 \%$ & $12 \%$ & $0 \%$ \\
\hline (w) Nitrates (NO3-) & $\mathrm{g}$ & 1.58 & $0 \%$ & $0 \%$ & $27 \%$ & $73 \%$ & $0 \%$ & $0 \%$ & 11 & $0 \%$ & $89 \%$ & $0 \%$ & $11 \%$ & $0 \%$ \\
\hline (w) Oils (unspecified) & $\mathrm{g}$ & 32 & $17 \%$ & $0 \%$ & $6 \%$ & $33 \%$ & $44 \%$ & $0 \%$ & 36 & $68 \%$ & $2 \%$ & $0 \%$ & $30 \%$ & $0 \%$ \\
\hline (w) Suspended Matter (unspecified) & $\mathrm{g}$ & 217 & $22 \%$ & $0 \%$ & $3 \%$ & $11 \%$ & $64 \%$ & $0 \%$ & 226 & $87 \%$ & $3 \%$ & $0 \%$ & $11 \%$ & $0 \%$ \\
\hline Waste (nonhazardous) & $\mathrm{kg}$ & 193 & $0 \%$ & $0 \%$ & $97 \%$ & $1 \%$ & $1 \%$ & $0 \%$ & 29 & $14 \%$ & $77 \%$ & $0 \%$ & $8 \%$ & $0 \%$ \\
\hline E Feedstock Energy & MJ & 221 & $0 \%$ & $832 \%$ & $0 \%$ & $1961 \%$ & $587 \%$ & $-3280 \%$ & 399 & $0 \%$ & $835 \%$ & $0 \%$ & $1138 \%$ & $-1873 \%$ \\
\hline E Fuel Energy & MJ & 15,889 & $6 \%$ & $2 \%$ & $32 \%$ & $11 \%$ & $3 \%$ & $46 \%$ & 25,227 & $21 \%$ & $42 \%$ & $0 \%$ & $8 \%$ & $30 \%$ \\
\hline E Nonrenewable Energy & MJ & 16,081 & $6 \%$ & $14 \%$ & $31 \%$ & $38 \%$ & $11 \%$ & $0 \%$ & 13,705 & $38 \%$ & $15 \%$ & $0 \%$ & $48 \%$ & $0 \%$ \\
\hline E Renewable Energy & MJ & 29 & $3 \%$ & $1 \%$ & $50 \%$ & $38 \%$ & $8 \%$ & $0 \%$ & 11,920 & $0 \%$ & $100 \%$ & $0 \%$ & $0 \%$ & $0 \%$ \\
\hline E Total Primary Energy & MJ & 16,110 & $6 \%$ & $14 \%$ & $31 \%$ & $38 \%$ & $11 \%$ & $0 \%$ & 25,625 & $20 \%$ & $54 \%$ & $0 \%$ & $25 \%$ & $0 \%$ \\
\hline Eutrophication (water) & g eq. $\mathrm{PO}_{4}$ & 12 & $23 \%$ & $0 \%$ & $1 \%$ & $10 \%$ & $66 \%$ & $0 \%$ & 13 & $81 \%$ & $10 \%$ & $0 \%$ & $9 \%$ & $0 \%$ \\
\hline Depletion of Nonrenewable Resources & $\begin{array}{l}\text { frac. of } \\
\text { reserve*10 } 10^{15 /} \\
\text { yr }\end{array}$ & 28 & $5 \%$ & $18 \%$ & $16 \%$ & $53 \%$ & $9 \%$ & $0 \%$ & 32 & $23 \%$ & $26 \%$ & $0 \%$ & $50 \%$ & $0 \%$ \\
\hline Air Acidification & geq. $\mathrm{H}^{+}$ & 136 & $6 \%$ & $2 \%$ & $68 \%$ & $20 \%$ & $4 \%$ & $0 \%$ & 84 & $90 \%$ & $-25 \%$ & $0 \%$ & $34 \%$ & $0 \%$ \\
\hline Greenhouse Effect (direct, 100 years) & g eq. $\mathrm{CO}_{2}$ & $1,278,970$ & $12 \%$ & $2 \%$ & $34 \%$ & $8 \%$ & $2 \%$ & $42 \%$ & 938,746 & $38 \%$ & $12 \%$ & $0 \%$ & $12 \%$ & $38 \%$ \\
\hline
\end{tabular}


Table 75: Chaparral Biomass, Conc. Acid-Based Ethanol Production, and Lignin Cogeneration

\begin{tabular}{|c|c|c|c|c|c|c|c|c|c|c|c|c|c|c|}
\hline Article & Units & $\begin{array}{c}\text { OPTION 1: } \\
\text { Total }\end{array}$ & $\begin{array}{l}\text { Biomass } \\
\text { Burning }\end{array}$ & $\begin{array}{l}\text { Natural Gas: } \\
\text { Production }\end{array}$ & $\begin{array}{l}\text { Methanol: } \\
\text { Production }\end{array}$ & $\begin{array}{l}\text { MTBE: } \\
\text { Production }\end{array}$ & $\begin{array}{c}\text { MTBE } \\
\text { RFG: } \\
\text { Production } \\
\end{array}$ & $\begin{array}{c}\text { MTBE } \\
\text { RFG: Use }\end{array}$ & $\begin{array}{l}\text { OPTION 2: } \\
\text { Total }\end{array}$ & $\begin{array}{c}\text { Biomass } \\
\text { Harvesting }\end{array}$ & $\begin{array}{l}\text { Ethanol: } \\
\text { Production }\end{array}$ & $\begin{array}{l}\text { Ethanol: } \\
\text { Transport }\end{array}$ & $\begin{array}{l}\text { ETBE: } \\
\text { Production }\end{array}$ & $\begin{array}{l}\text { ETBE RFG: } \\
\text { Use }\end{array}$ \\
\hline (r) Bauxite (Al2O3, ore) & $\mathrm{kg}$ & 0.031 & $0 \%$ & $0 \%$ & $0 \%$ & 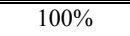 & $0 \%$ & $0 \%$ & 0.033 & 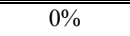 & 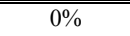 & $0 \%$ & $100 \%$ & $0 \%$ \\
\hline (r) Coal (in ground) & $\mathrm{kg}$ & 106 & $1 \%$ & $0 \%$ & $96 \%$ & $2 \%$ & $1 \%$ & $0 \%$ & 7.11 & $54 \%$ & $17 \%$ & $0 \%$ & $29 \%$ & $0 \%$ \\
\hline (r) Iron ( $\mathrm{Fe}$, ore) & $\mathrm{kg}$ & 0.021 & $0 \%$ & $0 \%$ & $1 \%$ & $99 \%$ & $0 \%$ & $0 \%$ & 0.022 & $0 \%$ & $0 \%$ & $0 \%$ & $100 \%$ & $0 \%$ \\
\hline (r) Limestone ( $\mathrm{CaCO} 3$, in ground) & $\mathrm{kg}$ & 16 & $1 \%$ & $0 \%$ & $98 \%$ & $0 \%$ & $1 \%$ & $0 \%$ & 46 & $1 \%$ & $99 \%$ & $0 \%$ & $0 \%$ & $0 \%$ \\
\hline (r) Natural Gas (in ground) & $\mathrm{kg}$ & 149 & $2 \%$ & $26 \%$ & $19 \%$ & $50 \%$ & $4 \%$ & $0 \%$ & 253 & $6 \%$ & $63 \%$ & $0 \%$ & $31 \%$ & $0 \%$ \\
\hline (r) Oil (in ground) & $\mathrm{kg}$ & 146 & $12 \%$ & $0 \%$ & $10 \%$ & $58 \%$ & $20 \%$ & $0 \%$ & 195 & $53 \%$ & $1 \%$ & $0 \%$ & $46 \%$ & $0 \%$ \\
\hline (r) Phosphate Rock (in ground) & $\mathrm{kg}$ & 0 & $0 \%$ & $0 \%$ & $0 \%$ & $0 \%$ & $0 \%$ & $0 \%$ & 0.046 & $0 \%$ & $100 \%$ & $0 \%$ & $0 \%$ & $0 \%$ \\
\hline (r) Potash (K2O, in ground) & $\mathrm{kg}$ & 0 & $0 \%$ & $0 \%$ & $0 \%$ & $0 \%$ & $0 \%$ & $0 \%$ & 0.011 & $0 \%$ & $100 \%$ & $0 \%$ & $0 \%$ & $0 \%$ \\
\hline (r) Uranium (U, ore) & $\mathrm{kg}$ & 0.00007 & $17 \%$ & $6 \%$ & $27 \%$ & $14 \%$ & $36 \%$ & $0 \%$ & 0.00010 & $66 \%$ & $22 \%$ & $0 \%$ & $12 \%$ & $0 \%$ \\
\hline Water Used (total) & liter & 186 & $1 \%$ & $0 \%$ & $7 \%$ & $89 \%$ & $2 \%$ & $0 \%$ & 17,363 & $0 \%$ & $29 \%$ & $0 \%$ & $71 \%$ & $0 \%$ \\
\hline Water: Unspecified Origin & liter & 179 & $0 \%$ & $0 \%$ & $7 \%$ & $93 \%$ & $0 \%$ & $0 \%$ & 184 & $0 \%$ & $6 \%$ & $0 \%$ & $94 \%$ & $0 \%$ \\
\hline (a) Carbon Dioxide (CO2, biomass) & $\mathrm{g}$ & $1,931,340$ & $100 \%$ & $0 \%$ & $0 \%$ & $0 \%$ & $0 \%$ & $0 \%$ & $1,814,130$ & $0 \%$ & $91 \%$ & $0 \%$ & $0 \%$ & $9 \%$ \\
\hline (a) Carbon Dioxide ( $\mathrm{CO} 2$, fossil) & $\mathrm{g}$ & $1,036,259$ & $5 \%$ & $1 \%$ & $37 \%$ & $8 \%$ & $2 \%$ & $46 \%$ & $1,129,100$ & $30 \%$ & $33 \%$ & $0 \%$ & $9 \%$ & $28 \%$ \\
\hline (a) Carbon Monoxide (CO) & $\mathrm{g}$ & 101,710 & $100 \%$ & $0 \%$ & $0 \%$ & $0 \%$ & $0 \%$ & $0 \%$ & 4,187 & $35 \%$ & $63 \%$ & $0 \%$ & $2 \%$ & $0 \%$ \\
\hline (a) Hydrocarbons (except methane) & $\mathrm{g}$ & 15,640 & $80 \%$ & $0 \%$ & $15 \%$ & $5 \%$ & $0 \%$ & $0 \%$ & 1,441 & $19 \%$ & $27 \%$ & $0 \%$ & $54 \%$ & $0 \%$ \\
\hline (a) Volatile Organic Compounds (VOC) & $\mathrm{g}$ & 18 & $0 \%$ & $0 \%$ & $0 \%$ & $0 \%$ & $100 \%$ & $0 \%$ & 0 & $0 \%$ & $0 \%$ & $0 \%$ & $0 \%$ & $0 \%$ \\
\hline (a) Ethanol & $\mathrm{g}$ & $2.96 \mathrm{E}-07$ & $0 \%$ & $0 \%$ & $100 \%$ & $0 \%$ & $0 \%$ & $0 \%$ & 0 & $0 \%$ & $0 \%$ & $0 \%$ & $0 \%$ & $0 \%$ \\
\hline (a) Furfural & $\mathrm{g}$ & 0 & $0 \%$ & $0 \%$ & $0 \%$ & $0 \%$ & $0 \%$ & $0 \%$ & 46 & $0 \%$ & $100 \%$ & $0 \%$ & $0 \%$ & $0 \%$ \\
\hline (a) HMF & $\mathrm{g}$ & 0 & $0 \%$ & $0 \%$ & $0 \%$ & $0 \%$ & $0 \%$ & $0 \%$ & 165 & $0 \%$ & $100 \%$ & $0 \%$ & $0 \%$ & $0 \%$ \\
\hline (a) Aldehydes & $\mathrm{g}$ & 1.69 & $1 \%$ & $6 \%$ & $88 \%$ & $3 \%$ & $2 \%$ & $0 \%$ & 0.55 & $15 \%$ & $76 \%$ & $0 \%$ & $9 \%$ & $0 \%$ \\
\hline (a) Formaldehyde & $\mathrm{g}$ & 0.33 & $17 \%$ & $1 \%$ & $40 \%$ & $12 \%$ & $30 \%$ & $0 \%$ & 0.78 & $44 \%$ & $50 \%$ & $0 \%$ & $6 \%$ & $0 \%$ \\
\hline (a) Benzene (C6H6) & $\mathrm{g}$ & 32 & $3 \%$ & $44 \%$ & $29 \%$ & $17 \%$ & $6 \%$ & $0 \%$ & 64 & $7 \%$ & $83 \%$ & $0 \%$ & $10 \%$ & $0 \%$ \\
\hline (a) Hydrogen Chloride $(\mathrm{HCl})$ & $\mathrm{g}$ & 55 & $1 \%$ & $0 \%$ & $96 \%$ & $2 \%$ & $1 \%$ & $0 \%$ & 3.35 & $53 \%$ & $13 \%$ & $0 \%$ & $34 \%$ & $0 \%$ \\
\hline (a) Hydrogen Fluoride (HF) & $\mathrm{g}$ & 6.73 & $1 \%$ & $0 \%$ & $98 \%$ & $0 \%$ & $1 \%$ & $0 \%$ & 0.28 & $78 \%$ & $19 \%$ & $0 \%$ & $2 \%$ & $0 \%$ \\
\hline (a) Hydrogen Sulfide (H2S) & $\mathrm{g}$ & 0.44 & $28 \%$ & $0 \%$ & $0 \%$ & $24 \%$ & $47 \%$ & $0 \%$ & 0.88 & $86 \%$ & $1 \%$ & $0 \%$ & $12 \%$ & $0 \%$ \\
\hline (a) Metals (unspecified) & $\mathrm{g}$ & 0.10 & $0 \%$ & $0 \%$ & $0 \%$ & $100 \%$ & $0 \%$ & $0 \%$ & 0.11 & $0 \%$ & $0 \%$ & $0 \%$ & $100 \%$ & $0 \%$ \\
\hline (a) Methane (CH4) & $\mathrm{g}$ & 5,707 & $80 \%$ & $8 \%$ & $7 \%$ & $3 \%$ & $2 \%$ & $0 \%$ & 2,412 & $10 \%$ & $81 \%$ & $0 \%$ & $9 \%$ & $0 \%$ \\
\hline (a) Nitrogen Oxides ( $\mathrm{NOx}$ as $\mathrm{NO} 2$ ) & $\mathrm{g}$ & 2,189 & $14 \%$ & $4 \%$ & $48 \%$ & $31 \%$ & $3 \%$ & $0 \%$ & 4,428 & $69 \%$ & $14 \%$ & $0 \%$ & $16 \%$ & $0 \%$ \\
\hline (a) Nitrous Oxide $(\mathrm{N} 2 \mathrm{O})$ & $\mathrm{g}$ & 23 & $18 \%$ & $1 \%$ & $74 \%$ & $2 \%$ & $5 \%$ & $0 \%$ & 39 & $83 \%$ & $15 \%$ & $0 \%$ & $1 \%$ & $0 \%$ \\
\hline (a) Particulates (unspecified) & $\mathrm{g}$ & 21,337 & $94 \%$ & $0 \%$ & $5 \%$ & $0 \%$ & $0 \%$ & $0 \%$ & 4,128 & $10 \%$ & $87 \%$ & $0 \%$ & $2 \%$ & $0 \%$ \\
\hline (a) Sulfur Oxides ( $\mathrm{SOx}$ as $\mathrm{SO} 2$ ) & $\mathrm{g}$ & 2,349 & $2 \%$ & $0 \%$ & $80 \%$ & $14 \%$ & $4 \%$ & $0 \%$ & 979 & $30 \%$ & $35 \%$ & $0 \%$ & $34 \%$ & $0 \%$ \\
\hline (w) Ammonia (NH4+, $\mathrm{NH} 3$, as $\mathrm{N}$ ) & $\mathrm{g}$ & 6.84 & $23 \%$ & $0 \%$ & $3 \%$ & $15 \%$ & $59 \%$ & $0 \%$ & 7.50 & $84 \%$ & $1 \%$ & $0 \%$ & $15 \%$ & $0 \%$ \\
\hline (w) BOD (Biochemical Oxygen Demand) & $\mathrm{g}$ & 46 & $23 \%$ & $0 \%$ & $8 \%$ & $9 \%$ & $60 \%$ & $0 \%$ & 49 & $89 \%$ & $2 \%$ & $0 \%$ & $9 \%$ & $0 \%$ \\
\hline (w) COD (Chemical Oxygen Demand) & $\mathrm{g}$ & 346 & $26 \%$ & $0 \%$ & $0 \%$ & $6 \%$ & $68 \%$ & $0 \%$ & 393 & $93 \%$ & $2 \%$ & $0 \%$ & $6 \%$ & $0 \%$ \\
\hline (w) Metals (unspecified) & $\mathrm{g}$ & 33 & $1 \%$ & $0 \%$ & $0 \%$ & $96 \%$ & $3 \%$ & $0 \%$ & 35 & $7 \%$ & $0 \%$ & $0 \%$ & $93 \%$ & $0 \%$ \\
\hline (w) Hydrocarbons (unspecified) & $\mathrm{g}$ & 5.23 & $0 \%$ & $0 \%$ & $0 \%$ & $99 \%$ & $1 \%$ & $0 \%$ & 5.53 & $2 \%$ & $0 \%$ & $0 \%$ & $98 \%$ & $0 \%$ \\
\hline (w) Phenol (C6H6O) & $\mathrm{g}$ & 0.87 & $24 \%$ & $0 \%$ & $3 \%$ & $12 \%$ & $61 \%$ & $0 \%$ & 0.94 & $88 \%$ & $1 \%$ & $0 \%$ & $11 \%$ & $0 \%$ \\
\hline (w) Nitrates (NO3-) & $\mathrm{g}$ & 1.42 & $0 \%$ & $0 \%$ & $27 \%$ & $73 \%$ & $0 \%$ & $0 \%$ & 19 & $0 \%$ & $94 \%$ & $0 \%$ & $6 \%$ & $0 \%$ \\
\hline (w) Oils (unspecified) & $\mathrm{g}$ & 29 & $18 \%$ & $0 \%$ & $6 \%$ & $32 \%$ & $44 \%$ & $0 \%$ & 35 & $69 \%$ & $2 \%$ & $0 \%$ & $28 \%$ & $0 \%$ \\
\hline (w) Suspended Matter (unspecified) & $\mathrm{g}$ & 200 & $24 \%$ & $0 \%$ & $3 \%$ & $10 \%$ & $63 \%$ & $0 \%$ & 222 & $88 \%$ & $2 \%$ & $0 \%$ & $10 \%$ & $0 \%$ \\
\hline Waste (nonhazardous) & $\mathrm{kg}$ & 173 & $0 \%$ & $0 \%$ & $97 \%$ & $1 \%$ & $1 \%$ & $0 \%$ & 109 & $4 \%$ & $94 \%$ & $0 \%$ & $2 \%$ & $0 \%$ \\
\hline E Feedstock Energy & MJ & 199 & $0 \%$ & $832 \%$ & $0 \%$ & $1961 \%$ & $587 \%$ & $-3280 \%$ & 358 & $0 \%$ & $835 \%$ & $0 \%$ & $1138 \%$ & $-1873 \%$ \\
\hline E Fuel Energy & MJ & 14,356 & $6 \%$ & $2 \%$ & $32 \%$ & $11 \%$ & $3 \%$ & $45 \%$ & 30,875 & $17 \%$ & $56 \%$ & $0 \%$ & $6 \%$ & $22 \%$ \\
\hline E Nonrenewable Energy & MJ & 14,529 & $6 \%$ & $13 \%$ & $31 \%$ & $38 \%$ & $11 \%$ & $0 \%$ & 19,220 & $27 \%$ & $43 \%$ & $0 \%$ & $30 \%$ & $0 \%$ \\
\hline E Renewable Energy & MJ & 26 & $4 \%$ & $1 \%$ & $50 \%$ & $38 \%$ & $8 \%$ & $0 \%$ & 12,013 & $0 \%$ & $100 \%$ & $0 \%$ & $0 \%$ & $0 \%$ \\
\hline E Total Primary Energy & MJ & 14,555 & $6 \%$ & $13 \%$ & $31 \%$ & $38 \%$ & $11 \%$ & $0 \%$ & 31,233 & $17 \%$ & $65 \%$ & $0 \%$ & $19 \%$ & $0 \%$ \\
\hline Eutrophication (water) & g eq. $\mathrm{PO}_{4}$ & 11 & $25 \%$ & $0 \%$ & $1 \%$ & $9 \%$ & $64 \%$ & $0 \%$ & 14 & $78 \%$ & $14 \%$ & $0 \%$ & $8 \%$ & $0 \%$ \\
\hline Depletion of Nonrenewable Resources & $\begin{array}{l}\text { frac. of } \\
\text { reserve*1 } 10^{15 /} \\
\text { yr }\end{array}$ & 26 & $5 \%$ & $17 \%$ & $16 \%$ & $53 \%$ & $9 \%$ & $0 \%$ & 40 & $18 \%$ & $46 \%$ & $0 \%$ & $35 \%$ & $0 \%$ \\
\hline Air Acidification & geq. $\mathrm{H}^{+}$ & 123 & $7 \%$ & $2 \%$ & $68 \%$ & $20 \%$ & $4 \%$ & $0 \%$ & 127 & $60 \%$ & $19 \%$ & $0 \%$ & $21 \%$ & $0 \%$ \\
\hline Greenhouse Effect (direct, 100 years) & g eq. $\mathrm{CO}_{2}$ & $1,163,299$ & $13 \%$ & $2 \%$ & $34 \%$ & $8 \%$ & $2 \%$ & $41 \%$ & $1,191,771$ & $30 \%$ & $35 \%$ & $0 \%$ & $8 \%$ & $27 \%$ \\
\hline
\end{tabular}


Table 76: Chaparral Biomass, Conc. Acid-Based Ethanol Production, and Lignin Biomass Power

\begin{tabular}{|c|c|c|c|c|c|c|c|c|c|c|c|c|c|c|}
\hline Article & Units & $\begin{array}{l}\text { OPTION 1: } \\
\text { Total }\end{array}$ & $\begin{array}{l}\text { Biomass } \\
\text { Burning }\end{array}$ & $\begin{array}{l}\text { Natural Gas: } \\
\text { Production }\end{array}$ & $\begin{array}{l}\text { Methanol: } \\
\text { Production }\end{array}$ & $\begin{array}{l}\text { MTBE: } \\
\text { Production }\end{array}$ & $\begin{array}{c}\text { MTBE } \\
\text { RFG: } \\
\text { Production } \\
\end{array}$ & $\begin{array}{c}\text { MTBE } \\
\text { RFG: Use }\end{array}$ & $\begin{array}{l}\text { OPTION 2: } \\
\text { Total }\end{array}$ & $\begin{array}{c}\text { Biomass } \\
\text { Harvesting }\end{array}$ & $\begin{array}{c}\text { Ethanol: } \\
\text { Production }\end{array}$ & $\begin{array}{l}\text { Ethanol: } \\
\text { Transport }\end{array}$ & $\begin{array}{l}\text { ETBE: } \\
\text { Production }\end{array}$ & $\begin{array}{l}\text { ETBE RFG: } \\
\text { Use }\end{array}$ \\
\hline (r) Bauxite (Al2O3, ore) & $\mathrm{kg}$ & 0.031 & $\overline{0 \%}$ & $0 \%$ & $0 \%$ & 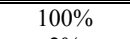 & $0 \%$ & $0 \%$ & 0.033 & $0 \%$ & $0 \%$ & $0 \%$ & $100 \%$ & $0 \%$ \\
\hline (r) Coal (in ground) & $\mathrm{kg}$ & 106 & $1 \%$ & $0 \%$ & $96 \%$ & $2 \%$ & $1 \%$ & $0 \%$ & -29 & $-13 \%$ & $121 \%$ & $0 \%$ & $-7 \%$ & $0 \%$ \\
\hline (r) Iron ( $\mathrm{Fe}$, ore) & $\mathrm{kg}$ & 0.021 & $0 \%$ & $0 \%$ & $1 \%$ & $99 \%$ & $0 \%$ & $0 \%$ & 0.022 & $0 \%$ & $0 \%$ & $0 \%$ & $100 \%$ & $0 \%$ \\
\hline (r) Limestone ( $\mathrm{CaCO} 3$, in ground) & $\mathrm{kg}$ & 16 & $1 \%$ & $0 \%$ & $98 \%$ & $0 \%$ & $1 \%$ & $0 \%$ & 46 & $1 \%$ & $99 \%$ & $0 \%$ & $0 \%$ & $0 \%$ \\
\hline (r) Natural Gas (in ground) & $\mathrm{kg}$ & 149 & $2 \%$ & $26 \%$ & $19 \%$ & $50 \%$ & $4 \%$ & $0 \%$ & 851 & $2 \%$ & $89 \%$ & $0 \%$ & $9 \%$ & $0 \%$ \\
\hline (r) Oil (in ground) & $\mathrm{kg}$ & 146 & $12 \%$ & $0 \%$ & $10 \%$ & $58 \%$ & $20 \%$ & $0 \%$ & 197 & $53 \%$ & $2 \%$ & $0 \%$ & $45 \%$ & $0 \%$ \\
\hline (r) Phosphate Rock (in ground) & $\mathrm{kg}$ & 0 & $0 \%$ & $0 \%$ & $0 \%$ & $0 \%$ & $0 \%$ & $0 \%$ & 0.046 & $0 \%$ & $100 \%$ & $0 \%$ & $0 \%$ & $0 \%$ \\
\hline (r) Potash (K2O, in ground) & $\mathrm{kg}$ & 0 & $0 \%$ & $0 \%$ & $0 \%$ & $0 \%$ & $0 \%$ & $0 \%$ & 0.011 & $0 \%$ & $100 \%$ & $0 \%$ & $0 \%$ & $0 \%$ \\
\hline (r) Uranium (U, ore) & $\mathrm{kg}$ & 0.000070 & $17 \%$ & $6 \%$ & $27 \%$ & $14 \%$ & $36 \%$ & $0 \%$ & -0.0014 & $-5 \%$ & $105 \%$ & $0 \%$ & $-1 \%$ & $0 \%$ \\
\hline Water Used (total) & liter & 186 & $1 \%$ & $0 \%$ & $7 \%$ & $89 \%$ & $2 \%$ & $0 \%$ & 17,362 & $0 \%$ & $29 \%$ & $0 \%$ & $71 \%$ & $0 \%$ \\
\hline Water: Unspecified Origin & liter & 179 & $0 \%$ & $0 \%$ & $7 \%$ & $93 \%$ & $0 \%$ & $0 \%$ & 183 & $0 \%$ & $5 \%$ & $0 \%$ & $95 \%$ & $0 \%$ \\
\hline (a) Carbon Dioxide (CO2, biomass) & $\mathrm{g}$ & $1,931,340$ & $100 \%$ & $0 \%$ & $0 \%$ & $0 \%$ & $0 \%$ & $0 \%$ & $1,702,150$ & $0 \%$ & $91 \%$ & $0 \%$ & $0 \%$ & $9 \%$ \\
\hline (a) Carbon Dioxide ( $\mathrm{CO} 2$, fossil) & $\mathrm{g}$ & $1,036,259$ & $5 \%$ & $1 \%$ & $37 \%$ & $8 \%$ & $2 \%$ & $46 \%$ & $2,490,670$ & $14 \%$ & $70 \%$ & $0 \%$ & $4 \%$ & $13 \%$ \\
\hline (a) Carbon Monoxide (CO) & $\mathrm{g}$ & 101,710 & $100 \%$ & $0 \%$ & $0 \%$ & $0 \%$ & $0 \%$ & $0 \%$ & 4,696 & $31 \%$ & $67 \%$ & $0 \%$ & $2 \%$ & $0 \%$ \\
\hline (a) Hydrocarbons (except methane) & $\mathrm{g}$ & 15,640 & $80 \%$ & $0 \%$ & $15 \%$ & $5 \%$ & $0 \%$ & $0 \%$ & 998 & $27 \%$ & $-5 \%$ & $0 \%$ & $78 \%$ & $0 \%$ \\
\hline (a) Volatile Organic Compounds (VOC) & $\mathrm{g}$ & 18 & $0 \%$ & $0 \%$ & $0 \%$ & $0 \%$ & $100 \%$ & $0 \%$ & 0 & $0 \%$ & $0 \%$ & $0 \%$ & $0 \%$ & $0 \%$ \\
\hline (a) Ethanol & $\mathrm{g}$ & $3.0 \mathrm{E}-07$ & $0 \%$ & $0 \%$ & $100 \%$ & $0 \%$ & $0 \%$ & $0 \%$ & 470 & $0 \%$ & $100 \%$ & $0 \%$ & $0 \%$ & $0 \%$ \\
\hline (a) Furfural & $\mathrm{g}$ & 0 & $0 \%$ & $0 \%$ & $0 \%$ & $0 \%$ & $0 \%$ & $0 \%$ & 6.89 & $0 \%$ & $100 \%$ & $0 \%$ & $0 \%$ & $0 \%$ \\
\hline (a) HMF & $\mathrm{g}$ & 0 & $0 \%$ & $0 \%$ & $0 \%$ & $0 \%$ & $0 \%$ & $0 \%$ & 0.10 & $0 \%$ & $100 \%$ & $0 \%$ & $0 \%$ & $0 \%$ \\
\hline (a) Aldehydes & $\mathrm{g}$ & 1.69 & $1 \%$ & $6 \%$ & $88 \%$ & $3 \%$ & $2 \%$ & $0 \%$ & 1.89 & $4 \%$ & $93 \%$ & $0 \%$ & $3 \%$ & $0 \%$ \\
\hline (a) Formaldehyde & $\mathrm{g}$ & 0.33 & $17 \%$ & $1 \%$ & $40 \%$ & $12 \%$ & $30 \%$ & $0 \%$ & 2.52 & $13 \%$ & $85 \%$ & $0 \%$ & $2 \%$ & $0 \%$ \\
\hline (a) Benzene (C6H6) & $\mathrm{g}$ & 32 & $3 \%$ & $44 \%$ & $29 \%$ & $17 \%$ & $6 \%$ & $0 \%$ & 287 & $2 \%$ & $96 \%$ & $0 \%$ & $2 \%$ & $0 \%$ \\
\hline (a) Hydrogen Chloride $(\mathrm{HCl})$ & $\mathrm{g}$ & 55 & $1 \%$ & $0 \%$ & $96 \%$ & $2 \%$ & $1 \%$ & $0 \%$ & 5.07 & $35 \%$ & $43 \%$ & $0 \%$ & $22 \%$ & $0 \%$ \\
\hline (a) Hydrogen Fluoride (HF) & $\mathrm{g}$ & 6.73 & $1 \%$ & $0 \%$ & $98 \%$ & $0 \%$ & $1 \%$ & $0 \%$ & 0.50 & $44 \%$ & $54 \%$ & $0 \%$ & $1 \%$ & $0 \%$ \\
\hline (a) Hydrogen Sulfide (H2S) & $\mathrm{g}$ & 0.44 & $28 \%$ & $0 \%$ & $0 \%$ & $24 \%$ & $47 \%$ & $0 \%$ & 0.90 & $84 \%$ & $3 \%$ & $0 \%$ & $12 \%$ & $0 \%$ \\
\hline (a) Metals (unspecified) & $\mathrm{g}$ & 0.10 & $0 \%$ & $0 \%$ & $0 \%$ & $100 \%$ & $0 \%$ & $0 \%$ & 0.11 & $0 \%$ & $0 \%$ & $0 \%$ & $100 \%$ & $0 \%$ \\
\hline (a) Methane (CH4) & $\mathrm{g}$ & 5,707 & $80 \%$ & $8 \%$ & $7 \%$ & $3 \%$ & $2 \%$ & $0 \%$ & 9,949 & $2 \%$ & $95 \%$ & $0 \%$ & $2 \%$ & $0 \%$ \\
\hline (a) Nitrogen Oxides ( $\mathrm{NOx}$ as $\mathrm{NO} 2$ ) & $\mathrm{g}$ & 2,189 & $14 \%$ & $4 \%$ & $48 \%$ & $31 \%$ & $3 \%$ & $0 \%$ & 6,199 & $49 \%$ & $39 \%$ & $0 \%$ & $12 \%$ & $0 \%$ \\
\hline (a) Nitrous Oxide $(\mathrm{N} 2 \mathrm{O})$ & $\mathrm{g}$ & 23 & $18 \%$ & $1 \%$ & $74 \%$ & $2 \%$ & $5 \%$ & $0 \%$ & 73 & $44 \%$ & $55 \%$ & $0 \%$ & $1 \%$ & $0 \%$ \\
\hline (a) Particulates (unspecified) & $\mathrm{g}$ & 21,337 & $94 \%$ & $0 \%$ & $5 \%$ & $0 \%$ & $0 \%$ & $0 \%$ & 4,808 & $9 \%$ & $89 \%$ & $0 \%$ & $2 \%$ & $0 \%$ \\
\hline (a) Sulfur Oxides ( $\mathrm{SOx}$ as $\mathrm{SO} 2$ ) & $\mathrm{g}$ & 2,349 & $2 \%$ & $0 \%$ & $80 \%$ & $14 \%$ & $4 \%$ & $0 \%$ & 322 & $93 \%$ & $-96 \%$ & $0 \%$ & $104 \%$ & $0 \%$ \\
\hline (w) Ammonia (NH4+, $\mathrm{NH} 3$, as $\mathrm{N}$ ) & $\mathrm{g}$ & 6.84 & $23 \%$ & $0 \%$ & $3 \%$ & $15 \%$ & $59 \%$ & $0 \%$ & 7.56 & $83 \%$ & $2 \%$ & $0 \%$ & $14 \%$ & $0 \%$ \\
\hline (w) BOD (Biochemical Oxygen Demand) & $\mathrm{g}$ & 46 & $23 \%$ & $0 \%$ & $8 \%$ & $9 \%$ & $60 \%$ & $0 \%$ & 50 & $87 \%$ & $4 \%$ & $0 \%$ & $9 \%$ & $0 \%$ \\
\hline (w) COD (Chemical Oxygen Demand) & $\mathrm{g}$ & 346 & $26 \%$ & $0 \%$ & $0 \%$ & $6 \%$ & $68 \%$ & $0 \%$ & 403 & $90 \%$ & $4 \%$ & $0 \%$ & $5 \%$ & $0 \%$ \\
\hline (w) Metals (unspecified) & $\mathrm{g}$ & 33 & $1 \%$ & $0 \%$ & $0 \%$ & $96 \%$ & $3 \%$ & $0 \%$ & 35 & $7 \%$ & $0 \%$ & $0 \%$ & $92 \%$ & $0 \%$ \\
\hline (w) Hydrocarbons (unspecified) & $\mathrm{g}$ & 5.23 & $0 \%$ & $0 \%$ & $0 \%$ & $99 \%$ & $1 \%$ & $0 \%$ & 5.53 & $2 \%$ & $0 \%$ & $0 \%$ & $98 \%$ & $0 \%$ \\
\hline (w) Phenol (C6H6O) & $\mathrm{g}$ & 0.87 & $24 \%$ & $0 \%$ & $3 \%$ & $12 \%$ & $61 \%$ & $0 \%$ & 0.95 & $87 \%$ & $1 \%$ & $0 \%$ & $11 \%$ & $0 \%$ \\
\hline (w) Nitrates (NO3-) & $\mathrm{g}$ & 1.42 & $0 \%$ & $0 \%$ & $27 \%$ & $73 \%$ & $0 \%$ & $0 \%$ & 19 & $0 \%$ & $94 \%$ & $0 \%$ & $6 \%$ & $0 \%$ \\
\hline (w) Oils (unspecified) & $\mathrm{g}$ & 29 & $18 \%$ & $0 \%$ & $6 \%$ & $32 \%$ & $44 \%$ & $0 \%$ & 35 & $69 \%$ & $3 \%$ & $0 \%$ & $28 \%$ & $0 \%$ \\
\hline (w) Suspended Matter (unspecified) & $\mathrm{g}$ & 200 & $24 \%$ & $0 \%$ & $3 \%$ & $10 \%$ & $63 \%$ & $0 \%$ & 227 & $86 \%$ & $4 \%$ & $0 \%$ & $10 \%$ & $0 \%$ \\
\hline Waste (nonhazardous) & $\mathrm{kg}$ & 173 & $0 \%$ & $0 \%$ & $97 \%$ & $1 \%$ & $1 \%$ & $0 \%$ & 104 & $4 \%$ & $94 \%$ & $0 \%$ & $2 \%$ & $0 \%$ \\
\hline E Feedstock Energy & MJ & 199 & $0 \%$ & $832 \%$ & $0 \%$ & $1961 \%$ & $587 \%$ & $-3280 \%$ & 358 & $0 \%$ & $835 \%$ & $0 \%$ & $1138 \%$ & $-1873 \%$ \\
\hline E Fuel Energy & MJ & 14,356 & $6 \%$ & $2 \%$ & $32 \%$ & $11 \%$ & $3 \%$ & $45 \%$ & 58,339 & $9 \%$ & $77 \%$ & $0 \%$ & $3 \%$ & $11 \%$ \\
\hline E Nonrenewable Energy & MJ & 14,529 & $6 \%$ & $13 \%$ & $31 \%$ & $38 \%$ & $11 \%$ & $0 \%$ & 48,218 & $11 \%$ & $77 \%$ & $0 \%$ & $12 \%$ & $0 \%$ \\
\hline E Renewable Energy & MJ & 26 & $4 \%$ & $1 \%$ & $50 \%$ & $38 \%$ & $8 \%$ & $0 \%$ & 10,479 & $0 \%$ & $100 \%$ & $0 \%$ & $0 \%$ & $0 \%$ \\
\hline E Total Primary Energy & MJ & 14,555 & $6 \%$ & $13 \%$ & $31 \%$ & $38 \%$ & $11 \%$ & $0 \%$ & 58,698 & $9 \%$ & $81 \%$ & $0 \%$ & $10 \%$ & $0 \%$ \\
\hline Eutrophication (water) & g eq. PO4 & 11 & $25 \%$ & $0 \%$ & $1 \%$ & $9 \%$ & $64 \%$ & $0 \%$ & 14 & $77 \%$ & $16 \%$ & $0 \%$ & $8 \%$ & $0 \%$ \\
\hline Depletion of Nonrenewable Resources & $\begin{array}{c}\text { frac. of } \\
\text { reserve*1015/y } \\
\mathrm{r}\end{array}$ & 26 & $5 \%$ & $17 \%$ & $16 \%$ & $53 \%$ & $9 \%$ & $0 \%$ & 110 & $7 \%$ & $80 \%$ & $0 \%$ & $13 \%$ & $0 \%$ \\
\hline Air Acidification & g eq. $\mathrm{H}^{+}$ & 123 & $7 \%$ & $2 \%$ & $68 \%$ & $20 \%$ & $4 \%$ & $0 \%$ & 145 & $52 \%$ & $29 \%$ & $0 \%$ & $18 \%$ & $0 \%$ \\
\hline Greenhouse Effect (direct, 100 years) & g eq. $\mathrm{CO} 2$ & $1,163,299$ & $13 \%$ & $2 \%$ & $34 \%$ & $8 \%$ & $2 \%$ & $41 \%$ & $2,722,247$ & $13 \%$ & $72 \%$ & $0 \%$ & $4 \%$ & $12 \%$ \\
\hline
\end{tabular}




\section{BACKGROUND}

Only recently has the LCA tool actually been concerned with the impacts on the environment of a system. By definition, the inventory component of an LCA, still the single focus of many LCA studies, is only concerned with the flows generated by the system (either consumed or emitted), and by definition, do not address the reception issue, i.e., the impacts on the environment.

In the most straightforward and transparent approach to LCI interpretation, the LCI results may be used as-is to help identify and prioritize opportunities for pollution prevention or increases in material and energy efficiency for processes within the life cycle. A particular advantage of LCI applied in this way is its comprehensiveness. LCAs help detect the shifting of environmental burdens from one life cycle stage to another (e.g., lower energy consumption during use, achieved at the cost of much higher manufacturing energy consumption), or from one media to another (e.g., lower air emissions at the cost of increased solid waste).

The subsequent stage, LCIA, addresses the issue of how to translate the flows previously compiled into environmental impacts. Some issues viewed as crucial for LCIA are:

- The amount of additional exposure data that would be needed to model actual impacts (as in human health risk assessment) is technically incompatible with the nature of LCA (several hundreds or thousands of processes connected together, each one generating dozens or hundreds of emissions), and does not correspond to its objectives. It should be recognized that LCA is one environmental management tool among several, and that LCA cannot replace a specific environmental impact analysis for a specific site (see Figure 82).

- Since LCIA aims at assessing potential impacts, LCA should not be considered as a predictive tool for assessing the actual impacts associated with a system, but rather as a tool providing comparative results for the functional unit considered. Moreover, the functional unit has often no reference to time or space considerations (which would be needed for predictive models), but is solely related to the function and performance of a system. As the modeling of environmental impacts improves, potential LCIA models should become more and more precise and integrate crucial notions such as thresholds (current approaches are all based on a "less-is-better" approach). Consequently, inventory data collection requirements could gradually increase with new parameters characterizing emissions' location, flow rate, key attributes of impacted media, etc.

- Existing approaches that result in a limited number of indices are highly controversial. They have been criticized because they do not separate the objective evaluation stage of the environmental impact on scientific grounds from the subjective "valuation" stage in which these impacts are traded off. Using such approaches is very dangerous from an industrial perspective, due to the following reasons:

* It tends to favor short-term arbitrary choices while masking their arbitrary nature behind quantitative approaches, which convey more rigor and objectivity than are truly involved. This is incompatible with industrial long-term investment and product design.

* The choices made might hide pollution displacement from one media to another or from one step to another.

In numerous cases, results of inventory or impact assessment have been conclusive enough so that no valuation was actually needed. Moreover, very often, the existence of trade-offs is by itself a crucial piece of information.

- For most impact categories, variability and uncertainties about impact potentials make any single numerical "equivalency factor" immediately contradictable and discreditable. Instead, LCIA methods need to be developed in which process data and results are considered in probabilistic terms. As for inventory results, uncertainties should be propagated and communicated to the decision-making audience. 


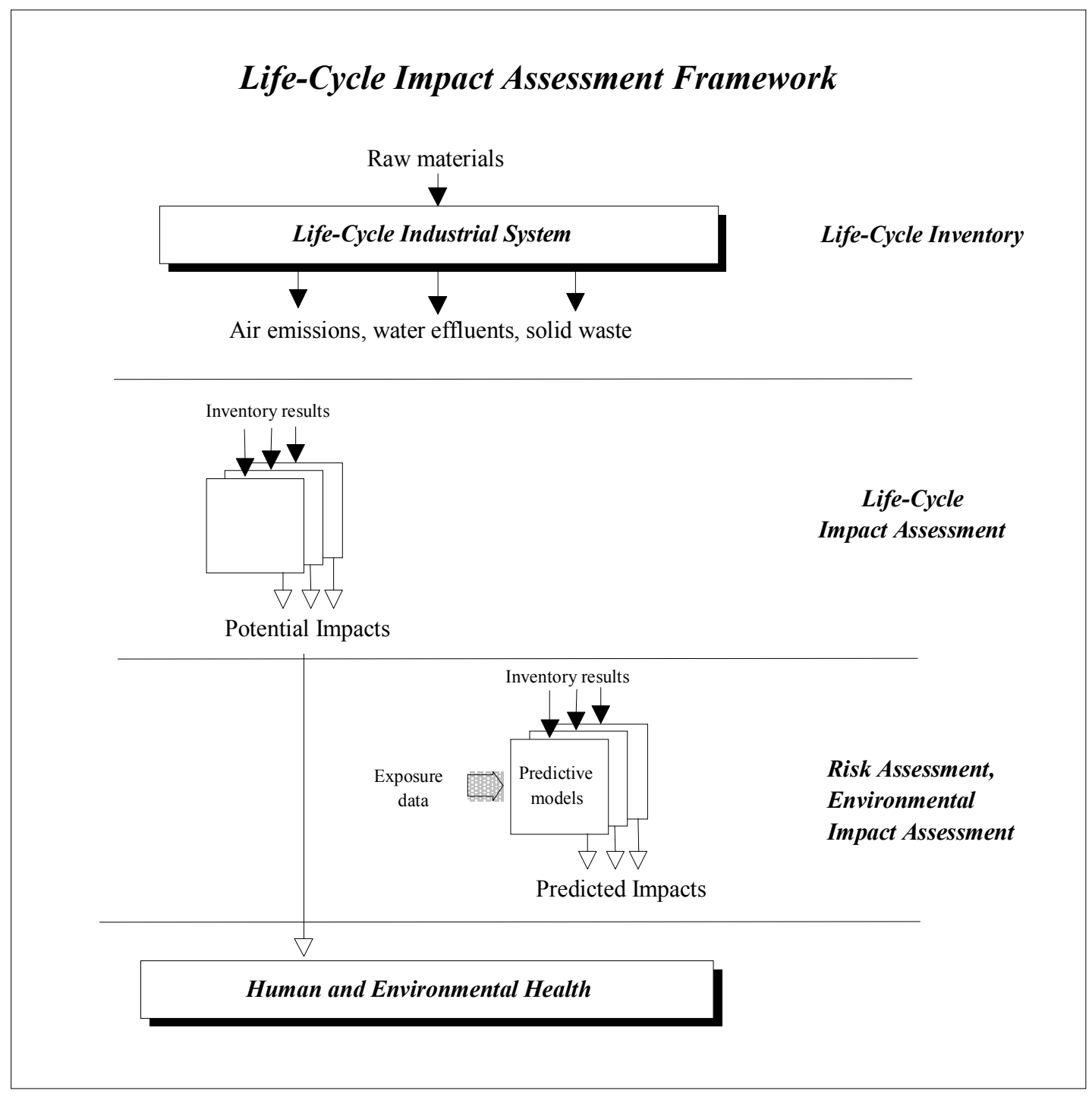

Figure 82: Life Cycle Impact Assessment Framework

\section{OVERVIEW OF LIFE CYCLE IMPACT ASSESSMENT INDICES}

\section{Greenhouse Potential}

The Greenhouse potential refers to the ability of some atmospheric gases to retain heat that is radiating from the earth. Models have been developed to quantify the contribution made by emissions of various substances to the greenhouse potential. Generally these models provide an indication of the change in the heat radiation absorption of the atmosphere. Global warming potentials (GWPs) have been calculated to compare the emission of different greenhouse gases [1].

The overall result of emission of these gases on the Greenhouse Potential (E) is calculated as follows:

$$
E=\sum G W P_{i} x m_{i}
$$


where, for a greenhouse gas i,

$\mathrm{m}_{\mathrm{i}}$ is the mass of the gas released (in $\mathrm{kg}$ ),

$\mathrm{GWP}_{\mathrm{i}}$ is its potential impact on global warming.

\section{Greenhouse potential is expressed in grams of $\mathrm{CO}_{2}$ equivalent.}

The following factors are used to calculate the greenhouse potential (Table 77).

Table 77: Greenhouse Gas Potential Factors

\begin{tabular}{ccc}
\hline Formula & Substance & $\boldsymbol{G W P}_{\boldsymbol{i}}$ \\
\hline \hline $\mathrm{CO}_{2}$ & Carbon dioxide & 1 \\
$\mathrm{CH}_{4}$ & Methane & 21 \\
$\mathrm{~N}_{2} \mathrm{O}$ & Nitrous Oxide & 310 \\
$\mathrm{CCl}_{4}$ & Carbon Tetrachloride & 1,400 \\
$\mathrm{CFCl}_{3}$ & CFC 11 & 4,000 \\
\hline
\end{tabular}

The potential impact on global warming of the gas $i$ can be defined as the ratio between the cumulative radiative force between present and a future time horizon (in this case, 20, 100 and 500 years) as a result of the release of a unit mass of greenhouse gas $i$ now, and an equal emission of the standard gas, carbon dioxide. The calculation of the GWP is based on understanding the fate of the emitted gas and the radiative effect associated with the amount remaining in the atmosphere.

\section{Acidification Potential}

Potential acidic deposition (onto soil, vegetation, and water) can be expressed as potential $\mathrm{H}^{+}$equivalents. Potentially acidifying emissions of $\mathrm{SO}_{2}, \mathrm{NO}_{\mathrm{x}}$, and $\mathrm{NH}_{\mathrm{x}}$ can be aggregated on the basis of their potential to form $\mathrm{H}^{+}$. In the calculation of $\mathrm{H}^{+}$equivalents, it is assumed that one mole $\mathrm{SO}_{2}$ will produce two moles $\mathrm{H}^{+}$, that one mole nitrogen oxide compounds $\left(\mathrm{NO}_{\mathrm{x}}\right)$ will produce one mole $\mathrm{H}^{+}$, and that one mole reduced nitrogen compounds $\left(\mathrm{NH}_{\mathrm{x}}\right)$ will produce one mole $\mathrm{H}^{+}$.

An acidification potential (AP) of a substance is calculated on the basis of the number of $\mathrm{H}^{+}$ions which can be produced per mole (given by the stoichiometry of the oxidation reaction) [2]. However, as emissions are specified in $\mathrm{kg}$ rather than in moles, the weight has to be divided by the molecular weight of the substance.

The factors used for acidification potential are listed in Table 78.

Table 78: Acidification Potential Reactions

\begin{tabular}{cllc}
\hline Formula & \multicolumn{1}{c}{ Substance } & \multicolumn{1}{c}{ Reaction } & AP \\
\hline $\mathrm{SO}_{2}$ & Sulfur dioxide & $\mathrm{SO}_{2}+\mathrm{H}_{2} \mathrm{O}+\mathrm{O}_{3} \rightarrow 2 \mathrm{H}^{+}+\mathrm{SO}_{4}{ }^{2-}+\mathrm{O}_{2}$ & 32 \\
$\mathrm{NO}_{x}$ & Nitrogen oxides & $\mathrm{NO}_{2}+\mathrm{OH}^{-} \rightarrow \mathrm{H}^{+}+\mathrm{NO}_{3}^{-}$ & 46 \\
$\mathrm{NH}_{3}$ & Ammonia & $\mathrm{NH}_{3}+2 \mathrm{O}_{2} \rightarrow \mathrm{H}^{+}+\mathrm{NO}_{3}{ }^{-}+\mathrm{H}_{2} \mathrm{O}$ & 17 \\
$\mathrm{HCl}$ & Hydrochloric acid & $\mathrm{HCl} \rightarrow \mathrm{H}^{+}+\mathrm{Cl}^{-}$ & 36.5 \\
$\mathrm{HF}$ & Hydrogen fluoride & $\mathrm{HF} \rightarrow \mathrm{H}^{+}+\mathrm{F}^{-}$ & 20 \\
\hline
\end{tabular}




\section{Eutrophication Potential}

Eutrophication is the addition of mineral nutrients to the soil or water, which increases production of cell biomass. In both media, the addition of mineral nutrients $(\mathrm{N}$ and $\mathrm{P})$ in large quantities result in generally undesirable shifts in the number of species in ecosystems and a reduction in the ecological diversity. In water, it tends to increase algae growth, that eventually die and sink to the deeper layers of the water body. The decomposition of this dead cell biomass requires the consumption of large amounts of oxygen, which can result in the death of other aquatic species, such as fish.

Another form of oxygen deficit may be caused by emissions of organic materials that can bind oxygen. These emissions are generally expressed as the biochemical oxygen demand (BOD) or the COD. The oxygen is mainly consumed by the biological degradation of organic content.

The eutrophication potential (EP) of a substance is calculated on the basis of its potential cell biomass formation. It is calculated in $\mathrm{N}$ equivalent, by considering the average ratio of $\mathrm{N}$ and $\mathrm{P}$ in cell biomass and the oxygen required for the breakdown of this cell biomass. The ratios for $\mathrm{N}, \mathrm{P}$, and $\mathrm{O}_{2}$ are 7, 1, and 142, respectively.

NPs are developed by analogy with the GWP. Therefore, phosphate ions have been chosen as the reference substance. A single index is produced for the eutrophication:

$$
\text { eutrophication potential }=\Sigma_{\mathrm{i}} \mathrm{EP}_{\mathrm{i}} \times \mathrm{m}_{\mathrm{i}}
$$

where $m_{i}$ is the weight (in $\mathrm{kg}$ ) of the substance released. The calculated quantity indicates the quantity of a $\mathrm{PO}_{4}$ emission with the same potential eutrophication effect.

The following classification factors (Table 79) are used for the eutrophication potential (source: CML, Environmental Life Cycle Assessment of Products, Guide - October 1992):

Table 79: Eutrophication Potential Factors

\begin{tabular}{ccc}
\hline Formula & Substance & EP \\
\hline \hline $\mathrm{PO}_{4}$ & Phosphates & 1 \\
$\mathrm{P}$ & Phosphorous & 3.06 \\
$\mathrm{~N}$ & Nitrogen & 0.42 \\
$\mathrm{NO}_{\mathrm{x}}$ & Nitrogen Oxides & 0.2 \\
$\mathrm{NH}_{3}$ & Ammonia & 0.42 \\
$\mathrm{COD}$ & Chemical Oxygen Demand & 0.022 \\
\hline
\end{tabular}

Natural Resources Depletion Index

Resource Depletion as an Environmental Issue

Resource depletion can be defined as the decreasing availability of natural resources. The resources considered in this impact are fossil and mineral resources, excluding biotic resources and associated impacts such as species extinction and loss of biodiversity. It is important to recognize that what is addressed in this index is the fact that some resources are depleted, not the fact that their extraction from the environment will generate impacts (e.g., methane emissions from coal mining).

Concepts

\section{Corresponding Inventory Flows}

The assessment of natural resources depletion can only be applied to a subset of the LCI flows called elementary flows, i.e., flows that are directly taken from the environment. A coal consumption of $1 \mathrm{~kg}$ at the power plant gate does not correspond to an elementary flow. Rather, it corresponds to a consumption of approximately $1.03 \mathrm{~kg}$ of coal in the ground, due to the losses in mining, processing, and transportation. 


\section{Availability Defined}

The notion of availability can be further defined. Natural resources depletion does not consider the availability within the economy, but rather within the "natural" environment. Excluded from this impact are "economic stocks" such as aluminum from aluminum cans or steel from used car bodies. Therefore, the availability is not measured within the whole economy, but only at the economy/environment "boundary." Furthermore, the availability is concerned with the availability within the primary extraction medium (e.g., iron ore available from the earth's crust) and not within the entire geosphere (which would include iron available in water bodies, atmosphere, plants, landfills, etc.).

\section{Resource versus Reserve}

Once the concept of availability has been defined, the notion of reserve of a resource needs also to be determined. Through the years, geologists, mining engineers, and others operating in the mineral field have used various terms to describe and classify mineral resources. Known resources can be classified from two standpoints: 1) purely geologic or physical/chemical characteristics — such as grade, tonnage, thickness, and depth — of the material in place, and 2) profitability analyses based on costs of extracting and marketing the material in a given economy at a given time. The former constitutes important objective scientific information of the resource and a relatively unchanging foundation upon which the latter economic delineation can be based.

For mineral resources, the reserve chosen for this index is the reserve base as defined by the U.S. Bureau of Mines: "part of an identified resource [3] $]^{32}$ that meets specified minimum physical and chemical criteria related to current mining and production practices, including those for grade, quality thickness, and depth. The reserve base encompasses those parts of the resources that have a reasonable potential for becoming economically available within planning horizons beyond those that assume proven technology and current economics. It includes those resources that are currently economic (reserve), marginally economic (marginal reserves) and currently subeconomic." By including economic and sub-economic considerations, the reserve base falls between the two extremes of economic reserve and ultimate reserve/resource base.

For fossil fuels (including uranium), the reserve chosen is based on information supplied by the World Energy Council (WEC). In order to be consistent with the reserve base used by the U.S. Bureau of Mines, the reserve chosen for fossil fuels has been defined as the addition of the WEC's "proved amount in place" (tonnage in place that has been both carefully measured and has also been assessed as exploitable under present and expected local economic conditions with existing available technology) and "estimated additional reserves recoverable" (quantity of the estimated additional amount in place which might become recoverable within foreseeable economic and technological limits).

It should be noted that what matters most in this impact assessment index is the availability of a relative scale allowing comparisons between resources rather than an estimation of the exact size of what is considered available for use. This is linked to the fact that Impact Assessment as performed within an LCA is of a comparative rather than predictive nature. It aims at assessing the relative potential impacts of different alternatives (i.e., natural resource depletion index of A versus B) rather than assessing the actual impacts of a system onto the environment (as it would be done in traditional risk assessment).

\section{Used Index}

Once the type reserve is identified, an index can be defined that will relate an inventory flow with the depletion of that resource. The proposed depletion index uses equivalency factors, i.e., each natural resource consumption recorded in the inventory is multiplied by the resource's weighting factor (or equivalency factor). As described in equation (1) of Figure 83, the total depletion index is then compiled by adding the previous intermediate results for all inventory flows considered.

Several methods can be used to produce the equivalency factors.

32 Opposed to identified resources are undiscovered resources, the existence of which is only postulated. 
In the first method described in equation (2), the inverse of reserve (in $\mathrm{kg}$ ) is used as a weighting factor. Such an index addresses the relative contribution of the LCA system to the depletion of the reserves (the larger the relative contribution, the bigger the index) as well as the size of the reserve (the larger the reserve, the smaller the index). However, it does not address the following problem: how long a given resource will continue to be available (the fact that the reserve is rapidly or slowly being depleted, which is directly related to the notion of sustainability, is not accounted for in this index).

In the second method, described in equation (3), the inverse of remaining years of use is used as a weighting factor. The number of remaining years of use is defined as the reserves divided by the total world-wide production (i.e., extraction). It represents the number of years for which current reserves will suffice at the current production (extraction) level. This index, however, does not correctly account for the size of the reserve: two resources with the same number of years will have the same indices irrespective of whether there are $1 \mathrm{~kg}$ or 1 million Mt reserves.

In the third method described in equation (4) and retained as a basis for the index, the inverse of remaining years of use and the reserve size are used as weighting factors. This index addresses both problems that were raised by the first two methods. It should be noted, however, that choosing higher (e.g. cubic) power for the reserve and production could generate a number of similar indices. ${ }^{33}$ Since there is no rational basis for doing so, the index has been kept as in equation (4). In order to facilitate the readability of the results, all equivalency factors have been multiplied by $10^{15}$ (as explained previously, the relative contribution of each resource is what matters most).

(1) Depletion $=\sum_{r e s}$ equivalency factor $r_{r e s} x$ inventory consumption $n_{r e s}$

(2) Depletion $=\sum_{\text {res }} \frac{1}{\text { reserve }}$ res $x$ inventoryconsumption ies

(3) Depletion $=\sum_{r e s} \frac{1}{\text { years }_{r e s}} x$ inventoryconsumption $_{r e s}=\sum_{r e s} \frac{\text { production }_{r e s}}{\text { reserve }_{r e s}} \times$ inventoryconsumption $_{r e s}$

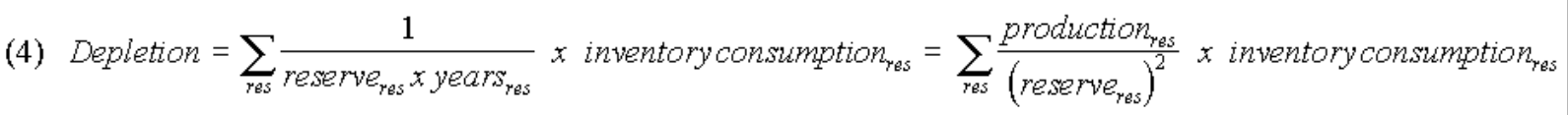

Figure 83: Natural Resource Depletion Impact Equations

33 It has been shown that in order to keep the index independent of the resource density, that the power of the reserve should be the power of the production plus one, which is the case in equation (4). 


\section{Appendix C: Potential California Biomass Availability}

\section{INTRODUCTION}

California is a diverse 100 million-acre area with approximately 70 million acres of wildlands susceptible to wildfires. Another 8 million acres of agriculture land are under cultivation. Currently, California has a growing population of 33 million people, each generating on the average, more than one ton of urban waste annually. The opportunities for creating a new ethanol industry in California rest on diverting wildland wastes from wildfire fuel, agriculture wastes from open-field burning, and urban wastes from being landfilled.

Annually, more and more state, federal, and local regulatory limitations are placed on agriculture-related open-field burning. In addition, the costs and losses associated with wildfires are increasing, with the average annual totals of wildfire suppression costs and losses exceeding $\$ 1$ billion in California alone. During peak years, wildfire costs and losses have reached more than $\$ 2$ billion. These problems and regulatory efforts to reduce the related environmental impacts are increasing the costs to continue wildlands and agriculture residues burning. The avoided costs of wildfire fuel loading reductions and disposing of agriculture residues using alternatives to open-field burning, offer significant economic and environmental benefits to using the biomass as feedstock for a new biomass-to-ethanol industry.

Thus, California has a major biomass waste disposal problem, annually contributing approximately 43 million tons of forest residues, sawmill residues, agriculture wastes, and urban wood wastes to California's waste streams. In addition, there are an estimated 2 million tons of chaparral burned annually on California wildlands, much of which is contributing to large environmental problems and economic losses.

This Appendix characterizes three scenarios of representative California biomass wastes that could be used as raw material in biomass-to-ethanol facilities:

- $\quad$ Rice straw that could be diverted from open-field burning in the Sacramento Valley.

- Biomass that could be harvested to reduce wildfire fuel loading from Northeastern California forest lands.

- Chaparral that could be harvested rather than burned to protect homes and other high-value environmental and economic assets in Southern California from catastrophic wildfires.

- The following sections:

- Identify the estimated biomass volumes and related biomass waste disposal problems,

- Discuss the potential for a new biomass-to-ethanol industry in California,

- Identify GIS maps of concentrations of biomass throughout the state,

- Make gross estimates of air pollutant emissions from existing open-field fires and wildfires, and

- Provide some assumptions and estimates for collection, harvesting, processing, and transportation costs to deliver each biomass type to a potential biomass-to-ethanol facility.

\section{ESTIMATED CALIFORNia Biomass VOLUMES}

Biomass can be classified into four categories: agriculture residues, forests and woodlands, chaparral, and urban (this last feedstock is not included in the current study).

\section{Agriculture Residues}

There are an estimated 20.5 million BDT of agriculture residues available annually in California. This includes rice, wheat, grass, and other grain straws, orchard prunings, orchard removals, grape prunings, cotton stalks, corn stalks, nutshells, food processing wastes, livestock wastes, and others.

Of the total agricultural residues produced, there are an estimated 1.5 million tons of rice straw produced on approximately 500,000 acres in California. Less than $2 \%$ is utilized as a raw material or by-product. The remainder is open-field burned or incorporated back into the soil. Rice straw and other agriculture residues are becoming more expensive to dispose of, as burning becomes less viable. Some of the reasons and related trends are: 
- Regulations and statutes are reducing volumes that can be open-field burned.

- Rice straw is the first agriculture residue where reductions in open-field burning are mandated by state law to be no more than $25 \%$ of the planted acreage by the year 2001 .

- Open-field burning of other agricultural wastes is also being reduced and will probably be eliminated.

\section{Forests and Woodlands}

There are an estimated 18 million BDT of forest and woodland biomass available annually in California. These include sawmill residues, logging slash, pre-commercial thinnings, fuel hazard reduction materials, etc. The following are some of the factors that influence forest biomass availability:

- Averages of approximately $\$ 1$ billion in costs/losses from wildfires annually, and the long-term trend is for costs and losses to continue to increase. A majority of these costs and losses can be avoided if the fuel loading is reduced by harvesting and transporting for use in a biomass-to-ethanol facility.

- Long-term cumulative increase in biomass fuel per acre (1.3\% annually on 14 of California's National Forests) since the post-European settlement.

- New state initiatives to identify high-risk, high-value wildfire areas and partially subsidize the diversion of biomass into commercial applications.

\section{Chaparral}

Because there has been little historical research on removal of chaparral for raw material, there is little known of the annual volume of chaparral physically and economically available in California. Depending upon which vegetation types are included, there are between 9 million and 20 million acres of chaparral in California. Most of these lands are covered with mixtures of brush and scrub oak, and are highly volatile fuels for the 10,000 California wildfires that, on average, occur each year. However, very little research has been done and little is known about this source of biomass. Based on limited empirical studies, total volumes of chaparral biomass per acre range from 6 to 51 green tons. Most of this material is not available for collection and processing because of potential environmental impacts, lack of access, and a low cost/benefit return for fuel loading reduction compared to the value of the resources and other assets being protected.

Using the existing empirical studies reflecting 6 to 51 green tons of chaparral per acre and 9 million acres of chaparral lands, there are an estimated 56 million to 459 million green tons of standing biomass on California chaparral lands. However, much of this fuel is on steep slopes with erosive granite soils, and is only available for wildfire consumption. It is not economically viable or environmentally acceptable to conduct clearcut harvesting of chaparral. However, it is viable to use and expand the existing manual harvesting of chaparral projects that are piling and open-field burning chaparral to reduce wildfire fuel loading and protect valuable assets such as homes, people, potable water, and environmentally sensitive areas.

There are two primary sources of existing chaparral collection efforts: 1) creating fuel breaks by hand clearing around high value assets, such as homes, reservoirs and environmentally sensitive wildland areas, and 2) as part of the state's wildland fire protection system, use of inmate crews and other publicly funded conservation crews to construct and maintain fuel breaks. These fuel breaks are used as primary fire suppression lines when wildfires burn through an area. All of the chaparral that is cut by these hand crews is piled and open-field burned, contributing to the air pollution. These manual fuel reduction efforts on chaparral lands are minimal compared to the total volume of excessive fuel loading on the millions of acres of chaparral lands. With additional economic market incentives, such as use of the material in a biomass-to-ethanol facility, and public subsidies to reduce the costs/losses of wildfires, these chaparral-harvesting efforts could be significantly expanded.

Lastly, major concentrations of chaparral are located near the state's population centers in Southern California. These chaparral masses contribute heavily to the fuel loading for large damaging wildfires. Coincidentally, these concentrations are also located in areas that suffer from some of the worst air quality in California, the South Coast Air Basin. Typically large wildfires burn in the summer, when air pollution is the highest. Thus, diversion of chaparral from burning will have a direct beneficial impact on reducing air pollutants during the smoggiest period of the year in Southern California. 
The 1997 Annual Report of the Department of Forestry and Fire Protection-Conservation Camp indicates that conservation camp crews located in Southern California reported a total of 35,111 activity person days devoted to Fire Defense Improvements and an additional 2,736 activity person days devoted to the Vegetation Management Program. In accomplishing these activities, crews had the potential to divert significant volumes of chaparral as raw material for a manufacturing product such as ethanol. In addition, expansion of the conservation camp program for fuel load reduction work could result in significantly more material available in the future.

\section{Urban Biomass}

There are an estimated 4.5 million BDT of urban biomass available annually in California. These include landscape and right-of-way prunings, tree removals, wood manufacturing product wastes, including furniture, pallet, dunnage, construction lumber residues, demolition materials, etc. Some of the trends that will cause future increases of urban wastes are:

- The annual volume of urban waste is increasing significantly, reflecting large population increases: currently 33 million, projected to reach as high as 50 million by the year 2018 .

- A 1990 California statute (B-939) requires cities and counties to divert 50\% of the waste materials from landfills to the reuse or recycle sectors by the year 2000. A major portion of this urban waste stream waste is biomass. Based on collection surveys, the biomass ranges from $6 \%-35 \%$ of the waste stream, depending on the geographical area of the state.

\section{Total California Biomass Available}

Using the above data, there are an estimated 43 million BDT of biomass available annually in California. In summary, the following conclusions are important to the use of this biomass for manufacturing facilities such as biomass-to-ethanol:

- The biomass is increasing annually, particularly in the urban waste stream and forests.

- Little is known about the volumes of chaparral available for use in biomass-to-ethanol facilities. This is an area needing significantly more research. Because, as referenced above, when large, damaging wildfires burn, they are in the summertime, during the smoggiest time of the calendar year. Thus, diversion of chaparral (from being burned) into a raw material will have a direct beneficial impact on reducing air pollutants during the smoggiest period of the year in Southern California and reducing the costs/losses from wildfires.

- Agriculture is also located in the areas of the state that fail to meet air quality standards, and is experiencing the greatest pressures for disposal alternatives.

- Because of the growing biomass waste disposal problems, there are likely to be additional state subsidies to divert materials into commercial use.

- Significant volumes of agriculture and forest biomass are burned, contributing to air quality and other environmental problems.

- Biomass waste disposal alternatives are decreasing and costs are increasing.

- Of the 43 million BDT of biomass generated in California annually, up to 9 million tons have been used in the biomass power plant industry. However, the biomass power plant industry is shutting down a significant number of their plants, reducing biomass usage to less than 6 million tons annually, thereby creating a surplus of biomass in the waste stream and driving the biomass fuel prices down from a peak of \$40/BDT to \$1518/BDT during the last 18 months. The power plant users of biomass have an objective to receive delivered feedstock at close to $\$ 0 / \mathrm{BDT}$.

- Three factors are increasing the volumes of biomass materials in the state's waste stream: population increases, increasing regulatory limitations and costs for disposing of biomass through burning or landfilling, and a significant volume of forest residue that needs to be disposed of to reduce wildfire threats on California's public and private timber, brush, and hardwood covered wildlands. 


\section{AREAS OF BIOMASS CONCENTRATIONS IN CALIFORNIA}

\section{Rice Straw Generation in the Sacramento Valley}

A review of the crop data within the County Agricultural Commissioners Crop Reports indicates that within the Sacramento Valley, approximately 490,000 acres of rice are currently grown annually.

Table 80 shows the acreage planted and estimated rice straw by county. This acreage is $96 \%$ of the total rice grown in California. It is estimated that approximately 3 BDT of straw are generated per acre for a total of nearly 1.5 million BDT of rice straw on an annual basis. The Sacramento Valley region is clearly a prime candidate for an ethanol plant site.

The rice-growing soils in Sacramento Valley are mostly heavy clay with high water tables, and can not viably grow any crop except rice. Of the approximately 500,000 acres of rice growing lands in the Sacramento Valley, it is estimated that 300,000 acres are the heavier clay soils that cannot be used for alternative crops. The remaining lands are silty clay and silty clay loams that can grow alternative crops. Because of the high water table and access to extensive supplies of surface water, growers in the rice area have very secure water supplies for irrigation. Unlike many other areas in California, the availability of well water as a backup for the rice growing area has meant that water availability is less limiting to rice than to most other California agricultural crops. Hence, the planted acreage has not dropped below the range of 325,000 to 500,000 acres (Table 81 ).

Table 80: Rice Acreage and Rice Straw Generation for the Sacramento Valley

\begin{tabular}{ccc}
\hline County & Rice Acreage $^{*}(\mathrm{acres} / \mathrm{yr})$ & Rice Straw $(\mathrm{BDT} / \mathrm{yr})$ \\
\hline \hline Butte & 98,200 & 294,600 \\
Colusa & 128,690 & 386,070 \\
Glenn & 83,686 & 251,058 \\
Placer & 16,800 & 50,400 \\
Sacramento & 8,650 & 25,950 \\
Sutter & 93,164 & 279,492 \\
Tehama & 1,500 & 4,500 \\
Yolo & 25,999 & 77,997 \\
Yuba & 35,880 & 107,640 \\
Total & 492,569 & $1,477,707$ \\
\hline
\end{tabular}

*Rice acreage based on County Agricultural Commissioner Crop Reports for 1996.

Table 81: California Rice Acreage Harvested, 1986-1997

\begin{tabular}{cc}
\hline Year & Acres \\
\hline \hline 1986 & 360,000 \\
1987 & 370,000 \\
1988 & 425,000 \\
1989 & 410,000 \\
1990 & 395,000 \\
1991 & 350,000 \\
1992 & 394,000 \\
1993 & 437,000 \\
1994 & 485,000 \\
1995 & 465,000 \\
1996 & 518,000 \\
1997 & 513,000 \\
\hline
\end{tabular}


The 1998 harvested acres is estimated to be approximately 470,000 acres. This lower acreage can be attributed primarily to the impact of the late spring rains caused by El Niño.

A review of the data prepared by the California Department of Food and Agriculture, Statistics Service indicates that during the period of 1990 through 1995, rice production averaged approximately 3.25 BDT per acre, ranging from a low of 3.04 BDT per acre to a high of 3.4 BDT per acre.

The following map (Figure 84) identifies the concentrations of rice straw in Northern California and reflects the potential areas that could be considered for locating biomass-to-ethanol facilities. Currently there are two proposed biomass-to-ethanol facilities that will use rice straw: one in the northern part of Sacramento County, and the other in Butte County.

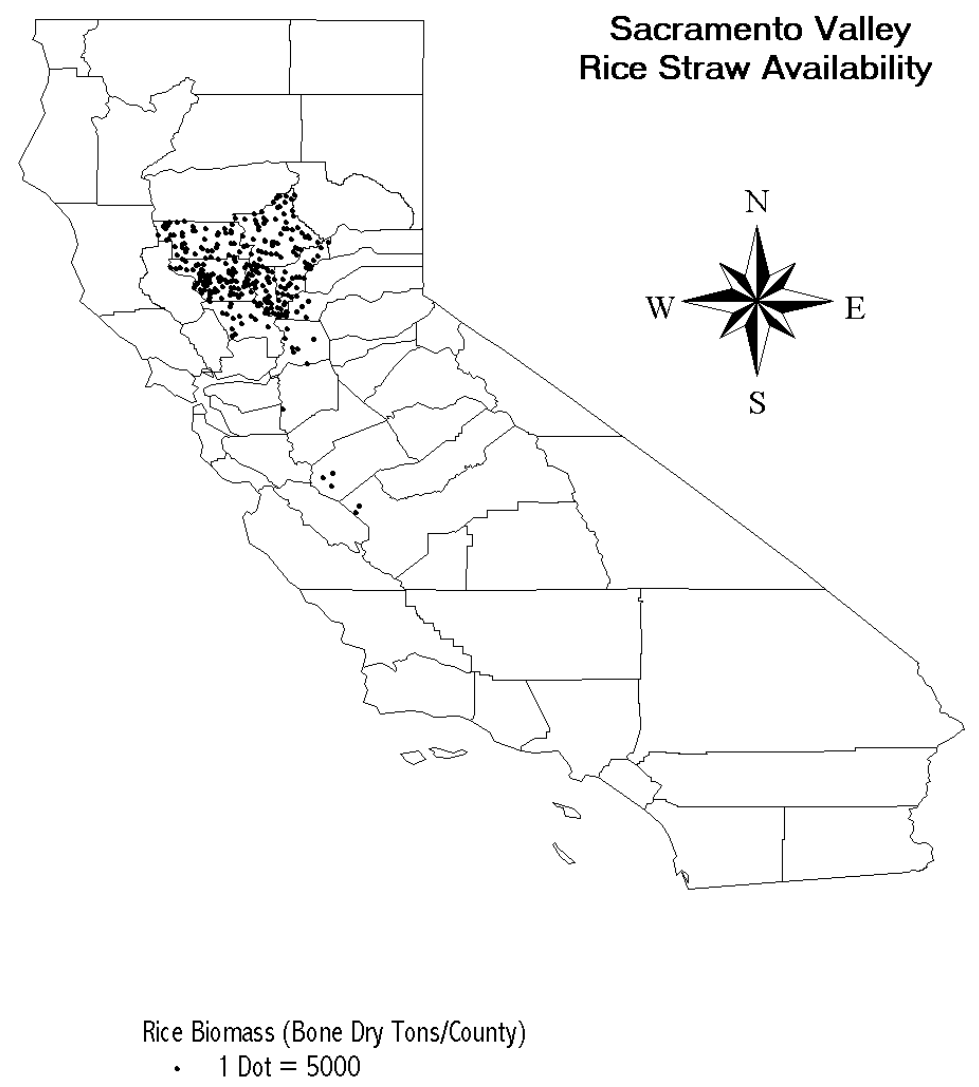

Figure 84: Sacramento Valley Rice Straw Availability

\section{Forest Residue Generation for Northeastern California}

Within California, over 2 billion board feet of timber are harvested annually. In the course of this harvest, wood residue is generated and much of it is disposed of by open burning. It is estimated that within California approximately 4.5 million BDT of biomass residue is generated during timber harvest and an additional 50\%, (approximately 2 million BDT) more residue is available from thinnings and fuel reduction treatments. 
Northeastern California is a region of concentrated forests, and hence, is identified as a good candidate for the development of an ethanol plant site. It is estimated that within the Northeastern California region a total of approximately 3 million BDT of forest residue are generated annually. Table 82 reflects the timber harvest, associated logging residue, and an estimate of the forest residue available from thinnings and fuel reduction for the counties in Northeastern California.

Table 82: Forest Residues in Northeastern California

\begin{tabular}{ccccc}
\hline County & Timber Harvest (MBF) & $\begin{array}{c}\text { Harvest Residue } \\
\text { (BDT) }\end{array}$ & $\begin{array}{c}\text { Thinning/Fuel } \\
\text { Reduction Residue } \\
\text { (BDT) }\end{array}$ & Total (BDT) \\
\hline \hline Butte & 86,867 & 171,128 & 85,564 & 256,692 \\
El Dorado & 73,140 & 144,086 & 72,043 & 216,129 \\
Lassen & 65,278 & 128,598 & 64,299 & 192,897 \\
Modoc & 30,342 & 59,774 & 29,887 & 89,661 \\
Nevada & 61,832 & 121,809 & 60,905 & 182,714 \\
Placer & 49,265 & 97,052 & 48,526 & 145,578 \\
Plumas & 105,651 & 208,132 & 104,066 & 312,198 \\
Shasta & 187,977 & 370,315 & 185,157 & 555,472 \\
Sierra & 58,327 & 114,904 & 57,452 & 172,356 \\
Siskiyou & 178,701 & 352,041 & 176,021 & 528,062 \\
Tehama & 103,753 & 204,393 & 102,196 & 306,589 \\
Yuba & 33,136 & 65,278 & 32,639 & 97,917 \\
Total & $\mathbf{1 , 0 3 4 , 2 6 9}$ & $\mathbf{2 , 0 3 7 , 5 1 0}$ & $\mathbf{1 , 0 1 8 , 7 5 5}$ & $\mathbf{3 , 0 5 6 , 2 6 5}$ \\
\hline
\end{tabular}

Figure 85 identifies the concentrations of forest residues in California and reflects the potential areas that could be considered for locating biomass-to-ethanol facilities. Currently there are two proposed biomass-to-ethanol facilities that will use forest residue: one in the Plumas County, and the other in Butte County.

\section{Factors Influencing Biomass Feedstock Availability}

Although there are presently considerable quantities of forest residue available in Northeastern California to be used as biomass feedstock, it is important to understand factors that will influence the amount of biomass feedstock available, such as:

Weather - The weather will influence the seasonal availability of forest residue as feedstock. This area can have winter rain and snows. The weather will not influence the quantity available but will affect the timing of collection. Winter rain and snow will limit forest operations and may increase delivered costs.

Wood Products Industry - The wood products industry will influence the amount of biomass available from timber harvesting operations. This industry has a cyclical history and during depressed times, mills may either reduce production or close.

Governmental Action - Certain governmental action could influence the amount of commercial timber available for harvesting; funding for public forest management and thinning, and changes in logging practices; all of which could influence the volume and cost of wood waste available from forest sources. 


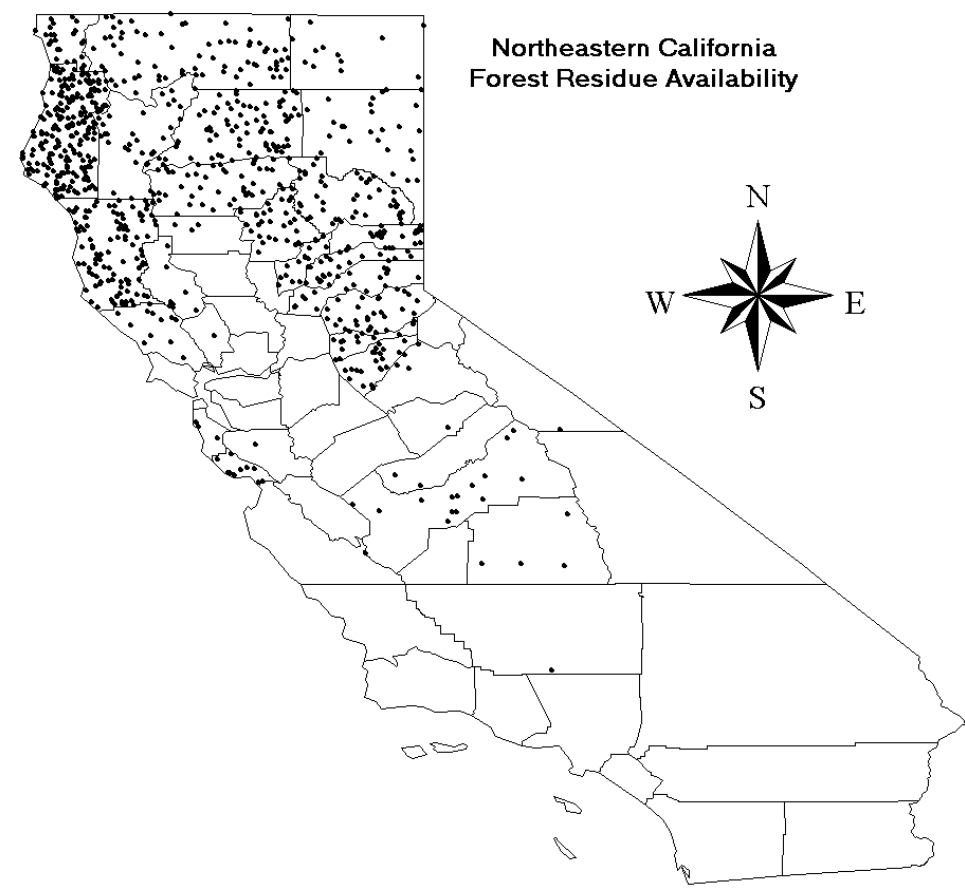

Forest Biomass (Bone Dry Tons/County)

- 1 Dot $=5000$

Data from State Board of

Equalization 1996 timber

harvest records

Figure 85: Forest Residue Biomass Potential

\section{Chaparral Residue Generation in Southern California}

Within California, there are between 9 million and 20 million acres of chaparral lands with an estimated 56 million to 459 million tons of standing biomass. During the past 10 years, an average of 102,926 acres has burned annually in wildfires. It is estimated that approximately 2 million tons of chaparral have burned each year.

Southern California is a region of concentrated chaparral residue that has experienced encroachment of urban development. The removal of these wildland fuels around homes and other high value environmental and economic assets as well as creating fuel breaks along ridges to use in wildfire suppression efforts can generate a portion of the feedstock requirement for the development of a biomass-to-ethanol plant.

The following map (Figure 86) identifies the concentrations of chaparral residues in Southern California and reflects the potential areas that could be considered for locating a biomass-to-ethanol facility. 


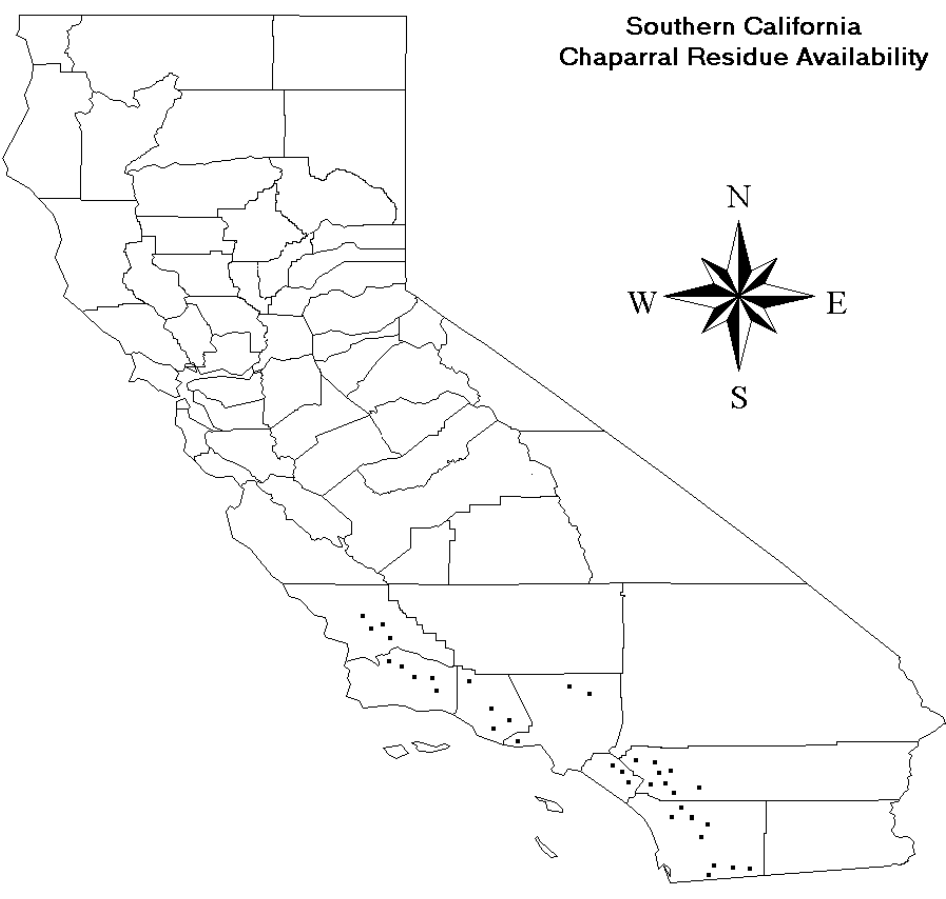

Chaparral Residue (Bone Dry Tons/County)

- 1 Dot $=5000$

Figure 86: Southern California Chaparral Residue Availability

\section{Projected Biomass Collection, Harvesting, Processing And Transportation Costs}

\section{Economics of Forest Residue as a Raw Material}

This section provides estimated costs of delivering forest residue from thinning operations on timberlands located within Northeastern California. The total cost of forest residue will vary depending upon the amount of subsidy that can be achieved from timberland owners from the private industrial sector and from the U.S. Forest Service on national forest lands. These subsidies can be in the form of payments per acre for accomplishing forest residue removal and for thinning as well as the value of sawlogs offered with the biomass material.

The cost of collection, harvesting, processing, and transportation can vary greatly from job to job depending upon factors such as tree size and density, slope of the ground, size of the project, and distance to the ethanol facility. The estimate shown in Table 83 was developed assuming fairly average site conditions and a subsidy of $\$ 375$ per acre from the U.S. Forest Service for accomplishing this thinning. Based upon these assumptions, the estimated cost of forest residue from this thinning sale would be \$22.16/BDT. 
Table 83: Estimated Cost of XYZ Thinning Sale Delivered to Ethanol Facility

\begin{tabular}{lc}
\hline \multicolumn{1}{c}{ Cost Item } & Estimated Cost $(\$ / B D T)$ \\
\hline \hline Shearing & $\$ 12.00$ \\
Skidding & $\$ 8.00$ \\
Chipping & $\$ 10.00$ \\
Other Site Work & $\$ 3.05$ \\
Road Maintenance \& Surface Rep. & $\$ 3.06$ \\
Stumpage & $\$ 2.26$ \\
Move In* & $\$ 0.25$ \\
Trucking @ \$200/load and 14.3 BDT/load & $\$ 13.99$ \\
Total Operator Cost & $\mathbf{\$ 5 2 . 6 1}$ \\
& \\
Forest Service Payment & $\$ 30.45$ \\
& \\
Total Cost to Facility & $\mathbf{\$ 2 2 . 1 6}$ \\
\hline
\end{tabular}

* Move in costs are spread over the entire contract of an estimated 10,000 BDT.

\section{Economics of Rice Straw as a Raw Material}

The total cost of baling rice straw and loading it aboard trucks is estimated at $\$ 19.53 / \mathrm{BDT}$. Including transportation costs yields an estimated cost of $\$ 26.05 / \mathrm{BDT}$ for delivering rice straw delivered directly to a user facility (Table 84 ). For the portion of straw that must be delivered to an off-site storage location for later delivery to the facility, there is an estimated additional cost of $\$ 11.87 / \mathrm{BDT}$. The grower's alternative cost of soil incorporation can be used as a base-line cost to the farmer, and an average cost of \$10-15/BDT can be deducted to derive a net cost of straw for off-field use. Using a more conservative $\$ 10 / \mathrm{BDT}$ credit, a net cost of $\$ 16.05 / \mathrm{BDT}$ is calculated. The actual cost to a project will depend on the plant size and the credit to be negotiated with various farmers.

\section{Table 84: Cost Estimates for Delivering Rice Straw to a User Facility}

Direct Delivery to Facility from Grower

\begin{tabular}{lc}
\hline \multicolumn{1}{c}{ Operation } & Estimated Cost (\$/BDT) \\
\hline \hline Swathing, raking, baling, roadsiding, and loading from & 19.53 \\
field & \\
Hauling to facility & 6.52 \\
Total FOB facility & 26.05 \\
Less Grower Credit & 10.00 \\
Total FOB facility, net basis & $\mathbf{1 6 . 0 5}$ \\
\hline
\end{tabular}

Delivery from Grower to Interim Storage, to Facility

\section{Operation}

Swathing, raking, baling, roadsiding, and loading from field

Hauling to facility

Unloading, storage, loading, transportation

Total FOB facility

Less Grower Credit

Total FOB facility, net basis
Estimated Cost (\$/BDT)

19.53

11.87

37.92

10.00

27.92 
Assuming that $50 \%$ of the rice straw will be delivered directly to the ethanol facility and will not require interim storage, it is estimated that the average delivered cost of rice straw delivered to an ethanol facility will be \$22/BDT.

\section{Economics of Chaparral as a Raw Material}

This section provides estimated costs of delivering chaparral residue from fuel reduction treatments on wildlands located within southern California. Some removal of this material is occurring with the use of inmate crews and other publicly funded conservation crews to construct and maintain fuel breaks by hand clearing, piling, and open burning chaparral to protect high-value assets such as homes, reservoirs, and environmentally sensitive areas. Where this is being done, the majority of the cost is already being covered and the cost of feedstock delivered to a facility would be equivalent to the cost of transportation or approximately \$10-15/BDT.

For the volume of chaparral residue that would be collected above the amount already being collected, the cost would need to be subsidized by those receiving the benefits. Based upon the biomass harvesting evaluation that was conducted by the CDF, Riverside Ranger Unit, in the spring of 1998, the total costs of collection, processing and loading of chaparral residue aboard a truck is estimated to be approximately $\$ 95 / \mathrm{BDT}$. The total cost of chaparral residue delivered to a facility will be directly related to the amount of subsidy that can be derived from homeowners adjacent to these wildlands as well as from state and federal agencies desiring to protect other high-value environmental and economic assets. 


\section{APPENDiX D: GASOLINE MODELING}

The flow chart shown in Figure 87 outlines the life cycle modeling of petroleum-based products used in this LCI study.

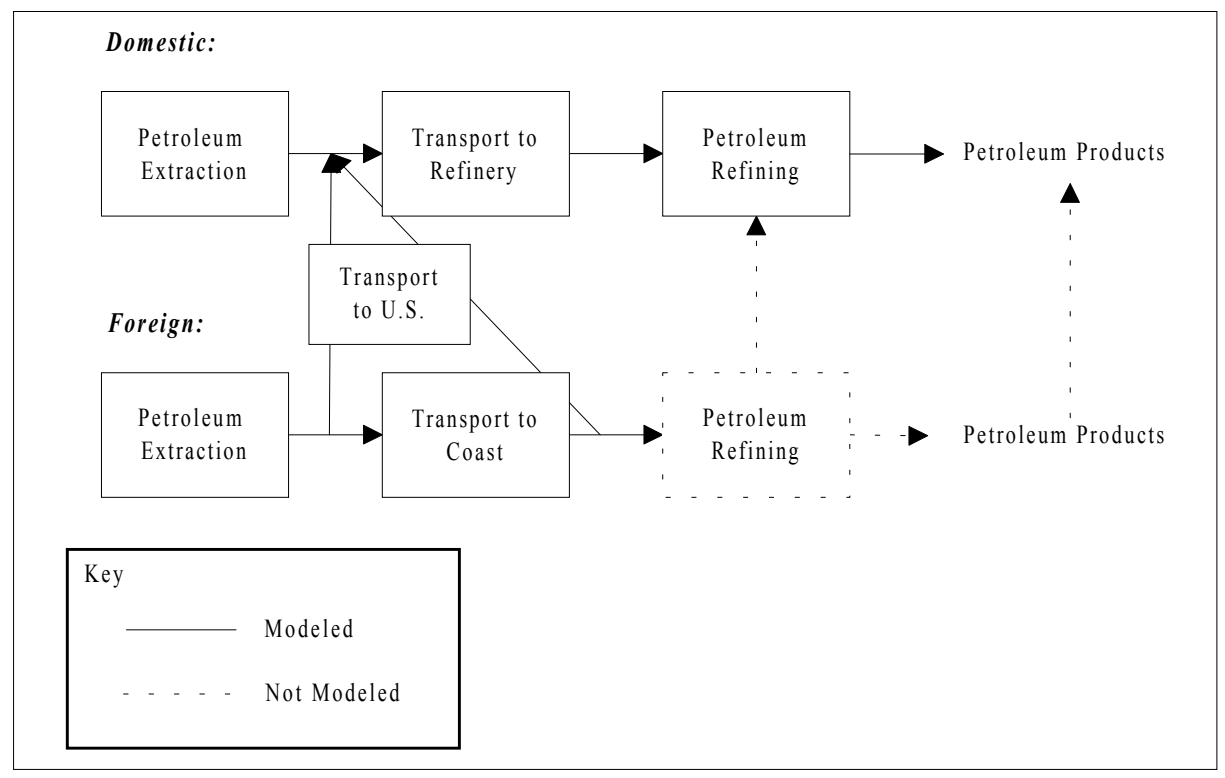

Figure 87: Petroleum Products Modeling

This Appendix describes each phase of the life cycle in more detail as shown in the following sub-sections:

- Crude Oil Extraction: This section describes the process flows associated with crude oil extraction from the ground and explains model assumptions.

- Crude Oil Transport to Refinery: This section explains how transportation is regionalized by the five different PADDs. It also explains how transportation distances were calculated and describes the different transportation models that are utilized to depict the transport of crude oil.

- Crude Oil Refining: This details the modeling of refinery process flows, including raw materials and energy use as well as emissions.

- Transportation to Distribution Facility: This section defines how transportation to a distribution facility is calculated or estimated.

\section{CRUde Oil EXTRaction}

Three separate methods for crude oil extraction or recovery are modeled in the overall petroleum extraction system, all based on a recent life cycle study of U.S. petroleum production processes [1]. The three methods involved are onshore production, offshore production, and enhanced recovery, the latter entailing the underground injection of steam (produced by natural gas boilers) or $\mathrm{CO}_{2}$ to enhance the extraction of crude oil. Percentages of total crude oil extraction by each process for domestic and foreign production are given in Table $85 .{ }^{34}$

\footnotetext{
34 Shares of each production type were obtained from the Oil \& Gas Journal Database, using numbers obtained in 1994. Note that the Enhanced/Advanced category includes all advanced crude oil extraction techniques except water flooding. It is assumed that steam flooding and $\mathrm{CO}_{2}$ injection will represent the largest portion of the Enhanced/Advanced techniques obtained from the Oil \& Gas Journal Database.
} 
Table 85: Production of Crude Oil by Technology Type and Origin

\begin{tabular}{ccc}
\hline Technology Type & $\begin{array}{c}\text { Domestic Crude Oil } \\
\text { Production }\end{array}$ & $\begin{array}{c}\text { Foreign Crude Oil } \\
\text { Production }\end{array}$ \\
\hline \hline Conventional Onshore & $69 \%$ & $77 \%$ \\
Conventional Offshore & $20 \%$ & $20 \%$ \\
Enhanced/Advanced & $11 \%$ & $3 \%$ \\
\hline
\end{tabular}

Of the total Enhanced/Advanced crude oil extraction techniques, steam injection is assumed to account for $63 \%$ of the total and $\mathrm{CO}_{2}$ injection is assumed to account for the remaining $37 \%$.

Each of these production types will be considered in more detail in the following sections.

\section{Conventional Onshore Extraction}

Figure 88 shows the system process diagram associated with conventional onshore crude oil extraction. It demonstrates the system boundaries and process flows considered for modeling conventional onshore crude oil extraction in this study.

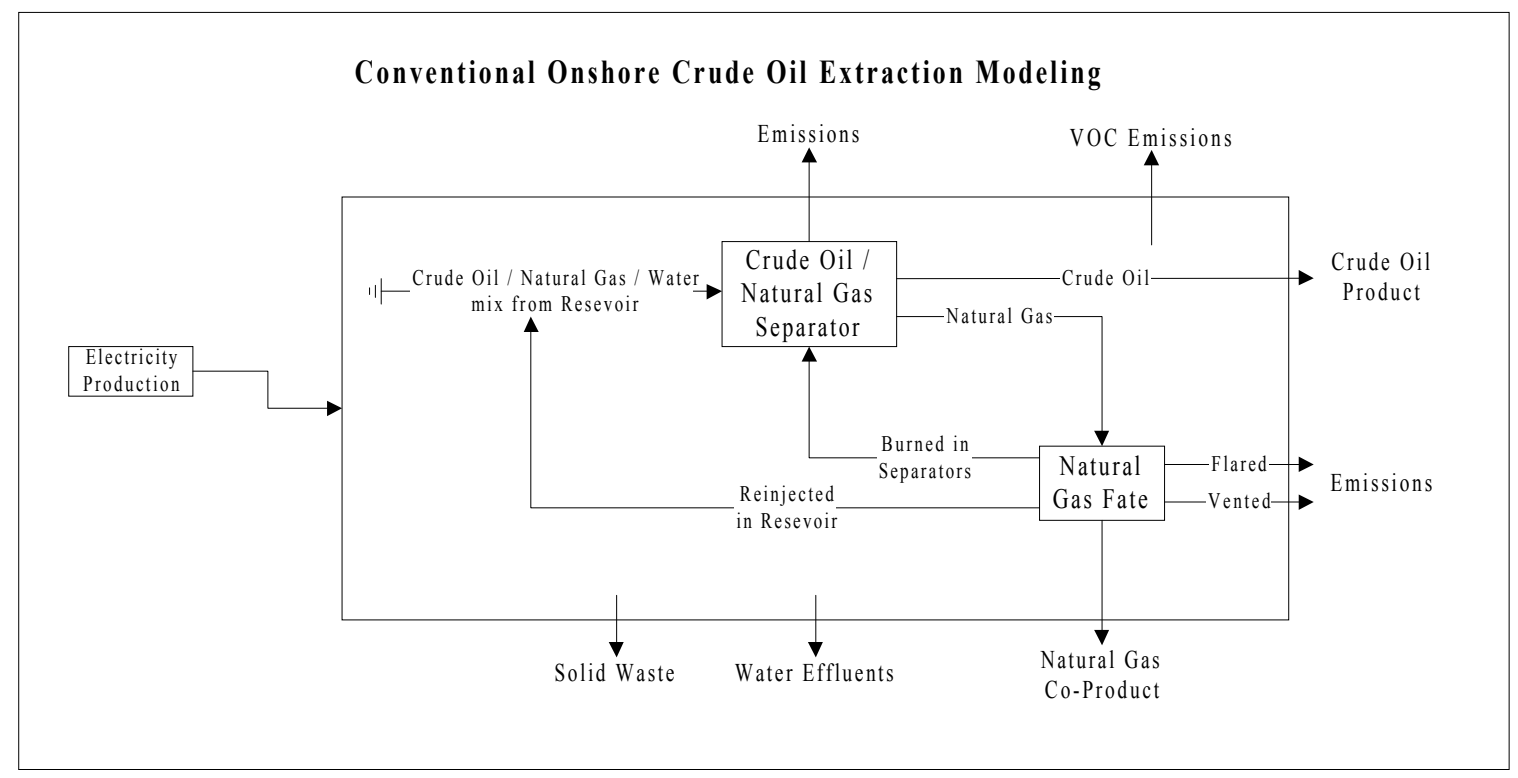

Figure 88: Conventional Onshore Crude Oil Extraction

Material Use

As is seen in Figure 88, the only material inputs required for conventional onshore crude oil extraction is the actual crude oil and natural gas in the ground. It is assumed that there is no loss of crude oil once it is extracted from the well. Therefore, to produce one $\mathrm{kg}$ of crude oil would require one $\mathrm{kg}$ of crude oil from the ground.

The life cycle environmental flows associated with the production of the capital equipment and facilities used in the extraction of crude oil are excluded from this study. However, the energy required for drilling and exploration are included in the study. For conventional onshore crude oil production, exploration and drilling energy represent approximately $0.75 \%$ of the energy in the produced crude oil [2]. This energy is primarily used for drilling. This energy is accounted for by decreasing the yield for crude oil extraction or by increasing the amount of crude oil in the ground needed to produce one $\mathrm{kg}$ of crude oil. Therefore, conventional onshore crude oil extraction would require $1.0075 \mathrm{~kg}$ of crude oil in the ground to produce one $\mathrm{kg}$ of crude oil. The material requirements for both domestic and foreign conventional onshore crude oil extraction are assumed to be the same. 


\section{Energy/Equipment Use}

Energy used in the actual extraction of crude oil is accounted for in this study. It primarily comes from the gross production of the well and from purchased electricity. Energy requirements for both domestic and foreign conventional onshore crude oil production are based on a 400-well production field (195 unproductive wells) located in the lower 48 states producing $4.98 \times 10^{9} \mathrm{~kg} / \mathrm{yr}\left(3.65 \times 10^{7} \mathrm{bbl} / \mathrm{yr}\right)$ of crude oil as follows [3]:

$$
\begin{array}{lll}
\text { Electricity: } & 10.7 \mathrm{kilowatt}-\mathrm{hr} / \mathrm{bbl} & \text { (used in pumping) } \\
\text { Natural Gas: } & 5.2 \mathrm{MJ} / \mathrm{bbl} & \text { (used in recovery) }
\end{array}
$$

Electricity is assumed to come from a standard U.S. grid while natural gas is assumed to come from gross production of the well. The LCI information on the production of electricity is included in the overall LCI of crude oil extraction and is taken from Ecobalance's database DEAM ${ }^{\mathrm{TM}}$.

Modeling of foreign crude oil extraction electricity use based on the standard U.S. grid is not necessarily an accurate representation of the actual electricity production used at foreign oil fields. However, foreign crude oil used in the U.S. is coming from all over the word and modeling of the exact electricity use at foreign fields would require studying each site individually ${ }^{35}$. Therefore, the U.S. standard grid was used as a surrogate for foreign electricity production. This is an estimate because foreign electricity production sources may not meet the same strict emission guidelines as in the United States.

\section{Process Emissions}

The process emissions from conventional onshore crude oil extraction include air, water, and solid waste emissions.

Water effluents are based on the amount of wastewater produced and the average composition of the wastewater. The amount of wastewater disposed of by conventional onshore crude oil production is found to be 0.7 liters $/ \mathrm{kg}$ of crude oil produced [4]. The actual wastewater produced is more than this but only 0.7 liters are actually released to the environment. The rest is treated on site through re-injection, evaporation, etc.

The constituents and concentrations of the wastewater are shown in the following table (Table 86).

Table 86: Crude Oil Production Wastewater Constituents and Concentrations

\begin{tabular}{cc}
\hline Constituent & Median Concentration $(\mathrm{mg} / \mathrm{l})$ \\
\hline \hline Arsenic & 0.02 \\
Benzene & 0.47 \\
\hline
\end{tabular}

Water effluents of oil and grease are estimated to be $1 \times 10^{-4} \mathrm{~kg} / \mathrm{kg}$ crude oil produced [3].

The emission factor for the production of solid waste is calculated as 0.0098 grams of solid waste for every $\mathrm{kg}$ of crude oil [1].

Air emissions from conventional onshore crude oil extraction come from the combustion of natural gas in the crude oil/natural gas separators, venting and flaring of natural gas as well as from volatilization (fugitive) emissions of crude oil.

The emission factors for natural gas combustion of the crude oil/natural gas separators were assumed to be the same as industrial boilers. This was an estimate since many of these burners are located in remote sites where requirements for emissions may be less stringent.

The natural gas venting/flaring emissions from crude oil extraction have been calculated based on a percentage of the gross natural gas production of the well. The following table (Table 87) outlines the natural gas venting/flaring calculations from conventional onshore crude oil extraction:

35 Actually, each U.S. crude oil production field would have its own mix of electricity use. However, the standard U.S. grid was used to represent an average situation. 
Table 87: Natural Gas Venting and Flaring from Crude Oil Wells

\begin{tabular}{cc}
\hline & $\begin{array}{c}\text { Conventional Onshore } \\
\text { Extraction }\end{array}$ \\
\hline \hline Gross NG extracted (kg/kg crude) & 0.47 \\
Domestic \% Flared & $1.22 \%$ \\
Domestic \% Vented & $0.03 \%$ \\
& \\
Foreign \% Flared & $4.53 \%$ \\
Foreign \% Vented & $0.12 \%$ \\
\hline
\end{tabular}

These numbers are based on the following sources:

Gross natural gas extracted - EIA Natural Gas Annual 1994, gives gross extraction of natural gas from crude oil wells. Crude oil production from EIA Petroleum Supply Annual 1997 (1994 crude oil production used). Domestic and foreign crude oil wells are assumed to produce the same amount of natural gas in relation to the crude oil produced.

Domestic \% Flared/Vented - EIA Natural Gas Annual 1994, gives the amount of natural gas vented/flared for onshore extraction. The percentage of flared/vented gas is assumed to be the same for total natural gas as for natural gas from crude oil wells.

Foreign \% Flared/Vented - EIA International Energy Annual 1995, gives the amount of natural gas flared/vented (1994 numbers used). The percentage of flared/vented gas is assumed to be the same for total natural gas as for natural gas from crude oil wells and for offshore and onshore extraction.

Assumptions:

$97.5 \%$ of the total flared/vented onshore natural gas was assumed to be flared ( $2.5 \%$ vented) [2].

From Table 87 above, it can be seen that the amount of domestic natural gas flared during conventional onshore crude oil extraction is $1.22 \%$ of the gross natural gas produced from the well. The amount of domestic natural gas that is vented is $0.03 \%$ of the gross natural gas produced by the well. Based on the amount of gas produced by the well, this relates to 0.0057 and $0.00014 \mathrm{~kg}$ of natural gas flared and vented respectively per $\mathrm{kg}$ of domestic onshore crude oil extracted.

From Table 87, the amount of foreign natural gas flared during conventional onshore crude oil extraction is $4.53 \%$ of the gross natural gas produced from the well. The amount of foreign natural gas that is vented is $0.12 \%$ of the gross natural gas produced by the well. This relates to 0.021 and $0.00056 \mathrm{~kg}$ of natural gas flared and vented respectively per $\mathrm{kg}$ of foreign onshore crude oil extracted.

The amount that is vented was assumed to be released as methane. The emissions from the amount that is flared are based on the emission factors for industrial flares.

VOC emissions from onshore crude oil extraction are shown in Table 88 as taken from a U.S. EPA report[5].

Table 88: VOC Emissions for Onshore Crude Oil Wells

\begin{tabular}{lc}
\hline \multicolumn{1}{c}{ Component } & Emission \\
\hline \hline Fugitive Emissions $(\mathrm{g} /$ well-yr) \\
Crude Oil Sumps & 180,000 \\
Crude Oil Pits & 4,000 \\
Total & 4,000 \\
\hline
\end{tabular}

These VOC emissions are further speciated as shown in Table 89 [5]. 
Table 89: Speciated VOC Data for Onshore Crude Oil Wells

\begin{tabular}{cc}
\hline Compound & Weight \% \\
\hline \hline Isomers of hexane & 9.9 \\
Isomers of heptane & 11.6 \\
Isomers of octane & 8.7 \\
C-7 Cycloparaffins & 1.6 \\
C-8 Cycloparaffins & 0.6 \\
Isomers of pentane & 5.6 \\
Methane & 38.0 \\
Ethane & 6.4 \\
Propane & 10.0 \\
n-Butane & 7.4 \\
iso-Butane & 0.4 \\
Benzene & 0.1 \\
\hline
\end{tabular}

In 1994 the average productivity of U.S. crude oil production wells was 1,555 $\mathrm{kg}$ of crude oil/day per well (11.4 bbl/day per well) [6]. Using this number, VOC emissions data can be calculated per kilograms of crude oil produced.

\section{Crude Oil Production}

Crude oil extracted from the ground by the different technologies must undergo an additional step before it is ready to be shipped to refineries. The crude oil extracted from the ground is a mixture of crude oil, natural gas, and water. Crude oil/natural gas separators operating in the field are used to separate the three components. These separators are assumed to be burning natural gas as explained in the previous sections. The combustion of this natural gas leads to air emissions. However, because natural gas is being produced as a coproduct of crude oil production, the emissions associated with the crude oil/natural gas separators, as well as other emission sources from crude oil extraction, need to be allocated between crude oil and natural gas production.

Conventional onshore crude oil extraction is assumed to produce natural gas as a coproduct. The amount of natural gas produced is shown (Table 90).

Table 90: Natural Gas Venting, Flaring, and Coproduct Production from Onshore Extraction Wells

\begin{tabular}{lc}
\multicolumn{1}{c}{ Parameter } & Value \\
Gross NG extracted (kg/kg crude) & 0.47 \\
Domestic \% Re-injected & $17.8 \%$ \\
Domestic \% Flared/Vented & $1.25 \%$ \\
\hline Foreign \% Re-injected & $9.98 \%$ \\
Foreign \% Flared/Vented & $4.65 \%$ \\
\hline Coproduct Domestic & $80.95 \% \times 0.47=0.38 \mathrm{~kg}$ \\
Coproduct Foreign & $85.37 \% \times 0.47=0.40 \mathrm{~kg}$
\end{tabular}

These numbers are based on the following sources:

Gross natural gas extracted - EIA Natural Gas Annual 1994, gives gross extraction of natural gas from crude oil wells. Crude oil production from EIA Petroleum Supply Annual 1997 (1994 crude oil production used). Domestic and foreign crude oil wells are assumed to produce the same amount of natural gas in relation to the crude oil produced. 
Domestic \% Re-injected - EIA Natural Gas Annual 1994, gives the amount of natural gas re-injected for both offshore and onshore extraction. The percentage of re-injected gas is assumed to be the same for total natural gas as for natural gas from crude oil wells.

Domestic \% Flared/Vented - EIA Natural Gas Annual 1994, gives the amount of natural gas vented/flared for both offshore and onshore extraction. The percentage of flared/vented gas is assumed to be the same for total natural gas as for natural gas from crude oil wells.

Foreign \% Re-injected - EIA International Energy Annual 1995, gives the amount of natural gas re-injected (1994 numbers used). The percentage of re-injected gas is assumed to be the same for total natural gas as for natural gas from crude oil wells and for offshore and onshore extraction.

Foreign \% Flared/Vented - EIA International Energy Annual 1995, gives the amount of natural gas flared/vented (1994 numbers used). The percentage of flared/vented gas is assumed to be the same for total natural gas as for natural gas from crude oil wells and for offshore and onshore extraction.

The amount of natural gas re-injected into the well and the amount of natural gas that is either vented or flared is not be considered to be a coproduct of crude oil extraction.

The following tables (Table 91 and Table 92) show the mass of crude oil and natural gas produced by the wells considered in this project:

Table 91: Production of Typical Domestic Conventional Onshore Crude Oil Well

\begin{tabular}{rcc}
\hline & Mass $(\mathrm{kg})$ & Mass $(\%)$ \\
\hline \hline Crude Oil: & 1 & $72 \%$ \\
Natural Gas: & 0.38 & $28 \%$ \\
\cline { 2 - 2 } Total: & 1.38 & \\
\hline
\end{tabular}

Table 92: Production of Typical Foreign Conventional Onshore Crude Oil Well

\begin{tabular}{ccc}
\hline & Mass $(\mathrm{kg})$ & Mass $(\%)$ \\
\hline \hline Crude Oil: & 1 & $71 \%$ \\
Natural Gas: & 0.40 & $29 \%$ \\
\cline { 2 - 2 } Total: & 1.40 & \\
\hline
\end{tabular}

Emissions from flaring, venting, crude oil/natural gas separators, and fugitive emissions as well as raw materials, and energy use are allocated between natural gas and crude oil production based on the mass percentage of crude oil produced. For example, with conventional domestic onshore crude oil production, $72 \%$ of the total emissions, raw materials, and energy use is allocated to crude oil.

\section{Conventional Offshore Extraction}

Figure 89 shows the system process diagram associated with conventional offshore crude oil extraction. It demonstrates the system boundaries and process flows considered for modeling conventional offshore crude oil extraction in this study.

\section{Material Use}

As is seen in Figure 89, the only material inputs required for conventional offshore crude oil extraction, accounted for in this study, is the actual crude oil and natural gas in the ground. It is assumed that there is no loss of crude oil once it is extracted from the well. Therefore, to produce one $\mathrm{kg}$ of crude oil would require one $\mathrm{kg}$ of crude oil from the ground.

The life cycle environmental flows associated with the production of the capital equipment and facilities used in the extraction of crude oil are excluded from this study. However, the energy required for drilling and exploration are 
included in the study. For conventional offshore crude oil production, exploration and drilling energy represents approximately $7 \%-8 \%$ of the energy in the produced crude oil [2]. The average, or $7.5 \%$, is used in this study, this energy is primarily used for drilling.

This energy is accounted for by decreasing the yield for crude oil extraction or by increasing the amount of crude oil in the ground needed to produce one $\mathrm{kg}$ of crude oil. Therefore, conventional offshore crude oil extraction would require $1.075 \mathrm{~kg}$ of crude oil in the ground to produce one $\mathrm{kg}$ of crude oil.

The material requirements for both domestic and foreign conventional offshore crude oil extraction are assumed to be the same.

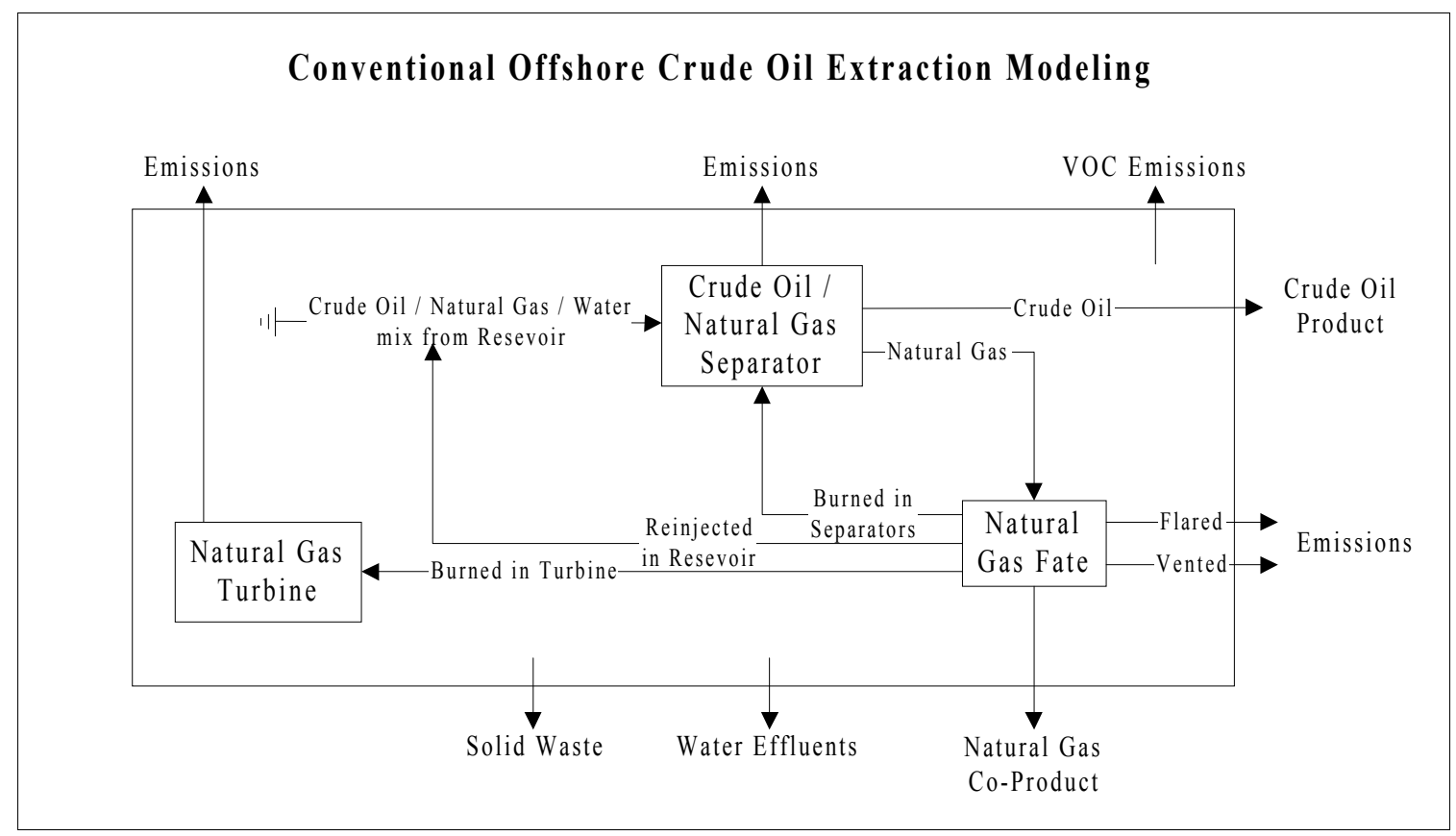

Figure 89: Conventional Offshore Crude Oil Extraction

\section{Energy/Equipment Use}

Energy used in the actual extraction of crude oil is accounted for in this study. It primarily comes from the gross production of the well. Energy requirements for both foreign and domestic conventional offshore crude oil production are based on an 18 well offshore platform producing $1.97 \times 10^{8} \mathrm{~kg}$ of crude oil $/ \mathrm{yr}\left(1.46 \times 10^{6} \mathrm{bbl} / \mathrm{yr}\right)$ [3] as follows ${ }^{36}$ :
Natural Gas:
$38.8 \mathrm{MJ} / \mathrm{bbl}$
(used in recovery)
Natural Gas:
$96.6 \mathrm{MJ} / \mathrm{bbl}$
(used to produce electricity for pumping and other needs)

The natural gas used for the crude oil / natural gas separators and for electricity production is assumed to come from gross production of the well.

\section{Process Emissions}

The process emissions from conventional offshore crude oil extraction include air, water, and solid waste emissions.

\footnotetext{
36 Electrical energy requirements are assumed to be met through the use of natural gas turbines.
} 
Water effluents are based on the amount of wastewater produced and the average composition of the wastewater. The amount of wastewater disposed of by conventional offshore crude oil production is found to be 10.14 liters $/ \mathrm{kg}$ of crude oil produced [7]. All of the wastewater produced is assumed to be released to the surrounding water.

The constituents and concentrations of the wastewater are shown in Table 93 [4].

Table 93: Crude Oil Production Wastewater Constituents and Concentrations

\begin{tabular}{cc}
\hline Constituent & Median Concentration $(\mathrm{mg} / \mathrm{l})$ \\
\hline \hline Arsenic & 0.02 \\
Benzene & 0.47 \\
\hline
\end{tabular}

Water effluents of oil and grease are estimated to be $2.8 \times 10^{-4} \mathrm{~kg} / \mathrm{kg}$ crude oil produced [7].

The emission factor for the production of solid waste is calculated as 0.0098 grams of solid waste for every $\mathrm{kg}$ of crude oil [1].

Air emissions from conventional offshore crude oil extraction come from the combustion of natural gas in the crude oil/natural gas separators and natural gas turbine, venting and flaring of natural gas as well as from volatilization (fugitive) emissions of crude oil.

The emission factors for natural gas combustion of the crude oil/natural gas separators were assumed to be the same as industrial boilers. This may be conservative since many of these burners are located in remote sites where requirements for emissions may be less stringent. The emission factors for natural gas combustion used to produce electricity are based on natural gas emission factors from a gas turbine.

The natural gas venting/flaring emissions from crude oil extraction have been calculated based on a percentage of the gross natural gas production of the well. The following table (Table 94) outlines the natural gas venting/flaring calculations from conventional offshore crude oil extraction:

Table 94: Natural Gas Venting and Flaring from Conventional Offshore Extraction Wells

\begin{tabular}{lc}
\multicolumn{1}{c}{ Parameter } & Value \\
Gross NG extracted (kg/kg crude) & 0.26 \\
Domestic \% Flared & $0.067 \%$ \\
Domestic \% Vented & $0.022 \%$ \\
\hline Foreign \% Flared & $3.49 \%$ \\
Foreign \% Vented & $1.16 \%$
\end{tabular}

These numbers are based on the following sources:

Gross natural gas extracted - EIA Natural Gas Annual 1994, gives gross extraction of natural gas from crude oil wells. Crude oil production from EIA Petroleum Supply Annual 1997 (1994 crude oil production used). Domestic and foreign crude oil wells are assumed to produce the same amount of natural gas in relation to the crude oil produced.

Domestic \% Flared/Vented - EIA Natural Gas Annual 1994, gives the amount of natural gas vented/flared for offshore extraction. The percentage of flared/vented gas is assumed to be the same for total natural gas as for natural gas from crude oil wells.

Foreign \% Flared/Vented - EIA International Energy Annual 1995, gives the amount of natural gas flared/vented (1994 numbers used). The percentage of flared/vented gas is assumed to be the same for total natural gas as for natural gas from crude oil wells and for offshore and onshore extraction.

Assumptions:

Seventy-five percent of the total flared/vented offshore natural gas was assumed to be flared ( $25 \%$ vented) [2].

From Table 94 above, it can be seen that, the amount of domestic natural gas flared during conventional offshore crude oil extraction is $0.067 \%$ of the gross natural gas produced from the well. The amount of domestic natural gas 
that is vented is $0.022 \%$ of the gross natural gas produced by the well. Based on the amount of gas produced by the well, this relates to 0.00017 and $0.000057 \mathrm{~kg}$ of natural gas flared and vented, respectively, per $\mathrm{kg}$ of domestic offshore crude oil extracted.

From Table 94 above, the amount of foreign natural gas flared during conventional offshore crude oil extraction is $3.49 \%$ of the gross natural gas produced from the well. The amount of foreign natural gas that is vented is $1.16 \%$ of the gross natural gas produced by the well. This relates to 0.0091 and $0.0030 \mathrm{~kg}$ of natural gas flared and vented, respectively, per $\mathrm{kg}$ of foreign offshore crude oil extracted.

The amount that is vented is assumed to be released as methane. The emissions from the amount that is flared are based on the emission factors for industrial flares.

VOC emissions for conventional offshore crude oil production are calculated based on Table 95 [1]:

Table 95: Speciated VOC Emissions for Offshore Crude Oil Production

\begin{tabular}{cc}
\hline Emission & $\begin{array}{c}\text { Rate } \\
(\mathrm{kg} / \mathrm{kg} \text { crude oil produced })\end{array}$ \\
\hline \hline Methane & $5.6 \times 10^{-5}$ \\
Formaldehyde & $1.9 \times 10^{-5}$ \\
Isomers of hexane & $3.0 \times 10^{-6}$ \\
Isomers of heptane & $2.3 \times 10^{-5}$ \\
Isomers of octane & $2.6 \times 10^{-6}$ \\
C-7 Cyloparaffins & $3.2 \times 10^{-6}$ \\
C-8 Cycloparaffins & $1.2 \times 10^{-6}$ \\
Isomers of pentane & $1.1 \times 10^{-5}$ \\
Ethane & $1.3 \times 10^{-5}$ \\
Propane & $2.0 \times 10^{-5}$ \\
n-Butane & $1.5 \times 10^{-5}$ \\
iso-Butane & $8.0 \times 10^{-7}$ \\
Benzene & $2.0 \times 10^{-7}$ \\
\hline
\end{tabular}

\section{Crude Oil Production}

Crude oil extracted from the reservoir by the different technology types must undergo an additional step before it is ready to be shipped to refineries. The crude oil is extracted from the reservoir in a mixture of crude oil, natural gas, and water. Crude oil/natural gas separators operating in the field are used to separate the three components. These separators are assumed to be burning natural gas as explained in the previous sections.

The combustion of this natural gas leads to air emissions. However, because natural gas is being produced as a coproduct of crude oil production, the emissions associated with the crude oil/natural gas separators, as well as other emission sources from crude oil extraction, need to be allocated between crude oil and natural gas production.

Conventional offshore crude oil extraction is assumed to produce natural gas as a coproduct. The amount of natural gas produced is shown in Table 96.

These numbers are based on the following sources:

Gross natural gas extracted - EIA Natural Gas Annual 1994, gives gross extraction of natural gas from crude oil wells. Crude oil production from EIA Petroleum Supply Annual 1997 (1994 crude oil production used). Domestic and foreign crude oil wells are assumed to produce the same amount of natural gas in relation to the crude oil produced.

Domestic \% Re-injected - EIA Natural Gas Annual 1994, gives the amount of natural gas re-injected for both offshore and onshore extraction. The percentage of re-injected gas is assumed to be the same for total natural gas as for natural gas from crude oil wells. 
Domestic \% Flared/Vented - EIA Natural Gas Annual 1994, gives the amount of natural gas vented/flared for both offshore and onshore extraction. The percentage of flared/vented gas is assumed to be the same for total natural gas as for natural gas from crude oil wells.

Foreign \% Re-injected - EIA International Energy Annual 1995, gives the amount of natural gas re-injected (1994 numbers used). The percentage of re-injected gas is assumed to be the same for total natural gas as for natural gas from crude oil wells and for offshore and onshore extraction.

Foreign \% Flared/Vented - EIA International Energy Annual 1995, gives the amount of natural gas flared/vented (1994 numbers used). The percentage of flared/vented gas is assumed to be the same for total natural gas as for natural gas from crude oil wells and for offshore and onshore extraction.

The amount of natural gas that is re-injected into the well and the amount of natural gas that is either vented or flared is not be considered to be a coproduct of crude oil extraction.

Table 96: Natural Gas Venting, Flaring, and Coproduct Production from Offshore Extraction Wells

\begin{tabular}{lc}
\multicolumn{1}{c}{ Parameter } & Value \\
Gross NG extracted (kg/kg crude) & 0.26 \\
Domestic \% Re-injected & $2.46 \%$ \\
Domestic \% Flared/Vented & $0.09 \%$ \\
\hline Foreign \% Re-injected & $9.98 \%$ \\
Foreign \% Flared/Vented & $4.65 \%$ \\
\hline Coproduct Domestic & $97.45 \% \times 0.26=0.25 \mathrm{~kg}$ \\
Coproduct Foreign & $85.37 \% \times 0.26=0.22 \mathrm{~kg}$
\end{tabular}

The following tables (Table 97 and Table 98) show the mass of crude oil and natural gas produced by the wells considered in this project:

Table 97: Production of Typical Domestic Conventional Offshore Crude Oil Well

\begin{tabular}{ccc}
\hline & Mass $(\mathrm{kg})$ & Mass $(\%)$ \\
\hline \hline Crude Oil: & 1 & 80 \\
Natural Gas: & 0.25 & 20 \\
\cline { 2 - 2 } Total: & 1.25 & \\
\hline
\end{tabular}

Table 98: Production of Typical Foreign Conventional Offshore Crude Oil Well

\begin{tabular}{rcc}
\hline & Mass (kg) & Mass (\%) \\
\hline \hline Crude Oil: & 1 & 82 \\
Natural Gas: & 0.22 & 18 \\
\cline { 2 - 2 } Total: & 1.22 & \\
\hline
\end{tabular}

Emissions from flaring, venting, crude oil/natural gas separators, and fugitive emissions as well as raw materials, and energy use are allocated between natural gas and crude oil production based on the mass percentage of crude oil produced. For example, with conventional domestic offshore crude oil production, $80 \%$ of the total emissions, raw materials, and energy use is allocated to crude oil.

\section{Advanced Onshore Extraction (Steam Injection)}

Figure 90 shows the system process diagram associated with advanced onshore crude oil extraction through the use of steam injection. It demonstrates the system boundaries and process flows considered for modeling advanced steam injection onshore crude oil extraction in this study. 


\section{Material Use}

As is seen in Figure 90, the only material inputs required for advanced steam injection onshore crude oil extraction, accounted for in this study, is the actual crude oil and natural gas in the ground. It is assumed that there is no loss of crude oil once it is extracted from the well. Therefore, to produce one $\mathrm{kg}$ of crude oil would require one $\mathrm{kg}$ of crude oil from the ground.

The life cycle environmental flows associated with the production of the capital equipment and facilities used in the extraction of crude oil are excluded from this study. However, the energy required for drilling and exploration are included in the study. For advanced steam injection onshore crude oil production exploration and drilling energy represents approximately $0.75 \%$ of the energy in the produced crude oil [2]. This energy is primarily used for drilling.

This energy is accounted for by decreasing the yield for crude oil extraction or by increasing the amount of crude oil in the ground needed to produce one $\mathrm{kg}$ of crude oil. Therefore, advanced steam injection onshore crude oil extraction would require $1.0075 \mathrm{~kg}$ of crude oil in the ground to produce one $\mathrm{kg}$ of crude oil.

The material requirements for both domestic and foreign advanced steam injection onshore crude oil extraction are assumed to be the same.

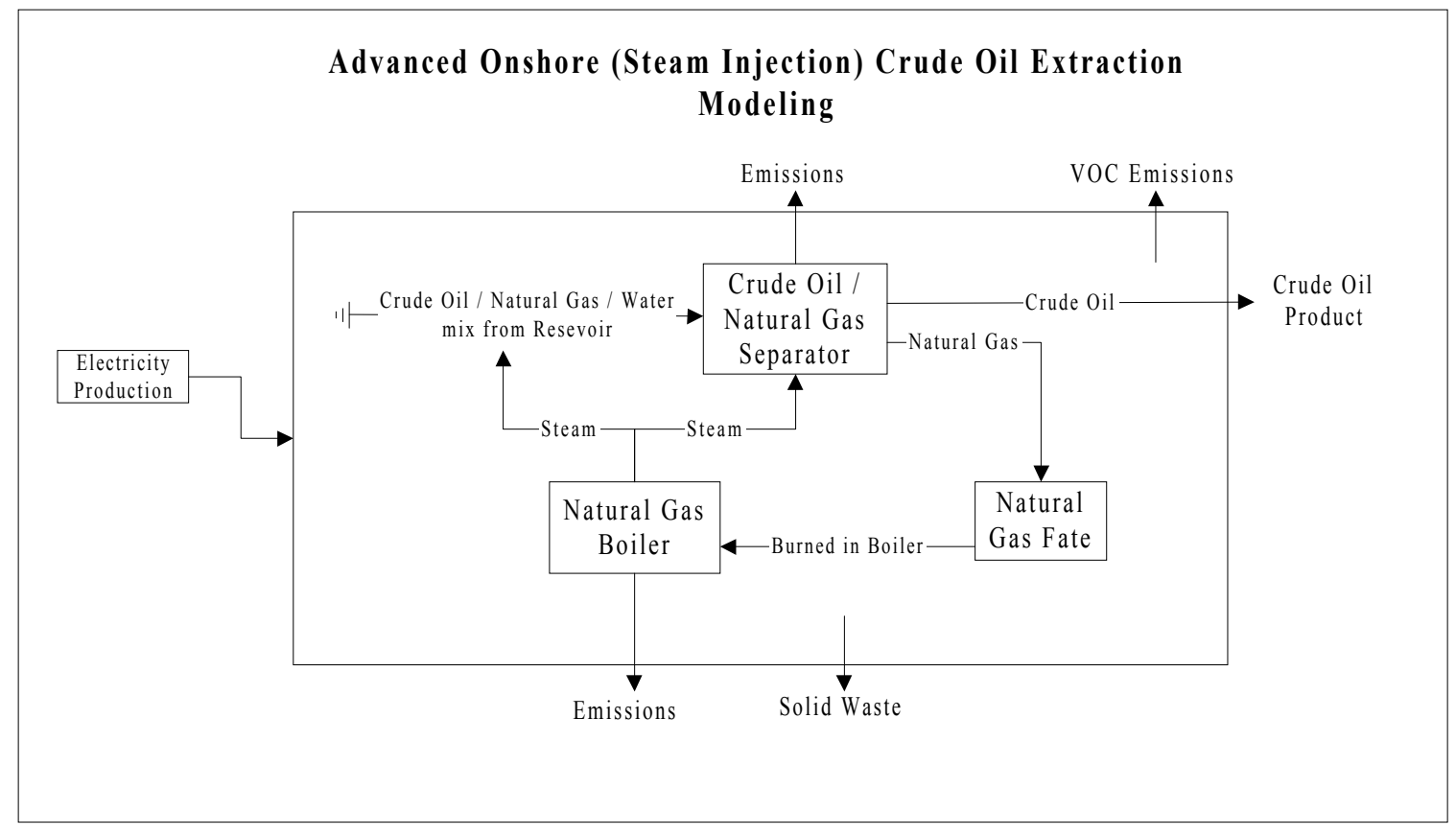

Figure 90: Advanced Onshore (Steam Injection) Crude Oil Extraction

\section{Energy/Equipment Use}

Energy used in the actual extraction of crude oil is accounted for in this study. It primarily comes from the gross production of the well and from purchased electricity. Energy requirements for both domestic and foreign advanced steam injection onshore crude oil production are based on a steam injection site located in the lower 48 states producing $4.7 \times 10^{9} \mathrm{~kg} / \mathrm{yr}\left(3.45 \times 10^{7} \mathrm{bbl} / \mathrm{yr}\right)$ of crude oil as follows [3]:
Electricity:
11.3 kilowatt-hr/bbl
(used in pumping)
Natural Gas:
$986 \mathrm{MJ} / \mathrm{bbl}$
(used in recovery and steam boiler)

This site is assumed to require the same amount of electricity as the conventional onshore crude oil extraction site modeled previously. However, since the amount of oil produced in the steam injection site is less than that of the conventional site, more electricity is required per bbl of oil. 
The steam used is assumed to be produced by natural gas fired boilers. The amount of steam used per year is estimated based on the amount of water used by the site $\left(1.06 \times 10^{10}\right.$ liters/yr $)$. The energy necessary to convert this water to steam is based on the enthalpy of the steam $\left(2.6 \mathrm{MJ} / \mathrm{kg} @\right.$ approximately $150 \mathrm{psi}$ and $\left.350^{\circ} \mathrm{F}\right)$ and a boiler efficiency of $80 \%$. The natural gas used in the crude oil/natural gas separators is assumed to be included in this value.

Electricity is assumed to come from a standard U.S. grid while natural gas is assumed to come from gross production of the well. The LCI information on the production of electricity is included in the overall LCI of crude oil extraction and is taken from Ecobalance's database DEAM ${ }^{\mathrm{TM}}$.

Modeling of foreign crude oil extraction electricity use based on the standard U.S. grid is not necessarily an accurate representation of the actual electricity production used at foreign oil fields. However, foreign crude oil used in the United States is coming from all over the word and modeling of the exact electricity use at foreign fields would require studying each site individually. Therefore, the U.S. standard grid was used as a surrogate for foreign electricity production. This is a conservative estimate because foreign electricity production sources may not meet the same strict emission guidelines as in the United States.

\section{Process Emissions}

The process emissions from advanced steam injection onshore crude oil extraction include air emissions and solid waste emissions.

No wastewater is assumed to be produced by advanced steam injection onshore crude oil extraction because it is all reused in steam production. Advanced steam injection onshore extraction is actually a net user of water. However, advanced steam injection onshore crude oil extraction is assumed to produce oil and grease, estimated to be $1 \times 10^{-4}$ $\mathrm{kg} / \mathrm{kg}$ crude oil produced [3] although no wastewater is produced.

The emission factor for the production of solid waste is calculated as 0.0098 grams of solid waste are produced for every $\mathrm{kg}$ of crude oil [1].

Air emissions from advanced steam injection onshore crude oil extraction come from the combustion of natural gas in a boiler as well as from volatilization (fugitive) emissions of crude oil.

VOC emissions from onshore crude oil extraction are shown in Table 99 as taken from a U.S. EPA report [5]. These VOC emissions are further speciated as illustrated in Table 100.

Table 99: VOC Emissions for Onshore Crude Oil Wells with $\mathrm{CO}_{2}$ Extraction

\begin{tabular}{|c|c|}
\hline Component & $\begin{array}{c}\text { Emission Factor } \\
\text { (g/well-yr) }\end{array}$ \\
\hline Fugitive Emissions & 180,000 \\
\hline Crude Oil Sumps & 4,000 \\
\hline Crude Oil Pits & 4,000 \\
\hline & 188,000 \\
\hline
\end{tabular}

In 1994 the average productivity of U.S. crude oil production wells was 1,555 $\mathrm{kg}$ of crude oil/day per well (11.4 bbl/day per well). Using this number, VOC emissions data can be calculated per kilograms of crude oil produced.

\section{Crude Oil Production}

Advanced onshore crude oil extraction is assumed to burn all of the natural gas produced by the well in order to generate the steam needed for injection. Therefore, no natural gas is produced as a coproduct of advanced steam injection onshore crude oil extraction.

Emissions from natural gas boilers and fugitive emissions, as well as raw materials and energy use, are allocated completely to crude oil production for advanced steam injection onshore crude oil extraction. 
Table 100: Speciated VOC Data for Onshore Crude Oil Wells

\begin{tabular}{cc}
\hline Compound & Weight \% \\
\hline \hline Isomers of hexane & 9.9 \\
Isomers of heptane & 11.6 \\
Isomers of octane & 8.7 \\
C-7 Cycloparaffins & 1.6 \\
C-8 Cycloparaffins & 0.6 \\
Isomers of pentane & 5.6 \\
Methane & 38.0 \\
Ethane & 6.4 \\
Propane & 10.0 \\
n-Butane & 7.4 \\
iso-Butane & 0.4 \\
Benzene & 0.1 \\
\hline
\end{tabular}

\section{Advanced Onshore Extraction (CO $\mathrm{O}_{2}$ Injection)}

Figure 91 shows the system process diagram associated with advanced onshore crude oil extraction through the use of $\mathrm{CO}_{2}$ injection. It demonstrates the system boundaries and process flows considered for modeling advanced $\mathrm{CO}_{2}$ injection onshore crude oil extraction in this study.

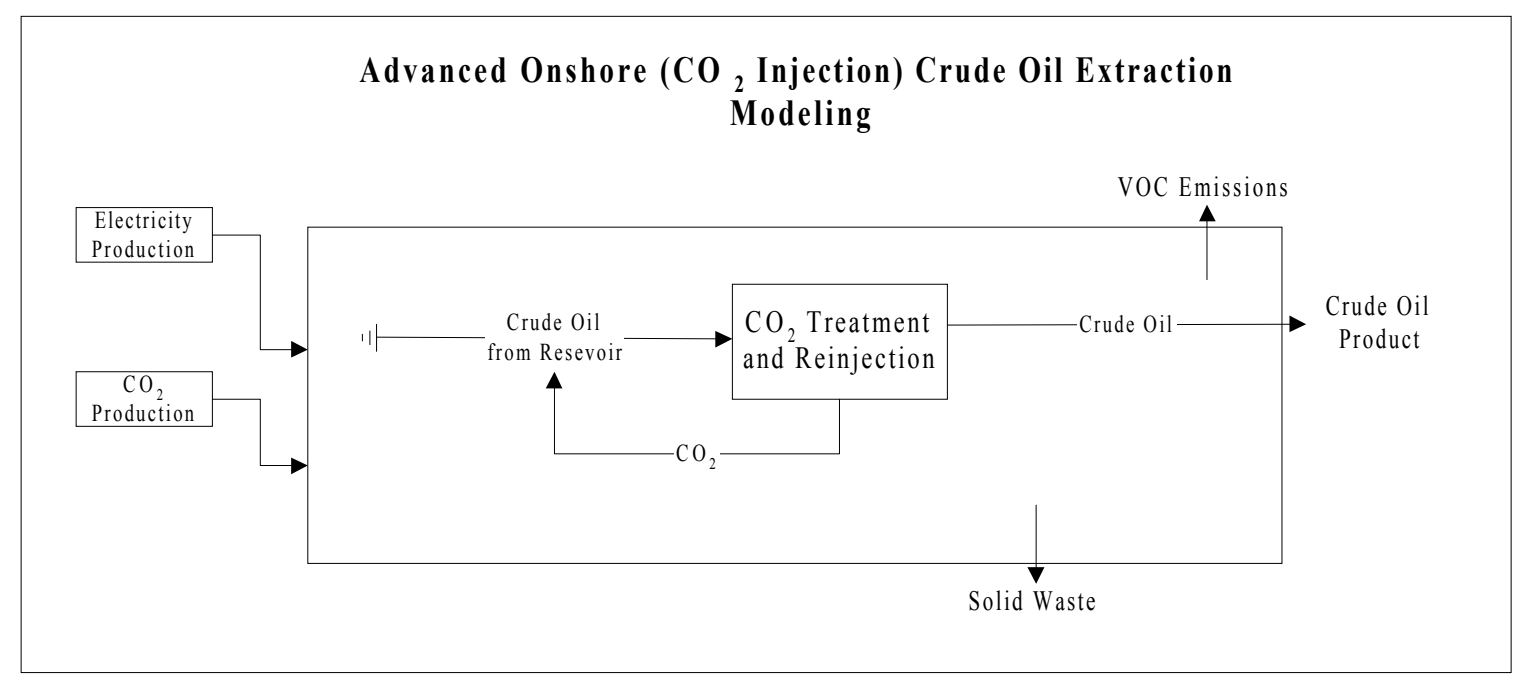

Figure 91: Advanced Onshore ( $\mathrm{CO}_{2}$ Injection) Crude Oil Extraction

\section{Material Use}

As is seen in Figure 91, the material inputs required for advanced $\mathrm{CO}_{2}$ injection onshore crude oil extraction, accounted for in this study, is the actual crude oil in the ground and the $\mathrm{CO}_{2}$ required for injection. A carbon dioxide gas injection well is assumed to require $4.6 \mathrm{~kg}$ of $\mathrm{CO}_{2}$ to be injected for every $1 \mathrm{~kg}$ of crude oil produced $\left(15,000 \mathrm{scf}\right.$ of $\mathrm{CO}_{2}$ per barrel of crude oil). Of this $\mathrm{CO}_{2}$ injected, half is assumed to be sequestered in the reserve. ${ }^{37}$

37 This sequestered $\mathrm{CO}_{2}$ is accounted for as a negative flow in the model. 
Therefore, only $2.3 \mathrm{~kg}$ of carbon dioxide gas will have to be produced for every $\mathrm{kg}$ of crude oil extracted. The production of the carbon dioxide gas is taken from Ecobalance's database DEAM ${ }^{\mathrm{TM}}$, based on separation from synthesis gas.

It is assumed that there is no loss of crude oil once it is extracted from the well. Therefore, to produce one $\mathrm{kg}$ of crude oil would require one $\mathrm{kg}$ of crude oil from the ground.

The life cycle environmental flows associated with the production of the capital equipment and facilities used in the extraction of crude oil are excluded from this study. However, the energy required for drilling and exploration are included in the study. For advanced $\mathrm{CO}_{2}$ injection onshore crude oil production exploration and drilling energy represents approximately $0.75 \%$ of the energy in the produced crude oil. This energy is primarily used for drilling.

This energy is accounted for by decreasing the yield for crude oil extraction or by increasing the amount of crude oil in the ground needed to produce one $\mathrm{kg}$ of crude oil. Therefore, advanced $\mathrm{CO}_{2}$ injection onshore crude oil extraction would require $1.0075 \mathrm{~kg}$ of crude oil in the ground to produce one $\mathrm{kg}$ of crude oil.

The material requirements for both domestic and foreign advanced $\mathrm{CO}_{2}$ injection onshore crude oil extraction are assumed to be the same.

\section{Energy/Equipment Use}

Energy used in the actual extraction of crude oil is accounted for in this study. Enhanced/advanced crude oil extraction by $\mathrm{CO}_{2}$ injection is assumed to require the same amount of electricity as the steam injection enhanced/ advanced crude oil extraction site shown previously. It is also assumed that this electricity is used for the separation, drying, compression, and injection of the carbon dioxide gas.
Electricity:
11.3 kilowatt-hr/bbl
(used in pumping)

Electricity is assumed to come from a standard U.S. grid. The LCI information on the production of electricity is included in the overall LCI of crude oil extraction and is taken from Ecobalance's database DEAM ${ }^{\mathrm{TM}}$ as described.

Modeling of foreign crude oil extraction electricity use based on the standard U.S. grid is not necessarily an accurate representation of the actual electricity production used at foreign oil fields. However, foreign crude oil used in the U.S. is coming from all over the word and modeling of the exact electricity use at foreign fields would require studying each site individually. Therefore, the U.S. standard grid was used as a surrogate for foreign electricity production. This is a conservative estimate because foreign electricity production sources may not meet the same strict emission guidelines as in the United States.

\section{Process Emissions}

The process emissions from advanced $\mathrm{CO}_{2}$ injection onshore crude oil extraction include air emissions and solid waste emissions.

No wastewater is assumed to be produced by advanced $\mathrm{CO}_{2}$ injection onshore crude oil extraction. However, advanced $\mathrm{CO}_{2}$ injection onshore crude oil extraction is assumed to produce oil and grease, estimated to be $1 \times 10^{-4}$ $\mathrm{kg} / \mathrm{kg}$ crude oil produced although no wastewater is produced [3].

The emission factor for the production of solid waste is calculated as 0.0098 grams of solid waste are produced for every $\mathrm{kg}$ of crude oil [1].

Air emissions from advanced $\mathrm{CO}_{2}$ injection onshore crude oil extraction come from volatilization (fugitive) emissions of crude oil.

VOC emissions from onshore crude oil extraction are shown in Table 101 as taken from a U.S. EPA report [5]. These VOC emissions are further speciated as shown in Table 102.

In 1994 the average productivity of U.S. crude oil production wells was 1,555 kg of crude oil/day per well (11.4 $\mathrm{bbl} /$ day per well). Using this number, VOC emissions data can be calculated per kilograms of crude oil produced.

In addition, the use of $\mathrm{CO}_{2}$ injection to enhance the production of crude oil is assumed to result in some sequestration of the injected $\mathrm{CO}_{2}$. It is assumed that half of the injected $\mathrm{CO}_{2}$ is sequestered and, therefore, is accounted for as a negative flow in the life cycle. 
Table 101: VOC Emissions for Onshore Crude Oil Wells

\begin{tabular}{lcc}
\hline \multicolumn{1}{c}{ Component } & Emission Factor $(\mathrm{g} /$ well-yr) \\
\hline \hline Fugitive Emissions & 180,000 \\
Crude Oil Sumps & 4,000 \\
Crude Oil Pits & 4,000 \\
& Total & 188,000 \\
\hline
\end{tabular}

Table 102: Speciated VOC Data for Onshore Crude Oil Wells

\begin{tabular}{cc}
\hline Compound & Weight \% \\
\hline \hline Isomers of hexane & 9.9 \\
Isomers of heptane & 11.6 \\
Isomers of octane & 8.7 \\
C-7 Cycloparaffins & 1.6 \\
C-8 Cycloparaffins & 0.6 \\
Isomers of pentane & 5.6 \\
Methane & 38.0 \\
Ethane & 6.4 \\
Propane & 10.0 \\
n-Butane & 7.4 \\
iso-Butane & 0.4 \\
Benzene & 0.1 \\
\hline
\end{tabular}

\section{Crude Oil Production}

It is assumed that advanced $\mathrm{CO}_{2}$ injection onshore crude oil extraction does not produce natural gas as a coproduct of crude oil extraction.

Fugitive emissions as well as raw materials, and energy use are allocated completely to crude oil production for advanced $\mathrm{CO}_{2}$ injection onshore crude oil extraction.

\section{CRUDe OIL TRANSPORT TO REFINERY}

The U.S. is broken up into PADDs in order to ensure that each region or PADD is supplied with enough petroleum for strategic defense reasons. The transportation distances used in this report are regionalized by these PADDs. However, there is no specific ton-mile information available for crude oil transportation per PADD. Therefore, certain assumptions have to be made regarding crude oil transportation as described in the following sections:

\section{Transportation Regionalization}

The amount of foreign and domestic crude oil transported into each PADD is estimated from refinery receipts of crude oil which is known for each PADD [8]. ${ }^{38}$ The following tables (Table 103 and Table 104) describe refinery receipt of crude oil for 11 different methods of transport and two different sources, foreign and domestic.

\footnotetext{
38 Data for 1993 were used because that was the latest year for which information used to calculate transportation distances could be found. 
Table 103: Refinery Receipts of Crude Oil by Source and by PADD (1993)

\begin{tabular}{ccccccc}
\hline \multirow{2}{*}{ Source } & \multicolumn{7}{c}{ Petroleum Administration for Defense District } \\
& $I$ & $I I$ & $I I I$ & $I V$ & $V$ & Total U.S. \\
\hline \hline Total: & $(\%)$ & $(\%)$ & $(\%)$ & $(\%)$ & $(\%)$ & $(\%)$ \\
Domestic & 2.68 & 56.03 & 39.37 & 81.33 & 90.12 & 50.41 \\
Foreign & 97.32 & 43.97 & 60.63 & 18.67 & 9.88 & 49.59 \\
Total: & 100 & 100 & 100 & 100 & 100 & 100 \\
\hline
\end{tabular}

Table 104: Refinery Receipts of Crude Oil by Method of Transportation and by PADD (1993)

\begin{tabular}{|c|c|c|c|c|c|c|c|c|c|c|c|c|}
\hline \multirow[t]{2}{*}{ Method } & \multicolumn{12}{|c|}{ Petroleum Administration for Defense District } \\
\hline & \multicolumn{2}{|c|}{$I$} & \multicolumn{2}{|c|}{ II } & \multicolumn{2}{|c|}{ III } & \multicolumn{2}{|c|}{$I V$} & \multicolumn{2}{|c|}{$V$} & \multicolumn{2}{|c|}{ Total U.S. } \\
\hline Pipeline: & \multicolumn{2}{|c|}{$(\%)$} & \multicolumn{2}{|c|}{$(\%)$} & \multicolumn{2}{|c|}{$(\%)$} & \multicolumn{2}{|c|}{$(\%)$} & \multicolumn{2}{|c|}{$(\%)$} & \multicolumn{2}{|c|}{$(\%)$} \\
\hline Domestic & 13.3 & & 96.9 & & 84.4 & & 86.8 & & 38.6 & & 71.9 & \\
\hline Foreign & & 0.17 & & 51.8 & & 22.9 & & 0 & & 0 & & 23.2 \\
\hline Canadian & & 4.59 & & 48.2 & & 0.31 & & 99.8 & & 18.1 & & 12.5 \\
\hline Tanker: & & & & & & & & & & & & \\
\hline $\begin{array}{l}\text { Domestic } \\
\text { Foreign }\end{array}$ & 1.73 & 90.7 & 0 & 0 & 0.78 & 75.7 & 0 & 0 & 59.5 & 70.5 & 20.2 & 62.4 \\
\hline Barge: & & & & & & & & & & & & \\
\hline $\begin{array}{l}\text { Domestic } \\
\text { Foreign }\end{array}$ & 10.7 & 4.57 & 0.19 & 0 & 11.8 & 1.12 & 0 & 0 & 0.67 & 11.4 & 4.57 & 1.92 \\
\hline $\begin{array}{l}\text { Tank Cars: } \\
\text { Domestic }\end{array}$ & 41.2 & & 0 & & 0.08 & & 0.65 & & 0.21 & & 0.34 & \\
\hline $\begin{array}{l}\text { Foreign } \\
\text { Trucks: }\end{array}$ & & 0 & & 0 & & 0 & & 0.19 & & 0 & & 0 \\
\hline $\begin{array}{l}\text { Domestic } \\
\text { Foreign }\end{array}$ & 33.1 & 0 & 2.93 & 0 & 2.99 & 0 & 13.1 & 0 & 0.98 & 0 & 2.98 & 0 \\
\hline $\begin{array}{l}\text { Total: } \\
\text { Domestic }\end{array}$ & 100 & & 100 & & 100 & & 100 & & 100 & & 100 & \\
\hline Foreign & & 100 & & 100 & & 100 & & 100 & & 100 & & 100 \\
\hline
\end{tabular}

Pipeline transportation is broken out for Canadian and other foreign sources. This is done to account for the fact that foreign oil, other than Canadian, must travel via tanker to the United States before it enters a domestic pipeline. ${ }^{39}$

\section{Transportation Distances}

The distances used in this project are based on national average distances. These distances were obtained through the following sources of data and methods of calculation:

39 Transportation of crude oil within foreign countries is limited to pipeline transport. This seems to be a fair estimate considering the small amount of crude oil shipped by alternative methods in the United States. About $15 \%$ of all foreign oil (excluding Canada) will travel in a foreign pipeline before being shipped to the United States. 
Domestic Tanker and Domestic Barge:

- Source of Data: Waterborne Commerce of the United States, Calendar Year 1993, Part 5 - National Summaries. Department of the Army, Corps of Engineers.

- Calculation Method: Army report lists tons and ton-miles of crude oil transported by tanker and barge on all U.S. waterways. Data listed are not just for refinery receipts but include all transport (including any transport to storage facilities). Average miles are calculated by dividing total ton-miles traveled by total tons transported. This is done separately for both tanker and barge.

Domestic Pipeline:

- Source of Data: Association of Oil Pipelines, using data from Annual Report (Form 6) of oil pipeline companies to the Federal Energy Regulatory Commission. EIA, Petroleum Supply Annual, 1993, Vol. 1.

- Calculation Method: Association of Oil Pipelines lists total ton-miles of crude oil carried in domestic pipelines. Petroleum Supply Annual lists refinery receipt of crude oil by PADD by method and source of transportation. Petroleum Supply Annual gives crude oil receipts in barrels which is converted to tons. ${ }^{40}$ Average miles are calculated by dividing total ton-miles of crude oil, carried in domestic pipelines, by tons of crude oil received at refineries via pipeline.

Domestic Rail:

- Source of Data: Association of Oil Pipelines, using data from Carload Way Bill Statistics, Report TD-1, Department of Transportation, Federal Railroad Administration, annual, and Freight Commodity Statistics, Association of American Railroads, annual. EIA, Petroleum Supply Annual, 1993, Vol. 1.

- Calculation Method: Association of Oil Pipelines lists total ton-miles of crude oil carried by rail in the United States. Petroleum Supply Annual lists refinery receipt of crude oil by PADD by method and source of transportation. Petroleum Supply Annual gives crude oil receipts in barrels which is converted to tons. Average miles are calculated by dividing total ton-miles of crude oil, carried by rail, by tons of crude oil received at refineries via railroad tank cars.

Domestic Truck:

- Source of Data: Association of Oil Pipelines, using data from Financial and Operating Statistics, American Trucking Association, Inc. EIA, Petroleum Supply Annual, 1993, Vol. 1.

- Calculation Method: Association of Oil Pipelines lists estimated total ton-miles of crude oil transported by motor carriers in the United States. Petroleum Supply Annual lists refinery receipt of crude oil by PADD by method and source of transportation. Petroleum Supply Annual gives crude oil receipts in barrels which is converted to tons. Average miles are calculated by dividing total ton-miles of crude oil, transported by motor carriers, by tons of crude oil received at refineries via truck.

Foreign Pipeline to Coast and Canadian Pipeline to the United States:

- The same value is used that was calculated for Domestic Pipeline.

Foreign Tanker:

- Source of Data: Delucchi, M.A., Emissions of Greenhouse Gases from the Use of Transportation Fuels and Electricity, Vol. 2 Argonne National Laboratory, 1993. EIA, Petroleum Supply Annual, 1994, Vol. 1.

- Calculation Method: The Petroleum Supply Annual lists imports of crude oil by country for each PADD (in barrels). PADD I crude oil is assumed to all arrive at New York. PADD II and III oil is assumed to arrive at Houston. (PADD II oil arrives at Houston and then is transported by pipeline, barge, etc. to its final destination). PADD V oil is assumed to arrive at Los Angeles. PADD IV does not receive any foreign oil other than Canada.

\footnotetext{
40 Conversion of crude oil from barrels to tons is done using the conversion factor of 6.62 bbls equals one ton.
} 
Nautical miles between ports of origin and U.S. ports (New York, Houston, and Los Angeles) are given in Delucchi's study, based on information from the Defense Mapping Agency [9]. From this information a weighted average is calculated, for each PADD, by multiplying barrels imported from each country by the distance from that country to the specified U.S. port of entry. These results, in barrel-miles for each PADD, are added together and then divided by the total number of barrels imported to get an average distance traveled by the foreign tankers (in miles).

Average mileage values for all modes of transportation are then converted into kilometers.

\section{Transportation Models}

Ecobalance maintains a database of transportation methods and environmental impacts associated with those methods. This database, $\mathrm{DEAM}^{\mathrm{TM}}$, is utilized to account for the environmental impacts of transporting crude oil from extraction sites to refinery locations.

The following sources of fuel are assumed for each method of transportation:

- Pipelines: Electricity, assume that U.S. pipelines draw from average U.S. power mix. Energy consumption: $0.0184 \mathrm{kWh}$ electricity per ton-mile [10].

- $\quad$ Rail and Trucks: \#2 diesel fuel

- Ocean Tankers and Barges: \#6 fuel oil

A problem arises with rail and trucks as they require $\# 2$ diesel fuel, which is the output of this model. This is handled by iterating the model for diesel fuel. The model was run the first time with surrogate values for production of \#2 diesel fuel. Then the new results of the model are taken and inserted back into the model to replace the previously used values for production of \#2 diesel fuel. The model is run again with the new values to obtain the final result.

Empty backhauls are taken into account for truck transportation.

The following figure (Figure 92) demonstrates graphically how crude oil transportation is regionalized in this project. Example percentages for mode of transport are given for PADD II to clarify how the information is used.

\section{Energy and Fugitive Emissions from Storage and Handling}

In addition to the energy requirements and subsequent emissions from the actual modes of transportation (e.g., truck diesel use and emissions, pipeline electricity requirements, and emissions from electricity production, etc.), there are also energy and emissions due to loading and unloading of the crude oil.

The loading and unloading of crude oil is assumed to require electricity for pumping. The amount of electricity used is based on the electricity required for pipeline transport. Pipelines are assumed to require $5.8 \times 10^{-5} \mathrm{MJ}$ of electricity per $1 \mathrm{~kg}$ transported $1 \mathrm{~km}$. For loading and unloading, it is assumed that the distance fuel would be pumped is 50 meters and that the energy required for pumping is linear with distance pumped. Therefore, $2.9 \times 10^{-6}$ $\mathrm{MJ}$ of electricity are required for loading and unloading one $\mathrm{kg}$ of fuel.

The emissions associated with loading and unloading trucks and rail cars were based on the following formula [11]:

$$
L_{L}=12.46 \frac{S P M}{T}\left(1-\frac{e f f}{100}\right)
$$

\section{Equation 1: Estimating Emissions from Loading and Unloading Trucks and Rail Cars}

Where:

$\mathrm{L}_{\mathrm{L}}=$ loading loss in pounds per 1000 gallons

$\mathrm{S}=$ saturation factor

$\mathrm{P}=$ true vapor pressure of fuel transported (psia)

$\mathrm{M}=$ molecular weight of fuel vapors (lb/lb-mole)

$\mathrm{T}=$ temperature of the fuel $\left({ }^{\mathrm{O}} \mathrm{R}=\left({ }^{\circ} \mathrm{F}+460\right)\right)$

eff $=$ overall reduction efficiency $(\%)$ 


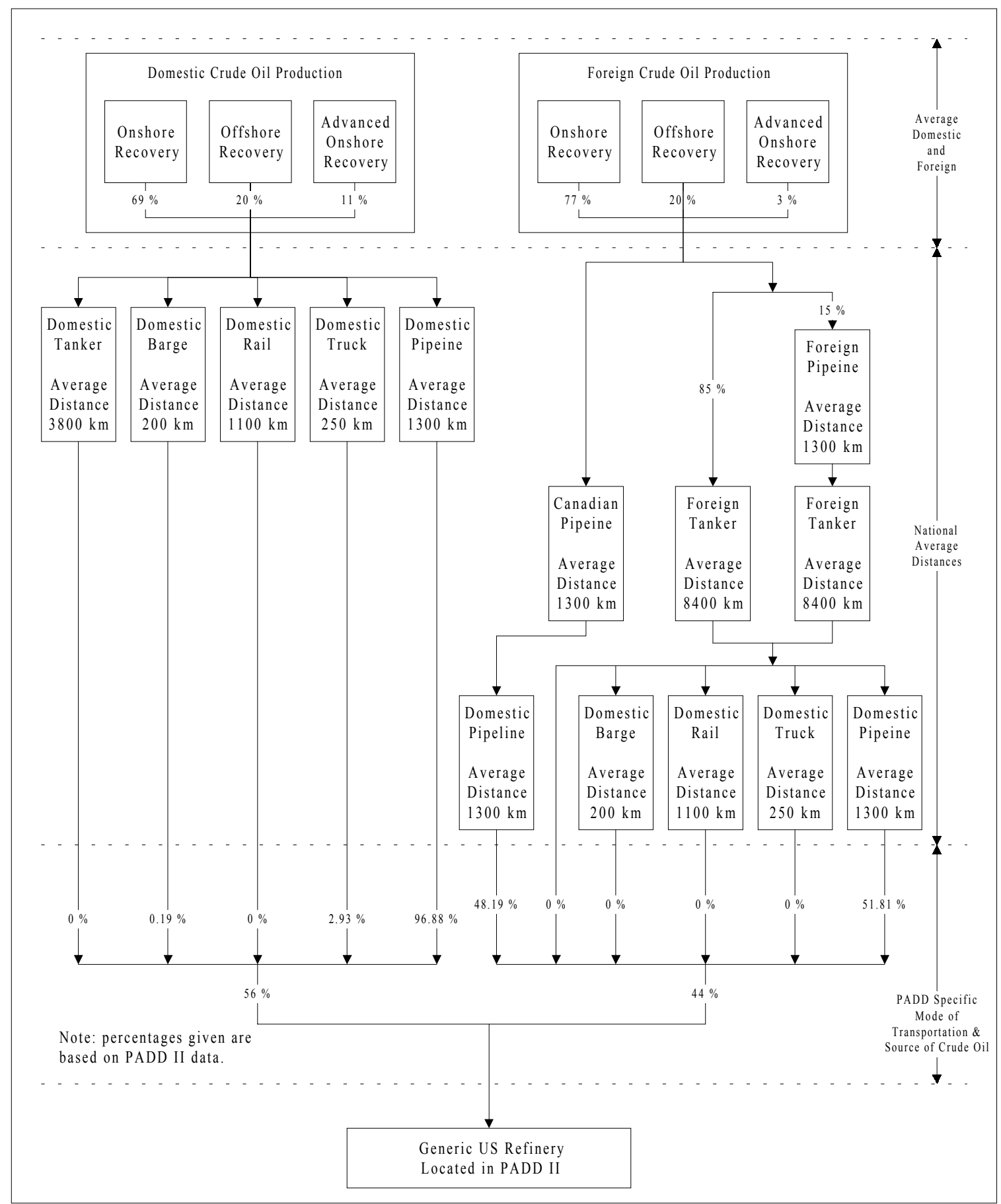

Figure 92: Crude Oil Transportation Modeling

The saturation factor is based on the type of carrier and the mode of operation. ${ }^{41}$ For this project an average $\mathrm{S}$ value is used that is the straight average of all possible operation modes.

41 The different types of carriers include normal service and vapor balance service in which the cargo truck retrieves the vapors displaced during product unloading and transports the vapors back to the loading terminal. Modes of operation include submerged and splash loading. 
The vapor pressure of the fuel (in this case, crude oil) is estimated at $60^{\circ} \mathrm{F}$ based on information in AP-42. The $\mathrm{M}$ (or molecular weight of the crude oil vapors) is also taken from information in AP-42. The temperature is assumed to be $60^{\circ} \mathrm{F}$ to match the vapor pressure and molecular weight data.

The reduction efficiency is a measure of how much of the vapors are collected and then subsequently controlled. In this case it is assumed that $70 \%$ of the vapors were collected and then $90 \%$ of those collected vapors were controlled to yield and overall efficiency of $63 \% .^{42}$

The emissions associated with loading and unloading tankers and barges were based on the following formula [11]:

$$
C_{L}=\left(C_{A}+1.84(0.44 P-0.42) \frac{M G}{T}\right)
$$

\section{Equation 2: Estimating Emissions from Loading and Unloading Tankers and Barges}

Where:

$\mathrm{C}_{\mathrm{L}}=$ total loading loss in pounds per 1000 gallons

$\mathrm{C}_{\mathrm{A}}=$ arrival emission factor $(\mathrm{lb} / 1000 \mathrm{gal})$

$\mathrm{P}=$ true vapor pressure of fuel transported (psia)

$\mathrm{M}=$ molecular weight of fuel vapors (lb/lb-mole)

$\mathrm{G}=$ vapor growth factor $=1.02$ (dimensionless)

$\mathrm{T}=$ temperature of the vapors $\left({ }^{\circ} \mathrm{R}=\left({ }^{\circ} \mathrm{F}+460\right)\right)$

eff $=$ overall reduction efficiency $(\%)$

The arrival emission factor is based on information in AP-42 and is determined by the condition of the transportation vessel upon arrival. In this project it is assumed to be an uncleaned vessel. ${ }^{43}$

The vapor pressure of the fuel (in this case, crude oil) is estimated at $60^{\circ} \mathrm{F}$ based on information in AP-42. The M (or molecular weight of the crude oil vapors) is also taken from information in AP-42. The temperature is assumed to be $60^{\circ} \mathrm{F}$ to match the vapor pressure and molecular weight data.

In addition to loading and unloading fugitive emissions there are also fugitive emissions associated with transit of the fuel. The emissions associated with truck, train, tanker, and barge transit were based on the following formula [11]:

$$
L_{T}=0.1 P W
$$

\section{Equation 3: Estimating Fuel Transit Emissions}

Where:

$\mathrm{L}_{\mathrm{T}}=$ transit losses in pounds per 1000 gallons per week

$\mathrm{P}=$ true vapor pressure of fuel transported (psia)

$\mathrm{W}=$ density of the condensed vapors $(\mathrm{lb} / \mathrm{gal})$

The vapor pressure of the fuel (in this case, crude oil) is estimated at $60^{\circ} \mathrm{F}$ based on information in AP-42. The W (or density of the condensed crude oil vapors) is also taken from information in AP-42. The value obtained for $\mathrm{L}_{\mathrm{T}}$ can be converted to pounds per 1000 gal per $\mathrm{km}$ based on the speed of the different modes of transportation used. The following conversion factors are computed from average speeds for the different modes of transport:
Tanker -1 week $=4,317.6 \mathrm{~km}$
Rail - 1 week $=10,752 \mathrm{~km}$
Barge -1 week $=2,167.2 \mathrm{~km}$
Truck $^{44}-1$ week $=5,792 \mathrm{~km}$

Figure 93 represents how the emissions from crude oil transportation are modeled in this project.

\footnotetext{
42 Both the $70 \%$ collection efficiency and $90 \%$ control efficiency are the low range of values reported in AP- 42 .

43 Therefore, no ballast emissions are accounted for.

44 Assuming the truck is running at $60 \mathrm{mph}$ for 10 hours a day and 6 days a week.
} 
Note that fugitive tank emissions from the storage of crude oil at the oil field are accounted for in crude oil extraction modeling. Also, fugitive tank emissions from the storage of crude oil at the refinery are accounted for in the crude oil refining model.

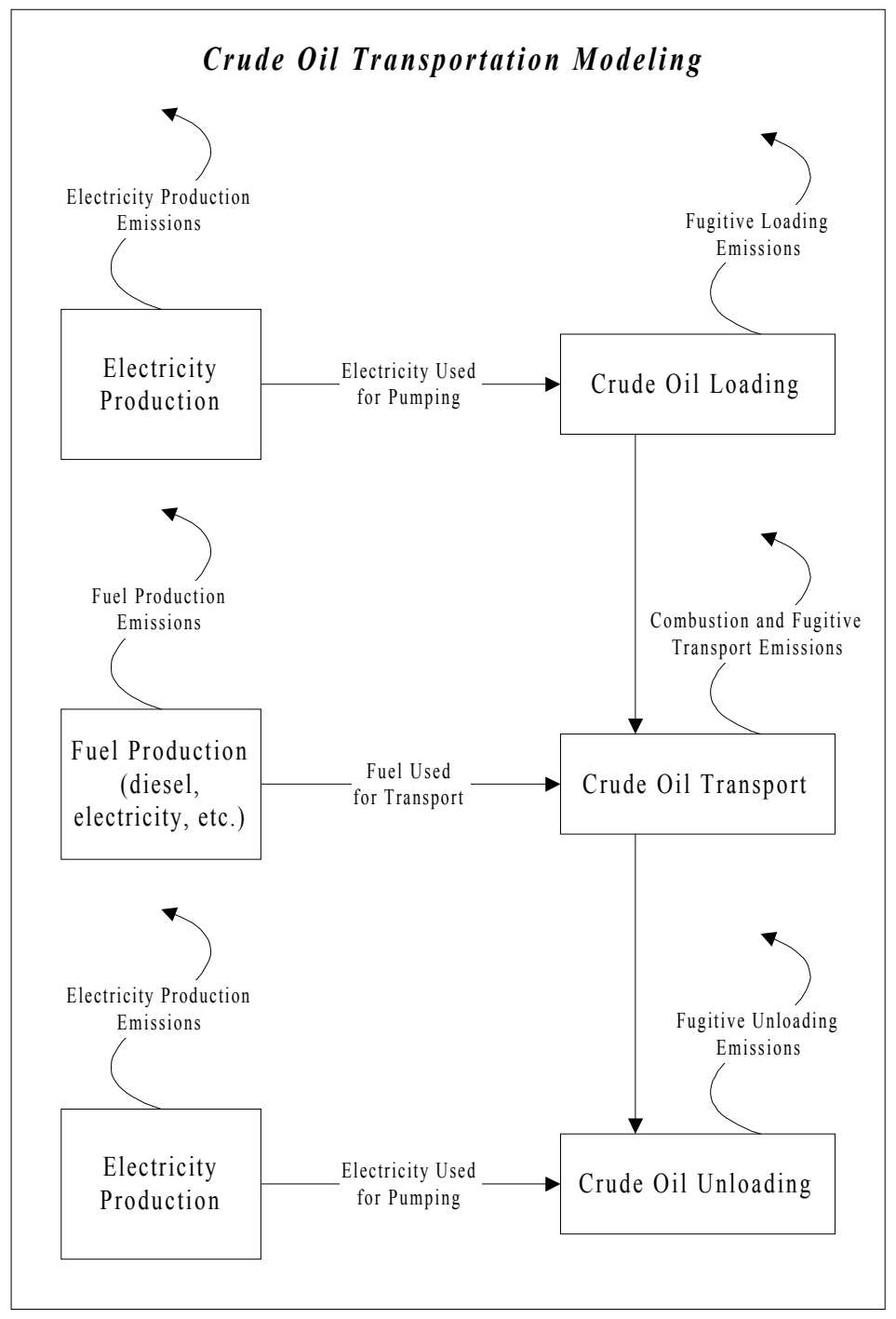

Figure 93: Crude Oil Transportation Modeling

\section{CRUde OiL REFining}

The modeling of crude oil production and transportation to a refinery have been described in the previous sections. This section of the report describes the system of refining crude oil into petroleum-based products as shown in Figure 94.

The modeling of petroleum refining is based on the U.S. refining averaged performance as opposed to a PADDspecific refinery. Therefore, the size and complexity of different refineries in different PADDs are not taken into account. 


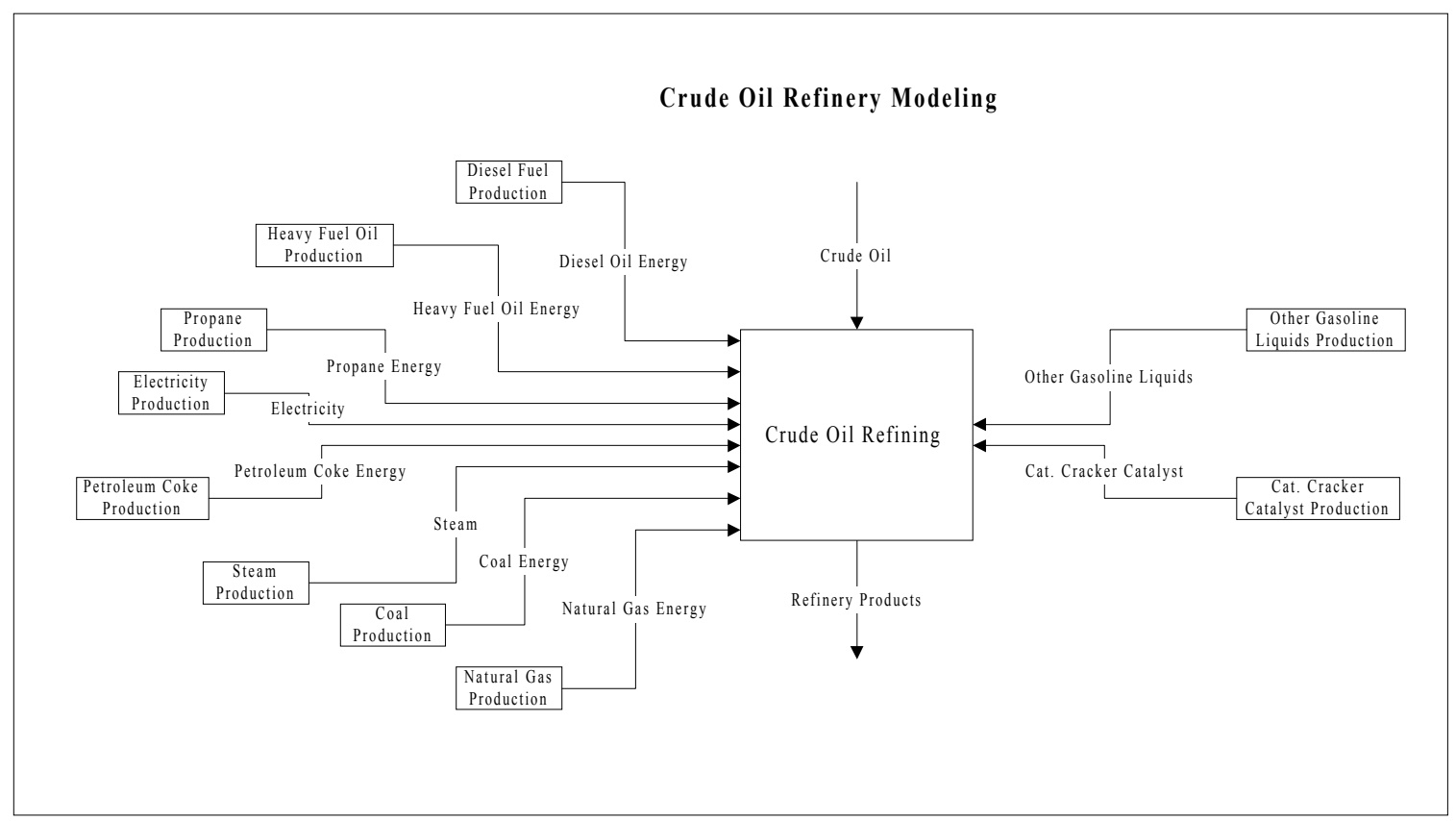

Figure 94: Petroleum Refining System Description

EIA data from the Petroleum Supply Annual 1994, Volume 1 were used to establish the volumetric flows for the U.S. refining industry. A closed mass and energy balance was created from the U.S. 1994 EIA refining data ${ }^{45}$. To accomplish this, the EIA volumetric data were converted to masses using input and product densities obtained from the literature for the streams. The energy flows were estimated from the same densities. Heat rejection to cooling water was based upon published literature values.

Other assumptions included:

- The crude gravity assumed was $32 \mathrm{deg}$ API from Bonner and Moore, refinery Economics Short Course Text, Feb 1994.

- $\quad$ Product densities were estimated for all streams from Bonner and Moore, except coke where the EIA definition of $5 \mathrm{bbl} /$ ton was used.

- The heating value of a fuel oil equivalent of $6 \mathrm{MM} \mathrm{Btu} / \mathrm{bbl}$ was used for refinery energy consumption data.

- Natural gas was assumed to have 1012 Btu/scf.

- Coal was assumed to be $24 \mathrm{MM} \mathrm{Btu/ton}$

- $\quad$ NBS Misc Pub 97 was used to estimate the heats of all petroleum materials below 50 deg API.

- $\quad$ Gasoline heating value was estimated from ANL/ESD-28 adjusted for HHV for summer RFG.

- Other liquids, oxygenates, and natural gasoline, were assumed to have a gravity equal to gasoline and a heating value typical of oxygenates. Unfinished oils were assumed to be fuel oil.

- Still gas mass was estimated assuming 23,500 Btu/lb for the gas (about 75\% methane), using $19350 \mathrm{Btu} / \mathrm{lb}$ and $0.887 \mathrm{spg}$ for the fuel oil equivalent barrel.

- The plant heat loss to cooling water was estimated from Gary and Handwerk, Petroleum Refining technology and economics, 3rd Edition, Marcel Dekker, NY, 1994. The authors provide a case study for a 100,000 bbl/day refinery of moderate complexity. The total reported cooling water duty is 1,252 gal/bbl crude fed at $30 \mathrm{~F}$ temperature rise. Fifty percent of the duty is used for boiler feed water heating.

\footnotetext{
45 Mass and energy balance was computed by Mike Graboski of the Colorado School of Mines.
} 
- It is assumed that plant convective and radiation heat losses are negligible.

- Electricity was charged at $3413 \mathrm{Btu} / \mathrm{kwh}$.

The results of the mass and energy balance were as follows:

The mass balance closed to within $0.5 \%$. Still gas and catalyst coke are burned in the plant and thus do not show up as useful products. The indicated crude used is $105.56 \%$ of the products on a fuel oil equivalent basis.

The energy balance closes to within $0.3 \%$. The energy inputs plus recycled still gas and coke amount to about $9.7 \%$ of the energy of the useful products out.

The energy balance suggests that an additional $2.6 \%$ is heat losses from the plant in cooling water. Thus the amount of energy consumed per gallon of low-sulfur diesel is 17,292 Btu.

The amount of crude to the refinery (from the EIA report) needs to be increased by $5.56 \%$ in the model to cover mass losses in still gas and catalyst coke. This impacts upstream recovery and transportation.

\section{Material Use}

For this report, it is assumed that the material required by the crude oil refinery includes the crude oil itself plus other petroleum-based feedstocks, purchased energy inputs and process catalysts, assumed to be catalytic cracking catalyst as shown in Figure 94 above. ${ }^{46}$

The amounts of crude oil and other petroleum based feedstocks required are taken from the total inputs to all U.S. refineries from EIA, Petroleum Supply Annual (1994) as described in the mass balance above.

The EIA report lists the total U.S. refinery inputs of crude oil, other gasoline liquids, and unfinished oils for 1994. The following table (Table 105) lists the amount of materials input to all U.S. refineries.

Table 105: Material Inputs to U.S. Refineries

\begin{tabular}{lcc}
\hline \multicolumn{1}{r}{ Flow Name } & Units & Value per Year \\
\hline \hline Crude Oil & $\mathrm{kg}$ & $6.95 \times 10^{11}$ \\
Other Gasoline Liquids & $\mathrm{kg}$ & $7.90 \times 10^{9}$ \\
Unfinished Oils & $\mathrm{kg}$ & $2.24 \times 10^{10}$ \\
\hline
\end{tabular}

For this project, unfinished oils are added to the total for crude oil input. The LCI results for the production of the other gasoline liquids are from Ecobalance's database and assumed to be produced from natural gas. The amount of crude to the refinery is increased by $5.56 \%$ to cover mass losses in still gas and catalyst coke.

The amount of catalytic cracking catalyst required is based on the uncontrolled particulate emissions from the catalytic cracker. It is assumed that all of the particulate produced by the catalytic cracker results from the loss of the catalyst. Therefore, the lost catalyst needs to be made up with additional inputs. Based on U.S. EPA AP-42 data for uncontrolled particulate emissions from catalytic cracking, $0.566 \mathrm{~g}$ of catalyst is required per liter of crude oil through the catalytic cracking units. Other catalyst inputs are much smaller than the cracking catalyst.

The production of catalytic cracking catalyst is taken from Ecobalance's database based on a Zeolite catalyst.

\section{Energy/Equipment Use}

Petroleum refineries draw most of their energy requirement from the crude oil stream. However, additional energy requirements and process needs are fulfilled through the following inputs (Table 106) as shown in Figure 94 [12] and mass balance above:

\footnotetext{
46 Import of hydrogen is not accounted for in this model. It is assumed that all of the hydrogen used is produced within the refinery. Therefore, the energy required by the refinery accounts for this hydrogen production. 
Table 106: Energy Inputs to Petroleum Refineries

\begin{tabular}{lcc}
\hline \multicolumn{1}{c}{ Flow Name } & Units & Value per Year \\
\hline \hline Natural Gas & MJ & $7.66 \times 10^{11}$ \\
Coal & MJ & $3.27 \times 10^{9}$ \\
Steam & MJ & $3.8 \times 10^{10}$ \\
Electricity & MJ elec. & $1.43 \times 10^{11}$ \\
Propane (C3H8, kg) & MJ & $6.21 \times 10^{10}$ \\
Diesel Oil (kg) & MJ & $3.16 \times 10^{9}$ \\
Heavy Fuel Oil & MJ & $6.13 \times 10^{10}$ \\
Coke & MJ & $1.77 \times 10^{10}$ \\
Other & MJ & $8.8 \times 10^{9}$ \\
\hline
\end{tabular}

These numbers are based on the total U.S. consumption of fuels at all refineries. The production of propane, diesel oil, heavy fuel oil, and coke could actually happen inside the refinery from the crude oil stream. However, EIA reports them as if they are imported. This approach accounts for the energy and emissions needed to produce the fuels. In addition to the fuels listed in the table above, the refinery also draws energy directly from the crude oil stream as shown in Table 107.

Table 107: Refinery Energy Sources from the Crude Oil Stream

\begin{tabular}{lcc}
\hline \multicolumn{1}{c}{ Flow Name } & Units & Value per Year \\
\hline \hline Still Gas & MJ & $1.52 \times 10^{12}$ \\
Catalyst Coke & MJ & $5.14 \times 10^{11}$ \\
\hline
\end{tabular}

The production of these fuels are assumed to be accounted for in the emissions and energy requirements of the refinery modeled here.

\section{Process Emissions}

Emissions from crude oil refining include air emissions, water effluents, and solid waste. The following sections describe how each of these is modeled from crude oil refining.

\section{Air Emissions}

Air emissions from crude oil refining are assumed to come from three sources:

1) Fuel Combustion

2) Process Emissions

3) Fugitive Emissions

Fuel combustion emissions are based on the amount and types of fuels consumed and emission factors for specific combustion devices. All the fuels used in the refinery are assumed to be combusted in industrial boilers. ${ }^{47}$

The emissions for electricity production are based on Ecobalance's database DEAM ${ }^{\mathrm{TM}}$ for the standard U.S. electricity grid. Emissions for purchased steam production are based on Ecobalance's database DEAM ${ }^{\mathrm{TM}}$ for the production of steam from natural gas.

47 Some of the natural gas imported to the refinery is used to produce hydrogen. Therefore, assuming the emissions from combustion of all the natural gas in an industrial boiler may overestimate the emissions of the refinery somewhat. This will only affect the combustion-related emissions of $\mathrm{NO}_{\mathrm{x}}, \mathrm{CO}, \mathrm{PM}$, and hydrocarbons, as hydrogen production still produces carbon dioxide. 
Process emissions for a petroleum refinery are based on emission factors published in EPA AP-42. The emission factors for petroleum refining processes are shown in Table 108:

Table 108: Petroleum Refining Process Emissions

\begin{tabular}{|c|c|c|c|c|c|c|}
\hline \multirow[b]{2}{*}{ Process } & \multicolumn{6}{|c|}{ Emission Factors } \\
\hline & Particulate & $\mathrm{SO}_{2}$ & $\mathrm{CO}$ & $\begin{array}{l}\text { Non-Methane } \\
\text { Hydrocarbons }\end{array}$ & $\mathrm{NO}_{2}$ & $\mathrm{CO}_{2}$ \\
\hline $\begin{array}{l}\text { Catalytic cracking } \\
\text { (g/L crackers feed) }\end{array}$ & 0.052 & 0.79 & -- & -- & 0.11 & 40.7 \\
\hline $\begin{array}{l}\text { Fluid coking } \\
\text { (g/L cokers feed) }\end{array}$ & 1.5 & -- & -- & -- & -- & -- \\
\hline $\begin{array}{l}\text { Vapor recovery/flare } \\
(\mathrm{g} / \mathrm{L} \text { refinery feed) }\end{array}$ & -- & 0.077 & 0.012 & 0.002 & 0.054 & -- \\
\hline $\begin{array}{l}\text { Sulfur recovery } \\
\text { (g/kg sulfur produced) }\end{array}$ & -- & 29 & -- & -- & -- & -- \\
\hline
\end{tabular}

Some assumptions have been made to arrive at the numbers shown in the previous table. They are:

- Catalytic cracking input is assumed to be a 80/20 split between Fluid Catalytic Cracking (FCC) and moving bed catalytic cracking units. All catalytic cracking units are assumed to have a $\mathrm{CO}$ boiler and electrostatic precipitator installed. Carbon monoxide and hydrocarbons burned in $\mathrm{CO}$ boiler are assumed to be converted to $\mathrm{CO}_{2}$.

- A vapor recovery and flaring system is assumed to be installed to control the emissions from the blowdown system. Blowdown hydrocarbon emissions are assumed to be converted to $\mathrm{CO}_{2}$. The amount of hydrocarbons produced is based on the emissions from one refinery in Yorktown, Virginia [13]. Based on the Yorktown study, $1.86 \mathrm{~g}$ of hydrocarbon emissions are produced per $\mathrm{kg}$ of crude oil into the refinery. If a $75 \%$ carbon content is assumed for the hydrocarbon emissions, then $5.11 \mathrm{~g}$ of $\mathrm{CO}_{2}$ is produced per $\mathrm{kg}$ of crude oil into the refinery.

- Emissions from the vacuum distillation column are assumed to be negligible.

- Claus recovery plant is assumed to recover $98.6 \%$ of sulfur in tail gas and have controlled emissions. This is the highest rate listed by U.S. EPA AP-42 for sulfur recovery. This corresponds to an emission factor of $29 \mathrm{~g}$ of $\mathrm{SO}_{\mathrm{x}}$ per $\mathrm{kg}$ of sulfur produced.

Flows associated with the different petroleum refinery processes are taken from EIA, Petroleum Supply Annual (1994) and are shown in Table 109:

Table 109: Refinery Process Flows

\begin{tabular}{lc}
\hline \multicolumn{1}{c}{ Process } & Associated flow \\
\hline \hline Catalytic cracking & $2.8 \times 10^{11}(\mathrm{~L}$ feed $/ \mathrm{yr})$ \\
Fluid coking & $8.9 \times 10^{10}(\mathrm{~L}$ feed $/ \mathrm{yr})$ \\
Vapor recovery/flare & $8.4 \times 10^{11}(\mathrm{~L}$ refinery feed $/ \mathrm{yr})$ \\
Sulfur recovery & $8.2 \times 10^{9}(\mathrm{~kg}$ sulfur produced $/ \mathrm{yr})$ \\
\hline
\end{tabular}

Fugitive emissions for a petroleum refinery are based on the emissions from one refinery in Yorktown, Virginia [13]. Based on the Yorktown study, $0.97 \mathrm{~g}$ of hydrocarbon emissions are produced per $\mathrm{kg}$ of crude oil into the refinery. 


\section{Water Effluents}

Water effluents from the refinery are based on the total amount of wastewater produced and the composition of the wastewater. Wastewater volume produced by the refinery is calculated using Table 110 [14]:

Table 110: Wastewater Production in Crude Oil Refineries

\begin{tabular}{lcccc}
\hline \multicolumn{1}{c}{ Wastewater Source } & $\begin{array}{c}\text { Emission } \\
\text { Factor } \\
(\mathrm{gal} / \mathrm{bbl})\end{array}$ & $\begin{array}{c}\text { Crude oil } \\
(\mathrm{bbl} / \mathrm{yr})\end{array}$ & $\begin{array}{c}\text { Crude oil } \\
(\mathrm{gal} / \mathrm{yr})\end{array}$ & $\begin{array}{c}\text { Crude oil } \\
(\mathrm{liter} / \mathrm{yr})\end{array}$ \\
\hline \hline $\begin{array}{l}\text { Crude Oil Storage, Desalting \& } \\
\text { Atmospheric Distillation }\end{array}$ & & & & \\
Gases Water Wash & 4.4 & $5.06 \times 10^{9}$ & $2.23 \times 10^{10}$ & $8.43 \times 10^{10}$ \\
Vacuum Distillation & 3.3 & $5.06 \times 10^{9}$ & $1.67 \times 10^{10}$ & $6.32 \times 10^{10}$ \\
Light Hydrocarbon & 7.3 & $2.53 \times 10^{9}$ & $1.85 \times 10^{10}$ & $6.99 \times 10^{10}$ \\
Hydrodesulfurization & & & & \\
Middle Distillates Hydrotreating & 1.9 & $9.49 \times 10^{8}$ & $1.80 \times 10^{9}$ & $6.82 \times 10^{9}$ \\
Catalytic Cracking & 5.2 & $3.58 \times 10^{9}$ & $1.86 \times 10^{10}$ & $7.04 \times 10^{10}$ \\
Hydrocracking & 9.5 & $1.77 \times 10^{9}$ & $1.68 \times 10^{10}$ & $6.37 \times 10^{10}$ \\
Coking & 4.5 & $3.67 \times 10^{8}$ & $1.65 \times 10^{9}$ & $6.25 \times 10^{9}$ \\
\hline
\end{tabular}

Wastewater composition in milligram per liter (mg/liter) is given in Table 111 [15]:

Table 111: Crude Oil Refinery Wastewater Composition

\begin{tabular}{|c|c|}
\hline Pollutant & Concentration (mg/liter) \\
\hline BOD & 1,300 \\
\hline COD & 11,000 \\
\hline TOC & 9,200 \\
\hline TSS & 5,900 \\
\hline Ammonia Nitrogen & 190 \\
\hline Phenols & 25 \\
\hline Sulfides & -- \\
\hline Oil and Grease & 500 \\
\hline Total Chromium & 16 \\
\hline
\end{tabular}

Solid Waste

Solid waste is computed from factors given in a recent study of refinery generation of solid waste [16]. The study gave totals for hazardous and nonhazardous wastes as shown in Table 112.

Table 112: Solid Waste Produced from Crude Oil Refining

\begin{tabular}{lc}
\hline \multicolumn{1}{c}{ Type of Waste } & Amount of Waste $(\mathrm{kg} / \mathrm{yr})$ \\
\hline \hline Hazardous & $1.6 \times 10^{9}$ \\
Nonhazardous & $2.6 \times 10^{9}$ \\
\hline
\end{tabular}




\section{Petroleum-Based Products Production}

Petroleum refineries produce a number of different products from the amount of crude oil that they receive. However, typically a study is only concerned with one specific product, (e.g., gasoline). Therefore, there needs to be a method of allocating total refinery energy use and total refinery emissions to only the production of one product. Additional complexity is introduced by the fact that the refinery product mix is variable, both among refineries and even with time for a given integrated refinery.

The simplest allocation procedure would be to allocate total refinery releases (and consumption) among the products on a mass output basis. The following table (Table 113) outlines how this would be done, based on the output of a generic U.S. refinery:

Table 113: Production of an Average U.S. Refinery

\begin{tabular}{lcc}
\hline \multicolumn{1}{c}{ Refinery Flow } & Mass $(\mathrm{kg} / \mathrm{yr})$ & Mass (\%) \\
\hline \hline Diesel Oil (<0.05\% Sulfur, kg): & $9.30 \times 10^{10}$ & $12.8 \%$ \\
Diesel Oil (>0.05\% Sulfur, kg): & $6.76 \times 10^{10}$ & $9.33 \%$ \\
Gasoline: & $3.08 \times 10^{11}$ & $42.5 \%$ \\
Heavy Fuel Oil: & $4.52 \times 10^{10}$ & $6.24 \%$ \\
Jet Fuel (kg): & $6.53 \times 10^{10}$ & $9.01 \%$ \\
Kerosene (kg): & $2.74 \times 10^{9}$ & $0.38 \%$ \\
Misc. Refinery Products (U.S., kg): & $2.19 \times 10^{9}$ & $0.30 \%$ \\
Petroleum Coke (kg): & $4.12 \times 10^{10}$ & $5.69 \%$ \\
LP Gas: & $1.92 \times 10^{10}$ & $2.66 \%$ \\
Asphalt (kg): & $2.72 \times 10^{10}$ & $3.75 \%$ \\
Lubricants (kg): & $8.87 \times 10^{9}$ & $1.22 \%$ \\
Petrochemical Feedstocks (kg): & $4.04 \times 10^{10}$ & $5.57 \%$ \\
Petroleum Waxes (kg): & $9.71 \times 10^{8}$ & $0.13 \%$ \\
Naphthas (kg): & $2.35 \times 10^{9}$ & $0.33 \%$ \\
Total: & $7.24 \times 10^{11}$ \\
\hline
\end{tabular}

However, this would result in the same LCI profile for every kg or refinery product regardless of its characteristics (e.g., one $\mathrm{kg}$ of diesel fuel would have the same profile as one $\mathrm{kg}$ of gasoline).

An objection to the mass allocation approach, which is based on output share, is that a $\mathrm{kg}$ of different refinery products requires different amounts of processing, thus requiring different amounts of energy input and leading to different amounts of releases.

An alternate allocation method would be one based on the share of the total process energy required to produce the refinery product.

This method of allocating refinery flows based on process energy requirements is outlined in the following steps:

- Calculate the percentage of total refinery energy used by each different process within the refinery.

- Calculate a specific refinery product's share of each process' energy consumption.

- Multiply the two results in order to get the percentage of total refinery energy allocated to a single refinery product production for each process. Adding the results of each process gives the percentage of total refinery energy allocated to a total single refinery product.

- Allocate emissions and energy use based on the percentage of total refinery energy allocated to a total single refinery product. (from step 3 above) 
Many different studies have been done in the past in order to estimate total refinery energy allocation to the different processes within a refinery [1]. These studies, however, were predominantly done in the late 1970s and early 1980s and their relevance to today's refinery processes is not fully known. This is complicated by the fact that refinery energy requirements are considered proprietary information so it is difficult to confirm the past studies findings.

For this project, an additional study done by White et al. [17] ${ }^{48}$ will be used with two studies listed by Delucchi [2] to help estimate refinery process energy allocation. This study may not be completely applicable, for the reasons outlined above, but it was found to be the most comprehensive and descriptive of what had been done.

The three refinery models list energy consumption for different refinery processes. This information is used to calculate the percentage of total refinery energy used by each different process within the refinery. ${ }^{49}$ The following table (Table 114) lists the results:

Table 114: Fraction of Total Refinery Energy Used by Each Process

\begin{tabular}{lcccc}
\hline & \multicolumn{4}{c}{ Fraction of Total Refinery Energy } \\
\hline \multicolumn{1}{c}{ Refinery Process } & Lawerence & Haynes & White et al. & Average \\
\hline \hline Crude distillation & 0.276 & 0.364 & 0.266 & 0.302 \\
Catalytic cracking & 0.314 & 0.065 & 0.124 & 0.168 \\
Thermal cracking & 0 & 0.033 & 0 & 0.011 \\
Hydrocracking & 0 & 0.044 & 0 & 0.015 \\
Desulfurization & 0.02 & 0 & 0.046 & 0.022 \\
Hydrotreating & 0 & 0.085 & 0.068 & 0.051 \\
Alkylation & 0.065 & 0.069 & 0.040 & 0.058 \\
Reforming & 0.191 & 0.225 & 0.140 & 0.185 \\
Coking & 0.038 & 0.032 & 0.077 & 0.049 \\
Visbreaking & 0 & 0.007 & 0 & 0.002 \\
Propylene concentration & 0.05 & 0 & 0 & 0.017 \\
Isomerization & 0.042 & 0.002 & 0 & 0.015 \\
Hydrogen & 0 & 0.025 & 0.070 & 0.032 \\
Depentanizer & 0 & 0 & 0.0167 & 0.006 \\
Naphtha Pretreater & 0 & 0 & 0.054 & 0.018 \\
Saturated gas plant & 0 & 0 & 0.035 & 0.012 \\
Unsaturated gas plant & 0 & 0 & 0.064 & 0.021 \\
Finishing and other & 0.003 & 0.055 & 0 & 0.019 \\
& 0.999 & 1.006 & 1.000 & 1.002 \\
\hline
\end{tabular}

For this study the average values for fraction of total refinery energy used by each process will be used. Averaging the values from the three studies is thought to help compensate for the differences in refinery configurations and size.

\footnotetext{
48 The authors were, at the time of the study, all members of Mobil Research and Development Corp., Princeton and Paulsboro, NJ.

49 Note: The White et al. refinery does not take into account increased energy requirements for producing low-sulfur diesel fuel. Therefore, energy values from White et al. for hydrogen manufacture and hydrodesulfurizer have been increased to account for removal of more sulfur. The increase is based on assuming that the energy consumption given in White et al. represented removal of $1.25 \%$ of the sulfur in the incoming crude (Crude oil $=1.5 \%$ sulfur, Diesel fuel $=0.25 \%$ sulfur). Then assume a liner increase in energy consumption based on removing $1.45 \%$ of the sulfur (low sulfur diesel fuel $=0.05 \%$ sulfur).
} 
An individual refinery product's share of each process' energy consumption can be calculated from information provided in a recent DOE study [1] and information on refinery production [12].

Table 115: Fraction of Refinery Process Energy Used by Types of Refinery Products

\begin{tabular}{lcccc}
\hline & \multicolumn{5}{c}{ Fraction of Process Energy } \\
\hline \multicolumn{1}{c}{ Refinery Process } & Gasoline & Distillate & Residual & Other \\
\hline \hline Crude distillation & 0.454 & 0.302 & 0.07 & 0.174 \\
Catalytic cracking & 0.55 & 0.365 & 0.085 & \\
Thermal cracking & 0.454 & 0.302 & 0.07 & 0.174 \\
Hydrocracking & 0.541 & 0.359 & & 0.1 \\
Desulfurization & 0.454 & 0.302 & 0.07 & 0.174 \\
Hydrotreating & 0.541 & 0.359 & & 0.1 \\
Alkylation & 1 & & & \\
Reforming & 1 & & & 0.1 \\
Coking & 0.541 & 0.359 & & 1 \\
Visbreaking & & 1 & \\
Propylene concentration & 1 & & & 0.1 \\
Isomerization & 1 & & & \\
Hydrogen & 0.541 & 0.359 & & 0.006 \\
Depentanizer & 0.994 & & & 0.11 \\
Naphtha Pretreater & 0.89 & & & 0.11 \\
Saturated gas plant & 0.89 & & & 0.07 \\
Unsaturated gas plant & 0.454 & 0.302 & \\
Finishing and other & & &
\end{tabular}

The DOE study allocates energy use in different refinery process areas to gasoline, total distillates and residual fuel in proportion to process energy output of the different products. ${ }^{50}$ Table 115 shows the results. The values in this table can be multiplied by the average fraction of total refinery energy used by each process to determine the total process energy required to produce each of the four different types of refinery fuels shown above. The results of this are shown in Table 116.

An example of how this is used to determine the allocation percentage for diesel fuel is shown as follows:

The results of Table 116 state that $22.3 \%$ of the total refinery energy is needed to produce distillate fuels.

However, total distillates, as described in the DOE study, include diesel fuel, jet fuel, kerosene, and residual fuel. The fraction of total distillates taken up by diesel fuel is shown in Table 117.

It is found that diesel fuel makes up 59\% of total distillate production on a mass basis.

This result can be combined with the energy fraction needed to produce total distillates to give diesel fuel's share of refinery energy consumption as follows:

$$
22.3 \% \times 59 \%=13.2 \%
$$

The same method is used to calculate the allocation percentage for the other refinery products used in this study. For gasoline an allocation of $64.3 \%$ is used directly from Table 32.

\footnotetext{
50 Allocation is based on the energy output of the three different products from each of the different refinery processes. For example alkylation, reforming, and isomerization produce only high-octane gasoline components. Therefore, the process energy associated with alkylation, reforming, and isomerization is allocated entirely to gasoline production.
} 
Table 116: Fraction of Total Refinery Energy Used by Category of Refined Product

\begin{tabular}{lcccc}
\hline \multicolumn{1}{c}{ Refinery Process } & \multicolumn{4}{c}{ Fraction of Total Refinery Energy } \\
\hline \hline Crude distillation & Gasoline & Distillate & Residual & Other \\
Catalytic cracking & 0.14 & 0.091 & 0.021 & 0.053 \\
Thermal cracking & 0.09 & 0.061 & 0.014 & 0 \\
Hydrocracking & 0.0050 & 0.0033 & 0.0008 & 0.0019 \\
Desulfurization & 0.008 & 0.0053 & 0 & 0.0015 \\
Hydrotreating & 0.0100 & 0.0066 & 0.00154 & 0.0038 \\
Alkylation & 0.028 & 0.018 & 0 & 0.0051 \\
Reforming & 0.058 & 0 & 0 & 0 \\
Coking & 0.19 & 0 & 0 & 0 \\
Visbreaking & 0.026 & 0.018 & 0 & 0.0049 \\
Propylene concentration & 0 & 0.0023 & 0 & 0 \\
Isomerization & 0 & 0 & 0 & 0.0167 \\
Hydrogen & 0.0147 & 0 & 0 & 0 \\
Depentanizer & 0.0171 & 0.0113 & 0 & 0.0032 \\
Naphtha Pretreater & 0.0056 & 0.0000 & 0 & 0.0000 \\
Saturated gas plant & 0.0178 & 0.0000 & 0 & 0.0001 \\
Unsaturated gas plant & 0.0105 & 0.0000 & 0 & 0.0013 \\
Finishing and other & 0.0189 & 0.0000 & 0 & 0.0023 \\
& 0.009 & 0.0058 & 0.0014 & 0.0034 \\
\cline { 2 - 5 } & 0.6429 & 0.2230 & 0.0390 & 0.0967 \\
\hline
\end{tabular}

Table 117: Diesel Fuel's Share of Total Distillates

\begin{tabular}{lcc}
\hline \multicolumn{1}{c}{ Distillates } & Mass $(\mathrm{kg} / \mathrm{yr})$ & Mass (\%) \\
\hline \hline Diesel Fuel: & $1.61 \times 10^{11}$ & $59 \%$ \\
Heavy Fuel Oil: & $4.52 \times 10^{10}$ & $17 \%$ \\
Jet Fuel (kg): & $6.53 \times 10^{10}$ & $24 \%$ \\
Kerosene (kg): & $2.74 \times 10^{9}$ & $1 \%$ \\
& Total: & $2.74 \times 10^{11}$ \\
\hline
\end{tabular}

\section{PETROLEUM PRODUCTS TRANSPORT}

The transport modeling of petroleum products from the refinery to a distribution center is shown in Figure 15.

It is assumed that a fraction of refinery products is shipped to local distributors an average distance of 100 miles. The remaining fraction is shipped via pipeline to a tank farm where it is in turn shipped by truck 100 miles to a distributor.

The fraction of refinery product shipped via pipeline is based on Association of Oil Pipelines, using data from Annual Report (Form 6) of oil pipeline companies to the Federal Energy Regulatory Commission. The report lists the percentage of total finished petroleum products that is shipped by pipelines, water carriers, motor carriers, and railroads. The report states that $59 \%$ of the finished petroleum products are shipped via pipeline. The remaining $41 \%$ is assumed to be transported by truck. 
The Association of Oil Pipelines report also lists total ton-miles of finished petroleum products carried in domestic pipelines. The total amount of petroleum products produced in the United States is also known. It is assumed that $59 \%$ of these petroleum products are shipped via pipeline. Average pipeline transportation miles are calculated by dividing total ton-miles of petroleum products, carried in domestic pipelines, by tons of petroleum products shipped via pipeline. The result is 595 miles of pipeline transport.

The transportation models from $\mathrm{DEAM}^{\mathrm{TM}}$ are used to model energy requirements and emissions from the two types of transportation.

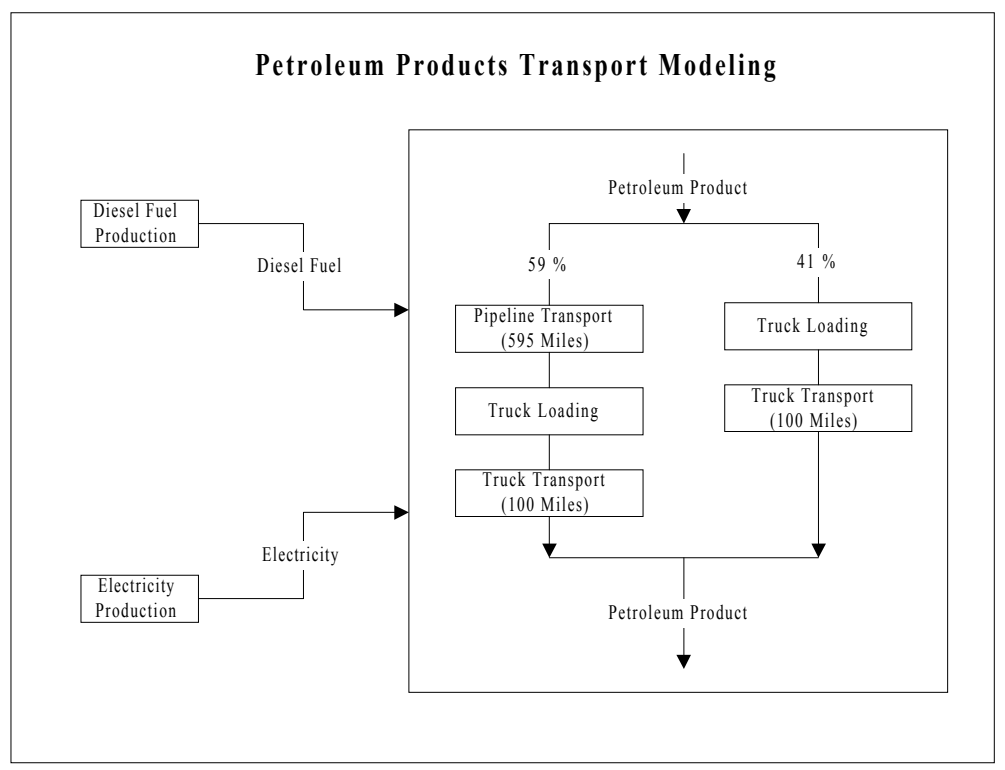

Figure 95: Petroleum Products Transportation Modeling 


\section{APPENDiX E: OXYGENATE OVERVIEW}

\section{OXYGENATES/GASOLINE OCTANE ENHANCERS}

In November 1990, the U.S. Government passed the Clean Air Act Amendments (CAAA). One of the new requirements was for gasolines sold in ambient-air-quality nonattainment areas to contain a minimum amount of oxygen. The U.S. consumption of various oxygenates/gasoline octane enhancers-before and after CAAA passage - is shown in Table 118 [1]. As can be seen, MTBE and ethanol/ETBE are the most widely used oxygenates.

Table 118: U.S. Consumption of Oxygenates/Gasoline Octane Enhancers

\begin{tabular}{|c|c|c|c|c|c|}
\hline Year & MTBE & Ethanol & $T A M E / E T B E^{51}$ & Methanol & Lead Alkyls \\
\hline & $\begin{array}{c}\text { (thousand barrels } \\
\text { per day) }\end{array}$ & $\begin{array}{c}\text { (thousand barre } \\
\text { per day) }\end{array}$ & $\begin{array}{c}\text { (thousand barrels } \\
\text { per day) }\end{array}$ & $\begin{array}{c}\text { (thousand barrels } \\
\text { per day) }\end{array}$ & $\begin{array}{c}\text { (millions of } \\
\text { pound per year) }\end{array}$ \\
\hline 1985 & 32.4 & 40 & 0 & 6.9 & 85 \\
\hline 1988 & 74.3 & 55 & 0 & 0 & 6 \\
\hline 1992 & 113.2 & 73 & 3 & 0 & negligible \\
\hline 1995 & 221 & 84 & 20 & 0 & negligible \\
\hline 1997 & 261 & 83 & 17 & 0 & 0 \\
\hline 2002 (estimate) & $265-285$ & $95-100$ & $21-24$ & 0 & 0 \\
\hline \multicolumn{6}{|c|}{ (thousands of metric tons per year) } \\
\hline 1985 & 1,395 & 1,847 & 0 & 317 & 39 \\
\hline 1988 & 3,192 & 2,540 & 0 & 0 & 3 \\
\hline 1992 & 4,866 & 3,324 & 134 & 0 & negligible \\
\hline 1995 & 9,504 & 3,878 & 890 & 0 & negligible \\
\hline 1997 & 11,245 & 3,832 & 756 & 0 & 0 \\
\hline 2002 (estimate) & $11,395-12,255$ & $4,384-4,615$ & $935-1,070$ & 0 & 0 \\
\hline
\end{tabular}

\section{MTBE}

MTBE is easily made by the selective reaction of isobutylene and methanol over an acidic ion-exchange resin catalyst, in the liquid phase. The resin typically consists of sulfonated styrene cross-linked with divinylbenzene. Reaction conditions are usually mild, with temperatures ranging from $30^{\circ} \mathrm{C}$ to $100^{\circ} \mathrm{C}$ and pressures between 7 and 14 atmospheres (100-200 psig). For MTBE to be economically competitive as an octane enhancer in gasoline, a low-cost isobutylene source is necessary.

Prior to the 1990 revision of the Clean Air Act, MTBE sold as an octane enhancer for gasoline. Its market value has, therefore, been closely tied to the industry's cost of gasoline and octane. To reflect its higher-than-gasoline octane, it is sold at a price higher than gasoline, usually in the range of $120 \%$ to $160 \%$ of gasoline. For 1997 , the MTBE demand for the United States was about 11 million metric tons per year (Table 118). Table 118 does not report the demand for 1996. Using amother source, the 1996 MTBE demand for the United States was estimated at 7.8 million metric tons per year (180,000 barrels per day), whereas the total estimated oxygenate demand for the United States was 16 million metric tons per year (373,000 barrels per day) of MTBE equivalents [2]. This MTBE estimate is lower than that can be intrapolated for 1996 from Table 118. Nonetheless, MTBE outstrips the other oxygenates/octane enhancers in consumption.

51 TAME: tertiary-amyl methyl ether 


\section{ETHANOL}

Ethanol is commonly used as an oxygenate in several nonattainment areas. Most of the ethanol is produced via fermentation using corn as a preferred raw material. The current production of corn-derived ethanol is in the range of 1.4-1.5 billion gallons ( $\sim 5.5$ billion liters) per year, most of which is used to formulate a $10 \%$ blend with gasoline.

\section{ETBE}

Ethanol, like methanol, reacts with dialkylated olefins such as isobutylene and isoamylene to produce ethers that can be used as octane enhancers in gasoline. ETBE is produced by the reaction of ethanol with isobutylene in the presence of an acidic ion-exchange resin catalyst. The process is similar to that used for the production of MTBE, however, the process conditions and the catalysts are selected to optimize the conversion of the reactive olefins with ethyl alcohol. The current production of ETBE in the United States is fairly modest. 


\section{APPENDIX F: Project MANAGEMENT AND REVIEW}

\section{Project Management}

The study partners established a steering committee, made up of representatives from state agencies, NREL, and project consultants to direct the LCA. NREL (Kiran Kadam) was responsible for the overall project management and execution.

\section{Steering Committee}

The steering committee membership is shown below.

Kiran Kadam (kiran kadam@,nrel.gov)

National Renewable Energy Laboratory (NREL), Golden, CO

Dean Simeroth (dsimerot@cleanair.arb.ca.gov)

Nelson Chan (nchan@cleanair.arb.ca.gov)

Richard Vincent (rvincent@cleanair.arb.ca.gov)

California Air Resources Board (CARB), Sacramento, CA

Bill Blackburn (bblackbu@energy.state.ca.us)

California Energy Commission (CEC), Sacramento, CA

Ken Nehoda (Ken_Nehoda@fire.Ca.Gov)

California Department of Forestry and Fire Protection (CDF), Sacramento, CA

Steve Schaffer (shaffer@cdfa.ca.gov)

Vashek Cervinka (cervinka@dcn.davis.ca.us)

California Food and Agriculture Agency (CFAA), Sacramento, CA

Vince Camobreco (Vincent_Camobreco@ecobalance.dames.com)

Brian Glazebrook (Brian_Glazebrook@ecobalance.dames.com)

Ecobalance, Inc., Bethesda, MD

Lloyd Forrest (loyd1640@aol.com)

Alan Jacobson(AlanJ123@aol.com)

TSS Consultants, Rancho Cordova, CA

\section{Project REVIEW}

The project was conducted in such a manner as to allow feedback from the stakeholders at various stages of the analysis (see Appendix G for the stakeholder list). The Scoping Document was sent to the stakeholders, and an open meeting was conducted in Sacramento (October 1997) to discuss scoping options and decisions. The Data Summary Document (containing data to be used in the analysis) was sent to the stakeholders for comment in April 1998. Stakeholder comments were incoporated into the final Scoping and Data Summary documents. The Final Report (which contains the LCA results, as well as the scoping decisions and data summary) was reviewed by a panel of experts in various fields before publication. 


\section{Review Committee}

The steering committee assembled an expert Review Committee to review the Final Report; the Committee membership is shown below.

Irshad Ahmed

Pure Energy Corporation

One World Trade Center - \#4573

New York, NY 10048

Telephone: (212) 938-6923, Fax: 839-0383

e-mail: ahmed@pure-energy.com

Mark Delucchi

University of California

Davis, CA 95616-8598

e-mail: madelucchi@ucdavis.edu

\section{Shari Friedman}

U.S. Environmental Protection Agency

401 M St. SW (2175)

Washington, DC 20460

Telephone: (202) 276-9718

e-mail: Friedman.Shari@epamail.epa.gov

Robert C. Grant

Research Division

California Air Resources Board

2020 L Street, PO Box 2815

Sacramento, CA 95812.

Telephone: (916) 3235774

e-mail: rgrant@arb.ca.gov

Bryan Jenkins

Biological \& Agriculture Engineering

One Shields Ave.

University of California

Davis, CA 95616-5294

Telephone: (530) 752-1422

e-mail: bmjenkins@ucdavis.edu
Pembina Institute for Appropriate Development

(PIAD)

Box 7558

Drayton Valley, Alberta,

Canada, T7A 1S7

Telephone: (780) 492-7210, Fax: (780) 492-2200

e-mail: raynolds@frodo.mece.ualberta.ca

John Sheehan

National Renewable Energy Laboratory

1617 Cole Blvd.

Golden, CO 80401

Telephone: (303) 384-6136, Fax: (303) 384-6877

e-mail: John_Sheehan@nrel.gov

Michael Wang

Center for Transportation Research

Energy Systems Division

Argonne National Laboratory

9700 South Cass Ave.

Argonne, IL 60439

e-mail: michael_wang@qmgate.anl.gov

Robert Wooley

National Renewable Energy Laboratory

1617 Cole Blvd.

Golden, CO 80401

Telephone: (303) 384-6825, Fax: (303) 384-6877

e-mail: Robert_Wooley@nrel.gov

Mark Yancey

National Renewable Energy Laboratory

1617 Cole Blvd.

Golden, CO 80401

Telephone: (303) 384-6858, Fax: (303) 384-6877

e-mail: Mark_Yancey@nrel.gov

Al Jessel ${ }^{52}$

Chevron Research

575 Market St., Rm. 2370

San Francisco, CA 94105

Telephone: (415) 894-3288

e-mail: AJJE@chevron.com

Marlo Raynolds

52 Partial Review Only 
APPENDIX G: STAKEHOLDER LIST

\begin{tabular}{|c|c|c|}
\hline Yuba-Sutter County Farm & Rick Best & Ken Corbin, APCO \\
\hline Bureau & Californians Against Waste & Feather River AQMD \\
\hline 475 Palora Ave. & 926 J St. - \#606 & 938 14th St. \\
\hline Yuba City, CA 95991 & Sacramento, CA 95814 & Marysville, CA 95901 \\
\hline Deborah Adler & Dave Bishell & Jim Duffield \\
\hline EPA National Vehicle Test Lab & California Forestry Association & Office of Energy \& New Uses \\
\hline 2565 Plymouth Rd. & 300 Capitol Mall - \#350 & Economic Research Serv./ U.S. \\
\hline Ann Arbor, MI 48105 & Sacramento, CA 95814 & Dept. of Ag. \\
\hline Telephone: (313) 668-4223, & Mark Black, APCO & 1301 New York Ave. NW \\
\hline \multirow[t]{2}{*}{ Fax: $741-7869$} & Tehama County APCD & Washington, DC 20005-4788 \\
\hline & P.O. Box 38 & (202) 501-6255 - FAX 501-6338 \\
\hline Warren Alford & 1750 Walnut St. & \\
\hline The Sierra Club & Red Bluff, CA 96080-0038 & Douglas Durante \\
\hline 1414 K St. - \#300 & & Clean Fuels Development \\
\hline \multirow[t]{2}{*}{ Sacramento, CA 95814} & Frank Carl & Coalition \\
\hline & Sacramento County Ag. & 1925 North Lynn St., Suite 725 \\
\hline Melvin Androus & Commissioner & Arlington, VA 22209 \\
\hline California Rice Research & 4137 Branch Center Road & \\
\hline Advisory Board & Sacramento, CA 95827 & Susan Engstrom \\
\hline P.O. Box 507 & & SMAQMD \\
\hline \multirow[t]{2}{*}{ Yuba City, CA 95992} & Joe Carrancho & 8411 Jackson Road \\
\hline & Rice Producers of California & Sacramento, CA 95826 \\
\hline Aeron Arlin & P.O. Box 726 & \\
\hline Western States Petroleum Assoc. & Maxwell, CA 95955 & Steven Epperson \\
\hline 1115 11th St. - \#150 & & Ultramar Inc. \\
\hline Sacramento, CA 95815 & Sandy Carey & 2402 E. Anaheim St. \\
\hline \multirow[t]{2}{*}{ (916) 444-9981 - FAX 444-8997 } & Greattan, Gersik & Wilmington, CA 90744 \\
\hline & 980 9th St. - 16th flr & \\
\hline John Ashounis & Sacramento, CA 95814-2736 & Merlin Fagan, Jr. \\
\hline Tosco Refining Company & & California Farm Bureau \\
\hline 2300 Clayton Road - \#1100 & Jeff Citron & Federation \\
\hline \multirow[t]{2}{*}{ Concord, CA 94520-2100 } & Sutter County Ag. Department & 1127 11th St. - \#626 \\
\hline & 142 Garden Highway & Sacramento, CA 95814 \\
\hline Derek Augood & Yuba City, CA 95991 & \\
\hline Battelle Memorial Res. Inst. & & Mark Fong \\
\hline 151 Camino Amigo Ct. & Sheri Clarke & CIWMB Waste Management \\
\hline Danville, CA 94526 & Publications Coordinator & Engineer \\
\hline \multirow[t]{2}{*}{ (510) 838-0470 } & Clean Cities Hotline & 8800 Cal Center Dr. \\
\hline & 9300 Lee Highway & Sacramento, CA 95826 \\
\hline Patrick Barnhart & Fairfax, VA 22031-1207 & (916) 255-2495 \\
\hline Colusa County Planning \& & 703/934-3012 - FAX & mfong@ciwmb.ca.gov \\
\hline Building & $703 / 934-3183$ & \\
\hline 220 12th St. & sclarke@icfkaiser.com & John Geohghan \\
\hline \multirow{2}{*}{ Colusa, CA 95932} & & Forest Resource Council \\
\hline & Susan Cohen & 1115 11th St. - \#100 \\
\hline Philip Bayles & Solano County Ag. & Sacramento, CA 95814 \\
\hline USDA Forest Service/Pacific & Commissioner & (916) $448-2162$ \\
\hline
\end{tabular}

Southwest 2000 West Texas Street

630 Sansome St.

San Francisco, CA 94111

(916) 573-2649 - FAX 573-2693
Rick Best

926 J St. - \#606

Dave Bishell

California Forestry Association

Mark Black, APCO

Tehama County APCD

1750 Walnut St

Red Bluff, CA 96080-0038

Frank Carl

Sacramento, CA 95827

Joe Carrancho

P.O. Box 726

Sandy Carey

Greattan, Gersik

980 9th St. - 16th flr

Jeff Citron

Sutter County Ag. Department

142 Garden Highway

Fairfield, CA 94533-4497
Ken Corbin, APCO

Feather River AQMD

14th St.

Jim Duffield

Office of Energy \& New Uses

Dept. of Ag.

Washington, DC 20005-4788

Douglas Durante

Clean Fuels Development

lition

Susan Engstrom

SMAQMD

8411 Jackson Road

Steven Epperson

Ultramar Inc.

2402 E. Anaheim St.

Merlin Fagan, Jr.

California Farm Bureau

Federation

1127 11th St. - \#626

Mark Fong

CIWMB Waste Management

Engineer 8800 Cal Center Dr.

Sacramento, CA 95826

(916) 255-2495

John Geohghan

Forest Resource Council

1115 11th St. - \#100

(916) 448-2162 
Greg Gilbert

Sacramento Metro. Air Quality

Mgmt. Dist.

8475 Jackson Rd. - \#200

Sacramento, CA 95826

(916) 386-7023

smogbuster@juno.com

Russell Goold

Western States Petroleum Assoc.

1115 11th St. - \#150

Sacramento, CA 95814

Telephone: (916) 498-7756

Fax: 444-8997

Larry Greene, APCO

Yolo-Solano AQMD

1947 Gallileo Court - \#103

David, CA 95616

Cindy Hassenjager

CA Renewable Fuels Council

3304 Yorba Linda Blvd. - \#249

Fullerton, CA 92631

(714) 990-3333

Janet Hathaway

Senior Attorney

Natural Resources Defense

Council

71 Stevenson St.

San Francisco, CA 94105

Heidi Hill

Tehama County Ag.

Commissioner

1750 Walnut St.

Red Bluff, CA 96080

James Hill

Cooperative Extension

U.S. Department of Agriculture

University of California

Oakland, CA 94612-3560

William Huffman

Farmers Rice Cooperative

2525 Natomas Park Dr.

P.O. Box 15223

Sacramento, CA 95851-0223

Kenneth Humphreys

Technology Systems Analysis

Pacific Northwest National

Laboratory

Battelle Blvd., - P.O. Box 999

Richland, WA 99352
Michael Jackson

P.O. Box 207

Quincy, CA 95971

Richard Johnson, APCO

Placer County APCD

11464 B Avenue

Auburn, CA 95603

Neal Johnson

Integrated Waste Mgmt. Board

Waste Prevention \& Market

Dev. Div.

8800 Cal Center Dr.

Sacramento, CA 95826

Richard Johnson, APCO

Placer County APCD

11464 B Ave.

Auburn, CA 95603

Robert Judd, Jr.

Cal-Tech Management

Associates

1330 21st St. - \#201

Sacramento, CA 95814

(916) 444-8333 - FAX 444-3314

Stephen Kaffka

University of California

Extension Agronomist

Room 159, Hunt Hall

Davis, CA 95616-8515

(916) 752-8108 - FAX 752-4361

Arnie Klan

Ark Energy

23046 Avenida De La Carlot -

\#400

Laguna Hills, CA 92653

Paul Knepprath

American Lung Association of

California

Government Relations

921 11th St. - \#700

Sacramento, CA 95814-2821

Tom Koehler

Parallel Products

2225 SE 59th

Portland, OR 97215

Neil Koehler

Parallel Products

12281 Arrow Route

Rancho Cucamonga, CA 91739
Harry Krug, APCO

Colusa County APCO/Ag

Comm

100 Sunrise Blvd. - Suite F

Colusa, CA 95932

James Lawrence

U.S. Forest Service

Pacific Southwest Region

630 Sansome St.

San Francisco, CA 94111

(415) 705-2870

Dennis Machida

California Tahoe Conservancy

2161 Lake Tahoe Blvd. (96150)

P.O. Box 7758

South Lake Tahoe, CA 96158

(916) 542-5584 - FAX 542-5591

Tad Mason

Pacific Wood Fuels Co.

3085 Crossroads Dr.

Redding, CA 96003-7928

(916) 224-3300 - FAX 224-3310

Patrick McLafferty

Pacific Management Dynamics

Corporation

1900 Point West Way - \#122

Sacramento, CA 95815

(916) 924-5200 - FAX 924-5236

Jerry Meral

Planning and Conservation

League Foundation

926 J Street - \#612

Sacramento, CA 95814

Tien Nguyen

U.S. Department of Energy,

EE-31

Washington, DC 20585-0121

Tel \& fax number 202-586-

7387, 202-586-9815

e-mail address:

tien.nguyen@ee.doe.gov.

Dermot O'Rien

Golden Cheese of California

1138 W. Rincon St.

Corona, CA 91720

(909) 737-9260

Lawrence Odle, APCO

Butte County AQMD

2525 Dominic Drive - Suite J

Chico, CA 95928 
Renee Pigeon

Natural Resources Canada

580 Booth St.

Ottawa, Ontario K1A 0E4

CANADA

(613) 943-8840

Larry Potts, Jr.

Collins Pine Company

P.O. Box 796

Chester, CA 96020

(916) 258-2111 - FAX 258-4266

Betty Riley

Sierra Planning Organization

560 Wall St. - Suite K

Auburn, CA 95603

(916) 823-4703 - FAX 823-4142

Robert Roan

USDA Soil Conservation

Service

251 Auburn Ravine - \#201

Auburn, CA 95603

(916) 823-5687

John Roberts/Robert Herkert

California Rice Industry

Association

701 University Ave. - \#205

Sacramento, CA 95825-6708

Ed Romano, APCO

Glenn County APCD

P.O. Box 351

Willows, CA 95988

Thomas Sanford

Harris, Sanford \& Baggett

P.O. Box 908

660 Ohio St.

Gridley, CA 95948

Gordon Schremp

California Energy Commission

$15169^{\text {th }}$ Street

MS23

Sacramento, CA 95814-5512

gschremp@energy.state.ca.us

John Sheehan

Plumas Corporation

P.O. Box 3880

91 Church Street

Quincy, CA 95971
Sharon Shoemaker

CA Institute of Food/Ag

Research

University of California

250 Cruess Hall

Davis, CA 95616-8598

(916) 752-2922

spshoemaker@ucdavis.edu

Lynn Suter

1127 11th St. - \#512

Sacramento, CA 95814

Tim Taylor

Sacramento Metropolitan

AQMD

8411 Jackson Rd.

Sacramento, CA 95826

Michael Theroux

Theroux Environmental

Consulting Services

4229 Northgate Blvd. - \#6B

P.O. Box 340099

Sacramento, CA 95834-0099

(916) 641-9603 - FAX 641-6142

mtheroux@softcom.net

Tim Treichelt

Georgia-Pacific Corporation

1201 K Street - Suite 1180

Sacramento, CA 95814

(916) 558-4994 - FAX 558-4996

tntreichel@gspac.com

Stefan Unnasch

Acurex Environmental

Corporation

P.O. Box 7044

555 Clyde Ave.

Mountain View, CA 94039

(415) 254-2413 - FAX 254-2496

Dan Weldon

California Forestlandowners

980 Ninth St. - \#1600

Sacramento, CA 95814

(916) 972-0273

Anthony Wetzl

Thermo Ecotek Corporation

735 Sunrise Ave. - \#160

Roseville, CA 95661

(916) 773-2940
John White

Sierra Club-Sacramento Valley

Group

P.O. Box 1335

Sacramento, CA 95812-1335

Paul Wueben

South Coast AQMD

21865 E. Copley Dr.

Diamond Bar, CA 91765-4182 
A key component of this project was the involvement of stakeholders and the review committee during project development and execution (Appendices $\mathrm{F}$ and $\mathrm{G}$ list the stakeholder and review committee members, respectively). Feedback was provided by stakeholders and reviewers at three stages of the project: a stakeholder meeting was held after the release of the initial scoping document, stakeholder comments were received on the initial data-summary document, and the review committee provided comments on the draft final report. Comments on the scoping and data-summary documents were incorporated into the final draft. This appendix lists the comments and suggestions of the review committee on the draft final report that were not directly accepted or deemed relevant by the authors and provides replies to the same.

\section{1) What about the issue of groundwater contamination by MTBE?}

The modeling of the fate of MTBE in groundwater can be considered an impact rather than an emission. A number of factors affect the leaching of MTBE into groundwater (e.g., the porosity of the soil, the location of the leak), which this model cannot take into consideration. No information was available on the water emissions of MTBE during the blending, transportation and storage stages, so no net MTBE water emissions were provided.

2) What are the temporal issues related to this study? What about the rice straw burning system or the fact that a tree used to make ethanol may not burn until 50 years from now?

LCA does not take into account the period over which the emissions occur. The use of an early-next-decade scenario was to define the technology that would be available for such a conversion of biomass to ethanol. Even if one scenario has lower overall emissions, these emissions may occur over a very short period or during high ozone concentration days where their impact would be greater.

3) What about other uses for the biomass sources? Soil incorporation for rice straw or making plywood out of the forest residue?

There are a lot of other options for the disposal of biomass other than burning or conversion to ethanol. However, this study only focused on the current situation, which is assumed to be burning, and one scenario in which biomass was converted to ethanol. The models developed and the information collected for this study could, however, be used to compare other options as part of future studies.

4) What about the economic feasibility of some of these choices? For example, is chaparral really a good biomass source?

The study was developed based on the reduction of rice-straw burning in California. Forest residue is also considered to be a large source of combustion emissions. Both of those feedstocks were assumed to be economically viable for production of ethanol, and there is currently some interest in developing commercial ethanol plants in California based on these feedstocks. Chaparral was similar to both of these feedstocks in that burning emissions were a significant concern. Hence, it was included in the study. However, not much work had been done to study chaparral or determine the economics of its use as an ethanol feedstock. Chaparral is decidely a less attractive feedstock for ethanol production than rice straw or forest residue. Nonetheless, the boundary choices were considered to be technically feasible, even if they may not be economically feasible at this point. To reiterate, chaparral's inclusion was motivated mainly by its similarity to rice straw and forest residue in terms of burning related emissions.

\section{5) Why are emissions from gas storage tanks considered negligible?}

The assumption was made that the emissions for blending would be small relative to the net emissions, and also that the two scenarios would have similar emissions thus offsetting each other.

6) Is the modeling of chaparral as "cutting and piling" prior to burning really accurate? Isn't standing fuel used for areas away from dwellings?

Chaparral use was based on material that is close to residential areas. The reason for this was that homeowners or state and local agencies might possibly be interested in removing the brush as a fire prevention tactic. 


\section{7) What about the use of COD and BOD in eutrophication potential?}

COD and BOD are a result of water effluents of organic matter, which are assumed to contribute to the growth of plants and algae, which results in eutrophication. The flows selected for inclusion into a eutrophication impact category were based on work done by the Centre of Environmental Science at Leiden University ("Environmental Life Cycle Assessment of Products - Guide and Backgrounds," October 1992, Leiden University, The Netherlands).

\section{8) Why isn't the allocation of co-products done by economic value rather than by mass?}

The use of economic value is a possible way of allocating emissions and energy use of a process over multiple products. In this way the use of economic value to allocate between corn steeped liqueur (CSL) and other corn products could result in lower burdens for the CSL than the use of mass allocation. This is due to the low economic value of the CSL compared to the other products. Different allocation approaches for CSL could affect the overall results because the upstream water effluents of CSL production are significant in the life cycle. However, the economic value of products is dependent on price, which is variable depending on the time and location resulting in uncertain life-cycle results. Also, allocating according to economic value could unevenly distribute emissions to products with a greater value even if they actually require less processing. The mass of a product does not necessarily correspond to its emissions or energy use but it was felt to be a better representation than the price.

\section{9) Why is the construction of capital goods not included?}

It was a scoping decision based on the fact that capital equipment burdens are often found to be negligible in the overall LCI.

\section{0) How is the benefit of electricity offset being taken into consideration?}

During ethanol production, lignin residue is used as a fuel to provide steam and electricity for the process. For some scenarios excess electricity is produced. This electricity is assumed to be sold to the grid and thus replace the production of an equivalent amount of electricity. The emissions for producing a given quantity of electricity from the California grid are subtracted from the ethanol production step. This could result in net negative emissions.

\section{1) Why is only $15 \%$ of the MTBE being offset?}

The baseline scenarios are restricted only to the production of MTBE within California due to limited isobutylene availabilty. Since $15 \%$ of the total MTBE demand is produced in California, the baseline scenarios are only replacing this amount. Factors such as size of the ethanol plant and transportation distances are based on this assumption. This means that the transport associated with the production of the other $85 \%$ of the MTBE that is produced out of state is ignored. A sensitivity analysis was performed which includes this additional 85\%. A sensitivity analysis was also performed on using ethanol directly as a reformulated fuel additive. This E10 scenario would be accurate for the entire oxygenate market because it is not dependent on isobutylene availabilty.

12) What about the issue of land impacts associated with the management of chaparral? How are they quantified?

Land impacts were not quantified because they cannot be considered an 'emission' from collection. They are more relevant to impact assessment, which we limited in this study to more global impact categories.

\section{3) Why aren't other impact categories, such as human health, being used in the analysis?}

Again, the impacts were limited to global categories. Collection of data for site- or temporal-specific impacts was beyond the scope of the study.

\section{4) How has the Ecobalance database been checked for quality?}

All of the data used in the model have undergone a peer review as part of this project to confirm the quality and representativeness of the data. Also, Ecobalance's models have been reviewed as part of their use in various projects. For example, the petroleum processing model was developed in a joint project with the USDA and USDOE and was validated by reviewers at that time. The electricity model has also been reviewed and validated by various industry representatives.

\section{5) Is soil erosion included in the impacts for natural resource depletion?}

The current impact values are relative to the depletion of global reserves. In the current impact assessment model, soil is not considered a natural resource, and soil erosion is not included in the natural resource depletion index. Moreover, it is difficult to quantify soil reserves, which are very location sensitive. 


\section{6) How is the nitrogen in straw and other biomass sources accounted for?}

The effects of the nitrogen present in the biomass on air emissions and water effluents for ethanol production are assumed to be negligible.

\section{7) What about a discussion of the economic implications of the model's assumptions?}

This study focused on environmental impacts and not on economics; however, the economic and technical feasibility of the options was considered in devising scenarios. The technology employed in the project was assumed to be representative of the early next decade. The process performance parameters were based on the best estimates available. The actual economics would depend on such factors as feedstock cost, debt/equity ratio, and government subsidies, the discussion of which is outside the scope of this study.

\section{8) What about alternative uses for the ligneous matter by-product, such as boiler fuel or soil nutrients?}

Other uses for the lignin were not considered, although many may exist. The use of the lignin for cogeneration was assumed to be the most likely use for the fuel. Any use has to have a large market because once a few plants are in operation small specialty markets would be swamped.

19) Currently the system boundaries are set so that the burning option of biomass disposal cannot be directly compared to other disposal options not considered here. Why was this done?

There were two functional units considered in this project, the disposal of biomass and the production and use of fuel oxygenate. The system boundaries were not only set to compare biomass burning with other disposal options but more to compare the current situation of biomass disposal and fuel oxygenate production/use to a future scenario in which both were performed simultaneously. The resultant system boundaries reflect the choice of "conversion to fuel oxygenates" as the other disposal option. This specificity of system boundaries ensues from the authors' motive to facilitate an explicit comparison of the current situation and future situations encompassing both biomass burning and fuel oxygenate use. A necessary outcome is that the study as modeled cannot be used to compare biomass burning directly with another disposal option. However, the database developed here will still be useful in conducting such a comparison. 


\section{APPENDIX I: REFERENCES}

\section{SECTION 1: Project OVERVIEW - REFERENCES}

1. National Renewable Energy Laboratory, Oak Ridge National Laboratory, and Pacific Northwest Laboratory, Fuel Cycle Evaluations of Biomass-Ethanol and Reformulated Gasoline (NREL/TP-463-4950), Golden, CO, November 1993.

2. Illinois Department of Commerce and Community Affairs, Fuel-Cycle Fossil Energy Use and Greenhouse Gas Emissions of Fuel Ethanol Produced from U.S. Midwest Corn, prepared by Wang, M., C. Saricks, and M. Wu, Center for Transportation Research, Argonne National Laboratory, Argonne, IL, December 1997.

3. Wang M., C. Saricks, and D. Santini, Fuel-Cycle Fossil Energy Use and Greenhouse Gas Emissions of Corn Ethanol, paper presented at the 8th Bio-Energy Conference, Madison, WI, October 5-8, 1998.

4. Morris D., and I. Ahmed, How Much Energy Does It Take to Make a Gallon of Ethanol?, Institute for Local Self-Reliance, Washington, DC, December 1992.

5. Shapori H., J. Duffield, and M. Graboski, Estimating the Net Energy Balance of Corn Ethanol, Economic Research Service, U.S. Dept. of Agriculture, Report \# 721, July 1995.

\section{SECTION 2: LIFE CYCLE ASSESSMENT PRINCIPLES - REFERENCES}

1. Society of Environmental Toxicology and Chemistry, A Conceptual Framework for Life-Cycle Impact Assessment, SETAC, Washington DC, 1993.

2. Society of Environmental Toxicology and Chemistry, A Technical Framework for Life-Cycle Assessments, SETAC, Washington DC, 1991.

3. Society of Environmental Toxicology and Chemistry, Guidelines for Life-Cycle Assessment: A "Code of Practice," SETAC, Washington DC, 1993.

4. Society of Environmental Toxicology and Chemistry, Life Cycle Assessment Data Quality: A Conceptual Framework, SETAC, Washington DC, 1994.

5. U.S. Environmental Protection Agency, Life Cycle Design Manual: Environmental Requirements and the Product System(EPA/600/R-92/226), Washington, DC, 1993.

6. U.S. Environmental Protection Agency, Life-Cycle Assessment: Inventory Guidelines and Principles (EPA/600R-92-245), Washington, DC, 1993.

7. U.S. Environmental Protection Agency, Guidelines for Assessing the Quality of Life-Cycle Inventory Analysis (EPA/530-R-95-010), Washington, DC, 1995.

8. International Organization for Standardization, Draft International Standard ISO/DIS 14040: Environmental management - Life cycle assessment - Principles and framework, ISO, Geneva, Switzerland, 1996.

9. International Organization for Standardization, Draft International Standard ISO/DIS 14041: Environmental management - Life cycle assessment - Goal and scope definition and inventory analysis, ISO, Geneva Switzerland, 1997.

10. Heijungs, R. J.B. Guinée, G. Huppes, R.M. Lankreijer, H.A. Udo de Haes, A. Wegener Sleeswijk, A.M.M. Ansems, P.G. Eggels, R. van Duin, and H.P. de Goede, Environmental Life Cycle Assessment of Products, Center of Environmental Science, University of Leiden, Netherlands, October 1992.

11. Society of Environmental Toxicology and Chemistry - Europe, Life-Cycle Assessment, SETAC Europe, Brussels, Belgium, 1992. 


\section{SECTION 4: MODELING - REFERENCES}

1. Delucchi, M. A., Emissions of Greenhouse Gases from the Use of Transportation Fuels and Electricity, Center for Transportation Research, Energy Systems Division, Argonne National Laboratory, Argonne, IL, 1993.

2. U.S. Environmental Protection Agency, AP-42: Compilation of Air Pollutant Emission Factors, Volume I, Fifth Edition, Department of Air and Radiation, Washington, DC, September 1997.

3. U.S. Department of Energy, Natural Gas Annual: Summary Statistics, Energy Information Administration, Washington, DC, 1996.

4. Gas Research Institute, Criteria Pollutant Emissions from Internal Combustion Engines in the Natural Gas Industry: Volume I, Technical Report (GRI-95/0270.1), Washington, DC, February 1996.

5. French Petroleum Institute, MTBE ETBE TAME: IFP Etherification Technology, Paris, France, 1994.

6. California Air Resources Board and California Department of Food and Agriculture, The 1997 Biennial Report to the Legislature--Progress Report on the Phase Down of Rice Straw Burning in the Sacramento Valley, Sacramento, CA, October 1997.

7. The Fertilizer Institute, Production Cost Surveys, for the year ended December 31, 1994, May 1995.

8. Dunn R. O., and L. W., Shoemaker, The Phillips STeam Active Reforming (STAR) Process for the Dehydrogenation of C3, C4 and C5 Paraffins, Phillips Petroleum Company, Bartlesville, OK, December 1992.

9. U.S. Department of Energy, Coal Industry Annual 1996, Energy Information Administration, Washington, DC, 1996.

10. R.J. Rudden Associates, Fuel Cycle Analysis: Issues and Comparative Case Studies with a Practical Approach, prepared for INGAA, 1993

11. U.S. Department of Energy, Energy Technology Characterizations Handbook, Environmental Pollution and Control Factors, Third edition (DOE/EP-0093), Assistant Secretary for Environmental Protection, Safety, and Emergency Preparedness, Energy, Washington, DC, March 1983.

12. Department of the Army, Waterborne Commerce of the United States, Calendar Year 1993, Part 5 - National Summaries, Corps of Engineers, 1993.

13. Babcock \& Wilcox Company, Steam, 40th ed., Barberton, OH, 1992.

14. Swiss Federal Office of Environment, Forests and Landscape, Environmental Series No. 132, Bern, Switzerland, February 1991.

15. El-Hinnawi, Environmental Impacts of Production and Use of Energy, Tycooli International, 1981.

16. Chamberland, A., and Levesque S., Hydroelectricity, an Option to Reduce Greenhouse Gas Emissions from Thermal Power Plants, Energy Construction Management, Vol. 37, Nos. 6-8.

17. Boustead, I., Eco-balance-Methodology for Commodity Thermoplastics, prepared for the European Centre for Plastics in the Environment, Brussels, Belgium, December 1992.

18. U.S. Department of Energy, Electric Utility Net Generation by NERC Region and Fuel Type (EIA-759), Energy Information Administration, Washington, DC, 1995.

19. Magaletti, M., Initial Report on Net System Power for 1997, prepared for the Energy Commission Business Meeting, California Energy Commission, Sacramento, CA, December 3, 1997.

20. Wang, M., GREET 1.0 - Transportation Fuel Cycles Model: Methodology and Use, Center for Transportation Research, Energy Systems Division, Argonne National Laboratory, Argonne, IL, 1996.

21. U.S. Department of Energy, Petroleum Supply Annual 1994 (DOE/EIA-0340(94)/1), Energy Information Administration, Washington, DC, May 1995.

22. U.S. Department of Energy, Petroleum Supply Annual 1993, Vol. 1, Energy Information Administration, Washington, DC, 1993. 
23. Association of American Railroads, Freight Commodity Statistics, annual, 1988, Washington D.C.

24. American Trucking Association, Inc., Financial and Operating Statistics, annual, 1988, Washington D.C.

25. Defense Mapping Agency, Distance Between Ports, Fifth edition, Publication 151, Hydrographic/ Topographic Center, Washington, DC, 1995.

26. White, J.R., J.F. Marshall, G.L. Shoemaker, and R.B. Smith, Hydrocarbon Process., 61(7), 95-102, July 1982.

27. U.S. Department of Energy, Model Year 1997 Fuel Economy Guide, Washington, DC, October 1997.

\section{SECTION 5: DATA QUALITY AND SOURCES- REFERENCES}

1. Society of Environmental Toxicology and Chemistry, Guidelines for Life-Cycle Assessment: A "Code of Practice," SETAC, Washington DC, 1993.

\section{APPENDIX B: IMPACT ASSESSMENT - REFERENCES}

1. International Panel on Climate Change (IPCC), The 1994 Report of Scientific Assessment Working Group of IPCC, Geneva, Switzerland, 1994.

2. Guinee, J. B., A Proposal for the Definition of Resource Equivalency Factors for Use in Product Life-Cycle Assessment in Development of a Methodology for the Environmental Life-Cycle Assessment of Products (thesis), Centre of Environmental Science, University of Leiden, Netherlands, 1995.

3. U.S. Department of the Interior, Mineral Commodity Summary 1994, Bureau of Mines, Washington, DC, 1994.

\section{APPENDIX D: GASOLINE MODELING - REFERENCES}

1. National Renewable Energy Laboratory, Oak Ridge National Laboratory, and Pacific Northwest Laboratory, Fuel Cycle Evaluations of Biomass-Ethanol and Reformulated Gasoline (NREL/TP-463-4950), Golden, CO, November 1993.

2. Delucchi, M. A., Emissions of Greenhouse Gases from the Use of Transportation Fuels and Electricity, Center for Transportation Research, Energy Systems Division, Argonne National Laboratory, Argonne, IL, 1993.

3. U.S. Department of Energy, Energy Technology Characterizations Handbook, Environmental Pollution and Control Factors, Third edition (DOE/EP-0093), Assistant Secretary for Environmental Protection, Safety, and Emergency Preparedness, Energy, Washington, DC, March 1983.

4. U.S. Environmental Protection Agency, Report to Congress: Management of Wastes from the Exploration, Development, and Production of Crude Oil, Natural Gas, and Geothermal Energy (EPA/530-SW-88-003), Office of Solid Waste and Emergency Response, Washington, DC, December 1987.

5. U.S. Environmental Protection Agency, Volatile Organic Compound (VOC)/Particulate Matter (PM) Speciation Data System: Version 1-32a, Air Quality Management Division, Office of Air Quality Planning and Standards, Research Triangle Park, NC, September 1990.

6. U.S. Department of Energy, Annual Energy Review 1994 (DOE/EIA-0384(94)), Energy Information Administration, July 1995.

7. U.S. Department of the Interior, Alaska Outer Continental Shelf-Chukchi Sea Oil \& Gas Lease Sale 126 Draft Environmental Impact Statement Volume I (MMS 90-0035), Minerals Management Service, Herndon, Virginia, July 1990.

8. U.S. Department of Energy, Petroleum Supply Annual 1993, Vol. 1, Energy Information Administration, Washington, DC, 1993. 
9. Defense Mapping Agency, Distance Between Ports, Fifth edition, Publication 151, Hydrographic/ Topographic Center, Washington, DC, 1995.

10. Banks, W. F., Energy Consumption in the Pipeline Industry (SAN-1171-1/3), prepared by Systems, Science, and Software for the U.S. Dept. of Energy, La Jolla, CA, December 1977.

11. U.S. Environmental Protection Agency, AP-42: Compilation of Air Pollutant Emission Factors, Volume I, Fifth Edition, Department of Air and Radiation, Washington, DC, September 1997.

12. U.S. Department of Energy, Petroleum Supply Annual 1994 (DOE/EIA-0340(94)/1), Energy Information Administration, Washington, DC, May 1995.

13. U.S. Environmental Protection Agency and Amoco, Pollution Prevention Project, Yorktown Refinery, Refinery Release Inventory, June 1992.

14. U.S. Environmental Protection Agency, VOC Emissions From Petroleum Refinery Wastewater Systems Background Information for Proposed Standards (EPA 450/3-85-001a), Washington, DC, 1985.

15. U.S. Department of Energy, Energy Technologies and the Environment (DOE/EH-0077), Washington, DC, October 1988.

16. The American Petroleum Institute, The Generation of Wastes and Secondary Materials in the Petroleum Refining Industry, Washington, DC, 1991.

17. White, J.R., J.F. Marshall, G.L. Shoemaker, and R.B. Smith, Hydrocarbon Process., 61(7), 95-102, July 1982.

\section{APPENDIX E: OXYGENATE OVERVIEW - REFERENCES}

1. Davenport, R.E., Gasoline Octane Improvers in Chemical Economics Handbook, SRI International, Menlo Park, CA, 1999.

2. Weirauch, W., Hydrocarbon Process., 74 (8), 23-25, August 1995. 


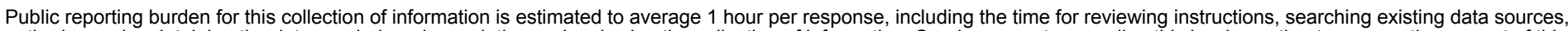

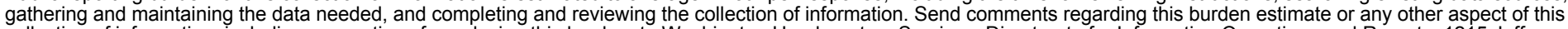

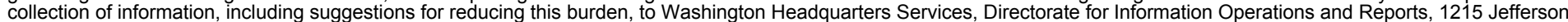
Davis Highway, Suite 1204, Arlington, VA 22202-4302, and to the Office of Management and Budget, Paperwork Reduction Project (0704-0188), Washington, DC 20503.
1. AGENCY USE ONLY (Leave blank)
2. REPORT DATE
May 1999
3. REPORT TYPE AND DATES COVERED
Technical Report

4. TITLE AND SUBTITLE

5. FUNDING NUMBERS

Environmental Life Cycle Implications of Fuel Oxygenate Production from California Biomass WG900101

\section{6. $\operatorname{AUTHOR}(\mathrm{S})$}

K.L. Kadam, V.J. Camobreco, B.E. Glazebrook, L.H. Forrest, W.A. Jacobson, D.C. Simeroth, W..J. Blackburn, K.C. Nehoda

\section{PERFORMING ORGANIZATION NAME(S) AND ADDRESS(ES)}

National Renewable Energy Laboratory, 1617 Cole Boulevard, Golden, CO 80401-3393

Ecobalance, Inc., 15204 Omega Dr., Rockville, MD 20850

TSS Consultants, 2890 Kilgore Road, Rancho Cordova, CA 95670

California Air Resources Board, 2020 L St., Sacramento, CA 95814

California Energy Commission, 1516 9th St., Sacramento, CA 95814

California Department of Forestry and Fire Protection, 1416 9th St., Sacramento, CA 94244

9. SPONSORING/MONITORING AGENCY NAME(S) AND ADDRESS(ES)

National Renewable Energy Laboratory

1617 Cole Boulevard

Golden, CO 80401-3393

8. PERFORMING ORGANIZATION REPORT NUMBER

\section{SUPPLEMENTARY NOTES}

12a. DISTRIBUTION/AVAILABILITY STATEMENT

National Technical Information Service

U.S. Department of Commerce

5285 Port Royal Road

Springfield, VA 22161 12b. DISTRIBUTION CODE

13. ABSTRACT (Maximum 200 words) Historically, more than $90 \%$ of the excess agricultural residue produced in California (approximately 10 million dry metric tons per year) has been disposed through open-field burning. Concerns about air quality have prompted federal, state, and local air quality agencies to tighten regulations related to this burning and to look at disposal alternatives. One use of this biomass is as an oxygenated fuel. This report focuses on quantifying and comparing the comprehensive environmental flows over the life cycles of two disposal scenarios: (1) burning the biomass, plus producing and using MTBE; and (2) converting and using ETBE.

14. SUBJECT TERMS

ETBE, MTBE, biomass, life cycle, bioethanol, open burning

15. NUMBER OF PAGES 204

16. PRICE CODE
18. SECURITY CLASSIFICATION OF THIS PAGE
19. SECURITY CLASSIFICATION OF ABSTRACT
20. LIMITATION OF ABSTRACT

Standard Form 298 (Rev. 2-89) Prescribed by ANSI Std. Z39-18 